Fernanda Manzano Sayeg

\title{
O TRATAMENTO DE QUESTÕES RELACIONADAS A SERVIÇOS NOS ACORDOS REGIONAIS DE COMÉRCIO: \\ UMA ANÁLISE DOS MODELOS ADOTADOS POR ESTADOS UNIDOS, UNIÃO EUROPEIA, CHINA E ÍNDIA COM VISTAS AO DESENVOLVIMENTO DE UM MODELO ADEQUADO E DESEJÁVEL PARA O MERCOSUL
}

Tese de Doutorado

Orientador: Professor Associado Umberto Celli Junior

Faculdade de Direito da Universidade de São Paulo São Paulo 2014 
Fernanda Manzano Sayeg

O TRATAMENTO DE QUESTÕES RELACIONADAS A SERVIÇOS NOS ACORDOS REGIONAIS DE COMÉRCIO: UMA ANÁLISE DOS MODELOS ADOTADOS POR ESTADOS UNIDOS, UNIÃO EUROPEIA, CHINA E ÍNDIA COM VISTAS AO DESENVOLVIMENTO DE UM MODELO ADEQUADO E DESEJÁ VEL PARA O MERCOSUL.

Tese de Doutorado apresentada à Faculdade de Direito da Universidade de São Paulo como parte dos requisites para obtenção do título de Doutora em Direito Internacional.

Orientador: Professor Associado Umberto Celli Junior 
Ao meu marido, Bruno Andrade Soares Silva, que já sabia do meu amor pela pesquisa quando nos conhecemos e me apoiou incondicionalmente neste projeto, ao meu filho, Bruno Sayeg Soares, que é minha maior fonte de alegria e inspiração. 


\section{AgRADECIMENTOS}

Ao meu marido Bruno, pelo carinho e apoio incondicional. Eu não teria conseguido finalizar esse trabalho sem o seu apoio.

Ao meu filho Bruno, que nasceu na fase final de elaboração da tese. Obrigada por toda a alegria que você me proporciona e peço desculpas pelos momentos em que estive longe de você para finalizar a minha tese.

Aos meus pais, Sérgio e Ivonete, que me incentivaram a continuar estudando e pesquisando. Muito obrigada pela sólida base familiar, a qual me fortalece em todos os momentos e em todos os projetos.

À Stephanie Scandiuzzi, pela ajuda tanto na fase de concepção quanto na realização da pesquisa.

À Karla C. M. Borges Furlaneto, minha amiga e colega no estudo dos temas relacionados ao comércio internacional desde 2002, pelo companheirismo na fase de obtenção dos créditos e pelo auxílio na estruturação da tese.

Aos professores Vera Thorstensen e Alberto do Amaral Junior, pelo auxílio acadêmico dado durante a elaboração dessa tese.

Um agradecimento especial ao meu orientador, Umberto Celli Junior, que me acompanha nesse percurso acadêmico desde a faculdade. Sua cordialidade e amizade sempre serão uma grande inspiração para mim como pessoa, docente e acadêmica. Muito obrigada pelo apoio em todos os momentos. Eu não conseguiria realizar essa pesquisa sob a orientação de qualquer outro professor. 


\section{RESUMO}

O comércio internacional de serviços é cada dia mais importante para as economias nacionais e para o comércio global. Por esse motivo, a liberalização comercial do setor de serviços tem sido objeto da maioria dos acordos regionais de comércio celebrados a partir de 1990. As normas sobre serviços estabelecidas por esses acordos coexistem com as normas do GATS, criadas no âmbito da OMC.

Não obstante, o Brasil e o Mercosul celebraram pouquíssimos acordos regionais de comércio, apenas no eixo Sul/Sul. Dentre esses acordos, o único que contém normas e procedimentos concretos para a liberalização do comércio de serviços é o $\mathrm{ACE} \mathrm{N}^{\mathrm{o}} 35$, entre Mercosul e Chile. Assim, verifica-se que o Mercosul não possui um modelo claro de normas para a abertura do setor de serviços. Não há diretrizes de política externa comum a respeito do tema, a despeito da relevância econômica desse setor para o Brasil e para os demais Estados-membros do bloco.

Por sua vez, os principais players do comércio internacional - Estados Unidos, Índia, China e União Europeia - estão inseridos em redes de preferências comerciais envolvendo bens e serviços, que foram construídas ao longo das últimas décadas. Os acordos regionais celebrados por esses players são um importante parâmetro para um modelo de acordo regional em serviços a ser desenvolvido para o Mercosul.

Para que o Brasil e o Mercosul não corram fiquem alijados desse processo de integração econômica, é necessário que se engajem no em negociação de preferências comerciais no setor de serviços com players importantes do comércio internacional. Para tanto, devem desenvolver um modelo próprio de regras para a abertura comercial do setor de serviços em acordos regionais de comércio, de forma a estarem mais capacitados para negociar esses acordos.

Palavras-chave: Comércio internacional; Comércio de serviços; GATS; Acordos regionais de comércio; Organização Mundial do Comércio; OMC; Regionalismo; Mercosul; Sistema Multilateral de Comércio. 


\section{ABSTRACT}

International trade in services is becoming more important for national economies and for the global commerce. Therefore, rules for the liberalization of the services sector are included in most of the regional trade agreements executed as of 1990. The rules established by these agreements coexist with the WTO rules established by the GATS.

Nevertheless, Brazil and Mercosur have signed very few regional trade agreements, which are exclusively South/South agreements. Among these agreements, the only one that contains specific rules and proceedings for the liberalization of the services sector is ACE $\mathrm{N}^{\circ} 35$, between Mercosur and Chile. Thus, Mercosur does not have established a pattern concerning regional trade agreement rules in the services sector. There are no common foreign policy guidelines on the subject, despite the economic importance of this sector for Brazil and for the other Member States.

The major international trade players - United States, India, China and the European Union - have built trade preferences networks involving goods and services over the past decades. Regional trade agreements concluded by those players are an important parameter for a pattern of regional trade agreement rules related to services to be developed by the Mercosur.

In order to avoid that Brazil and Mercosur are excluded from this economic integration process, it is necessary to engage in the negotiation of trade preferences in the service sector with major international trade players. Mercosur should develop its own set of rules for the liberalization of the service sector in regional trade agreements as to become more prepared to negotiate such agreements.

Key words: International trade; Trade in services; GATS; Regional trade agreements; World Trade Organization; WTO; Regionalism; Mercosur; Multilateral Trading System. 


\section{SUMÁRIO}

INTRODUÇÃ̃O 20

PARTE I - SISTEMA MULTILATERAL DE COMÉRCIO E REGIONALISMO

\section{CAPÍtUlo 1: O SISTEMA MULTILATRAL DE COMÉRCIO E O REGIONALISMO}

1. Introdução 30

2. O surgimento dos acordos regionais de comércio como uma exceção ao princípio da não discriminação 31

3. O debate sobre as vantagens e desvantagens dos acordos regionais de comércio: blocos de construção ou blocos de contenção?

4. Análise dos efeitos econômicos dos acordos regionais de comércio 34

5. Mudanças dos paradigmas da integração e a proliferação dos acordos regionais de comércio 41

6. Conclusões 43

\section{CAPÍTULO 2: A REGULAMENTAÇÃO DO TEMA SERVIÇOS NO SISTEMA MULTILATERAL DE COMÉRCIO}

1. Introdução 45

2. Estrutura 46

3. Escopo 48

4. Princípios e obrigações 49

5. Modelo para a assunção de compromissos 51

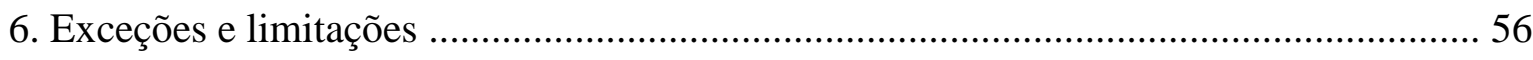

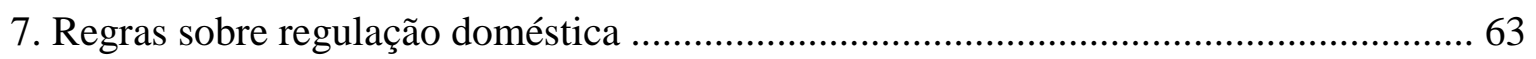

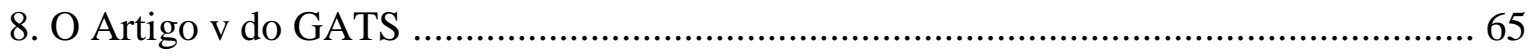

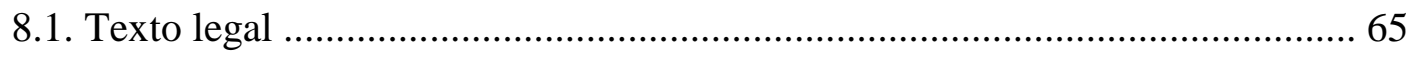

8.2. Principais semelhanças e diferenças entre o Artigo V do GATS e o Artigo XXIV do GATT 
8.3. Requisitos estabelecidos pelo Artigo V do GATS 66

8.3.1. Obrigações relacionadas ao comércio inter-partes 67

8.3.2. Necessidade de abrangência setorial substancial 67

8.3.3. Necessidade de eliminação das discriminações 68

8.3.4. Notificação 70

8.3.5. Manutenção do nível de compromissos em relação a outros Membros 71

8.3.6. Período de tempo razoável 72

8.3.7. Flexibilidades concedidas aos países em desenvolvimento 72

9. Conclusões 73

\section{CAPÍTULO 3: O REGIONALISMO E O COMÉRCIO DE SERVIÇOS}

1. Introdução 76

2. Histórico da inserção de regras sobre o comércio de serviços em acordos regionais .... 76

3. Fiscalização dos acordos regionais pela OMC

4. Consequências relacionadas à inserção de regras sobre o comércio de serviços em acordos regionais 81

4.1. O aprofundamento dos compromissos em serviços em relação àqueles assumidos no âmbito multilateral

4.2. Compatibilidade entre os compromissos em serviços celebrados no âmbito multilateral e no âmbito regional 87

5. Estágio atual dos acordos regionais de comércio vis-à-vis as regras do GATS 91

6. Conclusões 94

PARTE II - O COMÉRCIO DE SERVIÇOS NOS ACORDOS REGIONAIS DE COMÉRCIO CELEBRADOS POR MERCOSUL, ESTADOS UNIDOS, UNIÃO EUROPEIA, CHINA E ÍNDIA

\section{CAPÍTULO 1: OS ACORDOS REGIONAIS DE COMÉRCIO CELEBRADOS POR ESTADOS UNIDOS, UNIÃO EUROPEIA, CHINA E ÍNDIA E O COMÉRCIO DE SERVIÇOS}

1. Introdução 97 
2. Panorama do tratamento de serviços nos principais acordos regionais de comércio envolvendo os Estados Unidos 100

2.1. Modelo de lista adotado .......................................................................... 100

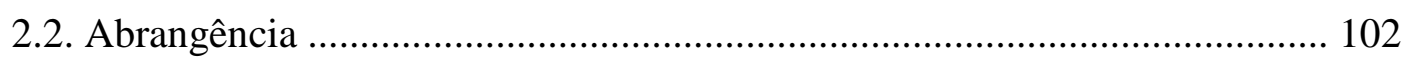

2.3. Obrigações e limitações de acesso a mercados ............................................. 104

2.4. Obrigações e limitações de tratamento nacional ......................................... 106

2.5. Reservas e exceções ................................................................................. 107

2.6. Transparência ......................................................................................... 108

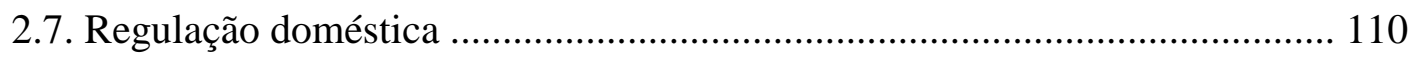

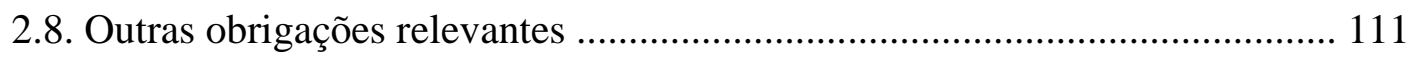

3. Panorama do tratamento de serviços nos principais acordos regionais de comércio

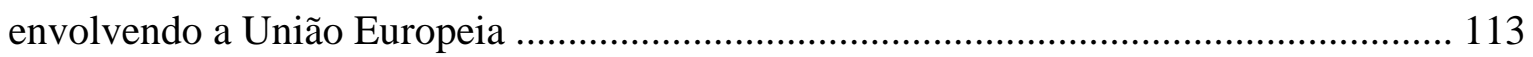

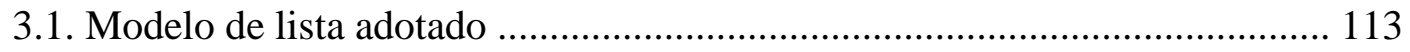

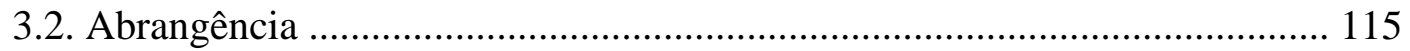

3.3. Obrigações e limitações de acesso a mercados ........................................... 117

3.4. Obrigações e limitações de tratamento nacional ........................................... 117

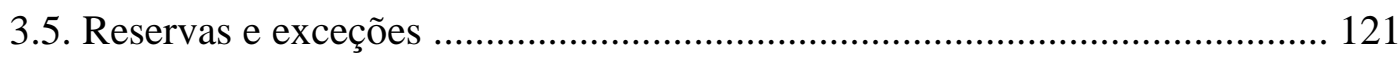

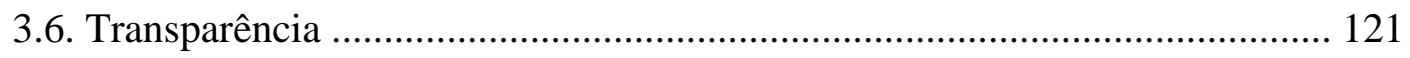

3.7. Regulação doméstica ............................................................................ 122

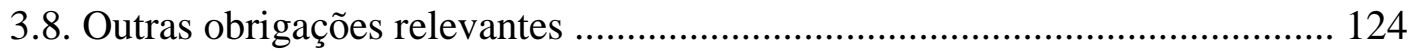

4. Panorama do tratamento de serviços nos principais acordos regionais de comércio

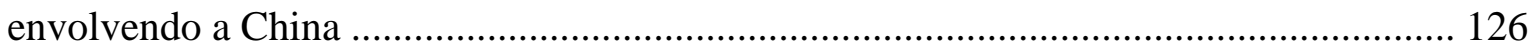

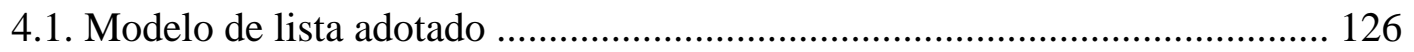

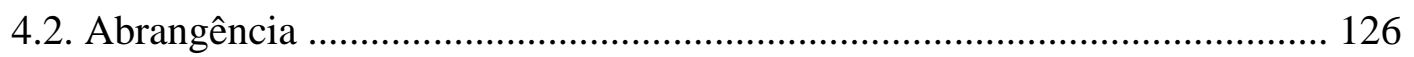

4.3. Obrigações e limitações de acesso a mercados .......................................... 128

4.4. Obrigações e limitações de tratamento nacional ......................................... 128

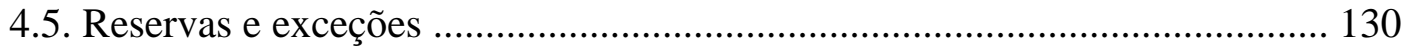

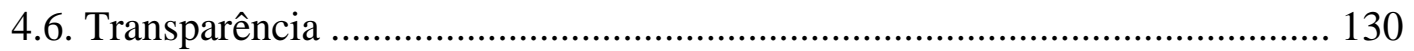

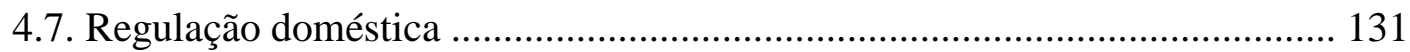

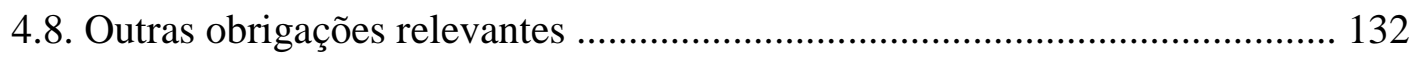

5. Panorama do tratamento de serviços nos principais acordos regionais de comércio

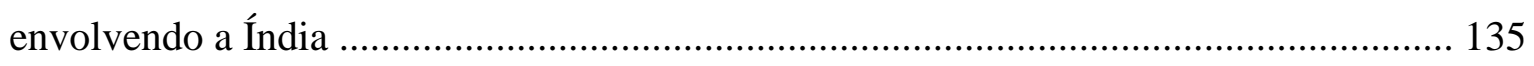

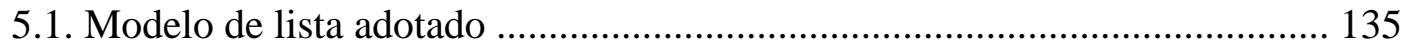

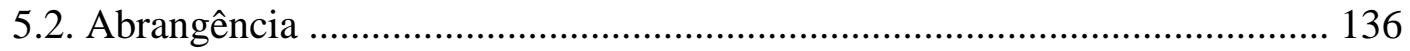


5.3. Obrigações e limitações de acesso a mercados

5.4. Obrigações e limitações de tratamento nacional .......................................... 138

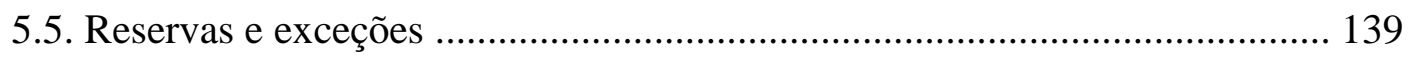

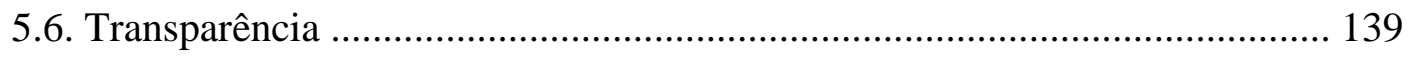

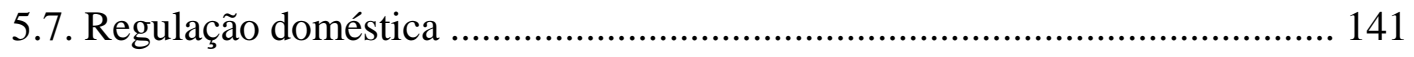

5.8. Outras obrigações relevantes ............................................................... 142

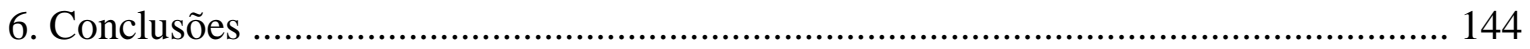

\section{CAPÍtUlO 2: O TRATAMENTO DO TEMA SERVIÇOS NOS ACORDOS REGIONAIS CELEBRADOS PELO MERCOSUL}

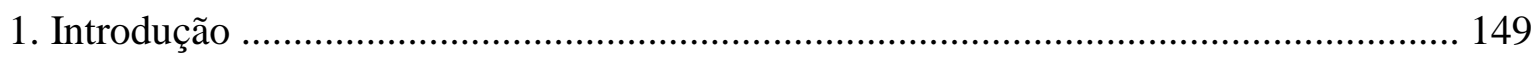

2. O Protocolo de Montevidéu e a liberalização do setor de serviços intrabloco ............. 149

3. A legislação do Mercosul relativa à celebração de acordos regionais de comércio extrabloco

4. Liberalização do setor de serviços nos acordos regionais de comércio celebrados pelo Mercosul 156

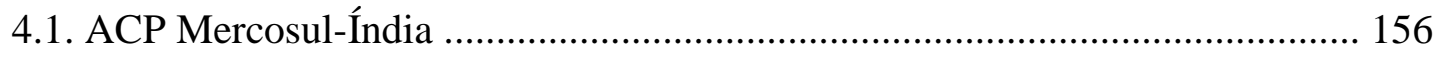

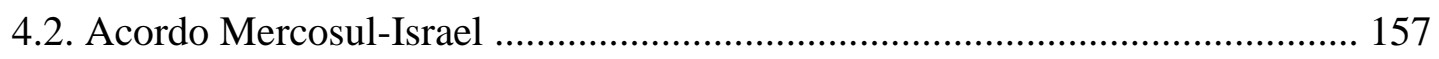

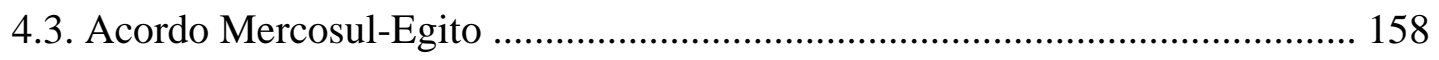

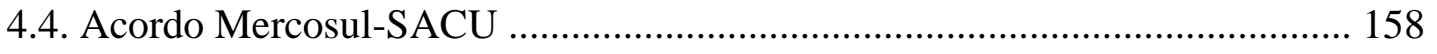

4.5. Acordo Mercosul-Palestina ............................................................................ 159

4.6. ACE Mercosul-Chile .............................................................................. 160

5. Acordos envolvendo o Mercosul em fase de negociação e a liberalização do comércio de

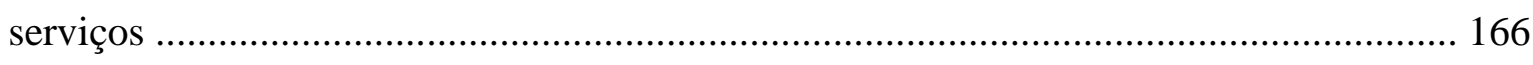

5.1. Acordo Mercosul-União Europeia ........................................................... 166

5.2. Ampliação do ACP Mercosul-Índia ........................................................... 169

5.3. ACE Mercosul-Colômbia ............................................................................. 169

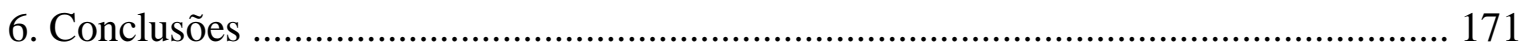

\section{CAPÍTULO 3: A ADOÇÃO DE UM MODELO DE ACORDO REGIONAL EM SERVIÇOS PELO MERCOSUL}


2. Lições extraídas da experiência dos Estados Unidos, União Europeia, China, Índia na liberalização regional do setor de serviços

3. Movimentos atuais para a liberalização do comércio de serviços, atualização e aprimoramento das regras existentes

3.1. O TISA 180

3.2. Os "mega acordos" 183

4. Proposição de um modelo de liberalização comercial em serviços para o Mercosul .. 185

5. Conclusões 188

CONSIDERAÇÕES FINAIS 191

\section{BIBLIOGRAFIA CONSULTADA}

1. Livros, artigos e periódicos 195

2. Legislação brasileira 212

3. Documentos internacionais 213

3.1. Documentos oficiais do GATT/OMC 213

3.2. Documentos oficiais do Mercosul 214

3.3. Documentos oficiais da ALADI 215

3.4. Acordos regionais de comércio 216

3.4.1. Acordos regionais de comércio celebrados pelos Estados Unidos .216 3.4.2. Acordos regionais de comércio celebrados pela União Europeia .. 217

3.4.3. Acordos regionais de comércio celebrados pela China 219

3.4.4. Acordos regionais de comércio celebrados pela Índia 220

3.4.5. Acordos regionais de comércio celebrados pelo Mercosul com Estados que não são membros da ALADI 220

4. Páginas da Internet 221

\section{ANEXOS}

\section{ANEXO I - RELAÇÃO DE ACORDOS DE LIVRE COMÉRCIO ANALISADOS}

Tabela 1 - Acordos celebrados pelos Estados Unidos 
Tabela 3 - Acordos celebrados pela China 232

Tabela 4 - Acordos celebrados pela Índia 234

Tabela 5 - Acordos celebrados pelo Mercosul 235

ANEXO II - ANÁLISE COMPARATIVA DAS PRINCIPAIS CLÁUSULAS SOBRE SERVIÇOS DOS ACORDOS DE LIVRE COMÉRCIO CELEBRADOS PELOS ESTADOS UNIDOS

Tabela 6 - NAFTA e CAFTA-DR 238

Tabela 7 - KORUS e Acordo Estados Unidos-Austrália 241

Tabela 8 - Acordos Estados Unidos-Bahrain e Estados Unidos-Chile 244

Tabela 9 - Acordos Estados Unidos-Colômbia e Estados Unidos-Israel 247

Tabela 10 - Acordos Estados Unidos-Jordânia e Estados Unidos-Marrocos 250

Tabela 11 - Acordos Estados Unidos-Omã e Estados Unidos-Peru 253

Tabela 12 - Acordos Estados Unidos-Panamá e Estados Unidos-Cingapura 256

\section{ANEXO III - ANÁLISE COMPARATIVA DAS PRINCIPAIS CLÁUSULAS SOBRE SERVIÇOS DOS ACORDOS DE LIVRE COMÉRCIO CELEBRADOS PELA UNIÃO EUROPEIA}

Tabela 13 - APE UE-CARIFORUM e Acordo UE-Costa do Marfim 260

Tabela 14 - Acordos UE-Argélia e UE-Egito 264

Tabela 15 - Acordos UE-Camarões e UE-Chile 266

Tabela 16 - Acordos UE-Israel e UE-Jordânia 268

Tabela 17 - ALC UE-Coreia e Acordo UE-México 271

Tabela 18 - Acordos UE-Marrocos e UE-África do Sul 275

Tabela 19 - Acordo UE-Tunísia 277

\section{ANEXO IV - ANÁLISE COMPARATIVA DAS PRINCIPAIS CLÁUSULAS SOBRE SERVIÇOS DOS ACORDOS DE LIVRE COMÉRCIO CELEBRADOS PELA CHINA}

Tabela 20 - Acordos China-ASEAN e China-Costa Rica 279

Tabela 21 - Acordos China-Chile e China-Nova Zelândia 283 
Tabela 22 - Acordos China-Cingapura e China-Paquistão

Tabela 23 - Acordo China-Peru

ANEXO V - ANÁLISE COMPARATIVA DAS PRINCIPAIS CLÁUSULAS SOBRE

SERVIÇOS DOS ACORDOS DE LIVRE COMÉRCIO CELEBRADOS PELA ÍNDIA

Tabela 24 - Acordos Índia-Coreia e Índia-Cingapura 294

Tabela 25 - Acordos Índia-Japão e Índia-Malásia 299

ANEXO VI - ANÁLISE COMPARATIVA DAS PRINCIPAIS CLÁUSULAS SOBRE SERVIÇOS DOS ACORDOS DE LIVRE COMÉRCIO CELEBRADOS PELO MERCOSUL

Tabela 26 - Acordos Mercosul-Índia e Mercosul-Israel 304

Tabela 27 - Acordos Mercosul-Egito e Mercosul-SACU 306

Tabela 28 - Acordo Mercosul-Palestina e ACE Mercosul-Chile 308

Tabela 29 - ACE Mercosul-Colômbia 311 


\section{LISTA DE ABREVIATURAS}

ACE - Acordo de Complementação Econômica

ACP - Acordo de Comércio Preferencial

ALADI - Associação Latino-Americana de Integração

ALC - Acordo de Livre Comércio

ANZCERTA - Acordo Comercial sobre Relações Econômicas entre Austrália e Nova Zelândia

APE - Acordo de Parceria Econômica

CAFTA-DR - Acordo de Livre Comércio República Dominicana-América Central-

Estados Unidos

CAN - Comunidade Andina de Nações

CMC -- Conselho do Mercado Comum

CUFSTA - Acordo de Livre Comércio entre Canadá e Estados Unidos

EUA - Estados Unidos da América

FMI - Fundo Monetário Internacional

GATS - Acordo Geral sobre o Comércio de Serviços

GATT - Acordo Geral sobre Tarifas e Comércio

IBGE - Instituto Brasileiro de Geografia e Estatística

ISA - Acordo Internacional de Serviços

KORUS - Acordo de Livre Comércio Entre os Estados Unidos da América e a República da Coreia

Mercosul - Mercado Comum do Sul

NAFTA - Acordo de Livre Comércio da América do Norte

OACI - Organização da Aviação Civil Internacional

OCDE - Organização para a Cooperação Econômica e para o Desenvolvimento

OMC - Organização Mundial do Comércio

PIB - Produto Interno Bruto

SACU - União Aduaneira da África Austral

TISA - Acordo para o Comércio de Serviços

TPP - Parceria Transpacífica

TTIP - Parceria Transatlântica de Comércio e Investimento

UE - União Europeia

UNCTAD - Conferência das Nações Unidas para o Comércio e o Desenvolvimento 


\section{LISTA DE ACORDOS}

ACE Mercosul-Chile - Acordo de Complementação Econômica n. ${ }^{\circ} 35$

ACE Mercosul-Colômbia - Acordo de Complementação Econômica n. ${ }^{\circ} 59$

Acordo China-ASEAN - Acordo-quadro para Cooperação Econômica Abrangente entre a Associação das Nações do Sudeste Ásiático e a República Popular da China

Acordo China-Chile -Acordo de Livre Comércio entre o Governo da República Popular da China e o Governo da República Popular do Chile

Acordo China-Cingapura - Acordo de Livre Comércio entre o Governo da República Popular da China e o Governo da República de Cingapura

Acordo China-Costa Rica - Acordo de Livre Comércio entre o Governo da República Popular da China e o Governo da República de Costa Rica

Acordo China-Nova Zelândia - Acordo de Livre Comércio entre o Governo da República Popular da China e o Governo da Nova Zelândia

Acordo China-Paquistão - Acordo sobre o Programa Preliminar para o Acordo de Livre Comércio entre o Governo da República Popular da China e o Governo da República Islâmica do Paquistão

Acordo China-Peru - Acordo de Livre Comércio entre o Governo da República do Peru e o Governo da República Popular da China

Acordo de Euro-Mediterrânico que cria uma Associação entre as Comunidades Europeias e os seus Estados-Membros, por um lado, e o Reino Hachemita da Jordânia, por outro

Acordo Estados Unidos- Cingapura - Acordo de Livre Comércio entre Estados Unidos e Cingapura 
Acordo Estados Unidos-Austrália - Acordo de Livre Comércio entre Austrália e Estados Unidos

Acordo Estados Unidos-Bahrain - Acordo de Livre Comércio entre Estados Unidos e Bahrain

Acordo Estados Unidos-Chile - Acordo de Livre Comércio entre Estados Unidos e Chile

Acordo Estados Unidos-Colômbia - Acordo de Promoção Comercial entre Estados Unidos e Colômbia

Acordo Estados Unidos-Israel - Acordo para o Estabelecimento de uma Área de Livre Comércio entre o Governo de Israel e o Governo dos Estados Unidos da América

Acordo Estados Unidos-Jordânia - Acordo entre os Estados Unidos da América e o Reino Hachemita da Jordânia para o Estabelecimento de uma Área de Livre Comércio

Acordo Estados Unidos-Marrocos - Acordo de Livre Comércio entre Estados Unidos e Marrocos

Acordo Estados Unidos-Omã - Acordo entre o Governo dos Estados Unidos da América e o Governo do Sultanato de Omã para o Estabelecimento de uma Área de Livre Comércio

Acordo Estados Unidos-Panamá - Acordo de Promoção Comercial entre Estados Unidos e Panamá

Acordo Estados Unidos-Peru - Acordo de Promoção Comercial entre Estados Unidos e Peru

Acordo Índia-Cingapura - Acordo de Parceria Econômica Abrangente entre a República da Índia e a República de Cingapura

Acordo Índia-Coreia - Acordo de Parceria Econômica Abrangente entre a República da Coreia e a República da Índia 
Acordo Índia-Malásia - Acordo de Parceria Econômica Abrangente entre o Governo da República da Índia e o Governo da República da Malásia

Acordo Mercosul-Egito - Acordo de Livre Comércio entre o Mercosul e a República Árabe do Egito

Acordo Mercosul-Índia - Acordo de Comércio Preferencial entre o Mercosul e a República da Índia

Acordo Mercosul-Israel - Acordo de Livre Comércio entre o Mercosul e o Estado de Israel Acordo Mercosul-SACU - Acordo Preferencial de Comércio entre o Mercado Comum do Sul (MERCOSUL) e a União Aduaneira da África do Sul (SACU)

Acordo Mercosul-Palestina - Acordo de Livre Comércio entre o Mercosul e o Estado da Palestina; Acordo-Quadro de Comércio e Cooperação Econômica entre o Mercosul e a Autoridade Nacional Palestina

Acordo UE-África do Sul - Acordo sob a forma de Troca de Cartas relativo à aplicação provisória do Acordo de Comércio, Desenvolvimento e Cooperação entre a Comunidade Europeia e os seus Estados-Membros, por um lado, e a República da África do Sul, por outro

Acordo UE-Algéria - Acordo Euro-Mediterrânico que cria uma associação entre a Comunidade Europeia e os seus Estados-Membros, por um lado, e a República Argelina Democrática e Popular, por outro

Acordo UE-Camarões - Acordo Intercalar para um Acordo de Parceria Econômica entre a Comunidade Europeia e os seus Estados-Membros, por um lado, e a Parte África Central, por outro

Acordo UE-Chile - Acordo de Associação entre a União Europeia e o Chile 
Acordo UE-Chile - Acordo que estabelece uma associação entre as Comunidades Europeias e os seus Estados-membros, por um lado, e a República do Chile, por outro

Acordo UE-Costa do Marfim - Acordo de Parceria Econômica Intercalar entre a Costa do Marfim, por um lado, e a Comunidade Europeia e os seus Estados-Membros, por outro

Acordo UE-Egito - Acordo Euro-Mediterrânico que estabelece uma Associação entre as Comunidades Europeias e os seus Estados-membros, por um lado, e a República Árabe do Egito, por outro

Acordo UE-Israel - Acordo Euro-Mediterrânico que cria uma associação entre as Comunidades Europeias e os seus Estados-membros, por um lado, o Estado de Israel, por outro

Acordo UE-Jordânia - Acordo de Associação entre a União Europeia e o Reino da Jordânia

Acordo UE-Marrocos - Acordo Euro-Mediterrânico que cria uma Associação entre as Comunidades Europeias e os seus Estados-membros, por um lado, e o Reino do Marrocos, por outro

Acordo UE-México - Acordo de Parceria Econômica, de Concertação Política e de Cooperação entre a Comunidade Europeia e os seus Estados-Membros, por um lado, e os Estados Unidos Mexicanos, por outro

Acordo UE-Tunísia - Acordo Euro-Mediterrânico que estabelece uma Associação entre as Comunidades Europeias e os seus Estados-membros, por um lado, e a República da Tunísia, por outro

ALC UE-Coreia - Acordo de Livre Comércio entre a União Europeia e os seus EstadosMembros, por um lado, e a República da Coreia, por outro 
APE UE-CARIFORUM - Acordo de Parceria Econômica entre os Estados do CARIFORUM, por um lado, e a Comunidade Europeia e os seus Estados-Membros, por outro

CAFTA-DR - Acordo de Livre Comércio entre República Dominicana, América Central e Estados Unidos

KORUS - Acordo de Livre Comércio entre os Estados Unidos da América e a República da Coreia

NAFTA - Acordo de Livre Comércio da América do Norte 


\section{INTRODUÇÃO}

O comércio internacional de serviços é cada dia mais importante para as economias nacionais e para o comércio global. No Brasil, serviços responderam por quase $70 \%$ do PIB em $2013^{1}$, percentual equivalente àquele verificado em países desenvolvidos, como os Estados Unidos ${ }^{2}$. Além disso, ao longo da última década, os investimentos estrangeiros diretos em serviços têm crescido mais rapidamente do que os investimentos estrangeiros diretos relacionados com o comércio de bens ${ }^{3}$. De acordo com a OMC, em 2012, as exportações totais de serviços cresceram $2 \%$ em termos de volume, ao passo que as exportações de bens estiveram estagnadas ${ }^{4}$.

De fato, os avanços nas tecnologias de informação e de telecomunicações têm ampliado o escopo de serviços que podem ser prestados de forma transfronteiriça. As pessoas estão viajando mais para o exterior para consumir turismo, educação e serviços de saúde, ou para prestar serviços de construção civil ou de desenvolvimento de software. Cada vez mais, empresas estabelecidas em determinado Estado são autorizadas a prestar serviços relevantes em outros Estados, tais como energia, telecomunicações e transportes, seja de forma direta, seja por meio de subsidiárias locais.

\footnotetext{
${ }^{1}$ Fonte: IBGE.

2 "Services currently represent more than two thirds of World Gross Domestic Product (GDP). The share of services value added in GDP tends to rise significantly with the countries" level of income, standing at $73 \%$ on average in high income countries (77\% in the United States), against $54 \%$ and $47 \%$ respectively in middle- and low- income countries. Even in the latter group, the production of services is generally a core economic activity, whose contribution to GDP is above that of both industry and agriculture". ORGANIZAÇÃO MUNDIAL DO COMÉRCIO. Measuring Trade In Services. Novembro de 2010. P. 7. Disponível em: 〈http://www.wto.org/english/res_e/statis_e/services_training_module_e.pdf $>$. Acesso em: 12 jul. 2014.

3 "Services account for a large and growing share of both production and employment in most countries. In developing countries, the average share of services in GDP increased from around 40 per cent in 1965 to around 50 per cent in recent years, while in the OECD countries, the average share increased over the same period from 54 per cent to over 60 per cent. Many of the fastest growing sectors in many countries are services like telecommunications, software, and finance.

The share of services in world trade and investment has also been increasing. They have been among the fastest growing components of world trade, growing by over 15 per cent per annum since 1980. Services trade, as estimated from balance of payments statistics, was around $\$ 2.1$ billion in 2004, representing over one-fifth of world trade in goods and services. This value is certainly understated, because much "trade" in services takes place through an established presence, i.e. via FDI, and hence generates local activity and value added that do not appear as exports in balance of payments statistics.

Today, more than half of annual world FDI flows are in services, and the value of sales abroad by foreign afliates of US service firms is estimated to be 3.5 times greater than their cross-border exports. B. COPELAND; A.MATTOO. The Basic Economics of Services Trade. A. MATTOO; R. M. STERN; G. ZANNI. A Handbook of International Trade in Services. Nova Iorque: Oxford University Press, 2007, p. 86.

${ }^{4}$ Fonte: International Trade Ststistics 2013. Disponível em:

<http://www.wto.org/english/res_e/statis_e/its2013_e/its13_toc_e.htm〉. Acesso em: 12 jul. 2014.
} 
Por isso, as exportações de serviços são um fator determinante para o crescimento da economia mundial e a liberalização comercial de serviços deve ser uma prioridade para o Brasil e para os demais Estados-membros da OMC. Estima-se, inclusive, que os ganhos resultantes da abertura do comércio de serviços podem ser muito maiores que aqueles alcançados com a liberalização do comércio de bens ${ }^{5}$.

Desde 1995, o comércio internacional de serviços encontra-se regulado multilateralmente pelo GATS, acordo que faz parte do quadro normativo da OMC. O GATS criou regras para o comércio internacional de serviços, além de implementar um sistema para a liberalização do setor, por meio da negociação de compromissos de acesso a mercados. Contudo, atualmente, o comércio internacional de serviços é regulado não apenas pelas normas da OMC, mas também por centenas de acordos regionais de comércio $^{6}$, os quais criam normas e preferências comerciais para seus signatários, formando um sistema paralelo de regras em relação à OMC.

A partir dos anos 1990, observou-se um aumento significativo no número de acordos regionais de comércio, em virtude, sobretudo, das paralisações observadas nas negociações da Rodada de Doha, na OMC. Ao longo dos 46 anos de funcionamento do GATT, foram realizadas apenas 124 notificações de acordos regionais de comércio. Nos 20 primeiros anos de funcionamento da OMC, o número praticamente triplicou. Em 12 de julho de 2014, 438 acordos regionais envolvendo o comércio de bens ou de serviços haviam sido notificados à OMC, totalizando 585 notificações desde o GATT. Desse total, 379 acordos encontravam-se em vigor nesta data ${ }^{7}$. De acordo com o Secretariado da OMC, praticamente todos os membros da OMC são Parte de um ou mais acordos regionais de comércio, sendo que alguns deles são Parte de mais de $20 \operatorname{acordos}^{8}$.

Além da proliferação no número de acordos regionais, houve ampliação no escopo destes acordos ao longo das duas últimas décadas. Enquanto os acordos celebrados no âmbito do GATT objetivavam apenas à redução das tarifas de importação de bens, os

\footnotetext{
${ }^{5}$ Vide A. MATTOO; R. M. STERN; G. ZANNI, 2007, p. 3.

6 Conforme convencionado pela OMC, o termo 'acordo regional de comércio' compreende acordos bilaterais, uniões aduaneiras e acordos plurilaterais de livre comércio, em seus diferentes níveis de integração. Portanto, não serão objeto desta tese os acordos recíprocos ou preferenciais de comércio, que têm lastro na Cláusula de Habilitação, e os acordos bilaterais de investimento. Para mais informações sobre os tipos de acordo regional de comércio e as diferenças entre acordos regionais e acordos preferenciais ou recíprocos, vide: BANCO MUNDIAL. Global Economic Prospects. Trade, Regionalism and Development. 2005. Disponível em: <http://www.siteresources.worldbank.org>. Acesso em: 20 jun. 2012. P. 28.

${ }^{7}$ Fonte: OMC (<http://www.wto.org/english/tratop_e/region_e/regfac_e.htm>). Acesso em: 12 jul. 2014.

8 "Nearly all of the WTO's Members have notified participation in one or more RTAs (some Members are party to twenty or more)". Vide: 〈http://www.wto.org/english/tratop_e/region_e/reffac_e.htm>. Acesso em: 15 jul. 2012.
} 
novos acordos são muito mais abrangentes, contemplando normas relacionadas ao comércio de bens e serviços, investimentos estrangeiros, defesa comercial, barreiras técnicas, barreiras sanitárias e fitossanitárias, solução de controvérsias, direitos de propriedade intelectual, regras de origem, entre outros. Dos 379 acordos regionais em vigor em 12 de julho de 2014, 412 foram notificados no âmbito do Artigo XXIV do GATT, 39 foram notificados no âmbito da Cláusula de Habilitação e 134 foram notificados no âmbito do Artigo V do GATS ${ }^{9}$.

Observa-se, assim, que uma parcela significativa dos Estados-membros da OMC têm optado pelo caminho do regionalismo para regular o comércio internacional de serviços. Entre esses Estados-membros, merecem destaque Estados Unidos, União Europeia, Índia e China. Atualmente, esses quatro são os principais players do comércio internacional. De acordo com estatísticas recentes da OMC, esses Estados-membros são os maiores exportadores e importadores de bens e de serviços do mundo ${ }^{10}$. União Europeia, Índia China e Estados Unidos também estão entre os principais signatários de acordos regionais. Segundo a OMC, em 12 de julho de 2014, estavam em vigor 14 acordos regionais envolvendo os Estados Unidos, 16 envolvendo a Índia, 12 envolvendo a China e 37 envolvendo a União Europeia ${ }^{112}$.

Além disso, estes players estão envolvidos nas negociações de "mega acordos" regionais, tais como: o TTIP, envolvendo Estados Unidos e União Europeia; o TPP, envolvendo Austrália, Brunei Darussalam, Canadá, Chile, Estados Unidos, Japão, Malásia, México, Nova Zelândia, Peru, Cingapura e Vietnã; e a Associação Econômica Integral Regional, envolvendo os Estados-membros da ASEAN, Austrália, China, Coreia, Japão, Índia e Nova Zelândia ${ }^{13}$. Esses acordos terão um impacto significativo nos fluxos de comércio globais de bens e serviços e, possivelmente, estabelecerão precedentes para futuras negociações comerciais multilaterais.

\footnotetext{
${ }^{9}$ Fonte: OMC (<http://www.wto.org/english/tratop_e/region_e/regfac_e.htm〉). Acesso em: 12 jul. 2014.

${ }^{10}$ De acordo com estatísticas da OMC, no ano de 2012, a União Europeia foi o maior exportador de bens e serviços, seguido pela China, que foi o segundo maior exportador de mercadorias e o terceiro maior exportador de serviços, e pelos Estados Unidos, que foram o terceiro maior exportador de mercadorias e o seguindo maior exportador de serviços. A Índia foi apenas o décimo quarto maior exportador de bens e o quinto principal exportador de serviços, em 2012. Vide: Trade Profiles 2013. Disponível em: <http://www.wto.org/english/res_e/publications_e/trade_profiles13_e.htm>. Acesso em: 12 jul. 2014.

${ }^{11}$ Inclui os acordos para incorporação de novos Membros e exclui acordos celebrados individualmente por Estados Membros.

${ }^{12}$ Fonte: OMC (<http://rtais.wto.org >). Acesso em: 12 jul. 2014.

13 BANCO INTERAMERICANO DE DESENVOLVIMENTO (BID), INSTITUTO PARA A INTEGRAÇÃO DA AMÉRICA LATINA E DO CARIBE (INTAL). Como as negociações de mega-acordos influirão na América Latina? Carta Mensal INTAL N 204, Agosto 2013, p. 10. Disponível em: <http://www10.iadb.org/intal/cartamensual/Cartas/PDF/204/pt/CartaMensal204_Coluna\%20de\%20An\%C3 $\%$ A1lise_Art1.pdf>. Acesso em: 14 mai. 2014.
} 
O Brasil, por sua vez, é Parte de pouquíssimos acordos regionais de comércio, todos no eixo Sul/Sul. Além dos acordos com Estados-membros da ALADI ${ }^{14}$, o Brasil, por meio do Mercosul ${ }^{15}$, é Parte de apenas cinco acordos regionais, a saber: acordos Mercosul-Índia, Mercosul-Israel, Mercosul-Egito, Mercosul-Palestina e Mercosul-SACU. Apenas dois desses acordos - Mercosul-Israel e Mercosul-Egito - preveem a liberalização do comércio de serviços inter-Partes, a ser realizada no futuro, sem prazo definido. Não obstante, o único acordo envolvendo o Brasil e o Mercosul que contém normas e procedimentos concretos para a liberalização do comércio de serviços inter-Partes é o $\mathrm{ACE} \mathrm{N}^{\circ} 35$, entre Mercosul e Chile. Atualmente, o bloco está envolvido na negociação de um acordo de livre comércio ambicioso com a União Europeia há mais de 10 anos. Se concluído, esse acordo será o mais importante acordo regional celebrado pelo bloco. Serviços é um dos temas chave desse acordo, em razão dos interesses ofensivos da União Europeia nesse setor.

A análise dos acordos regionais celebrados pelo Mercosul permite que se conclua que o bloco sul-americano não possui um modelo claro de normas para a abertura do setor de serviços. Não há diretrizes de política externa comum a respeito do tema, a despeito da relevância econômica desse setor para o Brasil e para os demais Estados-membros do Mercosul.

Desse modo, no cenário atual, os principais players do comércio internacional estão inseridos em redes de preferências comerciais envolvendo bens e serviços, construídas ao longo das últimas décadas, que devem se expandir ainda mais com os "mega acordos". Esse cenário é preocupante para o Brasil e para o Mercosul, que possuem preferências comerciais pouco significativas, limitadas à liberalização do comércio de bens, no eixo Sul/Sul. Ademais, não há diretrizes de política externa comum nem um modelo de acordo para a abertura comercial do setor de serviços.

Além disso, alguns Membros da OMC com interesses ofensivos no setor de serviços, como Estados Unidos e União Europeia, lideram a iniciativa para a negociação um novo acordo plurilateral sobre o comércio de serviços, o TISA, que poderá, futuramente, substituir o GATS. O único Estado-membro do Mercosul que participa dessa negociação é o Paraguai. Consequentemente, Brasil e Mercosul correm o risco de ficar isolados das

\footnotetext{
${ }^{14}$ Atualmente, o Brasil e o Mercosul são Parte dos seguintes acordos comerciais celebrados no âmbito da ALADI: Mercosul-Chile (ACE-35); Mercosul-Bolívia (ACE-36); Brasil-México (ACE-53); MercosulMéxico (ACE-54); Automotivo Mercosul-México (ACE-55); Mercosul-Peru (ACE-58); Mercosul-Colômbia, Equador e Venezuela (ACE-59); Brasil-Guiana (ACE-38); Brasil-Suriname (ACE-41); Brasil-Venezuela (ACE-69); Mercosul-Cuba (ACE-62).

${ }^{15}$ Conforme estabelecido pela Decisão CMC No. 32/00, os Estados-membros do Mercosul só poderiam negociar acordos comerciais com terceiros países ou blocos de países de forma conjunta, salvo com Estadosmembros da ALADI.
} 
redes de preferências comerciais e de aderir às regras multilaterais relativas a serviços que foram elaboradas sem a sua participação.

O que se pretende demonstrar nessa tese é que o Brasil e o Mercosul precisam se engajar, imediatamente, no processo de negociação de preferências comerciais no setor de serviços com players importantes do comércio internacional, sob pena de perderem mercado e ficarem alijados desse processo de integração econômica. Para tanto, Brasil e o Mercosul devem refletir e desenvolver um modelo próprio de regras para a abertura comercial do setor de serviços em acordos regionais de comércio, de forma a estarem mais capacitados para negociar esses acordos. Esse modelo deve possibilitar a abertura comercial do setor de serviços sem abrir mão de questões importantes para o bloco e para seus Membros, como a manutenção de espaço para a realização de políticas públicas.

A presente tese foi desenvolvida por meio da análise dos acordos regionais celebrados por Estados Unidos, Índia, China e União Europeia, com o intuito de verificar em que medida tais acordos poderiam servir como parâmetro para um modelo de acordo regional em serviços a ser desenvolvido para o Mercosul. Esses players foram escolhidos em razão do importante papel desempenhado por eles no âmbito do comércio internacional, bem como por sua experiência e liderança na celebração de acordos regionais de comércio.

A metodologia empregada no desenvolvimento da tese foi baseada nos métodos histórico e comparativo-dedutivo.

Para contextualizar o tema objeto da tese, foi apresentada uma breve descrição sobre as principais características dos acordos regionais de comércio, com vistas a explicar a relação jurídica entre regionalismo e Sistema Multilateral de Comércio e os efeitos econômicos desses acordos. Com isso, buscou-se esclarecer que o regionalismo é um fenômeno permitido e autorizado pela própria OMC e que, embora haja controvérsias sobre os efeitos dos acordos regionais sobre o próprio Sistema Multilateral de Comércio, trata-se de uma realidade irreversível. Também foi apresentada uma análise evolutiva de como regras sobre o comércio de serviços foram inseridas em acordos regionais. Essa perspectiva histórica pretende demonstrar não apenas de que modo o sistema composto pelos acordos regionais tornou-se um sistema normativo próprio, mas também quais são as principais características dos acordos regionais do século XXI.

O enfoque comparativo-dedutivo foi aplicado na análise das principais características do GATS, a saber: estrutura do Acordo, escopo de aplicação, princípios, exceções e o modo pelo qual ocorre a liberalização do comércio de serviços entre os Membros da OMC. 
A explicação sobre a as normas multilaterais aplicáveis ao setor de serviços é relevante para a construção do tema objeto de estudo, visto que as normas existem nos acordos de livre comércio que foram construídas a partir dos princípios regulamentados no GATS e devem ser compatíveis com esse acordo.

O método comparativo-dedutivo foi utilizado para analisar os acordos regionais celebrados por Mercosul, Estados Unidos, União Europeia, Índia e China que disciplinam o comércio de serviços. Após o exame detalhado das cláusulas relevantes desses acordos, foi possível verificar quais são os pontos comuns e as principais diferenças entre as abordagens adotadas por esses players, em termos de metodologia para assunção de compromissos, escopo dos compromissos, regulação doméstica, obrigações e limitações de tratamento nacional e acesso a mercados, entre outras normas relevantes para a liberalização comercial do setor de serviços.

Desse modo, por meio da conjugação de elementos históricos, jurídicos, econômicos e políticos, realizou-se uma análise crítica e comparativa dos acordos regionais de comércio celebrados pelo Mercosul, Estados Unidos, União Europeia, Índia e China no tocante ao tema serviços, com vistas a verificar qual o modelo mais adequado aos interesses e objetivos do bloco sul-americano para a abertura comercial desse setor.

A presente tese foi dividida em duas partes. Na Parte I, foram estudadas as principais características do Sistema Multilateral de Comércio e dos acordos regionais de comércio em relação ao setor de serviços, com foco na relação entre esses dois sistemas. Na Parte II, o foco foi o tratamento dado por Mercosul, Estados Unidos, União Europeia, China e Índia ao comércio de serviços nos acordos regionais de comércio que foram celebrados por cada um desses players. Cada parte foi dividida em 3 capítulos.

$\mathrm{Na}$ Parte I, o Capítulo 1 abordou a relação entre os acordos regionais de comércio e o Sistema Multilateral de Comércio. Esse capítulo descreveu os acordos regionais como uma exceção autorizada pela própria OMC. Na sequência, foram analisadas as teorias econômicas e jurídicas relacionadas a esse tema para verificar quais são os efeitos econômicos dos acordos regionais e quais principais vantagens e desvantagens desses acordos. Nesse sentido, também foi analisado se os acordos regionais constituem blocos de construção ou blocos de contenção. Por fim, foi explicado como os acordos regionais se descolaram do Sistema Multilateral de Comércio a partir dos anos 1990, tornando-se uma realidade incontestável e irreversível.

No Capítulo 2, foram analisadas as principais características do GATS, acordo que regula o comércio sobre serviços da OMC, de modo a possibilitar a compreensão de como 
se dá a regulamentação multilateral do tema. Esse Capítulo apresentou os conceitos que foram analisados nos capítulos seguintes, os quais possibilitaram que se efetuasse uma comparção entre o tratamento de determinadas questões nos acordos regionais de comércio e no GATS. O Artigo V do GATS foi analisado de forma detalhada, visto que esse Artigo contém as regras aplicáveis à integração regional no setor de serviços.

No Capítulo 3, a inserção de regras sobre o comércio de serviços em acordos regionais foi analisada sob a perspectiva histórica, com vistas a verificar como se deu a evolução do tratamento do tema serviços em âmbito regional. Foram avaliadas as principais consequências da inserção de regras sobre o comércio de serviços em acordos regionais e quais os desafios que essa regulação tem apresentado à OMC. Na sequência, foi examinada a forma pela qual se dá a compatibilização dos acordos regionais com as regras multilaterais do GATS. Após essa análise, foi apresentado o debate acerca da análise comparativa entre as disposições dos acordos regionais de comércio e os dispositivos do GATS, que resulta na classificação dos acordos regionais em "GATS-plus", "GATSminus" e "GATS-extra".

No Capítulo 1 da Parte II, foram analisados os acordos regionais celebrados por Estados Unidos, União Europeia, China e Índia que contêm cláusulas relativas à abertura comercial do setor de serviços. A partir da análise comparativa desse acordos, foi possível obter um panorama completo e abrangente das regras mais frequentemente utilizadas por Estados Unidos, União Europeia, China e Índia para regular o comércio de serviços, em âmbito regional, com ênfase nos seguintes aspectos: (i) Escopo do capítulo sobre serviços; (ii) Forma de assunção dos compromissos, ou seja, se a lista de compromissos adotada pelo acordo é negativa (modelo NAFTA) ou positiva (modelo GATS); (iii) Existência de regras sobre regulação doméstica; (iv) Existência de regras sobre transparência; (v) Se o tratamento nacional é determinado pelos mesmos parâmetros adotados pelo GATS; (vi) Se o acesso a mercados é determinado pelos mesmos parâmetros quantitativos adotados pelo GATS. Assim, foi possível avaliar as principais vantagens e desvantagens do modelo adotado por cada um desses players.

A respeito da metodologia empregada na análise realizada no Capítulo 1 da Parte II, cumpre notar que foram examinados apenas os acordos regionais envolvendo o comércio de serviços celebrados por Estados Unidos, União Europeia, Índia, China e Mercosul com Estados, grupos de Estados e organizações internacionais ${ }^{16}$ que contêm alguma previsão

\footnotetext{
${ }^{16}$ Como é o caso da ASEAN.
} 
relativa à liberalização do comércio de serviços entre as Partes. Portanto, acordos celebrados com regiões administrativas não foram analisados. Também não foram analisados os acordos relativos à liberalização comercial em serviços celebrados pela União Europeia com outros Estados europeus ${ }^{17}$. Com relação ao corte temporal, foram analisados somente os acordos que estavam em vigor em 15 de fevereiro de 2013. Também não foram analisados os acordos que não tratam do comércio de serviços ou que não criam obrigações recíprocas para as Partes.

No Capítulo 2, foi examinado como o Mercosul trata o tema serviços nos acordos regionais que foram celebrados pelo bloco e nos acordos que estão em negociação. Para que fosse possível compreender o posicionamento do Mercosul a respeito da liberalização comercial do setor de serviços, foi realizada uma análise da liberalização do setor intrabloco e de quais as diretrizes e limitações impostas à celebração de acordos regionais pelos Estados-membros. Desse modo, foi possível verificar a existência de um padrão quanto às principais cláusulas adotadas pelo Mercosul nos acordos regionais celebrados pelo bloco. A respeito da metodologia empregada na análise realizada nesse Capítulo, foram analisados todos os acordos celebrados pelo Mercosul com Estados que não são Membros da ALADI. Com relação aos ACE celebrados pelo Mercosul com no âmbito da ALADI, apenas foram analisados os ACE Mercosul-Chile e Mercosul-Colômbia, visto que os demais não possuem disposições relevantes para a liberalização do comércio de serviços.

No Capítulo 3, foi realizada uma análise crítica entre o tratamento dado a serviços pelos acordos regionais celebrados por Estados Unidos, União Europeia, China, Índia, de um lado, e pelo Mercosul, de outro, com vistas a verificar qual seria o melhor modelo de acordo regional para o Mercosul no que se refere à liberalização do comércio de serviços. Também foram analisados dois movimentos atuais para a liberalização do comércio de serviços que buscam a atualização e o aprimoramento das regras existentes, a saber: o TISA e os "mega acordos", como o TPP e o TTIP. Por fim, foi proposto um modelo de liberalização comercial em serviços que poderia ser adotado pelo Brasil ou pelo Mercosul nos acordos regionais que venham a celebrar, bem como qual deve ser o posicionamento do Brasil e do Mercosul em face das novas tendências para a liberalização do comércio de serviços.

${ }^{17}$ Albânia, Montenegro, Sérvia e República da Macedônia. 
Ao final desta tese, foram apresentadas as considerações finais tanto em relação ao modelo de regras que deve ser adotado pelo Brasil e pelo Mercosul para a abertura comercial do setor de serviços, quanto em relação à posição que deve ser adotada pelo Brasil e pelo Mercosul nas negociações de acordos regionais de comércio. 
PARTE I

SISTEMA MULTILATERAL DE COMÉRCIO E REGIONALISMO 


\section{CAPÍTULO 1: O SISTEMA MULTILATRAL DE COMÉRCIO E O REGIONALISMO}

\section{INTRODUÇÃO}

Atualmente, um dos grandes desafios do Sistema Multilateral de Comércio consiste na coordenação entre as regras comerciais estabelecidas multilateralmente no âmbito da OMC e as regras estabelecidas pelos acordos regionais de comércio.

A partir dos anos 1990, observou-se um aumento significativo no número de acordos regionais. Entre os fatores que propiciaram a proliferação dos acordos regionais nos últimos anos, encontra-se o fato de que é mais fácil negociar bilateral ou regionalmente o acesso aos mercados de bens e serviços de outros Membros e normas comerciais de um modo geral do que negociá-los multilateralmente. Isso porque muitos Membros da OMC relutam em assumir compromissos substanciais em âmbito multilateral, já que as preferências concedidas nos compromissos assumidos em serviços terão que ser estendidas a todos os demais Membros ${ }^{18}$.

Não há como negar que esses acordos tornaram-se uma fonte importante de regras internacionais relativas ao comércio de bens e serviços. Além da proliferação no número de acordos regionais, observou-se a ampliação no seu escopo ao longo das duas últimas décadas.

Enquanto os acordos celebrados no âmbito do GATT objetivavam apenas à redução das tarifas de importação de bens, os novos acordos são muito mais abrangentes, contemplando normas relacionadas ao comércio de bens e serviços, investimentos estrangeiros, defesa comercial, barreiras técnicas, barreiras sanitárias e fitossanitárias, solução de controvérsias, direitos de propriedade intelectual, regras de origem, entre outros.

Logo, não é de estranhar que a importância econômica dos acordos regionais de comércio também esteja aumentando. Estima-se que, atualmente, mais da metade do

\footnotetext{
18 "Given the reluctance of many countries to make substantial commitments multilaterally, a growing number of countries resort to including services in preferential agreements as a means of improving access to foreign markets as well as developing and establishing international rules on trade in services". T. COTTIER;M. MOLINUEVO. Article V GATS Economic Integration. In: R. WOLFRUM; P.-T. STOLL; C. FEINÄUGLE (ed.). WTO - Trade in Services. Leiden: Martinus Nijhoff Publishers, 2008, p. 127.
} 
comércio internacional de bens seja efetuada por preferências estabelecidas em acordos desse tipo ${ }^{19}$.

Em vista da relevância crescente dos acordos regionais de comércio e do seu alcance cada vez mais amplo, em termos das áreas do comércio internacional por eles abrangidas, é inevitável que o Sistema Multilateral de Comércio tenha que se adequar à nova realidade e buscar uma coexistência harmônica entre os diferentes sistemas de preferências comerciais existentes.

\section{O SURGIMENTO dOS ACORDOS REGIONAIS DE COMÉRCIO COMO UMA EXCEÇÃO AO PRINCÍPIO DA NÃO DISCRIMINAÇÃO}

Os acordos regionais de comércio e a concessão de preferências comerciais não são um fenômeno recente ${ }^{20}$. Contudo, verifica-se que, desde a criação do GATT, um número maior de Estados tem assumido obrigações comerciais vinculantes, seja em âmbito multilateral, regional, ou bilateral. Também se verifica que essas obrigações são cada vez mais abrangentes em termos de escopo e mostram-se, por vezes, conflitantes entre si.

De fato, foi com o surgimento do GATT, o primeiro acordo multilateral sobre o comércio de bens, que foi regulamentada a possibilidade de celebração de acordos regionais como uma exceção ao princípio da não discriminação. O GATT, que entrou em vigor em 1948, consistia em um conjunto de regras aplicáveis ao comércio de bens entre as Partes Contratantes. Seu principal objetivo era a promoção da abertura do comércio internacional por meio da redução das tarifas aduaneiras. Para alcançar esse objetivo, as Partes Contratantes estabeleceram como um dos princípios do comércio internacional de bens a não discriminação, consubstanciada na Cláusula de Tratamento Geral de Nação Mais Favorecida (Art. I do GATT). Tal princípio determina que qualquer espécie de privilégio relativo a direitos aduaneiros concedidos às Partes Contratantes deva ser

\footnotetext{
${ }^{19}$ Vide A. ESTEVADEORDAL; K. SUOMINEN; R. THE. Regional Rules in the Global Trading System. Cambridge: Cambrigde Unversity Press, 2009, p. 1.

20 "Global trade relations have never been uniform or monolithic and regional trading arrangements have been around for centuries. Regional trading arrangements have encompassed empires and colonial spheres of influence, bilateral commercial treaties and, more recently, multilateral agreements. They have often overlapped and interacted, creating a trade landscape defined less by clear-cut choices between regionalism and multilateralism - or discrimination and nondiscrimination - than by the complex interplay, even competition, among multiple trade regimes". ORGANIZAÇÃO MUNDIAL DO COMÉRCIO. World Trade Report 2011. P. 5. Disponível em: <www.wto.org>. Acesso em: 10 jul. 2012.
} 
automaticamente estendido aos produtos similares comercializados com qualquer outra Parte Contratante ${ }^{21}$.

Não obstante o GATT proibir a adoção de medidas discriminatórias entre as Partes Contratantes, o próprio Acordo previu algumas exceções ao Tratamento Geral de Nação Mais Favorecida, sendo a principal delas a exceção prevista no Art. XXIV ${ }^{22}$. O Art. XXIV do GATT determina que uma Parte contratante pode conceder tratamento mais favorável às Partes Contratantes que também são partes em Uniões Aduaneiras ou Áreas de Livre Comércio $^{23}$. Durante a vigência do GATT, a exceção ao princípio da não discriminação foi ampliada, de forma unilateral, para possibilitar a concessão de preferências comerciais a países em desenvolvimento, com fundamento na Cláusula de Habilitação ${ }^{24}$.

Portanto, embora representem uma exceção ao princípio da não discriminação, os acordos regionais envolvendo o comércio de bens foram reconhecidos como legítimos e legais pelo GATT. Esse entendimento foi incorporado pela OMC. Além da manutenção do Art. XXIV e da Cláusula de Habilitação, o escopo das normas multilaterais que permitiam a discriminação entre os Membros em virtude de acordos regionais foi ampliado por meio

21 “ARTIGO I - TRATAMENTO GERAL DE NAÇÃO MAIS FAVORECIDA - 1. Qualquer vantagem, favor, imunidade ou privilégio concedido por uma parte contratante em relação a um produto originário de ou destinado a qualquer outro país será imediata e incondicionalmente estendido ao produtor similar, originário do território de cada uma das outras partes contratantes ou ao mesmo destinado". Decreto $n^{\circ} 313$, de 30 de julho de 1948, que autoriza o Poder Executivo a aplicar, provisoriamente, o Acordo Geral sobre Tarifas Aduaneiras e Comércio; reajusta as tarifas aduaneiras e dá outras providências. Disponível em: <www.mre.gov.br>. Acesso em: 10 out. 2010.

${ }^{22}$ Também constitui exceção ao artigo I do GATT a diferenciação de impostos de importação e exportação, quando se tratar de aspectos relacionados à política pública ou à segurança, nos termos dos Art. XX e do artigo XXI do GATT, respectivamente.

23 “Art. XXIV - 2. As disposições do presente Acordo não deverão ser interpretadas como obstáculo:a) às vantagens concedidas por uma Parte contratante a países limítrofes, para facilitar o tráfego de fronteira; b) à formação de uma união aduaneira ou à conclusão de um acordo provisório necessário à realização de uma união aduaneira sob reserva, por um lado, de que os direitos de Alfândega e outras regulamentações das trocas comerciais impostas por uma união ou um acordo dessa natureza, ou as margens de preferência mantidas por tais convenções no que diz respeito às relações comerciais com as Partes Contratantes não sejam, no conjunto, mais elevados ou mais rigorosos do que eram em média os direitos e as regulamentações aplicáveis às trocas comerciais ou às margens de preferência em vigor antes da formação dessa união alfandegária ou à conclusão desse acordo nos territórios que constituem a união e, por outro lado que qualquer acordo provisório dessa natureza comporte um plano e um programa definidos para a realização, em prazo razoável, de tal união aduaneira". Decreto $n^{\circ} 313$, de 30 de julho de 1948, que autoriza o Poder Executivo a aplicar, provisoriamente, o Acordo Geral sobre Tarifas Aduaneiras e Comércio; reajusta as tarifas aduaneiras e dá outras providências. Disponível em: 〈www.mre.gov.br〉. Acesso em: 10 out. 2010.

${ }^{24}$ A "Decisão sobre Tratamento Diferenciado e mais Favorável, Reciprocidade e Maior Participação dos Países em Desenvolvimento" foi adotada pelas Partes Contratantes do GATT durante a Rodada Tóquio, em 1979, e estabelece a possibilidade de concessão de preferências comerciais, de forma unilateral, para países em desenvolvimento, com a finalidade de reduzir ou eliminar mutuamente as barreiras comerciais entre estes. A Cláusula de Habilitação também foi incorporada às regras da OMC, mas, por se tratar de um tipo distinto de acordo, que é concedido por um Membro de forma unilateral, ele não será objeto da presente tese. Para mais informações sobre a Cláusula de Habilitação, vide ACORDO GERAL SOBRE TARIFAS E COMÉRCIO. L/4903. Decision of 28 November 1979. Acesso em: 15 jul. 2012. 
do estabelecimento, no GATS, de regras semelhantes às do Artigo XXIV do GATT para os acordos regionais que contemplem o comércio de serviços.

Não há consenso a respeito do efeito desse tipo de acordo sobre o Sistema Multilateral de Comércio. Há doutrinadores que alegam que os acordos regionais têm um efeito positivo para o comércio internacional, ao passo que outros entendem que estes acordos não só não trazem efeitos positivos, como o próprio conceito da não discriminação tem sido erodido com a sua proliferação.

A seguir, serão abordadas as principais críticas feitas aos acordos regionais sob a ótica jurídica e econômica.

\section{O DEBATE SOBRE AS VANTAGENS E DESVANTAGENS DOS ACORDOS REGIONAIS DE COMÉRCIO: BLOCOS DE CONSTRUÇÃO OU BLOCOS DE CONTENÇÃO?}

Por um lado, há estudiosos que alegam que, na prática, os acordos regionais são positivos para o Sistema Multilateral de Comércio. Para eles, os acordos regionais resultam no aprofundamento da liberalização comercial, à medida que reduzem tarifas de importação e barreiras não tarifárias além do consolidado na OMC. Esses estudiosos entendem que há uma tendência de que as novas regras para o comércio criadas em âmbito regional sejam consolidadas multilateralmente, ainda que a posteriori, o que ampliaria o escopo da liberalização comercial ${ }^{25}$. Por esse motivo, os acordos regionais funcionariam como "blocos de construção" (building blocs) das regras multilaterais, acelerando progressivamente as negociações comerciais e aumentando o número de Membros da $\mathrm{OMC}^{26}$.

Por outro lado, há estudiosos que entendem que os acordos regionais são contrários à lógica do Sistema Multilateral de Comércio, que consiste na liberalização comercial por meio da não discriminação entre os Membros, exceto em circunstâncias excepcionais. Uma vez que os acordos regionais excluem outros países da liberalização, estes constituem um sistema dominado pela discriminação, o que contraria a lógica do Sistema Multilateral de Comércio e resulta em normas conflitantes e/ou contraditórias em relação às normas da OMC. O principal defensor dessa posição é Jagdish Bhagwati.

25 Entre aqueles que defendem esta posição, encontram-se Thomas Cottier e Martín Molinuevo. Vide COTTIER; MOLINUEVO, 2008, p. 126-127.

${ }^{26}$ Vide ESTEVADEORDAL; SUOMINEN; THE, 2009, p. 2. 
Segundo Bhagwati, o atual Sistema Multilateral de Comércio é composto por uma enorme gama de acordos bilaterais e regionais complexos e sobrepostos, com disposições conflitantes e contraditórias sobre o comércio de bens e de serviços. Tais acordos criariam restrições e estruturas regulatórias complexas, que tornariam o livre comércio cada vez mais difícil e custoso, aumentando os custos de transação associados à atividade comercial $^{27}$. Essa questão será abordada no item 1.3.3. abaixo, quando tratarmos dos efeitos econômicos dos acordos regionais. Assim, os acordos regionais funcionariam como "blocos de contenção" (stumbling blocs), que podem prejudicar um dos princípios fundamentais do livre comércio, a saber, o princípio da não discriminação ${ }^{28}$.

A seguir, será realizada uma breve análise dos efeitos econômicos dos acordos regionais de comércio, de modo a verificar se essa seria a opção mais eficiente de liberalização sob a ótica da análise econômica ou se o multilateralismo traz mais ganhos em eficiência do que o regionalismo.

\section{ANÁliSE DOS EFEITOS ECONÔMICOS DOS ACORDOS REGIONAIS DE COMÉRCIO}

É inegável que o cenário ideal para os economistas seria aquele no qual o comércio fosse verdadeiramente livre, com a troca fácil de bens e serviços entre empresas e consumidores através das fronteiras. Segundo William Watson e Viet D. Do, os governos interviriam apenas para corrigir falhas de mercado, o que não significaria discriminar entre os prestadores de serviços ou comerciantes nacionais e estrangeiros. Consequentemente, vigoraria a lei da vantagem comparativa e os bens e serviços seriam fornecidos pelo fornecedor economicamente mais eficiente, que cobraria preços inferiores aos dos seus concorrentes $^{29}$.

Nesse contexto, os acordos regionais de comércio representam - ou deveriam representar - um movimento em direção ao livre comércio. Se o comércio internacional

27 J. BHAGWATI. Termites in the Trading System How Preferential Agreements Undermine Free Trade. Nova York: Oxford University Press, 2008.

${ }^{28}$ Vide ESTEVADEORDAL; SUOMINEN; THE, 2009, p. 3.

29 "At the end of trade economists' rainbow is full free trade, a world in which consumers and firms can exchange goods and services as easily across international boundaries as within countries. It would not be a pure laisser-faire world: governments would still intervene to try to correct market failures. But addressing such failures generally would not require discriminating against foreign sellers of goods and services. As a result, the laws of comparative advantage would cause such goods and services to be provided by whomever could provide them most cheaply". W. WATSON; V. D. DO. Economic Analysis of Regional Trade

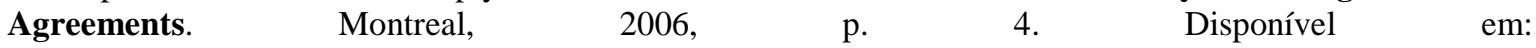
<http://www.mcgill.ca/files/economics/economicanalysisof.pdf>. Acesso em: 20 jun. 2012. 
sem barreiras tarifárias ou não tarifárias é a política mais eficiente do ponto de vista econômico, qualquer movimento em sua direção deveria ser benéfico ao consumidor. Assim, seria lógico supor que, em um mundo em que ainda existem barreiras comerciais, sejam elas tarifárias ou não tarifárias, quanto maior o número de áreas em que efetivamente há livre comércio, melhor.

Contudo, o senso comum se choca com os resultados obtidos pela teoria da análise econômica em relação à integração regional ao longo das últimas décadas. De modo geral, um mundo mais liberalizado do ponto de vista comercial, mas que ainda não é totalmente liberalizado, pode não produzir mais bem estar do que um mundo menos liberalizado ${ }^{30}$.

Em trabalho pioneiro publicado em 1950, Jacob Viner ${ }^{31}$ sugeriu uma nova metodologia para distinguir os efeitos benéficos dos efeitos prejudiciais de um acordo regional de comércio. Segundo a teoria de Viner, para que seja possível constatar se os acordos regionais são eficientes do ponto de vista econômico, é necessário analisar se eles resultam na criação de comércio (trade creation) ou no desvio de comércio (trade diversion). Para essa teoria econômica, embora o livre comércio seja considerado a política comercial economicamente mais eficiente, não é verdade que um passo na direção da liberalização resultaria, necessariamente, em maior eficiência econômica. Um acordo regional de comércio aumentará o bem-estar de um país e resultará em maior eficiência econômica e ganhos de bem estar à medida que resultar em criação de comércio. Por sua vez, um acordo regional resultará em menor eficiência econômica se resultar em desvio de comércio.

A liberalização do comércio para os bens de determinado Estado, em virtude da celebração de um acordo regional de comércio, resultará na redução dos impostos de importação e barreiras não tarifárias às demais Partes Contratantes do acordo. Assim, uma Parte de um acordo regional terá maior interesse em exportar para outra Partes Contratantes do acordo do que para um terceiro Estado, com o qual ele não possui acordo regional. Como consequência, é muito provável que os consumidores do Estado importador trocarão os bens fornecidos por produtores nacionais pelos bens de fornecedores da Parte Contratante do acordo, se os preços destes forem mais baixos. A esse mecanismo, Viner denominou de criação de comércio.

\footnotetext{
${ }^{30}$ WATSON; DO, 2006, p. 4 -5.

31 Jacob Viner introduziu esses conceitos em seu livro The Customs Union Issue. NewYork: Carnegie Endowment for International Peace, publicado em 1950.
} 
Assim, seria lógico esperar que a criação de comércio estimulasse o aumento do comércio intrabloco e, em teoria, levasse ao aperfeiçoamento na alocação eficiente de recursos escassos, resultando em ganhos de bem estar não só para os produtores, mas também para os consumidores. O desvio de comércio, por sua vez, foi descrito por Viner como uma mudança no padrão de consumo doméstico de um fornecedor internacional mais barato para um fornecedor de um Estado parceiro mais caro, em decorrência da celebração de um acordo regional de comércio ${ }^{32}$.

Alguns tipos de acordo regional de comércio, como as Uniões Aduaneiras, pressupõem a adoção de uma Tarifa Externa Comum. Isso significa que todos os Estados que não são Parte do acordo regional estão sujeitos ao pagamento de um mesmo imposto de importação para exportar determinado bem aos Estados Partes do acordo. Já os Estados Partes do acordo estão, de modo geral, isentos do pagamento de impostos de importação. Se a Tarifa Externa Comum for muito elevada, é provável que os produtores mais eficientes, mas que não são beneficiários do acordo e que antes forneciam produtos aos consumidores a preços menores, sejam substituídos por fornecedores menos eficientes. Estes fornecedores têm um custo de produção mais elevado, mas, em decorrência das barreiras comerciais impostas aos Estados que não são partes, seus produtos tornaram-se mais competitivos do que os produtos dos fornecedores tradicionalmente mais eficientes ${ }^{33}$.

Os prejuízos resultantes dessa política comercial são evidentes. De acordo com a teoria econômica, o protecionismo consubstanciado na forma de imposto de importação resulta em peso morto ou perdas de bem estar social. Consequentemente, pela teoria da criação ou desvio de comércio, de modo geral, não seria economicamente eficiente que um Estado liberalizasse seu mercado por meio de acordos regionais. Seria mais eficiente, do ponto de vista econômico, que a liberalização ocorresse multilateral, e não regionalmente.

Outra teoria econômica muito aplicada para explicar as políticas comerciais internacionais é a teoria do segundo melhor, que foi formalizada por Richard Lipsey e

\footnotetext{
${ }^{32}$ Para verificar como esta teoria é comprovada por meio de modelos econométricos, vide H. MUKUNOKI. Understanding the Effects of Preferential Trade Agreements: A Theoretical Overview. Bulletin of Gakushuin University Research Institute of Economics and Management, No. 19, Dezembro de 2005. P. Disponível em: 〈http://www-cc.gakushuin.ac.jp/ 20030012/paper/GEM19-mukunoki.pdf〉. Acesso em: 28 jun. 2012. J. CHEONG; K.-Y. WONG. Economic Integration, Trade Divertion and Welfare Change. 30 de novembro de 2007. Disponível em: <http://faculty.washington.edu/karyiu/papers/trade-divert.pdf >. Acesso em: 28 jun. 2012.

${ }^{33}$ Cumpre ressaltar que nem sempre o desvio de comércio terá efeitos prejudiciais ao consumidor. Em alguns casos, o bem estar de uma nação poderá aumentar mesmo com a existência de desvio de comércio, dependendo da situação concreta verificada no Estado em questão e dos preços cobrados pelos fornecedores de bens e serviços que serão afetados pelo acordo comercial. Vide R. J. WONNACOTT. Free-Trade Agreements: For Better or Worse? The American Economic Review. Vol. 86, No. 2, (May, 1996), São Francisco: American Economic Association, 2006, p. 64.
} 
Lancaster Kelvin, em $1956^{34}$. De acordo com essa teoria, quando há distorções ou imperfeições em um mercado, adicionar outra distorção (na forma de políticas comerciais, como uma remoção de barreiras tarifárias e não tarifárias) poderia aumentar o bem estar ou a eficiência econômica.

Antes de um país ingressar em um acordo regional de comércio, ele já está sujeito a distorções em vigor na forma de barreiras tarifárias. Isso significa que o equilíbrio inicial pode ser caracterizado como um equilíbrio secundário (ou o segundo melhor equilíbrio). Quando um acordo de livre comércio é formado, algumas dessas distorções são removidas, notadamente as tarifas aduaneiras e barreiras não tarifárias em relação às demais Partes Contratantes do acordo. Contudo, remanescem outras distorções, tais como as tarifas aduaneiras aplicadas em relação aos Estados que não são partes do acordo.

Desse modo, conclui-se que, se a remoção parcial das barreiras tarifárias causa efeitos negativos em virtude das tarifas que continuaram em vigor em face de terceiros Estados, os ganhos de eficiência obtidos com a liberalização do comércio regional poderiam ser anulados pelos efeitos negativos sobre o bem estar causados pelas barreiras remanescentes em relação a Estados que não são partes do acordo, reduzindo substancialmente os ganhos de bem estar nacionais resultantes do acordo. Isso é, na essência, o mesmo que ocorre quando há desvio de comércio. Quando um acordo regional faz com que os bens fornecidos por um produtor mais eficiente sejam substituídos pelos bens de um fornecedor menos eficiente, há redução de bem estar. Embora a economia também se beneficie da eliminação de distorções domésticas, se esses benefícios forem inferiores à perda de eficiência do fornecedor, então haverá queda de bem estar nacional. Portanto, em vista da aplicação pura da teoria do segundo melhor, de modo geral, seria possível afirmar que a liberalização comercial resultaria em maiores ganhos de eficiência se um país removesse todas as suas barreiras comerciais em relação a todos os países.

Tanto a teoria desenvolvida por Viner quanto a teoria do segundo melhor foram criticadas em relação à confiabilidade das conclusões em uma análise genérica ${ }^{35}$. Em vista das limitações e dos resultados pouco confiáveis da aplicação pura das teorias da criação

\footnotetext{
${ }^{34}$ R. G. LIPSEY; K. LANCASTER. The General Theory of Second Best. The Review of Economic Studies. Oxford: Oxford University Press, 1956 - 1957. Vol. 24, No. 1, p. 11-32. Disponível em: <http://www.jstor.org/stable/10.2307/2296233>. Acesso em: 28 jun. 2012.

35 "Given the second-best environment, it is impossible to draw strong general conclusions about the desirability of forming an RTA from the perspective either of members or of the rest of the world, from theory alone. There are tradeoffs, and empirical work is required to make any welfare judgments in particular cases". M. E. BURFISHER; S. ROBINSON; K. THIERFELDER. Regionalism: Old and New, Theory and Practice. MTID Discussion Paper No. 65. Fevereiro de 2004. Disponível em: <http://ageconsearch.umn.edu/bitstream/16137/1/mt040065.pdf>. Acesso em: 29 jun. 2012.
} 
de distorção de comércio e da teoria do segundo melhor, os economistas têm incorporado outros elementos e teorias econômicas na análise dos efeitos dos acordos regionais de comércio.

Conforme já mencionado, Jagdish Bhagwati apontou como uma consequência econômica negativa importante dos acordos regionais o aumento dos custos de transação. Para Bhagwati, cada acordo regional possui uma rede complexa de normas relativas a preferências tarifárias, barreiras técnicas, compras governamentais, antidumping, subsídios, salvaguardas, regras de origem, entre outras. Esses sistemas jurídicos paralelos resultantes dos acordos regionais somam-se às normas comerciais multilaterais da $\mathrm{OMC}, \mathrm{o}$ que faz com que um mesmo produto esteja sujeito a um grande número de normas, tornando o conhecimento e o cumprimento de todas essas normas muito difícil para o agente econômico ${ }^{36}$. Bhagwati denominou esse fenômeno complexo de normas de "Spaguetti Bowl" 37.

Assim, os custos de transação relacionados às exportações para determinado Estado, em razão dos acordos regionais dos quais é Parte, podem ser tão elevados a ponto de se tornarem um verdadeiro empecilho ao comércio ${ }^{38}$.

Como se trata de uma questão muito recente e complexa, o tema do aumento dos custos de transação relacionados a acordos de livre comércio foi muito pouco abordado pela doutrina. Ainda não existe sequer modelo econômico que permita mensurar esses custos de forma adequada e precisa ${ }^{39}$.

O modelo de concorrência imperfeita, a teoria dos jogos e a diferenciação de produto são outros componentes que passaram a ser incluídos na análise econômica do regionalismo ${ }^{40}$. Ao introduzir esses novos elementos, acredita-se que será possível calcular

\footnotetext{
36 "The world trading system is characterized by a chaotic crisscrossing of preferences, with a plethora of different trade barriers applying to products depending on which countries they originate from. This is a fool's way of doing trade — not only does it destroy the efficient allocation of resources, but it flies in the face of the fact that today it is becoming almost impossible to define which product is whose. It is hard to believe that sensible men in charge of trade policy today, including the USTR, the EU Trade Commissioner and other luminaries of trade are so unmindful of the fact that, in the name of free trade, they are damaging the world trading system through discriminatory PTAs as much as the protectionists did in the 1930s". J. BHAGWATI. Reshaping the WTO. 2005. Disponível em: <http://time.dufe.edu.cn/wencong/bhagwati/FEEER.Final.pdf>. Acesso em: 20 jun. 2012.

${ }^{37}$ BHAGWATI, 2005, p. 1-15.

${ }^{38}$ WATSON; DO, 2006, p. 11.

39 "Unfortunately, at the moment the literature has produced many more questions than answers. We evidently are some distance from being able to generalize about how much greater transaction costs may be in a spaghetti-bowl world than they are in a not perfectly- liberalized WTO world". WATSON; DO, 2006, p. 13.

40 "Winters (1997) develops a model with imperfect competition to analyze terms-of-trade effects of an RTA, particularly on non-RTA members. He argues that it is incorrect to compute changes in exports from the nonmember countries to RTA countries and draw welfare conclusions. ROW exports are a very poor indicator of
} 
as alterações das exportações dos Estados que não são partes do acordo regional para os Estados que o são e tirar conclusões mais precisas sobre o bem-estar. Da mesma forma, o modelo analítico desenvolvido por Grossman e Helpman em 1995, que se baseia na formação política como o resultado de lobby e competição contributiva entre as indústrias, introduz o elemento político na análise. Segundo esses autores, a necessidade de viabilidade política pode vir a contrariar o interesse social do acordo. Isso pode ser verificado quando o aumento das exportações resulta de desvio de comércio, de modo a atender os interesses de industriais e lobistas em detrimento dos contribuintes, que terão seu bem estar reduzido ${ }^{41}$.

As teorias econômicas apontadas acima se referem exclusivamente ao comércio de bens. De fato, o tema serviços é muito recente no comércio internacional, tendo sido regulamentado, em âmbito multilateral, apenas em 1995, no GATS. Da mesma forma, os acordos regionais passaram a tratar desse tema também a partir dos anos 1990. Logo, a análise econômica nunca havia se preocupado em estudar os efeitos dos acordos regionais na esfera do comércio de serviços.

Com relação ao setor de serviços, é mais difícil encontrar estudos sobre os efeitos econômicos de um acordo regional para esse setor do que em relação ao setor de bens. Em primeiro lugar, trata-se de um setor que só ganhou relevância em termos comerciais nas últimas três décadas ${ }^{42}$. Não obstante, a maioria dos acordos regionais celebrados na atualidade contém cláusulas a esse respeito. Em segundo lugar, em virtude da diversidade de modos de prestação e de natureza imaterial das operações comerciais realizadas nessa modalidade, que abrange desde o movimento de pessoas físicas ao movimento de capitais, acredita-se que as estatísticas disponíveis carecem de precisão. Além disso, muitos dos dados estatísticos disponíveis dizem respeito apenas a países desenvolvidos. Em terceiro lugar, a lógica do setor de serviços é muito diferente da lógica do setor de bens, o que faz

ROW welfare. He develops a theoretical model to analyze the welfare impacts of an RTA on non-members and argues that they depend on changes in its terms of trade, levels of output, number of firms, existing trade restrictions and induced investment effects. His proposed analysis of price changes relies on new trade theory tools of imperfect competition and product differentiation". BURFISHER; ROBINSON; THIERFELDER, 2004, p. 33-34.

${ }^{41}$ BURFISHER; ROBINSON; THIERFELDER, 2004, p. 34.

${ }^{42}$ A esse respeito, ressalte-se que até mesmo o uso da expressão "comércio de serviços" é relativamente novo. Essa expressão foi utilizada, pela primeira vez, apenas em 1972, no relatório elaborado por peritos convocados pela OCDE para examinar as perspectivas comerciais dos Membros em face das transformações estruturais das sociedades industrializadas. A expressão "comércio de serviços" foi utilizada para substituir a expressão "transações com invisíveis", que era utilizada até então para designar o comércio de serviços. A. MERCADANTE. Acordo Geral sobre o Comércio de Serviços: Aspectos Jurídicos. P. B. CASELLA; A. de A. MERCADANTE (org). Guerra Comercial ou Integração Mundial pelo Comércio? A OMC e o Brasil. São Paulo: LTr, 1998, p. 414. 
com que uma análise econômica clássica, focada em ganhos de bem estar resultantes da criação de comércio com parceiros pelo não pagamento de tarifas de importação, não seja adequada para o setor ${ }^{43}$.

Assim, conclui-se que as teorias econômicas descritas acima, que foram desenvolvidas para estudar a liberalização comercial regional ou bilateral em relação ao setor de bens, não podem ser utilizadas para avaliar os ganhos de bem estar gerados por um acordo comercial em relação ao setor de serviços, sendo necessário adaptá-las às particularidades desse setor.

Em sua análise sobre as eficiências geradas pela liberalização preferencial de um setor particular de serviços, Aaditya Mattoo e Carten Fink ${ }^{44}$ concluíram que um Estado tenderia a se beneficiar com essa medida em comparação com o status quo ${ }^{45}$. Isso ocorre porque, como as barreiras que são impostas possuem natureza regulatória e não tarifária, elas não apenas impedem o acesso a determinado mercado, como também não geram receitas $^{46}$. Desse modo, o desvio de comércio não resultará em custos elevados, tal qual ocorre com o comércio de bens. Além disso, o aumento da concorrência e a exploração de economias de escala também fortalecem a posição de que há ganhos com os acordos preferenciais de comércio no que se refere a serviços ${ }^{47}$.

Mattoo e Fink destacam, ainda, que a liberalização não preferencial deve gerar maiores ganhos em comparação com os acordos preferenciais de comércio, visto que possibilita a prestação de serviços pelos fornecedores que o fazem a custos mais competitivos. Adicionalmente, a liberalização não preferencial deve resultar em um regime menos complexo do que o preferencial e, por conseguinte, terá menores custos de

\footnotetext{
${ }^{43}$ Quando se fala da liberalização em serviços, é importante esclarecer que as barreiras impostas aos prestadores de serviços estrangeiros são de natureza regulatória, e não de natureza tarifária, como ocorre no comércio de bens.

${ }^{44}$ Vide A. MATTOO; C. FINK. Regional Agreements and Trade Services - Policy Issues. Policy Research Working Paper Series No 2852. World Bank. Junho de 2002, p. 4-6. Disponível em: <http://econpapers.repec.org/paper/wbkwbrwps〉. Acesso em: 10 jul. 2012.

${ }^{45}$ Este é um termo muito utilizado para descrever a liberalização no comércio de serviços. Em resumo, status quo refere-se ao estado atual das restrições estabelecidas por determinado Estado para a prestação de serviços, em seu território, por pessoas físicas e jurídicas estrangeiras.

46 "Compared to the status quo, a country is likely to gain from preferential liberalization of services trade at a particular point of time - as distinct from the more ambiguous conclusions emerging for goods trade. The main reason is that barriers are often prohibitive and not revenue generating, so there are few costs of trade divertion". MATTOO; FINK, 2002, p. 2.

47 "An the case of goods trade, the scope for increased competition and exploitation of scale economies, as well as the possibility of inducing knowledge spillovers, strengthens the presumption that a country would gain from a preferential agreement in services". MATTOO; FINK, 2002, p. 2.
} 
administração para as agencias governamentais e menores custos de transação para o setor privado $^{48}$.

Por fim, o estudo em análise destacou que um dos resultados da liberalização comercial preferencial em serviços será o desvio de comércio, no sentido de que a tendência é de que os primeiros fornecedores a ganhar espaço não sejam posteriormente substituídos pelos fornecedores mais eficientes que não são beneficiados pelo acordo regional $^{49}$. Assim, a liberalização comercial tende a comprovar a teoria do segundo melhor também no setor de serviços ${ }^{50}$.

\section{MUDANÇAS DOS PARADIGMAS DA INTEGRAÇÃO E A PROLIFERAÇÃO DOS ACORDOS REGIONAIS DE COMÉRCIO}

Não obstante a crítica aos efeitos prejudiciais dos acordos regionais sobre as regras multilaterais de comércio, a partir dos anos 1990, houve a celebração de muitos acordos dessa natureza em todo o mundo, incluindo aqueles que contêm regras sobre o comércio de serviços. Denominou-se esse movimento de "novo regionalismo".

O termo "novo regionalismo" refere-se ao fato de os acordos celebrados a partir dessa época não terem como principal motivação a proximidade física entre os Estados, contrariando a tendência verificada até então ${ }^{51}$. Muitas vezes, as Partes dos acordos regionais celebrados a partir da década de 1990 estão localizadas em diferentes regiões do planeta.

Nesse sentido, ressalte-se que os acordos celebrados no âmbito do novo regionalismo envolvem Estados de dimensões e renda per capita variados, que apresentam níveis de

${ }^{48}$ C. FINK; F. JANSEN. Services Provisions in RTAs. R. BALDWIN; P. LOW. Multilarizing Regionalism. Challenges for the Global Trading System, Cambridge: Cambridge University Press, 2009, p. 229.

49 "While the elimination of preferences for trade in goods may lead to a relatively painless switch to more efficient sources of supply, the entry of more efficient service providers may be durably deterred if their competitive advantage do not offset the advantages conferred by incumbency”. MATTOO; FINK, 2002, p. 27.

${ }^{50}$ FINK, Carsten; JANSEN, Fink, 2009, p. 230.

51 "These two elements characterize the "new regionalism", a term that is somewhat misleading, since in reality it refers to trade agreements that are mostly bilateral and concluded between countries in different regions". UNCTAD. Trade and Development Report, 2007. Chapter III - The "New Regionalism" and North-South Trade Agreements. Nova Iorque e Genebra: 2007, p. 54. Disponível em: <http://archive.unctad.org/templates/Page.asp?intItemID=4329\&lang=1>. Acesso em: 8 jul. 2012. 
desenvolvimento diversos, à diferença do que ocorria com os acordos regionais de comércio anteriores, que envolviam parceiros com nível de desenvolvimento semelhante ${ }^{52}$.

Os acordos celebrados a partir dessa década também se diferenciavam dos acordos anteriores por conterem elementos encontrados em acordos com um nível mais profundo de liberalização comercial, como uniões aduaneiras e monetárias. Trata-se de questões relacionadas à harmonização de políticas nacionais, cooperação monetária e financeira, projetos de infraestrutura, bem como compromissos para a redução de barreiras nas áreas de investimentos estrangeiros, compras governamentais, serviços e concorrência ${ }^{53}$.

Entre a década de 1990 e os dias atuais, verificou-se intensificação na celebração dos acordos regionais de comércio. Contudo, o regionalismo que vemos no século XXI possui características e objetivos distintos do modelo descrito acima, que predominou no final do século XX.

Segundo Richard Baldwin, o regionalismo do século XXI não tem como principal objetivo o acesso aos mercados dos parceiros comerciais. Os acordos recentes são motivados por um conjunto de forças políticas e econômicas diferente, que deriva das mudanças observadas no cenário produtivo, no qual os fluxos de serviços e investimentos, que antes ocorriam dentro das fábricas, passaram a ser realizados nas fronteiras internacionais. A circulação de ideias, capitais, mão de obra, entre outros fatores de produção, ocorre em âmbito internacional ${ }^{54}$.

De fato, a produção de bens sofreu uma revolução importante no final do século XX, com a internacionalização dos canais fornecimento. Os produtos deixaram de ser fabricados unicamente em um Estado. É cada vez mais frequente a compra de insumos (partes e componentes) importados, a produção do bem em um Estado e a exportação do produto final para outro Estado. Esse fluxo comercial, por sua vez, gerou aumento nos investimentos diretos estrangeiros e em serviços de infraestrutura.

Esse novo contexto de produção tem duas consequências importantes: (i) a liberalização regulatória passa a ter um papel mais relevante que a liberalização tarifária

\footnotetext{
${ }^{52}$ Vide CONFERÊNCIA DAS NAÇÕES UNIDAS PARA O COMÉRCIO E O DESENVOLVIMENTO, $2007,54$.

${ }^{53}$ Vide BURFISHER; ROBINSON; THIERFELDER, 2004, p.14-15.

54 "The top panel illustrates 20th century trade; trade is dominated by goods made in factories in one nation and sold to customers in another. There are complex two-way flows of goods, people, and ideas (the doubleheaded arrows) but primarily within factories. The lower panel illustrates 21 st century trade. Here factories and offices have been unbundled internationally thus creating the trade-investment-service nexus where some of the complex two-way flows that used to take place within factories and offices now take place across international borders". R. BALDWIN. 21st Century Regionalism: Filling the gap between 21st century trade and 20th century trade rules. Organização Mundial do Comércio. Staff Working Paper ERSD-201108, 23 de maio de 2011, p. 6 .
} 
nos acordos comerciais internacionais; (ii) para atender as necessidade de um comércio internacional cada vez mais complexo, é necessário que as regras comerciais sejam cada vez mais complexas.

Isso posto, Baldwin aponta como uma característica importante do regionalismo do século XXI o fato de os acordos firmados nesse contexto serem cada vez mais profundos em termos de compromissos celebrados, os quais, muitas vezes, avançam além das regras da $\mathrm{OMC}^{55}$. Em relação às preferências tarifárias, esses acordos também não poderiam ser considerados como preferenciais, visto que grande parte dos produtos está sujeita a tarifas de importação aplicadas de zero por cento, que são cobradas em base de Nação Mais Favorecida $^{56}$. Desse modo, a celebração de um acordo regional certamente visa a outros objetivos, além do acesso a mercados.

A essa característica somam-se o elevado número de acordos bilaterais de investimentos celebrados entre parceiros de acordos regionais de comércio e o fato de que as tarifas aplicadas à importação de bens têm sido progressiva e unilateralmente reduzidas pelos Estados que as mantinham elevadas, como os Estados latino-americanos. A grande preocupação com relação a essa questão consiste na inexistência de um movimento recíproco para a redução nas tarifas aplicadas por Estados que já as mantinham em níveis inferiores, como os Estados europeus, ou para a consolidação dessas tarifas na $\mathrm{OMC}^{57}$.

\section{CONCLUSÕES}

Em vista do exposto, conclui-se que os acordos comerciais se descolaram do Sistema Multilateral de Comércio a partir dos anos 1990, de modo que, atualmente, existe um sistema normativo paralelo àquele da $\mathrm{OMC}$, com regras complexas, que, muitas vezes, extrapolam em complexidade as regras celebradas em âmbito multilateral. Essa é uma realidade incontestável e irreversível, pelo menos em curto prazo, visto que as negociações multilaterais encontram-se totalmente paralisadas.

Esse novo cenário das relações comerciais exige que se deixem de lado as discussões sobre a possibilidade de os acordos regionais prejudicarem as regras multilaterais de

\footnotetext{
55 'Using their new dataset, WTO (2011) concludes that RTAs have been getting increasingly 'deep' with most of the provision being legally enforceable. As they note: "The pattern observed suggests that deepening commitments in these areas, i.e., going beyond commitments in the WTO, continue to be a major driving force for recent RTAs". BALDWIN, 2011, p. 11.

${ }^{56}$ BALDWIN, 2011, p. 13.

${ }^{57}$ BALDWIN, 2011, p. 17.
} 
comércio e busque-se refletir de que modo essas regras podem coexistir de forma harmônica. Por essa razão, é possível afirmar que o regionalismo do século XXI impõe muitos desafios, sendo um dos mais relevantes a convivência entre as normas estabelecidas bilateral ou regionalmente e aquelas criadas no âmbito do Sistema Multilateral de Comércio $^{58}$.

Nesse sentido, a OMC, no Relatório Anual de 2011, propõe que se promova a "multilateralização do regionalismo, ou seja, que as questões tratadas nos acordos regionais de comércio sejam levadas a essa organização e analisadas por meio de "soft law" ${ }^{59}$. Desse modo, seria possível avançar em relação à interpretação legal dos acordos regionais e, simultaneamente, assegurar coerência entre essas normas e aquelas criadas multilateralmente, sem que se instaurasse um conflito entre elas. Contudo, passados quase três anos da publicação do Relatório Anual pela $\mathrm{OMC}$, ainda não houve qualquer progresso a esse respeito.

\footnotetext{
${ }^{58}$ Vide BALDWIN, 2011, p. 17.

59 "The rationale for using a "soft law" approach would be to allow WTO members to better understand their respective priorities and interests, with a view eventually to unblocking progress towards legal interpretations of particular provisions that would ensure coherence. However, the soft law approach is not without risk as soft law and hard law could become antagonistic to one another if the underlying conditions for cooperation are absent. As a result of global production sharing, new forces favourable to the multilateralization of regionalism may have emerged. The extent to which deep integration measures in PTAs have the potential to generate the same sort of costly spaghetti/noodle bowl as preferential tariffs is still a matter for debate, but there may be a role for the WTO to reduce these transaction costs". ORGANIZAÇÃO MUNDIAL DO COMÉRCIO, 2011, p. 16.
} 


\section{CAPÍtulO 2: A REGULAMENTAÇÃO DO TEMA SERVIÇOS NO SISTEMA MULTILATERAL DE COMÉRCIO}

\section{INTRODUÇÃO}

A regulamentação do comércio de serviços no âmbito do Sistema Multilateral de Comércio é recente. Enquanto o GATT, acordo que regula o comércio internacional de bens, foi celebrado em 1947, o tema serviços só foi objeto de um acordo multilateral, o GATS, em 1994. Até então, o comércio internacional de serviços era caracterizado pela falta de regras jurídicas internacionais específicas ${ }^{60}$.

O GATS foi celebrado ao final da Rodada Uruguai, em 15 de abril de 1994, juntamente com o Acordo da OMC e com os demais acordos dessa organização, e encontra-se em vigor desde $1^{\circ}$ de janeiro de $1995^{61}$. Trata-se de um acordo inovador não apenas por ser o primeiro instrumento multilateral a regulamentar o tema serviços, mas, sobretudo, por ser bastante flexível, assumindo a forma de um acordo-quadro, resultante de uma fórmula compromisso ${ }^{62}$.

Neste capítulo, serão analisadas as principais características do acordo sobre serviços da OMC, de modo a possibilitar a compreensão de como é a regulamentação multilateral do tema, para que, nos próximos capítulos, seja possível comparar o tratamento dessas questões nos acordos regionais de comércio estudados na presente tese. Será dado maior enfoque ao Artigo V do GATS, que regulamenta a integração regional em serviços, com a análise dos requisitos e das obrigações impostas por esse artigo.

Logo, os temas examinados neste capítulo serão os seguintes: (i) a estrutura do GATS; (ii) o escopo do GATS; (iii) os princípios e obrigações aplicáveis ao comércio internacional de serviços; (iv) o modelo adotado pelo acordo para a assunção de compromissos; (v) as exceções e limitações ao GATS; (vi) as regras sobre regulação doméstica; (vii) as regras sobre integração regional em serviços.

\footnotetext{
${ }^{60}$ Vide MERCADANTE, 1998, p. 415.

${ }^{61}$ No Brasil, o Decreto 1.355 , de 30 de dezembro de 1994, incorporou ao ordenamento interno os resultados da Rodada Uruguai, aceitando integralmente a respectiva ata final. Decreto $\mathbf{n}^{\circ} \mathbf{1 . 3 5 5}$, de 30 de dezembro de 1994, que promulga a Ata Final que incorpora os resultados da Rodada Uruguai de negociações comerciais multilaterais do GATT. Disponível em: <www.mre.gov.br〉. Acesso em: 15 dez. 2010.

${ }^{62}$ Conforme explica o Professor Umberto Celli Junior, em decorrência das duras negociações entre países desenvolvidos e países em desenvolvimento ocorridas na Rodada Uruguai, o GATS assumiu a forma de acordo-quadro, no qual se estabelecem apenas diretrizes, conceitos, princípios e regras essenciais sobre o comércio internacional de serviços. U. CELLI JUNIOR, Comércio de Serviços na OMC: Liberalização, Condições e Desafios. Curitiba: Juruá, 2009, p. 80.
} 


\section{ESTRUTURA}

O GATS possui uma estrutura flexível, que é muito diferente da estrutura do GATT, cujas normas aplicam-se ao comércio de bens. Estruturalmente, o GATS pode ser dividido em quatro partes fundamentais, a saber: (i) o acordo propriamente dito; (ii) anexos que determinam princípios e regras para setores de serviços específicos e o anexo que regula as exceções ao Artigo II do GATS; (iii) as listas com os compromissos de liberalização; (iv) as listas de setores excluídos da aplicação do Artigo II do GATS ${ }^{63}$.

A primeira parte do GATS é o acordo propriamente dito (framework), que estabelece os princípios e regras gerais aplicáveis ao comércio internacional de serviços, bem como os conceitos gerais que se aplicam a medidas que afetem o comércio de serviços. Essa parte é está subdividida em seis subpartes ${ }^{64}$, com vinte e quatro artigos.

A segunda parte do GATS é composta por alguns anexos, a saber: (i) Anexo sobre as Exceções ao Artigo II do GATS (princípio de nação mais favorecida); (ii) Anexo sobre Movimento de Pessoas Físicas; (iii) Anexo sobre Serviços de Transporte Aéreo; (iv) Anexo sobre Serviços Financeiros; (v) Segundo Anexo sobre Serviços Financeiros; (vi) Anexo sobre Telecomunicações; (vii) Anexo sobre Negociações de Serviços Básicos de

${ }^{63}$ De acordo com Vera Thorstensen: "O Acordo foi negociado em quatro partes distintas. A primeira estabelece um quadro de regras para regulamentar o setor de serviços, incluindo princípios gerais e obrigações, além de conceitos gerais que se aplicam às medidas que afetam o comércio internacional de serviços. A segunda contém anexos que determinam princípios e regras para setores específicos, demonstrando a diversidade dos serviços prestados (movimento de pessoas físicas, serviços financeiros, telecomunicações e serviços de transporte aéreo). A terceira estabelece, para cada membro do Acordo, uma série de compromissos de liberalização para cada setor, ou de acesso a mercado, de tratamento nacional, nas áreas de comércio e investimento, que foram incluídos nas listas nacionais de cada membro do Acordo. A quarta estabelece listas de setores onde os membros não estão aplicando temporariamente o princípio de Nação Mais Favorecida, que proíbe a discriminação entre países”. Já o embaixador Luiz Felipe P. Lampreia entende que: "No que diz respeito a serviços, o acordo alcançado na Rodada compreende três elementos: Acordo Geral sobre o Comércio de Serviços (Gats), acordo-quadro, cujas obrigações básicas se aplicam a todos os países membros; anexos referentes a situações especiais em setores específicos (movimento de mãode-obra, serviços financeiros, telecomunicações, transportes aéreos); e listas nacionais de compromissos de liberalização (vide parágrafo inicial), que poderão ser ampliados pela via da negociação". V. THORSTENSEN, OMC - Organização Mundial do Comércio: as regras do comércio internacional e a nova rodada de negociações multilaterais. São Paulo: Aduaneiras, 2001, p. 196; L. F. P. LAMPREIA, Resultados da Rodada Uruguai: uma tentativa de síntese. Revista Estudos Avançados. São Paulo, v. 9, n. 23, p. 247-260, jan./abr. 1995. Disponível em: <http://www.scielo.br/scielo.php?pid=S0103$40141995000100016 \&$ script=sci_arttext $>$. Acesso em: 18 dez. 2007.

${ }^{64}$ As seis partes que compõem o texto do GATS são as seguintes: (i) Parte I - Escopo e definição; (ii) Parte II - Obrigações gerais e disciplinas; (iii) Parte III - Compromissos específicos; (iv) Parte IV - Liberalização progressiva; (v) Parte V - Questões institucionais; (vi) Parte VI - Questões finais. 
Telecomunicação ${ }^{65}$. Portanto, os dois primeiros anexos da segunda parte do GATS regulamentam as exceções ao princípio de nação mais favorecida e o modo 4 de prestação de serviços (movimento de pessoas físicas), respectivamente, enquanto os demais anexos regulamentam setores de serviços específicos ${ }^{66}$.

Já a terceira parte do GATS consiste no conjunto das listas com os compromissos de liberalização assumidos pelos Membros na área de serviços. Nas listas de compromissos estão relacionados os setores e subsetores de serviços e os modos de prestação a que os Membros se comprometem a garantir acesso aos fornecedores de outros Membros.

A quarta e última parte do GATS é composta pelo conjunto de listas nas quais os Membros se eximem da aplicação do Artigo II, isto é, concedem um tratamento mais favorável a determinado prestador de serviços de um Membro sem a obrigação de estendêlo aos demais Membros.

Além dos documentos listados anteriormente, também integram o GATS as decisões do Conselho para o Comércio de Serviços e do Conselho Geral da OMC relativas a serviços, as declarações ministeriais e os protocolos relativos a certos setores de serviços ${ }^{67}$.

${ }^{65}$ Vide R. L. PUPO, Acordo Geral sobre o Comércio de Serviços - GATS. U. CELLI JUNIOR (org.), Comércio de Serviços na OMC. Curitiba: Juruá Editora, 2005, p. 44 .

${ }^{66}$ Com relação aos anexos ao GATS e aos temas objeto dos anexos, o Embaixador Luiz Felipe P. Lampreia observa que: "Os anexos ao GATS referem-se a movimento de mão-de-obra; serviços financeiros (sobretudo bancos e seguros); telecomunicações; serviços de transporte aéreo; telecomunicações básicas; e serviços marítimos. Em face das inúmeras dificuldades encontradas na negociação desses anexos, foi decidida, nos momentos finais do processo concluído em 15 de dezembro de 1993, a criação de grupos setoriais e/ou a prorrogação do prazo para uma definição final sobre as ofertas e derrogações N.M.F. Assim, no caso de movimento de pessoas, acordou-se que, no seio do grupo que foi instalado em 15 de maio e cujos trabalhos devem estar encerrados dentro de um prazo de seis meses após a entrada em vigor da WTO, poderão ser negociados compromissos específicos, sendo, porém, de se prever que, com a preocupação dos países desenvolvidos em torno das questões de imigração, sejam lentos os progressos nessa área. Para serviços financeiros não foi criado grupo de negociação, mas adiada a data para confirmação final dos compromissos iniciais ou das derrogações n.m.f. para seis meses após a entrada em vigor do acordo constitutivo da WTO. Quanto a transportes marítimos, o que se acordou, além da criação de grupo negociador, foi a suspensão das decisões finais sobre ofertas e derrogações até junho de 1996, prazo para encerramento dos trabalhos do grupo". LAMPREIA, 1995, p. 11.

${ }^{67}$ No módulo sobre Serviços do Curso de Solução de Controvérsias da Conferência das Nações Unidas para o Comércio e o Desenvolvimento (UNCTAD), o GATS foi definido como: “(...) uma estrutura complexa de direitos, derrogações/exceções e compromissos específicos. Suas obrigações não podem ser compreendidas sem a devida referência a todos os textos legais relevantes, quais sejam: o próprio texto do GATS; as exceções ao tratamento MFN dadas em razão do Anexo de Exceções ao Artigo II e aquelas listadas nas listas de compromissos; os compromissos em acesso a mercado, tratamento nacional e compromissos adicionais, os Anexos ao GATS, que tratam de determinados setores, como o Serviço de Transporte Aéreo, Serviços Financeiros, Serviços de Transporte Marítimo, Telecomunicações e Movimento de Pessoas Naturais, Decisões e Declarações Ministeriais e Protocolos subsequentes relativos a certos setores de serviços que passaram a integrar o Acordo. Dependendo do assunto particular de determinada disputa, a regra a ser aplicada pode estar contida em um ou mais desses documentos”. ORGANIZAÇÃO DAS NAÇÕES UNIDAS PARA O COMÉRCIO E O DESENVOLVIMENTO. Curso de Solução de Controvérsias: Organização Mundial do Comércio. Capítulo 3.13 - GATS. Nova Iorque/Genebra: 2003, p. 5. Disponível em: <http://www.unctad.org/pt/docs/edmmisc232add31_pt.pdf>. Acesso em: 10 jul. 2012. 


\section{ESCOPO}

Pode-se dizer que são objeto do GATS todas as medidas governamentais que afetem o comércio de serviços ${ }^{68}$. As únicas exceções referem-se a: (i) serviços, em qualquer setor ou modo, prestados no exercício da autoridade governamental e (ii) direitos de tráfego aéreo e serviços diretamente relacionados com o exercício de direitos de tráfego aéreo, que são regulamentados por outra organização internacional, a $\mathrm{OACI}^{69}$.

De acordo com o Artigo I.3, itens b e c, do GATS, um serviço é considerado como prestado no exercício da autoridade governamental sempre que não for prestado em bases comerciais ou em concorrência com um ou mais prestadores de serviços ${ }^{70}$.

Apesar de, em teoria, o GATS ser aplicável à maioria das medidas dos governos nacionais que afetam o comércio de serviços, são poucas as obrigações estabelecidas no acordo que se dirigem a esse universo mais amplo, merecendo destaque entre elas as obrigações de tratamento de nação mais favorecida e de transparência. Outras obrigações fundamentais previstas pelo GATS, como acesso a mercados e tratamento nacional, aplicam-se somente aos compromissos específicos assumidos pelos Membros em suas listas de compromissos. Assim, pode-se dizer que, ao contrário do GATT, cujas normas aplicam-se praticamente a todo o comércio de bens, as normas do GATS somente incidirão sobre os setores de serviços e as modalidades de prestação nos quais os Membros da OMC assumiram compromissos ${ }^{71}$.

As obrigações gerais, aplicáveis a todos os setores e modos de prestação de serviços, foram regulamentadas no GATS nos seguintes artigos: (i) Artigo II, sobre tratamento de nação mais favorecida no âmbito do comércio de serviços; (ii) Artigo III, sobre

68 O termo "medidas" foi definido no Artigo XXVIII do GATS como qualquer medida praticada por um Membro, seja na forma de lei, regulamento, norma, ato administrativo, decisão ou em qualquer outra forma ${ }^{68}$. Já o Artigo I.3 do GATS esclarece que o termo "medidas" - no contexto das medidas governamentais a que o GATS se aplica - abrange medidas impostas por governos federais, estaduais ou municipais, bem como por órgãos não governamentais no exercício de poderes delegados por governos ou autoridades federais, estaduais ou municipais.

${ }^{69}$ Para mais informações sobre a OACI, vide: <http://www.icao.int>. Acesso em: 7 jan. 2012.

70 “3 - Para os propósitos deste Acordo:

(...)

autoridades regionais e locais e pelos órgãos não governamentais dentro de seu território.

b) "Serviços" inclui qualquer serviço em qualquer setor exceto aqueles prestados no exercício da autoridade governamental.

c) Um serviço prestado no exercício da autoridade governamental significa qualquer serviço que não seja prestado em bases comerciais, nem em competição com um ou mais prestadores de serviços". Decreto $\mathbf{n}^{\circ}$ 1.355, de 30 de dezembro de 1994, que promulga a Ata Final que incorpora os resultados da Rodada Uruguai de negociações comerciais multilaterais do GATT. Disponível em: 〈www.mre.gov.br〉. Acesso em: 10 jun. 2012.

${ }^{71}$ UNCTAD, 2003, p. 5. 
transparência; (iii) Artigo V, que trata de integração econômica e permite a celebração de acordos de integração regional envolvendo o comércio de serviços; (iv) Artigo VI, sobre regulação doméstica; (v) Artigo XII, que trata de compras governamentais na área de serviços.

\section{PRINCÍPIOS E OBRIGAÇÕES}

A obrigação substancialmente mais relevante prevista no GATS consiste no tratamento de nação mais favorecida aos serviços e aos prestadores de serviços de todos os Membros da OMC em relação aos setores de serviços que são objeto de compromissos. Essa obrigação está regulamentada no Artigo II do GATS ${ }^{72}$.

O tratamento de nação mais favorecida deriva do princípio da não discriminação. Este princípio, que já havia sido regulamentado no GATT para o comércio de bens, versa, essencialmente, sobre a proibição de discriminar entre os Membros da OMC. Ao adotá-lo, o GATS estabelece que, no comércio de serviços, um Membro não pode conceder aos serviços e aos prestadores de serviços (sejam eles pessoas físicas ou pessoas jurídicas) de determinado Membro tratamento menos favorável do que concede aos serviços e prestadores de serviços similares de outro Membro. Portanto, todo e qualquer privilégio concedido a um Membro deve ser automaticamente estendido aos demais.

É importante notar que a obrigação de tratamento de nação mais favorecida contida no Artigo II.1 do GATS aplica-se de forma ampla a todas as medidas tomadas por um Membro que afetem o comércio de serviços, em todos os serviços sujeitos à aplicação do GATS (ou seja, que são objeto de compromissos), excluindo-se apenas as medidas incluídas pelos Membros em suas respectivas listas de exceção ao princípio de nação mais favorecida, em conformidade com Anexo ao GATS que regula tais exceções ${ }^{73}$. Portanto,

\footnotetext{
72 “Artigo II - Tratamento de Nação Mais Favorecida

1. Com respeito a qualquer medida coberta por este Acordo, cada membro deve conceder imediatamente e incondicionalmente aos serviços e prestadores de serviços de qualquer outro membro, tratamento não menos favorável do que aquele concedido a serviços e prestadores de serviços similares de qualquer outro país.

2. Um membro poderá manter uma medida incompatível com o parágrafo 1 desde que a mesma esteja listada e satisfaça as condições do Anexo II sobre Isenções ao art. II.

3. As disposições deste Acordo não devem ser interpretadas de forma a impedir que qualquer membro conceda vantagens a países adjacentes destinadas a facilitar o intercâmbio de serviços produzidos e consumidos localmente em zonas de fronteira contígua". Decreto $n^{\circ} 1.355$, de 30 de dezembro de 1994 , que promulga a Ata Final que incorpora os resultados da Rodada Uruguai de negociações comerciais multilaterais do GATT. Disponível em: <www.mre.gov.br>. Acesso em: 10 jun. 2011.

${ }^{73}$ Sobre o tratamento do princípio de cláusula de nação mais favorecida no GATS, o Embaixador Luiz Felipe Lampreia ressalta que: "Tal como o Acordo Geral sobre Tarifas e Comércio (Gatt), o Gats (Acordo Geral sobre Comércio de Serviços) contém uma cláusula de nação mais favorecida. Prevê, ao mesmo tempo, a
} 
pela cláusula de nação mais favorecida, todos os compromissos específicos em serviços consolidados por um Membro serão igualmente aplicáveis aos demais Membros da OMC, salvo os setores objeto dos compromissos que estiverem sujeitos a exceções de cláusula de nação mais favorecida. No entanto, nos setores de serviços que não estão sujeitos a compromissos, os Membros poderão dar tratamento mais favorecido a outro Membro, sem que seja necessário estender esse tratamento aos demais Membros da OMC.

A segunda obrigação mais relevante estabelecida pelo GATS consiste na concessão de tratamento nacional aos prestadores de serviços estrangeiros. Essa obrigação foi prevista no Art. XVII do GATS ${ }^{74}$.

Da mesma forma que ocorre com a cláusula de nação mais favorecida, o tratamento nacional é um princípio regulamentado no GATT para o comércio de bens que foi relativizado no GATS, no âmbito do comércio de serviços. Enquanto no GATT todos os Estados devem garantir que não seja dado tratamento mais discriminatório ao prestador estrangeiro do que ao prestador nacional, no GATS, a obrigação fundamental da não discriminação aplica-se tão somente aos setores de serviços especificamente inscritos nas listas de compromissos dos Membros.

A obrigação do tratamento nacional contida no Artigo XVII também não se aplica a todas as medidas que afetem o comércio de serviço, mas apenas aos setores de serviços relacionados nas listas de compromissos dos Membros, na coluna sobre tratamento nacional. Entretanto, para os setores nos quais os Membros consolidaram compromissos, o Membro não pode manter ou impor medida (lei, regulamentos, política ou prática) que discrimine os serviços ou prestadores de serviços estrangeiros em relação aos serviços ou prestadores de serviços nacionais similares.

Os Membros podem estabelecer limitações ao tratamento nacional em suas listas de compromissos, ou seja, medidas que confiram tratamento mais discriminatório ao prestador estrangeiro do que ao prestador nacional. É proibida, porém, qualquer forma de

possibilidade de que sejam indicadas isenções específicas para certas atividades em condições que são estipuladas anexas". LAMPREIA, 1995, p. 10.

74 "1 - Nos setores inscritos em sua lista, e salvo condições e qualificações ali indicadas, cada membro outorgará aos serviços e prestadores de serviços de qualquer outro membro, com respeito a todas as medidas que afetem a prestação de serviços, um tratamento não menos favorável do que aquele que dispensa a seus próprios serviços similares e prestadores de serviços similares.

Nota de rodapé: Os compromissos específicos assumidos sob o presente Artigo não serão interpretados no sentido de exigir de qualquer membro compensação por desvantagens competitivas intrínsecas que resultem do caráter estrangeiro dos serviços ou prestadores de serviços pertinentes”. Decreto $\mathbf{n}^{\circ} \mathbf{1 . 3 5 5}$, de 30 de dezembro de 1994, que promulga a Ata Final que incorpora os resultados da Rodada Uruguai de negociações comerciais multilaterais do GATT. Disponível em: <www.mre.gov.br>. Acesso em: 10 jun. 2012. 
discriminação entre prestadores de serviços estrangeiros e nacionais, incluindo a concessão de subsídios, exceto se especificada nas listas de compromissos.

O GATS previu, ademais, que a obrigação de transparência seria aplicável ao comércio de serviços. Essa obrigação, que é de extrema relevância para as relações comerciais internacionais em geral, estabelece a obrigatoriedade de publicação, pelos Membros, de todas as leis, regulamentos, decisões judiciais e regras administrativas que afetem o comércio internacional de $\operatorname{serviços}^{75}$. Nessa linha, o Artigo III do GATS determina que todos os Membros da OMC publiquem imediatamente as medidas de aplicação geral relevantes que tenham relação ou afetem a operacionalidade do GATS. Requer, outrossim, que os Membros informem o Conselho para o Comércio de Serviços, imediatamente ou, pelo menos, anualmente, sobre a introdução ou alteração de leis, regulamentações ou diretrizes administrativas que afetem significativamente os setores de serviços abrangidos em seus compromissos específicos.

\section{MODELO PARA A ASSUNÇÃO DE COMPROMISSOS}

Costuma-se dizer que o GATS é uma fórmula compromisso. Isso quer dizer que esse acordo contém regras gerais aplicáveis a todo o comércio internacional de serviços, bem como regras relativas às sucessivas e futuras negociações comerciais, que resultariam na

\footnotetext{
75 “Artigo III

Transparência

3.1 Cada Membro deve publicar prontamente e, salvo em circunstâncias emergenciais, pelos menos até a data de entrada em vigor, todas as medidas relevantes de aplicação geral pertinentes ao presente Acordo ou que afetem sua operação. Acordos internacionais dos quais um Membro seja parte relativos ao comércio de serviços ou que afetem tal comércio também devem ser publicados.

3.2 Quando a publicação referida no parágrafo 1 não for possível as informações devem ser tornadas públicas por outros meios.

3.3 Cada Membro deve informar o Conselho para o Comércio de Serviços prontamente ou pelo menos uma vez por ano da introdução ou modificação de quaisquer novas legislações, regulamentações ou normas administrativas que afetem significativamente o comércio de serviços coberto por seus compromissos específicos assumidos sob este Acordo.

3.4 Cada Membro deve responder prontamente a todos os pedidos de informação específica apresentados por qualquer outro Membro a respeito de medidas de aplicação geral ou acordos internacionais referidos no parágrafo 1. Cada Membro também deve estabelecer pontos focais para fornecer, mediante solicitação, informações para qualquer outro Membro sobre tais matérias e igualmente sobre aquelas mencionadas no parágrafo 3. Os pontos focais devem ser estabelecidos até dois anos após a entrada em vigor do Acordo Constitutivo da OMC. Para países em desenvolvimento individualmente, poderá ser acordada flexibilidade quanto ao período de estabelecimento de ditos pontos focais.

3.5 Qualquer Membro pode notificar o Conselho para o Comércio de Serviços de qualquer medida adotada por qualquer outro Membro que considere afetar a operação deste Acordo". Decreto n ${ }^{\circ} \mathbf{1 . 3 5 5}$, de 30 de dezembro de 1994, que promulga a Ata Final que incorpora os resultados da Rodada Uruguai de negociações comerciais multilaterais do GATT. Disponível em: <www.mre.gov.br>. Acesso em: 10 jun. 2012.
} 
gradual liberalização do setor $^{76}$. A flexibilidade característica do GATS está relacionada com o fato de que a liberalização do comércio de serviços é realizada por meio de listas de compromissos positivas.

A esse respeito, é importante esclarecer que, em âmbito multilateral, a liberalização do comércio internacional de serviços tem características distintas da liberalização no setor de bens. No setor de bens, as regras negociadas nos Acordo da OMC são aplicadas a todos os segmentos, o que se denomina negociação "de cima para baixo" (top down). Já as negociações no setor de serviços são progressivas, materializando-se por meio da consolidação de cada setor e subsetor de serviços em listas de compromissos. Esse tipo de negociação é denominada "de baixo para cima" (bottom up) $)^{77}$.

$\mathrm{Na}$ liberalização por meio de listas negativas, também conhecida como top-down ou list it or lose it approach, todos os setores em questão estarão incluídos nos compromissos de liberalização, exceto aqueles que forem expressamente excluídos, em caráter excepcional. Essas exceções devem ser revistas periodicamente, por meio de consultas ou negociações com aos Membros interessados. Portanto, caso a opção seja pela liberalização por meio de listas negativas, a priori, nenhum setor está excluído dos compromissos de liberalização.

Por sua vez, na liberalização por meio de listas positivas, também denominada bottom-up, apenas os setores que forem incluídos nas listas serão objeto dos compromissos de liberalização. Portanto, ao optar pela liberalização por meio de listas positivas, a priori, nenhum setor está incluído nos compromissos de liberalização ${ }^{78}$.

A lógica subjacente a esses dois mecanismos, de listas negativas e de listas positivas, é bem diferente. No mecanismo de listas negativas, a lógica é de que a liberalização seja horizontal ou completa, em termos de acesso a mercados, e que haja tratamento não discriminatório irrestrito. No mecanismo de listas positivas, a lógica é de que seja definido um nível mínimo de liberalização ou não discriminação, que não pode ser alterado em virtude de mudanças na política interna de determinado Estado ${ }^{79}$.

\footnotetext{
${ }^{76}$ Vide U. CELLI JUNIOR. Os acordos de serviços (GATS) e de investimentos (TRIMS) na OMC: espaço para políticas de desenvolvimento. São Paulo, 2006. Disponível em: <http://www.usp.br/prolam/downloads/gats.pdf>. Acesso em: 9 jan. 2008.

${ }^{77}$ Vide U. CELLI JUNIOR, 2009, p. 95.

${ }^{78}$ Para mais informações sobre as principais características dos mecanismos de listas positivas e negativas, vide P. SAUVÉ; A. MATTOO. Regionalism in Services Trade. A. MATTOO; R. M. STERN; G. ZANNI,, 2007, p. 254.

${ }^{78}$ Vide SAUVÉ; MATTOO, 2007, p. 254- 255.

79 “(...) However, the underlying logic of the two techniques is very different. In the negative list approach, the underlying logic (and the practice in most relevant cases) establishes a horizon (to say the least) of full liberalization (in the case of a rule on market access) or of unrestricted nondiscriminatory treatment (in the
} 
Com relação às consequências de se optar pelo modelo de liberalização por listas positivas ou por listas negativas, não é possível generalizar se a opção por um ou por outro mecanismo é mais eficiente em termos de liberalização comercial. Como as listas negativas podem ter exceções, dependendo do número de exceções inscritas por um Membro, é possível que apenas um pequeno número de setores esteja sujeito aos compromissos. Por outro lado, no caso de listas positivas, se não houver comprometimento em termos de aumentar o número de setores e modos de prestação inscritos na lista e de diminuir as limitações aos compromissos, os efeitos da liberalização serão mínimos ${ }^{80}$. Portanto, na prática, tanto no modelo de liberalização por meio de listas positivas quanto de listas negativas, os Membros podem excluir setores sensíveis da liberalização ${ }^{81}$.

A abertura comercial na área de serviços possui dois pilares, a saber: (i) o acesso a mercados, regulamentado no Artigo XVI do GATS e (ii) o tratamento nacional, previsto no Artigo XVII do GATS. Como já explicado, as obrigações relacionadas ao acesso ao mercado e ao tratamento nacional aplicam-se apenas aos setores e modos de prestação de serviços que os Membros inscreveram nas listas de compromissos. Destarte, pode-se dizer que, no comércio de serviços, tanto o nível quanto a forma de proteção são resultantes de negociações entre os Membros da $\mathrm{OMC}^{82}$.

case of a rule on treatment). In the positive list approach, the underlying logic is different: the idea is to define a "floor" of liberalization or nondiscrimination not to be rolled back by changes in internal policies". R. TORRENT. The Legal Toolbox for Regional Integration: A Legal Analysis from an Interdisciplinary Perspective. ELSNIT Conference (Barcelona, 26th and 27th of October 2007), p. 9-10. Disponível em: http://www.iadb.org/intal/intalcdi/PE/2012/11120a18.pdf. Acesso em: 31 dez. 2013.

80 "Experts in the jargon argue very often that "negative" and "positive" lists can lead to the same results. The argument is as obvious as it is misleading:

- Of course, the content of a general obligation can be nearly nullified if the exceptions (the negative list) are very broad and deep in scope (or if a "horizontal" exception is included). And the content of an obligation whose scope is determined through a positive list can be very broad and deep if the list is very large". R. TORRENT, op. cit., p. 9.

${ }^{81}$ A respeito das vantagens e desvantagens de um e outro método de liberalização comercial, pode-se dizer que se, por um lado, o mecanismo de listas positivas possui a vantagem de permitir uma maior flexibilidade em termos de setores incluídos e tipos de compromissos, por outro, trata-se de um mecanismo pouco transparente. Como os membros precisam listar apenas as medidas discriminatórias de acesso a mercado e tratamento nacional relacionadas aos setores e modos de prestação em que assumiram compromissos, os investidores estrangeiros e os demais membros não serão capazes de discernir quais políticas nacionais se aplicam aos setores e modos de prestação que não são objeto de compromisso. Já no caso do mecanismo de listas negativas, os membros devem listar todas as medidas em vigor em seus territórios que possam afetar o comércio internacional de serviços, em âmbito federal, estadual e municipal. Por outro lado, ao optar pela liberalização comercial por meio de listas negativas os membros devem se comprometer a não adotar novas medidas discriminatórias e/ou que restrinjam o acesso aos setores de serviços em seus territórios. Tal determinação aplica-se tanto aos setores de serviços existentes quanto àqueles que ainda não existem ou não foram regulamentados na data em que o acordo entrar em vigor.

${ }^{82}$ De acordo com Aaditya Mattoo e Marcelo Olarreaga: "There are two basic rules: the market access provision (Article XVI) simply lists a set of measures, mostly different types of quotas, that cannot be maintained in scheduled sectors unless pre-specified.3 And the national treatment provision (Article XVII) prohibits any form of discrimination (including through subsidies) against foreign services and foreign service suppliers again unless pre-specified.4 Thus, in the services context, both the level and the form of 
Por acesso a mercados em serviços entendem-se as obrigações mínimas de tratamento que um Membro necessita dar ao serviço e ao prestador de serviços estrangeiro para possibilitar que determinado serviço seja prestado para seus nacionais, em seu território. São, portanto, medidas que garantem o acesso do prestador estrangeiro e a prestação de serviços no território de outro Membro ou para nacionais desse Estado.

$\mathrm{O}$ artigo XVI do GATS dispõe que cada Membro deve firmar compromissos de acesso a mercados em relação a setores de serviços específicos por meio da inscrição destes em sua lista de compromissos específicos. Em contraposição às obrigações gerais, que se aplicam a todos os serviços e prestadores de serviços, os compromissos em acesso a mercados limitam-se aos setores de serviços devidamente inscritos na lista de compromissos de cada Membro. Dessa forma, um Membro não está submetido a qualquer compromisso de acesso a mercados com relação aos setores de serviços que não estão inscritos em sua lista de compromissos específicos.

No tocante a acesso a mercados, as regras do GATT refletem o fato de que, no comércio internacional de bens, as mercadorias precisam ser transportadas fisicamente do Estado de origem ao destinatário final do bem, que está localizado em outro Estado. O serviço, por sua vez, pode ser prestado, em âmbito internacional, de quatro modos distintos. A prestação de serviços no modo 1 (prestação transfronteiriça) é semelhante ao que se verifica na área de bens, visto que contempla a movimentação do prestador localizado em um Estado para o consumidor, que está localizado em outro Estado. Entretanto, os modos 2, 3 e 4 contemplam a movimentação do consumidor do serviço, do capital ou do prestador de serviços do território de um Membro para o território de outro Membro.

Outro aspecto importante do mecanismo adotado pelo GATS consiste no fato de que os compromissos assumidos pelos Membros não precisam, necessariamente, refletir o status quo regulatório existente em determinado Estado. Isso equivale a dizer que, mesmo que um Membro assuma compromissos, estes não precisam corresponder necessariamente à situação de fato verificada no território daquele Membro com relação ao acesso e ao tratamento dado ao prestador estrangeiro ${ }^{83}$.

protection are the outcome of negotiations between WTO Members". A. MATTOO; M. OLARREAGA. Reciprocity across modes of supply in the World Trade Organization: A negotiating formula. Washington: Banco $\quad$ Mundial, 2000. Disponível em: wds.worldbank.org/servlet/WDSContentServer/WDSP/IB/2000/08/14/000094946_00072705354792/Render ed/PDF/multi_page.pdf >. Acesso em: 7 jul. 2012.

83 "Under a GATS-like, hybrid approach to scheduling liberalization commitments, countries agree to undertake national treatment and market access commitments specifying (through reservations in scheduled 
Por outro lado, a ausência de compromissos assumidos por um Membro em determinado setor não significa que o prestador estrangeiro não tenha acesso a esse setor de serviços. Um Membro pode manter um regime muito liberal em termos de acesso a mercados em determinado setor de serviços, mas mesmo assim decidir não assumir compromissos com relação àquele setor. Entretanto, sem a consolidação de compromissos, não há garantia de que esse Membro continuará adotando uma política liberal com relação ao setor.

Como os Membros não têm a obrigação de assumir compromissos em serviços, os compromissos consolidados demonstram: (i) o grau de sensibilidade ou de interesse em determinado setor; (ii) a importância ou aceitação dos diferentes modos de prestação de serviços, do ponto de vista dos Membros que assumiram compromissos; (iii) a prevalência de diferentes tipos de barreiras ao comércio, reveladas pelas limitações de acesso a mercados e tratamento nacional inscritas nas listas de compromissos ${ }^{84}$.

Por fim, uma característica importante do modelo de abertura comercial adotado pelo GATS refere-se à forma de condução das negociações. O GATS estabeleceu que as negociações em acesso a mercados seriam bilaterais e realizadas por meio do mecanismo de pedidos e ofertas (request offer approach). Em linhas gerais, por esse mecanismo, cada um dos Membros informa aos demais os setores, subsetores ${ }^{85}$ e modos de prestação de serviços ${ }^{86}$ que gostariam que os demais Membros se comprometessem a liberalizar ${ }^{87}$.

areas) the nature of treatment or access offered to foreign services or foreign-service suppliers. Under such an approach, countries retain the full right to undertake no commitments. In: such instances, they are under no legal obligation to supply information to their trading partners on the nature of discriminatory or accessimpeding regulations maintained at the domestic level.

A related feature of the GATS that tends to be replicated in RTAs that espouse a bottom-up approach to liberalization is to afford countries the possibility of making commitments that do not necessarily reflect or lock-in (i.e., are made below) the regulatory status quo (a long-standing practice in tariff negotiations that was replicated in a GATS setting)". SAUVÉ; MATTOO, 2000, 255 p.

84 "The absence of a commitment therefore does not mean that supply is not permitted. A country may maintain a very liberal regime while making no GATS commitments at all—but without commitments there is no guarantee that it will stay liberal. (...) They nevertheless throw useful light on three important issues: the degree of sensitivity, or of trade interest, of different sectors as revealed by the number of countries making commitments on them; the relative importance, or acceptability, of the different modes of supply from the view point of the scheduling country; and the prevalence of different types of trade barriers, as revealed by the limitations on market access and national treatment which governments have scheduled". ORGANIZAÇÃO MUNDIAL DO COMÉRCIO. Market Access: Unfinished Business. Post Uruguay Round Issues - Special Studies No. 6. Genebra, 2001, 101 p. Disponível em: <http://www.wto.int/english/res_e/booksp_e/special_study_6_e.pdf>. Acesso em: 7 jul. 2012.

85 Os setores e subsetores de serviços estão relacionados no seguinte documento: ORGANIZAÇÃO MUNDIAL DO COMÉRCIO. MTN.GNS/W/120, Services Sectoral Classification List, de 10 de julho de 1991. Disponível em: <http://gatt.stanford.edu>. Acesso em: 10 jan. 2012.

${ }^{86}$ A saber: Modo 1 - prestação transfronteiriça de serviços (cross-border supply); (ii) Modo 2 - consumo no exterior (consumption abroad); (iii) Modo 3 - presença comercial (commercial presence); e (iv) Modo 4 presença de pessoas físicas (movement of natural persons). 
Na hipótese de determinado Membro concluir ser de seu interesse assumir algum dos compromissos que constam dos pedidos enviados pelos demais Membros, ele o fará. No entanto, esse Membro pode não acatar os pedidos dos outros Membros se não lhe convier, visto que cada Estado tem a prerrogativa de assumir compromissos apenas nos setores que deseja liberalizar. Isso porque o GATS tem como princípio o respeito à autonomia regulatória dos Membros da OMC, a qual abrange, além do poder regulatório, o poder dos Estados de introduzir novas leis que lhes permitam alcançar seus objetivos de política pública em seus territórios, de acordo com as assimetrias existentes entre o grau de desenvolvimento regulatório dos diferentes Membros ${ }^{88}$.

\section{EXCEÇÕES E LIMITAÇÕES}

Assim como ocorre no GATT no âmbito do comércio de bens, o GATS contém disposições relativas a exceções de caráter geral, que têm como objetivo manter ou proteger objetivos de política pública e a segurança nacional. Essas exceções estão contempladas, respectivamente, nos Artigos XIV e XIV bis do GATS ${ }^{89}$. Esses artigos permitem que as normas do GATS sejam excepcionadas em circunstâncias específicas, como será visto adiante.

O Artigo XIV do GATS permite que um Membro adote as seguintes exceções às normas multilaterais de comércio com vistas à proteção ou à manutenção de seus objetivos de política pública: (a) medidas necessárias para proteger a moral ou manter a ordem pública; (b) medidas necessárias para proteger a vida e a saúde das pessoas e dos animais

\footnotetext{
${ }^{87}$ Para maiores informações sobre como são realizados os pedidos e ofertas nas negociações comerciais em serviços, vide ORGANIZAÇÃO MUNDIAL DO COMÉRCIO. Technical Aspects of Requests and Offers Summary of presentation by the Secretariat on the WTO Seminar on the GATS, de 20 de fevereiro de 2002. Disponível em: <http://www.wto.org/english/tratop_e/serv_e/requests_offers_approach_e.doc>. Acesso em: 10 jan. 2012.

${ }^{88}$ Em relação aos resultados das negociações para a criação de um acordo sobre serviços para os PEDs, na Rodada Uruguai, Ciro Leal M. da Cunha aponta que “(...) a conclusão da Rodada Uruguai foi satisfatória para os subdesenvolvidos. Esses países lograram, em grande medida, a preservação de seus interesses, obtendo tratamento especial como as medidas de salvaguarda dos Artigos IV, XII e XIX - devido à inegável assimetria entre Sul e Norte no tocante à competitividade do terciário. Ainda, a inclusão da modalidade "movimento de pessoas naturais" no âmbito do GATS teria sido uma conquista do Sul, que possui evidentes vantagens comparativas nesse nicho. Em contrapartida, representou grande concessão aos desenvolvidos a inclusão do princípio do tratamento nacional, ainda que específica para cada setor. Da mesma forma, os desenvolvidos, especialmente os EUA, lograram a aceitação da presença comercial como modalidade englobada pelo GATS. A propósito, entendemos essa modalidade de prestação de serviços, de longe, a mais importante no comércio internacional". C. L. M. da CUNHA. A introdução do comércio de serviços na regulação multilateral do comércio: Breve histórico. U. CELLI JUNIOR (org.). Comércio de Serviços na OMC. Curitiba: Juruá Editora, 2005, p. 38.

${ }^{89}$ LAMPREIA, 1995, p. 10.
} 
ou para a preservação dos vegetais; (c) medidas necessárias para assegurar a observância das leis e regulamentos que não sejam incompatíveis com as disposições do GATS (como medidas relacionadas à prevenção de práticas dolosas ou fraudulentas, aos meios de lidar com efeitos do não cumprimento de contratos de serviços, à proteção da privacidade dos indivíduos em relação ao processamento e à disseminação de dados pessoais, à proteção da confidencialidade dos registros e contas dos indivíduos e à segurança); (d) medidas incompatíveis com o Artigo XVII sempre que a diferença de tratamento tenha por objetivo assegurar a cobrança ou a coleta de impostos diretos em relação a serviços ou prestadores de serviços de outros Membros; (e) medidas incompatíveis com o Artigo II, sempre que a diferença de tratamento resulte de um acordo ou em disposições destinadas a evitar a dupla tributação $^{90}$. O GATS determina, ainda, que tais medidas não devem ser aplicadas de

90 “Art. 14

1 - Sob reserva de que as medidas abaixo enumeradas não sejam aplicadas de forma que constituam um meio de discriminação arbitrário ou injustificável entre países em que prevaleçam condições similares ou uma restrição encoberta ao comércio de serviços, nenhuma disposição do presente Acordo será interpretada no sentido de impedir que um membro adote ou aplique medidas:

a) necessárias para proteger a moral ou manter a ordem pública;

b) necessárias para proteger a vida e a saúde das pessoas e dos animais ou para a preservação dos vegetais;

c) necessárias para assegurar a observância das leis e regulamentos que não sejam incompatíveis com as disposições do presente Acordo, inclusive aquelas com relação a:

i) prevenção de práticas dolosas ou fraudulentas ou aos meios de lidar com efeitos do não-cumprimento dos contratos de serviços;

ii) proteção da privacidade dos indivíduos em relação ao processamento e à disseminação de dados pessoais e a proteção da confidencialidade dos registros e contas individuais;

iii) segurança.

d) incompatíveis com o art.17, sempre que a diferença de tratamento tenha por objetivo assegurar a imposição ou coleta eqüitativa ou efetiva de impostos diretos em relação a serviços ou prestadores de serviços de outros membros;

- se aplicam a prestadores de serviços não residentes em reconhecimento ao fato de que a obrigação fiscal dos não residentes é determinada com respeito aos itens tributáveis cuja fonte ou localização se faça no território do membro; ou

- se aplicam a não residentes a fim de assegurar a imposição ou coleta de tributos no território do membro; ou - se aplicam a residentes ou não-residentes a fim de impedir a evasão ou a fraude fiscal, incluindo-se medidas de execução; ou

- se aplicam aos consumidores de serviços prestados dentro ou a partir do território de outro membro a fim de assegurar a imposição ou coleta de tributo de tais consumidores derivados de fontes situadas no território do membro; ou

- estabeleçam distinção entre prestadores de serviços sujeitos a impostos sobre itens tributáveis em nível mundial de outros prestadores de serviços, em reconhecimento à diferença existente entre os mesmos quanto à natureza da base impositiva; ou

- determinem, atribuam ou repartam rendas, lucros, ganhos, perdas, deduções ou crédito de pessoas residentes ou sucursais, ou entre pessoas vinculadas ou sucursais de uma mesma pessoa, a fim de salvaguardar a base impositiva do membro.

Os termos e conceitos fiscais que figuram na alínea "d" do art.14 na presente nota de rodapé de página são determinados segundo as definições e conceitos fiscais, ou as definições e conceitos equivalentes ou similares, contidas na legislação nacional do membro que adote a medida.

e) incompatíveis com o art.2, sempre que a diferença de tratamento resulte de um acordo destinado a evitar a dupla tributação ou de disposições destinadas a evitar a dupla tributação contidas em qualquer outro acordo ou convênio internacional pelo qual o membro esteja vinculado". Decreto $\mathbf{n}^{\circ} \mathbf{1 . 3 5 5}$, de 30 de dezembro de 
forma a constituir um meio arbitrário ou injustificado de discriminação entre os Membros nos quais condições similares prevaleçam, nem devem representar restrições disfarçadas ao comércio internacional de serviços.

Além dessas exceções, o GATS regulamentou a possibilidade de os Membros excepcionarem a cláusula de nação mais favorecida, regulamentada no Artigo II do GATS. Conforme visto anteriormente, o Artigo II do GATS determina que será dado tratamento de nação mais favorecida a todos os Membros da OMC, em todos os setores de serviços consolidados nas listas de compromissos. No entanto, poderá ser concedido tratamento diferenciado a determinado Membro da OMC desde que esse tratamento tenha origem em: (i) acordos bilaterais que abarquem o setor de serviços, nos termos do Art. V do GATS; (ii) leis nacionais que requeiram tratamento recíproco ou concedam preferências especiais a determinado Estado; (iii) outros acordos regionais ou econômicos que não satisfaçam o critério do Artigo V do GATS, sobre acordos regionais que tratam do comércio de serviços, como, por exemplo, acordos que não abrangem todos os setores de serviços, que englobam apenas um modo de prestação de serviços ou que não tenham por objetivo a liberalização completa do comércio de serviços entre as Partes desse acordo regional ${ }^{91}$.

As exceções descritas nos itens (i) e (iii) acima serão desenvolvidas no item 7, adiante. As exceções derivadas de leis nacionais que requerem tratamento recíproco ou que concedem preferências especiais a determinado Estado devem ser apontadas pelos Membros em sua lista de exceções à cláusula de nação mais favorecida, conforme regulamentado no Artigo II.1 do GATS. Nessa lista, os Membros podem indicar que conferirão tratamento mais favorável aos serviços e prestadores de serviços de um Membro em detrimento de outro Membro, sem a obrigação de estendê-lo aos demais.

O GATS determina que os Membros devem estabelecer um prazo de vigência para as exceções à cláusula de nação mais favorecida elencadas em suas respectivas listas de compromissos, observando o prazo máximo de duração de dez anos, sujeito a alterações

1994, que promulga a Ata Final que incorpora os resultados da Rodada Uruguai de negociações comerciais multilaterais do GATT. Disponível em: <www.mre.gov.br〉. Acesso em: 10 jun. 2012.

91 “Artigo II - Tratamento de Nação Mais Favorecida

1. Com respeito a qualquer medida coberta por este Acordo, cada membro deve conceder imediatamente e incondicionalmente aos serviços e prestadores de serviços de qualquer outro membro, tratamento não menos favorável do que aquele concedido a serviços e prestadores de serviços similares de qualquer outro país.

2. Um membro poderá manter uma medida incompatível com o parágrafo 1 desde que a mesma esteja listada e satisfaça as condições do Anexo II sobre Isenções ao Artigo II.

3. As disposições deste Acordo não devem ser interpretadas de forma a impedir que qualquer membro conceda vantagens a países adjacentes destinadas a facilitar o intercâmbio de serviços produzidos e consumidos localmente em zonas de fronteira contígua" Decreto $n^{\circ} \mathbf{1 . 3 5 5}$, de 30 de dezembro de 1994, que promulga a Ata Final que incorpora os resultados da Rodada Uruguai de negociações comerciais multilaterais do GATT. Disponível em: <www.mre.gov.br>. Acesso em: 10 jun. 2011. 
nas rodadas de negociações para a liberalização do comércio ${ }^{92}$. Os Membros devem notificar o Conselho para o Comércio de Serviços sempre que o prazo de vigência da exceção cláusula de nação mais favorecida listada chegar ao fim, informando se a medida objeto da exceção está em conformidade com o parágrafo 1 do Artigo II do GATS ${ }^{93}$.

O GATS estabelece, ademais, que o Conselho para o Comércio de Serviços examinaria as listas de exceções à cláusula de nação mais favorecida cinco anos após o GATS entrar em vigor, com o intuito de determinar se as exceções ainda seriam necessárias e qual seria a data da próxima revisão ${ }^{94}$. De fato, o Conselho para o Comércio de Serviços tem realizado um trabalho de revisão de todas as derrogações ao Artigo II.1 do GATS apresentadas pelos Membros ao final da Rodada Uruguai, com o objetivo de examinar se estão presentes as condições que tornaram essas exceções necessárias, em 1994. Não obstante, atualmente, as listas de exceções à cláusula de nação mais favorecida continuam em vigor.

\section{REGRAS SOBRE REGULAÇÃO DOMÉSTICA}

Diferentemente do que ocorre com o comércio de bens, no qual a principal barreira ao livre comércio são as alíquotas de importação, no comércio internacional de serviços as barreiras são regulatórias e legais ${ }^{95}$. Isso significa que os prestadores de serviços, sejam

\footnotetext{
92 “5 - A isenção das obrigações enunciadas no parágrafo $1^{\circ}$ do art.2 concedida a um membro expirará na data prevista na isenção.

6 - Em princípio, tais isenções não deveriam exceder um período de dez anos. Em todo caso, estarão sujeitas a negociações em rodadas de liberalização do comércio subseqüentes". Decreto $\mathbf{n}^{\circ} \mathbf{1 . 3 5 5}$, de 30 de dezembro de 1994, que promulga a Ata Final que incorpora os resultados da Rodada Uruguai de negociações comerciais multilaterais do GATT. Disponível em: <www.mre.gov.br>. Acesso em: 10 jun. 2011.

93 “7 - Cada membro notificará o Conselho para o Comércio de Serviços, ao fím do período da isenção, de que as medidas incompatíveis foram postas em conformidade com o parágrafo $1^{\circ}$ do art.2 do Acordo". Decreto $\mathbf{n}^{\circ} \mathbf{1 . 3 5 5}$, de 30 de dezembro de 1994, que promulga a Ata Final que incorpora os resultados da Rodada Uruguai de negociações comerciais multilaterais do GATT. Disponível em: <www.mre.gov.br〉. Acesso em: 10 jun. 2011.

94 “3 - O Conselho para o Comércio de Serviços examinará todas as isenções concedidas por período superior a cinco anos. O primeiro destes exames se realizará no máximo cinco anos após a entrada em vigor do Acordo Constitutivo da OMC.

4 - Em cada exame, o Conselho para o Comércio de Serviços deverá:

a) examinar se ainda subsistem as condições que criaram a necessidade da isenção;

b) determinar a data de um novo exame eventual". Decreto $\mathbf{n}^{\circ} \mathbf{1 . 3 5 5}$, de 30 de dezembro de 1994, que promulga a Ata Final que incorpora os resultados da Rodada Uruguai de negociações comerciais multilaterais do GATT. Disponível em: <www.mre.gov.br>. Acesso em: 10 jun. 2012.

${ }^{95}$ Sobre esse tópico, Aaditiya Mattoo e Pierre Sauvé alegam que: "Trade in Services, far more than trade in goods, is affected by a variety of domestic regulations, ranging from qualification and licensing requirements and procedures in professional services,, procompetitive regulation in telecommunications, and other network services, to unviversal access requirements in health and education services.” MATTOO, Aaditya; SAUVÉ,
} 
eles pessoas físicas ou jurídicas, ao prestarem determinado serviço em um Membro da OMC que não seja seu Estado de origem, em qualquer dos quatro modos, enfrenta limitações em relação à sua entrada, estabelecimento ou às condições de competitividade com os prestadores locais. Tais limitações são impostas por leis, decisões e outras normas jurídicas, em todas as esferas administrativas (federal, estadual, municipal ou equivalentes), bem como por decisões judiciais e de órgãos da administração pública.

O GATS contém normas que protegem o prestador estrangeiro, visto que estabelecem, de forma restritiva, quais as possibilidades de limitação à atuação de empresas estrangeiras em determinado mercado, bem como as circunstâncias nas quais os serviços e os prestadores estrangeiros recebem tratamento menos favorável do que aquele concedido aos serviços e empresas originários do Estado em questão.

Em razão da importância da dimensão regulatória no processo de liberalização comercial no setor de serviços, foi inserido no GATS um Artigo que trata do tema regulamentação doméstica, o Artigo VI. "Regulamentação doméstica" refere-se a todas as medidas de aplicação geral, no território de um Membro, que afetam o comércio de serviços. Essas medidas de aplicação geral são ferramentas governamentais que permitem que se verifiquem a competência e a habilidade de determinado prestador de serviços, seja ele pessoa física ou jurídica. Tais medidas também podem definir a maneira pela qual um serviço é prestado e, por isso, são mecanismos importantes para se garantir a qualidade, a expertise, a segurança ambiental, o resultado e o uso de determinados métodos de produção.

Assim, a existência de regras claras no que concerne à regulamentação doméstica objetiva garantir transparência ao ingresso e à atuação de pessoas físicas e jurídicas estrangeiras em determinado setor, impedindo que os compromissos em acesso a mercados em serviços sejam prejudicados por normas jurídicas nacionais extremamente restritivas. Em razão da sua relevância para o processo de liberalização comercial, o Artigo VI é considerado como a terceira perna do tripé para o acesso aos mercados de serviços, que é composto pelo Artigo XVI do GATS, relativo a acesso a mercados, e pelo Artigo XVII do GATS, sobre tratamento nacional ${ }^{96}$.

Pierre. Domestic Regulation \& Services Liberalization. Washington: Banco Mundial e Oxford University Press, 2003, p. 1.

${ }^{96}$ Sobre a diferença entre esses Artigos, Aaditya Mattoo e Pierre Sauvé alegam que: "Whereas article XVI primarily addresses all (i.e., discriminatory and nondiscriminatory) quantitative restrictions affecting services trade and article XVII disciplines overtly discriminatory treatment of foreign services and services providers, Article VI aims to discipline more opaque forms of protection embedded in domestic regulatory conduct". MATTOO; SAUVÉ, 2003, p. 3. 
Ressalte-se que o Artigo VI do GATS tem como objetivo estabelecer regras aplicáveis às normas de regulamentação doméstica nacionais com o mínimo de influência possível na autonomia regulatória dos Membros da $\mathrm{OMC}^{97}$. Logo, é importante determinar em que medida as leis nacionais devem se basear nos princípios de eficiência econômica e governabilidade $^{98}$. Contudo, a diferença entre regras multilaterais claras e transparentes, que transmitam segurança jurídica aos prestadores de serviços estrangeiros, e regras multilaterais que reduzem a autonomia regulatória do Estado e, consequentemente, o poder de implementar políticas públicas pode ser muito tênue. Por essa razão, o Artigo VI tornou-se um dos mais importantes e polêmicos Artigos do GATS.

Nos termos desse Artigo, todo Membro deverá garantir que as medidas que afetem o comércio de serviços sejam administradas de maneira razoável, objetiva e imparcial (Art. VI: $\left.1^{99}\right)$. Esse Artigo determina, ademais, que os Membros devem manter ou instituir tribunais judiciais, arbitrais, administrativos ou procedimentos que ofereçam uma revisão rápida para as decisões administrativas que afetem o comércio de serviços, sempre que for consistente com a estrutura constitucional ou natureza do sistema legal do Membro em questão (Art. VI: $2^{100}$ ). Sempre que for necessária autorização para a prestação de um serviço objeto de compromisso específico, as autoridades competentes do Membro devem fornecer, sem atraso injustificável, informações relativas ao status da análise do requerimento de autorização ou de sua decisão a respeito desse requerimento ao requerente (Art. VI: $3^{101}$ ). Trata-se, portanto, do reconhecimento expresso do direito do prestador de serviços estrangeiro de obter informações sobre decisões regulatórias e administrativas,

\footnotetext{
${ }^{97}$ Apesar de sua importância no processo de liberalização do comércio internacional de serviços, o Artigo VI é provisório por natureza, pois se pretende que as normas por ele estabelecidas sejam incorporadas à prática e às legislações nacionais dos Estados-membros da OMC.

98 MATTOO; SAUVÉ, op. cit., p. 3.

99 "1. In sectors where specific commitments are undertaken, each Member shall ensure that all measures of general application affecting trade in services are administered in a reasonable, objective and impartial manner."

100 "2. (a) Each Member shall maintain or institute as soon as practicable judicial, arbitral or administrative tribunals or procedures which provide, at the request of an affected service supplier, for the prompt review of, and where justified, appropriate remedies for, administrative decisions affecting trade in services. Where such procedures are not independent of the agency entrusted with the administrative decision concerned, the Member shall ensure that the procedures in fact provide for an objective and impartial review.

(b) The provisions of subparagraph (a) shall not be construed to require a Member to institute such tribunals or procedures where this would be inconsistent with its constitutional structure or the nature of its legal system."

101 "3. Where authorization is required for the supply of a service on which a specific commitment has been made, the competent authorities of a Member shall, within a reasonable period of time after the submission of an application considered complete under domestic laws and regulations, inform the applicant of the decision concerning the application. At the request of the applicant, the competent authorities of the Member shall provide, without undue delay, information concerning the status of the application."
} 
bem como de recorrer às esferas administrativa e judicial sempre que se sentir prejudicado por alguma decisão de um órgão governamental.

O GATS estabelece, também, que cada Membro deve instituir procedimentos adequados para a verificação da competência dos profissionais de qualquer outro Membro (VI:6) ${ }^{102}$. Por fim, prevê a realização de negociações para o desenvolvimento de disciplinas necessárias para assegurar que as medidas relativas a requisitos e procedimentos para qualificação, normas técnicas e requisitos e procedimentos para licenciamento não constituam barreiras desnecessárias ao comércio de serviços ${ }^{103}$.

De acordo com o GATS, as cinco medidas a que se refere o Artigo VI:4 (requisitos e procedimentos para qualificação, requisitos e procedimentos para licenciamento, e normas técnicas) devem ser estabelecidas com base em critérios objetivos e transparentes, como a competência e a habilidade de prestar o serviço. Além disso, é importante que essas normas não sejam tão difíceis de se cumprir a ponto de representarem um custo maior do que o necessário para assegurar a qualidade na prestação do serviço. No caso de procedimentos para licenciamento, eles não podem representar em si mesmos uma restrição à prestação do serviço. Na ausência de regulamentação do Artigo VI:4, o Artigo VI: $5^{104}$ determina que esses critérios sejam aplicados a quaisquer novas medidas capazes de anular ou prejudicar os compromissos assumidos pelos Membros em suas listas de compromissos.

Com relação à aplicabilidade, é importante mencionar que Artigo VI:I estabelece que as disposições sobre regulamentação doméstica aplicam-se apenas aos setores de serviços para os quais os Membros assumiram compromissos específicos. No entanto, há uma discordância entre os Membros em relação ao alcance da aplicabilidade das

102 "6. In sectors where specific commitments regarding professional services are undertaken, each Member shall provide for adequate procedures to verify the competence of professionals of any other Member."

${ }^{103}$ A respeito da previsão de negociações sobre regulamentação doméstica previstas no Artigo VI:4 do GATS, Aaditya Mattoo e Pierre Sauvé observam que: "Unable to complete all aspects of the incipient GATS framework before the Uruguay Round's conclusion, services negotiators agreed on language in Article VI:4 calling for further work on disciplines that would help ensure the regulatory measures affecting services trade are reasonable, objective, and impartial. Work in this area is designed to address the fact that nontransparent, unfair and unduly burdensome regulations at the national level may undermine the value of market access commitments freely entered into by WTO members". MATTOO; SAUVÉ, 2003, p. 3.

104 "5. (a) In sectors in which a Member has undertaken specific commitments, pending the entry into force of disciplines developed in these sectors pursuant to paragraph 4, the Member shall not apply licensing and qualification requirements and technical standards that nullify or impair such specific commitments in a manner which:

(i) does not comply with the criteria outlined in subparagraphs 4(a), (b) or (c); and

(ii) could not reasonably have been expected of that Member at the time the specific commitments in those sectors were made.

(b) In determining whether a Member is in conformity with the obligation under paragraph 5(a), account shall be taken of international standards of relevant international organizations applied by that Member." 
disciplinas do item VI:4, ou seja, se elas se aplicariam a todos os setores de serviços, incluindo aqueles que fossem consolidados no futuro, ou somente àqueles que já são objeto de compromissos específicos, como estabelecido no item VI:1.

\section{O ARTIGO V DO GATS}

\subsection{Texto legal}

Conforme visto acima, o Artigo V do GATS regulamenta as normas sobre integração econômica em matéria de serviços. Esse artigo estabelece o seguinte:

“Artigo V - Integração Econômica

1. O presente Acordo não impedirá nenhum de seus Membros de ser parte ou de celebrar um acordo que liberalize o comércio de serviços entre as partes do mesmo, à condição que tal acordo:

a) tenha uma cobertura setorial substancial ${ }^{1}$; e

b) estabeleça a ausência ou eliminação, no essencial, de toda discriminação entre as partes no sentido do artigo XVII nos setores compreendidos pela alínea (a) por meio:

i) da eliminação das medidas discriminatórias existentes, e/ou

ii) da proibição de medidas discriminatórias novas ou que aumentem a discriminação, seja na data de entrada em vigor daquele acordo ou sob a base de um período de tempo razoável, exceto para as medidas permitidas em virtude dos artigos XI, XII, XIV e XIV bis.

2. Ao se determinar se são cumpridas as condições estabelecidas pela alínea (b) do parágrafo 1, poder-se-á levar em consideração as relações de dito acordo com um processo mais amplo de integração econômica ou liberalização do comércio entre os países de que se trate.

3. a) Nos casos em que países em desenvolvimento sejam partes de um acordo do tipo referido no parágrafo 1 , será prevista flexibilidade relativa às condições estabelecidas pelo parágrafo $1^{\circ}$, em particular pela alínea (b), em consonância com o nível de desenvolvimento dos países envolvidos, tanto em geral, quanto em setores e subsetores individuais.

b) Não obstante o disposto no parágrafo 6, no caso de um acordo a que se refere o parágrafo 1 de que participem unicamente países em desenvolvimento poder-se-á conceder tratamento mais favorável às pessoas jurídicas que sejam propriedade ou que estejam sob o controle de pessoas físicas das partes de dito acordo.

4. Todo acordo do tipo a que se refere o parágrafo 1 estará destinado a facilitar o comércio entre as partes e não elevará, com respeito a nenhum outro Membro alheio ao acordo, o nível global de barreiras ao comércio de serviços nos respectivos setores e subsetores relativamente ao nível aplicável antes do acordo. 
5. Se, por ocasião da conclusão, ampliação ou qualquer modificação importante de qualquer acordo pertinente ao parágrafo 1, um Membro tencione retirar ou modificar um compromisso específico de maneira incompatível com os termos e condições enunciados em sua lista, deverá notificar tal modificação ou retirada com um mínimo de 90 dias de antecedência, e será aplicável aos procedimentos nos parágrafos 2 a 4 do artigo XXI.

6. Os provedores de serviços de qualquer outro Membro que sejam pessoas jurídicas constituídas sob a legislação de uma parte em um acordo do tipo a que se refere o parágrafo 1 terão direito ao tratamento concedido em virtude de tal acordo, à condição de que realizem operações comerciais substantivas no território das partes naquele acordo.

7. a) Os Membros que sejam partes em um acordo do tipo a que se refere o parágrafo 1 deverão notificar prontamente o Conselho para o Comércio de Serviços sobre aquele acordo e toda ampliação importante do mesmo. Também devem colocar à disposição do Conselho informações relevantes que este venha a solicitar. O Conselho poderá estabelecer um grupo de trabalho para examinar dito acordo ou ampliação ou modificação do mesmo e reportar ao Conselho quanto a sua compatibilidade com o presente artigo.

b) Os Membros que sejam partes em qualquer acordo a que se refere o parágrafo 1, que seja implementado na base de um período de tempo determinado, deverão reportar periodicamente ao Conselho para o Comércio de Serviços sobre sua implementação. O Conselho poderá estabelecer um grupo de trabalho para examinar os relatórios se julgar necessário.

c) Com base nos relatórios dos grupos de trabalho a que se referem as alíneas (a) e (b) do presente parágrafo, o Conselho poderá fazer recomendações às partes caso julgue apropriado.

8. Um Membro que seja parte em um acordo a que se refere o parágrafo 1 não poderá pedir compensação pelos benefícios que possam resultar de tal acordo para qualquer outro Membro.

1. Entende-se esta condição em termos de número de setores, volume de comércio afetado e modos de prestação. Para satisfazer esta condição tais acordos não devem prever a exclusão a priori de nenhum modo de prestação". ${ }^{105}$

Verifica-se, assim, que os acordos regionais que contemplam a liberalização do comércio de serviços são, a priori, compatíveis com as regras multilaterais de comércio. Contudo, é necessário que tais acordos atendam às condições estabelecidas no Artigo V.

Os requisitos estabelecidos nesse dispositivo são vinculativos, tal como os demais artigos dos Acordos da OMC, e, em caso de não cumprimento, não será possível alegar que o acordo regional em questão está em conformidade com a legislação da OMC. Note-se que tais requisitos aplicam-se a todos os Membros, mas não têm efeito sobre acordos regionais celebrados entre Não-Membros da OMC. Porém, os acordos celebrados entre um Membro da OMC e um Não-Membro estão sujeitos à disciplina do Artigo V do GATS em

105 Decreto $^{\circ} \mathbf{1 . 3 5 5}$, de 30 de dezembro de 1994, que promulga a Ata Final que incorpora os resultados da Rodada Uruguai de negociações comerciais multilaterais do GATT. Disponível em: 〈www.mre.gov.br〉. Acesso em: 10 jun. 2011. 
relação à Parte que é Membro da OMC. Esse entendimento tem fundamento no Artigo II:1 do GATS, que determina que, se for concedido tratamento mais favorável aos serviços e prestadores de serviços "de qualquer outro país" com relação em um acordo regional, os Membros da OMC devem assegurar que pelo menos suas próprias obrigações atendam aos requisitos previstos no Artigo V do GATS ${ }^{106}$.

\subsection{Principais semelhanças e diferenças entre o Artigo V do GATS e o Artigo XXIV do GATT}

Como visto anteriormente, o Artigo V do GATS pode ser considerado como a reprodução do Artigo XXIV do GATT para o comércio de serviços. De fato, há muitas semelhanças entre ambos.

Tanto o Art. XXIV do GATT quanto o Art. V do GATS visam a estabelecer diretrizes para que haja um equilíbrio entre as motivações econômicas e políticas das Partes do acordo e os interesses dos Membros que não são signatários. Ambos os artigos impedem que haja restrições ao acesso dos Membros que são Parte no acordo aos mercados dos Membros que são Parte destes. Também não pode haver distorção nas condições de concorrência em razão do acordo regional.

Note-se, ainda, que o caput do Artigo V:1 refere-se apenas à "liberalização do comércio de serviços", sem estabelecer quais os tipos de acordos abrangidos pelo Acordo. Diferentemente do GATS, o Artigo XXIV do GATT declara, explicitamente, que seus dispositivos aplicam-se a áreas de livre comércio e uniões aduaneiras. Logo, o Artigo V do GATS opera com base em um conceito único de integração econômica ${ }^{107}$.

Por fim, uma crítica que se coloca em relação a ambos os artigos consiste no fato de que o mesmo conceito vago que consta no Artigo XXIV do GATT, de que seja eliminada substancialmente toda discriminação entre as Partes do acordo, foi praticamente replicado no GATT $^{108}$.

\footnotetext{
${ }^{106}$ Vide COTTIER; MOLINUEVO, 2008, p. 130.

${ }^{107}$ Vide COTTIER; MOLINUEVO, 2008, p. 129.

108 "Whoever had hoped that vague concepts such as 'substantially all the trade' could be given clearer meaning, would have been disappointed. One of the possibly weakest provisions of the GATT, judged by its lack of clarity, has thus found its equivalent in the GATS". R. ADLUNG; P. MORRISON. Less than the GATS: 'Negative Preferences' in Regional Services Agreements. Journal of International Economic Law, Oxford, Oxford University Press, vol. 13, n. 4, p. 1103-1143, 2010, p. 1108.
} 


\subsection{Requisitos estabelecidos pelo Artigo V do GATS}

O Artigo V do GATS possibilita que os Membros celebrem acordos regionais que abranjam o comércio de serviços e estabelece as condições que devem ser cumpridas para que o acordo seja considerado legítimo. Em outras palavras, apenas os acordos regionais que cumprirem os requisitos previstos no Artigo V serão considerados compatíveis com o GATS, e, consequentemente, as Partes do acordo que forem Membros da OMC não poderão ser acionadas no âmbito do Órgão de Solução de Controvérsias. Por sua vez, os Membros que forem Parte de um acordo regional que não cumpra com os requisitos previstos no Artigo V do GATS poderão ser acionados no Órgão de Solução de Controvérsias por descumprir a obrigação prevista na cláusula de nação mais favorecida.

Essa questão foi objeto de análise pelo Órgão de Solução de Controvérsias no caso Canadá-Automóveis $^{109}$. Nesse caso, o Painel analisou se uma exceção ao imposto de importação sobre as importações de automóveis, de partes de motor e de materiais correlatos concedida a um número limitado de empresas seria compatível com as regras da OMC. Em sua defesa, o Canadá alegou que o tratamento diferenciado teria como fundamento a Área de Livre Comércio da América do Norte ("NAFTA") e, por isso, deveria ser considerado como uma exceção à cláusula de nação mais favorecida prevista no Artigo II do GATS em vista do Artigo V:1 desse mesmo Acordo. O Painel concluiu que a alegação do Canadá era infundada, uma vez que a medida adotada por este país não garantia tratamento mais favorável a todos os serviços e prestadores de serviços das Partes Contratantes do NAFTA ${ }^{110}$. A conclusão do Painel não foi objeto de apelação.

109 WT/DS139/R, WT/DS142/R Report of the Panel, Canada - Certain Measures Affecting the Automotive Industry, adotado em 19 de fevereiro de 2000. Disponível em: 〈http://www.wto.org>. Acesso em: 9 jun. 2011.

110 "Even assuming that the [Canadian measures at issue] could be brought within the scope of the services liberalization provisions of NAFTA, we note that the import duty exemption under the [measures at issue] is accorded to a small number of manufacturers/wholesalers of the United States to the exclusion of all other manufacturers/wholesalers of the United States and of Mexico. The [measures at issue], therefore, provide more favourable treatment to only some and not all services and service suppliers of Members of NAFTA, while, according to Article V:1(b), an economic integration agreement has to provide for 'the absence or elimination of substantially all discrimination, in the sense of Article XVII', in order to be eligible for the exemption from Article II of the GATS.

Although the requirement of Article $\mathrm{V}: 1(\mathrm{~b})$ is to provide non-discrimination in the sense of Article XVII (National Treatment), we consider that once it is fulfilled it would also ensure non-discrimination between all service suppliers of other parties to the economic integration agreement. It is our view that the object and purpose of this provision is to eliminate all discrimination among services and service suppliers of parties to an economic integration agreement, including discrimination between suppliers of other parties to an economic integration agreement. In other words, it would be inconsistent with this provision if a party to an economic integration agreement were to extend more favourable treatment to service suppliers of one party than that which it extended to service suppliers of another party to that agreement. 
A seguir, serão analisadas as principais condições determinadas pelo Artigo $\mathrm{V}$ do GATS para que um acordo regional seja considerado compatível com as regras da OMC.

\subsubsection{Obrigações relacionadas ao comércio inter-partes}

O Artigo V: 1 do GATS define as obrigações que os acordos regionais devem observar, em termos de comércio, para que este seja considerado como compatível com as regras da OMC. De acordo com esse artigo, o comércio de serviços abrangido pelo acordo deve atender a dois conceitos básicos, a saber: o conceito de cobertura setorial substancial (Artigo V: 1(a)) e o de eliminação de substancialmente todas as discriminações existentes (Artigo V: 1(b)) em relação ao fluxo comercial inter-partes ${ }^{111}$.

\subsubsection{Necessidade de abrangência setorial substancial}

A primeira condição estabelecida no Artigo V:1(a) do GATS consiste na necessidade de que o acordo regional tenha abrangência setorial substancial em termos de número de setores de serviços, volume de comércio afetado e modos de prestação de serviços, conforme esclarece a nota de rodapé $n^{\circ} 1$ desse artigo. No entanto, o Acordo não traz nenhuma definição sobre a quantidade de setores de serviços, o volume de comércio ou o número de modos que devem ser objeto de compromissos em um acordo regional para que se considere que o acordo está em conformidade com o requisito previsto no Artigo V:1 do GATS.

Moreover, it is worth recalling that Article $\mathrm{V}$ provides legal coverage for measures taken pursuant to economic integration agreements, which would otherwise be inconsistent with the MFN obligation in Article II. Paragraph 1 of Article V refers to 'an agreement liberalizing trade in services'. Such economic integration agreements typically aim at achieving higher levels of liberalization between or among their parties than that achieved among WTO Members. Article V:1 further prescribes a certain minimum level of liberalization which such agreements must attain in order to qualify for the exemption from the general MFN obligation of Article II. In this respect, the purpose of Article V is to allow for ambitious liberalization to take place at a regional level, while at the same time guarding against undermining the MFN obligation by engaging in minor preferential arrangements. However, in our view, it is not within the object and purpose of Article V to provide legal coverage for the extension of more favourable treatment only to a few service suppliers of parties to an economic integration agreement on a selective basis, even in situations where the maintenance of such measures may explicitly be provided for in the agreement itself'. WT/DS139/R, WT/DS142/R Report of the Panel, Canada - Certain Measures Affecting the Automotive Industry, adotado em 19 de fevereiro de 2000. Disponível em: 〈http://www.wto.org〉. Acesso em: 9 jun. 2011.

${ }^{111}$ Vide CELLI JUNIOR et al. MERCOSUR in South-South Agreements: In the middle of two models of regionalism. Instituto Virtual da Organização para a Cooperação Econômica e o Desenvolvimento: 2010. Disponível em: <http://vi.unctad.org/resources-mainmenu-64/digitallibrary? $\mathrm{i}=\mathrm{VI} \& \mathrm{op}=\mathrm{all} \& \mathrm{q}=$ Mercosur+in+Southsouth+Agreements\%3A+In+the+Middle+of+Two+Models+of+Regionalism+\&act=search\&option=com_gsli nk>. Acesso em: 13 jun. 2011. P. 18. 
De acordo com Thomas Cottier e Martín Molinuevo, a exclusão de mais de um ou dois dos 11 setores identificados na Lista de Classificação Setorial (W120 ${ }^{112}$ ) no acordo regional representaria uma abrangência não substancial ${ }^{113}$. Sobre essa questão, Rudolf Adlung e Peter Morrison apontam que os 11 setores de serviços relacionados na Lista de Classificação Setorial não possuem a mesma importância em termos econômicos. O setor de serviços profissionais, por exemplo, abrangeria um número maior de atividades econômicas significativas do que outros setores, como o de serviços de entretenimento ${ }^{114}$.

Embora alguns doutrinadores tenham buscado estabelecer parâmetros mais precisos para o conceito previsto no Artigo V:1(a) do GATS, a OMC não se pronunciou sobre o assunto.

\subsubsection{Necessidade de eliminação das discriminações}

O Artigo V:1(b) do GATS determina que o acordo regional deverá estabelecer a ausência ou a eliminação de substancialmente toda discriminação entre as Partes, nos setores abrangidos pela alínea (a) desse mesmo artigo, por meio da eliminação das medidas discriminatórias existentes, e/ou da proibição de novas medidas discriminatórias ou de medidas que aumentem a discriminação, seja na data de entrada em vigor daquele acordo ou dentro de um período de tempo razoável, exceto para as medidas permitidas pelos artigos XI, XII, XIV e XIV bis.

Diferentemente do que ocorre com o conceito de abrangência setorial substancial previsto no Artigo V:1(a), o GATS não apresenta nenhum esclarecimento sobre o conceito de eliminação de substancialmente toda discriminação. A incerteza em torno deste ponto central é o significado de "substancialmente todos" e, por conseguinte, a possibilidade de implementação de medidas discriminatórias em um acordo regional.

No caso Turquia-Têxteis, que examina o escopo o Artigo XXIV:8 (a)(i) do GATT no que se refere à abrangência setorial de acordos regionais em relação a bens, o Órgão de Apelação confirmou o entendimento do Painel no sentido de que o termo "substancialmente todo o comércio" ("substancially all the trade") não poderia ser interpretado como "todo o comércio" ("all the trade"), mas certamente significa mais do

${ }^{112}$ MTN.GNS/W/120. Services Sectoral Classification List. 10 de julho de 1991. Disponível em: <www.wto.org>. Acesso em: 15 jun. 2012.

${ }^{113}$ COTTIER; MOLINUEVO, 2008, p. 131

${ }^{114}$ ADLUNG; MORRISON. 2010, p. 1110. 
que "uma parte do comércio" ("some of the trade") ${ }^{115}$. Desse modo, o Órgão de Apelação da OMC garantiu flexibilidade aos Membros no que se refere ao conceito.

Embora o texto do Artigo V:1 do GATS não seja idêntico ao texto do Artigo XXIV:8 (a)(i) do GATT, é possível estabelecer uma analogia entre os dois Artigos, já que ambos se referem à exceção ao princípio da não discriminação em virtude de acordos regionais de comércio e estabelecem as condições para que tais acordos sejam considerados compatíveis com as regras do Sistema Multilateral de Comércio. Ademais, tanto o GATT quanto o GATS são anexos ao Acordo Constitutivo da OMC e, em conformidade com o Artigo 31.2 da Convenção de Viena sobre o Direito dos Tratados ${ }^{116}$, um artigo do GATT poderia ser considerado como "contexto" para interpretação de um artigo do GATS.

Note-se, ainda, que, em algumas ocasiões, o Órgão de Apelação da OMC interpretou o sentido de determinados dispositivos do GATS com base no tex to e na interpretação dada por esse Órgão a Artigos correlatos do GATT. Como exemplo, cite-se a interpretação dada ao Artigo XIV do GATS pelo Órgão de Apelação no caso EUA-Jogos de Azar. Nesse caso, o Órgão de Apelação considerou que ambos os artigos têm o mesmo objetivo e utilizam uma linguagem similar ${ }^{117}$.

115 "48. Sub-paragraph 8(a)(i) of Article XXIV establishes the standard for the internal trade between constituent members in order to satisfy the definition of a "customs union". It requires the constituent members of a customs union to eliminate "duties and other restrictive regulations of commerce" with respect to "substantially all the trade" between them. Neither the GATT CONTRACTING PARTIES nor the WTO Members have ever reached an agreement on the interpretation of the term "substantially" in this provision. It is clear, though, that "substantially all the trade" is not the same as all the trade, and also that "substantially all the trade" is something considerably more than merely some of the trade." WT/DS34/AB/R, Turkey Restrictions on Imports of Textile and Clothing Products, adotado em 19 de novembro de 1999. Disponível em: <http://www.worldtradelaw.net/reports/wtoab/turkey-textiles(ab).pdf>. Acesso em: 13 jun. 2011.

116 “Artigo 31 - Regra Geral de Interpretação

(...) 2. Para os fins de interpretação de um tratado, o contexto compreenderá, além do texto, seu preâmbulo e anexos:

a) qualquer acordo relativo ao tratado e feito entre todas as partes em conexão com a conclusão do tratado;

b) qualquer instrumento estabelecido por uma ou várias partes em conexão com a conclusão do tratado e aceito pelas outras partes como instrumento relativo ao tratado." Convenção de Viena sobre o Direito dos Tratados. Disponível em: <http://www2.mre.gov.br/dai/dtrat.htm>. Acesso em: 13 jun. 2011.

117 "1. Article XIV of the GATS sets out the general exceptions from obligations under that Agreement in the same manner as does Article XX of the GATT 1994. Both of these provisions affirm the right of Members to pursue objectives identified in the paragraphs of these provisions even if, in doing so, Members act inconsistently with obligations set out in other provisions of the respective agreements, provided that all of the conditions set out therein are satisfied. Similar language is used in both provisions, notably the term "necessary" and the requirements set out in their respective chapeaux. Accordingly, like the Panel, we find previous decisions under Article XX of the GATT 1994 relevant for our analysis under Article XIV of the GATS.

2. Article XIV of the GATS, like Article XX of the GATT 1994, contemplates a "two-tier analysis" of a measure that a Member seeks to justify under that provision. A panel should first determine whether the challenged measure falls within the scope of one of the paragraphs of Article XIV. This requires that the challenged measure address the particular interest specified in that paragraph and that there be a sufficient nexus between the measure and the interest protected. The required nexus-or "degree of connection"- 
Não obstante o Órgão de Solução de Controvérsias ter esclarecido, nos casos citados, parte dos requisitos descritos no Artigo V:1(b) do GATS, permanecem dúvidas a respeito de como deve ser avaliada a eliminação das medidas discriminatórias existentes (em termos de números de setores, de modos de prestação, entre outros).

Com relação ao período de tempo razoável para a eliminação das medidas discriminatórias existentes, é possível considerar, por analogia, que se aplica o disposto no Entendimento Sobre A Interpretação do Artigo XXIV do Acordo Geral sobre Tarifas e Comércio $1994^{118}$, que determina que esse prazo não deva ser superior a 10 anos.

\subsubsection{Notificação}

Outro requisito importante estabelecido pelo Artigo V do GATS consiste na notificação dos acordos regionais envolvendo o comércio de serviços aos órgãos competentes. Desse modo, a OMC poderá avaliar se o tratamento discriminatório previsto em um acordo regional atende as condições estabelecidas no GATS e, consequentemente, pode ser considerado compatível com as normas da OMC.

Os acordos regionais celebrados no âmbito do Art. XXIV do GATT devem ser notificados ao Conselho para o Comércio de Bens. Os acordos regionais celebrados no âmbito do Art. V do GATS, por sua vez, devem ser notificados ao Conselho para o Comércio de Serviços. Já os acordos preferenciais celebrados no âmbito da Cláusula de Habilitação devem ser notificados ao Comitê de Comércio e Desenvolvimento ${ }^{119}$

É importante notar que, no caso da notificação de acordos a que se refere o Art. XXIV do GATT, o Conselho para o Comércio de Bens adotará os termos de referência e

between the measure and the interest is specified in the language of the paragraphs themselves, through the use of terms such as "relating to" and "necessary to". Where the challenged measure has been found to fall within one of the paragraphs of Article XIV, a panel should then consider whether that measure satisfies the requirements of the chapeau of Article XIV." WT/DS285/AB/R, United States - Measures Affecting the Cross-Border Supply of Gambling and Betting Services, adotado em 20 de abril de 2005. Disponível em: $<$ http://docsonline.wto.org/imrd/gen_searchResult.asp?RN=0\&searchtype=browse\&q1=\%28\%40meta\%5FS ymbol+WT\%FCDS285\%FCAB\%FCR\%2A+and+not+RW\%2A\%29\&language=1>. Acesso em: 13 jun. 2011.

118 “3. O "prazo razoável de tempo" referido no parágrafo 5(c) do Artigo XXIV só deve exceder dez anos em casos excepcionais. Nos casos em que acreditarem que os dez anos são insuficientes, os membros partes de um acordo interino fornecerão explicação completa ao Conselho para o Comércio de Bens sobre a necessidade de um período mais longo". Entendimento Sobre a Interpretação do Artigo XXIV do Acordo Geral sobre Tarifas e Comércio 1994. Disponível em: <http://www.mdic.gov.br/arquivo/secex/omc/acordos/portugues/08artxxiv.pdf>. Acesso em: 19 jun. 2011.

${ }^{119}$ Para mais informações sobre o mecanismo de transparência da OMC relativo a acordos regionais, vide: WT/L/61. Transparency Mechanism for Regional Trade Agreements, de 18 de dezembro de 2006. Disponível em: <http://docsonline.wto.org>. Acesso em: 19 out. 2010. 
repassará a análise do acordo ao Comitê de Acordos Regionais da OMC. No caso dos acordos relativos ao Art. V do GATS, o Conselho para o Comércio de Serviços decidirá se repassará ou não o exame do acordo ao Comitê de Acordos Regionais. Portanto, ao contrário do que ocorre com os acordos envolvendo o comércio de bens, no caso de serviços, o exame pelo Conselho para o Comércio de Serviços é opcional ${ }^{120}$.

O formato da notificação descrito no Artigo V:7 do GATS foi estabelecido no documento Diretrizes Para Notificações no Âmbito do Acordo Geral sobre o Comércio de Serviços $^{121}$. Em 20 de fevereiro de 1998, o Comitê de Acordos Regionais fez recomendações ao Conselho para o Comércio de Serviços a respeito de como deveria ser realizada a notificação dos acordos regionais a este Comitê ${ }^{122}$. Em 23 e 24 de novembro de 1998, o Conselho para o Comércio de Serviços tomou ciência dos procedimentos recomendados, como diretrizes gerais a respeito das notificações e informações sobre acordos regionais de comércio submetidos ao referido Comitê ${ }^{123}$. Até julho de 2012, 104 acordos regionais haviam sido notificados ao Comitê de Acordos Regionais da OMC com fundamento no Artigo V do GATS ${ }^{124}$.

\subsubsection{Manutenção do nível de compromissos em relação a outros Membros}

Os Artigos V:4 e V:5(i) do GATS estabelecem algumas condições que visam a garantir que o acordo regional não prejudicará os Membros da OMC que não são Parte do mesmo, a fim de evitar que os compromissos assumidos regionalmente por determinado Membro sejam incompatíveis com suas obrigações multilaterais. Segundo tais Artigos, o acordo regional não poderá aumentar ou restringir o comércio de serviços entre as os Membros que são Parte e aqueles que não são Parte do acordo, em relação a setores ou

\footnotetext{
120 Work of the Committee on Regional Trade Agreements (CRTA). Disponível em: <http://www.wto.org/english/tratop_e/region_e/regcom_e.htm>. Acesso em: 27 jan. 2014.

${ }^{121} \mathbf{S} / \mathbf{L} / \mathbf{5}$, Guidelines for Notifications under the General Agreement on Trade in Services, adotado pelo Conselho de Serviços em 1 de março de 1995. Disponível em: 〈http://docsonline.wto.org>. Acesso em: 18 jun. 2011.

${ }^{122}$ Vide S/C/M/31. Council for Trade in Services - Report of the Meeting Held on 23 and 24 November 1998 - Note by the Secretariat, de 9 de dezembro de 1998. S/C/W/92. Procedures on Reporting on Regional Trade Agreements, de 4 de janeiro de 1999. Disponíveis em: 〈http://docsonline.wto.org〉. Acesso em: 18 jun. 2011.

${ }^{123}$ Vide WT/REG/M/36. Committee on Regional Trade Agreements - Thirty-Sixth Session - Note on the Meeting of 29 - 30 March 2004. 7 de abril de 2004. Para.10. Disponíveis em: <http://docsonline.wto.org>. Acesso em: 18 jun. 2011.

${ }^{124}$ Vide CELLI JUNIOR et al, 2010, p. 21.
} 
subsetores de serviços que não foram originariamente incluídos em seu escopo. Caso um ajuste na lista de compromissos assumidos por determinado Membro, no âmbito do GATS, seja necessária, em virtude de sua adesão a um acordo regional, os Estados devem providenciar a notificação dessas modificações no prazo de 90 dias ${ }^{125}$.

\subsubsection{Período de tempo razoável}

O Artigo V:I (b) do GATS determina que um acordo regional que compreenda o comércio de serviços deverá entrar em vigor dentro de um período de tempo razoável. De acordo com o $\$ 3^{\circ}$ do Entendimento Sobre a Interpretação do Artigo XXIV do Acordo Geral sobre Tarifas e Comércio 1994, o prazo razoável para que um acordo regional celebrado no âmbito do artigo XXIV do GATT entre em vigor não deve ser superior a 10 $\operatorname{anos}^{126}$. Como não há, no GATS, previsão expressa sobre qual seria esse período, por analogia, entende-se que se aplica o prazo estabelecido para acordos regionais que regulamentam o comércio de bens.

\subsubsection{Flexibilidades concedidas aos países em desenvolvimento}

O Artigo V:3 do GATS estabelece normas diferenciadas para acordos regionais de comércio dos quais participam países em desenvolvimento. Nesse artigo, o GATS faz distinção entre dois tipos de acordos regionais que regulamentam o comércio de serviços: acordos envolvendo países desenvolvidos e países em desenvolvimento que são Membros da OMC (Artigo V:3(a)) e acordos envolvendo apenas países em desenvolvimento Membros da OMC (Artigo V:3 (b)).

Para o primeiro tipo de acordo, o GATS estabelece que será concedida flexibilidade em relação à abrangência dos compromissos assumidos em âmbito regional, bem como em relação às condições para a eliminação das medidas discriminatórias existentes, em consonância com o nível de desenvolvimento das Partes, tanto em termos gerais quanto em relação aos setores e subsetores de serviços individualmente considerados.

${ }^{125}$ Vide CELLI JUNIOR et al, 2010, p. 19. ADLUNG; MORRISON. 2010, p. 1114.

${ }^{126}$ Entendimento Sobre a Interpretação do Artigo XXIV do Acordo Geral sobre Tarifas e Comércio 1994. Disponível em: <http://www.mdic.gov.br/arquivo/secex/omc/acordos/portugues/08artxxiv.pdf>. Acesso em: 19 jun. 2011. 
No caso de um acordo do qual sejam Parte apenas países em desenvolvimento Membros da OMC, o GATS estabelece que só será concedido tratamento mais favorável às pessoas jurídicas que sejam propriedade ou que estejam sob o controle de pessoas físicas das Partes de tal acordo.

Nota-se, portanto, que o Artigo V concede tratamento diferenciado aos países em desenvolvimento, quando estes forem Parte de acordos regionais com países desenvolvidos, garantindo que a liberalização comercial no setor de serviços, no âmbito bilateral ou regional, também seja determinada em função do nível de desenvolvimento de cada Parte.

\section{CONCLUSÕES}

Como visto neste capítulo, o GATS é um acordo único na OMC, que contém um modelo próprio de assunção de compromissos e possui muitas flexibilidades. Contudo, estas flexibilidades fazem com que a liberalização comercial esteja condicionada à vontade dos Membros de aprofundarem seus compromissos em serviços, os quais deverão ser estendidos a todos os demais Membros, em virtude do princípio da não discriminação.

Por outro lado, o próprio GATS excepciona esse princípio no Artigo V, ao possibilitar que os Membros concedam preferências em sede de acordos regionais, desde que sejam respeitados os requisitos estabelecidos para esse tipo de acordo, notadamente abrangência setorial substancial e eliminação das discriminações existentes entre as Partes Contratantes.

Conforme será abordado de forma mais detalhada nos próximos capítulos, nos últimos anos, houve um aumento exponencial no número de acordos regionais abrangendo serviços, o que muitos autores atribuem à paralisação das negociações multilaterais ${ }^{127}$. Esse cenário gera um grande número de desafios em termos jurídicos.

\footnotetext{
127 "Com efeito, em um contexto de negociações paralisadas na Organização Mundial do Comércio (OMC), os Acordos Preferenciais de Comércio (APCs) têm continuado a proliferar. Os APCs envolvendo serviços representam um fenômeno ainda recente, mas já oferecem caminhos alternativos ou complementares às regras multilaterais". J. H. RORIZ; L. da S. TASQUETO. O comércio de serviços regulado pelos acordos preferenciais de comércio. In I. T. M. OLIVEIRA; M. R. SANCHEZ BADIN (org.). Tendências regulatórias nos acordos preferenciais de comércio no século XXI: os casos de Estados Unidos, União Europeia, China e Índia. Brasília: Ipea, 2013, p. 170. Disponível em: $<$ http://repositorio.ipea.gov.br/bitstream/11058/2528/1/Livro_Tendencias_regulatorias_nos_acordos_prefere nciais_de_com\%C3\%A9rcio_no_s\%C3\%A9culo_XXI\%20os_casos_de_Estados_Unidos_Uni\%C3\%A3o_Europeia_China_e_\%C3\%8Dndia.pdf $>$. Acesso em: 14 fev. 2014.
} 
Nesse contexto, é importante observar se os requisitos previstos no Artigo $\mathrm{V}$ do GATS têm sido observados, se os acordos regionais mantêm os princípios adotados pelo GATS, se contêm regras sobre regulação doméstica ou se, por sua vez, criam regras diferenciadas para regular o tema. Também é importante verificar como se dá a compatibilidade entre as normas sobre serviços nos planos regional e multilateral, de modo a manter a coerência na governança global internacional. Tais questões serão abordadas nos próximos capítulos. 


\section{CAPÍTULO 3: O REGIONALISMO E O COMÉRCIO DE SERVIÇOS}

\section{INTRODUÇÃO}

A celebração de acordos regionais de comércio tem aumentado significativamente nos últimos anos. A maioria desses acordos regula, entre outros temas, o comércio de serviços entre as Partes Contratantes.

Embora o tema serviços seja objeto de acordos regionais há cerca de duas décadas apenas, devido à importância desse setor para as economias nacionais, observou-se uma rápida expansão no tratamento dessa matéria nesse tipo de acordo. Atualmente, são raros os acordos regionais que não o abrangem. Por outro lado, as negociações sobre serviços na OMC avançaram pouco desde 2000, o que sugere ter ocorrido uma transferência das negociações do ambiente multilateral para os acordos regionais.

Logo, faz-se necessário estudar como o tema serviços tem sido regulado em âmbito regional, quais desafios essa regulação tem apresentado à OMC e como se dá a compatibilização desses acordos regionais com as regras multilaterais do GATS.

\section{HISTÓRICO DA INSERÇÃO DE REGRAS SOBRE O COMÉRCIO DE SERVIÇOS EM ACORDOS REGIONAIS}

A liberalização do comércio de serviços em âmbito regional ocorreu antes da liberalização em âmbito multilateral. De acordo com Michel Arslanian Neto, o primeiro acordo regional a tratar do tema foi o NAFTA, que entrou em vigor um ano antes do GATS, em 1 de janeiro de $1994^{128}$.

Segundo a base de dados de acordos regionais da OMC (RTA Database), o NAFTA foi o primeiro acordo regional envolvendo o comércio de serviços notificado à OMC com base no Art. V do GATS. A despeito desse fato, os acordos regionais seguintes, que também abrangem o comércio de serviços, entraram em vigor antes ou na mesma data que o NAFTA, mas foram notificados posteriormente à OMC: (i) Tratado constitutivo da Comunidade Europeia, que entrou em vigor em $1^{\circ}$ de janeiro de 1958; (ii) Tratado que instituiu a Área Econômica Europeia, que entrou em vigor em $1^{\circ}$ de janeiro de 1994; (iii)

\footnotetext{
${ }^{128}$ M. ARSALANIAN NETO. A liberalização do comércio de serviços do Mercosul. Brasília: Fundação Alexandre Gusmão, 2010, p. 30.
} 
Acordo comercial sobre relações econômicas entre Austrália e Nova Zelândia, que entrou em vigor em $1^{\text {o }}$ de janeiro de $1989^{129}$.

A evolução do tema serviços em acordos regionais foi rápida e apresentou crescimento substancial a partir do início das negociações multilaterais de serviços, em $2000^{130}$. Ao final de 2006, a OMC já contabilizava a existência de 54 acordos regionais envolvendo o comércio de serviços, dos quais apenas 5 entraram em vigor antes da conclusão da Rodada Uruguai ${ }^{131}$. Em apenas sete anos, entre 2000 e 2007, foram celebrados 42 acordos regionais, bilaterais ou plurilaterais pelos Membros da OMC abrangendo o comércio de serviços ${ }^{132}$.

Nos acordos negociados a partir de 2000, os principais demandantes nas negociações sobre serviços na OMC engajaram-se na celebração de acordos de livre comércio abrangendo este tema com Estados que não eram seus vizinhos imediatos. Cite-se, por exemplo, os Estados Unidos, que celebraram acordos com Austrália ${ }^{133}$, Bahrain $^{134}$, Chile $^{135}$ e Cingapura ${ }^{136}$, entre outros, e a União Europeia, que celebrou acordos com países como Chile $^{137}$ e México ${ }^{138}$.

\footnotetext{
${ }^{129}$ Vide RTA Database (http://rtais.wto.org/UI/PublicMaintainRTAHome.aspx).

${ }^{130}$ A esse respeito, explicam Martin Roy, Juan Marchetti e Hoe Lim: "As often pointed out, the number of preferential trade agreements has increased at a great and steady pace since the establishment of the WTO in 1995. Apart from Mongolia, all Members are party to a PTA of one form or another. As of 15 June 2006, 197 PTAs in force had been notified to the GATT/WTO since 1947 under either GATT Article XXIV, the Enabling Clause, or GATS Article V. 106 of these agreements have been notified since 2000, including 80 since 2002, i.e., concurrently with the Doha Round negotiations. PTAs encompassing services are more novel. Since trade rules on services are a more recent phenomenon (the Canada-US free trade agreement in 1989 and the GATS in 1995 were key precursors), it is understandable that only 36 new PTAs have been notified under GATS Article V. However, notifications for services agreements have grown at a faster pace than others: 29 of these agreements (more than 3/4) have been notified since the start of the WTO services negotiations in 2000, of which 10 were in 2005-2006 and 12 in 2003-2004, during key phases of the Doha Round". J. A. MARCHETTI; M. ROY; L. HOE. Services Liberalization in the New Generation of Preferential Trade Agreements (PTAs): How Much Further than the GATS? Staff Working Paper ERSD-2006-07. World Trade Organization, Economic Research and Statistics Division. Setembro de 2006, p. 6-7. Disponível em: 〈http://www.wto.org/english/res_e/reser_e/ersd200607_e.pdf>. Acesso em: 1 jan. 2013.

${ }^{131}$ Vide C. FINK; M. JANSEN. Services provisions in regional trade agreements: stumbling or building blocks for multilateral liberalization? Agosto de 2007, p. 1. Disponível em: <http://www.cepr.org/meets/wkcn/2/2380/papers/Fink-Jansen.pdf >. Acesso em: 10 ago. 2013.

${ }^{132}$ Vide J. A. MARCHETTI; M. ROY. Services Liberalization in the WTO and in PTAs. In J. A. MARCHETTI; M. ROY (ed.). Opening markets for trade in services. Countries and sectors in Bilateral and WTO negotiations. New York: Cambridge University Press, 2008, p. 72.

${ }_{133}$ Acordo de Livre Comércio Estados Unidos-Austrália, que entrou em vigor em 1 de janeiro de 2005.

${ }^{134}$ Acordo de Livre Comércio Estados Unidos-Bahrain, que entrou em vigor em 11 de janeiro de 2006.

${ }_{135}$ Acordo de Livre Comércio Estados Unidos-Chile, que entrou em vigor em 1 de janeiro de 2004.

${ }^{136}$ Acordo de Livre Comércio Estados Unidos-Cingapura, que entrou em vigor em 1 de janeiro de 2004.

${ }^{137}$ Acordo de Associação UE-Chile, que entrou em vigor em 1 de março de 2005.

${ }^{138}$ Acordo de Parceria Econômica, Coordenação Política e Cooperação UE-México, que entrou em vigor em 2000.
} 
$\mathrm{Na}$ sequência, outros Membros passaram a celebrar acordos envolvendo serviços com atores com os quais não tinham proximidade geográfica, como é caso da Índia, China, Austrália, Nova Zelândia, Chile, México, Índia, Hong Kong, Suíça, Noruega, Tailândia, Malásia, Coreia e Cingapura. Os Membros da OMC que se engajaram nesses acordos representam mais de $80 \%$ do comércio mundial de serviços ${ }^{139}$.

Outra característica a ser observada nos acordos celebrados a partir dos anos 2000 consiste no fato de eles envolverem um país desenvolvido e um em desenvolvimento ou dois ou mais países em desenvolvimento ${ }^{140}$. De modo geral, acordos regionais envolvendo pelo menos um país desenvolvido tendem a incluir o componente de serviços, enquanto a maioria dos acordos entre países em desenvolvimento não inclui este componente. Observa-se, contudo, que essa tendência está mudando. Dos 47 acordos regionais envolvendo serviços notificados à OMC até 2007, 29 envolvem países desenvolvidos como uma das Partes, 6 envolvem apenas países desenvolvidos e 18 foram celebrados por países desenvolvidos e em desenvolvimento ${ }^{141}$.

O movimento em análise levou muitos doutrinadores a denominar os novos acordos regionais de "acordos preferenciais bilaterais", em contraposição aos acordos celebrados antes de 2000, que eram denominados de "acordos regionais", por envolverem predominantemente Membros com grande proximidade geográfica ou localizados em uma mesma região ${ }^{142}$. Porém, a OMC ainda denomina tais acordos de "acordos regionais", independentemente de as Partes estarem situadas em uma mesma região geográfica. A terminologia "acordos preferenciais não recíprocos" continua sendo utilizada para designar os acordos com fundamento na Cláusula de Habilitação ${ }^{143}$.

\footnotetext{
${ }^{139}$ Vide J. MARCHETTI; M. ROY, Martin; L. HOE. 2006, p. 7.

${ }^{140}$ Segundo Juan Marchetti, Martin Roy e Lim Hoe: "Another apparent feature of the recent wave of services agreements is that they most often bring together developing and developed countries. The US-Australia PTA is the only one between developed countries since 2000. Agreements between developing economies are more common, e.g., the agreements signed by Mexico and Chile with Central American countries (between developing countries). In general, trade agreements involving at least one developed country tend to include services components (exceptions include agreements notified by the EC with African and Middle Eastern countries), while the majority of trade agreements between developing countries include no services commitments, although that trend seems to now be changing". J. MARCHETTI; M. ROY; L. HOE. 2006, p. 7

${ }^{141}$ J. A. MARCHETTI;M. ROY (ed.)., 2008, p. 72.

${ }^{142}$ BHAGWATI, 2008, p. 13.

143 "When a WTO member enters into a regional integration arrangement through which it grants more favourable conditions to its trade with other parties to that arrangement than to other WTO members' trade, it departs from the guiding principle of non-discrimination defined in Article I of GATT, Article II of GATS, and elsewhere. WTO Members are however permitted to enter into such arrangements under specific conditions which are spelled out in three sets of rules:

- Paragraphs 4 to 10 of Article XXIV of GATT (as clarified in the Understanding on the Interpretation of Article XXIV of the GATT 1994) provide for the formation and operation of customs unions and free-trade areas covering trade in goods ;
} 
A esse respeito, note-se, ademais, que os acordos em análise foram denominados de "acordos de segunda geração" em contraposição àqueles celebrados no início dos anos 1990, denominados de "acordos de primeira geração". A principal característica dos acordos de primeira geração consiste no fato de eles enfocarem a eliminação de restrições ao movimento transfronteiriço de bens, sejam barreiras tarifárias ou não tarifárias. Já os acordos de segunda geração, baseados no modelo NAFTA, abrangem não apenas a eliminação de restrições transfronteirças, mas também as barreiras originárias do modo pelo qual os governos organizam e regulam suas economias, incluindo compras governamentais e política de concorrência ${ }^{144}$.

Por fim, note-se que, nos últimos anos, houve aumento no interesse dos Membros da OMC por celebrarem acordos regionais que abranjam o tema serviços. De acordo com a base de dados de acordos regionais da OMC, em 31 de julho de 2013, havia 249 acordos regionais em vigor, sendo que 129, ou seja, 51,8\% deles englobavam o comércio de serviços ${ }^{145}$. Esses números mostram que tem crescido o interesse pela inclusão de serviços em acordos regionais, haja vista que, apenas alguns anos atrás, em 2010, 84 dos 205 acordos em vigor englobavam esse tema, o que equivale a cerca de $40 \%{ }^{146}$ do número total de acordos.

- the so-called Enabling Clause (i.e., the 1979 Decision on Differential and More Favorable Treatment, Reciprocity and Fuller Participation of Developing Countries) refers to preferential trade arrangements in trade in goods between developing country Members; and

- Article V of GATS governs the conclusion of RTAs in the area of trade in services, for both developed and developing countries.

Other non-generalized preferential schemes, for example non-reciprocal preferential agreements involving developing and developed countries, require Members to seek a waiver from WTO rules. Such waivers require the approval of three quarters of WTO Members. Examples of such agreements which are currently in force include the US - Caribbean Basin Economic Recovery Act (CBERA), the CARIBCAN agreement whereby Canada offers duty-free non-reciprocal access to most Caribbean countries, Turkey-Preferential treatment for Bosnia-Herzegovina and the EC-ACP Partnership Agreement". Disponível em: <http://www.wto.org/english/tratop_e/region_e/regrul_e.htm>. Acesso em: 28 jan. 2014.

${ }^{144}$ Nas palavras de Mirvat Sewadeh: "The "first generation" or "LAIA-type" agreements focus mainly on eliminating restrictions to the movement of goods across borders (tariffs and non-tariff measures). They use the framework of the 1980 Treaty of Montevideo, LAIA's founding charter. The "second generation" agreements, in addition to cross-border restrictions, focus on barriers arising from how governments organize and regulate their economies through government procurement, the enforcement of intellectual property rights, the regulation of service sectors and the administration of competition policies. The second generation, NAFTA-like agreements also include the elimination of tariffs and a Harmonized System (HS)based methodology for rules of origin". General Background on Regional Trade Agreements in Latin America, $\quad$ p. $6.0 m$ Disponível <http://siteresources.worldbank.org/INTRANETTRADE/Resources/LACAgreementsBkgrd.pdf>. Acesso em: 26 jan. 2014.

${ }_{145}$ Vide < http://www.wto.org/english/tratop_e/region_e/region_e.htm>. Último acesso em: 3 fev. 2014.

146 "While services RTAs are overall a recent phenomenon, they have become very quickly an integral part of the overall RTA landscape. Over 40\% (84 out of 205) of physical regional trade agreements (including goods and services components) notified until November 2010 have a services component as illustrated by chart 2". Vide P. LATRILLE; J. LEE. Services rules in regional trade agreements. How diverse and how creative 


\section{FISCALIZAÇÃO DOS ACORDOS REGIONAIS PELA OMC}

Conforme explicado anteriormente na Parte III, os acordos regionais que regulamentam o comércio de serviços têm fundamento legal no Artigo V do GATS. Este Artigo define as obrigações que os acordos regionais devem observar, em termos de comércio, para que sejam considerados compatíveis com as regras da OMC, a saber: possuir cobertura setorial substancial (Artigo V: 1(a)) e eliminar substancialmente todas as discriminações existentes (Artigo V: 1(b)) em relação ao fluxo comercial inter-partes ${ }^{147}$.

De acordo com o referido Artigo, a celebração de novos acordos regionais abrangendo o comércio de serviços que possuam cobertura setorial substancial e eliminem substancialmente as discriminações no comércio inter-partes deve ser notificada à OMC. Como visto anteriormente, embora a prerrogativa de análise de tais acordos seja do Conselho de Serviços, na prática, essa análise é delegada ao Comitê sobre Acordos Regionais da $\mathrm{OMC}^{148}$. Além de examinar os acordos regionais e elaborar relatórios com recomendações sobre o assunto, também é atribuição do Comitê considerar as implicações sistêmicas dos acordos e a relação entre eles e o Sistema Multilateral de Comércio, bem como elaborar recomendações para o Conselho Geral ${ }^{149}$.

O exame dos acordos pelo Comitê sobre Acordos Regionais da OMC tem dois objetivos: dar publicidade à celebração de novos acordos a todos os Membros, o que se coaduna com o princípio da transparência, e possibilitar que os Membros avaliem a consistência dos acordos regionais em face das regras multilaterais de comércio. Não

as compared to the GATS multilateral rules? WTO Working Paper. Genebra, Outubro de 2012, p. 4. Disponível em: <http://www.wto.org/english/res_e/reser_e/ersd201219_e.htm>. Acesso em: 16 jan. 2013.

147 Vide U. CELLI JUNIOR et al. MERCOSUR in South-South Agreements: In the middle of two models of regionalism. Instituto Virtual da Organização para a Cooperação Econômica e o Desenvolvimento: 2010. Disponível em: <http://vi.unctad.org/resources-mainmenu-64/digitallibrary? $=$ VI\&op=all\&q=Mercosur+in+South-

south+Agreements $\% 3 \mathrm{~A}+\mathrm{In}+$ the+Middle+of+Two+Models+of+Regionalism+\&act=search\&option=com_gsli nk>. Acesso em: 13 jun. 2011. P. 18.

${ }^{148}$ Conforme explicação extraída do website da OMC: "RTAs falling under Article XXIV are notified to the Council for Trade in Goods (CTG) which adopts the terms of reference and transfers the agreement to the CRTA for examination. The notification of agreements falling under the Enabling Clause is made to the Committee on Trade and Development (CTD). The agreement is placed in the agenda of the CTD meeting where a debate is held, but, generally, no in-depth examination in the CRTA is requested by the CTD. RTAs covering trade in services concluded by any WTO Members, whether developed or developing, are notified to the Council for Trade in Services (CTS). The CTS may decide to pass the agreement to the CRTA for examination - but unlike the case of RTAs notified under Article XXIV of the GATT, such examination is optional, not mandatory". Disponível em: <http://www.wto.org/english/tratop_e/region_e/regcom_e.htm>. Acesso em: 27 jan. 2014.

${ }^{149}$ Vide WT/L/127. Committee On Regional Trade Agreements. 7 de fevereiro de 1996. Disponível em: <http://www.wto.org/english/tratop_e/region_e/regcom_e.htm>. Acesso em: 27 jan. 2014. 
obstante, a análise de compatibilidade entre os acordos regionais e as regras da OMC não tem sido realizada. De acordo com Umberto Celli Junior, o Comitê sobre Acordos Regionais nunca examinou de forma aprofundada e conclusiva a compatibilidade de um acordo regional com a OMC, por falta de vontade política dos próprios Membros da OMC e pela rapidez com que tais acordos são celebrados ${ }^{150}$. Segundo o autor, o exame de compatibilidade não é realizado porque nenhum dos acordos regionais passaria no teste ${ }^{151}$.

De fato, desde 1995, nenhum relatório sobre a compatibilidade entre os acordos regionais e as regras da OMC é finalizado. Segundo o próprio website da organização, isso se deve à falta de consenso entre os Membros do Comitê, ocasionada pelos seguintes motivos: (i) não há clareza sobre se a decisão deste órgão é acionável ou não no sistema de solução de controvérsias da OMC; (ii) a interpretação das provisões da OMC é controvertida; (iii) e problemas institucionais podem decorrer da ausência de regras da OMC ou da discrepância entre as regras da OMC e aquelas contidas nos acordos regionais $^{152}$.

Para resolver esse impasse e em busca de um relação harmoniosa entre os acordos regionais e as regras multilaterais de comércio, na Quarta Conferência Ministerial em Doha, Qatar, os Membros da OMC laçaram negociações multilaterais, as quais incluíram, no parágrafo 29 da Declaração de Doha, o tema acordos regionais. O referido parágrafo estabeleceu o início de negociações multilaterais com vistas a esclarecer e aprimorar as disciplinas relativas a acordos regionais, de modo a solucionar definitivamente quaisquer controvérsias relacionadas à avaliação individual dos acordos em análise. Outra questão que foi colocada pela Declaração de Doha consistiu na consideração dos aspectos

\footnotetext{
${ }^{150}$ A esse respeito, Umberto Celli Junior explica o seguinte: "De acordo com as regras da OMC, a criação dos APC por meio de Tratados Internacionais deve ser notificada ao Comitê sobre Acordos Regionais (“CAR”). O CAR tem a prerrogativa de elaborar relatórios e recomendações às partes dos APC. Dessa forma, haveria a possibilidade de o CAR reconhecer inconsistências das regras dos APC com o sistema multilateral de comércio, caso não formassem uma união aduaneira ou uma zona de livre comércio, nos termos do artigo XXIV do GATT, ou mesmo violassem as disposições do Artigo V do GATS e da Cláusula de Habilitação. Porém, nunca foi feito um exame detido, aprofundado e conclusivo da compatibilidade de um APC com a OMC, por falta de vontade política dos próprios membros da OMC e pela velocidade vertiginosa com que se proliferaram os APC'. U. CELLI JUNIOR. A Organização Mundial do Comércio e o regionalismo do século XXI. Densidades, Buenos Aires, n. 9, 2012, p. 95-96.

151 "A rigor, sempre se soube que nenhum dos APC passaria no teste de compatibilidade." U. CELLI JUNIOR, 2012, p. 96.

${ }^{152}$ Segundo a própria Organização Mundial do Comércio: "However, no examination report has been finalized since 1995 because of lack of consensus. One problem derives from the possible links between CRTA-consistency judgement and the dispute settlement process. In addition, there are long-standing controversies about the interpretation of the WTO provisions against which RTAs are assessed, and institutional problems arising either from the absence of WTO rules (e.g. on preferential rules of origin), or from discrepancies between WTO rules and those contained in some RTAs". Disponível em: <http://www.wto.org/english/tratop_e/region_e/regcom_e.htm>. Acesso em: 27 jan. 2014.
} 
desenvolvimentistas nas negociações relacionadas a acordos regionais, já que a preocupação com esses aspectos de tais acordos não consta no texto do Art. XXIV do GATT, mas apenas no texto do Art. V do GATS ${ }^{153}$.

O prazo original para a conclusão da Rodada de Doha era 1 de janeiro de 2005. Não obstante, até o momento, as negociações a que se refere o parágrafo 29 da Declaração de Doha não foram concluídas. Desse modo, o exame de compatibilidade entre os acordos regionais e as regras multilaterais de comércio continua não sendo realizado pelo Comitê sobre Acordos Regionais da OMC, incluindo acordos celebrados no âmbito do Art. V do GATS.

\section{CONSEQUENCIAS RELACIONADAS À INSERÇÃO DE REGRAS SOBRE O COMÉRCIO DE SERVIÇOS EM ACORDOS REGIONAIS}

Como já mencionado ao longo deste trabalho, observou-se um aumento considerável dos acordos regionais de comércio que englobam o comércio de serviços desde os anos 2000. A inserção de regras sobre o comércio de serviços em acordos regionais tem consequências positivas e negativas. A principal consequência positiva - e mais óbvia - consiste no aprofundamento da liberalização do comércio de serviços, que tende a ser mais difícil em âmbito multilateral que em âmbito bilateral ou plurilateral. Como consequências negativas para os acordos regionais abrangendo o setor de serviços, destaca-se a falta de clareza sobre como se dará a compatibilização entre compromissos regionais e multilaterais.

\subsection{O aprofundamento dos compromissos em serviços em relação àqueles assumidos no âmbito multilateral}

Como explicado anteriormente, os acordos regionais de comércio representam uma exceção permitida pelo Sistema Multilateral de Comércio. Isso ocorre porque, embora ess

\footnotetext{
153 O parágrafo 29 da Declaração de Doha determina que: "We also agree to negotiations aimed at clarifying and improving disciplines and procedures under the existing WTO provisions applying to regional trade agreements. The negotiations shall take into account the developmental aspects of regional trade agreements.".

Disponível

em:

<http://www.wto.org/english/thewto_e/minist_e/min01_e/mindecl_e.htm\#rules>. Acesso em: 29 jan. 2014.
} 
sistema se baseie no princípio da não discriminação ${ }^{154}$, ele contempla expressamente a possibilidade de celebração de acordos regionais.

Muitos autores entendem que os acordos regionais criam restrições e estruturas regulatórias complexas que tornam o livre comércio cada vez mais difícil e custoso. Jagdish Bhagwati é um dos autores que defendem que os acordos em questão funcionam como "blocos de contenção" (stumbling blocs) à liberalização comercial, visto que são uma exceção a um princípio basilar do livre comércio, qual seja, o princípio da não discriminação $^{155}$. À medida que os acordos regionais excluem outros países da liberalização, resultam em um sistema dominado pela discriminação. Para tais autores, esse sistema não apenas contraria a lógica do Sistema Multilateral de Comércio, mas também cria normas conflitantes e/ou contraditórias em relação àquelas da OMC.

Outros autores entendem que os acordos em análise não são conflitantes com a lógica do Sistema Multilateral de Comércio. Para eles, a discriminação resultante das preferências comerciais funcionaria, ao contrário, como um incentivo para que governos que não fazem parte de um acordo busquem ingressar na negociação de acordos regionais de comércio ${ }^{156}$.

Há, ainda, autores que defendem que a discriminação resultante dos acordos em serviços não ajuda nem prejudica a liberalização multilateral. A esse respeito, Carsten Fink e Marion Jansen explicam que, se Estados que não são Parte de acordos regionais beneficiam-se de compromissos de liberalização regional, não há razão para que eles busquem a liberalização multilateral. Nesse caso, passar da liberalização regional para a multilateral não alterará as condições concorrenciais existentes entre partes de um acordo regional $^{157}$.

\footnotetext{
${ }^{154}$ Sobre o princípio da não discriminação e sua relevância para o sistema multilateral de comércio, Bernard Hoeckman, Wlliam Martin e Carlos Alberto Primo Braga explicam o seguinte: "The multilateral trade system rests on the principle of non-discrimination. The most-favored-nation (MFN) clause embodied in Article I of the General Agreement on Tariffs and Trade (GATT) was the defining principle for a system that emerged in the post-World War II era largely in reaction to the folly of protectionism and managed trade that contributed to the global economic depression of the 1930s". B. M. HOECKMAN; W. J. MARTIN; C. A. PRIMO BRAGA. Quantifying the Value of Preferences and Potential Erosion Losses. B. M. HOECKMAN; W. J. MARTIN; C. A. PRIMO BRAGA. Trade Preference Erosion: Measurement and Policy Response. Wold Bank Publications. Washington, 2009, p. 1. Disponível em: <http://econ.worldbank.org/WBSITE/EXTERNAL/EXTDEC/EXTRESEARCH/EXTPROGRAMS/EXTTR ADERESEARCH/0,,contentMDK:21067622 pagePK:64168182 piPK:64168060 theSitePK:544849,00.htm 1. Acesso em: 3 fev. 2014.

${ }^{155}$ ESTEVADEORDAL; SUOMINEN; THE, 2009, p. 3.

${ }^{156}$ C. FINK; M. JANSEN, 2007, p. 18.

157 "A fundamental assumption underlying all these models is that RTAs lead to actual discrimination. If nonparties benefit from RTA liberalization commitments, the political economy forces that alter governments' attitude towards multilateral liberalization in these models are not unleashed. Indeed, a move from regional to multilateral liberalization would hardly alter the competitive conditions in RTA parties. From this view, we may conclude that weakly discriminatory services RTAs neither help nor hinder the multilateral cause." C. FINK; M. JANSEN, 2007, p. 18.
} 
O fenômeno do regionalismo em serviços possui características distintas do que ocorre com o comércio de bens. As preferências comerciais, por exemplo, não têm origem tarifária, como ocorre no caso de bens, mas são caracterizadas pela redução ou eliminação das barreiras vigentes a prestadores de serviços não preferenciais ${ }^{158}$. Segundo ensinam Baldwin, Evenett e Low, acordos regionais em serviços dão acesso preferencial a mercados de duas formas, a saber: (i) os prestadores de serviços de uma Parte são tratados como prestadores locais no que se refere à regulação e a impostos; (ii) é dado melhor acesso ao prestador de uma Parte que a outros prestadores. Note-se, ademais, que, a questão do reconhecimento das qualificações profissionais também está atrelada ao acesso a mercados pelos prestadores de serviços estrangeiros ${ }^{159}$.

$\mathrm{Na}$ prática, verifica-se que os Membros da OMC preferem comprometer-se a liberalizar um maior número de serviços, setores e modos de prestação em âmbito regional do que por meio do GATS. Isso se deve ao fato de a liberalização multilateral estar sujeita ao princípio da reciprocidade, o que significa que qualquer compromisso em serviços concedido a um Membro, na OMC, deve ser estendido aos demais. O mesmo não ocorre nos acordos regionais, que constituem uma exceção ao referido princípio.

Nesse sentido, Juan A. Marchetti e Martin Roy observam que, com a proliferação dos acordos regionais, muitos Membros da OMC têm segurado suas ofertas em serviços, no âmbito do GATS, para terem setores de serviços e serviços a liberalizar nos acordos regionais ${ }^{160}$. Essa estratégia faz com que se verifique uma maior liberalização do comércio de serviços no âmbito bilateral ou plurilateral do que multilateral.

É importante observar que o nível de aprofundamento dos compromissos em serviços em acordos regionais está atrelado às regras de origem estabelecidas nos referidos acordos. Diferentemente do que ocorre no caso de bens, cujas regras de origem dependem prioritariamente do nível de transformação de um produto em determinado território, no caso de serviços, as regras de origem possuem natureza distinta, com foco na origem do prestador de serviços.

Essa questão encontra-se regulamentada pelo Art. V:6 do GATS, que estabelece que os provedores de serviços de qualquer outro Membro que sejam pessoas jurídicas constituídas sob a legislação de uma Parte em um acordo regional terão direito ao

\footnotetext{
${ }^{158}$ B. M. HOECKMAN; W. J. MARTIN; C. A. PRIMO BRAGA, 2009, p. 7.

${ }^{159}$ R. BALDWIN; S. EVENETT; P. LOW. Multilaterizing non-tariff RTA commitments. In: R. BALDWIN; P. LOW. Multilarizing Regionalism. Challenges for the Global Trading System, Cambridge: Cambridge University Press, 2009, p.90-91.

${ }^{160}$ J. A. MARCHETTI; M. ROY (ed.), 2008, p. 93.
} 
tratamento preferencial concedido pelo acordo, desde que realizem operações comerciais substanciais no território de uma das Partes.

Nos acordos regionais, as regras de origem assumem a seguinte forma com relação ao prestador do serviço, seja ele pessoa física ou jurídica: (i) critério da jurisdição de origem do prestador, seja o local de incorporação da pessoa jurídica ou o país de cidadania/residência da pessoa física; (ii) critério de localização das atividades econômicas do prestador do serviço, o que, no caso de empresas, deve ser interpretado como o país em que desenvolverem atividades substanciais; (iii) critério de propriedade ou controle de empresas $^{161}$.

Carsten Fink e Marion Jansen apontam que há cinco categorias de acordos regionais envolvendo serviços, a saber: (i) compromissos que reproduzem, no todo ou em parte, os compromissos assumidos no GATS; (ii) compromissos que vão além dos compromissos assumidos no GATS, mas não implicam maior liberalização comercial; (iii) compromissos que implicam liberalização e que são implementados de forma não discriminatória; (iv) compromissos que implicam liberalização e que possuem regras de origem liberais; (v) compromissos que implicam liberalização e que possuem regras de origem restritivas ${ }^{162}$.

A primeira categoria de acordos regionais não oferece uma maior abertura de mercados em relação aos compromissos existentes no GATS. O único beneficio desses compromissos consiste na possibilidade de se invocar o sistema de controvérsias previsto no Acordo para a implementação de compromissos em serviços. Note-se que os compromissos são não discriminatórios em relação à sua aplicação para Partes e não Partes do acordo regional.

A segunda categoria também não implica maior liberalização comercial. Embora ela seja composta por compromissos que vão além daqueles assumidos no GATS, esses consistem na consolidação da política existente (status quo) em relação a determinado serviço ou setor de serviços. Portanto, o passo além representa apenas a formalização de uma política em vigor, e não o aprofundamento dos compromissos em serviços. A principal vantagem dessa medida reside no fato de uma alteração na política vigente poder ser questionada no órgão de solução de controvérsias estabelecido no acordo. Nessa

\footnotetext{
${ }^{161}$ A esse respeito, Carten Fink e Marion Jansen observam o seguinte: "In the case of modes 1 and 2, rather than using a value added criterion, services RTAs merely stipulate that liberalization measures apply to services that are supplied from or in the territory of another party. It is not clear from this definition to what extent services relying on imported services inputs would be eligible for trade preferences. In the case of modes 3 and 4, RTAs do not provide for any rule of origin for services". C. FINK; M. JANSEN, 2007, p. 7.

${ }^{162}$ C. FINK. Service PTAs: Friends or Foes of Multilateralism? In J. A. MARCHETTI; R. ROY (ed.), 2008, p. 118 .
} 
categoria, as medidas para a liberalização do comércio de serviços também são adotadas de forma não discriminatória.

Os compromissos da terceira categoria representam um aprofundamento no nível de liberalização do GATS que se dá de forma não discriminatória, ou seja, não haverá discriminação na sua aplicação para Partes e não Partes do acordo regional. Sua principal vantagem consiste no fato de que, ao consolidar compromissos em novos setores de serviços e serviços ainda não consolidados, o Estado não poderá retroceder em relação ao nível de liberalização assumido. Desta forma, cria-se um ambiente com maior segurança jurídica para o prestador de serviços estrangeiro. Além disso, quando um Estado decide liberalizar determinado setor de serviços para uma Parte de um acordo regional, a tendência é que ele conceda o mesmo benefício a outras não Partes.

A quarta e a quinta categorias referem-se a compromissos novos assumidos de forma discriminatória. A diferença entre elas consiste nas regras de origem adotadas. Na quarta categoria, as regras de origem são mais liberais, o que significa que o acordo regional não discrimina em razão da nacionalidade do prestador de serviços. Já na quinta categoria, as regras de origem são restritivas, isto é, a nacionalidade do prestador de serviço é um critério determinante para que ele possa ter acesso às preferências concedidas no âmbito do acordo regional.

A esse respeito, note-se, ainda, que a grande maioria dos acordos regionais adota regras de origem liberais, pelas quais o tratamento preferencial no âmbito do acordo é estendido a todos os prestadores de serviços que estiverem sediados e tiverem operações comerciais substanciais em pelo menos uma Parte, independentemente da origem de seu controle.

Em vista das cinco categorias de acordos regionais, faz-se necessário examinar em quais delas há maior número de compromissos em serviços, o que significa um maior nível de liberalização. Trata-se de uma tarefa árdua, haja vista a complexidade dos acordos regionais envolvendo serviços, que possuem diferentes modos de prestação, tipos de barreiras e modalidades de liberalização.

Uma tentativa de mensurar os compromissos em questão pode ser visualizada no estudo desenvolvido por Roy, Marchetti e Lim, cujo foco consistiu em avaliar a cobertura setorial dos compromissos em serviços celebrados nos modos 1 e 3 em 28 acordos regionais, os quais foram negociados por $29 \mathrm{Membros}^{163}$ da OMC desde $2000^{164}$. Nesse

\footnotetext{
${ }^{163}$ A União Europeia foi contabilizada como um Membro.

${ }^{164}$ Vide J. MARCHETTI; M. ROY; L. HOE. 2006.
} 
estudo, os autores calcularam, em uma primeira etapa, o número de setores de serviços que não foram objeto de compromissos nos acordos regionais, considerando os 152 sub-setores da Lista de Classificação Setorial (W120 ${ }^{165}$ ), e, em uma segunda etapa, avaliaram se houve avanço em relação ao nível dos compromissos vigentes no GATS em 1994 e àqueles que estavam sendo negociados no âmbito deste Acordo desde 2000.

Com base nos acordos regionais analisados, Roy, Marchetti e Lim concluíram que houve avanços importantes nas preferências comerciais em serviços em comparação com os compromissos assumidos no GATS e também com as ofertas que foram apresentadas no âmbito das negociações multilaterais, que tiveram início em 2000. Os autores observaram a existência de novos compromissos em um grande número de serviços e setores de serviços que não eram objeto de compromisso ou de oferta no GATS, além de uma melhoria nos compromissos que já constavam de listas de compromissos ou de ofertas. Os compromissos novos, no mínimo, consolidaram o status quo em determinado serviço ou setor. Com relação ao nível dos compromissos, foi observada uma grande variação nos acordos analisados, mas, em muitos casos, os compromissos em serviços igualavam ou superavam os pedidos apresentados durante o processo de negociações.

A conclusão do estudo em questão é de que um número significativo de acordos regionais celebrados a partir de 2000 prevê a liberalização efetiva do setor de serviços e uma situação mais favorável do que aquela obtida no GATS ou nas negociações multilaterais da $\mathrm{OMC}^{166}$.

Em vista do exposto, verifica-se que os compromissos em serviços resultantes de acordos regionais, de fato, tendem a representar um aprofundamento em relação aos compromissos assumidos no âmbito do GATS. Esse é, sem dúvida, um dos fatores que têm motivado a celebração desse tipo de acordo nos últimos anos.

${ }^{165}$ MTN.GNS/W/120. Services Sectoral Classification List. 10 de julho de 1991. Disponível em: <www.wto.org >. Acesso em: 15 jun. 2012.

${ }^{166}$ A esse respeito, João Henrique Ribeiro Roriz e Lucas da Silva Tasquetto apontam o seguinte: "Mesmo não esperando que boa parte dos compromissos assumidos nos APCs resulte em uma liberalização real - com a remoção de restrições anteriormente aplicadas - os membros envolvidos nestes acordos têm assumido compromissos em uma proporção de subsetores de serviços muito superior ao que tinham assumido no GATS ou ainda em relação ao que tinham proposto nas ofertas da Rodada Doha. Este contraste com o GATS é ainda superior no caso dos países em desenvolvimento, cujos compromissos tendem a ser mais limitados na esfera multilateral (OMC, 2011, p. 134).” J. H. R. RORIZ,; L. da S. TASQUETO,. 2013, p. 189. 


\subsection{Compatibilidade entre os compromissos em serviços celebrados no âmbito multilateral e no âmbito regional}

A celebração de compromissos em serviços pelos Membros tanto no âmbito do GATS quanto em acordos regionais resulta em uma série de questionamentos a respeito de como se dará a compatibilização entre eles.

Em primeiro lugar, destaca-se que a falta de clareza em relação a diversos requisitos regulamentados no Artigo V do GATS gera incerteza a respeito dos critérios que devem ser observados pelos acordos regionais que tratam do comércio de serviços, sobretudo quanto aos métodos que devem ser utilizados para quantificar sua abrangência e a eliminação ou redução de medidas discriminatórias.

De modo geral, os questionamentos que se colocam com mais frequência em relação a esse tema referem-se a: (i) como devem ser interpretados os requisitos do Artigo V: 1 (a) em relação ao número de setores, subsetores e modos de prestação de serviços abrangidos pelo acordo regional; (ii) quais são os tipos de medidas discriminatórias que devem ser considerados como exceções legítimas da obrigação imposta no Artigo V:1 (b) para a ausência ou eliminação de substancialmente todas as medidas discriminatórias; (iii) como devem ser interpretados os requisitos do Artigo V: 1 (b), tendo em vista negociações previstas nos Artigos VII (Reconhecimento), X (Medidas Emergenciais de Salvaguarda), XIII (Compras Governamentais), XV (Subsídios) do GATS; (iv) como ficariam as restrições à participação de empresas estrangeiras nas compras governamentais de serviços e à concessão de subsídios para os fornecedores de serviços, em face da necessidade de que os acordos regionais eliminem todas as formas de discriminação.

A respeito da verificação da cobertura setorial de um acordo regional e de seu nível de liberalização em relação aos compromissos assumidos por suas Partes na OMC, há quatro cenários possíveis, considerando-se as ofertas mais recentes de acesso a mercados realizadas no contexto da Rodada de Doha. Esses cenários seriam: (i) a inexistência de compromissos em qualquer contexto; (ii) a existência dos mesmos compromissos no GATS e no acordo regional; (iii) o acordo regional contém compromissos melhorados em relação aos compromissos existentes na OMC; (iv) um acordo regional estende a cobertura setorial por meio da inclusão de compromissos em serviços que não constam das listas de compromissos do GATS. Segundo Rudolf Adlung e Peter Morrison, existiria, ainda, um quinto cenário, que tende a ser ignorado, talvez por não ser óbvio: os compromissos 
assumidos nos acordos regionais por pelo menos uma das Partes teriam ficado aquém dos compromissos consolidados por esta no âmbito do GATS, em um ou mais setores. Adlung e Morrison alegam que a existência deste quinto cenário é mais do que hipotética e teria sido comprovada por informações preliminares de um projeto que está sendo realizado pela $\mathrm{OCDE}^{167}$.

Em vista do exposto, é necessário que sejam definidos, em detalhe, quais devem ser os requisitos mínimos a serem atendidos pelos acordos regionais que tratam do comércio de serviços. Essa definição mais detalhada dos requisitos previstos no Artigo V do GATS não afastará a existência de questões complexas de interpretação. Por exemplo, as disposições dos acordos regionais podem ser elaboradas em termos mais restritivos do que os compromissos correspondentes no GATS, o que resultaria em condições mais restritivas de acesso na esfera regional. Seria possível argumentar, por exemplo, que as entradas relevantes simplesmente serviriam para explicar de forma mais clara o que estaria abrangido no compromisso e, portanto, não implicariam limitações aos compromissos já assumidos em âmbito multilateral.

Nesse sentido, ressalte-se que uma grande dificuldade para a definição de regras mais precisas no âmbito do Artigo V do GATS consiste na existência de quatro modos de prestação de serviços e na abrangência do GATS para além do comércio transfronteiriço de produtos, consumo no exterior e presença comercial de prestadores de serviços estrangeiros.

Independentemente das dificuldades que se colocam, não há dúvida sobre a importância de estabelecer critérios mínimos mais detalhados em relação aos requisitos que devem ser atendidos pelos acordos regionais que envolvem serviços para que estes possam ser considerados como não discriminatórios e, consequentemente, compatíveis com as normas da OMC. O estabelecimento desses critérios é especialmente importante se considerarmos que a tendência será de aumento no número de acordos preferenciais que compreendem o comércio de serviços.

Há diversos problemas que podem decorrer da incompatibilidade dos acordos regionais com as normas da OMC. Existem casos em que uma previsão de um acordo regional não é incompatível com o texto do GATS, mas distinta e não possui equivalente no acordo multilateral. Há também casos mais complexos, incluindo aqueles em que os Membros optam por reproduzir apenas alguns dispositivos do GATS nos acordos

${ }^{167}$ ADLUNG; MORRISON. 2010, p. 1104-1105. 
regionais. Muitas vezes as Partes optam, deliberadamente, por não incluir ou omitir determinada previsão em um acordo regional, porque subentende-se que a regra multilateral será aplicável em qualquer caso ${ }^{168}$.

Nesse contexto, é importante esclarecer que os acordos comerciais, sejam eles bilaterais, regionais ou multilaterais, são tratados internacionais por natureza e, portanto, estão em pé de igualdade no direito internacional. Assim, os acordos da OMC, por si sós, não têm hierarquia superior aos acordos regionais. Eventuais inconsistências entre os acordos da OMC e as condições estabelecidas em acordos regionais por si sós não afetam a existência e a validade de um acordo desse tipo. Cottier e Molinuevo ensinam que tais acordos têm uma vida própria e permanecem válidos e vinculantes para as Partes, apesar de sua incompatibilidade com as regras da $\mathrm{OMC}^{169}$.

De acordo com Pierre Latrille e Jouneyoung Lee, para solucionar as contradições entre dispositivos do GATS e dos acordos regionais, deve-se observar, em primeiro lugar, os princípios de lex specialis e lex posteriori. Logo, prevaleceria a lei mais específica (lex specialis) e, em caso de ausência desta, a lei a mais recente (lex posteriori). Segundo tais autores, na ausência de regras novas, o texto original do GATS seria aplicável às Partes do acordo. Ocorre que a omissão de determinado dispositivo pode indicar que ele não se aplica ao acordo regional. Esse problema também é verificado quando uma previsão citada no acordo regional é idêntica a uma previsão do GATS, mas uma das notas de rodapé não é reproduzida no acordo ${ }^{170}$.

\footnotetext{
${ }^{168}$ Vide P. LATRILLE; J. LEE, 2012, p. 7.

169 "In general public international law, the law of treaties as well as WTO law, multilateral rules and preferential rules have not yet been defined in a hierarchical relationship. All trade agreements, whether bilateral, regional or multilateral, are international treaties in nature. They stand on an equal footing in international law. Hence, WTO agreements per se have no legal supremacy over EIAs. Inconsistencies of preferential rules with WTO agreements and conditions set for preferential trade do not per se affect the existence and validity of an economic integration agreement. Such agreements have a life of their own. They remain valid and binding upon their parties despite their inconsistency with WTO rules". COTTIER; MOLINUEVO, 2008, p. 128.

170 "Legally speaking in the absence of a new and different rule, the original GATS rule still applies between the Parties. However, it could also be that the RTA parties deliberately wished to discard the omitted provision; or because it is understood that the multilateral rule will apply in any case, there is no need to repeat it; or to avoid repeating a provision found in another chapter (e.g. exceptions, dispute settlement, definitions, etc.). Sometimes the context of the provision was helpful to determine which of these may have applied. For instance when the RTA foresees a best endeavour obligation for the Parties to respect the proportionality principles of GATS Article VI.4 in the administration of their technical standards, qualification requirements and procedures and licensing requirements but does not sanction it by a nullification or impairment procedure as in Article VI.5 of the GATS, the omission seems to indicate clearly that there is no nullification or impairment procedure foreseen by the RTA. Thus, the RTA rules clearly differ from the GATS rules. But even in this clear cut case, the question of the application of the Lex generalis (here the nullification or impairment clause of the GATS) to the bilateral relationship remains open (so-called "GATS minus" problem). Similarly the repetition of a GATS provision but without a footnote, when other footnotes are reproduced, suggests that the omission is deliberate (e.g., Footnote 8 to Article XVI
} 
A respeito dessa questão, os próprios Membros apresentaram sua posição ao Secretariado da OMC em diversas ocasiões, no sentido de que as previsões omitidas aplicam-se à relação bilateral ${ }^{171}$. Contudo, ainda não há um posicionamento oficial da OMC acerca do tema.

É inegável que eventuais inconsistências entre os acordos regionais e as normas multilaterais têm implicações jurídicas que não podem ser desprezadas. Os acordos regionais e as disposições desses acordos que não são compatíveis com os requisitos estabelecidos no Artigo V do GATS podem deixar de se beneficiar da isenção de tratamento de Nação Mais Favorecida. Isso significa que outros Membros afetados têm, portanto, o direito de se opor a tais acordos no processo de análise realizado pelo Comitê de Acordos Regionais, ou solicitar que sejam estendidas as preferências concedidas bilateral ou regionalmente, com base no Artigo II do GATS.

Outra opção seria contestar a compatibilidade de determinado acordo regional com as normas da OMC perante o Órgão de Solução de Controvérsias. Caso o Órgão de Solução de Controvérsias confirme a inconsistência do acordo, as Partes poderão estender as preferências a todos os demais Membros que não são Partes do acordo, conforme determina a Cláusula de Nação Mais Favorecida, ou oferecer compensação. Na falta de oferta ou aceitação de compensação, os Membros terão direito de pedir autorização ao Órgão de Solução de Controvérsias para suspender suas concessões e buscar a aplicação da decisão por meio de retaliação, de acordo com artigos 21 e 22 do Entendimento sobre Solução de Controvérsias.

Até o presente momento, os Membros da OMC têm relutado em questionar se os acordos regionais atendem aos requisitos mínimos estabelecidos no Artigo V do GATS, seja no âmbito do Comitê de Acordos Regionais, seja no âmbito do Órgão de Solução de Controvérsias. O principal motivo da falta de questionamento é de fácil compreensão: uma vez que praticamente todos os Membros da OMC são Partes de acordos regionais, muitos deles envolvendo o comércio de serviços, é preferível não alegar a inconsistência de um acordo envolvendo outros Membros, sob o risco de que os acordos regionais dos quais se é Parte também sejam objeto de questionamento, pelos mesmos motivos. Talvez a saída para esse dilema esteja no estabelecimento de uma hierarquia entre as regras do Sistema Multilateral de Comércio, concedendo às normas da OMC uma função constitucional, a 
fim de garantir a compatibilidade dos acordos regionais com suas normas e evitar os efeitos distorcivos ao comércio causados pelos acordos regionais que são incompatíveis com Artigo V do GATS.

\section{ESTÁGIO ATUAL dOS ACORDOS REGIONAIS DE COMÉRCIO VIS-À-VIS AS REGRAS DO GATS}

Nos últimos anos, diversos autores dedicaram-se a examinar como as disposições dos acordos regionais de comércio coincidem, regridem e avançam em relação aos dispositivos do GATS $^{172}$.

Nesse sentido, os acordos regionais têm sido classificados como "WTO-minus", "WTO-plus" ou "WTO-extra". A primeira categoria refere-se aos acordos que contêm regras menos abrangentes do que aquelas da OMC. A segunda caracteriza os acordos regionais que vão além dos compromissos celebrados no âmbito da OMC e, portanto, representam um avanço em relação aos compromissos multilaterais. Já a terceira categoria refere-se a acordos que regulam questões que não são tratadas pela OMC, como é o caso de políticas de concorrência ${ }^{173}$. Por analogia, no tocante a serviços, os acordos regionais têm sido denominados de "GATS-plus", "GATS-minus" e "GATS-extra".

Em um estudo realizado por Henrik Horn, Petros Mavroidis e André Sapir ${ }^{174}$, foram analisados os acordos regionais celebrados por Estados Unidos e União Europeia vis à vis os compromissos assumidos por estes Membros na OMC, com o intuito de verificar se o que foi acordado regionalmente representava um incremento ou não em relação aos compromissos multilaterais em serviços. A conclusão dos autores foi de que, com relação ao GATS, os acordos celebrados pelos Estados Unidos contêm algumas obrigações que vão além daquelas consolidadas na OMC. É o caso da previsão contida no acordo entre

\footnotetext{
${ }^{172}$ Como, por exemplo, Henrik Horn, Petros Mavroidis, André Sapir, Rudolf Adlung e Sébastien Miroudot. 173 Sobre a terminologia "WTO plus" e "WTO extra", Henrik Horn, Petros C. Mavroidis e André Sapir explicam o seguinte: "In order to do this, we divide the subjects covered by these agreements into two categories: 'WTO plus' (WTO+), and 'WTO extra' (WTO-X). The first category corresponds to those provisions of PTAs which come under the current mandate of the WTO, where the parties undertake bilateral commitments going beyond those they have accepted at the multilateral level. An example would be a reduction in tariffs. By contrast, the WTO-X category comprises those PTA provisions that deal with issues lying outside the current WTO mandate. An example would be a commitment on labour standards". H. HORN; P. C. MAVROIDIS; A. SAPIR, 2008, p. 4.

${ }^{174}$ H. HORN; P. C. MAVROIDIS; A. SAPIR, 2008.
} 
Estados Unidos e Chile de que as Partes podem comunicar e comentar leis ainda não promulgadas que afetem o comércio de serviços ${ }^{175}$.

Em outro trabalho, Rudolf Adlung e Sébastien Miroudot estudaram 66 acordos regionais e concluíram que a vasta maioria destes acordos contém compromissos do tipo "GATS-minus" 176. A tendência de celebrar compromissos regionais menos abrangentes foi verificada nos acordos regionais mais recentes em maior quantidade do que nos acordos mais antigos. Também se observou uma maior incidência desses compromissos em acordos do tipo Norte-Sul e naqueles inspirados no modelo NAFTA ${ }^{177}$.

Sébastien Miroudot, Jehan Sauvage e Marie Sudreau, por sua vez, analisaram os compromissos em acesso a mercados e tratamento nacional setoriais celebrados em 56 acordos regionais e chegaram à conclusão de que os acordos regionais tendem a ser GATSplus, à medida que alcançaram um nível de liberalização maior que o GATS em tratamento nacional e acesso a mercados. Os autores veem um claro progresso tanto em relação à extensão dos compromissos a novos setores de serviços quanto à redução de barreiras $^{178 .}$

A classificação dos compromissos assumidos em âmbito regional como "GATSminus" pode indicar potenciais riscos de incompatibilidade entre as regras regionais e multilaterais em serviços. Nesse caso, as obrigações assumidas no acordo regional são

175 "The EC approach is akin to that followed by the GATS. Reciprocal offers will be made, and the preferential trade in services will be based more or less on the same principles as those governing the GATS. This does not mean that EC commitments are shallow on this point: there are agreements, like CARIFORUM, where the services component is quite substantial. The US has adopted a more daring attitude in this context. Martin, Marchetti, and Lim (2007) report that the US has, on occasion, opted for obligations that cannot be found in GATS: for example, in its agreement with Chile, the US has included an obligation whereby both parties must communicate to the other party services-related laws at the draft stage, that is, before the law has been actually enacted. The other party will thus be in a position to comment upon it in advance and, although its comments are not binding on the legislating party, a rather active integration process is being fostered. The US did not manage to insert similar clauses in all its PTAs. No such vetting clause exists in GATS, where Article III imposes a general transparency obligation, and the possibility for cross-notifications". H. HORN; P. C. MAVROIDIS; A. SAPIR, 2008, p. 51-52.

176 "GATS-minus commitments, i.e. commitments that fall short of their counterparts in the relevant GATS schedules, can be found in a vast majority of the 66 RTAs included in our dataset". R. ADLUNG; S. MIROUDOT. Poison in the wine? Tracing gats-minus commitments in regional trade agreements. WTO Staff Working Paper. Genebra, Fevereiro de 2012, p. 20. Disponível em: <http://www.wto.org/english/res_e/reser_e/ersd201204_e.htm>. Acesso em: 3 fev. 2014.

${ }^{177}$ R. ADLUNG; S. MIROUDOT, 2012, p. 20.

178 "The overall picture emerging from the dataset is that services RTAs tend to be GATS-plus in so far as they have achieved a higher degree of market access and national treatment commitments. This is good news if RTAs are to be seen as a "testing ground" for future multilateral liberalisation. There would appear already to be sufficient progress in the extension of market access and national treatment commitments to new services sectors, as well as reductions in restrictive barriers, to consider the multilateralisation of RTA commitments." S. MIROUDOT; J. SAUVAGE; M. SUDREAU. Multilateralising Regionalism: How Preferential Are Services Commitments in Regional Trade Agreements. OECD Trade Policy Papers, No. 106, Dezembro de 2010, p. 14. Disponível em: 〈http://dx.doi.org/10.1787/5km362n24t8n-en>. Acesso em: 15 fev. 2014. 
menos vinculantes do que aquelas assumidas no $\operatorname{GATS}^{179}$. Há casos, inclusive, de acordos que criam barreiras ao comércio de serviços que não existem no GATS $^{180}$, o que é um contrassenso em relação ao objetivo de liberalização comercial.

É possível eliminar a insegurança decorrente dos compromissos caracterizados como "GATS-minus," desde que sejam renegociados os compromissos do GATS afetados ou os compromissos regionais em questão. Até o momento, nenhuma iniciativa foi tomada nesse sentido $^{181}$. Outra possibilidade seria que os acordos regionais contivessem uma cláusula de nação mais favorecida, que levaria o compromisso multilateral a prevalecer em caso de eventual inconsistência com o GATS ${ }^{182}$.

O relatório anual de 2011 da OMC foi dedicado ao tema acordos regionais e abordou a questão de eventuais inconsistências entre as regras multilaterais e regionais de comércio. Esse documento aponta algumas soluções para que haja maior coerência entre as regras comerciais, a saber: (i) acelerar a liberalização do comércio multilateral como forma de reduzir as eventuais incoerências entre as normas de ambos os níveis; (ii) corrigir as deficiências no quadro regulatório da $\mathrm{OMC}$, incluindo o esclarecimento do texto dos artigos XXIV do GATT e V do GATS que ainda são passíveis de controvérsias, seja por meio de negociação, seja por meio de uma disputa no Órgão de Solução de Controvérsias da OMC; (iii) adotar soft law para complementar o conjunto de normas vigente; (iv) multilateralizar o regionalismo, o que significa estender as preferências comerciais existentes a outras Partes, de forma não discriminatória ${ }^{183}$.

De acordo com a OMC, os quatro enfoques propostos não são mutuamente excludentes. Sua adoção objetiva reforçar a compatibilidade e a coerência, o que significa garantir que os acordos regionais contribuam para a cooperação e liberalização comercial não discriminatória.

\footnotetext{
${ }^{179}$ A respeito dessa questão, Rudolf Adlung e Peter Morrison entendem que: "The existence of 'negative preferences' or 'GATS-minus commitments' may prove relevant for several reasons: in particular, they could impinge on an agreement's legal status under the GATS and help create a trading system beyond the WTO". R. ADLUNG; P. MORRISON, 2010, p. 1103.

180 "Again, there are several interpretative issues with respect to these GATS-minus commitments, but there are clear cases where RTA schedules of commitments include barriers that do not appear in GATS. This is where RTAs can be "foes" rather than "friends" of multilateral obligations, by introducing provisions where parties are less bound than under the GATS. This is also a relevant issue when looking at the multilateralisation of services commitments". S. MIROUDOT; J. SAUVAGE; M. SUDREAU, 2010, p. 15.

181 "Moreover, there have been neither renegotiations of GATS commitments under Article XXI with a view to neutralising the minus features in any of the disconnected agreements, nor amendments that would have removed these features or inserted a comprehensive MFN clause in the RTAs concerned". R. ADLUNG; S. MIROUDOT, 2012, p. 21.

${ }^{182}$ R. ADLUNG; S. MIROUDOT, 2012, p. 20.

${ }^{183}$ World Trade Report 2011, p. 189-190.
} 
Contudo, para que isso seja possível, é necessário que haja um diálogo entre as fontes legislativas da OMC e dos subsistemas regionais, o que significa, segundo Umberto Celli Junior, uma aplicação simultânea, coerente e coordenada de tais fontes legislativas convergentes como normas situadas em um mesmo nível hierárquico ${ }^{184}$. Para tanto, devese esquecer a ideia de que as normas da OMC seriam hierarquicamente superiores àquelas contidas nos acordos regionais e tratá-las como normas situadas no mesmo patamar.

Independentemente da solução adotada, a busca de uma coexistência harmônica entre as regras comerciais multilaterais e regionais é fundamental para que haja coerência na governança global internacional.

\section{CONCLUSÕES}

Neste capítulo, foi analisada a evolução do tratamento do tema serviços em âmbito regional, bem como as principais consequências e desafios desse tipo de acordo para o GATS e para o Sistema Multilateral de Comércio como um todo.

Conforme visto nessa tese, tudo indica que os acordos regionais continuarão aumentando e que conterão regulações cada vez mais sofisticadas e abrangentes, o que resultará em uma complexidade legislativa ainda maior do que a atual. A celebração de acordos regionais com regras do tipo "GATS-minus" e "GATS-extra" evidencia algumas dificuldades adicionais, haja vista a necessidade de compatibilização dessas regras com as normas do GATS, sob o risco de existência de regras incompatíveis sobre a mesma questão nos planos regional e multilateral.

Diante desse fato, é imperioso que se estude como será feita a compatibilização dos acordos regionais com as regras multilaterais do GATS e que se encontre uma solução definitiva para esta questão, visto que ainda não há uma resposta mais conclusiva. Apresentaram-se aqui algumas sugestões, as quais, em hipótese alguma, implicam uma solução definitiva, à medida que tratam apenas de questões relacionadas ao tema sob análise e, portanto, não pretendem esgotá-lo.

\footnotetext{
${ }^{184}$ A respeito dessa questão, merece destaque o entendimento do Professor Umberto Celli Junior, para o qual: "Como destacado por Alberto do Amaral Júnior, esse "diálogo" das fontes ocorre entre regras horizontais, que se encontram no mesmo nível hierárquico. É diferente da relação normativa hierárqica decorrente do jus cogens consagrado pela Convenção de Viena. Nesse caso, o que existe é apenas um "monólogo", uma vez que as normas superiores preponderam necessariamente sobre aquelas que se situam em patamar inferior. Esse diálogo implica buscar, sem prejuízo das soluções tradicionais de conflitos de tratados previstas na Convenção de Viena, coordenação flexível e útil das fontes, isto é aplicação simultânea, coerente e coordenada de fontes legislativas convergentes”. U. CELLI JUNIOR., 2012, p. 100.
} 
De todo modo, faz-se necessária uma reflexão aprofundada sobre como as normas do Sistema Multilateral de Comércio poderão dialogar com as regras regionais de comércio no que se refere ao tema serviços, de forma a garantir maior coerência e eficácia a ambos os sistemas. Para que isso ocorra, é necessário que se abandone a presunção de superioridade hierárquica das normas do Sistema Multilateral de Comércio sobre as normas do sistema regional de comércio. 
PARTE II

O COMÉRCIO DE SERVIÇOS NOS ACORDOS REGIONAIS DE COMÉRCIO CELEBRADOS POR MERCOSUL, ESTADOS UNIDOS, UNIÃO EUROPEIA, CHINA E ÍNDIA 


\section{CAPÍTULO 1: OS ACORDOS REGIONAIS DE COMÉRCIO CELEBRADOS POR ESTADOS UNIDOS, UNIÃO EUROPEIA, CHINA E ÍNDIA E O COMÉRCIO DE SERVIÇOS}

\section{INTRODUÇÃO}

Tendo em vista o impasse nas rodadas de negociações multilaterais, observa-se que o desenvolvimento das disciplinas sobre o comércio de serviços tem sido transferido aos acordos regionais de comércio.

Assim, na Parte II desta tese, serão analisados os acordos regionais de comércio adotados por alguns dos principais players do comércio internacional nos dias atuais Estados Unidos, União Europeia, Índia e China -, de modo a verificar como estes atores regulamentam o tema serviços em âmbito regional e, a partir de uma análise comparativa, concluir qual desses modelos seria o mais adequado para o Mercosul.

A respeito da metodologia utilizada, foram estudados os acordos envolvendo o comércio de serviços celebrados por Estados Unidos, União Europeia, Índia, China com Estados, grupos de Estados e organizações internacionais ${ }^{185}$ que continham alguma previsão relativa à liberalização do comércio de serviços entre as Partes. Portanto, acordos celebrados com regiões administrativas ${ }^{186}$ não foram analisados. Também não foram analisados os acordos relativos à liberalização comercial em serviços celebrados pela União Europeia com outros Estados europeus ${ }^{187}$. Com relação ao corte temporal, foram analisados somente os acordos que se encontravam em vigor em 15 de fevereiro de 2013. A relação completa dos acordos analisados encontra-se no Anexo I à presente tese.

Não foram analisados acordos que, embora tenham sido notificados à $\mathrm{OMC}$, não se encontravam em vigor na data em questão. Também não foram analisados os acordos que não envolviam o comércio de serviços ou que não criavam obrigações recíprocas para ambos os Estados Partes.

Em cada um dos acordos, foram estudadas apenas as cláusulas que tratam, direta ou indiretamente, do comércio internacional de serviços, com o intuito de verificar quais são os pontos comuns e as diferenças entre eles com relação ao tema em questão.

\footnotetext{
${ }^{185}$ Como é o caso da ASEAN.

${ }^{186}$ Hong Kong e Taipei Chinês, no caso da China.

${ }^{187}$ Albânia, Montenegro, Sérvia e República da Macedônia.
} 
As questões analisadas em cada acordo regional foram as seguintes:

Escopo do capítulo sobre serviços: analisa-se se os serviços e setores de serviços que estão abrangidos pelas regras do capítulo sobre serviços do acordo regional, além dos serviços e setores que estão excluídos do escopo do capítulo;

(ii) Forma de assunção dos compromissos: se a lista de compromissos adotada pelo acordo é negativa (modelo NAFTA) ou positiva (modelo GATS);

(iii) Modos de prestação de serviços abrangidos: análise dos modos de prestação de serviços que são cobertos pelo acordo (modo 1 - prestação transfronteiriça; modo 2 - consumo no exterior; modo 3 - presença comercial; e modo 4 - movimento de pessoas físicas), considerando-se as definições estabelecidas no Art. I:2 do GATS;

(iv) Regras sobre regulação doméstica: análise do capítulo de serviços para verificar se o acordo possui ou não regras sobre regulação doméstica e qual o escopo dessas regras;

(v) Regras setoriais específicas: análise do texto do acordo para verificar se há regras específicas sobre determinados setores de serviços no capítulo sobre serviços ou em forma de anexos e quais são essas regras;

(vi) Capítulo específico sobre investimentos relacionados a serviços: se existe ou não um capítulo no acordo para regular investimentos relacionados a serviços;

(vii) Regras sobre transparência: análise do capítulo sobre serviços para verificar a existência de regras específicas sobre transparência e, em caso positivo, qual o seu escopo;

(viii) Tratamento nacional: análise do capítulo sobre serviços para verificar qual a abrangência das obrigações e das limitações de tratamento nacional e se os parâmetros adotados no acordo são semelhantes àqueles adotados pelo GATS, a saber: impossibilidade de discriminação entre serviços similares (like services) e entre prestadores de serviços similares (like services suppliers) dos Membros da OMC / Partes do acordo;

(ix) Acesso a mercados: análise do capítulo sobre serviços para verificar qual a abrangência das obrigações e das limitações de acesso a mercados e se 
os parâmetros adotados são quantitativos, como aqueles adotados pelo Art. XVI do GATS;

(x) Obrigações permissivas: análise do capítulo sobre serviços para verificar se possui regras que possibilitam o tratamento desigual entre as Partes contratantes do acordo, tais como salvaguardas emergenciais, cláusulas desenvolvimentistas, entre outras;

(xi) Cláusula de nação mais favorecida ratione materiae et temporis: análise do capítulo sobre serviços para verificar se há previsão de extensão de novas concessões dadas a terceiros às Partes do acordo;

(xii) Exceções à Cláusula de Nação Mais Favorecida: análise do capítulo sobre serviços para verificar se este possibilita ou não que as Partes contratantes excepcionem a cláusula de nação mais favorecida (non conforming measures);

(xiii) Regra de origem (denial of benefits): análise do capítulo sobre serviços para verificar se há ou não previsão de regra de origem para que um serviço ou prestador se beneficie do acordo e, em caso positivo, se esta é caracterizada pela existência de operações comerciais substanciais na Parte em que o serviço for prestado ou por qualquer outra forma;

(xiv) Procedimento para modificação dos compromissos: análise do capítulo sobre serviços para verificar se há previsão de procedimentos para a modificação dos compromissos e quais são esses procedimentos;

(xv) Procedimento para futuras negociações: análise do capítulo sobre serviços para verificar se há previsão de procedimentos para futuras negociações entre as Partes contratantes;

(xvi) Criação de comitês para supervisionar a evolução do acordo: análise do capítulo sobre serviços para verificar se há previsão de criação de comitês para supervisionar o funcionamento do acordo.

A partir da análise dos itens relacionados acima, será possível obter um panorama completo e abrangente das regras mais frequentemente utilizadas por Estados Unidos, União Europeia, China e Índia para regular o comércio de serviços, em âmbito regional, bem como avaliar as principais vantagens e desvantagens de cada modelo.

É importante destacar que o presente estudo não visa a realizar uma análise setorial dos compromissos específicos em serviços ou uma comparação das regras ou compromissos celebrados nos acordos regionais com as normas e compromissos 
celebrados por esses mesmos Membros na OMC. Eventualmente, é possível que tanto uma quanto outra sejam utilizadas, de forma acessória, apenas para enriquecer a análise comparativa dos acordos regionais que são objeto da presente tese.

A seguir, serão apresentadas as principais conclusões resultantes da análise comparativa dos acordos regionais estudados em relação a Estados Unidos, União Europeia, Índia e China. As conclusões relativas ao Mercosul serão apresentadas no capítulo seguinte. As tabelas com os resultados completos das pesquisas encontram-se no Anexo II.

\section{PANORAMA DO TRATAMENTO DE SERVIÇOS NOS PRINCIPAIS ACORDOS REGIONAIS DE COMÉRCIO ENVOLVENDO OS ESTADOS UNIDOS}

\subsection{Modelo de lista adotado}

A grande maioria dos acordos regionais celebrados pelos Estados Unidos adota o modelo NAFTA no tocante ao comércio de serviços. O modelo GATS foi utilizado em apenas um acordo (Estados Unidos-Jordânia). Por sua vez, o Acordo Estados Unidos-Israel não pode ser classificado nem como um modelo nem como outro, visto que contém regras muito preliminares sobre o comércio de serviços inter-partes, bem distantes do complexo arcabouço jurídico dos dois modelos ora citados.

Embora o CUSFTA tenha sido o primeiro acordo regional celebrado pelos Estados Unidos a entrar em vigor, o que aconteceu em 1989, foi o NAFTA, negociado alguns anos depois, que deu o tom aos acordos que viriam a ser celebrados pelo país e que atualmente predominam na região ${ }^{188}$.

\footnotetext{
188 Sobre as negociações que resultaram na adoção do modelo de lista negativa pelo NAFTA, Sherry Stephenson e Maryse Robert ensinam o seguinte: "The crafters of NAFTA in the early 1990s took a different path from the negotiators of the WTO GATS, though both agreements were being negotiated simultaneously. While political caution on the part of developing countries dictated a very timid approach to the structure of the GATS as well as the adoption of a "positive list" or gradual approach to the undertaking of market access commitments, the NAFTA negotiators took the opposite track of high ambition. Spurred by the active participation of the business community, they abandoned the CUSFTA model, which applied only to a list of covered services where services that were not covered were not subject to the obligations of the agreement, to famously adopt the alternative "negative list" approach to market opening. Although often mistakenly understood as meaning a complete liberalization of service restrictions, in reality the "negative list" translated into an across-the-board legal assurance of access for service providers and investors at the level of existing regulations". Innovations of Regionalism in Services in the Americas. NCCR Trade Working Paper No
} 
Os negociadores do NAFTA visavam que a liberalização do comércio de serviços fosse abrangente, razão pela qual adotaram o método top-down, que já havia sido utilizado para o setor de serviços no ANZCERTA ${ }^{189}$. Adotar o método top-down significa que há uma lista negativa de compromissos e apenas as medidas, setores de serviços e atividades expressamente excluídos do escopo do acordo no momento de sua celebração não serão objeto de compromisso. Quaisquer medidas, setores de serviços e atividades não mencionados na lista por uma Parte contratante estarão sujeitos à liberalização - o que é denominado de list it or loose it approach -, não podendo, assim, ser impedido o acesso a mercado ou ser adotada qualquer barreira ou tratamento discriminatório ao prestador ou serviço estrangeiro.

As medidas expressamente excluídas do escopo do acordo são denominadas de "medidas não conformes" (non-conforming measures). Tais medidas são relacionadas em Anexos aos acordos regionais e podem vir a ser liberalizadas futuramente, por meio de consultas ou negociação entre as Partes Contratantes ${ }^{190}$.

É importante notar que a exclusão de medidas não conformes apenas incide sobre as medidas existentes à época em que o acordo foi celebrado. Uma vez que a medida não conforme é eliminada, a política comercial da Parte é automaticamente consolidada no nível mais liberal. Já com relação à exclusão de certos setores, subsetores e atividades, as partes podem excluir do escopo do acordo tanto aqueles existentes no momento em que este foi celebrado quanto os futuros ${ }^{191}$.

2011/34, maio de 2011, p. 3-4. Disponível em: < http://www.nccr-trade.org/fileadmin/user_upload/nccrtrade.ch/wp2/people/WPInnovations\%20of\%20Regionalism\%20in\%20Services\%20-\%20Americas\%20\%20May\%202011\%20FINAL.pdf>. Acesso em: 3 mar. 2014.

189 "First used (for trade in services only, in the absence of an investment chapter) by Australia and New Zealand in ANZCERTA, the approach was further developed by Canada, Mexico, and the United States in NAFTA in 1994". A. MATTOO; P. SAUVÉ. Services, In J.-P.CHAUFFOUR; J.-C. MAUR (ed.). Preferential Trade Agreements Policies for Development: A handbook. Washington D.C.: Banco Mundial, 2011, p. 251. Disponível em: <http://wbi.worldbank.org/wbi/news/2011/07/11/preferential-tradeagreement-policies-development>. Acesso em: 10 jul. 2012.

${ }^{190}$ A respeito do conceito de lista negativa, vide P. SAUVÉ. The relationship between regional trade agreements and the multilateral trading system. Outubro 2002, p. 16 . Disponível em: $<$ http://search.oecd.org/officialdocuments/displaydocumentpdf/?doclanguage=en \&cote=td/tc/wp(2002)27/fin al>. Acesso em: 1 mar. 2014.

${ }^{191}$ Federico Ortino aborda as diferencas entre as medidas não conformes e setores, sub-setores e atividades excluídos dos acordos regionais e cita, como exemplo, o tratamento dado pelo acordo de livre comércio entre Estados Unidos e Cingapura. Veja-se: "Those RTAs that follow the NAFTA model usually allow a party to exclude both certain measures and certain sectors/sub-sectors/activities. For example, Article 8.7 of the USSingapore FTA provides that the national treatment obligation does not apply to (1) "any existing nonconforming measure that is maintained by a Party at the central level of government [and] at a regional level of government as set out by that Party in its Schedule to Annex 8A" and (2) "any measure that a Party adopts or maintains with respect to sectors, sub-sectors or activities as set out in its Schedule to Annex 8B." The difference between the two set of reservations is that, at least in principle, the exclusion of 'non-conforming measure' can apply only to existing measures: provisions such as Article 8.7 of the US-Singapore FTA seems 


\subsection{Abrangência}

Com relação à abrangência dos acordos regionais celebrados por Estados Unidos que seguem o modelo NAFTA, as regras contidas no capítulo sobre serviços aplicam-se apenas ao comércio transfronteiriço, como indicado no próprio título do capítulo (CrossBorder Trade in Services). A abrangência dos acordos é detalhada nas definições, como pode ser visto no excerto abaixo, extraído do texto do NAFTA:

"Para os propósitos deste capítulo:

prestação transfronteiriça de um serviço ou comércio transfronteiriço de serviços significa a prestação de um serviço:

(a) do território de uma Parte ao território de outra Parte,

(b) no território de uma Parte pela pessoa daquela Parte a uma pessoa de outra Parte,

(c) pelo nacional de uma Parte no território de outra Parte,

mas não inclui a prestação de um serviço no território de uma Parte por meio de um investimento, como definido no Artigo 1139 (Definições de Investimentos), naquele território" $" 192$.

Isso significa que o capítulo sobre serviços regula apenas os modos 1 (prestação transfronteiriça), 2 (consumo no exterior) e 4 (movimento temporário de pessoas físicas). O modo 3 (presença comercial) é regulado no capítulo sobre investimentos, que está presente em todos os acordos do modelo NAFTA celebrados pelos Estados Unidos.

Sobre essa questão, note-se que a diferenciação entre os quatro modos de prestação de serviços previstos no GATS entre serviços ou investimentos foi incorporada pelo

to imply that once the non-conforming measure is eliminated, the party's policy will automatically be bound at the more liberal level. On the other hand, the exclusion of certain sectors/sub-sectors/activities applies to both existing and future measures". Regional Trade Agreements and Trade in Services. In: S. LESTER; B. MERCURIO. Bilateral and regional trade agreements: commentary and analysis (ed.). Nova York: Cambridge University Press, 2009, p. 202-203.

192 Tradução livre do texto original em inglês: "For purposes of this Chapter: cross-border provision of a service or cross-border trade in services means the provision of a service:

(a) from the territory of a Party into the territory of another Party,

(b) in the territory of a Party by a person of that Party to a person of another Party, or

(c) by a national of a Party in the territory of another Party,

but does not include the provision of a service in the territory of a Party by an investment, as defined in Article 1139 (Investment Definitions), in that territory". North American Free Trade Agreement. Disponível em: <http://www.ustr.gov/trade-agreements/free-trade-agreements/north-american-free-tradeagreement-nafta>. Acesso em: 20 mai. 2014. 
NAFTA e, posteriormente, por outros acordos celerados pelos Estados Unidos, mas não possui correspondente no Acordo da OMC. Entretanto, o capítulo sobre investimentos dos acordos celebrados pelos Estados Unidos não trata unicamente de investimentos relacionados a serviços, mas regula investimentos de forma ampla, incluindo ativos intangíveis ${ }^{193}$.

A estrutura adotada pelos acordos celebrados pelos Estados Unidos não efetua qualquer discriminação entre os três modos de prestação de serviços abarcados por eles. Pelo contrário, pode-se dizer que os acordos em análise são caracterizados por neutralidade modal, traduzida no tratamento praticamente equânime que é dado a todos os modos de prestação $^{194}$.

A respeito do modo 4, o tratamento dado a esse modo pelos acordos baseados no NAFTA é mais restritivo do que o tratamento dado pelo GATS. Se, por um lado, o GATS regula o movimento temporário de pessoas físicas como um todo, por outro, o NAFTA e os acordos que adotam esse modelo regulam apenas o movimento temporário de profissionais ${ }^{195}$. Também há a exclusão de quaisquer obrigações relacionadas a visto ou emprego. Alguns acordos regulam essa questão em capítulos específicos, como é o caso do Acordo Estados Unidos-Cingapura ${ }^{196}$.

Quanto aos setores de serviços abrangidos pelos acordos, de modo geral, todos os setores estão incluídos, exceto: (a) serviços financeiros, salvo se o serviço financeiro for fornecido por um investimento coberto que não seja coberto em uma instituição financeira; (b) licitações governamentais; (c) transporte aéreo doméstico e internacional ou serviços de apoio correlatos, com exceção de serviços de reparo e manutenção de aeronaves enquanto não estiverem em serviço, serviços especializados, subsídios ou concessões governamentais e serviços prestados no exercício de autoridade governamental ${ }^{197}$.

193 A título de exemplo, cite-se o Acordo Estados Unidos-Austrália, no qual o capítulo sobre investimentos incide sobre as seguintes medidas adotadas ou mantidas por pelas Partes:

"ARTICLE 11.1 : SCOPE AND COVERAGE

1. This Chapter applies to measures adopted or maintained by a Party relating to:

(a) investors of the other Party;

(b) covered investments; and

(c) with respect to Articles 11.9 and 11.11, all investments in the territory of the Party". Australia-United States Free Trade Agreement. Disponível em: <http://www.ustr.gov/trade-agreements/free-tradeagreements/australian-fta>. Acesso em: 20 mai. 2014.

${ }^{194}$ S. STEPHENSON; M. ROBERT, 2011, p. 6.

${ }^{195}$ S. STEPHENSON; M. ROBERT, 2011, p. 8.

196 Vide Capítulo 11 ("Chapter 11 : Temporary Entry of Business Persons"). United States - Singapore Free Trade Agreement. Disponível em: <http://www.ustr.gov/trade-agreements/free-tradeagreements/singapore-fta/final-text>. Acesso em: 20 mai. 2014.

${ }^{197}$ Por exemplo, no Acordo Estados Unidos-Peru, o capítulo sobre serviços não incide sobre os seguintes serviços: "4. This Chapter does not apply to: 
Outra característica dos acordos que adotaram o modelo NAFTA consiste no fato de que alguns setores de serviços são regulados em capítulos separados, em razão de sua importância, a saber: (i) serviços financeiros; (ii) serviços de telecomunicação; (iii) comércio eletrônico. Cada um desses capítulos contém disciplinas próprias para a liberalização desses setores. Além disso, todos os acordos em questão contêm um anexo sobre serviços profissionais, com o intuito de facilitar o movimento de profissionais e promover o reconhecimento de equivalência de qualificações. Alguns contêm, ainda, um anexo sobre serviços de entrega expressa, como é o caso dos acordos Estados UnidosChile, Estados Unidos-Marrocos e KORUS.

\subsection{Obrigações e limitações de acesso a mercados}

Como consequência do modelo de liberalização em serviços adotado pelos Estados Unidos, as obrigações de acesso a mercados têm aplicação abrangente, cobrindo todas as medidas, serviços e setores de serviços, exceto aqueles que compreendem as medidas, serviços e setores de serviços sobre os quais o acordo não incide ou que foram especificados pelas Partes. Essa é uma diferença significativa em relação ao modelo adotado pelo GATS, segundo o qual as obrigações de tratamento nacional aplicam-se somente aos serviços e setores de serviços objeto de compromissos específicos.

(a) financial services as defined in Article 12.20 (Definitions), except that paragraph 3 applies where the financial service is supplied by a covered investment that is not a covered investment in a financial institution (as defined in Article 12.20) in the Party's territory;"

(b) "government procurement" or "procurement", as defined in Article 1.3 (Definitions of General Application);

(c) air services, including domestic and international air transportation services, whether scheduled or nonscheduled, and related services in support of air services, other than:

(i) aircraft repair and maintenance services during which an aircraft is withdrawn from service, and

(ii) specialty air services; or

(d) subsidies or grants provided by a Party, including government-supported loans, guarantees, and insurance.

Annex 11-A sets forth an understanding of the Parties related to subparagraph (d).

5. This Chapter does not impose any obligation on a Party with respect to a national of another Party seeking access to its employment market, or employed on a permanent basis in its territory, and does not confer any right on that national with respect to that access or employment.

6. This Chapter does not apply to services supplied in the exercise of governmental authority in a Party's territory. A "service supplied in the exercise of governmental authority" means any service which is supplied neither on a commercial basis, nor in competition with one or more service suppliers.

7. Nothing in this Chapter or any other provision of this Agreement shall be construed to impose any obligation on a Party regarding its immigration measures, including admission or conditions of admission for temporary entry". United States-Peru Trade Promotion Agreement. Disponível em: <http://www.ustr.gov/trade-agreements/free-trade-agreements/peru-tpa/final-text>. Acesso em: 20 mai. 2014. 
No GATS, as limitações de acesso a mercados e tratamento nacional podem ser listadas pelos Membros entre os níveis mínimos ou máximos e, portanto, podem não refletir a prática regulatória vigente em um Membro. Essa possibilidade resulta em menor transparência para os prestadores de serviços e menor segurança jurídica. No modelo NAFTA, eventuais restrições de acesso a mercados existentes devem ser justificadas e serão consolidadas no nível legal vigente no momento da celebração do acordo, o que assegura maior previsibilidade e segurança jurídica aos prestadores estrangeiros ${ }^{198}$.

Embora o NAFTA não contenha uma cláusula específica para regulamentar os tipos de medidas restritivas ao acesso a mercados que não podem ser adotadas, como ocorre no GATS, os acordos posteriores celebrados pelos Estados Unidos passaram a regulamentar essa questão ${ }^{199}$. Nesses acordos, foram adotados praticamente os mesmos critérios existentes no $\operatorname{GATS}^{200}$, a saber: (i) proibição de limitar o número de prestadores de serviços, seja na forma de quotas, monopólio, prestadores exclusivos ou requerimento de teste de necessidade econômica; (ii) proibição de limitar o valor total de uma transação de serviços ou ativos na forma de quotas numéricas ou requerimento de teste de necessidade econômica; (iii) proibição de limitar o número total de operações de serviços ou a quantidade da produção de serviços expressa em termos de unidades numéricas na forma de quotas numéricas ou requerimento de teste de necessidade econômica; (iv) proibição de limitar o número total de pessoas naturais que podem ser empregadas em um setor de serviços específico ou que um prestador de serviços pode empregar e que são necessários para, e diretamente relacionados à, prestação de um serviço específico na forma de quotas

\footnotetext{
${ }^{198}$ Vide S. STEPHENSON; M. ROBERT, 2011, p. 10-11.

199 A respeito da inexistência de uma cláusula específica sobre limitações de acesso a mercados no NAFTA, Federico Ortino ensina o seguinte: "Other older RTAs, such as NAFTA, on the other hand, do not have a specific provision on 'market access' but include a similar provision addressing 'quantitative restrictions', which are defined as 'non-discriminatory measures that impose limitations on: (a) the number of service providers, whether in the form of a quota, a monopoly or an economic needs test, or by any other quantitative means; or (b) the operations of any service provider, whether in the form of a quota or an economic needs test, or by any other quantitative means". F. ORTINO, 2009, p. 204.

200 Acerca da semelhança entre as restrições de acesso a mercados contidas nos acordos mais recentes celebrados pelos Estados Unidos e o Artigo XVI do GATS, comentam Aaditya Mattoo e Pierre Sauvé: “A number of earlier PTAs, however, particularly those concluded in the Western Hemisphere and modeled on North American Free Trade Agreement (NAFTA), were actually weaker than GATS, committing parties solely to making such restrictions fully transparent in annexes listing nonconforming measures and to a bestendeavors approach to their progressive dismantling in the future. (In contrast, under GATS, WTO members undertake policy bindings in sectors, subsectors, and modes of supply against which market access commitments are scheduled.) The WTO-minus provisions of earlier agreements are no longer found in the newest-generation PTAs entered into by the United States, Canada, and other countries that had initially agreed to the lower standard of treatment. The newer language is similar to that found early on in Mercosur and in the various PTAs to which EU members are party; it prohibits the introduction of new nondiscriminatory quantitative restrictions on any scheduled commitments and sectors, mirroring the similar requirement in GATS Article XVI". A. MATTOO; P. SAUVÉ, 2011, p. 247.
} 
numéricas ou requerimento de teste de necessidade econômica; (v) restrição ou requisição de tipos específicos de pessoas jurídicas ou joint ventures por meio das quais um serviço

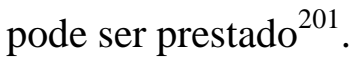

Observa-se que a cláusula que trata de acesso a mercados nos acordos regionais mais recentes celebrados pelos Estados Unidos possui uma pequena diferença em relação às limitações de acesso a mercados regulamentadas no Art. XVI:2 do GATS, uma vez que não replica o item (f), que proibir e limitar a participação de capital estrangeiro em termos de porcentagem máxima de detenção de participação societária ou de valor total do investimento estrangeiro. Contudo, essa omissão mostra-se indiferente em termos de liberalização, pois as regras relativas a tratamento nacional já seriam suficientes para impedir a discriminação em razão da participação societária estrangeira ${ }^{202}$.

Outra caraterística das regras sobre serviços dos acordos adotados pelos Estados Unidos consiste na proibição de adoção de requisitos de presença local. Por isso, uma Parte Contratante não pode requerer que os prestadores de serviços da outra Parte estabeleçam ou mantenham escritórios comerciais, tenham pessoa jurídica ou tenham presença comercial no país para se beneficiarem do $\operatorname{acordo}^{203}$.

\subsection{Obrigações e limitações de tratamento nacional}

Da mesma forma que ocorre com acesso a mercados, as obrigações de tratamento nacional também têm incidência abrangente, conforme o modelo do NAFTA, e, portanto, aplicam-se a todos os serviços e prestadores de serviços das Partes contratantes, exceto

201 A título de exemplo, cite-se que, no Acordo Estados Unidos-Cingapura, as limitações de acesso a mercados estão reguladas no Artigo 8.5, a saber: "A Party shall not adopt or maintain, either on the basis of a regional subdivision or on the basis of its entire territory, measures that:

(a) limit

(i) the number of service suppliers whether in the form of numerical quotas, monopolies, exclusive service suppliers or the requirement of an economic needs test;

(ii) the total value of service transactions or assets in the form of numerical quotas or the requirement of an economic needs test;

(iii) the total number of service operations or the total quantity of services output expressed in terms of designated numerical units in the form of quotas or the requirement of an economic needs test;

(iv) the total number of natural persons that may be employed in a particular service sector or that a service supplier may employ and who are necessary for, and directly related to, the supply of a specific service in the form of numerical quotas or the requirement of an economic needs test; and

(b) restrict or require specific types of legal entity or joint venture through which a service supplier may supply a service". United States-Singapore Free Trade Agreement. Disponível em: <http://www.ustr.gov/trade-agreements/free-trade-agreements/singapore-fta>. Acesso em: 20 mai. 2014.

${ }^{202}$ Vide F. ORTINO, 2009, p. 203-204.

${ }^{203}$ Vide L. A. GLICK. Understanding the North America Free Trade Agreement: Legal and Business Consequences of NAFTA. $3^{\text {a }}$. ed. Alphen aan den Rijn: Wolters Kluwer Law \& Business, 2010, p. 41. 
aqueles que estão expressamente excluídos da incidência do acordo. Note-se que essa questão é tratada de forma muito distinta pelo GATS, segundo o qual as obrigações de tratamento nacional incidem apenas sobre os serviços e setores de serviços objeto de compromissos específicos.

Os acordos analisados também utilizam parâmetros um pouco diferentes do GATS no que se refere ao conteúdo das obrigações de tratamento nacional. Nesses acordos, é utilizada a expressão "circunstâncias similares" (like circumstances) em vez da expressão "serviços similares e prestadores de serviços similares" (like services e like service suppliers) utilizado pelo GATS ${ }^{204}$. Como consequência, nos acordos baseados no modelo NAFTA, a extensão do tratamento nacional às Partes Contratantes está atrelada à existência de circunstâncias similares, e não à existência de serviços ou prestadores de serviços similares, como ocorre no GATS. Essa diferença é relevante. Como o beneficiário da obrigação (prestadores de serviços no modelo NAFTA e serviços e prestadores de serviços no modelo GATS) e o elemento de comparação (circunstâncias similares no modelo NAFTA e similares no modelo GATS) são diferentes, é bastante provável que a abrangência das obrigações de um e de outro acordo também seja interpretada de forma $\operatorname{distinta}^{205}$.

\subsection{Reservas e exceções}

A maioria dos acordos regionais adotados pelos Estados Unidos contém dois anexos com medidas que representam exceções às obrigações estabelecidas nos capítulos sobre serviços, a saber: (i) anexo contendo medidas que estão sujeitas ao "mecanismo de

\footnotetext{
${ }^{204}$ Vejamos, por exemplo, como essa questão foi tratada no texto do KORUS:

"1. Each Party shall accord to service suppliers of another Party treatment no less favorable than that it accords, in like circumstances, to its own service suppliers.

2. The treatment to be accorded by a Party under paragraph 1 means, with respect to a regional level of government, treatment no less favorable than the most favorable treatment accorded, in like circumstances, by that regional level of government to service suppliers of the Party of which it forms a part". Free Trade Agreement Between the United States of America and the Republic of Korea. Disponível em: <http://www.ustr.gov/trade-agreements/free-trade-agreements/korus-fta>. Acesso em: 20 mai. 2014.

${ }^{205}$ Sobre a interpretação das obrigações de tratamento nacional em serviços dos acordos inspirados no NAFTA e no GATS, Federico Ortino chama a atenção para a seguinte questão: "The interpretations rendered by NAFTA and WTO dispute settlement panels/tribunals with regard to the national treatment obligation in the context of trade in services (as well as in other contexts such as trade in goods and investment) shows the relevance of these textual differences. For example, the phrase 'in like circumstances' has been employed by NAFTA tribunals not just to determine the competitive relationship between foreign and domestic enterprises (as the phrase 'like' has been interpreted by WTO panels) but also as a de facto public policy justification mechanism". F. ORTINO, 2009, p. 201.
} 
catraca" (ratchet mechanism) e (ii) anexo contendo medidas ou setores de serviços permanentemente excepcionados da aplicação das disciplinas do acordo.

$\mathrm{O}$ "mecanismo de catraca" possui esse nome por ser um mecanismo que leva à liberalização comercial em sentido único, garantindo que, uma vez retiradas determinadas restrições, estas não possam ser reintroduzidas ${ }^{206}$. Ele foi utilizado pela primeira vez no NAFTA e, desde então, passou a ser inserido nos demais acordos que adotam esse modelo. Sua principal característica consiste no fato de que todas as medidas vigentes após a conclusão do acordo e que propiciam maior acesso a mercados serão automaticamente consideradas vinculantes. Logo, a Parte não poderá regredir com relação àquela medida ou adotar medidas mais restritivas, salvo mediante compensação ou renegociação com a outra Parte.

Assim, o "mecanismo de catraca" não apenas oferece garantia de manutenção do regime consolidado, como também assegura que nele será incluída qualquer nova medida tomada unilateralmente pelas partes em vista de uma maior liberalização. Consequentemente, acordos regionais que possuem "mecanismo de catraca" tendem a ser mais dinâmicos do que os acordos regionais baseados no modelo GATS, pois, nos primeiros, a liberalização comercial pode ocorrer automaticamente, ao passo que, nos últimos, a liberalização está condicionada à realização de negociações entre as Partes.

\subsection{Transparência}

Em vista da natureza do modelo de liberalização comercial adotado pelos Estados Unidos no plano regional, há necessidade de que as Partes Contratantes forneçam informações detalhadas, de forma transparente, sobre as barreiras ao comércio de serviços que se encontram em vigor, as quais serão denominadas de "medidas não conformes".

As medidas não conformes são descritas detalhadamente em anexos aos acordos regionais. As Partes devem apresentar informações sobre cada medida não conforme mantida, incluindo o título e a norma jurídica a que se refere, o setor que ela afeta, uma indicação da principal disciplina que ela viola, bem como uma breve descrição de seu

\footnotetext{
${ }^{206}$ Sobre os benefícios do "mecanismo de catraca" para o processo de liberalização comercial, João Henrique Ribeiro Roriz e Lucas da Silva Tasquetto afirmam o seguinte: "Ou seja, nos acordos em que se faz presente, não só há uma garantia da manutenção do regime consolidado, como também passa a ser incluído nele qualquer nova medida tomada unilateralmente pelas partes no sentido de uma maior liberalização (Miroudot, 2011, p. 312-314). Isto cria um movimento de sentido único, liberalizante, garantindo que, uma vez retiradas as restrições, estas não possam ser reintroduzidas". J. H. R. RORIZ; L. da S. TASQUETO. 2013, p. 176.
} 
conteúdo, de modo que o prestador de serviço estrangeiro possa tomar conhecimento da existência da medida e de seu conteúdo ${ }^{207}$.

Os acordos preveem, ademais, que, para medidas futuramente adotadas pelas Partes Contratantes que possam afetar o comércio de serviços, deverá ser realizada a notificação e ser dada oportunidade para que a outra Parte do acordo apresente seus comentários ${ }^{208}$. Antes não vinculante, essa regra começa a se tornar juridicamente obrigatória a partir dos Acordos Estados Unidos-Chile e Estados Unidos-Cingapura ${ }^{209}$. Em alguns acordos, como é o caso dos Acordos Estados Unidos-Chile e Estados Unidos-Austrália ${ }^{210}$, a Parte deverá apresentar comentários escritos às propostas recebidas ${ }^{211}$.

Há uma grande diferença no nível de transparência imposto pelo GATS e pelos acordos regionais adotados pelos Estados Unidos. No acordo da OMC, as obrigações sobre transparência requerem apenas que os Membros indiquem o tipo de restrição que afeta determinado setor, publiquem as medidas que afetem o comércio de serviços e criem pontos de contato para responder aos pedidos de informações apresentados por outras Partes. Assim, as principais diferenças em relação ao modelo NAFTA consistem na

${ }^{207}$ Vide S. STEPHENSON e M. ROBERT, 2011, p. 6.

${ }^{208}$ No Acordo Estados Unidos-Chile, por exemplo, a questão da notificação de novas medidas e a oportunidade para comentários da outra Parte é tratada da seguinte forma: "Article 11.7: Transparency in Development and Application of Regulations

Further to Chapter Twenty (Transparency):

(...) (b) at the time it adopts final regulations relating to the subject matter of this Chapter, each Party shall, to the extent possible, including upon request, address in writing substantive comments received from interested persons with respect to the proposed regulations; and

(c) to the extent possible, each Party shall allow a reasonable period of time between publication of final regulations and their effective date". United States-Chile Free Trade Agreement. Disponível em: 〈http://www.ustr.gov/trade-agreements/free-trade-agreements/chile-fta/final-text >. Acesso em: 20 mai. 2014. 209 "One innovation beyond GATS is the provision in some PTAs that members afford the opportunity (to the extent possible, i.e., on a "best-endeavors" basis) for prior comment on proposed changes to services regulations. Increasingly, such provisions are becoming legally binding. This is notably the case in NorthSouth PTAs, following a trend initiated by the FTAs between the United States and Chile and between the United States and Singapore. The latter development offers an interesting example of what could be described as "tactical" or "demonstration-effect" regionalism, with advances at the PTA level creating precedents that their proponents hope will facilitate their subsequent replication at the multilateral level". A. MATTOO e P. SAUVÉ, 2011, p. 243-247.

210 “ARTICLE 10.8 : TRANSPARENCY IN DEVELOPMENT AND APPLICATION OF REGULATIONS Further to Chapter Twenty (Transparency):

1. Each Party shall maintain or establish appropriate mechanisms for responding to inquiries from interested persons regarding its regulations relating to the subject matter of this Chapter.

2. If a Party does not provide advance notice and opportunity for comment pursuant to Article 20.2 (Publication), it shall, to the extent possible, address in writing the reasons therefore.

3. At the time it adopts final regulations relating to the subject matter of this Chapter, each Party shall, to the extent possible, including on request, address in writing substantive comments received from interested persons with respect to the proposed regulations.

4. To the extent possible, each Party shall provide notice of the requirements of final regulations prior to their effective date". Australia-United States Free Trade Agreement. Disponível em: <http://www.ustr.gov/trade-agreements/free-trade-agreements/australian-fta/final-text $>$. Acesso em: 20 mai. 2014.

${ }^{211}$ Vide Vide F. ORTINO, 2009, p. 206. 
inexistência de regulamentação sobre oportunidade para os Membros apresentarem comentários às propostas de alteração nas regulações internas que afetam o comércio de serviços abrangido pelo acordo regional ${ }^{212}$.

\subsection{Regulação doméstica}

No que diz respeito às disciplinas sobre regulação doméstica, da mesma forma que ocorre com as obrigações de acesso a mercados, o NAFTA não possui um artigo específico sobre essa questão. As obrigações relativas ao tema estão dispostas em um artigo sobre licenciamento e certificação profissional inserido no capítulo sobre serviços ${ }^{213}$.

Por sua vez, os acordos regionais que foram celebrados pelos Estados Unidos posteriormente ao NAFTA já possuem um artigo específico com regras sobre o tema, de

212 "É criado um precedente no âmbito do comércio regional na esperança de que possa facilitar sua subsequente replicação no nível multilateral”. J. H. R. RORIZ; L. da S. TASQUETO. 2013, p. 179-180.

213 "Article 1210: Licensing and Certification

1. With a view to ensuring that any measure adopted or maintained by a Party relating to the licensing or certification of nationals of another Party does not constitute an unnecessary barrier to trade, each Party shall endeavor to ensure that any such measure:

(a) is based on objective and transparent criteria, such as competence and the ability to provide a service;

(b) is not more burdensome than necessary to ensure the quality of a service; and

(c) does not constitute a disguised restriction on the cross-border provision of a service.

2. Where a Party recognizes, unilaterally or by agreement, education, experience, licenses or certifications obtained in the territory of another Party or of a non-Party:

(a) nothing in Article 1203 shall be construed to require the Party to accord such recognition to education, experience, licenses or certifications obtained in the territory of another Party; and

(b) the Party shall afford another Party an adequate opportunity to demonstrate that education, experience, licenses or certifications obtained in that other Party's territory should also be recognized or to conclude an agreement or arrangement of comparable effect.

3. Each Party shall, within two years of the date of entry into force of this Agreement, eliminate any citizenship or permanent residency requirement set out in its Schedule to Annex I that it maintains for the licensing or certification of professional service providers of another Party. Where a Party does not comply with this obligation with respect to a particular sector, any other Party may, in the same sector and for such period as the noncomplying Party maintains its requirement, solely have recourse to maintaining an equivalent requirement set out in its Schedule to Annex I or reinstating:

(a) any such requirement at the federal level that it eliminated pursuant to this Article; or

(b) on notification to the non-complying Party, any such requirement at the state or provincial level existing on the date of entry into force of this Agreement.

4. The Parties shall consult periodically with a view to determining the feasibility of removing any remaining citizenship or permanent residency requirement for the licensing or certification of each other's servisse providers.

5. Annex 1210.5 applies to measures adopted or maintained by a Party relating to the licensing or certification of professional service providers". North American Free Trade Agreement. Disponível em: <http://www.ustr.gov/trade-agreements/free-trade-agreements/north-american-free-trade-agreement-nafta>. Acesso em: 20 mai. 2014. 
modo a evitar que os ganhos obtidos com a liberalização comercial sejam prejudicados por obstáculos normativos ${ }^{214}$.

Trata-se de um artigo bastante simples, que praticamente replica o texto dos Artigos VI:3 e VI:4 do GATS sobre autorização para a prestação de serviço e requisitos e procedimentos em matéria de qualificação, normas técnicas e requisitos em matéria de licenças ${ }^{215}$. A única inovação consiste na previsão de atualização da disciplina sobre regulação doméstica no caso de evolução do tema nas negociações em curso na OMC ou em outros foros dos quais ambas as partes participem, de modo a incorporar o resultado dessas negociações a esses acordos regionais.

\subsection{Outras obrigações relevantes}

A regulamentação de serviços dos acordos celebrados pelos Estados Unidos é omissa em relação a restrições quantitativas não discriminatórias que possam impedir o acesso ao mercado de serviços e as regras de origem. Os acordos em análise limitam-se a estabelecer a obrigação de que as Partes Contratantes relacionem as medidas quantitativas não discriminatórias mantidas no anexo de medidas não conformes e empenhem seus melhores esforços para a remoção de tais medidas no futuro $^{216}$. Não há proibição de introdução de

214 "This new strengthened NAFTA template thus incorporated some of the key features of the WTO GATS that had been missing, including the disciplining of quantitative restrictions and restrictive forms of association on service activities, as well attempting to ensure that domestic regulations in the forms of qualification and licensing requirements and procedures are based on objective and transparent criteria and are not "more burdensome than necessary to ensure the quality of the service." The strengthened transparency disciplines also were designed to ensure that opaque regulations do not take away from the market opening gains of the services agreements". S. STEPHENSON; M. ROBERT, 2011, p. 13.

215 A título de exemplo, veja-se o texto do artigo 11.7. do Acordo Estados Unidos-Peru, que trata de regulação doméstica:

" 1 . Where a Party requires authorization for the supply of a service, the Party's competent authorities shall, within a reasonable time after the submission of an application considered complete under its laws and regulations, inform the applicant of the decision concerning the application. At the request of the applicant, the Party's competent authorities shall provide, without undue delay, information concerning the status of the application. This obligation shall not apply to authorization requirements that are within the scope of Article 11.6.2.

2. With a view to ensuring that measures relating to qualification requirements and procedures, technical standards, and licensing requirements do not constitute unnecessary barriers to trade in services, each Party shall endeavor to ensure, as appropriate for individual sectors, that such measures are:

(a) based on objective and transparent criteria, such as competence and the ability to supply the service;

(b) not more burdensome than necessary to ensure the quality of the service; and

(c) in the case of licensing procedures, not in themselves a restriction on the supply of the service". Disponível em: <http://www.ustr.gov/trade-agreements/free-trade-agreements/peru-tpa/final-text>. Acesso em: 20 mai. 2014.

${ }^{216}$ A título de exemplo, vide como essa questão é tratada no Acordo Estados Unidos-Peru: "Article 11.6: Non-Conforming Measures

1. Articles $11.2,11.3,11.4$, and 11.5 do not apply to:

(a) any existing non-conforming measure that is maintained by a Party at: 
novas restrições quantitativas, como previsto no GATS e em outros acordos para os setores em que há compromissos específicos ${ }^{217}$.

Os acordos celebrados pelos Estados Unidos adotam uma regra de origem (denial of benefits) liberal, pela qual os benefícios do acordo apenas são denegados a pessoas jurídicas que não conduzam atividades comerciais substanciais em uma Parte Contratante. Assim, na prática, terceiros países que investem em empresas que não desenvolvem atividades comerciais ou cujas atividades são irrelevantes não se beneficiam do acordo.

De modo geral, os benefícios decorrentes dos acordos celebrados pelos Estados Unidos poderão ser denegados quando ocorrerem as seguintes hipóteses: (i) se o serviço for prestado por uma empresa pertencente ou controlada por nacionais de uma não Parte, em certas circunstâncias, tais como inexistência de relações diplomáticas ou proibição de operações com determinada empresa; (ii) se o serviço for prestado por empresa que não exerça operações comerciais substanciais no território de nenhuma Parte, exceto na Parte que denegar o benefício, e for pertencente ou controlada por pessoas de uma não Parte ou da Parte que denegar o benefício ${ }^{218}$. Caso seja verificada a última hipótese, é necessário

(i) the central level of government, as set out by that Party in its Schedule to Annex I,

(ii) a regional level of government, as set out by that Party in its Schedule to Annex I, or

(iii) a local level of government;

(b) the continuation or prompt renewal of any non-conforming measure referred to in subparagraph (a); or

(c) an amendment to any non-conforming measure referred to in subparagraph (a) to the extent that the amendment does not decrease the conformity of the measure, as it existed immediately before the amendment, with Articles 11.2, 11.3, 11.4, or 11.5.

2. Articles 11.2, 11.3, 11.4, and 11.5 do not apply to any measure that a Party adopts or maintains with respect to sectors, subsectors, or activities as set out in its Schedule to Annex II". United States-Peru Trade Promotion Agreement. Disponível em: <http://www.ustr.gov/trade-agreements/free-trade-agreements/perutpa/final-text>. Acesso em: 20 mai. 2014.

${ }^{217}$ A respeito da diferença do tratamento desse tema no GATS, nos acordos que seguem o modelo NAFTA e em outros acordos regionais, Pierre Sauvé ensina o seguinte: "While RTAs covering services typically address non-discriminatory quantitative restrictions that impede access to services markets (addressed under Article XVI of the GATS), many agreements, particularly those concluded in the Western Hemisphere and modelled on the NAFTA, are weaker than the GATS, committing parties solely to making such measures fully transparent in annexes listing nonconforming measures and to a best endeavours approach as regards their progressive dismantling in future. In contrast, under GATS, WTO members undertake policy bindings in sectors, sub-sectors and modes of supply against which market access commitments are scheduled. Many other RTAs, such as MERCOSUR and the various RTAs to which EU Members are party, introduce a prohibition on the introduction of new non-discriminatory QRs on any scheduled commitment and sector, mirroring a similar requirement under the GATS." P. SAUVÉ. The relationship between regional trade agreements and the multilateral trading system. Outubro 2002, p. 9. Disponível em:

$<$ http://search.oecd.org/officialdocuments/displaydocumentpdf/?doclanguage=en\&cote=td/tc/wp(2002)27/fin al>. Acesso em: 1 mar. 2014.

${ }^{218}$ No Acordo Estados Unidos-Austrália, por exemplo, essa questão é tratada no Artigo 10.11, a saber: “ARTICLE 10.11 : DENIAL OF BENEFITS

1. A Party may deny the benefits of this Chapter to a service supplier of the other Party if the service supplier is an enterprise owned or controlled by persons of a non-Party, and the denying Party:

(a) does not maintain diplomatic relations with the non-Party; or

(b) adopts or maintains measures with respect to the non-Party or a person of the non- Party that prohibit transactions with the enterprise or that would be violated or circumvented if the benefits of this Chapter were 
proceder com a realização de consultas e a notificação da Parte afetada.

\section{PANORAMA DO TRATAMENTO DE SERVIÇOS NOS PRINCIPAIS ACORDOS REGIONAIS DE COMÉRCIO ENVOLVENDO A UNIÃO EUROPEIA}

\subsection{Modelo de lista adotado}

Diferentemente do que ocorre com os Estados Unidos, a União Europeia não tem tratado o tema serviços de forma padrão nos acordos regionais celebrados pelo bloco que se encontravam em vigor em 2013. Cada um dos treze acordos analisados possui características próprias com relação ao formato, escopo e obrigações.

Houve uma evolução progressiva nos acordos regionais celebrados pela União Europeia. Os acordos celebrados com Chile, Coreia e CARIFORUM são os mais complexos em relação ao tratamento do tema serviços. Os três acordos criam obrigações para ambas as Partes com relação à regulação doméstica, acesso a mercados e tratamento nacional, além de possuirem listas de compromissos. Dos três, o acordo de livre comércio com a Coreia é considerado o mais ambicioso já celebrado pela União Europeia, em razão dos temas abrangidos e do tratamento dado a eles ${ }^{219}$. Esse acordo está sendo utilizado, inclusive, como modelo para os acordos que estão sendo negociados pelo bloco com Canadá, Mercosul, Cingapura e Malásia, entre outros parceiros ${ }^{220}$.

Observa-se que muitos dos acordos regionais celebrados pela União Europeia são acordos-quadro que preveem apenas que as Partes se comprometerão a tomar todas as medidas necessárias para ampliar seu escopo de aplicação, o que inclui a celebração de compromissos em serviços. Entre os acordos que possuem essa característica citem-se os acordos celebrados com Camarões, Costa do Marfim, Israel, Marrocos e Tunísia. Em

accorded to the enterprise.

2. A Party may deny the benefits of this Chapter to a service supplier of the other Party if the service supplier is an enterprise owned or controlled by persons of a non-Party or of the denying Party that has no substantial business activities in the territory of the other Party". Australia-United States Free Trade Agreement. Disponível em: 〈http://www.ustr.gov/trade-agreements/free-trade-agreements/australian-fta/final-text>. Acesso em: 20 mai. 2014.

219 Vide HORNG, Der-Chin. Reshaping the EU's FTA Policy in a Globalizing Economy: The Case of the EU-Korea FTA. Journal of World Trade, N. 46, Ed. 2. Kluwer Law International, 2012, pp. 301.

${ }^{220}$ A relação atualizada dos acordos regionais que estão sendo negociados pela União Europeia encontra-se em: <http://ec.europa.eu/enterprise/policies/international/facilitating-trade/free-trade/index_en.htm\#h2-2>. Acesso em: 20 abr. 2014. 
outros acordos, como aqueles celebrados com África do Sul, México, Jordânia e Egito, as Partes reafirmam o assumido no GATS e se comprometem a alargar seu âmbito de aplicação na área serviços, respeitando as obrigações assumidas multilateralmente. Em nenhum dos dois tipos de acordo mencionados há obrigações concretas relativas aos setores e modos de prestação de serviços.

Apenas nos acordos celebrados com Chile, CARIFORUM e Coreia há obrigações efetivas em serviços. Tais acordos contêm previsão expressa de que os compromissos serão assumidos na forma de lista positiva. No entanto, como será visto a seguir, apenas o acordo com o Chile replica de forma literal as cláusulas do GATS e, por isso, é o acordo que mais se aproxima do modelo adotado pela OMC. Os demais seguem apenas parcialmente o modelo do GATS, uma vez que as Partes adotaram lista de compromissos positiva, mas também uma lista negativa de restrições de acesso a mercados e/ou tratamento nacional, por meio da qual ocorre o trancamento do status quo regulatório para os serviços e setores de serviços consolidados pelas Partes ${ }^{221}$. Isso significa que, na realidade, o ALC UE-Coreia e o APE UE-CARIFORUM adotam um modelo híbrido de acordo no que se refere à liberalização de serviços, com elementos do modelo NAFTA e do modelo GATS.

Assim, tendo em vista a previsão contida na maioria dos acordos celebrados pela União Europeia de respeito aos compromissos assumidos no GATS e o fato de que os acordos celebrados com Chile, CARIFORUM e Coreia já foram celebrados com listas positivas em serviços, tudo indica que a União Europeia continuará adotando esse modelo em seus compromissos futuros sobre serviços no âmbito regional. Apesar disso, é bastante provável que o modelo adotado não seja idêntico ao GATS, mas mais próximo do Acordo celebrado com a Coreia.

\footnotetext{
${ }^{221}$ A respeito dessa questão, um estudo do South Centre sobre o APE UE-CARIFORUM aponta o seguinte: "The CARIFORUM EPA draws partially from the GATS model. It however also departs from the GATS model in several important areas. For example GATS is a positive list allowing WTO members to choose sub-sectors, obligation and modes where they will take commitments. In the CARIFORUM EPA, while services commitments are scheduled on a positive list basis, commercial presence reservations are scheduled on a negative list basis for the non-services sectors. (...). Schedule sets out the reservations taken by the signatory CARIFORUM States with respect to measures that do not conform with obligations set out in Title II of the EPA (market access and national treatment obligations on investment and services). Only sectors in which there are reservations or limitations are listed but the Schedule covers all sub-sectors of the sectors listed above. Sub-sectors of A, B, C and D that are not listed are open in all signatory CARIFORUM States without limitations in market access or national treatment. CARIFORUM States that are not listed in subsectors included in this list are open without limitations on market access or national treatment in these subsectors". South Centre. Negotiating services Free Trade Agreements (FTAs) with the European Union: Some issues for developing countries to consider. Analytical Note SC/AN/TDP/EPA/21, junho de 2009, p. 4-5. Disponível em: <http://www.southcentre.int/wp-content/uploads/2013/08/AN_EPA21_Negotiating-ServicesFTAs-with-EU_EN.pdf>. Acesso em: 1 mai. 2014.
} 
A adoção do modelo de lista positiva não significa necessariamente que o player utilizará os mesmos métodos para a assunção de compromissos adotados no GATS. Por exemplo, no APE UE-CARIFORUM, os países do CARIFORUM utilizam uma lista de compromissos com os quatro modos de prestação de serviços, como no GATS, e o bloco europeu utiliza quatro listas de compromissos, a saber: (i) lista relativa à presença comercial, incluindo investimentos em atividades de fabricação; (ii) lista relativa a serviços transfronteiriços; (iii) lista relativa ao modo 4 (funcionários-chave e pós-graduados); (iv) lista relativa a serviços contratuais e prestadores de serviços independentes ${ }^{222}$. $\mathrm{O}$ mesmo modelo de lista de compromisso é utilizado no acordo celebrado com a Coreia, no qual a União Europeia adota três listas de compromissos, a saber: (i) lista relativa a serviços transfronteiriços; (ii) lista relativa presença comercial; (iii) lista relativa ao modo 4 (funcionários chave e pós-graduados). A Coreia, tal qual os países do CARIFORUM, adota o mesmo modelo de lista de compromissos do GATS.

\subsection{Abrangência}

Observa-se que o termo "estabelecimento" está presente na maioria dos títulos dos capítulos sobre serviços nos acordos regionais celebrados pela União Europeia. Por exemplo, no acordo entre União Europeia e Coreia, o Capítulo 7 é denominado "Prestação Transfronteiriça de Serviços, Estabelecimento e Comércio Eletrônico". Já o capítulo que se refere a serviços no acordo entre União Europeia e Chile (Título III) é denominado "Comércio em Serviços e Estabelecimento". Isso reflete a importância dada pelos países europeus aos compromissos no modo 3 , relativo à presença comercial.

No que tange à abrangência dos acordos regionais celebrados pela União Europeia, a maioria deles engloba todos os modos de prestação de serviços previstos no GATS. Como ocorre em diversos acordos de livre comércio, os compromissos nos modos 1 e 2 são consolidados como prestação transfronteiriça de serviços, os compromissos no modo 3 ora são consolidados como presença comercial $^{223}$, ora como estabelecimento ${ }^{224}$, e os

\footnotetext{
${ }^{222}$ Vide P. LATRILLE; J. LEE. Services rules in regional trade agreements. How diverse and how creative as compared to the GATS multilateral rules? WTO Working Paper. Genebra, Outubro de 2012, p. 8. Disponível em: 〈http://www.wto.org/english/res_e/reser_e/ersd201219_e.htm〉. Acesso em: 16 jan. 2013.

${ }_{223}^{223}$ APE UE-CARIFORUM.

${ }^{224}$ ALC UE-Coreia e Acordo UE-Chile.
} 
compromissos no modo 4 são consolidados como presença temporária de pessoas naturais para negócios.

É importante notar que, mesmo nos acordos que abrangem todos os modos, as normas são muito mais detalhadas e os compromissos mais profundos em relação aos modos 1 e 3. Por exemplo, no ALC UE-Coreia, há uma seção intitulada "Presença temporária de pessoas naturais para negócios", que regula o modo 4 de prestação de serviço. No entanto, não há compromissos efetivos nesse modo, apenas a menção de que o Comitê de Comércio adotará lista de compromissos sobre o acesso contratual de prestadores de serviços e profissionais liberais de uma Parte ao território da outra Parte, o que levará em conta os resultados dessas negociações no âmbito do GATS. No Acordo com CARIFORUM, por sua vez, os compromissos no modo 4 abrangem apenas profissionais-chave para determinada empresa (gerentes e especialistas) e trainees com diploma de graduação.

A opção da União Europeia de celebrar compromissos em serviços prioritariamente nos modos 1, 2 e 3 reflete a política do bloco com relação aos compromissos no modo 4. A União Europeia vê o movimento de pessoas físicas e a presença comercial ou estabelecimento como modos correlatos. Permitir a presença de profissionais de alto escalão é importante apenas para garantir a eficiência dos investimentos no exterior ${ }^{225}$.

Os acordos celebrados pela União Europeia divergem em relação aos serviços que não são abrangidos pelos acordos. De modo geral, as obrigações assumidas no capítulo sobre serviços não incidem sobre: (i) serviços audiovisuais; (ii) cabotagem marítima nacional; (iii) serviços de transporte aéreo nacional ou internacional diretamente relacionados ao exercício de direitos de tráfico aéreo, exceto manutenção e reparação de aeronaves, venda e a comercialização de serviços de transporte aéreo, serviços de reserva computadorizada e outros serviços complementares; (iv) licitações públicas; (v) subsídios e subvenções governamentais; (vi) medidas que afetem pessoas físicas que pretendam entrar no mercado de trabalho de uma Parte; (vii) medidas referentes à cidadania, residência ou emprego permanente; (viii) serviços prestados no exercício da autoridade governamental.

Por fim, note-se que os acordos celebrados pela União Europeia tendem a tratar de investimentos relacionados a serviços no próprio capítulo relativo a serviços,

\footnotetext{
225 "What this means is that mode 4 is effectively linked to commercial presence. The Europeans see foreign investment and the movement of key corporate and professional personnel as inseparable. This reflects the requirements of transnational firms for their managers to work internationally". SOUTH CENTRE, 2009, p. $7-8$.
} 
diferentemente do que ocorre nos acordos celebrados pelos Estados Unidos, que contêm um capítulo específico com regras sobre o tema.

\subsection{Obrigações e limitações de acesso a mercados}

Os acordos que contém listas de compromissos - acordos com CARIFORUM, Chile e Coreia - são os únicos que possuem obrigações específicas de acesso a mercados. De modo geral, a União Europeia tende a replicar as obrigações e limitações de acesso a mercados previstas no GATS no que forem aplicáveis ao modo de prestação aos quais os compromissos se referem.

No APE UE-CARIFORUM, há regras específicas sobre acesso a mercados nos capítulos 2 e 3, que tratam dos modos 3 (presença comercial) e 1 (prestação transfronteiriça), respectivamente. Em relação à presença comercial, foram adotados os mesmos parâmetros quantitativos adotados pelo GATS, com exceção do impedimento à limitação em relação ao número de pessoas físicas que podem ser empregadas por determinado prestador ou setor, previsto no artigos XVI: $(\mathrm{d})^{226}$. Já com relação à prestação transfronteiriça, as Partes replicaram as mesmas limitações estabelecidas nos artigos XVI: (a), (b) e (c) do GATS ${ }^{227}$.

No Acordo UE-Chile, foram reproduzidos os mesmos parâmetros do GATS para acesso a mercados.

Já no ALC UE-Coreia, com relação à prestação transfronteiriça de serviços, foram replicadas apenas as alíneas (a), (b) e (c) do Art. XVI do GATS. Com relação a estabelecimento, os parâmetros se assemelham às alíneas (a), (b), (c), (e) e (f) do artigo XVI do GATS, com algumas adaptações textuais ${ }^{228}$.

\subsection{Obrigações e limitações de tratamento nacional}

Há obrigações específicas sobre tratamento nacional nos acordos celebrados pela União Europeia com CARIFORUM, Chile, Coreia, Argélia e Jordânia. Isso significa que,

\footnotetext{
${ }^{226}$ De fato, tal limitação não faria sentido em relação ao modo 3 de prestação de serviço.

227 A limitação em relação ao número de pessoas físicas que podem ser empregadas por determinado prestador ou setor, ao tipo de sociedade ou à participação de capital e investidores estrangeiros, regulamentadas nos artigos XVI: (d), (e) e (f) do GATS não se aplicam ao modo 2 de prestação de serviços.

${ }^{228}$ Por exemplo, foi utilizado o termo "estabelecimento" em substituição à expressão "prestadores de serviços", de modo a adequar o texto genérico do GATS, aplicável aos quatro modos de prestação de serviços, ao modo de prestação de serviço a que as obrigações se referem.
} 
mesmo em acordos em que não há lista de compromissos, as Partes buscaram estabelecer obrigações que garantissem o tratamento igualitário entre os serviços e prestadores de serviços.

De modo geral, a União Europeia buscou adaptar o texto contido no GATS às obrigações de cada um dos acordos, sem, no entanto, alterar seu sentido.

No APE UE-CARIFORUM, há regras sobre tratamento nacional nos capítulos 2 e 3, que regulam os compromissos assumidos pelas Partes nos modos 3 e 1 de prestação de serviços, respectivamente. Em relação ao modo 3, que trata de presença comercial, em vez da expressão "serviços e prestadores de serviços similares" (like services and services suppliers), foi utilizada a expressão "presença comercial e investidores similares" (like commercial presences and investors). A expressão utilizada é mais específica ao modo de prestação a que as obrigações se referem e sua utilização não altera em nada o sentido do texto original do GATS. Além disso, foi adicionado um quarto parágrafo, que replica uma nota de rodapé do GATS determinando que os compromissos específicos assumidos no âmbito do acordo não devem ser interpretados de forma a exigir das Partes uma compensação por desvantagens competitivas inerentes que possam resultar do caráter estrangeiro das presenças comerciais e investidores relevantes ${ }^{229}$. Para os compromissos celebrados no modo 1, foram mantidos os mesmos parâmetros do GATS (like services and like services suplliers). Assim como nos compromissos em modo 3, foi inserido um quarto parágrafo, que estabelece que os compromissos específicos assumidos no âmbito do acordo não devem ser interpretados de forma a exigir das Partes uma compensação por desvantagens competitivas inerentes que possam resultar do caráter estrangeiro dos serviços ou prestadores de serviços relevantes ${ }^{230}$.

O ALC UE-Coreia seguiu o mesmo modelo do APE UE-CARIFORUM. Nesse acordo, o parâmetro do GATS também foi utilizado com relação ao modo 1 de prestação

\footnotetext{
229 “Art. 68 (...) 4. Specific commitments assumed under this Article shall not be construed to require the EC Party or the Signatory CARIFORUM States to compensate for inherent competitive disadvantages which result from the foreign character of the relevant commercial presences and investors". Economic Partnership Agreement between the CARIFORUM States, of the one part, and the European Community and its Member States, of the other part. Disponível em: $<$ http://ec.europa.eu/world/agreements/prepareCreateTreatiesWorkspace/treatiesGeneralData.do?redirect=tru e\&treatyId=7407>. Acesso em: 20 mai. 2014.

230 “Art. 77 (...) 4. Specific commitments assumed under this Article shall not be construed to require the EC Party or the Signatory CARIFORUM States to compensate for inherent competitive disadvantages which result from the foreign character of the relevant services or services suppliers". Economic Partnership Agreement between the CARIFORUM States, of the one part, and the European Community and its Member States, of the other part. Disponível em:

$<$ http://ec.europa.eu/world/agreements/prepareCreateTreatiesWorkspace/treatiesGeneralData.do?redirect=tru e\&treatyId=7407>. Acesso em: 20 mai. 2014.
} 
de serviços. Com relação ao modo 3 , em vez da expressão "serviços e prestadores de serviços similares" (like services and services suppliers), foi utilizada a expressão "estabelecimentos e investidores similares" (like establishments and investors). De fato, a expressão utilizada é mais específica para o modo de prestação a que as obrigações se referem e sua utilização não altera em nada o sentido do texto original do GATS. Foi inserido, igualmente, um quarto parágrafo, que estabelece que os compromissos específicos assumidos no âmbito do acordo não devem ser interpretados de forma a exigir das Partes uma compensação por desvantagens competitivas inerentes que possam resultar do caráter estrangeiro dos serviços/estabelecimentos ou prestadores de serviços/investidores relevantes ${ }^{231}$.

No acordo celebrado com o Chile, utilizou-se o mesmo parâmetro do GATS, que abrange a concessão de tratamento nacional a "serviços e prestadores de serviços similares" (like services and services suppliers) da outra Parte.

No acordo celebrado com a Argélia, há previsão de tratamento nacional apenas aos "prestadores de serviços similares” (like services suppliers) da outra Parte. Não há menção a "serviços similares" (like services).

O acordo que possui obrigações mais detalhadas de tratamento nacional é aquele celebrado com a Jordânia. A União Europeia comprometeu-se a conceder tratamento não menos favorável em três níveis distintos, a saber: (i) para o estabelecimento de empresas da Jordânia, será concedido tratamento não menos favorável do que o concedido a terceiros países; (ii) com respeito às operações das subsidiárias de empresas da Jordânia estabelecidas nos Estados-membros da União Europeia, será concedido tratamento não menos favorável do que aquele concedido às empresas comunitárias; (ii) para as operações das sucursais de empresas da Jordânia estabelecidas nos Estados-membros, será concedido tratamento não menos favorável do que aquele concedido a sucursais de empresas de terceiros países. A Jordânia, por sua vez, assumiu as seguintes obrigações de tratamento nacional: (i) para o estabelecimento de empresas da União Europeia, será concedido tratamento não menos favorável do que o concedido às empresas da Jordânia ou a terceiros países, o que for mais benéfico; (ii) com relação às operações das sucursais e subsidiárias de empresas dos Estados-membros da União Europeia estabelecidos na Jordânia, será concedido tratamento não menos favorável do que aquele concedido às empresas da

${ }^{231}$ Vide Art. 7.6. (4) e Art. 7.12. (4) do ALC UE-Coreia. Free trade Agreement between the European Union and its Member States, of the one part, and the Republic of Korea, of the other part. Disponível em: <http://eur-lex.europa.eu/legal-content/en/ALL/?uri=OJ:L:2011:127:TOC>. Acesso em: 20 mai. 2014. 
Jordânia ou a terceiros países, o que for mais benéfico ${ }^{232}$. Note-se que as obrigações de tratamento nacional deste Acordo referem-se apenas ao modo 3.

Observa-se, assim, que foram utilizados conceitos distintos em relação às obrigações de tratamento nacional da União Europeia e da Jordânia. Enquanto as obrigações da primeira estão vinculadas aos conceitos de "empresas de serviços similares" e "sucursais de empresas similares" (like services companies / like branches of companies), as obrigações da segunda não contêm a expressão "similar", que permite algum tipo de discricionariedade à Parte na concessão do tratamento nacional. Da mesma forma que ocorre com outros acordos, não há qualquer referência à expressão "prestadores de serviços similares" (like services suppliers).

O Acordo UE-Jordânia possui anexos em que foram listadas as reservas da Jordânia e da União Europeia com relação a tratamento nacional. Também há um artigo contendo obrigações específicas de tratamento nacional para o transporte marítimo ${ }^{233}$.

232 “Article 30

1. (a) The Community and its Member States shall grant for the establishment of Jordanian companies treatment no less favourable than that accorded to like services companies of any third country.

(b) Without prejudice to the reservations accorded to its Annex V, the Community and its Member shall grant to subsidiaries of Jordanian companies established in a Member State treatment no less favourable than that accorded to any like Community company, in respect of their operations.

(c) The Community and its Member States shall grant to branches of Jordanian companies, established in Member State, treatment no less favourable than accorded to like branches of companies of any third country, in respect of their operations.

2. (a) Without prejudice to the reservations listed in Annex VI, Jordan shall grant for the establishment of Community companies in its territory treatment no less favourable than that accorded to its own companies or to companies of any third country, whichever is the better.

(b) Jordan shall grant to subsidiaries and branches of Community companies, established in its territory, in respect of their operations, treatment no less favourable than that accorded to its own companies or branches, or to Jordanian subsidiaries or branches of companies of any third country, whichever is the better". EuroMediterranean Agreement establishing an Association between the European Communities and their Member States, of the one part, and the Hashemite Kingdom of Jordan, of the other part. Disponível em: <http://eur-lex.europa.eu/LexUriServ/LexUriServ.do?uri=OJ:L:2002:129:SOM:EN:HTML>. Acesso em: 20 mai. 2014.

233 "Article 39

(...) Each Party shall grant, inter alia, a treatment no less favourable than that accorded to its own ships, for the ships used for the transport of goods, passengers or both, and operated by nationals or companies of the other Party, with respect to access to ports, the use of infrastructure and auxiliary maritime services of those ports, as well as related fees and charges, customs facilities and the assignment of berths and facilities or loading and unloading". Euro-Mediterranean Agreement establishing an Association between the European Communities and their Member States, of the one part, and the Hashemite Kingdom of Jordan, of the other part. Disponível em: <http://eurlex.europa.eu/LexUriServ/LexUriServ.do?uri=OJ:L:2002:129:SOM:EN:HTML>. Acesso em: 20 mai. 2014. 


\subsection{Reservas e exceções}

Como poucos dos acordos celebrados pela União Europeia possuem compromissos efetivos em serviços e aqueles que possuem tais obrigações determinam que a liberalização se dará por meio de lista de compromissos positiva, há poucas reservas e exceções aos compromissos assumidos. A maioria dessas reservas refere-se a exceções de tratamento nacional ou de cláusula de nação mais favorecida.

O acordo entre União Europeia e Jordânia possibilita que as Partes façam reservas em relação às obrigações de tratamento nacional nos Anexos V e VI. Os acordos celebrados pelo bloco europeu com Coreia e Chile, por sua vez, permitem que as Partes estabeleçam exceções de cláusula de nação mais favorecida, nos Anexos 7-B e C e VII, respectivamente.

No APE UE-CARIFORUM, as Partes também podem estabelecer limitações de acesso a mercados e tratamento nacional à presença comercial e aos investidores da outra Parte em relação aos compromissos assumidos. Tais limitações devem ser apresentadas no Anexo IV.

\subsection{Transparência}

Regras específicas sobre transparência relacionadas ao comércio de serviços foram previstas apenas nos acordos regionais celebrados pela União Europeia com CARIFORUM e Coreia. Estas regras referem-se, basicamente, à prestação de informações de modo a possibilitar a implementação dos compromissos em serviços assumidos no âmbito do acordo.

No APE UE-CARIFORUM, foram estabelecidas regras de transparência em serviços no Capítulo 5, as quais determinam a necessidade de transparência na resposta aos pedidos de outras Partes para o fornecimento de informações sobre as medidas abrangidas pelo acordo. Também determinam que as Partes devem estabelecer um ou mais pontos de contato (enquiry points) para fornecer as informações solicitadas por investidores estrangeiros ou prestadores de serviços nacionais de outras Partes.

No ALC UE-Coreia, as regras relativas a transparência no comércio de serviços integram o mecanismo de transparência que abrange todo o Acordo, sendo esse mecanismo regulamentado no Capítulo 12. Entre outras obrigações, as Partes devem adotar as 
seguintes medidas: (i) publicar antecipadamente que pretendem adotar ou aditar, possibilitando que os interessados apresentem comentários de medidas; (ii) estabelecer pontos de contato e de questionamentos (enquiry and contact points); (iii) possibilitar a revisão de medidas por meio de procedimentos administrativos.

Especificamente com relação a serviços, o Artigo 7.22 do ALC UE-Coreia prevê que as Partes respondam prontamente a pedidos de informação da outra Parte a respeito dos seguintes temas: (i) acordos internacionais e normas que afetem o comércio de serviços entre as Partes, incluindo reconhecimento mútuo; (ii) normas e critérios de licenciamento e certificação de prestadores de serviços. Há, também, regras que garantem a confidencialidade de informações, a necessidade de publicidade das exigências de preenchimento dos pedidos de prestação de serviços e que regulam os procedimentos para decisões sobre pedidos de prestação de serviços. A esse respeito, merece destaque a determinação para que a autoridade regulatória da Parte decida sobre um pedido de prestação de um serviço no prazo de 120 dias. Caso não seja possível chegar a uma decisão nesse passo, é necessário notificar a Parte interessada e apresentar justificativa para a demora $^{234}$.

\subsection{Regulação doméstica}

Grande parte dos acordos regionais celebrados pela União Europeia que contêm regras sobre serviços possui um artigo ou capítulo sobre regulação doméstica.

Os acordos celebrados com Argélia e Jordânia são bastante similares em relação às obrigações de regulação doméstica. Nenhum dos acordos contém regras sobre regulação doméstica propriamente ditas, mas estabelecem algumas limitações à adoção de normas internas relacionadas a serviços pelas Partes. $\mathrm{O}$ acordo com Argélia prevê que as normas de regulação doméstica estão sujeitas a limitações de política pública, segurança e saúde. Além disso, as Partes podem adotar medidas prudenciais para proteger a estabilidade de seu sistema financeiro, desde que essas medidas não sejam mais restritivas do que o

\footnotetext{
234 “6. A Party's regulatory authority shall make an administrative decision on a completed application of an investor or a cross-border service supplier of the other Party relating to the supply of a service within 120 days, and shall promptly notify the applicant of the decision. An application shall not be considered complete until all relevant hearings are held and all necessary information is received. Where it is not possible for a decision to be made within 120 days, the regulatory authority shall notify the applicant without undue delay and shall endeavour to make the decision within a reasonable period of time thereafter". Free trade Agreement between the European Union and its Member States, of the one part, and the Republic of Korea, of the other part. Disponível em: <http://eur-lex.europa.eu/legalcontent/en/ALL/?uri=OJ:L:2011:127:TOC>. Acesso em: 20 mai. 2014.
} 
necessário para atingir esse objetivo. Quanto ao movimento de pessoas naturais, as Partes podem adotar regulamentos e normas relativos à entrada, estadia e condições de trabalho, desde que sua adoção não anule ou comprometa as vantagens provenientes do acordo. Por sua vez, no acordo celebrado com a Jordânia, há previsão de que nada no acordo poderá impedir que as Partes regulem a entrada, estadia, trabalho, condições de trabalho e estabelecimento de pessoas físicas e a prestação de serviços, desde que não prejudiquem os anulem os benefícios do Acordo. Há, ademais, previsão de limitações à regulação doméstica em virtude de política pública, segurança e saúde.

Os acordos celebrados pela União Europeia dispõem de normas mais detalhadas sobre regulação doméstica são os acordos celebrados com CARIFORUM, Chile e Coreia. Não por acaso, esses são os únicos acordos que possuem listas positivas de compromissos.

No APE UE-CARIFORUM, há regras sobre regulação doméstica relativas a reconhecimento mútuo, transparência, procedimento para autorização, como concessão de licenças de funcionamento. A maior parte das regras trata de questões setoriais específicas nos seguintes setores de serviços: telecomunicações, serviços financeiros, serviços de courier, serviços de computação, transporte marítimo e turismo.

$\mathrm{O}$ acordo com o Chile possui regras sobre regulação doméstica relativas a requisitos e procedimentos para licenciamento e certificação muito similares às do GATS. Neste acordo também há previsão de realização de consultas para a exclusão do requerimento de cidadania ou residência permanente para licenciamento ou certificação.

No ALC UE-Coreia, as regras sobre regulação doméstica interna referem-se às seguintes questões: (i) autorização para prestação de um serviço; (ii) existência de tribunais (judiciais, arbitrais ou administrativos) que posam rever as decisões a respeito de autorizações para prestação de um serviço; (iii) transparência; (iv) direito de regulamentar a prestação de serviços no que tange a qualificações, normas técnicas; (v) requisitos em matéria de concessão de licenças. Há, ainda, previsão de que as Partes têm o direito de regulamentar a admissão ou a permanência temporária de pessoas físicas no seu território, incluindo a possibilidade de adotar as medidas necessárias para proteger a integridade das suas fronteiras e assegurar ordem na travessia de pessoas físicas. 


\subsection{Outras obrigações relevantes}

Com relação à cláusula de nação mais favorecida, embora o acordo com a Coreia estabeleça que o tratamento mais favorável dado a serviços e a prestadores de serviços de terceiros Estados será estendido às Partes do acordo, este expressamente exclui os setores em que há compromissos setoriais ou horizontais decorrentes de outros acordos regionais celebrados pelas Partes que são muito mais abrangentes do que aqueles decorrentes do presente $\mathrm{Acordo}^{235}$, os quais foram relacionados no Anexo $7-\mathrm{B}^{236}$. Note-se que a extensão

235 "Os critérios para avaliar se os compromissos setoriais ou horizontais decorrentes de outros acordos regionais celebrados pelas Partes são muito mais abrangentes do que aqueles resultantes do ALC UE-Coreia foram estabelecidos no preâmbulo ao Anexo 7-B, a saber: "1. For the purposes of Articles 7.8.2 and 7.14.2, to be of a significantly higher level, obligations stipulated in a regional economic integration agreement shall either create an internal market on services and establishment_or encompass both the right of establishment and the approximation of legislation. The evaluation of the level of the obligations.

(a) The right of establishment referred to in this paragraph means an obligation to abolish in substance all barriers to establishment among the parties to the regional economic integration agreement by the entry into force of that agreement. The right of establishment shall include the right of nationals of the parties to the regional economic integration agreement to set up and manage undertakings under the conditions laid down for nationals by the legislation of the country where such establishment is effected shall be conducted on the basis of sectoral or horizontal commitments;

(b) The approximation of legislation referred to in this paragraph means:

(i) the alignment of the legislation of one or more of the parties to the regional economic integration agreement with the legislation of the other party or parties to that agreement; or

(ii) the incorporation of common legislation into the legal order of the parties to the regional economic integration agreement. Such alignment or incorporation shall be taking place, and is deemed to take place only from such time that it has been enacted into the domestic legal order of the party or parties to the regional economic integration agreement". Free trade Agreement between the European Union and its Member States, of the one part, and the Republic of Korea, of the other part. Disponível em: <http://eur-lex.europa.eu/legal-content/en/ALL/?uri=OJ:L:2011:127:TOC>. Acesso em: 20 mai. 2014.

236 "Article 7.8

MFN treatment

1. With respect to any measures covered by this Section affecting the cross-border supply of services, unless otherwise provided for in this Article, each Party shall accord to services and service suppliers of the other Party treatment no less favourable than that it accords to like services and service suppliers of any third country in the context of an economic integration agreement signed after the entry into force of this Agreement.

2. Treatment arising from a regional economic integration agreement granted by either Party to services and service suppliers of a third party shall be excluded from the obligation in paragraph 1, only if this treatment is granted under sectoral or horizontal commitments for which the regional economic integration agreement stipulates a significantly higher level of obligations than those undertaken in the context of this Section as set out in Annex 7-B.

3. Notwithstanding paragraph 2 , the obligations arising from paragraph 1 shall not apply to treatment granted:

(a) under measures providing for recognition of qualifications, licences or prudential measures in accordance with Article VII of GATS or its Annex on Financial Services;

(b) under any international agreement or arrangement relating wholly or mainly to taxation; or

(c) under measures covered by the MFN exemptions listed in Annex 7-C'. Free trade Agreement between the European Union and its Member States, of the one part, and the Republic of Korea, of the other part. Disponível em: <http://eur-lex.europa.eu/legal-content/en/ALL/?uri=OJ:L:2011:127:TOC>. Acesso em: 20 mai. 2014. 
não se refere a novas concessões, mas àquelas existentes quando o Acordo entrou em vigor.

No APE UE-CARIFORUM, a União Europeia compromete-se a estender às Partes o tratamento mais favorável resultante de outros acordo regionais de comércio celebrados pelo bloco após a entrada em vigor do acordo. Por sua vez, os países do CARIFORUM comprometem-se a estender aos Estados-membros da União Europeia o tratamento mais favorável resultante de outros acordos regionais que o bloco celebrar com "qualquer grande potência comercial"237. O termo "qualquer grande potência comercial" é definido como qualquer país desenvolvido ou qualquer país que tenha participação superior a $1 \%$ ao ano nas exportações mundiais de mercadorias ou qualquer grupo de países atuando, individual ou coletivamente, ou por meio de acordo de integração econômica, que possua,

${ }^{237}$ Article 70

Most-favoured-nation treatment

1. With respect to any measures affecting commercial presence covered by this Chapter:

(a) the EC Party shall accord to commercial presences and investors of the Signatory CARIFORUM States a treatment no less favourable than the most favourable treatment applicable to like commercial presences and investors of any third country with whom it concludes an economic integration agreement after the signature of this Agreement;

(b) the Signatory CARIFORUM States shall accord to the commercial presences and investors of the EC Party a treatment no less favourable than the most favourable treatment applicable to like commercial presences and investors of any major trading economy with whom they conclude an economic integration agreement after the signature of this Agreement.

2. When a Party or a Signatory CARIFORUM State concludes a regional economic integration agreement creating an internal market or requiring the parties thereto to significantly approximate their legislation with a view to removing nondiscriminatory obstacles to commercial presence and to trade in services, the treatment that such Party or Signatory CARIFORUM State grants to commercial presences and investors of third countries in sectors subject to the internal market or to the significant approximation of legislation is not covered by the provision of paragraph 1

3. The obligations set out in paragraph 1 shall not apply to treatment granted:

(a) under measures providing for recognition of qualifications, licences or prudential measures in accordance with Article VII of the GATS or its Annex on Financial Services,

(b) under any international agreement or arrangement relating wholly or mainly to taxation, or

(c) under measures benefiting from the coverage of an MFN exemption listed in accordance with Article II.2 of the GATS.

4. For the purpose of this provision, a 'major trading economy' means any developed country, or any country accounting for a share of world merchandise exports above $1 \%$ in the year before the entry into force of the economic integration agreement referred to in paragraph 1, or any group of countries acting individually, collectively or through an economic integration agreement accounting collectively for a share of world merchandise exports above $1,5 \%$ in the year before the entry into force of the economic integration agreement referred to in paragraph 1.

5. Where any Signatory CARIFORUM State becomes party to an economic integration agreement with a third party referred to in paragraph $1(\mathrm{~b})$ and that agreement provides for more favourable treatment to such third party than that granted by the Signatory CARIFORUM State to the EC Party pursuant to this Agreement, the Parties shall enter into consultations. The Parties may decide whether the concerned Signatory CARIFORUM State may deny the more favourable treatment contained in the economic integration agreement to the EC Party. The Joint CARIFORUM-EC Council may adopt any necessary measures to adjust the provisions of this Agreement". Economic Partnership Agreement between the CARIFORUM States, of the one part, and the European Community and its Member States, of the other part. Disponível em:

<http://ec.europa.eu/world/agreements/prepareCreateTreatiesWorkspace/treatiesGeneralData.do?redirect=tru e\&treatyId=7407> . Acesso em: 20 mai. 2014. 
coletivamente, participação superior a $1,5 \%$ ao ano nas exportações mundiais de mercadorias, a serem aferidas antes da entrada em vigor do APE UE-CARIFORUM.

Desse modo, a obrigação de nação mais favorecida prevista no APE UECARIFORUM não é recíproca, dado que os benefícios dos acordos celebrados com países cujas exportações de mercadorias são inferiores aos limites determinados no acordo não podem ser estendidas à União Europeia. Na realidade, trata-se de uma previsão desenvolvimentista ${ }^{238}$.

\section{PANORAMA DO TRATAMENTO DE SERVIÇOS NOS PRINCIPAIS ACORDOS REGIONAIS DE COMÉRCIO ENVOLVENDO A CHINA}

\subsection{Modelo de lista adotado}

Todos os acordos regionais celebrados pela China que foram objeto de análise adotam o modelo do GATS para a celebração de compromissos em serviços. Isso significa que as obrigações de tratamento nacional e acesso a mercados incidem apenas sobre os setores e sub-setores de serviços e modos de prestação que foram objeto de compromisso no âmbito do acordo.

Nas listas de compromissos, as Partes deverão inscrever as seguintes informações: (i) os termos, limitações e condições de acesso a mercados; (ii) as condições e qualificações referentes ao tratamento nacional; (ii) as obrigações relativamente aos compromissos adicionais; (iv) se necessário, o prazo para a implementação do compromisso e a data em que entrará em vigor.

\subsection{Abrangência}

A China também segue o modelo do GATS em relação aos modos de prestação de serviços abrangidos pelos acordos regionais dos quais é Parte. Os quatro modos de prestação previstos no acordo sobre serviços da OMC podem ser objeto de compromissos

\footnotetext{
${ }^{238}$ Vide P. LATRILLE e J. LEE, 2012, p. 23.
} 
regionais celebrados por este país. Ressalte-se que, no acordo celebrado com Cingapura, a regulamentação dos compromissos no modo 4 são objeto de capítulo específico ${ }^{239}$.

Com relação à cobertura, o Acordo com ASEAN abrange todas as medidas adotadas pelas Partes que afetem o comércio de serviços, exceto: (i) medidas adotadas no exercício da autoridade governamental; (ii) regulações ou requerimentos relacionados à contratação de serviços para fins governamentais; (iii) medidas de natureza tributária das Filipinas ${ }^{240}$.

Nos demais acordos celebrados pela China - China-Peru, China-Nova Zelândia, China-Cingapura, China-Paquistão, China-Costa-Rica e China-Chile -, são abrangidas todas as medidas que afetem o comércio de serviços, exceto: (i) medidas adotadas no exercício da autoridade governamental no território de outra Parte; (ii) compras governamentais; (iii) subsídios ou aportes governamentais; (iv) serviços diretamente relacionados aos direitos de tráfico aéreo, com exceção de serviços de reparo e manutenção de aeronaves, a comercialização de serviços de transporte aéreo e serviços de reservas computadorizadas.

O acordo com a Nova Zelândia não abrange medidas que afetem pessoas físicas em busca de empregos em outra Parte ${ }^{241}$.

Já os acordos com Peru, Costa Rica e Paquistão possuem as seguintes restrições adicionais: (i) transporte marítimo de cabotagem e (ii) medidas que afetem pessoas físicas buscando acesso ao mercado de empregos de uma Parte ou relacionadas à cidadania, residência e emprego de forma permanente. Contudo, os Acordos não afetam o direito das

\footnotetext{
${ }^{239}$ Capítulo 9 - Movimento de Pessoas Físicas.

240 "Article 2
}

Scope

1. This Agreement applies to measures ${ }^{3}$ by the Parties affecting trade in services.

2. This Agreement shall not apply to:

(a) services supplied in the exercise of governmental authority within the territory of each Party;

(b) regulations or requirements governing the procurement by governmental agencies of services purchased for governmental purposes and not with a view to commercial resale or with a view to use in the supply of services for commercial sale.

3. The exclusion of taxation measures by the Philippines from the scope of this Agreement shall be further discussed by all Parties before the entry into force of the Agreement". Agreement on Trade in Services of the Framework Agreement on Comprehensive Economic Co-operation between the Association of Southeast Asian Nations and the People's Republic of China. Disponível em: <http://fta.mofcom.gov.cn/topic/chinaasean.shtml>. Acesso em: 20 mai. 2014.

241 "Article 105 Scope (...)

2. This Chapter shall not apply to: (...)

(d) measures affecting natural persons seeking access to the employment market of a Party". Free Trade Agreement Between the Government of the People's Republic of China and the Government of New

Zealand. Disponível em: <fta.mofcom.gov.cn/topic/ennewzealand.shtml>. Acesso em: 20 mai. 2014. 
Partes de adotar medidas para regular a entrada de pessoas físicas em seus territórios, desde que tais medidas não prejudiquem ou anulem os benefícios deles decorrentes ${ }^{242}$.

$\mathrm{O}$ acordo com o Peru também exclui da incidência do acordo os seguintes setores de serviços: (i) serviços financeiros que não estejam especificados nas listas de compromissos específicos, dado que as obrigações sobre esses serviços serão reguladas de acordo com o GATS, e (ii) serviços de telecomunicações, visto que as obrigações relacionadas com esses serviços serão reguladas de acordo com o respectivo Anexo do $\operatorname{GATS}^{243}$.

O acordo com o Chile também não incide sobre transporte marítimo nacional de cabotagem e serviços financeiros ${ }^{244}$.

Em relação a regras sobre investimentos, os acordos celebrados pela China possuem um capítulo específico e/ou um acordo sobre o tema. De todo modo, não há cláusulas relacionando serviços e investimentos nos capítulos ou acordos sobre serviços dos quais a China é Parte.

\subsection{Obrigações e limitações de acesso a mercados}

Em todos os acordos celebrados pela China que foram objeto de análise, há previsão de que a Parte concederá aos serviços e prestadores de serviços da outra Parte tratamento

\footnotetext{
${ }^{242}$ Vide Artigo 91 do Acordo China-Costa Rica, Artigo 105 do Acordo China-Peru e Artigo 2 do Acordo China-Paquistão.

243 “Article 105: Scope and Coverage (...)

7. This Chapter, except for the list of financial services specific commitments in the Schedules of Specific Commitments under this Agreement, does not apply to measures affecting the supply of financial services as defined in subparagraph 5(a) of the GATS Annex on Financial Services. The obligations of each Party with respect to measures affecting the supply of financial services shall be in accordance with its obligations under GATS, the GATS Annex on Financial Services and the GATS Second Annex on Financial Services, and subject to any reservations thereto. The said obligations are hereby incorporated into this Agreement, and the schedule of financial services specific commitments of Annex 6 (Schedules of Specific Commitments) of this Agreement shall apply.

8. In addition to the provisions of this Chapter, the rights and obligations of the Parties in respect of telecommunication services shall also be governed by the provisions of:

(a) the GATS Annex on Telecommunications; and

(b) the GATS Reference Paper developed in the Negotiating Group on Basic Telecommunications attached to each Party's GATS schedules of commitments, which are hereby incorporated into this Chapter, mutatis mutandis, as if those provisions were fully set out herein". Free Trade Agreement Between the Government of the Republic of Peru and the Government of the People's Republic of China. Disponível em: <http://fta.mofcom.gov.cn/topic/enperu.shtml>. Acesso em: 20 mai. 2014.

244 "Article 1 Scope and Coverage (...)

2. This Supplementary Agreement does not apply to:
}

(a) financial services;

(...) (d) national maritime cabotage". Supplementary Agreement on Trade in Services of the Free Trade Agreement between China and Chile.. Disponível em: <http://fta.mofcom.gov.cn/topic/enchile.shtml>. Acesso em: 20 mai. 2014. 
não menos favorável do que aquele relacionado em sua respectiva Lista de Compromissos. As limitações para acesso a mercados adotadas nos acordos em questão apenas replicam as disposições do GATS a respeito do assunto.

Além das limitações previstas no GATS, o Acordo China-Nova Zelândia contém uma cláusula que determina que as Partes não poderão estabelecer restrições a transferências e pagamentos internacionais em questões que sejam objeto de compromissos específicos, exceto em relação ao Art. 202 do Acordo, relativos a medidas para proteger a balança de pagamentos, e por determinação do $\mathrm{FMI}^{245}$.

\subsection{Obrigações e limitações de tratamento nacional}

Em relação às obrigações de tratamento nacional, a maioria dos acordos celebrados pela China replica o conteúdo do Artigo XVII do GATS. A única exceção é o Acordo celebrado com o Peru.

Todos os acordos regionais celebrados pela Índia utilizam os mesmos parâmetros do GATS para a concessão de tratamento nacional, qual seja, para os setores e modos que são objeto de compromisso específico, a Parte concederá aos serviços e prestadores de serviços da outra Parte tratamento não menos favorável do que aquele concedido a seus próprios serviços e prestadores de serviços similares (like services and services suppliers).

No entanto, a cláusula de tratamento nacional contida no acordo celebrado com o Peru tem redação ligeiramente distinta daquela adotada pelos GATS e pelos demais acordos analisados. Essa cláusula condiciona a concessão do tratamento nacional aos serviços e aos prestadores de serviços da outra Parte à existência de circunstâncias semelhantes ${ }^{246}$. Além disso, o acordo com o Peru não contém os dois últimos parágrafos do

245 "Article 114 Payments and Transfers

1. Except in the circumstances envisaged in Article 202, a Party shall not apply restrictions on international transfers and payments for current transactions relating to its specific commitments.

2 Nothing in this Chapter shall affect the rights and obligations of the Parties as members of the International Monetary Fund under the Articles of Agreement of the International Monetary Fund ("Articles of Agreement"), including the use of exchange actions which are in conformity with the Articles of Agreement, provided that a Party shall not impose restrictions on any capital transactions inconsistently with its specific commitments regarding such transactions, except under Article 202 or at the request of the International Monetary Fund". Free Trade Agreement Between the Government of the People's Republic of China and the Government of New Zealand. Disponível em: <fta.mofcom.gov.cn/topic/ennewzealand.shtml>. Acesso em: 20 mai. 2014.

246 "Article 106: National Treatment

In the sectors inscribed in its Schedule, and subject to any conditions and qualifications set out therein, each Party shall accord to services and service suppliers of the other Party treatment no less favourable than that it accords, in like circumstances, to its own services and service suppliers". Free Trade Agreement Between 
Artigo XVII do GATS, que estabelecem em que situações o tratamento entre os serviços e os prestadores de serviços nacionais e estrangeiros deve ser considerado equivalente.

\subsection{Reservas e exceções}

Nos acordos regionais celebrados pela China, as exceções consistem apenas nas limitações do acesso a mercados e tratamento nacional, as quais devem ser inscritas nas listas de compromissos de cada Parte.

\subsection{Transparência}

Todos os acordos regionais celebrados pela China possuem regras de transparência relacionadas a medidas que afetem o comércio regional de serviços.

Três dos acordos analisados - China-Paquistão, China-ASEAN e China-Cingapura limitam-se a incorporar integralmente o texto do Artigo III do GATS ${ }^{247}$.

Os acordos China-Peru, China-Costa Rica e China-Chile possuem capítulos específicos sobre transparência, que se aplicam a todas as disposições dos Acordos. Não obstante, no que tange às obrigações de transparência relacionadas especificamente ao comércio de serviços, os três acordos possuem cláusulas idênticas, que fazem referência ao capítulo sobre transparência e estabelecem as seguintes obrigações: (i) necessidade de as Partes estabelecerem e manterem mecanismos apropriados para responderem às solicitações de pessoas interessadas sobre suas leis e regulamentos relacionados ao acordo; (ii) que, na medida do possível, sejam levados em consideração os comentários substanciais realizados por partes interessadas sobre novas leis e regulamentos; (iii) que haja um período de tempo razoável entre a promulgação de novas leis e regulamentos e sua entrada em vigor ${ }^{248}$.

Por fim, o acordo China-Nova Zelândia determina apenas a necessidade de publicação de acordos internacionais sobre ou que afetem o comércio de serviços dos quais

the Government of the Republic of Peru and the Government of the People's Republic of China. Disponível em: Disponível em: <http://fta.mofcom.gov.cn/topic/enperu.shtml>. Acesso em: 20 mai. 2014.

${ }^{247}$ Artigo 3 do Acordo China-ASEAN, Artigo 73 do Acordo China-Cingapura e Artigo 3 do Acordo ChinaPaquistão.

${ }^{248}$ Artigo 114 do Acordo China-Peru, Artigo 100 do Acordo China-Costa Rica e Artigo 8 do Acordo ChinaChile. 
a Parte é signatária, a qual deverá ser realizada por meio dos pontos de contato previstos no Acordo $^{249}$.

\subsection{Regulação doméstica}

A respeito de regulação doméstica, o GATS foi a fonte de inspiração para as regras regionais adotadas pela China sobre o tema. Alguns acordos celebrados pela China adotam obrigações quase idênticas àquelas contidas no Artigo VI do GATS, ao passo que outros adotam obrigações um pouco mais simplificadas.

De modo geral, as cláusulas sobre regulação doméstica contidas nos acordos regionais envolvendo a China determinam as seguintes obrigações às Partes: (i) garantir que todas as medidas que afetem o comércio de serviços sejam administradas de forma razoável, objetiva e imparcial; (ii) garantir a existência de regras claras sobre requerimentos de licenciamento, normas técnicas, entre outras, de modo que não constituam barreiras desnecessárias ao comércio de serviços; (iii) garantir que as autoridades respondam prontamente a requerimentos, sempre que uma autorização para a prestação do serviço for necessária.

Além de assumir as obrigações descritas acima, nos acordos celebrados pela China com ASEAN, Nova Zelândia, Cingapura e Peru, as Partes também se comprometeram a estabelecer ou manter tribunais ou procedimentos que sejam objetivos e imparciais para a revisão de medidas administrativas que afetem o comércio de serviços, exceto se essa previsão for inconstitucional ou não estiver prevista no sistema jurídico da Parte ${ }^{250}$.

249 "Article 116 Transparency

1. Each Party shall publish international agreements pertaining to or affecting trade in services to which that Party is a signatory.

2. Any information provided under this Article shall be conveyed through the contact points referred to in Article 118". Free Trade Agreement Between the Government of the People's Republic of China and the Government of New Zealand. Disponível em: <fta.mofcom.gov.cn/topic/ennewzealand.shtml>. Acesso em: 20 mai. 2014.

${ }^{250}$ Artigo 110 (2) do Acordo China-Peru, 65 (2) do Acordo China-Cingapura, Artigo 5(2) do Acordo ChinaASEAN e Artigo 111 (2) do Acordo China-Nova Zelândia. Vide, por exemplo, como o tema é tratado no Acordo China-Cingapura:

"ARTICLE 65

Domestic Regulation (...)

2. (a) Each Party shall maintain or institute as soon as practicable, judicial, arbitral or administrative tribunals or procedures which provide, at the request of an affected service supplier, for the prompt review of, and where justified, appropriate remedies for, administrative decisions affecting trade in services. Where such procedures are not independent of the agency entrusted with the administrative decision concerned, the Party shall ensure that the procedures in fact provide for an objective and impartial review.

(b) The provisions of sub-paragraph (a) shall not be construed to require a Party to institute such tribunals or procedures where this would be inconsistent with its constitutional structure or the nature of its legal system". 
Os acordos celebrados com Cingapura e com Nova Zelândia contêm uma cláusula que replica o conteúdo do Artigo VI:6 do GATS. A referida cláusula determina que, em relação aos setores de serviços profissionais que foram objeto de compromissos específicos, a Parte mantenha procedimentos adequados para verificar a competência dos profissionais da outra Parte ${ }^{251}$.

Os acordos China-Costa Rica, Chile-China, Peru-China e Paquistão-China também contemplam a possibilidade de revisão das regras sobre regulação doméstica previstas nestes acordos, caso venha a ocorrer a regulamentação do Art. VI do GATS na OMC ${ }^{252}$.

Por fim, note-se que apenas os acordos com Chile e Paquistão contêm uma cláusula que determina que as Partes realizem consultas periódicas com o objetivo de remover a necessidade de vistos ou residência para o licenciamento e a certificação de provedores de serviços 253254 .

\subsection{Outras obrigações relevantes}

Todos os acordos regionais celebrados pela China contêm regras relativas à possibilidade de denegação dos benefícios (denial of benefits) resultantes dos próprios

Free Trade Agreement Between the Government of the People's Republic of China and the Government of the Republic of Singapore. Disponível em: <fta.mofcom.gov.cn/topic/ensingpore.shtml>. Acesso em: 20 mai. 2014.

${ }^{251}$ Artigos 65 (6) do Acordo China-Cingapura e 111 (6) do Acordo China-Nova Zelândia.Vide, por exemplo, como o tema é tratado no Acordo China-Nova Zelândia:

"Article 111 Domestic Regulation (...)

6. In sectors where specific commitments regarding professional services are undertaken, each Party shall provide for adequate procedures to verify the competence of professionals of the other Party". Free Trade Agreement Between the Government of the People's Republic of China and the Government of New Zealand. Disponível em: <fta.mofcom.gov.cn/topic/ennewzealand.shtml>. Acesso em: 20 mai. 2014.

${ }^{252}$ Artigo 6 (3) do Acordo China-Chile, 5 (2) do Acordo China-Paquistão, 96 (5) do Acordo China-Costa Rica e 110 (5) do Acordo China-Peru.

${ }^{253}$ Artigo 6 (5) do Acordo China-Chile e 5 (4) do Acordo China-Paquistão. Vide, por exemplo, como o tema é tratado no Acordo China-Paquistão:

"Article 5 Domestic Regulation (...)

4. The Parties shall consult periodically with a view to determining the feasibility of removing any remaining citizenship requirement for the licensing or certification of each other's service suppliers". Agreement on the Early Harvest Programme for the Free Trade Agreement Between the Government of the People's Republic of China and the Government of the Islamic Republic of Pakistan. Disponível em: <fta.mofcom.gov.cn/topic/enpakistan.shtml>. Acesso em: 20 mai. 2014.

${ }^{254}$ Acerca da especificidade das obrigações relativas à regulação doméstica contidas no Acordo ChinaPaquistão, Rupa Chanda explica o seguinte: "The China-Pakistan FTA, while most similar to the GATS in its provisions on domestic regulation, has an additional clause which is not found in any of the other PTAs. This clause requires the parties to consult periodically to determine the feasibility on removing any remaining nationality requirements for licensing and certification of each other's services suppliers. Thus, the specific issue on domestic regulations which link provision on a service to nationality is given importance in this PTA”. Mapping the Universe of Services Disciplines in Asian Ptas. P. SAUVÉ; A. SHINGAL. The Preferential Liberalization of Trade in Services: Comparative Regionalism. Cheltenham: Edward Elgar Publishing, 2014, p. 248. 
acordos. Como será visto a seguir, a maioria deles adota o critério de operações comerciais substanciais.

Segundo dispõem os acordos celebrados com Chile, Peru e Costa Rica, uma Parte poderá denegar os benefícios do acordo nas seguintes circunstâncias: (i) aos prestadores de serviços da outra Parte, se o serviço for prestado por pessoa jurídica detida ou controlada por pessoas de não Parte e a pessoa jurídica não desenvolver operações substanciais na outra Parte; (ii) aos prestadores de serviços da outra Parte, se o serviço for prestado por pessoa jurídica detida ou controlada por pessoas da Parte que denegar o benefício e a pessoa jurídica não desenvolver operações substanciais na outra Parte. Nesses acordos, também está previsto que a denegação do benefício deve ser comunicada à outra Parte, por escrito $^{255}$.

Os acordos celebrados pela China que não adotam o critério acima, de operações comerciais substanciais, são aqueles com Cingapura e ASEAN. Tais acordos preveem que poderão ser denegados os benefícios nos seguintes casos: (i) à prestação de serviços, caso este seja prestado do território de uma não Parte; (ii) à prestação de serviços de transporte marítimo, se o serviço for prestado por uma embarcação registrada em uma não Parte ou for prestado por uma pessoa originária de uma não Parte que utilize a embarcação, no todo ou em parte; (iii) ao prestador de serviços, caso este seja originário de uma não $\operatorname{Parte}^{256}$.

${ }^{255}$ Artigo 10 do Acordo China-Chile, Artigo 113 do Acordo China-Peru e Artigo 99 do Acordo China-Costa Rica.Vide, por exemplo, como o tema é tratado no Acordo China-Chile:

"Article 10 Denial of Benefits

1. A Party may deny the benefits of this Supplementary Agreement to:

(a) service suppliers of the other Party where the service is being supplied by a juridical person that is owned or controlled by persons of a non-Party and the juridical person has no substantive business activities in the territory of the other Party, or

(b) service suppliers of the other Party where the service is being supplied by a juridical person that is owned or controlled by persons of the denying Party and the juridical person has no substantive business activities in the territory of the other Party.

2. Upon a written request of the other Party, the denying Party shall inform in writing and consult with the other Party on the specific case of denial as referred to in paragraph 1 of this Article". Supplementary Agreement on Trade in Services of the Free Trade Agreement between China and Chile. Disponível em: <http://fta.mofcom.gov.cn/topic/enchile.shtml>. Acesso em: 20 mai. 2014.

${ }^{256}$ Artigo 31 do Acordo China-ASEAN e Artigo 75 do Acordo China-Cingapura. Vide, por exemplo, como o tema é tratado no Acordo China-ASEAN:

"Article 31

Denial of Benefits

A Party may deny the benefits of this Agreement:

(a) to the supply of a service, if it establishes that the service is supplied from or in the territory of a nonParty;

(b) in the case of the supply of a maritime transport service, if it establishes that the service is supplied:

(i) by a vessel registered under the laws of a non-Party; and

(ii) by a person of a non-Party which operates and/or uses the vessel in whole or in part.

(c) to a service supplier that is a juridical person, if it establishes that it is not a service supplier of another 
O acordo China-Paquistão adota um critério híbrido para a denegação de benefícios, que engloba o conceito de operações comerciais substanciais, mas também possui um componente diplomático. Segundo esse acordo, as Partes poderão denegar os benefícios concedidos caso sejam verificadas as seguintes circunstâncias: (i) aos prestadores de serviços da outra Parte, se o serviço for prestado por pessoa jurídica detida ou controlada por pessoas originárias de Estados não Partes e a pessoa jurídica não desenvolver operações substanciais no território da outra Parte; (ii) aos prestadores de serviços da outra Parte, se o serviço for prestado por pessoa jurídica detida ou controlada por pessoas da Parte que denegar os benefícios e a pessoa jurídica não desenvolver operações substanciais na outra Parte; (iii) aos prestadores de serviços da outra Parte, se o serviço for prestado por pessoa jurídica detida ou controlada por pessoas originárias de uma não Parte e a Parte que denegar o benefício não mantiver relações diplomáticas com essa não Parte ${ }^{257}$.

Ressalte-se que, para que sejam denegadas as preferências comerciais nas hipóteses (i) e (ii) acima, há necessidade de realização de notificação e consultas com a Parte prejudicada. Contudo, para a denegação de preferências a que se refere o item (iii), não é necessário realizar tal procedimento.

No tocante à extensão das preferências obtidas em outras negociações, apenas o Acordo China-Nova Zelândia contém cláusula de nação mais favorecida, a qual prevê que haverá a extensão das preferências nos setores e sub-setores de serviços objeto de compromissos específicos. Contudo, esse tratamento foi limitado a acordos posteriores, não sendo possível a extensão das preferências garantidas por acordos bilaterais ou multilaterais celebrados antes do referido $\operatorname{Acordo}^{258}$.

Disponível em: <http://fta.mofcom.gov.cn/topic/chinaasean.shtml〉. Acesso em: 20 mai. 2014.

257 "Article 24 Denial of benefits

1. Subject to prior notification and consultation, a Party may deny the benefits of this Agreement to:

(a) service suppliers of the other Party where the service is being supplied by a juridical person that is owned or controlled by persons of a non-Party and the juridical person has no substantial business activities in the territory of the other Party, or

(b) service suppliers of the other Party where the service is being supplied by a juridical person that is owned or controlled by persons of the denying Party and the juridical person has no substantial business activities in the territory of the other Party.

2. A Party may deny the benefits of this Agreement to a service supplier of the other Party where the Party establishes that the service is being supplied by a juridical person that is owned or controlled by persons of a non-Party, and that denying Party does not maintain diplomatic relations with the non-Party." Agreement on the Early Harvest Programme for the Free Trade Agreement Between the Government of the People's Republic of China and the Government of the Islamic Republic of Pakistan. Disponível em: <fta.mofcom.gov.cn/topic/enpakistan.shtml>. Acesso em: 20 mai. 2014.

258 "Article 107 Most-Favoured-Nation Treatment

1. In respect of the services sectors listed in Annex 9, and subject to any conditions and qualifications set out therein, each Party shall accord to services and service suppliers of the other Party treatment no less favourable than that it accords to like services and service suppliers of a third country.

2. Notwithstanding paragraph 1 , the Parties reserve the right to adopt or maintain any measure that accords 
Especificamente com relação a serviços acessórios à agricultura e florestas, a China estabeleceu que só não seria concedido tratamento mais favorável aos Membros da OCDE. Isso possibilitaria que o país concedesse, em um futuro acordo regional com um país não Membro da OCDE, tratamento mais favorável aos prestadores de serviço desse país do que ele concede aos prestadores da Nova Zelândia, preservando, assim, seu direito de conceder um tratamento mais favorável a países em desenvolvimento ${ }^{259}$.

\section{PANORAMA DO TRATAMENTO DE SERVIÇOS NOS PRINCIPAIS ACORDOS REGIONAIS DE COMÉRCIO ENVOLVENDO A ÍNDIA}

\subsection{Modelo de lista adotado}

Os acordos regionais celebrados pela Índia são bastante fiéis ao modelo do GATS ${ }^{260}$. Nos quatro acordos analisados no presente trabalho, há previsão de que as Partes assumirão compromissos em serviços por meio de listas positivas, nas quais serão relacionados: (i) os termos, limitações e condições de acesso a mercados; (ii) as condições e qualificações referentes ao tratamento nacional; (ii) as obrigações relativamente aos compromissos

differential treatment to third countries under any free trade agreement or multilateral international agreement in force or signed prior to the date of entry into force of this Agreement.

3. For greater certainty, paragraph 2 includes, in respect of agreements on the liberalisation of trade in goods or services or investment, any measures taken as part of a wider process of economic integration or trade liberalization between the parties to such agreements". Free Trade Agreement Between the Government of the People's Republic of China and the Government of New Zealand. Disponível em: <fta.mofcom.gov.cn/topic/ennewzealand.shtml>. Acesso em: 20 mai. 2014.

${ }^{259}$ Vide P. LATRILLE e J. LEE, 2012, p. 16.

${ }^{260}$ Sobre o acordo celebrado entre Cingapura e Índia, e as semelhanças entre este acordo e o GATS, Biswajit Nag e Debdeep De ensinam o seguinte: "The CECA has followed the GATS-type positive list approach wherein each country schedules the sectors it wishes to liberalize. The architecture of the CECA services agreement is similar to that of GATS. It comprises the definitions and scope, specific commitments and general obligations, and finally the denial of benefits clause. All the four key objectives of GATS - namely, market access, national treatment, disciplining domestic regulation and transparency - are as detailed in the CECA as they are in GATS. Further, the CECA also adopts almost all the general obligations of GATS, namely, disciplines on domestic regulation, recognition and transparency among others. Market access and national treatment continue to be specific commitments in the CECA, which are liberalized on a sector-bysector basis, similar to GATS". Services in Regional Trade Agreements: Implications for India. International Trade Research Series, Working Paper N. 05-08, Setembro 2008, p. 16. Disponível em: < http://mpra.ub.unimuenchen.de/15871/>. Acesso em: 5 mai. 2014. 
adicionais; (iv) se necessário, o prazo para a implementação desses compromissos; (v) quando aplicável, a data de entrada em vigor ${ }^{261}$.

\subsection{Abrangência}

Todos os acordos celebrados pela Índia abrangem os quatro modos de prestação de serviços definidos pelo GATS. Contudo, os direitos e obrigações relativos ao modo 4, que consiste no movimento de pessoas físicas, é tratado em capítulo independente do capítulo sobre o comércio de serviços.

Com relação ao escopo dos compromissos em serviços, os acordos celebrados pela Índia diferem em relação à abrangência das normas sobre serviços. De modo geral, as obrigações assumidas no capítulo sobre serviços não incidem sobre: (i) medidas que afetem os direitos de tráfego aéreo, exceto manutenção e reparação de aeronaves, venda e a comercialização de serviços de transporte aéreo, serviços de reserva computadorizada; (ii) serviços prestados no âmbito da autoridade governamental; (iii) subsídios e subvenções governamentais; (iv) medidas que afetem pessoas físicas que buscam acesso ao mercado de empregos de uma Parte ou medidas relacionadas à cidadania, residência ou emprego, de forma permanente; (v) compras governamentais.

No Acordo com a Coreia, foi previsto que novos serviços e serviços que não forem tecnicamente ou tecnologicamente exequíveis quando o Acordo entrou em vigor, caso se tornem exequíveis, poderão ser incorporados ao capítulo em questão, seja por meio de revisão, seja a pedido de uma Parte ${ }^{262}$.

Com relação às regras relativas a investimentos, os acordos celebrados pela Índia que regulam o comércio de serviços também possuem um capítulo específico sobre investimentos. Não obstante, os acordos celebrados com Cingapura e Coreia contêm um artigo que regulamenta a relação entre serviços e investimentos, no qual as Partes elencam alguns artigos do capítulo sobre Investimentos que se aplicam a medidas que afetem a prestação de serviços por meio de presença comercial, apenas no caso de elas se

\footnotetext{
${ }^{261}$ Vide Capítulo 8 do Acordo Índia-Coreia; Capítulo 9 do Acordo Índia-Cingapura; Capítulo 7 do Acordo Índia-Japão; e Capítulo 9 do Acordo Índia-Malásia.

262 "Article 6. New services, including new financial services, shall be considered for possible incorporation into this Chapter at future reviews held in accordance with Article 6.19, or at the request of either Party immediately. The supply of services which are not technically or technologically feasible when this Agreement comes into force shall, when they become feasible, also be considered for possible incorporation at future reviews or at the request of either Party immediately." Comprehensive Economic Partnership Agreement Between the Republic of Korea and the Republic of India. Disponível em: <http://rtais.wto.org/UI/PublicShowMemberRTAIDCard.aspx?rtaid=715>. Acesso em: 20 mai. 2014.
} 
relacionarem a um investimento, independentemente de o serviço ou setor de serviço estar consolidado na lista de compromissos específicos da outra Parte. Da mesma forma, as Partes elencam alguns artigos do capítulo sobre Investimentos que se aplicam a medidas que afetem a prestação de serviços financeiros por meio de presença comercial ${ }^{263}$.

\subsection{Obrigações e limitações de acesso a mercados}

Todos os acordos celebrados pela Índia que foram objeto de análise seguem o modelo do GATS em relação às obrigações de acesso a mercados. Tais acordos preveem que, para os setores e modos que são objeto de compromisso específico, a Parte concederá aos serviços e prestadores de serviços da outra Parte tratamento não menos favorável do que aquele relacionado na respectiva Lista de Compromissos.

Em complementação à regra básica de acesso a mercados, o Acordo Índia-Japão determina que, se uma Parte assumir compromissos no modo prestação transfronteiriça e o movimento de capitais constituir parte importante desse serviço, essa Parte se comprometerá a permitir o movimento de capital. Da mesma forma, se uma Parte assumir

263 Essa questão foi tratada da seguinte forma no Acordo Índia-Coreia: “ARTICLE 6.23: SERVICESINVESTMENT LINKAGE

1. For the avoidance of doubt, the Parties confirm, in respect of this Chapter, that:

(a) subject to paragraph 2, the following articles of Chapter Ten (Investment) apply, mutatis mutandis, to measures affecting the supply of service by a service supplier of a Party through commercial presence in the territory of the other Party, only to the extent that they relate to an investment, regardless of whether or not such a service sector is scheduled in a Party's Schedule of specific commitments in Annex 6-A or 6-B:

(i) Article 10.4 (Minimum Standard of Treatment);

(ii) Article 10.10 (Transfers);

(iii) Article 10.12 (Expropriation and Compensation);

(iv) Article 10.13 (Losses and Compensation);

(v) Article 10.14 (Subrogation);

(vi) Article 10.15 (Special Formalities and Information Requirements);

(vii) Article 10.19 (Access to the Judicial and Administrative Procedures); and

(viii) Article 10.21 (Settlement of Disputes between a Party and an Investor of the other Party); and

(b) Article 10.22 (Entry into Force, Duration and Termination) shall be applicable to paragraph (a).

2. Notwithstanding Article 10.2 (Scope and Coverage), the following articles of Chapter Ten (Investment) apply, mutatis mutandis, to measures affecting the supply of financial services by a service supplier of a Party through commercial presence in the territory of the other Party, only to the extent that they relate to an investment, regardless of whether or not such a service sector is scheduled in a Party's Schedule of specific commitments in Annex 6-A or 6-B:

(a) Article 10.12 (Expropriation and Compensation); and

(b) Article 10.21 (Settlement of Disputes between a Party and an Investor of the other Party) solely for claims that a Party has breached Article 10.12 (Expropriation and Compensation)". Comprehensive Economic Partnership Agreement Between the Republic of Korea and the Republic of India. Disponível em: <http://rtais.wto.org/UI/PublicShowMemberRTAIDCard.aspx?rtaid=715>. Acesso em: 20 mai. 2014. 
compromissos no modo presença comercial, ela também se comprometerá a permitir a transferência de capital para o seu território ${ }^{264}$.

Quanto às limitações para acesso a mercados, os quatro acordos analisados trazem as mesmas hipóteses para as quais uma Parte pode limitar o acesso a mercados de serviços à outra Parte que foram regulamentadas no GATS. O Acordo Índia-Japão prevê, ainda, que as Partes devem buscar reduzir os seguintes requerimentos para o acesso de um prestador de serviço da outra Parte: (i) que estabeleça ou mantenha um escritório de representação ou qualquer outra forma de empresa; ou (ii) que seja residente em sua área ${ }^{265}$.

\subsection{Obrigações e limitações de tratamento nacional}

Nos quatro acordos analisados, as obrigações de tratamento nacional utilizam parâmetro idêntico ao GATS, a saber: para os setores e modos que são objeto de compromisso específico, a Parte concederá aos serviços e prestadores de serviços da outra Parte tratamento não menos favorável do que aquele concedido a seus próprios serviços e prestadores de serviços similares (like services and services suppliers).

Em dois acordos regionais - entre Índia e Coreia e entre Índia e Cingapura - foram inseridos dois parágrafos que não existem do Artigo XVII GATS ${ }^{266}$. O primeiro parágrafo está relacionado a investimentos adicionais de um prestador de serviços de uma Parte e que for controlado pelo prestador de serviços da outra Parte. Trata-se de uma situação em que é importante identificar a origem do investimento para, posteriormente, aplicar as regras relativas ao tratamento nacional. Segundo consta nos referidos acordos, qualquer estabelecimento, aquisição adicional ou expansão de investimentos por um prestador de

\footnotetext{
264 “Article 59 (...)

Note: If a Party undertakes a market-access commitment in relation to the supply of a service through the mode of supply referred to in subparagraph (m)(i) of Article 58 and if the cross-border movement of capital is an essential part of the service itself, that Party is thereby committed to allow such movement of capital. If a Party undertakes a market-access commitment in relation to the supply of a service through the mode of supply referred to in subparagraph (m)(iii) of Article 58, it is thereby committed to allow related transfers of capital into its Area". Comprehensive Economic Partnership Agreement Between Japan and the Republic of India. Disponível em:

<http://rtais.wto.org/UI/PublicShowMemberRTAIDCard.aspx?rtaid=173>. Acesso em: 20 mai. 2014.

265 “Article 59 (...)

3. Each Party shall endeavour to reduce the requirements for a service supplier of the other Party to establish or maintain a representative office or any form of enterprise or to be resident in its Area, as a condition for the cross-border supply of a service”. Comprehensive Economic Partnership Agreement Between Japan and the Republic of India. Disponível em:

<http://rtais.wto.org/UI/PublicShowMemberRTAIDCard.aspx?rtaid=173>. Acesso em: 20 mai. 2014.

266 Vide A.P.C. Subhashini Abeysinghe. Services trade in South Asia: the India-Sri Lanka CEPA. P. SAUVÉ; A. SHINGAL, 2014, p. 301-302.
} 
serviços que for incorporado, constituído ou organizado sob as leis de uma Parte e que for controlado pelo prestador de serviços da outra Parte deve ser considerado como um investimento da outra Parte para fins de tratamento nacional ${ }^{267}$. O segundo parágrafo determina que o tratamento nacional também abranja o tratamento concedido em nível local ou regional ${ }^{268}$. Esse dispositivo refere-se à estrutura federativa da Índia, pela qual os governos estaduais podem adotar normas relativas a serviços que concedam tratamento mais favorável aos prestadores estrangeiros do que no restante do país.

Por fim, no Acordo com o Japão, há previsão de que os compromissos específicos assumidos não poderão ser utilizados de forma a compensar desvantagens competitivas resultantes da prestação de serviços por estrangeiros ${ }^{269}$.

\subsection{Reservas e exceções}

Nos acordos regionais celebrados pela Índia, as exceções consistem apenas nas limitações ao acesso a mercados e de tratamento nacional, as quais devem ser inscritas nas listas de compromissos de cada Parte.

\subsection{Transparência}

Tanto no acordo com Cingapura quanto no acordo com a Coreia, há obrigações de transparência relacionadas ao comércio de serviços. Essas regras determinam que cada Parte deverá publicar prontamente as medidas que afetem sua operacionalização do

${ }^{267}$ Vide, por exemplo, o texto do Acordo Índia-Cingapura: “Article 7.4 (...)

2. Any subsequent establishment, acquisition and expansion of investments by a service supplier that is incorporated, constituted, set up or otherwise duly organized under the law of a Party, and which is owned by a service supplier of the other Party, shall be regarded as an investment of the other Party, for the purpose of determining the applicable treatment to be accorded under this paragraph 7-5". Comprehensive Economic Cooperation Agreement Between the Republic of India and the Republic of Singapore. Disponível em: <http://rtais.wto.org/UI/PublicShowMemberRTAIDCard.aspx?rtaid=10>. Acesso em: 20 mai. 2014.

${ }^{268}$ Vide, por exemplo, o texto do Acordo Índia-Cingapura: "Article 7.4 (...)

3. The treatment to be accorded by a Party under paragraph 1 means, with respect to a regional or local level, treatment no less favourable than the most favourable treatment accorded by that regional or local level to like service suppliers of the Party of which it forms a part". Comprehensive Economic Cooperation Agreement Between the Republic of India and the Republic of Singapore. Disponível em: <http://rtais.wto.org/UI/PublicShowMemberRTAIDCard.aspx?rtaid=10>. Acesso em: 20 mai. 2014.

269 “Article 60 (...)

Note: Specific commitments assumed under this Article shall not be construed to require either Party to compensate for any inherent competitive disadvantages which result from the foreign character of the relevant services or service suppliers". Comprehensive Economic Partnership Agreement Between Japan and the Republic of India. Disponível em:

<http://rtais.wto.org/UI/PublicShowMemberRTAIDCard.aspx?rtaid=173>. Acesso em: 20 mai. 2014. 
capítulo sobre serviços, exceto em situações emergenciais. Os acordos internacionais assinados por uma Parte que afetem a prestação de serviços também deverão ser publicados. Se a publicação dessas medidas e dos acordos não for possível, a Parte deverá levá-las ao conhecimento público por outra forma. Adicionalmente, cada Parte deverá responder prontamente aos pedidos da outra Parte a respeito de informações sobre medidas de aplicação geral ou acordos internacionais e estabelecer um ou mais pontos de contato para fornecer informações específicas que forem solicitadas pela outra Parte ${ }^{270}$.

No acordo com o Japão, há apenas duas obrigações relacionadas a transparência, a saber: (i) que as autoridades competentes de uma Parte respondam prontamente aos questionamentos da outra Parte ou de prestadores de serviços da outra Parte, por meio de pontos de contato; (ii) que as Partes preparem, encaminhem à outra Parte e publiquem uma lista com todas as medidas existentes no escopo do capítulo sobre serviços que são inconsistentes com as obrigações de acesso a mercados e tratamento nacional, se possível, até 5 anos após o Acordo entrar em vigor. Na lista, as Partes deverão indicar as seguintes informações: (i) o setor de serviços, sub-setor de serviços ou assunto a que a medida se refere; (ii) o tipo de inconsistência (acesso a mercados e/ou tratamento nacional); (iii) a fonte ou autoridade responsável pela medida; (iv) a descrição sucinta da medida. Essa lista será revisada anualmente e revista quando necessário ${ }^{271}$.

${ }^{270}$ Vide Artigo 7.1.8 do Acordo Índia-Cingapura e Artigo 6.20 do Acordo Índia-Coreia.
271 “Article 66

Transparency

1. The competent authorities referred to in paragraph 2 of Article 4 shall, upon request by the other Party or service suppliers of the other Party, promptly respond to specific questions from, and provide information to, the other Party or the service suppliers with respect to matters referred to in Article 4, including requirements and procedures for licensing and qualification, through enquiry points. The enquiry points shall be notified to the other Party by diplomatic note on the date of entry into force of this Agreement.

2. Each Party shall endeavour to prepare, forward to the other Party and make public a list providing all existing measures, within the scope of this Chapter, at the central governmental level, and prefectural governmental level in the case of Japan and governmental level of states and Union territories in the case of India, which are inconsistent with Articles 59 and/or 60, whether or not these measures are included in its Schedule of Specific Commitments in Annex 6. The list shall include the following elements and shall be reviewed annually and revised as necessary:

(a) sector and sub-sector or matter;

(b) type of inconsistency (i.e. Market Access and/or

National Treatment);

(c) legal source or authority of the measure; and

(d) succinct description of the measure.

Note: The list under this paragraph will be made solely for the purposes of transparency, and shall not be construed to affect any rights and obligations of a Party under this Chapter. The Parties understand that the list as required in this paragraph shall be prepared if possible within five years after the entry into force of this Agreement". Comprehensive Economic Partnership Agreement Between Japan and the Republic of India. Disponível em: <http://rtais.wto.org/UI/PublicShowMemberRTAIDCard.aspx?rtaid=173>. Acesso em: 20 mai. 2014. 
Por sua vez, no acordo celebrado com a Malásia, não há regras de transparências específicas no capítulo sobre serviços. As regras sobre transparência foram tratadas em capítulo específico (Capítulo 13) e determinam que serão observados os seguintes procedimentos pelas Partes: (i) publicação dos procedimentos, leis e regulamentos, de modo a garantir sua publicidade antes da entrada em vigor e permitir que sejam feitos comentários a seu conteúdo; (ii) manutenção de procedimentos administrativos imparciais que prestem as informações solicitadas e possibilitem a prestação de esclarecimentos e informações adicionais antes da decisão final sobre determinada questão; (iii) possibilidade de revisão das decisões administrativas; (iv) notificação das decisões e a prestação de informações, no idioma inglês, em domínio de acesso público ${ }^{272}$.

\subsection{Regulação doméstica}

Em relação ao tema regulação doméstica, as obrigações previstas nos acordos celebrados pela Índia são muito semelhantes àquelas contidas no Artigo VI do GATS.

De modo geral, os quatro acordos estabelecem as mesmas obrigações para as Partes, a saber: (i) garantir que todas as medidas que afetem o comércio de serviços sejam administradas de forma razoável, objetiva e imparcial; (ii) estabelecer ou manter tribunais ou procedimentos para a revisão de medidas administrativas que afetem o comércio de serviços, que devem ser objetivos e imparciais, exceto se essa previsão for inconstitucional ou inconsistente com seu sistema jurídico; (iii) se houver necessidade de autorização, as autoridades competentes devem informar prontamente o status do requerimento; e (iv) nos setores em que há compromissos específicos em serviços profissionais, a Parte estabelecerá procedimentos adequados para verificar a competência dos profissionais da outra Parte.

Os acordos também estabelecem que as Partes discutirão regras específicas sobre qualificação, licenciamento e normas técnicas desenvolvidos no âmbito do parágrafo IV do Art. 6 do GATS, com vistas a incorporar tais disciplinas nos Acordos e garantir que elas não constituam barreiras desnecessárias ao comércio regional de serviços.

${ }^{272}$ Vide Capítulo 13 do Acordo Índia-Malásia. 


\subsection{Outras obrigações relevantes}

Alguns acordos celebrados pela Índia relacionam as hipóteses nas quais a Parte poderá denegar as preferências concedidas aos serviços e prestadores de serviços da outra Parte (denial of benefits). Ressalte-se que, em todos os acordos, a denegação está sempre condicionada à realização de notificação e consultas com a outra Parte.

No acordo com a Coreia, foi estabelecido que poderão ser denegadas preferências concedidas no âmbito do Acordo caso sejam verificadas as seguintes circunstâncias: (i) se um serviço for prestado no território de uma não Parte; (ii) no caso de transporte marítimo, se o serviço for prestado por uma embarcação registrada sob as leis de uma não Parte e operada por pessoa que seja de uma não Parte; (iii) se o serviço for prestado por uma pessoa jurídica que é detida ou controlada por pessoas de uma não Parte ou da Parte que denegar o benefício e que não tenha atividades operacionais reais e contínuas ou operações substanciais no território da outra Parte; (iv) se o prestador de serviço for uma pessoa jurídica detida ou controlada por pessoa de uma não Parte e a Parte que denegar o benefício adotar ou mantiver medidas que incluam a notificação ou uma ordem a respeito da não Parte ou da pessoa da não Parte que proibir operações com a pessoa jurídica ou que sejam violadas ou prejudicadas se os benefícios desse capítulo se aplicarem a essa pessoa jurídica $^{273}$.

De forma semelhante, os acordos celebrados pela Índia com Malásia e com Cingapura preveem a denegação de preferências concedidas no âmbito do Acordo e contemplam as circunstâncias relacionadas nos itens (i) e (ii) acima, entre outras.

273 “ARTICLE 6.22: DENIAL OF BENEFITS

Subject to prior notification and consultation, a Party may deny the benefits of this Chapter:

(a) to the supply of a service, if it establishes that the service is supplied from or in the territory of a country that is not a Party to this Agreement;

(b) in the case of the supply of a maritime transport service, if it establishes that the service is supplied by

(i) a vessel registered under the laws of a non-Party, and

(ii) a person which operates or uses the vessel in whole or in part but which is of a non-Party;

(c) to a service provider of the other Party where the Party establishes that the service is being provided by a juridical person that is owned or controlled by persons of a non-Party or of the denying Party and that has no real and continuous business activities or no substantive business operations in the territory of the other Party; or

(d) to a service supplier of the other Party if the service supplier is a juridical person owned or controlled by persons of a non-Party, and the denying Party adopts or maintains measures which include notification or an order, with respect to the non- Party or a person of the non-Party that prohibit transactions with the juridical person or that would be violated or circumvented if the benefits of this Chapter were accorded to the juridical person". Comprehensive Economic Partnership Agreement Between the Republic of Korea and the Republic of India. Disponível em:

<http://rtais.wto.org/UI/PublicShowMemberRTAIDCard.aspx?rtaid=715>. Acesso em: 20 mai. 2014. 
Segundo o acordo entre Índia e Cingapura, a denegação também poderá ocorrer nas seguintes hipóteses: (i) para a prestação de um serviço por meio de presença comercial, se a Parte estabelecer, em determinado momento, que a pessoa de uma não Parte detém ou controla, ou adquiriu propriedade ou controle, sob o prestador do serviço; (ii) para a prestação de um serviço a partir ou no território de outra Parte, se a Parte estabelecer que o serviço é prestado por um prestador que é detido ou controlado por uma pessoa da Parte que denegar o benefício ${ }^{274}$.

No Acordo entre Índia e Malásia, está prevista a denegação de preferências para a prestação de um serviço a partir ou no território de outra Parte, se a Parte estabelecer que o serviço é prestador por um prestador que é detido ou controlado por uma pessoa de uma não Parte e a Parte que denegar o benefício: (i) não mantiver relações diplomáticas com a não Parte; ou (ii) adotar ou mantiver medidas com respeito à não Parte que proíba operações com as pessoas jurídicas ou por meio de outras formas de presença comercial, tais como uma agência ou escritório de representação, que serão violadas ou prejudicadas se os benefícios deste capítulo forem acordados à pessoa jurídica ou por meio de outras formas de presença comercial ${ }^{275}$.

274 “ARTICLE 7.23: DENIAL OF BENEFITS

1. Subject to prior notification and consultation, a Party may deny the benefits of this Chapter:

(a) to the supply of a service, if it establishes that the service is supplied from or in the territory of a country that is not a Party to this Agreement;

(b) in the case of the supply of a maritime transport service, if it establishes that the service is supplied: (i) by a vessel registered under the laws of a non-Party, and (ii) by a person which operates and/or uses the vessel in whole or in part but which is of a non-Party;

(c) to the supply of a service through commercial presence, if the Party establishes at any time that persons of a non-Party own or control, or have acquired ownership or control over through subsequent transactions, the service supplier;

(d) to the supply of a service from or in the territory of the other Party, if the Party establishes that the service is supplied by a service supplier that is owned or controlled by a person of the denying Party". Comprehensive Economic Cooperation Agreement Between the Republic of India and the Republic of Singapore. Disponível em: <http://rtais.wto.org/UI/PublicShowMemberRTAIDCard.aspx?rtaid=10>. Acesso em: 20 mai. 2014.

275 "Article 8.16

Denial of Benefits

1. Subject to prior notification and consultation, a Party may deny the benefits of this Chapter:

(a) to the supply of a service, if it establishes that the service is supplied from or in the territory of a country that is not a Party to this Agreement;

(b) in the case of the supply of a maritime transport service, if it establishes that the service is supplied: (i) by a vessel registered under the laws of a non-Party; and

(ii) by a person which operates and/or uses the vessel in whole or in part but which is of a non-Party; (c) to the supply of a service from or in the territory of the other Party, if the Party establishes that the service is supplied by a service supplier that is owned or controlled by a person of a non-Party and the denying Party:

(i) does not maintain diplomatic relations with the non-Party; or

(ii) adopts or maintains measures with respect to the non-Party that prohibit transactions with the juridical person, or through other forms of commercial presence such as a branch or representative office that would be violated or circumvented if the benefits of this Chapter were accorded to the juridical person or through other forms of commercial presence such as a branch or representative office". Comprehensive Economic 
Por fim, cumpre notar que os acordos celebrados pela Índia com Japão, Coreia e Cingapura preveem a extensão dos compromissos contidos nos novos acordos que envolvam o comércio de serviços celebrados com uma não Parte a esses países, caso eles sejam mais benéficos ${ }^{276}$.

\section{CONCLUSÕES}

Por meio da análise dos acordos regionais de comércio, cujas principais cláusulas foram apresentadas neste capítulo, foi possível concluir que os Estados Unidos têm adotado a postura mais homogênea em relação a seus parceiros comerciais. Esse país tem conseguido implementar o mesmo modelo para a liberalização comercial em serviços a todos aqueles com os quais negocia. Por outro lado, União Europeia, China e Índia são mais flexíveis em relação ao modelo adotado para a liberalização comercial em serviços, buscando acomodar os interesses da outra Parte.

Nesse sentido, observa-se que a União Europeia é mais agressiva em acordos com países desenvolvidos do que em acordos com países em desenvolvimento. Isso ficou evidente no acordo com a Coreia, que é um país em desenvolvimento e um importante parceiro comercial europeu. As normas sobre serviços que constam do acordo com a Coreia foram bem mais complexas com relação aos demais acordos celebrados pelo bloco europeu, possivelmente em razão do interesse comercial no mercado coreano ${ }^{277}$.

Quanto ao modelo de lista de compromissos adotado, dos acordos analisados, apenas aqueles celebrados pelos Estados Unidos adotam o modelo de lista negativa baseado no NAFTA. Os acordos celebrados pela União Europeia, pela China e pela Índia adotam o modelo de lista positiva, o que garante maior flexibilidade às Partes. Assim, elas podem eleger os setores, sub-setores e modos que serão objeto de compromissos específicos e as limitações de acesso a mercados e tratamento nacional aplicáveis, podendo, inclusive, assumir compromissos que não refletem o status quo regulatório. Além disso, as partes não

Cooperation Agreement Between the Government of the Republic of India and the Government of Malaysia. Disponível em: <http://rtais.wto.org/UI/PublicShowMemberRTAIDCard.aspx?rtaid=544>. Acesso em: 20 mai. 2014.

276 Vide Artigo 6.3 do Acordo Índia-Coreia; Artigo 7.6 do Acordo Índia-Cingapura; Artigo 63 do Acordo Índia-Japão.

277 “Again the EU is likely to distinguish between least developed and developing countries that it is unlikely to push very hard, and the more important emerging markets where the EU service sector is looking for progress." Stephen Woolcock. European Union policy towards Free Trade Agreements. ECIPE Working

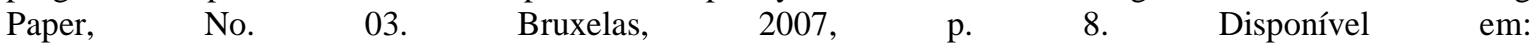
http://www.felixpena.com.ar/contenido/negociaciones/anexos/2010-09-european-union-policy-towards-freetrade-agreements.pdf. Acesso em: 19 abr. 2014. 
se comprometem em relação a medidas não conformes, existentes ou futuras, e não possuem obrigação legal de fornecer informações aos parceiros comerciais sobre a natureza das regulações discriminatórias ou de medidas que impeçam o acesso ao mercado doméstico.

Por sua vez, o modelo adotado pelos Estados Unidos possibilita uma liberalização comercial mais eficaz e transparente, em virtude de dois fatores: a lista de medidas não conformes e o "mecanismo de catraca" (ratchet mechanism). Como visto neste capítulo, a lista de medidas não conformes relaciona todos os setores de serviços e medidas que não serão liberalizados no acordo, com exceção daqueles especificados pelas Partes em suas listas de reservas. Já o "mecanismo de catraca" consolida as restrições aos serviços e prestadores de serviços estrangeiros existentes no momento de celebração do acordo, permitindo apenas a remoção dessas medidas discriminatórias, nunca sua reintrodução.

A esse respeito, é importante notar que, não obstante a União Europeia utilize o modelo de lista positiva para assunção de compromissos em serviços em âmbito regional, alguns acordos celebrados determinam o trancamento do status quo regulatório para as limitações de acesso a mercados e tratamento nacional para os setores e sub-setores de serviços consolidados, mecanismo que é típico do modelo NAFTA ${ }^{278}$. O mesmo não ocorre com Índia e China, que buscam seguir integralmente o modelo GATS nos acordos regionais que celebram com seus parceiros comerciais.

Com relação aos modos de prestação de serviços abrangidos pelas regras dos acordos regionais, verifica-se que Estados Unidos, Índia e China foram bastante consistentes no tratamento dessa questão. Os acordos celebrados pela Índia e pela China possuem capítulos sobre serviços ou acordos suplementares sobre serviços que abrangem os quatro modos de prestação definidos pelo GATS. Não obstante, nos acordos envolvendo a Índia, os direitos e obrigações relativos ao modo 4 costumam ser tratados em um capítulo independente. Os acordos regionais celebrados pelos Estados Unidos possuem um capítulo sobre serviços, que regula apenas os modos 1, 2 e 4, visto que as obrigações relativas ao modo 3 estão incluídas no capítulo sobre investimentos. Apenas o bloco europeu adotou uma postura distinta sobre o tema em cada acordo, sendo que, na maioria dos casos, as obrigações regionais sobre serviços referem-se somente aos modos 1,3 e 4.

Acerca das medidas que estão excluídas das obrigações assumidas no acordo ou capítulo sobre serviços, há certa homogeneidade no tratamento do tema pelos quatro

\footnotetext{
${ }^{278}$ Vide South Centre, 2009, p. 4-5.
} 
players em análise. Em geral, são excluídos do âmbito de aplicação dos compromissos os serviços prestados no âmbito da autoridade governamental, incluindo compras governamentais, as medidas que afetem os direitos de tráfego aéreo, exceto manutenção e reparação de aeronaves, venda e a comercialização de serviços de transporte aéreo, serviços de reserva computadorizada, subsídios e subvenções governamentais.

A abrangência das obrigações de acesso a mercados e de tratamento nacional depende do modelo de liberalização comercial em serviços adotado pelo acordo regional. Nos acordos celebrados pelos Estados Unidos, essas obrigações têm aplicação abrangente sobre todas as medidas, serviços e setores de serviços, exceto sobre aqueles excluídos da incidência do acordo ou que foram especificados pelas Partes. Por outro lado, nos acordos celebrados por União Europeia, Índia e China, que adotam o modelo de liberalização do GATS, as obrigações de acesso a mercados e de tratamento nacional incidem somente sobre os setores, sub-setores e modos de prestação de serviços que são objeto de compromissos específicos. A esse respeito, é curioso observar que a União Europeia buscou estabelecer obrigações de tratamento nacional mesmo nos acordos menos sofisticados, que não preveem a liberalização comercial do setor de serviços por meio de lista de compromissos.

Em relação às limitações de acesso a mercados, os acordos regionais envolvendo União Europeia, a China e a Índia são muito semelhantes, à medida que tendem a replicar parâmetros contidos no GATS. Os acordos regionais envolvendo os Estados Unidos posteriores ao NAFTA também adotam praticamente os mesmos critérios do GATS, dele diferindo apenas em relação à proibição de limitações à participação de capital estrangeiro e à impossibilidade de adoção de requisitos de presença local.

A respeito das limitações de tratamento nacional, a maioria dos acordos celebrados pela China e pela Índia reproduz o conteúdo do Artigo XVII do GATS, com algumas exceções, as quais foram abordadas no decorrer deste capítulo. Os acordos celebrados por União Europeia e Estados Unidos, por sua vez, partem dos parâmetros adotados pelo GATS, adaptando seu texto às particularidades dos modos de prestação de serviços a que as limitações se aplicam.

Em geral, os acordos regionais celebrados por Estados Unidos, União Europeia, China e Índia analisados contêm regras sobre regulação doméstica, que não trazem inovações significativas em relação à disciplina do Artigo VI do GATS. Alguns acordos tratam de questões de interesse particular das Partes envolvidas, como a necessidade de discussões para remoção de necessidade de vistos ou residência para o licenciamento e a 
certificação de provedores de serviços. De modo geral, há uma previsão de atualização das disciplinas sobre regulação doméstica no caso de evolução do tema na OMC.

Há uma diferença significativa nas obrigações relacionadas a transparência contidas nos acordos regionais celebrados pelos Estados Unidos e pelos demais players. Como regra, os acordos celebrados por China, Índia e União Europeia preveem obrigações muito mais simples do que os acordos celebrados pelos Estados Unidos, já que, no modelo de liberalização comercial por listas negativas, eventuais restrições de acesso a mercados existentes são consolidadas no nível legal vigente no momento da celebração do acordo, garantindo maior previsibilidade e segurança jurídica aos prestadores estrangeiros.

Nos acordos envolvendo os Estados Unidos, as Partes devem apresentar informações detalhadas sobre cada medida não conforme que for mantida, de modo que o prestador de serviços estrangeiro possa tomar conhecimento da existência da medida e de seu conteúdo. Em relação às novas medidas que vierem a ser criadas ou adotadas pelas partes que possam afetar o comércio regional de serviços, deve ser realizada notificação e ser dada oportunidade à outra Parte para apresentar seus comentários. Nos acordos regionais envolvendo China, Índia e União Europeia, as obrigações sobre transparência consistem, basicamente, na indicação do tipo de restrição que afeta determinado setor, na publicação das medidas que afetem o comércio de serviços e na criação de pontos de contato para responder aos pedidos de informação apresentados por outros Membros.

Por fim, há outras obrigações relevantes para a liberalização comercial em serviços que são tratadas com detalhes por alguns players e praticamente ignoradas por outros. A esse respeito, merecem destaque a cláusula de nação mais favorecida e a cláusula que trata de regra de origem em serviços (denial of benefits) em determinado acordo regional.

Não há um tratamento uniforme dado à cláusula de tratamento de nação mais favorecida nos acordos analisados. Apenas um dos acordos envolvendo a China, celebrado com a Nova Zelândia, possui cláusula de nação mais favorecida, ao passo que todos os acordos celebrados pela Índia, Estados Unidos e União Europeia possuem essa cláusula. Não há explicação para essa diferença ${ }^{279}$.

\footnotetext{
${ }^{279}$ Sobre o tratamento diferenciado desse cláusula, Pierre Latrille e Jouneyoung Lee apontam o seguinte: "About $20 \%$ of the agreements of the sample, mostly involving at least one party from Asia, do not have a MFN clause.56 In particular, out of eight RTAs that China is a party, and surveyed in this paper, seven do not have an MFN provision.

It is striking that while all NAFTA type and all EU type agreement have MFN clauses, 40\% of GATS type agreements and a similar percentage of "other" agreements do not. There is no clear explanation for such a "family split". Maybe some of the users of the GATS formula found the strong MFN clause of the GATS too difficult to accommodate or to tone down, while the NAFTA users had the ready-made solution of lodging reservations for existing and future non-conforming, non MFN measures”. P. LATRILLE e J. LEE, 2012, p.
} 
A cláusula que trata de regra de origem em serviços é uma cláusula relevante, visto que estabelece em que medida os não Membros poderão se beneficiar das disposições de determinado acordo regional ${ }^{280}$. A regra de origem relativa ao comércio de serviços está presente nos acordos regionais celebrados por Estados Unidos, Índia e China. Grande parte dos acordos celebrados por Estados Unidos utiliza um critério híbrido, que avalia a existência de relações diplomáticas ou proibição de operações com determinada empresa e a existência de operações comerciais substanciais no território de uma das Partes. A maioria dos acordos envolvendo a China utiliza apenas o critério de operações comerciais substanciais. A Índia, por sua vez, não adota apenas o critério de controle do capital do prestador de serviços. Os acordos celebrados pela União Europeia não contêm disposições nesse sentido.

23.

${ }^{280}$ A esse respeito, vide P. SAUVÉ; A. SHINGAL. Reflections on the nature of preferences in services. 2014, p. 408. 


\section{CAPÍTULO 2: O TRATAMENTO DO TEMA SERVIÇOS NOS ACORDOS REGIONAIS CELEBRADOS PELO MERCOSUL}

\section{INTRODUÇÃO}

O presente capítulo tem por objetivo analisar como o comércio de serviços tem sido tratado nos acordos regionais celebrados pelo Mercosul. Seu intuito é comparar a política do bloco sul-americano com o tratamento dado a esse tema pelos principais players do comércio internacional - Estados Unidos, União Europeia, Índia e China -, que foi abordado no capítulo anterior.

Para tanto, é necessário examinar como o comércio de serviços é tratado em âmbito regional, isto é, quais são as principais normas e a política do Mercosul para a liberalização comercial desse setor intrabloco. Na sequência, serão analisados os acordos regionais de comércio envolvendo o Mercosul, com o intuito de identificar se a liberalização do setor de serviços é tratada neles e quais são as principais disposições relativas ao tema em cada um. Com relação aos ACE celebrados pelo Mercosul com outros Estados-membros da ALADI, apenas serão analisados os ACE Mercosul-Chile e Mercosul-Colômbia, visto que os demais não possuem disposições relevantes para a liberalização do comércio de serviços.

Assim, serão estudados os seguintes acordos celebrados pelo Mercosul até 15 fevereiro de 2013 ${ }^{281}$ : (i) ACP Mercosul-Índia; (ii) Acordo Mercosul-Egito; (iii) Acordo Mercosul-Israel; (iv) Acordo Mercosul-SACU; (v) Acordo Mercosul-Palestina; (vi) ACE Mercosul-Chile. Por fim, serão estudados os acordos de livre comércio envolvendo o Mercosul que se encontravam em negociação em 15 de fevereiro de 2013, quais sejam: (i) Acordo Mercosul-União Europeia; (ii) ACP Mercosul-Índia, em fase de ampliação; (iii) ACE Mercosul-Colômbia.

\section{O PROTOCOLO DE MONTEVIDÉU E A LibERALIZAÇÃO DO SETOR DE SERVIÇOS INTRABLOCO}

O setor de serviços é um pilar importante para a consolidação do Mercosul. Nesse sentido, note-se que o próprio Artigo $1^{\circ}$ do Tratado de Assunção, celebrado em 1991 por

${ }^{281} \mathrm{O}$ corte refere-se à data de celebração, e não à vigência do acordo. Alguns dos acordos celebrados até 15 fevereiro de 2013 ainda não haviam entrado em vigor nessa mesma data. 
Brasil, Argentina, Uruguai e Paraguai ${ }^{282}$ e que é o Acordo Constitutivo do bloco, determinou que a criação do mercado comum implicaria a livre circulação de $\operatorname{serviços}^{283}$, a qual se daria por meio de qualquer medida de efeito equivalente à eliminação dos direitos alfandegários e restrições não tarifárias à circulação de bens ${ }^{284}$.

Embora o objetivo da livre circulação de serviços como parte do projeto de formação do mercado comum tenha sido descrito no Tratado de Assunção, a liberalização comercial do setor foi regulamentada seis anos mais tarde, em 1997, com a celebração do Protocolo de Montevidéu ${ }^{285}$.

O Protocolo de Montevidéu reconheceu a importância da livre circulação do comércio de serviços para o desenvolvimento das economias dos Estados-membros do Mercosul, para o aprofundamento da união aduaneira e para a progressiva conformação do mercado comum ${ }^{286}$. Estabeleceu também que o programa de liberalização do comércio de serviços do Mercosul seria completado no prazo de dez anos a partir da sua entrada em vigor $^{287}$. Para tanto, foi escolhido o mesmo modelo de liberalização progressiva do GATS, que já havia entrado em vigor à época de sua celebração ${ }^{288}$. Assim, a livre circulação de

${ }^{282}$ Estados-membros originais do Mercosul. Atualmente, a Venezuela e a Bolívia também integram o bloco como membros plenos.

${ }^{283}$ A respeito do conceito de "livre circulação de serviços", Michel Arsalanian Neto aponta que se trata de um conceito mais ambicioso que o conceito de liberalização, relcionado à ideia de liberalização completa. Vide M. ARSALANIAN NETO, 2010, p. 96.

284 “CAPÍTULO I - Propósitos, Princípios e Instrumentos

ARTIGO 1

Os Estados Partes decidem constituir um Mercado Comum, que deverá estar estabelecido a 31 de dezembro de 1994, e que se denominará "Mercado Comum do Sul" (MERCOSUL).

Este Mercado comum implica:

A livre circulação de bens, serviços e fatores produtivos entre os países, através, entre outros, da eliminação dos direitos alfandegários e restrições não tarifárias à circulação de mercadorias e de qualquer outra medida de efeito equivalente". Tratado para a Constituição de um Mercado Comum entre a República Argentina, a República Federativa do Brasil, a República do Paraguai e a República Oriental do Uruguai. Disponível em: <http://www.mercosul.gov.br/normativa/tratados-e-protocolos/tratado-deassuncao-1/?searchterm=tratado\%20assuncao $>$. Acesso em: 18 ago. 2013.

${ }^{285}$ Vide Michel Arsalanian Neto, 2010, p. 98.

286 Vide Protocolo de Montevidéu sobre o Comércio de Serviços do Mercosul. Disponível em: <http://www.planalto.gov.br/ccivil_03/_Ato2007-2010/2008/Decreto/D6480.htm>. Acesso em: 9 mai. 2014.

${ }^{287}$ O Protocolo de Montevidéu entrou em vigor no dia 7 de dezembro de 2005.

${ }^{288}$ Sobre o Protocolo de Montevidéu ter sido inspirado no modelo GATS, Michel Arsalanian Neto explica o seguinte: "Desde 1997, o MERCOSUL conta com instrumento específico - o Protocolo de Montevidéu -, inspirado no Acordo Geral sobre o Comércio de Serviços (GATS, na sigla em inglês), da Organização Mundial do Comércio (OMC), para regular o processo de liberalização comercial no setor. (...) A negociação do Protocolo de Montevidéu deu-se quando o GATS havia acabado de entrar em vigor e foi concomitante às negociações dos Protocolos de Serviços Financeiros e de Telecomunicações da OMC. Isso explica, em parte, o fato de o instrumento do MERCOSUL ter sido tão influenciado em seus princípios e estrutura pelo padrão multilateral. Tanto mais que o mecanismo de liberalização progressiva que caracteriza o GATS, e que seria reproduzido pelo Protocolo de Montevidéu, harmonizava-se com o sentido de cautela da posição brasileira. Abandonou-se a abordagem setorial da Comissão de Serviços do SG-10, em favor do tratamento horizontal de todos os setores de serviços, conforme a metodologia multilateral'. M. ARSALANIAN NETO, 2010, p. 98-99. 
serviços no Mercosul é baseada em listas positivas, cujos compromissos seriam aprofundados em rodadas de negociação periódicas e sucessivas, o que dá aos Estadosmembros flexibilidade na escolha dos setores e serviços a serem consolidados e a manutenção de espaço para a implementação de políticas públicas de seu interesse ${ }^{289}$.

Até o momento, foram realizadas sete rodadas de negociação, sendo a última em 2009, que permitiram aumento progressivo no nível de compromissos específicos assumidos pelos Estados-membros nas suas respectivas listas de compromissos específicos $^{290}$.

Em 2008, foi promulgado o Plano de Ação para o Aprofundamento do Programa de Liberalização do Comércio de Serviços no âmbito do Mercosul ${ }^{291}$, com vistas a concluir a livre circulação do comércio de serviços intrabloco até 2015, conforme estabelecido no Protocolo de Montevidéu. Para tanto, foram estabelecidos prazos e tarefas a serem cumpridos pelos Estados-membros, que culminariam, em 2014, com a eliminação das últimas restrições à livre circulação de serviços, relacionadas às limitações e de acesso a mercado e tratamento nacional nos setores altamente sensíveis, à harmonização/complementação dos quadros regulatórios, ao aprofundamento das disciplinas do Mercosul sobre regulamentação doméstica e à eliminação das medidas de regulamentação doméstica identificadas como entraves ao comércio intrazona.

Observa-se, assim, que os Estados-membros do Mercosul reconhecem a importância do comércio de serviços como elemento imprescindível para a formação de um mercado comum e estão buscando cumprir com os prazos estabelecidos no Protocolo de Montevidéu para a livre circulação de serviços entre seus Estados-membros. Contudo, em razão da complexidade envolvendo a harmonização de políticas regulatórias e eliminação

\footnotetext{
289 "In any event, the Protocol of Montevideo essentially reproduces the main characteristics of GATS, which favour developing countries: flexibility; progressive liberalization through positive lists of specific commitments; and the maintenance of members"e policy space to implement policies through the regulation of services sectors and subsectors. As in the case of GATS, the essence of its framework and structure should remain unchanged". U. CELLI JUNIOR., M. SALLES, D. TUSSIE; J. PEIXOTO. MERCOSUR in SouthSouth Agreements: In the middle of two models of regionalism. Instituto Virtual da Organização para a Cooperação Econômica e o Desenvolvimento: 2010, p. 40-41. Disponível em: $<$ http://vi.unctad.org/resources-mainmenu-64/digital-library?i=VI\&op=all\&q=Mercosur+in+Southsouth+Agreements $\% 3 \mathrm{~A}+\mathrm{In}+$ the+Middle+of+Two+Models+of+Regionalism+\&act=search\&option=com_gsli nk>. Acesso em: 13 jun. 2011.

${ }^{290}$ Vide S. STEPHENSON e M. ROBERT. Innovating regionalism: the Americas. Pierre Sauvé; Anirud Shingal, 2014, p. 104.

${ }^{291}$ MERCOSUL/CMC/DEC. $\mathrm{N}^{\circ}$ 49/08 - Plano de ação para o aprofundamento do programa de liberalização do comércio de serviços no âmbito do Mercosul. Disponível em: <http://www.mercosur.int/msweb/portal\%20intermediario/Normas/normas_web/Decisiones/PT/2008/DEC_0 49 -

2008_PT_Plano\%20de\%20A\%C3\%A7ao\%20Liberaliza\%C3\%A7ao\%20Comercio\%20Servi\%C3\%A7os.do c). Acesso: 9 mai. 2014.
} 
de restrições de acesso a mercados e tratamento nacional em setores estratégicos para os governos dos Estados que integram o Mercosul, é pouco provável que esse prazo seja cumprido.

\section{A LEGISLAÇÃO DO MERCOSUL RELATIVA À CELEBRAÇÃo DE ACORDOS REGIONAIS DE COMÉRCIO EXTRABLOCO}

A lógica de constituição de um mercado comum, como aquele existente na União Europeia e que se busca alcançar pelo Mercosul, implica, entre outros aspectos, a necessidade de que os Estados-membros adotem uma política comercial externa comum ${ }^{292}$.

No Mercosul, esse objetivo foi previsto no Artigo 1 do Tratado de Assunção, que estabelece como implicações da constituição do bloco sul-americano a adoção de uma política comercial comum em relação a terceiros Estados ou agrupamentos de Estados, a coordenação de posições em foros econômico-comerciais regionais e internacionais e a coordenação de políticas macroeconômicas e setoriais entre os Estados-membros em assuntos de comércio exterior ${ }^{293}$. A fim de possibilitar a relação do bloco com outros países, blocos econômicos e organismos internacionais, o Protocolo de Ouro Preto, de dezembro de 1994, dotou o Mercosul de personalidade jurídica de direito internacional ${ }^{294}$.

292 “CAPÍTULO I - Propósitos, Princípios e Instrumentos ARTIGO 1

Os Estados Partes decidem constituir um Mercado Comum, que deverá estar estabelecido a 31 de dezembro de 1994, e que se denominará "Mercado Comum do Sul" (MERCOSUL).

Este Mercado comum implica:

(...) O estabelecimento de uma tarifa externa comum e a adoção de uma política comercial comum e relação a terceiros Estados ou agrupamentos de Estados e a coordenação de posições em foros econômico-comerciais regionais e internacionais;

A coordenação de políticas macroeconômicas e setoriais entre os Estados Partes - de comércio exterior, agrícola, industrial, fiscal, monetária, cambial e de capitais, de outras que se acordem -, a fim de assegurar condições adequadas de concorrência entre os Estados Partes, e

O compromisso dos Estados Partes de harmonizar suas legislações, nas áreas pertinentes, para lograr o fortalecimento do processo de integração". Tratado para a Constituição de um Mercado Comum entre a República Argentina, a República Federativa do Brasil, a República do Paraguai e a República Oriental do Uruguai. Disponível em: <http://www.mercosul.gov.br/normativa/tratados-e-protocolos/tratado-de-assuncao1/?searchterm=tratado\%20assuncao $>$. Acesso em: 18 ago. 2013.

${ }^{293}$ Vide U. CELLI JUNIOR. Teoria Geral da Integração: Em Busca de um Modelo Alternativo. A. A. MERCADANTE; U. CELLI JUNIOR; L. ROCHA DE ARAÚJO. Blocos Econômicos e Integração na América Latina, África e Ásia. Curitiba: Juruá, 2006, p. 32-33.

294 "CAPÍTULO II - Personalidade Jurídica

Artigo 34

O Mercosul terá personalidade jurídica de Direito Internacional". Protocolo Adicional ao Tratado de Assunção sobre a Estrutura Institucional do Mercosul (Protocolo de Ouro Preto). Disponível em: <http://www.sice.oas.org/trade/mrcsrp/ourop/ouropinp.asp>. Acesso em: 21 mai. 2014. 
Desta sorte, a celebração de acordos comerciais para a liberalização do comércio de bens e serviços pelo Mercosul com outros países e blocos não apenas é possível, mas também é compatível com a lógica desse tipo de mecanismo de integração regional. Como visto anteriormente, o Artigo V do GATS possibilita que os Membros da OMC celebrem acordos que visem a liberalizar o comércio de serviços com outros Membros, desde que cumpridas as exigências estabelecidas nesse artigo, a saber: os referidos acordos possuam cobertura setorial substancial e eliminem ou reduzam as restrições existentes.

Nesse sentido, em 2000, o Conselho Mercado Comum do Mercosul proferiu a Decisão CMC No. 32/00, que estabelece a política a ser seguida pelo bloco em relação à celebração de acordos comerciais com terceiros países ou blocos de países extra-zona nos quais se outorgue preferência tarifária. De acordo com o texto da própria Decisão CMC No. 32/00, em virtude da necessidade do Mercosul de contar com uma política comercial externa comum, os Estados-membros entenderam que se fazia necessário priorizar as negociações como bloco em detrimento das negociações de acordos comerciais de forma bilateral. Isso significa que, a partir de então, os Estados-membros só poderiam negociar acordos comerciais com terceiros países ou blocos de países de forma conjunta. No entanto, foi estabelecida a necessidade de se preservar, por um período adicional, as preferências comerciais negociadas bilateralmente com os Estados-membros da ALADI com os quais não se havia finalizado a negociação de um quadro normativo para regular as relações comerciais entre tais países e o Mercosul. Esse prazo adicional terminou em 30 de junho de $2001^{295}$.

Portanto, a partir da Decisão CMC No. 32/00, os países do Mercosul passaram a negociar em conjunto seus acordos comerciais com outros países ou grupos de países, o

295““(...) CONSIDERANDO:

Que a constituição de um mercado comum implica, entre outros aspectos, a necessidade de contar com uma política comercial externa comum.

Que os Estados Partes têm manifestado a necessidade de preservar, por um período adicional, as preferências comerciais negociadas bilateralmente com os países membros da ALADI com os quais não se finalizou a negociação de um marco normativo que regule as relações comerciais entre eles e o MERCOSUL.

Que os Estados Partes entendem que é necessário priorizar as negociações como bloco estabelecendo uma data limite para a negociação de acordos bilaterais.

O CONSELHO DO MERCADO COMUM

DECIDE:

Art. $1^{\circ}$.- Reafirmar o compromisso dos Estados Partes do MERCOSUL de negociar de forma conjunta acordos de natureza comercial com terceiros países ou blocos de países extra-zona nos quais se outorguem preferências tarifárias.

Art. $2^{\circ}$.- A partir de 30 de junho de 2001, os Estados Partes não poderão assinar novos acordos preferenciais ou acordar novas preferências comerciais em acordos vigentes no marco da ALADI, que não tenham sido negociados pelo MERCOSUL". MERCOSUL/CMC/Dec. $\mathbf{N}^{\mathbf{0}}$ 32/00: Relançamento do Mercosul Relacionamento Externo. Disponível em: <http://www.sice.oas.org/trade/mrcsrs/decisions/dec3200p.asp>. Acesso em: 9 mai. 2014. 
que faz com que as posições negociadoras do bloco precisem ser previamente acordadas em reuniões internas de coordenação.

Não obstante, discute-se, atualmente, a possibilidade de um Membro do Mercosul celebrar acordos com outros Estados e blocos econômicos de forma independente. De fato, uma negociação com apenas dois Estados é muito mais fácil do que uma negociação com, no mínimo, sete Estados. Ademais, a ausência de coordenação e consenso entre os Estados-membros do Mercosul, que passam por problemas políticos e econômicos tão distintos, pode inviabilizar acordos regionais importantes, como o que está sendo negociado com a União Europeia. Em um cenário em que os acordos regionais estão se proliferando com muita facilidade por todo o planeta, o mecanismo estabelecido na Decisão CMC No. 32/00 pode levar ao isolamento comercial do bloco.

Além da vontade política dos Estados-membros do Mercosul de abandonarem a obrigatoriedade de celebrar acordos comerciais em conjunto, conforme previsto na Decisão CMC No. 32/00, uma mudança de posicionamento a respeito desse tema também poderia ser justificada juridicamente. O artigo 42 do Protocolo de Ouro Preto estabelece que as normas elaboradas pelos órgãos do Mercosul previstos no Artigo 2 do referido Protocolo Conselho do Mercado Comum, Grupo Mercado Comum e Comissão de Comércio do Mercosul - terão caráter obrigatório e deverão, quando necessário, ser incorporadas aos ordenamentos jurídicos dos Estados-membros, por meio dos procedimentos previstos nas respectivas legislações nacionais ${ }^{296}$. Contudo, nem todas as normas promulgadas pelos órgãos a que se refere o Artigo 2 do Protocolo de Ouro Preto estariam dispensadas de incorporação pelas legislações nacionais, mas apenas as normas estritamente organizacionais.

Posteriormente, as normas a que se refere o Artigo 42 do Protocolo de Ouro Preto foram objeto de regulamentação pelo Conselho Mercado Comum na Decisão. No 23/00, que determinou as hipóteses nas quais as normas promulgadas por este órgão, prelo Grupo Mercado Comum e pela Comissão de Comércio do Mercosul não precisariam ser incorporadas aos ordenamentos jurídicos dos Estados-membros, a saber: (i) se os Estadosmembros entenderem, de forma conjunta, que o conteúdo da norma trata de assuntos relacionados ao funcionamento interno do Mercosul, o que será explicitado no texto da

296 "Artigo 42

As normas emanadas dos órgãos do Mercosul previstos no Artigo 2 deste Protocolo terão caráter obrigatório e deverão, quando necessário, ser incorporadas aos ordenamentos jurídicos nacionais mediante os procedimentos previstos pela legislação de cada país". Protocolo Adicional ao Tratado de Assunção sobre a Estrutura Institucional do Mercosul (Protocolo de Ouro Preto). Disponível em: <http://www.sice.oas.org/trade/mrcsrp/ourop/ouropinp.asp>. Acesso em: 9 mai. 2014. 
norma, sendo que esta entrará em vigor a partir de a sua aprovação; (ii) se o conteúdo da norma estiver contemplado na legislação nacional do Membro, caso em que a Coordenação Nacional realizará a notificação, indicando a norma nacional já existente que contenha o conteúdo da norma do Mercosul em questão ${ }^{297}$.

Em vista do exposto, considerando que a Decisão CMC No. 32/00 é posterior ao Protocolo de Ouro Preto e à Decisão CMC No. 23/00, que ela não regula um assunto relacionado ao funcionamento interno do Mercosul e que seu conteúdo não estava previamente contemplado nas legislações nacionais de todos os Estados-membros, como é o caso do Brasil, seria necessário proceder à internalização da referida Decisão para que ela tivesse validade jurídica, nos termos dos Artigos 40 e 42 do Protocolo de Ouro Preto, o que nunca ocorreu. Nesse sentido, cumpre notar que o mesmo vale para a Decisão CMC No. 23/00, que nunca foi internalizada pelos Estados-membros do Mercosul, sob o argumento de regulamentar aspectos da organização e do funcionamento do bloco ${ }^{298}$.

Mesmo que a CMC entendesse que a incorporação da Decisão CMC No. 32/00 não seria necessária, em razão de o conteúdo dessa norma regulamentar aspectos da organização e do funcionamento do bloco, essa decisão seria inconsistente com a prática do Mercosul. Isso porque compromissos da mesma natureza, em outros casos, foram incorporados como obrigação internacional por meio da adoção de protocolos ao ACE-18, no âmbito da $\mathrm{ALADI}^{299}$.

Independentemente das discussões acerca da validade jurídica da Decisão CMC No. 32/00 e da necessidade de os Estados-membros do Mercosul negociarem acordos regionais de forma individual, desde 2000, o bloco tem seguido a diretriz imposta pela referida

\footnotetext{
297 “Art. 5.- As normas emanadas dos órgãos do MERCOSUL não necessitarão de medidas internas para a sua incorporação, nos termos do artigo 42 do Protocolo de Ouro Preto, quando:

a) os Estados Partes entendam, conjuntamente, que o conteúdo da norma trata de assuntos relacionados ao funcionamento interno do MERCOSUL. Este entendimento será explicitado no texto da norma com a seguinte frase: "Esta norma (Diretiva, Resolução ou Decisão) não necessita ser incorporada ao ordenamento jurídico dos Estados Partes, por regulamentar aspectos da organização ou do funcionamento do MERCOSUL". Estas normas entrarão em vigor a partir de a sua aprovação.

b) o conteúdo da norma estiver contemplado na legislação nacional do Estado Parte

. Neste caso a Coordenação Nacional realizará a notificação prevista no Artigo 40 (i) nos termos do Artigo 2 desta Resolução, indicando a norma nacional já existente que contenha o conteúdo na norma MERCOSUL em questão. Esta comunicação se realizará dentro do prazo previsto para a incorporação da norma. A SAM comunicará este fato aos demais Estados Partes". MERCOSUL/CMC/DEC. No 23/00 - Relançamento do Mercosul - Incorporação da Normativa Mercosul ao Ordenamento Jurídico dos Estados Partes. Disponível em: <http://www.sice.oas.org/trade/mrcsrs/decisions/dec2300p.asp>. Acesso em: 9 mai. 2014.

${ }^{298}$ Vide O. A. D. CANÇADO TRINDADE. O Mercosul no direito brasileiro: incorporação de normas e segurança jurídica. Belo Horizonte, Del Rey: 2006, p. 65.

${ }^{299}$ A respeito desse assunto, vide C. M. B. CONZENDEY. O Sistema de Incorporação das Normas do Mercosul à Ordem Jurídica Interna. A. C. VAZ (Org.) Dimensões da integração no Mercosul. Brasília: Cadernos do CEAM, No. 7, 2002, p. 45-61.
} 
normativa e seus Estados-membros têm se engajado na celebração de alguns acordos regionais visando a liberalização do comércio de bens e serviços, de forma coordenada. A seguir, serão analisados os acordos regionais de comércio envolvendo o Mercosul, com o intuito de identificar se a liberalização do setor de serviços é um dos temas abrangidos ou não por seu escopo e, em caso positivo, quais são as principais disposições sobre o tema.

\section{LIBERALIZAÇÃO DO SETOR DE SERVIÇOS NOS ACORDOS REGIONAIS DE COMÉRCIO CELEBRADOS PELO MERCOSUL}

\subsection{ACP Mercosul-Índia}

O ACP Mercosul-Índia, que foi celebrado em janeiro de 2004 e entrou em vigor em junho de 2009, foi o primeiro acordo regional de comércio que o bloco sul-americano celebrou com país de fora do continente americano.

Trata-se de um acordo que visa a concessão de preferências tarifárias e outras condições mais benéficas na importação de bens, constituindo, assim, o primeiro passo para a criação de uma área de livre comércio Mercosul-Índia ${ }^{300}$.

Portanto, não há qualquer disposição no ACP Mercosul-Índia sobre a liberalização do comércio de serviços entre as Partes.

\footnotetext{
300 "Artigo 2

As Partes acordam concluir este Acordo de Comércio Preferencial como um primeiro passo rumo à criação de uma área de livre comércio entre o MERCOSUL e a República da Índia.

CAPÍTULO II - Liberalização do Comércio

Artigo 3

Os Anexos I e II deste Acordo contêm os produtos para os quais preferências tarifárias e outras condições são acordadas para sua importação dos respectivos territórios das Partes Signatárias.

a) O Anexo I contém os produtos para os quais preferências tarifárias são concedidas pelo MERCOSUL à República da Índia.

b) O Anexo II contém os produtos para os quais preferências tarifárias são concedidas pela República da Índia ao MERCOSuL". Acordo de Comércio Preferencial entre o Mercosul e a República da Índia. Disponível em:

<http://www.mdic.gov.br/sitio/interna/interna.php?area=5\&menu=1405\&refr=405> Acesso em: 12 mai. 2014.
} 


\subsection{Acordo Mercosul-Israel}

O Acordo de Livre Comércio entre o Mercosul e o Estado de Israel, assinado em dezembro de 2007, foi o primeiro celebrado pelo bloco com um país não Membro da ALADI.

Embora este Acordo preveja a criação de uma área de livre comércio, em um primeiro momento, as Partes buscaram apenas eliminar as barreiras ao comércio de bens e facilitar a circulação deles entre seus territórios ${ }^{301}$.

A respeito da liberalização do comércio de serviços, as Partes reconhecem a importância dessa área e, em seus esforços para aprofundar e expandir gradualmente suas relações econômicas, comprometem-se a considerar as possíveis modalidades para iniciar negociações sobre acesso a mercados em serviços no âmbito do Comitê Conjunto, tendo como base o modelo do GATS, quando aplicável ${ }^{302}$. O Acordo não definiu nenhum prazo para a assunção de compromissos nesse setor.

O Acordo de Livre Comércio entre o Mercosul e o Estado de Israel está em vigor desde o dia 28 de abril de 2010, com a publicação do Decreto ${ }^{\circ} 7.159$, de 27 de abril de $2010^{303}$.

301 “Artigo 2 - Estabelecimento da Área de Livre Comércio

As Partes deste Acordo, coerentes com o Artigo XXIV do Acordo Geral sobre Tarifas e Comércio (GATT) de 1994, estabelecem uma área de livre comércio.

Artigo 3 - Objetivos

Os objetivos deste Acordo, conforme estabelecido mais especificamente em suas disposições, são:

1. eliminar as barreiras ao comércio de bens e facilitar sua circulação entre os territórios das Partes;

2. promover as condições de livre concorrência na área de livre comércio;

3. aumentar substancialmente as oportunidades de investimento nos territórios das Partes e aumentar a cooperação em áreas que sejam de interesse mútuo das Partes;

4. criar procedimentos eficazes para a implementação, aplicação e cumprimento deste Acordo e sua administração conjunta; e

5. estabelecer um marco para aprofundar a cooperação bilateral e multilateral para expandir e ampliar os benefícios do Acordo". Acordo de Livre Comércio entre o Mercosul e o Estado de Israel. Disponível em: $\langle\mathrm{http} / / /$ www.mdic.gov.br/sitio/interna/interna.php?area=5\&menu=1404\&refr=405>. Acesso em: 12 mai. 2014.

302 "Artigo 9- Investimentos e Comércio de Serviços

1. As Partes reconhecem a importância das áreas de investimentos e de comércio de serviços. Em seus esforços para aprofundar e expandir gradualmente suas relações econômicas, as Partes considerarão, no Comitê Conjunto, as possíveis modalidades para iniciar negociações sobre acesso a mercados em investimentos e sobre comércio de serviços, tendo como base a arquitetura do GATS, quando aplicável". Acordo de Livre Comércio entre o Mercosul e o Estado de Israel. Disponível em: <http://www.mdic.gov.br/sitio/interna/interna.php?area=5\&menu=1404\&refr=405>. Acesso em: 12 mai. 2014.

303 Disponível em: <http://www.planalto.gov.br/ccivil_03/_Ato2007-2010/2010/Decreto/D7159.htm>. Acesso em: 12 mai. 2014. 


\subsection{Acordo Mercosul-Egito}

O Acordo Mercosul-Egito, celebrado em agosto de 2010, determina a criação de uma área de livre comércio entre as Partes ${ }^{304}$. No entanto, as obrigações estabelecidas neste Acordo referem-se, prioritariamente, à abertura ao mercado bilateral de bens, por meio da desgravação tarifária de produtos do interesse de ambas as Partes.

Em relação ao setor de serviços, o Acordo Mercosul-Egito possui uma cláusula que prevê a possibilidade de entendimentos, no futuro, para ampliação do escopo do acordo para essa área. As Partes expressaram sua intenção de lograr uma liberalização gradual do setor de serviços, que ocorrerá em conformidade com as disposições do GATS. Para tanto, determinaram a criação de um Comitê Misto, no âmbito do qual se reunirão para analisar as possíveis modalidades para a abertura das negociações de acesso a mercados no comércio de serviços $^{305}$. O Acordo não definiu nenhum prazo para que as Partes assumam compromissos no setor de serviços.

Note-se que o Acordo Mercosul-Egito ainda não entrou em vigor ${ }^{306}$.

\subsection{Acordo Mercosul-SACU}

Em dezembro de 2008, foi celebrado o Acordo de Comércio Preferencial entre Mercosul e SACU. Primeiro, foram iniciadas negociações apenas com a África do Sul, com vistas a um acordo para a criação de uma área de livre comércio e maior cooperação econômica e de investimentos. No entanto, em outubro de 2003, as negociações evoluíram

304 “Article 3 - Establishment of the Free Trade Area

The Parties and Signatory Parties to this Agreement, consistent with Article XXIV of the GATT 1994 and the Decision on Differential and More Favorable Treatment, Reciprocity and Fuller Participation of Developing Countries of 1979, hereby establish a free trade area". Acordo de Livre Comércio entre o Mercosul e a República Árabe do Egito. Disponível em:

<http://www.mdic.gov.br/sitio/interna/interna.php?area=5\&menu=2716\&refr=405>. Acesso em: 12 mai. 2014.

305 “Article 24 -Trade in Services

1. The Parties and Signatory Parties shall aim at achieving gradual liberalization and the opening of their markets for trade in services in accordance with the provisions of the WTO General Agreement on Trade in Services (hereinafter referred to as "GATS").

2. In their efforts to gradually deepen and broaden their economic relations, the Parties will consider, in the Joint Committee, the possible modalities for opening negotiations on market access on trade in services, on the basis of the GATS framework". Acordo de Livre Comércio entre o Mercosul e a República Árabe do Egito. Disponível em: <http://www.mdic.gov.br/sitio/interna/interna.php?area=5\&menu=2716\&refr=405>. Acesso em: 12 mai. 2014.

${ }^{306}$ Informação disponível em:

<http://www.mdic.gov.br/sitio/interna/interna.php?area=5\&menu=2716>. Acesso em: 12 mai. 2014. 
para envolver a união aduaneira formada pela África do Sul, Namíbia, Botsuana, Lesoto e Suazilândia. A SACU pretendia ir diretamente para um acordo de livre comércio, mas aceitou iniciar com um acordo de preferências fixas.

O Acordo celebrado entre Mercosul e SACU estabelece margens de preferências tarifárias fixas como um primeiro passo para a criação de uma Área de Livre Comércio entre as Partes. Não há qualquer previsão em relação à liberalização do setor de serviços.

Ressalte-se que o Acordo Mercosul-SACU ainda não está em vigor ${ }^{307}$.

\subsection{Acordo Mercosul-Palestina}

O Acordo de Livre Comércio entre o Mercosul e o Estado da Palestina, assinado em dezembro de 2011, baseou-se no Acordo-Quadro de Comércio e Cooperação Econômica entre o bloco e a Autoridade Nacional Palestina, de dezembro de 2010.

O referido Acordo determina que será criada uma área de livre comércio entre as Partes e tem os seguintes objetivos: (i) eliminação de barreiras ao comércio e facilitação de circulação de mercadorias entre os territórios das Partes; (ii) promoção de condições de concorrência leal na área de livre comércio; (iii) aumentar substancialmente as oportunidades de investimento nos territórios das Partes e a cooperação em áreas de interesse mútuo; (iv) criação de procedimentos eficazes para a implementação, aplicação e cumprimento do Acordo e sua administração conjunta; (v) estabelecimento de um quadro para a cooperação bilateral e multilateral para expandir e melhorar os benefícios do Acordo $^{308}$.

Com relação ao comércio de serviços, as Partes reconhecem a importância das áreas de investimentos e comércio de serviços. Em seus esforços para aprofundar e expandir

\footnotetext{
${ }^{307}$ Informação disponível em:

<http://www.mdic.gov.br/sitio/interna/interna.php?area=5\&menu=2339\&refr=405>. Acesso em: 12 mai. 2014.

308 "Article 3 - Objectives

The objectives of this Agreement, as elaborated more specifically in its provisions are to:

1. eliminate barriers to trade in, and facilitate the movement of goods between the territories of the Parties;

2. promote conditions of fair competition in the free trade area;

3. increase substantially investment opportunities in the territories of the Parties, and increase cooperation in areas which are of mutual interest to the Parties;

4. create effective procedures for the implementation, application and compliance with this Agreement, and its joint administration; and

5. establish a framework for further bilateral and multilateral cooperation to expand and enhance the benefits of this Agreement". Acordo de Livre Comércio entre Mercosul e o Estado da Palestina. Disponível em:

<http://www.mdic.gov.br/sitio/interna/interna.php?area=5\&menu=3381\&refr=405>. Acesso em: 12 mai. 2014.
} 
gradualmente suas relações econômicas, considerarão, na Comissão Mista, as possíveis modalidades de abertura das negociações sobre acesso a mercados em investimentos e comércio de serviços, com base no quadro do GATS, conforme aplicável ${ }^{309}$.

\subsection{ACE Mercosul-Chile}

O ACE No 35 foi celebrado entre Mercosul e Chile em junho de 1996, no âmbito da ALADI, e internalizado no Brasil pelo Decreto n. ${ }^{\circ}$ 2075, de 19 de novembro do mesmo ano. O referido acordo tem entre seus objetivos: (i) o estabelecimento de arcabouço jurídico e institucional de cooperação e integração econômica e física que contribua para a criação de um espaço econômico ampliado, que tenda a facilitar a livre circulação de bens e serviços e a plena utilização dos fatores produtivos; (ii) o estabelecimento de uma área de livre comércio entre as Partes, em um prazo máximo de 10 anos, mediante a expansão e diversificação do intercâmbio comercial e a eliminação das restrições tarifárias e não tarifárias que afetam o comércio recíproco ${ }^{310}$.

A respeito da livre circulação de serviços, as Partes determinaram que a liberalização, a expansão e a diversificação progressiva do comércio de serviços em seus territórios ocorreria em prazo a ser definido, de acordo com os compromissos assumidos por elas no GATS ${ }^{311}$.

309 "FINAL PROVISIONS

Article 1 - Evolutionary Clause (...)

2. The Parties recognize the importance of the areas of investments and trade in services. In their efforts to gradually deepen and broaden their economic relations, they will consider in the Joint Committee the possible modalities for opening negotiations on market access on investments and trade in services, on the basis of the GATS framework as applicable". Acordo de Livre Comércio entre Mercosul e o Estado da Palestina. Disponível em:

<http://www.mdic.gov.br/sitio/interna/interna.php?area=5\&menu=3381\&refr=405>. Acesso em: 12 mai. 2014.

310 “Artigo 1. O presente Acordo tem por objetivos:

- Estabelecer o arcabouço jurídico e institucional de cooperação e integração econômica e física que contribua à criação de um espaço econômico ampliado, que tenda a facilitar a livre circulação de bens e serviços e a plena utilização dos fatores produtivos;

- Formar uma área de livre comércio entre as Partes Contratantes em um prazo máximo de 10 anos, mediante a expansão e diversificação do intercâmbio comercial e a eliminação das restrições tarifárias e não tarifárias que afetam o comércio recíproco;

- Promover o desenvolvimento e a utilização da infra-estrutura física, com especial ênfase no estabelecimento de interconexões bioceânicas;

- Promover e estimular os investimentos recíprocos entre os agentes econômicos das Partes Signatárias; - Promover a complementação e cooperação econômica, energética, científica e tecnológica".

Acordo De Complementação Econômica $\mathbf{N}^{\circ} 35$ Celebrado entre os Governos dos Estados Partes do Mercosul e o Governo da República do Chile.. Disponível em: <http://www.mdic.gov.br/sitio/interna/interna.php?area=5\&menu=461>. Acesso em: Acesso em: 12 mai. 2014.

311 “TÍTULO XIII 
Em 26 de maio de 2009, foi celebrado o $53^{\circ}$ Protocolo Adicional ao ACE $\mathrm{N}^{\mathrm{o}} 35$, que aprovou o Protocolo sobre o Comércio de Serviços entre o Mercosul e o Chile. O referido Protocolo estabelece regras detalhadas sobre a liberalização do setor de serviços entre as Partes, que seguem o modelo estabelecido no GATS. Desse modo, a liberalização do comércio de serviços entre as Partes será realizada por meio de listas positivas, nas quais serão especificados os setores de serviços, sub-setores de serviços e modos de prestação objeto de compromissos específicos, além dos termos, limitações e condições em matéria de acesso a mercados e de tratamento nacional e as obrigações relativas aos compromissos adicionais $^{312}$.

De acordo com o Artigo II, o Protocolo incide sobre os quatro modos de prestação de serviços descritos no GATS. São medidas abrangidas pelo Protocolo todas aquelas adotadas pelas Partes que afetem o comércio de serviços entre o Chile e os Estados Partes de Mercosul, com exceção das seguintes: (i) medidas relacionadas a direitos de tráfego aéreo e ao exercício de tais direitos, exceto serviços de reparação e manutenção de aeronaves, enquanto a aeronave estiver fora de serviço, venda e comercialização dos serviços de transporte aéreo e serviços de sistemas de reserva informatizados; (ii) compras

\section{SERVIÇOS}

Artigo 34.- As Partes Signatárias promoverão a liberalização, a expansão e a diversificação progressiva do comércio de serviços em seus territórios, em prazo a ser definido e de acordo com os compromissos assumidos no Acordo Geral sobre Comércio de Serviços (GATS).

Artigo 35.- Para os fins do presente Título, define-se "comércio de serviços" como a prestação de um serviço: a. do Território de uma das Partes Signatárias para o território da outra Parte; b. no território de uma Parte Signatária para um consumidor de serviços de outra Parte Signatária; c. por um fornecedor de serviços de uma Parte Signatária mediante presença comercial no território da outra Parte Signatária;

d. por um fornecedor de serviços de uma Parte Signatária mediante a presença de pessoas físicas de uma Parte Signatária no território da outra Parte Signatária.

Artigo 36.- Para a consecução dos objetivos enunciados no precedente Artigo 34, as Partes Contratantes concordam em iniciar os trabalhos com vistas a avançar na definição dos aspectos do Programa de Liberalização para os setores de serviços objetos de comércio". Acordo De Complementação Econômica No 35 Celebrado entre os Governos dos Estados Partes do Mercosul e o Governo da República do Chile. Disponível em: <http://www.mdic.gov.br/sitio/interna/interna.php?area=5\&menu=461〉. Acesso em: Acesso em: 12 mai. 2014.

312 "Artigo V. Listas de compromissos específicos

1. Os compromissos específicos assumidos por cada uma das Partes Signatárias à luz dos Artigos III (Tratamento Nacional) e IV (Acesso a Mercados) estão estabelecidos nas Listas incluídas no Anexo III. Com respeito aos setores em que tais compromissos são assumidos, em cada Lista se especificarão:

(a) os termos, limitações e condições em matéria de acesso a mercados;

(b) as condições e ressalvas em matéria de tratamento nacional; e

(c) as obrigações relativas aos compromissos adicionais a que se refere o Artigo VI (Compromissos Adicionais)". Acordo de Complementação Econômica $\mathbf{N}^{\circ} 35$ Celebrado entre os Governos dos Estados Partes do Mercosul e o Governo da República do Chile. Quinquagésimo Terceiro Protocolo Adicional. Protocolo Sobre o Comércio de Serviços entre o Mercosul e o Chile. Disponível em: <http://www.mdic.gov.br/sitio/interna/interna.php?area=5\&menu=461>. Acesso em: Acesso em: $12 \mathrm{mai}$. 2014. 
governamentais; (iii) subsídios ou doações concedidas por uma Parte ou empresa do Estado $^{313}$

A respeito das limitações de tratamento nacional, o Protocolo determina que as Partes não outorguem aos serviços e aos prestadores de serviços da outra Parte tratamento menos favorável do que aquele que dispensa a seus próprios serviços similares ou prestadores de serviços similares ${ }^{314}$. Portanto, observa-se que também nesse aspecto o Protocolo segue o conceito estabelecido no Artigo XVII do GATS de serviços e prestadores de serviços similares (like services and like service supliers).

O Protocolo prevê seis hipóteses em que as Partes podem limitar o acesso de serviços e prestadores de serviços estrangeiros a seus mercados, as quais coincidem com aquelas previstas no Artigo XVI GATS, a saber: (i) limitações quanto ao número de prestadores de serviços; (ii) limitações quanto ao valor total dos ativos ou das operações de serviços; (iii) limitações quanto ao número total de operações de serviços ou à quantidade total de

313 “Artigo II. Âmbito de aplicação

1. O presente Protocolo aplica-se às medidas adotadas ou mantidas pelas Partes Signatárias que afetem o comércio de serviços entre o Chile e os Estados Partes de MERCOSUL, incluídas aquelas relativas:

(a) à prestação de um serviço;

(b) à compra, pagamento ou utilização de um serviço;

(c) ao acesso a serviços ao público em geral por prescrição das Partes Signatárias, e a utilização dos mesmos, por motivo da prestação de um serviço;

(d) à presença, incluída a presença comercial, de pessoas de uma Parte Signatária no território de outra Parte Signatária para a prestação de um serviço.

2. Este Protocolo não se aplica às medidas que uma Parte Signatária adote ou mantenha quanto aos direitos de tráfego aéreo e aos serviços diretamente relacionados ao exercício de tais direitos, salvo:

(a) os serviços de reparação e manutenção de aeronaves enquanto a aeronave estiver fora de serviço;

(b) a venda e comercialização dos serviços de transporte aéreo; e

(c) os serviços de sistemas de reserva informatizados (SRI).

3. Nenhuma das disposições do presente Protocolo será interpretada no sentido de impor qualquer obrigação com respeito às compras governamentais.

4. As disposições do presente Protocolo não se aplicarão a subsídios ou doações concedidas por uma Parte Signatária ou empresa do Estado, incluídos os empréstimos, garantias e seguros outorgados pelo governo. As Partes Contratantes revisarão a questão dos subsídios relacionadas com o comércio de serviços, levando em conta as disciplinas que sejam estabelecidas de acordo com o mandato contido no Artigo XV do Acordo Geral sobre o Comércio de Serviços, que forma parte do Acordo de Marraqueche, pelo qual se estabelece a Organização Mundial de Comércio (GATS)". Acordo de Complementação Econômica $\mathbf{N}^{\circ} 35$ Celebrado entre os Governos dos Estados Partes do Mercosul e o Governo da República do Chile. Quinquagésimo Terceiro Protocolo Adicional. Protocolo Sobre o Comércio de Serviços entre o Mercosul e o Chile. Disponível em: <http://www.mdic.gov.br/sitio/interna/interna.php?area=5\&menu=461>. Acesso em: Acesso em: 12 mai. 2014.

314 “Artigo III. Tratamento nacional

1. Nos setores inscritos em sua Lista e sob as condições e as ressalvas que nela possam se estabelecer, cada Parte Signatária outorgará aos serviços e aos prestadores de serviços da outra Parte Signatária, com respeito a todas as medidas que afetem a prestação de serviços, um tratamento não menos favorável do que aquele que dispensa a seus próprios serviços similares ou prestadores de serviços similares.". Acordo de Complementação Econômica $\mathbf{N}^{\circ} 35$ Celebrado entre os Governos dos Estados Partes do Mercosul e o Governo da República do Chile. Quinquagésimo Terceiro Protocolo Adicional. Protocolo Sobre o Comércio de Serviços entre o Mercosul e o Chile. Disponível em: <http://www.mdic.gov.br/sitio/interna/interna.php?area=5\&menu=461>. Acesso em: Acesso em: $12 \mathrm{mai}$. 2014. 
serviços produzidos; (iv) limitações quanto ao número total de pessoas físicas que podem ser empregadas em um determinado setor de serviços ou que um prestador de serviços pode empregar; (v) medidas que restrinjam ou exijam tipos específicos de pessoa jurídica ou de empreendimento conjunto para a prestação de um serviço; (vi) limitações quanto à participação de capital estrangeiro ${ }^{315}$.

As obrigações relacionadas à regulação doméstica estabelecidas pelo Protocolo também são similares àquelas previstas no Artigo VI do GATS, a saber: (i) nos setores em que forem assumidos compromissos específicos, as medidas de aplicação geral serão administradas de maneira razoável, objetiva e imparcial; (ii) nos setores em que forem assumidos compromissos específicos, as medidas relativas a requisitos e procedimentos em matéria de qualificação, padrões técnicos e requisitos em matéria de licenças serão baseadas em critérios objetivos e transparentes e não constituirão restrição disfarçada ao comércio; (iii) quando for exigida autorização para a prestação de um serviço objeto de compromisso específico, as autoridades competentes da Parte, informarão o solicitante da decisão concernente a sua solicitação dentro de um prazo razoável a partir da apresentação de uma solicitação e fornecerão, a pedido do solicitante, sem demora injustificada, informação referente à situação da solicitação; (iv) as Partes celebrarão consultas periódicas para determinar se é possível eliminar restrições remanescentes em matéria de

315 "Artigo IV. Acesso a mercados (...)

2. Nos setores em que são assumidos compromissos de acesso a mercados, as medidas que nenhuma das Partes Signatárias manterá ou adotará, seja no âmbito de uma subdivisão regional ou da totalidade de seu território, a menos que em sua Lista especifique o contrário, são definidas como segue:

(a) limitações quanto ao número de prestadores de serviços, seja na forma de contingentes numéricos, monopólios ou prestadores exclusivos de serviços ou mediante a exigência de teste de necessidade econômica;

(b) limitações quanto ao valor total dos ativos ou das transações de serviços na forma de contingentes numéricos ou mediante a exigência de teste de necessidade econômica;

(c) limitações quanto ao número total de operações de serviços ou à quantidade total de serviços produzidos, expressas em unidades numéricas indicadas sob forma de contingentes ou mediante a exigência de teste de necessidade econômica;

(d) limitações ao número total de pessoas físicas que possam ser empregadas em um determinado setor de serviços ou que um prestador de serviços possa empregar e que sejam necessárias à prestação de um serviço específico e estejam diretamente relacionadas a este, sob forma de contingentes numéricos ou mediante a exigência de teste de necessidade econômica;

(e) medidas que restrinjam ou exijam tipos específicos de pessoa jurídica ou de empreendimento conjunto ("joint venture") por meio dos quais um prestador de serviços de outra Parte Signatária possa prestar um serviço; e

(f) limitações quanto à participação de capital estrangeiro expressas como limite percentual máximo de posse de ações por estrangeiros ou relativas ao valor total dos investimentos estrangeiros individuais ou agregados". Acordo de Complementação Econômica $\mathbf{N}^{\circ} 35$ Celebrado entre os Governos dos Estados Partes do Mercosul e o Governo da República do Chile. Quinquagésimo Terceiro Protocolo Adicional. Protocolo Sobre o Comércio de Serviços entre o Mercosul e o Chile. Disponível em: <http://www.mdic.gov.br/sitio/interna/interna.php?area=5\&menu=461>. Acesso em: Acesso em: 12 mai. 2014. 
cidadania ou de residência permanente relativas à concessão de licenças ou certificados de seus respectivos prestadores de serviços.

Cumpre notar que o Protocolo contempla outras duas questões importantes relacionadas às regras de regulação doméstica. A primeira consiste na manutenção da flexibilidade para que cada Parte possa regulamentar e continuar introduzindo novas regulamentações, em seus territórios, para atingir seus objetivos de política nacional, conforme previsto no preâmbulo do GATS. A segunda se refere à possibilidade de que as Partes desenvolvam disciplinas sobre regulamentação doméstica no âmbito do acordo, com base nos resultados das negociações sobre o tema na $\mathrm{OMC}^{316}$.

As normas relativas a transparência previstas no Protocolo estabelecem as seguintes obrigações às Partes: (i) publicar todas as medidas pertinentes de aplicação geral que afetem o comércio regional de serviços, no mais tardar na data de sua entrada em vigor, incluindo os acordos internacionais que elas assinem com outros Estados; (ii) informar prontamente à Comissão Administradora do ACE No 35 sobre a adoção ou modificação de leis, regulamentos ou diretrizes administrativas que possam afetar significativamente o comércio regional de serviços; (iii) responder prontamente a todos os pedidos de informação apresentados pela outra Parte acerca de medidas de aplicação geral abrangidas

316 “Artigo VII. Regulamentação Doméstica

1. Nada no presente Protocolo será interpretado no sentido de impedir o direito de cada Parte Signatária, de acordo com o estabelecido no Artigo V (Listas de Compromissos Específicos), de regulamentar e de introduzir novas regulamentações dentro de seus próprios territórios para atingir seus objetivos de política nacional.

2. Nos setores em que compromissos específicos sejam assumidos, cada Parte Signatária velará para que todas as medidas de aplicação geral que afetem o comércio de serviços sejam administradas de maneira razoável, objetiva e imparcial.

3. Cada Parte Signatária velará, igualmente, para que, nos setores nos quais compromissos específicos sejam assumidos, as medidas relativas aos requisitos e procedimentos em matéria de qualificação, padrões técnicos e requisitos em matéria de licenças sejam baseados em critérios objetivos e transparentes e não constituam restrição encoberta à prestação de um serviço.

4. As Partes Contratantes considerarão o desenvolvimento de futuras disciplinas sobre regulamentação doméstica no âmbito do presente Protocolo, que levarão em conta os resultados das negociações sobre o tema na Organização Mundial do Comércio.

5. Quando for exigida autorização para a prestação de um serviço em relação ao qual tenha sido assumido um compromisso específico, as autoridades competentes da respectiva Parte Signatária, dentro de um prazo razoável a partir da apresentação de uma solicitação que se considere completa segundo as leis e os regulamentos nacionais pertinentes, informarão o solicitante da decisão concernente a sua solicitação. A pedido do solicitante, as autoridades competentes da Parte Signatária fornecerão, sem demora injustificada, informação referente à situação da solicitação.

6. As Partes Contratantes celebrarão, periodicamente, consultas com o intuito de determinar se é possível eliminar restrições remanescentes em matéria de cidadania ou de residência permanente relativas à concessão de licenças ou certificados de seus respectivos prestadores de serviços”. Acordo de Complementação Econômica $\mathbf{N}^{\circ} 35$ Celebrado entre os Governos dos Estados Partes do Mercosul e o Governo da República do Chile. Quinquagésimo Terceiro Protocolo Adicional. Protocolo Sobre o Comércio de

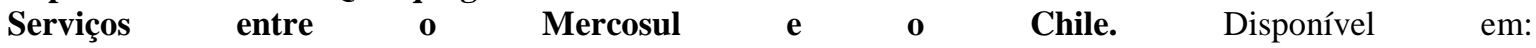
<http://www.mdic.gov.br/sitio/interna/interna.php?area=5\&menu=461>. Acesso em: Acesso em: $12 \mathrm{mai}$. 2014. 
pelo Protocolo; (iv) prestar, quando solicitada, informação aos prestadores de serviços da outra Parte sobre as questões sujeitas a notificação no âmbito do Protocolo; (v) designar um ponto focal para facilitar a comunicação com a outra Parte a respeito das questões a que se refere o Artigo IX do Protocolo ${ }^{317}$.

Outra cláusula relevante do Protocolo elenca as hipóteses nas quais poderá haver denegação de benefícios conferidos aos prestadores de serviços da outra Parte, a saber: (i) se o prestador de serviços for uma pessoa que não seja considerada como das Partes Signatárias, tal qual se define no Protocolo; ou (ii) se o prestador de serviços prestar o serviço a partir do ou no território de uma não-Parte. Em ambos os casos, há necessidade de notificação prévia e realização de consultas ${ }^{318}$.

O Protocolo prevê, ainda, que todo acordo bilateral vigente entre uma Parte do Mercosul e o Chile, ou que uma Parte do Mercosul firme com o Chile, prevalecerá para as Partes Signatárias envolvidas no referido acordo bilateral sobre os compromissos assumidos no presente instrumento, se estabelecerem condições mais favoráveis ${ }^{319}$.

\section{7 “Artigo IX. Transparência}

1. Cada Parte Signatária publicará prontamente e, salvo em situações de força maior, no mais tardar na data de sua entrada em vigor, todas as medidas pertinentes de aplicação geral que se refiram ao presente Protocolo ou afetem seu funcionamento. Outrossim, cada Parte Signatária publicará os acordos internacionais que assine com qualquer país e que se refiram a, ou afetem, o comércio de serviços.

2. Cada Parte Signatária informará, prontamente, à Comissão Administradora do ACE 35, a adoção de novas leis, regulamentos ou diretrizes administrativas ou a introdução de modificações às leis, regulamentos ou diretrizes administrativas já existentes que considere afetar significativamente o comércio de serviços compreendido por seus compromissos específicos, em virtude do presente Protocolo.

3. Cada Parte Signatária responderá, com presteza, a todos os pedidos de informação específicos apresentados pela outra Parte Contratante acerca de quaisquer medidas de aplicação geral a que se refere o parágrafo 1. De igual modo, de acordo com sua legislação interna, cada Parte Signatária, por intermédio de suas autoridades competentes, prestará, quando solicitada, informação aos prestadores de serviços da outra Parte Contratante sobre as questões sujeitas a notificação, segundo o parágrafo 2.

4. Para facilitar a comunicação das Partes Contratantes sobre a matéria de que trata o presente Artigo, cada uma das Partes Signatárias designará um ponto focal”. Acordo de Complementação Econômica $\mathbf{N}^{\circ} 35$ Celebrado entre os Governos dos Estados Partes do Mercosul e o Governo da República do Chile. Quinquagésimo Terceiro Protocolo Adicional. Protocolo Sobre o Comércio de Serviços entre o Mercosul e $\quad$ o $\quad$ Chile. $\quad$ Disponível em: <http://www.mdic.gov.br/sitio/interna/interna.php?area=5\&menu=461>. Acesso em: Acesso em: 12 mai. 2014.

318 “Artigo XVII. Denegação de benefícios

Uma Parte Signatária poderá denegar os benefícios derivados deste Protocolo, mediante prévia notificação e realização de consultas, aos prestadores de serviços da outra Parte Signatária se o prestador de serviços:

a) for uma pessoa que não seja considerada como das Partes Signatárias, tal como se define no presente Protocolo; ou

b) prestar o serviço a partir do ou no território de uma não-Parte". Acordo de Complementação Econômica $\mathbf{N}^{\circ} 35$ Celebrado entre os Governos dos Estados Partes do Mercosul e o Governo da República do Chile. Quinquagésimo Terceiro Protocolo Adicional. Protocolo Sobre o Comércio de Serviços entre o Mercosul e $\quad$ o $\quad$ Chile. $\quad$ Disponível em: <http://www.mdic.gov.br/sitio/interna/interna.php?area=5\&menu=461>. Acesso em: Acesso em: 12 mai. 2014.

319 "Artigo XXI Acordos bilaterais 
Os compromissos específicos foram consolidados no Anexo III ao $53^{\circ}$ Protocolo Adicional ao ACE No 35. Cada Estado-membro do Mercosul consolidou compromissos em serviços individualmente.

O referido Protocolo está em vigor entre o Brasil e o Chile desde junho de 2011.

\section{ACORDOS ENVOLVENDO O MERCOSUL EM FASE DE NEGOCIAÇÃO E A LIBERALIZAÇÃO DO COMÉRCIO DE SERVIÇOS}

\subsection{Acordo Mercosul-União Europeia}

Um possível acordo de livre comércio entre o Mercosul e União Europeia é, sem dúvida, o acordo mais relevante desse tipo envolvendo o bloco sul-americano e certamente um dos mais relevantes para o bloco europeu, seja em razão da relevância política das Partes, seja em razão do impacto econômico que se espera alcançar com a parceria ${ }^{320}$.

As negociações entre o Mercosul e União Europeia para a celebração de um acordo de livre comércio, denominado Acordo de Associação Bi-regional, foram lançadas em 1999, mas ficaram suspensas de 2004 a 2010, em virtude de impasses nas ofertas apresentadas em 2004.

Em maio de 2004, o Mercosul e a União Europeia apresentaram suas ofertas de liberalização comercial recíproca. Contudo, nas ofertas apresentadas, verificou-se que os pedidos do Mercosul em agricultura não foram atendidos, assim como não foram contemplados os pedidos da União Europeia em alguns setores de serviços (como serviços

Todo acordo bilateral vigente entre uma Parte Signatária do MERCOSUL e o Chile, ou que uma Parte Signatária do MERCOSUL firme com o Chile, prevalecerá, para as Partes Signatárias envolvidas no referido acordo bilateral, sobre os compromissos assumidos no presente instrumento, se estabelecerem condições mais favoráveis, observado o Artigo I.2 do presente Protocolo". Acordo de Complementação Econômica $\mathbf{N}^{\circ} 35$ Celebrado entre os Governos dos Estados Partes do Mercosul e o Governo da República do Chile. Quinquagésimo Terceiro Protocolo Adicional. Protocolo Sobre o Comércio de Serviços entre o Mercosul e o Chile. <http://www.mdic.gov.br/sitio/interna/interna.php?area=5\&menu=461>. Acesso em: Acesso em: 12 mai. 2014.

${ }^{320}$ Segundo informações disponibilizadas na página na Internet da Comissão Europeia, a União Europeia é o primeiro parceiro comercial do Mercosul, representando 20\% do comércio total do Mercosul. O Mercosul é o oitavo parceiro comercial mais importante da União Europeia, sendo responsável por 3\% do comércio total do bloco europeu. As exportações de bens da União Europeia para o Mercosul têm aumentado de forma constante ao longo dos últimos anos, passando de $€ 28$ bilhões em 2007 para $€ 57$ bilhões em 2012. A União Europeia é, também, um grande exportador de serviços comerciais para o Mercosul ( $€ 16$ bilhões em 2011), bem como o maior investidor estrangeiro na região. Vide http://ec.europa.eu/trade/policy/countries-andregions/regions/mercosur/. Acesso em: 13 mai. 2014. 
financeiros, telecomunicações, transportes e seguros), investimentos, compras governamentais e propriedade intelectual. No mês de julho daquele ano, ambos os lados se comprometeram verbalmente a melhorar suas ofertas. Porém, em setembro, tanto a União Europeia quanto o Mercosul apresentaram ofertas ainda menos ambiciosas em relação àquelas apresentadas em maio, o que instaurou um clima bastante negativo nas negociações, levando, por fim, à sua interrupção ${ }^{321}$.

Especificamente com relação ao comércio de serviços, ao longo dessa primeira etapa de negociações, os representantes dos dois blocos começaram a desenvolver um capítulo relacionado ao tema, que, porém, não chegou a ser finalizado em 2004. De todo modo, um aspecto importante dessa minuta de capítulo que afeta a dinâmica das negociações consiste na previsão de que a liberalização comercial do setor seria realizada com base na metodologia adotada pelo GATS ${ }^{322}$.

A respeito das ofertas em serviços apresentadas em 2004, contrariamente ao que ocorreu com as ofertas de bens, estas foram feitas por país, e não por bloco. Assim, a oferta de serviços do Mercosul de 2004 detalha, para cada Estado-membro, quais são os setores e as medidas que constituem o compromisso do Mercosul. Portanto, não há um compromisso único, acordado, harmonizado e plenamente idêntico para todo o Mercosul ${ }^{323}$. A esse respeito, note-se que os demais Estados-membros no Mercosul já possuíam ofertas mais liberais em serviços consolidadas na OMC, o que fez com que houvesse um diferencial importante entre as ofertas do Brasil e dos demais Estados-Membros. Não obstante, o Brasil apresentou uma oferta aperfeiçoada em relação à sua oferta na $\mathrm{OMC}$, que, no entanto, foi considerada insuficiente para atender às pretensões do bloco europeu ${ }^{324}$.

Em abril de 2010, as negociações entre as Partes foram retomadas com o intuito de negociar um acordo comercial amplo, englobando não apenas bens industriais e agrícolas, mas também serviços, regras relativas a compras governamentais, propriedade intelectual, facilitação do comércio e barreiras técnicas. Para o comércio de bens, busca-se a redução a

\footnotetext{
321 Vide FEDERAÇÃO DO COMÉRCIO DE BENS, SERVIÇOS E TURISMO DO ESTADO DE SÃO PAULO - FECOMÉRCIO SP. Cadernos FECOMÉRCIO de Economia Internacional, No. 2, Setembro de 2007, p. 16. Disponível em: <www.fecomercio.com.br/cms-site/Files/.../8ff402c2b9_caderno30.pdf>. Acesso em: 13 mai. 2014.

${ }^{322}$ Vide FEDERAÇÃO DO COMÉRCIO DE BENS, SERVIÇOS E TURISMO DO ESTADO DE SÃO PAULO - FECOMÉRCIO SP, 2007, p. 19.

${ }^{323}$ A oferta relativa a serviços do Mercosul, que foi apresentada à União Europeia em 2004, está disponível em: <http://www.mdic.gov.br/sitio/interna/interna.php?area=5\&menu=2280>. Acesso em: 13 mai. 2014.

${ }^{324}$ Vide FEDERAÇÃO DO COMÉRCIO DE BENS, SERVIÇOS E TURISMO DO ESTADO DE SÃO PAULO - FECOMÉRCIO SP, 2007, p. 20.
} 
zero das alíquotas de importação aplicáveis a $90 \%$ do valor do comércio entre os dois blocos $^{325}$.

Desde 2010, Mercosul e União Europeia têm se reunido frequentemente no âmbito do Comitê de Negociações Bi-Regionais. Até 2013, as negociações se concentraram na elaboração do quadro normativo do Acordo, que inclui as normas relativas a temas como defesa comercial, solução de controvérsias, concorrência, barreiras técnicas, medidas sanitárias e fitossanitárias, investimentos, serviços, entre outros. A partir de 2014, o foco das reuniões bilaterais serão os pedidos e as ofertas em acesso a mercados de bens e serviços, com vistas à conclusão do acordo.

Com relação ao quadro normativo do acordo para o comércio de serviços, não foi divulgada nenhuma informação oficial acerca do que já foi acordado pelas Partes no âmbito do Comitê de Negociações Bi-Regionais. Considerando que a União Europeia possui um grande interesse ofensivo no setor de serviços e que uma abertura ampla em relação a esse setor é imprescindível para que exista um acordo entre os dois blocos, é legítima a expectativa de que, por proposta dos europeus, o capítulo sobre o tema se aproxime daquele adotado no acordo com a Coreia. Se essa expectativa for concretizada, o capítulo sobre serviços adotará o modelo do GATS de listas positivas para a assunção de compromissos nesse setor, os quais abrangerão os modos 1, 3 e 4 de prestação de serviços. As obrigações serão bastante detalhadas e completas, mas aceitáveis para o Brasil e demais Estados-membros do Mercosul, uma vez que o modelo GATS garante flexibilidade para que as Partes liberalizem apenas os serviços e setores que desejarem, podendo, inclusive, inscrever limitações de acesso a mercados e tratamento nacional.

Acerca das ofertas na área de serviços, é bastante provável que a oferta do Mercosul continue sendo específica por Estado-membro, haja vista não existir uma harmonização regulatória intrabloco. É possível que os compromissos dos Estados-membros do Mercosul reflitam uma real abertura comercial, e não apenas a consolidação do status quo vigente, o que por si só já seria um avanço em comparação com as obrigações assumidas por esses Estados no âmbito do GATS, em 1994. Considerando o grande interesse da União Europeia na abertura do setor de serviços, a mera consolidação do status quo certamente seria considerada um passo muito pequeno em prol da liberalização comercial, o que poderia, inclusive, inviabilizar um acordo.

325 Fontes: Fontes: Ministério do Desenvolvimento, Indústria e Comércio Exterior do Brasil (<http://www.mdic.gov.br//sitio/interna/interna.php?area=5\&menu=2635\&refr=1893>) e Comissão Europeia (<http://ec.europa.eu/trade/policy/countries-and-regions/regions/mercosur/>). Acesso em: 13 mai. 2014. 


\subsection{Ampliação do ACP Mercosul-Índia}

Como visto no item 4.1. acima, o ACP Mercosul-Índia, que entrou em vigor em junho de 2009, é considerado um primeiro passo para a criação de uma área de livre comércio Mercosul-Índia. Esse acordo não contempla a liberalização do comércio de serviços entre as Partes, mas apenas a concessão de preferências tarifárias e outras condições mais benéficas na importação de bens.

Em julho de 2013, a Índia demonstrou aos sócios do Mercosul interesse em estabelecer um cronograma de discussões com vistas à ampliação do ACP Mercosul-Índia. O formato da ampliação e de um possível aprofundamento do acordo vigente, todavia, ainda não foi definido.

Em 23 de novembro de 2009, realizou-se, em Montevidéu, a I Reunião do Comitê de Administração Conjunta do ACP Mercosul-Índia, em que se confirmou a vontade das partes de aprofundar o ACP. A segunda Reunião do Comitê ocorreu na Índia, em junho de 2010.

Em 2013, o governo brasileiro realizou uma consulta pública sobre o acesso a mercado de bens ${ }^{326}$ para mapear o interesse do setor privado brasileiro e, desse modo, construir seu posicionamento nas negociações para ampliação do ACP. No entanto, não houve nenhum andamento posterior ou qualquer manifestação ou consulta pública relacionada ao setor de serviços ${ }^{327}$.

Em vista do exposto, não há qualquer evidência de que, caso haja a ampliação do ACP envolvendo Mercosul e Índia, as Partes pretendam incluir o setor de serviços no escopo desse acordo.

\subsection{ACE Mercosul-Colômbia}

Em outubro de 2004, os Estados-membros do Mercosul celebraram com Colômbia, Equador e Venezuela, então membros da CAN, o $\mathrm{ACE} \mathrm{N}^{\circ}$ 59, que entrou em vigor em

\footnotetext{
${ }^{326}$ Consulta Pública instituída pela Circular SECEX N ${ }^{\circ}$ 46, de 12 de agosto de 2013.

327 Fontes: Ministério do Desenvolvimento, Indústria e Comércio Exterior do Brasil (<http://www.desenvolvimento.gov.br/sitio/interna/interna.php?area=5\&menu=4010\&refr=1893>) e Ministério de Relações Exteriores do Brasil (<http://www.itamaraty.gov.br/o-ministerio/conheca-oministerio/america-do-sul/dnc-i-2013-divisao-de-negociacoes-extra-regionais-do-mercosul-i/negociacoescomerciais-mercosul-2013-india>). Acesso em: 13 mai. 2014.
} 
abril de 2005. O acordo foi incorporado ao ordenamento jurídico brasileiro por meio do Decreto $\mathrm{n}^{\mathrm{o}} 5361$, de 31 de janeiro de $2005^{328}$.

O ACE No 59 tem como principais objetivos (i) o desenvolvimento harmônico na região, (ii) o estabelecimento de um quadro jurídico e institucional de cooperação e integração econômica e física que contribua para a criação de um espaço econômico ampliado, facilitando a livre circulação de bens e serviços, e (iii) a criação de uma área de livre comércio ${ }^{329}$.

Com relação à liberalização regional do comércio de serviços, as Partes se comprometeram a promover a adoção de medidas para facilitar a prestação de serviços e, em prazo a ser definido pela Comissão Administradora do ACE $N^{\circ}$ 59, a estabelecer mecanismos adequados para a liberalização, expansão e diversificação progressiva do comércio de serviços nos seus territórios, conforme os direitos, obrigações e compromissos assumidos na OMC e em outros foros regionais e hemisféricos ${ }^{330}$.

Na III Reunião Ordinária da Comissão Administradora ACE N ${ }^{\circ}$ 59, que se realizou em outubro de 2008, foi criado um Grupo Ad-hoc de Serviços Mercosul-Colômbia. Esse Grupo tem como objetivo o estabelecimento de um Protocolo Adicional ao ACE No 59

\footnotetext{
${ }^{328}$ Disponível em: <http://www.planalto.gov.br/ccivil_03/_Ato2004-2006/2005/Decreto/D5361.htm>. Acesso em: 13 mai. 2014.

329 “OBJETIVOS E ALCANCE

Artigo 1 - O presente Acordo tem os seguintes objetivos:

- Estabelecer o marco jurídico e institucional de cooperação e integração econômica e física que contribua para a criação de um espaço econômico ampliado que vise a facilitar a livre circulação de bens e serviços e a plena utilização dos fatores produtivos, em condições de concorrência entre as Partes Contratantes;

- Formar uma área de livre comércio entre as Partes Contratantes mediante a expansão e a diversificação do intercâmbio comercial e a eliminação das restrições tarifárias e não-tarifárias que afetam o comércio recíproco;

- Alcançar o desenvolvimento harmônico na região, levando em conta as assimetrias derivadas dos diferentes níveis de desenvolvimento econômico das Partes Signatárias;

- Promover o desenvolvimento e a utilização da infra-estrutura física, com especial ênfase no estabelecimento de corredores de integração, que permitam a diminuição de custos e a geração de vantagens competitivas no comércio regional recíproco e com terceiros países fora da região;

- Promover e impulsionar os investimentos entre os agentes econômicos das Partes Signatárias;

- Promover a complementação e cooperação econômica, energética, científica e tecnológica;

- Promover consultas, quando for o caso, nas negociações comerciais que se efetuem com terceiros países e agrupamentos de países extra-regionais". Acordo de Complementação Econômica No. 59 Assinado entre os Estados Partes do Mercosul e os Países Membros da Comunidade Andina. Disponível em: <http://www.mdic.gov.br/sitio/interna/interna.php?area=5\&menu=468>. Acesso em: 13 mai. 2014.

330 “TÍTULO XV - SERVIÇOS

Artigo 28 - As Partes Contratantes promoverão a adoção de medidas tendentes a facilitar a prestação de serviços. Igualmente, e em um prazo a ser definido pela Comissão Administradora, as Partes Signatárias estabelecerão os mecanismos adequados para a liberalização, expansão e diversificação progressiva do comércio de serviços nos seus territórios, conforme os direitos, obrigações e compromissos derivados da participação respectiva no Acordo Geral sobre o Comércio de Serviços da OMC (GATS), assim como em outros foros regionais e hemisféricos". Acordo de Complementação Econômica Assinado entre os Estados Partes do Mercosul e os Países Membros da Comunidade Andina. Disponível em: <http://www.mdic.gov.br/sitio/interna/interna.php?area=5\&menu=468>. Acesso em: 13 mai. 2014.
} 
para inclusão do setor de serviços no âmbito do referido Acordo. As negociações no âmbito do Grupo Ad-hoc de Serviços Mercosul-Colômbia ainda estão em andamento ${ }^{331}$.

Até o momento, não foi divulgada nenhuma informação sobre qual o modelo de liberalização em serviços que deve ser adotado no Protocolo. Contudo, tendo em vista o posicionamento adotado pelo Mercosul em outros foros bilaterais e multilaterais sobre a liberalização do comércio de serviços, é bastante provável que o Protocolo Adicional ao ACE $N^{\circ} 59$ sobre serviços seja muito semelhante ao Protocolo Adicional ao ACE $N^{0} 35$, que aprovou o Protocolo sobre o Comércio de Serviços entre o Mercosul e o Chile, seguindo, desse modo, o modelo de liberalização progressiva adotado pelo GATS.

\section{CONCLUSÕES}

A análise dos acordos regionais de comércio celebrados pelo Mercosul realizada neste Capítulo comprova que tanto o Brasil quanto o bloco sul-americano avançaram muito pouco na formação de preferências comerciais, sobretudo em relação à liberalização do comércio de serviços.

De fato, desde os anos 1990, o Brasil teve como foco as negociações multilaterais, que propiciaram ao país alcançar uma posição de destaque em diversos foros multilaterais, como na OMC, que atualmente é dirigida pelo Embaixador brasileiro Roberto Azevedo. Consequentemente, o Brasil relegou os acordos regionais a segundo plano, em especial aqueles envolvendo países desenvolvidos.

Como foi visto em capítulos anteriores, na década de 2000, os Estados passaram a se engajar na celebração de diversos acordos de livre comércio abrangendo o setor de serviços com Estados que não eram seus vizinhos contíguos. Na contramão desse movimento, em 2000, foi promulgada a Decisão CMC No 32/00, que determinou que os Estados-membros do Mercosul apenas poderiam celebrar acordos comerciais em conjunto, com exceção de acordos com Estados-membros da ALADI que fossem negociados até 30 de junho de 2001. Como consequência dessa nova orientação de política comercial do Mercosul, poucos acordos regionais foram celebrados no âmbito da ALADI e alguns

331 Fontes: Ministério do Desenvolvimento, Indústria e Comércio Exterior do Brasil (http://www.mdic.gov.br/sitio/interna/interna.php?area=5\&menu=2280) e Ministério de Relações Exteriores do Brasil (<http://www.itamaraty.gov.br/temas/america-do-sul-e-integracao-regional/aladi/mercosulcolombia-equador-venezuela-ace-59>; $\quad<\mathrm{http}: / / w w w . i t a m a r a t y . g o v . b r / o-m i n i s t e r i o / c o n h e c a-o-$ ministerio/america-do-sul/departamento-da-america-do-sul-ii-das-ii/colombia/comissao-bilateral/ata-da-ireuniao-da-comissao-bilateral-brasil-colombia>). Acesso em:

13 mai. 2014. 
outros com países em desenvolvimento ${ }^{332}$.

Até o momento, o Mercosul celebrou apenas cinco acordos regionais de comércio com Estados de fora da região - a saber, com Índia, Israel, SACU, Egito e Palestina -, sendo que somente os acordos com Índia e Israel estão em vigor. Além de serem pouco numerosos, os acordos em questão também são pouco ambiciosos, muitas vezes abrangendo apenas um pequeno número de linhas tarifárias objeto de margens de preferência e restritos ao comércio de bens. Os acordos com Israel e Egito contêm a previsão de uma liberalização do comércio de serviços a ser realizada no futuro, sem prazo definido.

Atualmente, o Mercosul está negociando a ampliação do acordo de preferências comerciais celebrado com a Índia, que não faz qualquer menção à liberalização do setor de serviços, além de um amplo acordo de livre comércio com a União Europeia, no qual a liberalização de serviços é um componente importante para que haja um acordo entre as Partes. Se concluído, o acordo com a União Europeia será um marco importante para o bloco sul-americano. Além de ser o primeiro acordo celebrado com um bloco de países desenvolvidos, será o mais relevante economicamente e o mais abrangente em termos dos temas abarcados. No que se refere à liberalização do setor de serviços, embora não tenham sido disponibilizadas informações sobre a estrutura do acordo que está em negociação, há evidências de que deve ser adotado o modelo do GATS para assunção de compromissos em serviços, que é flexível e atende aos interesses do Brasil e do Mercosul.

Entre os acordos celebrados com Estados-membros da ALADI, o único que contém disposições detalhadas e compromissos efetivos para a liberalização do comércio regional de serviços é o ACE No 35, celebrado entre Mercosul e Chile, que segue o modelo de liberalização flexível e progressiva do GATS. No âmbito da ALADI, merecem destaque, igualmente, as negociações que ocorrem no Grupo Ad-hoc de Serviços MercosulColômbia, as quais têm como objetivo o estabelecimento de um Protocolo Adicional ao ACE N 59 para inclusão do setor de serviços no âmbito do referido Acordo. Ainda não há previsão para a conclusão dos trabalhos realizados pelo Grupo Ad-hoc de Serviços

\footnotetext{
${ }^{332}$ Sobre essa questão, Umberto Celli Junior ensina o seguinte: "Brazil's strategy of prioritizing the multilateral negotiations resulted in the PTA negotiations being relegated to a second plan, especially those with the developed countries. On the other hand, as of 2000, when MERCOSUR's Decision No. 32, which established that its members must negotiate all trade agreements as a trading block, came into force6, a few PTA were executed with the Latin American Integration Association's (LAIA) countries and others with countries outside the region but in the political South/South axis". Brazil in the South America economy and in the international scenario. Disponível em:

<http://disciplinas.stoa.usp.br/pluginfile.php/115627/mod_resource/content/2/Umberto\%20Celli\%20-

\%20paperfordiscussion.pdf >. Acesso em: 5 jan 2013. P. 3
} 
Mercosul-Colômbia.

Em razão do pequeno número de acordos regionais de comércio celebrados pelo Mercosul que contemplam a liberalização de serviços, não é possível visualizar a existência de um padrão quanto às principais cláusulas adotadas. Fica claro, porém, que o bloco sul-americano prefere que a liberalização do comércio de serviços com outros Estados siga o modelo do GATS. Isso significa que, para os Estados-membros do Mercosul, é importante que a abertura comercial do setor de serviços seja flexível e progressiva e possibilite a manutenção do espaço para realização de políticas públicas.

A respeito da forma pela qual as ofertas são apresentadas, em razão da inexistência de uma harmonização regulatória intrabloco, as ofertas e compromissos deverão ser apresentados separadamente para cada Estado-membro, e não para o Mercosul como um todo. Essa prática já foi adotada no $\mathrm{ACE} \mathrm{N}^{\mathrm{o}} 35$, no qual cada Estado-membro do Mercosul consolidou compromissos em serviços individualmente. Da mesma forma, nas negociações com a União Europeia em 2004, o Mercosul apresentou ofertas em serviços separadas para cada Estado-membro do bloco.

De todo modo, tendo em vista o contexto atual de negociações de acordos regionais abrangendo o comércio de serviços e a necessidade de inserção do bloco sul-americano nesse cenário, é necessário avaliar qual seria o modelo de liberalização regional em serviços que mais atende aos interesses do Brasil e do Mercosul. 


\section{CAPÍtUlO 3: A ADOÇÃO DE UM MODELO DE ACORDO REGIONAL EM SERVIÇOS PELO MERCOSUL}

\section{INTRODUÇÃO}

Conforme visto no capítulo anterior, nos últimos anos, o Mercosul engajou-se na celebração de poucos acordos regionais, sobretudo no âmbito da ALADI e com Estados e blocos que se encontram no eixo político Sul/Sul ${ }^{333}$. Alguns desses acordos contêm disposições sobre o comércio de serviços que estabelecem as condições para futura abertura comercial do setor. Desses, apenas um acordo, o ACE $N^{\circ} 35$, celebrado entre Mercosul e Chile, possui compromissos específicos em serviços e está em vigor.

Como o número de acordos regionais de comércio celebrados pelo Mercosul que contemplam a liberalização de serviços ainda é muito pequeno, não é possível considerar que o bloco tenha desenvolvido um modelo de acordo para esse tema. Por outro lado, tendo em vista a possibilidade de que o bloco venha a celebrar acordos dessa natureza com outros parceiros em um futuro próximo, é inevitável que se reflita sobre o modelo mais adequado para o Mercosul, considerando as diretrizes de política externa comunitária, as limitações jurídicas e os interesses de seus Estados-membros.

Neste capítulo, será analisado qual seria o modelo de acordo regional em serviços mais adequado para o Mercosul. Essa reflexão terá como ponto de partida as lições extraídas da experiência de Estados Unidos, União Europeia, China e Índia com esse tipo de acordo.

Na sequência, serão expostas as tendências atuais para a liberalização do comércio internacional de serviços, que objetivam também atualizar e aprimorar as regras existentes, de modo a adequá-las à realidade do século XXI.

Com base nas informações apresentadas neste capítulo, será feita uma reflexão sobre qual dos diferentes modelos de liberalização do comércio de serviços melhor atenderia aos interesses comerciais e políticos dos Estados-membros do Mercosul.

Por fim, serão avaliados quais os principais obstáculos para que o bloco sulamericano e para seus Estados-membros promovam uma liberalização efetiva do setor de serviços em negociações de acordos regionais, bem como as alternativas existentes para a

\footnotetext{
${ }^{333}$ Exceção feita à União Europeia, que, desde 2000, negocia um acordo com o Mercosul.
} 
efetiva inserção desse bloco e/ou de seus Estados-membros nos movimentos atuais que objetivam a abertura comercial e o aprimoramento das regras multilaterais vigentes.

\section{LIÇÕES EXTRAÍDAS DA EXPERIÊNCIA DOS ESTADOS UNIDOS, UNIÃO EUROPEIA, CHINA, ÍNDIA NA LIBERALIZAÇÃO REGIONAL DO SETOR DE SERVIÇOS}

A partir da pesquisa realizada nesta tese, observa-se que, ao longo das últimas três décadas, os principais players do comércio internacional construíram, cada um a seu modo, modelos próprios de acordos regionais, os quais possuem semelhanças e diferenças em relação ao modo para assunção de compromissos e regras.

Os Estados Unidos têm adotado regras bastante uniformes para a liberalização do comércio de serviços em seus acordos regionais, que se baseiam no capítulo sobre serviços contido no NAFTA ${ }^{334}$, com aperfeiçoamentos posteriores em áreas como transparência e limitações de acesso a mercados e tratamento nacional ${ }^{335}$.

No que diz respeito à experiência da China, Índia e União Europeia, embora esses três players tenham adotado o mesmo método para a abertura do comércio regional de serviços, com muitas referências ao GATS, há diferenças consideráveis na arquitetura dos acordos celebrados por cada um desses players.

A União Europeia, depois de assinar alguns acordos mais genéricos, que contêm majoritariamente compromissos de cooperação para uma futura liberalização do comércio de serviços, redefiniu sua política comercial para o setor. O ALC UE-Coreia é um marco que demonstra a intenção do bloco europeu de dar maior importância às negociações regionais e bilaterais para a abertura comercial de serviços. Nesse acordo, observa-se um maior detalhamento de regras relativas à liberalização do comércio de serviços, além da adoção de mecanismos que visam a promover maior liberalização, como o trancamento do status quo regulatório para os setores e subsetores objeto de compromissos específicos.

China e Índia, por sua vez, começam a desenhar regras mais alinhadas a seus interesses específicos em seus últimos acordos, por vezes protegendo na medida do possível seus mercados, por outras aprofundando regras. Nos acordos celebrados pelos

\footnotetext{
${ }^{334}$ Cumpre notar que o único acordo regional celebrado pelos Estados Unidos cujo capítulo sobre serviços não se assemelha ao capítulo sobre serviços do NAFTA é aquele celebrado com a Jordânia, no qual as Partes adotam o modelo de lista positiva do GATS para a assunção de compromissos em serviços.

${ }^{335}$ Vide A. MATTOO; P. SAUVÉ, 2011, p. 247.
} 
dois países, observa-se que a base utilizada é o GATS e, a partir das regras desse Acordo, as Partes negociaram obrigações mais detalhadas nos temas de seu interesse. Por exemplo, a Índia, que tem interesse em garantir o acesso aos mercados de terceiros países aos prestadores de serviços indianos em modo 4, inseriu nos acordos dos quais é Parte um capítulo específico para regular esse modo. Já a China tem se mostrado muito flexível e pouco agressiva nas regras aplicáveis ao comércio de serviços, o que é um reflexo do ainda pequeno desenvolvimento do setor de serviços no país asiático, o que tende a mudar no futuro próximo.

A arquitetura dos acordos regionais ou capítulos sobre a liberalização do comércio de serviços dependerá, basicamente, do método para a assunção de compromissos adotado. De modo geral, os acordos regionais tendem a seguir o método de lista negativa ou o método de lista positiva. Conforme visto em capítulos anteriores, União Europeia, Índia, China e Mercosul têm optado pelo modelo do GATS de lista positiva, ao passo que os Estados Unidos têm preferido o modelo de lista negativa preconizado pelo NAFTA.

Contudo, está cada vez mais difícil definir os acordos regionais como pertencentes a uma ou outra categoria. Alguns deles têm introduzido variações ao combinar elementos do modelo GATS e do modelo NAFTA, como é o caso do APE UE-CARIFORUM. Como já foi explicado nesta tese, o referido acordo determina que as Partes consolidem o status quo regulatório para os compromissos adotados por meio de listas positivas, o que costuma ser uma característica do modelo NAFTA ${ }^{336}$. Ademais, a adoção do modelo de lista positiva não significa necessariamente que o player utilizará os mesmos métodos para a assunção de compromissos adotados no GATS. No ALC UE-Coreia e no APE UECARIFORUM, a Coreia e os países do CARIFORUM utilizam uma lista de compromissos

\footnotetext{
${ }^{336}$ Mario Marconini e Pierre Sauvé apontam que é crescente o número de acordos regionais que contêm elementos mistos dos modelos GATS e NAFTA. Veja-se: “A number of more recent PTAs, notably those negotiated by Japan, have sought to embed negative lists solely for transparency purposes. In this case, the legally binding commitments on services of the respective parties are governed by the hybrid scheduling approach found in the GATS. This approach adds the voluntary, positive selection of sectors, subsectors, and modes of supply used to schedule the commitments to the negative listing of limitations to national treatment and market access maintained in scheduled sectors, subsectors and modes of supply. Unlike the GATS, in which parties are free to determine the level of their positive bindings, the Japanese PTAs feature an obligation to lock positively listed commitments into the regulatory status quo. This approach has been replicated, most recently, in the Economic Partnership Agreement entered into by the member states of the European Community and the countries of the Caribbean Community (CARICOM) and the Dominican Republic (the CARIFORUM grouping) (see box 2.15)". Negotiating Trade in Services: A Practical Guide for Developing Countries. S. SAEZ (Ed.). Trade in Services Negotiations: A Guide for Developing Countries. Washington, D.C.: The World Bank. Junho 2010, p. 40. Disponível em: <http://elibrary.worldbank.org/doi/book/10.1596/978-0-8213-8410-7>. Acesso em: 15 mai. 2014.
} 
com os quatro modos de prestação de serviços, como no GATS, ao passo que o bloco europeu utiliza quatro listas de compromissos distintas ${ }^{337}$.

Não por acaso, os acordos que adotam o modelo de listas negativas, como aqueles celebrados pelos Estados Unidos, possuem as regras mais liberalizantes em relação ao comércio de serviços, à medida que preveem a abertura do setor por lista negativa e a incidência das regras de investimentos em serviços, além de outros mecanismos que visam a garantir o avanço da liberalização comercial no setor. Cite-se, por exemplo, o "mecanismo de catraca", que consolida o atual piso regulatório, ao mesmo tempo que obriga os signatários a revelar a natureza das medidas não conformes nos setores submetidos a reservas. Além de vantagens em termos de avanços na abertura comercial, esse mecanismo resulta em maior transparência, uma vez que as medidas não conformes são previamente relacionadas pelas Partes ${ }^{338}$.

No modelo de acordo adotado pela União Europeia, Índia e China, a transparência é mais limitada, haja vista que as Partes não são obrigadas a relacionar todas as medidas não conformes. A única exceção é o Acordo China-Japão, no qual as Partes estabeleceram a obrigação de publicar uma lista com todas as medidas existentes no escopo do capítulo sobre serviços que são inconsistentes com as obrigações de acesso a mercados e tratamento nacional.

Além disso, no modelo de acordo adotado pela União Europeia, Índia e China, os signatários mantêm a flexibilidade de celebrar compromissos a um nível abaixo do status quo regulatório, independentemente do nível de liberalização das medidas regulatórias domésticas. O trancamento do status quo regulatório não é garantido, exceto se houver alguma especificação em sentido contrário. É o caso, por exemplo, dos acordos ALC UECoreia e APE UE-CARIFORUM, nos quais as Partes estabeleceram que não poderão ser

\footnotetext{
${ }^{337}$ Vide P. LATRILLE; J. LEE, 2012, p. 8.

${ }^{338}$ A respeito do maior nível de transparência nos acordos regionais que adotam o modelo de lista negativa e de como isso pode ser utilizado pelos negociadores do próprio Estado, de forma positiva em futuras negociações, Aaditya Mattoo e Pierre Sauvé ensinam o seguinte: "Here again, and unlike GATS, which yields no information on the nature of nonconforming measures retained in what are typically sensitive sectors, negative-list agreements oblige signatories to reveal the nature of existing nonconforming measures in such reserved sectors.

The main governance-enhancing feature arising from the adoption of a negative-list approach is thus the greater level of transparency it can generate if adhered to properly. The information contained in reservation lists will be important to prospective traders and investors, who value the one-stop shopping attributes of a comprehensive inventory of potential restrictions in foreign markets. Such an inventory is also likely to benefit home-country negotiators, assisting them in establishing a hierarchy of impediments to tackle in future negotiations. This information can in turn lend itself more easily to formula-based liberalization-for instance, by encouraging members to agree to reduce or progressively phase out "revealed" nonconforming measures that may be similar across countries, such as quantitative limitations on foreign ownership in selected sectors (see Sauvé 1996)”. A. MATTOO; P. SAUVÉ, 2011, p. 252.
} 
ampliadas as limitações de acesso a mercados e tratamento nacional além daquelas relacionadas por elas para os compromissos assumidos no âmbito dos referidos acordos.

Outra característica inovadora de alguns acordos regionais consiste no fato de que os compromissos em modo 4 têm sido limitados apenas a profissionais de alto escalão e pósgraduados. É o caso de dois acordos celebrados pela União Europeia,' a saber: o ALC UECoreia e o APE UE-CARIFORUM. Esse enfoque é mais restritivo do que aquele adotado pelos acordos baseados no modelo NAFTA, que se limita a regular o movimento temporário de profissionais, e não de pessoas físicas, como definido no GATS. Observa-se, assim, que tanto os Estados Unidos quanto a União Europeia têm consolidado compromissos regionais no modo 4 que podem ser considerados aquém daqueles consolidados na $\mathrm{OMC}^{339}$.

A respeito da liberalização comercial propriamente dita, mesmo não esperando que boa parte dos compromissos assumidos nos acordos regionais resulte em uma abertura real dos mercados para serviços e prestadores de serviços estrangeiros, as Partes envolvidas nestes acordos têm assumido compromissos em um número de subsetores de serviços muito superior em relação aos compromissos assumidos no GATS ou em relação às ofertas apresentadas na Rodada Doha ${ }^{340}$. Esse contraste é ainda superior no caso dos países em desenvolvimento, cujos compromissos tendem a ser mais limitados na esfera multilateral $^{341}$.

Desse modo, observa-se que Estados Unidos, União Europeia, China e Índia desenvolveram regras específicas em acordos regionais para o setor serviços, as quais atingiram o objetivo a que se propunham, a saber, ser um conjunto normativo que possibilitasse a efetiva liberalização regional do setor de serviços. Esses modelos diversos de regras devem inspirar o Mercosul na escolha de um modelo próprio, que possibilite a inserção do bloco no sistema regional de comércio.

\footnotetext{
${ }^{339}$ Não há nenhum estudo que comprove esta hipótese. Segundo Rudolf Adlung e Peter Morrison, dada a natureza altamente restritiva de praticamente todos os compromissos no modo 4 celebrados no GATS, pode ser bastante difícil encontrar nos acordos regionais de comércio disposições aquém dos GATS que sejam tão evidentes como aquelas relativas aos modos 1 e 3. Vide R. ADLUNG; P. MORRISON, 2010, p. 1128.

340 Este resultado foi empiricamente comprovado por Martin Roy, que chegou à seguinte conclusão: "Overall, the dataset highlights that, on average, commitments undertaken in PTAs far outweigh those contained in GATS schedules, but also those offered in the current Round of negotiations". Services Commitments in Preferential Trade Agreements: Surveying the Empirical Landscape. NCCR Trade Working Paper No. 2012/2. Janeiro 2012, p. 15. Disponível em: <http://www.nccr-trade.org/publication/servicescommitments-in-preferential-trade-agreements-surveying-the-empirical-landscape/>. Acesso em: 17 jul. 2013.

${ }^{341}$ Vide M. ROY, 2012, p. 10.
} 


\section{MOVIMENTOS ATUAIS PARA A LibERALIZAÇÃO DO COMÉRCIO DE SERVIÇOS, ATUALIZAÇÃO E APRIMORAMENTO DAS REGRAS EXISTENTES}

Como visto nesta tese, o único acordo multilateral sobre o comércio de serviços, o GATS, foi negociado de 1986 a 1994 e entrou em vigor em 1995. Desde então, ocorreram inúmeras tentativas de atualizar e complementar o quadro regulatório do GATS, tanto no âmbito do Comitê para o Comércio de Serviços e de seus Grupos de negociação específicos quanto nas rodadas de negociação da OMC. Não obstante, os Membros não conseguiram chegar a um consenso em relação aos temas negociados. Por esse motivo, tanto as normas relativas a serviços quanto os compromissos de acesso a mercados nesse setor, em âmbito multilateral, são praticamente os mesmos desde 1995.

Por sua vez, desde as negociações da Rodada Uruguai, o mundo mudou significativamente. Os avanços tecnológicos resultaram em alterações nas praticas comerciais e na forma de prestação dos serviços. O aprofundamento da integração comercial resultou na necessidade de criação de normas regionais para o setor de serviços, as quais se distanciam, cada vez mais, das regras estabelecidas no âmbito da OMC. Portanto, as normas e compromissos multilaterais no setor de serviços precisam ser atualizados de modo a adequá-los à realidade do século XXI.

Na realidade, os Membros da OMC têm celebrado acordos regionais de comércio como uma forma de suplantar a inércia legislativa dessa Organização. Recentemente, observa-se a tendência de negociação de acordos regionais mais ambiciosos, complexos e abrangentes, envolvendo um grupo mais numeroso de países - os "mega acordos" - bem como a formação de grupos para a negociação de acordos plurilaterais ${ }^{342}$, com vistas a uma possível multilateralização dos temas tratados nesses dois tipos de acordos. A ampliação

\footnotetext{
${ }^{342}$ Os acordos plurilaterais são parte do Sistema Multilateral de Comércio desde o GATT. Dois acordos plurilaterais negociados durante a Rodada Tóquio - o Acordo sobre Compras Governamentais e o Acordo sobre Aviação Civil - foram incorporados ao Acordo Constitutivo da OMC (Anexo 4). Outros acordos plurilaterais foram negociados posteriormente e adotados por alguns Membros da OMC, como o Acordo sobre Serviços Financeiros e o Acordo sobre Serviços Básicos de Telecomunicações. É importante notar que os acordos plurilaterais devem cumprir com os requisitos estabelecidos nos Artigos XXIV do GATT e V do GATS, notadamente a necessidade de liberalização de substancialmente todo o comércio e de abrangência setorial substancial. Para mais informações sobre esse os acordos plurilaterais e sua compatibilização com a OMC, vide: M. NAKATOMI. Plurilateral Agreements: A Viable Alternative to the World Trade Organization? ADBI Working Paper Series n 439. Outubro de 2013. Disponível em: <http://www.adbi.org/working-paper/2013/10/24/5914.plurilateral.agreements.alternative.wto>. Acesso em: 11 jul. 2014.
} 
das regras e dos compromissos em serviços tem sido um dos principais objetivos desses dois tipos de iniciativa.

\subsection{O TISA}

Em maio de 2013, alguns Membros da OMC com interesse ofensivo no setor de serviços lançaram as negociações de um novo acordo sobre o comércio de serviços, denominado TISA ${ }^{343}$. Por trás dessa iniciativa está a Coalizão Global de Serviços (Global Services Coalition), entidade que reúne várias coalizões da indústria de serviços ${ }^{344}$, além de diversos grupos privados norte americanos, europeus e asiáticos ${ }^{345}$.

O grupo de membros da OMC que lançou as negociações do TISA se autodenomina "Verdadeiros Amigos do Comércio de Serviços" (Really Good Friends of Trade in ${ }^{343}$ Denominação posteriormente acordada para esse acordo, que foi, inicialmente, denominado de ISA.
${ }^{344}$ Para mais informações sobre as coalisões de serviços que compõem a Coalisão Global de Serviços, vide:
<http://www.esf.be/new/links/global-services-coalitions>. Acesso em: 10 jul. 2014 .
${ }^{345}$ Sobre o apoio do setor privado às negociações de um novo acordo sobre o comércio internacional de
serviços, Gary Clyde Hufbauer, J. Bradford Jensen e Sherry Stephenson apontam o seguinte: "The business
community in major service exporting countries has also come down unequivocally in favor of a plurilateral
approach to services negotiations. While this has been the position of the Australian Services Roundtable
(2008), it was also endorsed by the Hong Kong Coalition of Services Industries (2009). More recently the
plurilateral approach was advocated by all members of the Global Services Coalition in a press communiqué
issued in June 2011 . Likewise, British business leaders released an information note on "After Doha: Next
Generation Services Negotiations-Current Arguments for a Services-Only Approach" in July 2011 , signed
by J. A. Cooke, chairman of the Liberalisation of Trade in Services Committee. The note outlined alternative
forms of an International Services Agreement, which are reviewed later in this Policy Brief. Members of the
US Coalition of Services Industries (CSI) have promoted the idea of a plurilateral approach to services quite
forcefully and their advocacy can be found in several documents on the CSI website-most recently in a
January 2012 position paper entitled "Moving Services Liberalization Forward Using a Plurilateral
Approach." The paper argues that a plurilateral agreement would provide the vehicle for delivering new
services trade and investment liberalization that responds to the realities of 21 st century global business (CSI
2012).

The Services Task Force of the Pacific Economic Cooperation Council and the Asian Development Bank Institute (PECC and ADBI 2011) produced a well-argued and documented report on the basis of a multistakeholder conference held in June 2011, with private- and public-sector representatives alike urging the adoption of a plurilateral approach to the negotiation of a services agreement. In a similar vein, the Transatlantic Taskforce on Trade and Investment (2012), launched by the European Centre for International Political Economy and the German Marshall Fund of the United States, with membership including policy experts, business, and civil society, released a report in early 2012 recommending that, in light of the Doha Round experience, future trade deliberations “... should be decentralized, both in geographic and substantial terms, with new agreements based on "coalitions of the willing'." The Transatlantic Taskforce further recommends that such plurilateral agreements be confined to the participating countries, in order to avoid free-riding, but should remain open for other countries to join. It advocates starting with strategic sectors, namely services and the digital economy, for these negotiations. Rarely has the private sector around the world been so unanimous in advocating forward movement on liberalization of a specific area in such a coherent manner". G. C. HUFBAUER et al. Framework for the International Services Agreement. Peterson Institute for International Economics. Policy Brief PB12-10. Washington, DC. Abril de 2012, p. 9. Disponível em: <http://www.iie.com/publications/pb/pb12-10.pdf〉. Acesso em: 19 mai. 2014. 
Services). Esse grupo é composto por 22 Membros da $\mathrm{OMC}^{346}$ e pela União Europeia, os quais, em conjunto, representam cerca de $70 \%$ do comércio mundial de serviços. O Paraguai é o único Estado-membro do Mercosul que integra o grupo negociador do TISA. Assim, não participam dessa negociação Brasil, Argentina, Uruguai e Venezuela, além de outros importantes Membros da OMC, com destaque para China e Índia. Não obstante, em outubro de 2013, a China solicitou aprovação para ingressar nas negociações ${ }^{347}$.

De acordo com os "Verdadeiros Amigos do Comércio de Serviços", o TISA se propõe a ser um acordo ambicioso sobre o comércio internacional de serviços, com regras e compromissos de acesso a mercados abrangentes.

Em termos de arquitetura, os participantes acordaram que o TISA será baseado no GATS, de modo que alguns conceitos chave do segundo - tais como definições, escopo, acesso a mercados e tratamento nacional e exceções gerais e de segurança - seriam incorporados ao primeiro. Isso visa a garantir uma possível integração desse Acordo com o GATS $^{348}$.

Os participantes pretendem que o TISA resulte na celebração de novos e aperfeiçoados compromissos de acesso a mercados em serviços. Para tanto, acordaram que os compromissos em acesso a mercados serão celebrados da mesma forma que ocorre no GATS, ou seja, os compromissos serão consolidados em listas positivas, por meio do mecanismo de pedidos e ofertas ${ }^{349}$.

Quanto ao tratamento nacional, o TISA deve contemplar a possibilidade de que este seja aplicado de forma horizontal a todos os setores de serviços e modos de prestação de serviços. Exceções à aplicação horizontal devem ser relacionadas nas Listas de Compromissos das Partes. Os participantes também concordam que todos os compromissos, em princípio, reflitam o estado regulatório atual da Parte (standstill clause) e que a eliminação de medidas discriminatórias que venham a ser adotadas no futuro ocorra por meio do "mecanismo de catraca" 350 .

\footnotetext{
${ }^{346}$ Austrália, Canadá, Estados Unidos, Japão, Coreia, Chile, Taipé Chinês, Colômbia, Costa Rica, Hong Kong, Islândia, Israel, Liechtenstein, México, Nova Zelândia, Noruega, Paquistão, Panamá, Paraguai, Peru, Suíça e Turquia.

${ }^{347}$ Vide I. KOCH-WESER. Should China Join the WTO's Services Agreement? Março 2014. Disponível em: <http://www.uscc.gov/Research/should-china-join-wto\%E2\%80\%99s-services-agreement>. Acesso em: 19 mai. 2014.

348 COMISSÃO EUROPEIA. The Trade in Services Agreement ('TiSA'). Disponível em: <http://trade.ec.europa.eu/doclib/docs/2013/june/tradoc_151374.pdf>. Acesso em: 10 jul. 2014.

349 COMISSÃO EUROPEIA. The Trade in Services Agreement ('TiSA'). Disponível em: <http://trade.ec.europa.eu/doclib/docs/2013/june/tradoc_151374.pdf>. Acesso em: 10 jul. 2014.

350 COMISSÃO EUROPEIA. The Trade in Services Agreement ('TiSA'). Disponível em: <http://trade.ec.europa.eu/doclib/docs/2013/june/tradoc_151374.pdf〉. Acesso em: 10 jul. 2014.
} 
Ademais, disciplinas novas e aperfeiçoadas deverão ser elaboradas, em áreas como regulação doméstica, transporte marítimo, serviços de tecnologia da informação e comunicações, e-commerce, serviços relacionados à computação, serviços postais e de courrier, serviços financeiros, movimento temporário de pessoas físicas, compras governamentais de serviços e subsídios à exportação de serviços, com base nas propostas enviadas pelos participantes ${ }^{351}$.

Ainda não há clareza sobre qual será a relação entre o TISA e a OMC. Por esse motivo, é possível vislumbrar as seguintes alternativas: (i) um acordo no âmbito da OMC, com Cláusula de Nação Mais Favorecida; (ii) um acordo preferencial plurilateral da OMC; ou (iii) um acordo preferencial plurilateral externo à $\mathrm{OMC}^{352}$. Com base nas informações disponibilizadas até o momento, tudo indica que o TISA será um acordo preferencial plurilateral externo à OMC. Isso porque os participantes do TISA declararam que o acordo final estará aberto à adesão dos demais Membros da $\mathrm{OMC}^{353}$. Para que a multilateralização do TISA seja possível, no futuro, é importante que esse acordo cumpra com as condições para que seja considerado um acordo de integração econômica, conforme disposto no Artigo V do GATS. Outra opção aventada pela Comissão Europeia consistiria em incluir uma cláusula de acessão aos Membros da OMC interessados em aderir ao TISA, o que também poderia levar esse acordo à multilateralização ${ }^{354}$.

O impacto do TISA sobre o fluxo de comércio de serviços e sobre o Sistema Multilateral de Comércio ainda é incerto, à medida que dependerá do número de participantes envolvidos e, sobretudo, da forma com que esse acordo se relacionará com as regras da OMC. Os atuais participantes das negociações já representam mais de dois terços do comércio internacional de serviços. De acordo com um estudo do Peterson Institute, considerando apenas esses países, estima-se que o TISA levará ao aumento das exportações anuais de serviços em US\$ 78 bilhões. No entanto, segundo esse Instituto, os ganhos comerciais resultantes do acordo seriam $30 \%$ superiores se Brasil, Índia e China $\operatorname{aderissem}^{355}$.

351 COMISSÃO EUROPEIA. The Trade in Services Agreement ('TiSA'). Disponível em: <http://trade.ec.europa.eu/doclib/docs/2013/june/tradoc_151374.pdf>. Acesso em: 10 jul. 2014.

352 Vide J. A. MARCHETTI; M. ROY. The new kid on the block: The Trade in Services Agreement. Dezembro 2013. Disponível em: <http://www.voxeu.org/article/trade-services-agreement>. Acesso em: 19 mai. 2014.

${ }^{353}$ Vide página na Internet da Secretaria de Comércio Exterior e Desenvolvimento (Foreign Affairs, Trade and Development) do Canadá: <http://www.international.gc.ca/trade-agreements-accordscommerciaux/topics-domaines/services/tisa-acs.aspx?lang=eng>). Acesso em: 10 de jul. de 2014.

354 COMISSÃO EUROPEIA. The Trade in Services Agreement ('TiSA'). Disponível em: <http://trade.ec.europa.eu/doclib/docs/2013/june/tradoc_151374.pdf>. Acesso em: 10 jul. 2014.

355 "If Brazil, India, and China became parties to the ISA, the trade gains would expand by around 30 percent 


\subsection{Os "mega acordos"}

Além da negociação de um acordo plurilateral sobre serviços, os principais players do comércio internacional têm se engajado em negociar regras e compromissos de acesso a mercados em serviços em uma série de acordos regionais envolvendo um grande número de Partes, os quais têm sido denominados de "mega acordos". Esses acordos são considerados "mega" não apenas em razão do número de participantes, mas também em razão dos temas abrangidos e de congregarem participantes que representam um percentual bastante elevado do comércio internacional de bens e serviços ${ }^{356}$.

Atualmente, os principais "mega acordos" em negociação são os seguintes: (i) TTIP, envolvendo Estados Unidos e União Europeia; (ii) Acordo União Europeia-Japão; (iii) Acordo União Europeia-Índia; (iv) TPP, envolvendo Austrália, Brunei Darussalam, Canadá, Chile, Estados Unidos, Japão, Malásia, México, Nova Zelândia, Peru, Cingapura e Vietnã; (v) Associação Econômica Integral Regional, envolvendo os Estados-membros da ASEAN (Brunei Darussalam, Camboja, Indonésia, Laos, Malásia, Myanmar, Filipinas, Cingapura, Tailândia e Vietnã), Austrália, China, Coreia, Japão, Índia e Nova Zelândia; (vi) Aliança do Pacífico, envolvendo Chile, México, Colômbia, Peru e Costa Rica ${ }^{357}$. É importante notar que o Brasil e o Mercosul não participam das negociações de nenhum "mega acordo".

Os "mega acordos" têm por objetivo: (i) ampliar os laços de comércio e investimentos entre as Partes; (ii) criar novas regras comerciais em áreas ainda não cobertas pelos acordos da OMC; e (iii) estabelecer precedentes para futuras negociações comerciais multilaterais ${ }^{358}$. Portanto, as regras decorrentes desses acordos, assim como

using the same partial equilibrium methodology (Hufbauer, Schott, and Wong 2010, tables 3.1 and B.3)”. G. C. HUFBAUER et al. Abril de 2012, p. 19. Disponível em: <http://www.iie.com/publications/pb/pb1210.pdf>. Acesso em: 19 mai. 2014.

${ }^{356}$ B. KOTSCHWAR. The Mega-agreements - New Actors and New Rules. Presented at FGB-SP and the Center on Global Trade "The Impacts of Mega-agreements (TTIP and TPP) and the future of Mercosur". São Paulo, Brasil. 8 de maio de 2014. P. 7. Disponível em: <http://ccgi.fgv.br/sites/ccgi.fgv.br/files/u5/Megas\%20x\%20Mercosul\%208-5-2014.pdf>. Acesso em: 10 jul. 2014.

357 BANCO INTERAMERICANO DE DESENVOLVIMENTO (BID), INSTITUTO PARA A INTEGRAÇÃO DA AMÉRICA LATINA E DO CARIBE (INTAL), Agosto 2013, p. 10. Disponível em: <http://www10.iadb.org/intal/cartamensual/Cartas/PDF/204/pt/CartaMensal204_Coluna\%20de\%20An\%C3 \%A1lise_Art1.pdf >. Acesso em: 14 mai. 2014.

358 B. KOTSCHWAR, 8 de maio de 2014. P. 6. Disponível em:<http://ccgi.fgv.br/sites/ccgi.fgv.br/files/u5/Megas\%20x\%20Mercosul\%208-5-2014.pdf>. Acesso em: 10 jul. 2014. 
ocorre com o TISA, deverão influenciar significativamente as negociações multilaterais e regionais sobre o comércio internacional de serviços.

Dois “mega acordos" merecem especial atenção, a saber: o TPP e o TTIP. Juntos, os dois acordos congregam cerca de $50 \%$ do comércio internacional. O primeiro, que concentra $40 \%$ do PIB global e $25 \%$ das exportações totais, possui o ambicioso objetivo de redesenhar completamente o regime internacional de comércio e investimentos. Já o segundo, envolvendo Estados Unidos e União Europeia, poderá constituir a maior área de livre comércio do mundo e regras desenvolvidas para esse acordo possivelmente pautarão as relações econômicas e comerciais internacionais ${ }^{359}$.

Especificamente com relação às regras aplicáveis ao comércio de serviços, os participantes do TTIP pretendem que esse acordo resulte na abertura dos mercados de serviços dos Estados Unidos e da União Europeia no maior nível alcançado até hoje em acordos regionais de comércio. Além disso, pretendem liberalizar novos setores de serviços por meio da remoção de restrições de acesso a mercados, como, por exemplo, o setor de serviços de transporte aéreo ${ }^{360}$. Os participantes pretendem, ademais, que o acordo possua regras que garantam a transparência, imparcialidade e o devido processo com relação a licenciamento e requisitos e procedimentos para qualificação, bem como fortaleça as disciplinas regulatórias existentes em outros acordos regionais envolvendo os Estados Unidos e a União Europeia ${ }^{361}$.

No TPP, os debates acerca da liberalização do comércio de serviços ainda estão centrados na decisão sobre a adoção de uma lista positiva ou negativa de compromissos em serviços. Se por um lado os Estados Unidos, a Austrália e a Nova Zelândia defendem a liberalização por meio de listas negativas, por outro, o Vietnã tem adotado uma postura favorável à adoção de lista positiva ${ }^{362}$. Não obstante a forma pela qual se dará a

359 B. KOTSCHWAR, 8 de maio de 2014. P. 6. Disponível em:<http://ccgi.fgv.br/sites/ccgi.fgv.br/files/u5/Megas\%20x\%20Mercosul\%208-5-2014.pdf>. Acesso em: 10 jul. 2014; FÓRUM ECONÔMICO MUNDIAL. Mega-regional Trade Agreements Game-Changers or Costly Distractions for the World Trading System? Julho de 2014. P. 14. Disponível em: <http://www.weforum.org/reports/mega-regional-trade-agreements-game-changers-or-costly-distractionsworld-trading-system-0>. Acesso em: 11 jul. 2014.

${ }^{360}$ COMISSÃO EUROPEIA. Member States endorse EU-US trade and investment negotiations. Bruxelas, 14 de junho de 2013. Disponível em: <http://trade.ec.europa.eu/doclib/press/index.cfm?id=918> . Acesso em: 11 jul. 2014.

${ }^{361}$ UNITED STATES TRADE REPRESENTATIVE. Final Report of the U.S.-EU High Level Working Group on Jobs and Growth. 11 de fevereiro de 2013. Disponível em: <http://www.ustr.gov/about-us/pressoffice/reports-and-publications/2013/final-report-us-eu-hlwg>. Acesso em: 11 jul. 2014.

${ }^{362}$ Segundo Inkyo Cheong, ainda está longe de haver um consenso sobre a forma pela qual se dará a liberalização do comércio de serviços, no âmbito do TPP, Veja-se: "Viet Nam is having difficulties regarding negotiations in almost every sector, particularly the areas of services, investment, government procurement, protection of intellectual property rights, ISDS, environment, and labor, in addition to political issues such as 
liberalização do setor de serviços, o TPP deverá abranger serviços financeiros, incluindo seguros e serviços correlatos, serviços bancários e serviços correlatos, bem como serviços auxiliares de natureza financeira, os quais serão regulamentados em um anexo específico $^{363}$.

Observa-se, assim, que "mega acordos" como o TTIP e o TTP, se concluídos, poderão redesenhar as normas aplicáveis ao comércio internacional de bens e serviços. Da mesma forma que ocorre com o TISA, é possível que as regras sobre o comércio de serviços negociadas nos "mega acordos" sejam, posteriormente, adotadas em âmbito multilateral.

\section{PROPOSIÇÃO DE UM MODELO DE LIBERALIZAÇÃO COMERCIAL EM SERVIÇOS PARA O MERCOSUL}

O número de acordos regionais de comércio celebrados pelo Mercosul que contemplam a liberalização de serviços é muito pequeno. Consequentemente, não é possível considerar que o bloco tenha desenvolvido um modelo de acordo para esse tema.

Na realidade, o que se verifica é que o bloco sul-americano prescinde de uma política externa coesa na área de comércio exterior. É o governo de cada Estado-membro do Mercosul que define, caso a caso, qual deve ser o posicionamento do bloco sobre determinada questão comercial. Isso resulta na existência de uma grande dificuldade de coordenação entre os Estados-membros em questões comerciais, à medida que o posicionamento a ser adotado dependerá do interesse do atual governo sobre uma questão, e não de uma orientação de política comercial do bloco. Prova disso é o fato de que, não obstante a Decisão CMC No. 32/00 impossibilitar que um Estado-membro celebre, individualmente, acordos comerciais com países não Membros da ALADI, o Paraguai tem participado do grupo negociador do TISA.

the protection of human rights in relation to the US. Since many countries such as the US, Australia, and New Zealand want to negotiate for concessions of services and investment in a way of negative listings, Viet Nam officially decided to negotiate in positive listings. There has not been internal consensus on the negative listings approach yet, which can be a fundamental problem with other countries". Negotiations for the TransPacific Partnership Agreement: Evaluation and Implications for East Asian Regionalism. ADBI Working Paper Series $n^{\circ}$ 428. Julho de 2013. Disponível em:

<http://www.adbi.org/files/2013.07.11.wp428.trans.pacific.partnership.east.asian.regionalism.pdf>. Acesso em: 11 jul. 2014.

${ }^{363}$ R. MELÉNDEZ-ORTIZ, Mega-regionals: What Is Going on? FÓRUM ECONÔMICO MUNDIAL, Julho de 2014. P. 14. Disponível em: <http://www.weforum.org/reports/mega-regional-trade-agreements-gamechangers-or-costly-distractions-world-trading-system-0>. Acesso em: 11 jul. 2014. 
Assim, é muito difícil elaborar um modelo de acordo regional em serviços que atenda aos interesses do Mercosul, uma vez que não há clareza sobre quais seriam esses interesses e eles variam em virtude dos governos dos Estados-membros.

De modo geral, pode-se dizer que o Mercosul sempre se posicionou a favor do método de listas positivas adotado pelo GATS, que possibilita a liberalização progressiva do setor de serviços de baixo para cima (bottom up). A opção por esse método é adequada aos Estados-membros do bloco, visto que ele garante maior flexibilidade para os países consolidarem apenas os setores, subsetores e modos de prestação de serviços que tiverem interesse e condições de liberalizar. Além disso, as Partes podem manter o espaço para a realização de políticas públicas, por meio da regulação dos setores, subsetores e modos de prestação de serviços que não forem objeto de compromissos ${ }^{364}$.

Contudo, a opção pela consolidação de compromissos em serviços de baixo para cima (bottom up) pode tornar a abertura comercial em serviços muito lenta e, em última instância, inócua, como ocorre com a liberalização do setor de serviços intrabloco, no Mercosul, e com os poucos acordos regionais de comércio que contemplam serviços que foram celebrados por esse bloco. Isso porque as Partes geralmente consolidam setores e subsetores de serviços em nível inferior ao status quo regulatório. Mesmo em acordos em que há prazos pré-determinados para a negociação de novas regras e para a consolidação de novos compromissos, muitas vezes, esses prazos não são respeitados.

Para que o modelo do GATS de liberalização comercial em serviços seja eficaz, há necessidade de inclusão de uma cláusula standstill que leve ao trancamento do status quo regulatório. Essa cláusula ainda não foi adotada em nenhum acordo celebrado pelo Mercosul, mas é necessária para dar maior segurança jurídica aos prestadores de serviços das outras Partes do acordo. O "mecanismo de catraca" também pode ser incluído nos acordos a serem celebrados pelo Mercosul, com o intuito de propiciar uma liberalização comercial mais rápida e efetiva.

Outro aspecto que deve ser aperfeiçoado nos acordos celebrados pelo Mercosul está relacionado às regras sobre transparência e regulação doméstica. Quanto à transparência, é necessário garantir que as Partes do acordo tenham oportunidade para comentar sobre medidas que afetem ou possam afetar o comércio de serviços, independentemente de serem ou não discriminatórias. O ideal seria replicar as cláusulas que constam em acordos celebrados pelos Estados Unidos, as quais preveem comentários às medidas antes de elas

${ }^{364}$ U. CELLI JUNIOR, 2009, p. 132-133 
entrarem em vigor e a necessidade de apresentação de resposta por escrito a todas as manifestações enviadas pelos nacionais de outras Partes.

Os acordos em questão também devem prever prazos curtos para a revisão das regras e possibilidade de ampliação dos compromissos, os quais devem ser respeitados por todas as Partes. De nada adianta um acordo extremamente sofisticado se os prazos para revisão ou ampliação dos compromissos forem irrealistas ou muito longos.

Desse modo, é possível que o Mercosul continue baseando-se no modelo do GATS para a celebração de compromissos em serviços, como já vem fazendo nos poucos acordos regionais celebrados pelo bloco, desde que sejam realizados os ajustes propostos, os quais visam a garantir a efetividade da liberalização comercial do setor de serviços e maior segurança jurídica aos prestadores de serviços brasileiros e originários das outras Partes do acordo. Como visto nos capítulos anteriores, essa mesma fórmula tem sido utilizada com sucesso pela União Europeia nos acordos regionais de comércio celebrados pelo bloco.

No entanto, a existência de acordos que abranjam o comércio de serviços, por si só, não é suficiente. É necessário garantir que não haverá demora na incorporação desses acordos aos ordenamentos jurídicos dos Estados-membros.

Por fim, é importante notar que os Estados-membros do Mercosul possuem outra alternativa que não inviabiliza a negociação de acordos regionais de comércio e que também é baseada no modelo do GATS, que é participar das negociações do TISA. Conforme mencionado nesta tese, o Paraguai já participa das negociações desse acordo e é provável que outros players importantes irão aderir em breve, como é o caso da China. Além disso, há grandes chances de que esse acordo venha a ser multilateralizado e, no futuro, até mesmo substitua ou complemente o GATS.

Do ponto de vista formal, o modelo que tem sido aventado para o TISA não apresenta nenhum desconforto para o Mercosul. Como visto, em termos de arquitetura, o TISA deverá ser baseado no GATS, com a previsão de que os compromissos em serviços sejam consolidados em listas positivas, por meio do mecanismo de pedidos e ofertas. Além disso, o TISA deve replicar as cláusulas do GATS em relação aos seguintes temas: definições, escopo, acesso a mercados e tratamento nacional e exceções gerais e de segurança.

As diferenças em relação ao GATS relacionam-se à aplicação horizontal do tratamento nacional, à necessidade de que os compromissos em serviços reflitam o estado regulatório atual da Parte, à previsão de que a eliminação de medidas discriminatórias que 
venham a ser adotadas no futuro ocorra por meio do "mecanismo de catraca"365. Nenhuma dessas questões deve ser considerada como um empecilho a esse acordo para os Estadosmembros do Mercosul. Pelo contrário, devem ser vistas como cláusulas positivas, à medida que impulsionam a liberalização comercial do setor.

\section{CONCLUSÕES}

Como visto nesse capítulo, o atualmente, os principais players do comércio internacional têm dois caminhos paralelos à OMC para ampliar seus compromissos no setor de serviços e atualizar as regras do GATS, de modo a adequá-las às necessidades atuais dos consumidores de serviços, a saber: (i) o caminho da regionalização, com a celebração de acordos regionais que contém regras para a liberalização do comércio de serviços; e (ii) o caminho dos acordos plurilaterais, com a negociação do TISA. Qualquer que seja o caminho, o objetivo é um só: criar regras que levem à redução das barreiras e à ampliação do comércio internacional de serviços entre as Partes, com o intuito de que essas regras, no futuro, sejam incorporadas ao quadro normativo da OMC.

Conforme visto nessa tese, o Mercosul não é Parte de acordos regionais significativos na área de serviços. Da mesma forma, os Estados-membros do Mercosul não estão envolvidos nas negociações de “mega acordos". Com relação ao TISA, o Paraguai é o único Estado-membro do Mercosul que integra o grupo negociador desse acordo, o que evidencia que o bloco não tem um posicionamento coeso sobre esse tema.

Desse modo, observa-se que, em um momento em que estão sendo negociadas importantes regras relacionadas ao comércio internacional de serviço, as quais poderão, futuramente, complementar ou até mesmo substituir as regras multilaterais existentes sobre o tema, o Mercosul está afastado desse debate.

$\mathrm{Na}$ realidade, a inexistência de um modelo de acordo regional no setor de serviços deriva do fato de que o bloco sul americano prescinde de uma política externa na área de comércio exterior. Os governos de cada Estado-Membro é que definem, caso a caso, qual deve ser o posicionamento do bloco sobre determinada questão comercial. Isso resulta na existência de uma grande dificuldade de coordenação intra-bloco, que podem levar, inclusive, à necessidade de negociação de preferências comerciais separadamente, para

365 COMISSÃO EUROPEIA. The Trade in Services Agreement ('TiSA'). Disponível em: <http://trade.ec.europa.eu/doclib/docs/2013/june/tradoc_151374.pdf>. Acesso em: 10 jul. 2014. 
cada Estado-membro, como já foi aventado nas negociações que estão em curso com a União Europeia ${ }^{366}$. Contudo, essa opção é limitada pela Decisão CMC No. 32/00, que determina que acordos comerciais com Estados que não são Membros da ALADI devem negociados conjuntamente pelo bloco.

Não obstante a validade da Decisão CMC No. 32/00 ser questionável do ponto de vista jurídico, conforme demonstrado no capítulo anterior, a necessidade de coordenação entre os Estados-membros do Mercosul, estabelecida por essa Decisão, não é interessante para nenhum de seus Estados-membros. Portanto, o Mercosul deve permitir que cada Estado-membro negocie acordos regionais comércio individualmente. No atual estágio de integração do bloco sul americano, não faz sentido a apresentação de oferta ou celebração de compromissos em serviços de forma conjunta e integrada.

Assim, antes de mais nada, é importante que os Estados-membros do Mercosul reflitam sobre a viabilidade de o continuar negociando e celebrando acordos regionais apenas em bloco, em vista da inexistência de acordos significativos até este momento e das dificuldades que tem sido enfrentadas nas negociações do único acordo de livre comércio realmente ambicioso em que o bloco está envolvido, com a União Europeia.

Caso os Estados-membros do Mercosul decidam continuar celebrando acordos regionais em bloco, ele deve estar preparado para as negociações de novos acordos regionais de comércio. Nesse sentido, seria adequado pensar um modelo de acordo regional em serviços a ser adotado pelo Mercosul, com regras adequadas aos princípios e à realidade de seus Estados-membros, mas que, simultaneamente, garantam efetividade na liberalização regional do setor de serviços. Nesse sentido, os modelos desenvolvidos por americano Estados Unidos, União Europeia, China e Índia devem servir de fonte de inspiração para o modelo a ser adotado pelo Mercosul.

A partir dos poucos acordos regionais celebrados pelo bloco que abrangem o comércio de serviços e no posicionamento de seus Estados-membros nas negociações da OMC, sugere-se que Mercosul continue baseando as regras sobre serviços de seus acordos no modelo do GATS. No entanto, é necessário que sejam realizados alguns ajustes para garantir a efetividade da liberalização comercial do setor de serviços e maior segurança jurídica aos prestadores de serviços, de forma semelhante ao que se verifica em acordos recentes celebrados pela União Europeia, notadamente o ALC UE-Coreia e o APE UE-

366 F. PEÑA. Mercosur-EU: options if the goal is not achieved. Abril de 2013. Disponível em: <http://www.felixpena.com.ar/index.php?contenido=wpapers\&wpagno=documentos/2013-04-23-mercosureu-options-if-the-goal-is-not-achieved>. Acesso em: 12 jul. 2014. 
CARIFORUM. Isso possibilitará que o Mercosul desenvolva um modelo próprio de acordo regional em serviços, que possibilite a efetiva inserção do bloco no sistema regional de comércio.

Independentemente do modelo de acordo regional a ser adotado, deve o Mercosul participar das negociações do TISA, visto que há grandes chances de que as regras sobre o comércio de serviços que serão negociadas nesse acordo plurilateral sejam, posteriormente, adotadas em âmbito multilateral. 


\section{CONSIDERAÇÕES FINAIS}

Desde a década de 1990, a política externa do Brasil na área comercial teve como foco as negociações comerciais na esfera multilateral, sobretudo na OMC. Em razão desse posicionamento, o país alcançou uma posição de destaque nos foros multilaterais.

Fortalecendo a posição brasileira nos foros multilaterais e seguindo as orientações e regulamentações de política externa do bloco, o Brasil passou a vincular sua posição à do Mercosul. Mesmo atravessando diversas crises nas relações externas, como no episódio em que o bloco indicou dois candidatos à Diretoria da OMC, em $2005^{367}$, o Brasil relutou em desvencilhar-se do bloco e buscar um caminho independente.

Nesse período, o mundo presenciou uma ampliação no número de acordos regionais de comércio e a proliferação das preferências comerciais em diversas áreas, como o comércio de serviços. Contudo, a negociação de acordos regionais de comércio nunca foi considerada uma prioridade pelo Brasil ou pelo bloco sul-americano.

Atualmente, o que o Brasil e o Mercosul possuem em termos de preferências comerciais em serviços é muito pouco em comparação com os principais players do comércio internacional, tanto pelo pequeno número de acordos do qual ambos são Parte quanto em relação à elaboração de um modelo de acordo com as regras de seu interesse. $\mathrm{O}$ bloco está ficando para trás de outros Estados, inclusive de seus vizinhos sul-americanos, notadamente Peru, Colômbia e Chile, que seguiram os passos do México e celebraram acordos com Estados Unidos, União Europeia e Canadá ${ }^{368}$. Peru e Chile também possuem acordo com a China. Ao todo, o Chile é Parte de mais de 20 acordos regionais, o Peru de 16 acordos e a Colômbia de 10 acordos. Ressalte-se, ademais, que a maioria dos acordos celebrados por esses Estados contempla a liberalização do comércio de serviços ${ }^{369}$.

Isso fica ainda mais evidente quando se observam os movimentos e as negociações para a formação de acordos comerciais interregionais e regionais de grande porte e magnitude, que devem causar um grande impacto nos fluxos comerciais de bens e serviços, razão pela qual foram denominados de "mega acordos". Dentre estes, merece especial atenção a TPP, visto que concentra $40 \%$ do PIB global e possui o ambicioso objetivo de

\footnotetext{
${ }^{367}$ Na ocasião, o Brasil indicou o Embaixador brasileiro Luís Felipe de Seixas Corrêa e o Uruguai indicou Carlos Perez del Castillo na disputa pela direção da entidade.

${ }^{368}$ Vide U. CELLI JUNIOR. Brazil in the South America economy and in the international scenario. Disponível em:

<http://disciplinas.stoa.usp.br/pluginfile.php/115627/mod_resource/content/2/Umberto\%20Celli\%20\%20paperfordiscussion.pdf $>$. Acesso em: 5 jan 2013, p. 3.

${ }^{369}$ Fonte: OMC (<http://rtais.wto.org/UI/PublicMaintainRTAHome.aspx>). Acesso em: 13 mai. 2014.
} 
redesenhar completamente o regime internacional de comércio e investimentos. Já a TTIP, envolvendo Estados Unidos e União Europeia, poderá tornar-se a maior área de livre comércio do mundo e regras desenvolvidas para esse acordo possivelmente pautarão as relações econômicas e comerciais internacionais.

Além dos desafios impostos pelos acordos regionais, há também uma nova negociação em curso, que visa a estabelecer um novo quadro regulatório para o comércio internacional de serviços, após um período de mais de 20 anos no qual praticamente não houve evolução na elaboração de regras e na abertura de mercados em serviços na OMC. Trata-se do TISA, um acordo plurilateral sobre o comércio de serviços que visa a ampliar os compromissos existentes nesse setor e atualizar o quadro normativo do GATS. Embora o acordo seja negociado por apenas 23 Membros da OMC, que possuem interesses ofensivos no setor, é provável que ele estará disponível à adesão dos demais Membros da OMC.

Em vista do cenário atual de celebração de acordos regionais e plurilaterais importantes e da negociação de um novo quadro regulatório para o comércio de serviços, é imprescindível que o Brasil e o Mercosul se engajem, imediatamente, na negociação de preferências comerciais no setor de serviços, com players importantes do comércio internacional. Caso contrário, o Brasil e o Mercosul correm o risco de perder mercado e de ficarem isolados desse processo de integração econômica.

Há dois caminhos que podem ser adotados com vistas a garantir uma maior inserção do Brasil e do bloco no sistema de preferências comerciais. O primeiro caminho é a negociação de acordos regionais pelo Mercosul com outros players. O segundo caminho é a negociação de acordos regionais separadamente pelos Brasil e pelos demais Estadosmembros do Mercosul.

Conforme visto nesta tese, até hoje, os Estados-membros do Mercosul só negociaram acordos regionais de comércio com Estados e blocos pouco significativos. A obrigatoriedade de conciliar os anseios comerciais do Brasil com outros Estados-membros do Mercosul, os quais possuem interesses distintos, é um fator que dificulta o processo de negociação de acordos por esse bloco. Outro fator que pode inviabilizar uma negociação conjunta pelo Mercosul é a ausência de uma estratégia interna bem definida do bloco sobre a liberalização do comércio de serviços. Como visto, o Paraguai possui interesses ofensivos nessa área e, inclusive, participa das negociações relativas ao TISA. Os demais Estados-membros não possuem uma estratégia clara sobre esse tema. 
Caso as diferenças entre os Estados-membros do Mercosul sejam consideradas irreconciliáveis, o Brasil deve celebrar acordos regionais separadamente dos demais Estados-membros. Como já foi apontado nesta tese, embora a Decisão CMC No. 32/00 determine que os Estados-membros do Mercosul só possam negociar acordos regionais de comércio com terceiros países ou blocos de países de forma conjunta, a validade jurídica desse documento é questionável, visto que ele nunca foi internalizado no ordenamento jurídico brasileiro ou dos demais Estados-membros do Mercosul.

De todo modo, é importante que o Brasil não seja prejudicado pela incapacidade de coordenação interna entre os Estados-membros do Mercosul. Se o país não agir rapidamente, corre o risco de perder mercados para a exportação de seus serviços em relação a seus principais parceiros comerciais, pois esses já concederam preferências comerciais para outros países. Portanto, é imperiosa a inclusão do Brasil no regionalismo do século XXI, nem que para isso seja necessário que se redesenhe o Mercosul, de forma que os Estados-membros fiquem liberados para negociar acordos regionais individualmente.

Qualquer que seja o caminho adotado, para que o Brasil e/ou o Mercosul negociem preferências comerciais no setor de serviços, é necessário estabelecer um modelo próprio de acordo regional em serviços distinto daquele que tem sido adotado nas negociações das quais o Mercosul. Com isso, o Brasil e o Mercosul estarão mais capacitadso nas negociações de acordos regionais e não ficarão refém de um modelo imposto por outro Estado ou bloco.

Nesse sentido, sugere-se que Mercosul adote um modelo de acordo baseado no GATS, prática que já tem sido adotada nos poucos acordo celebrados pelo bloco. Contudo, será necessário realizar alguns ajustes para garantir a efetividade da liberalização comercial do setor de serviços e maior segurança jurídica aos prestadores de serviços, de forma semelhante ao que se verifica em dois acordos celebrados pela União Europeia, a saber: o ALC UE-Coreia e o APE UE-CARIFORUM. Esse modelo deve possibilitar a abertura comercial do setor de serviços sem abrir mão de questões importantes para o Brasil e para os outros Estados-membros do Mercosul, como a manutenção de espaço para a realização de políticas públicas.

Além das negociações de acordos regionais, o Brasil e/ou o Mercosul também devem aderir às negociações do TISA. Como visto nesta tese, o TISA é uma iniciativa importante para atualização das regras do GATS e ampliação dos compromissos em serviços, que congrega os principais exportadores de serviços. Como é bastante provável que o TISA 
seja, futuramente, adotado de forma multilateral, é importante que os demais Estadosmembros do Mercosul, e não apenas o Paraguai, participem ativamente dessa iniciativa. Além disso, a princípio, o TISA será baseado no modelo do GATS e adotará cláusulas semelhantes àquelas que foram propostas na presente tese como modelo de acordo a ser adotado pelo Brasil e/ou pelo Mercosul. Logo, acredita-se que o TISA será elaborado sobre parâmetros que seriam aceitáveis para o Brasil e para os Estados-membros do Mercosul.

Em vista do exposto, tanto o Brasil quanto o Mercosul deveriam repensar suas respectivas estratégias comerciais e econômicas. É fundamental acelerar a celebração de acordos regionais e estabelecer um modelo equilibrado, que permita a expansão comercial e a atração de investimentos, bem como a implantação de políticas de desenvolvimento, sob o risco de ficar ainda mais isolado em um mundo no qual as redes de preferências comerciais já estão sendo formadas há mais de uma década e de ter que jogar um jogo cujas regras foram elaboradas por outros players $^{370}$.

\footnotetext{
${ }^{370}$ Richard Baldwin faz analogia em relação ao Brasil e aos "mega acordos", a saber: "If the mega-regionals conclude, they will have been firmly embedded in international commerce; the members of TPP and TTIP account for over half of world trade. More precisely, they will be embedded in the domestic laws and regulations of all the host-nations that the Chinese, Indian and Brazilian companies will be looking at. Like it or not, Chinese, Indian and Brazilian companies will have to play by the rules that are now being written by the mega-regionals". The Systemic Impact. FÓRUM ECONÔMICO MUNDIAL. Julho de 2014. P. 24. Disponível em: <http://www.weforum.org/reports/mega-regional-trade-agreements-game-changers-or-costlydistractions-world-trading-system-0>. Acesso em: 11 jul. 2014.
} 


\section{BIBLIOGRAFIA CONSULTADA}

\section{LIVROS, ARTIGOS E PERIÓDICOS}

ADLUNG, Rudolf, MORRISON, Peter. Less than the GATS: 'Negative Preferences' in Regional Services Agreements. Journal of International Economic Law, Oxford, Oxford University Press, vol. 13, n. 4, 2010, p. 1103-1143.

How to design trade agreements in services: Top down or bottom up? rules? WTO Staff Working Paper. Genebra, Junho de 2013. Disponível em: <http://www.wto.org/english/res_e/reser_e/ersd201308_e.pdf>. Acesso em: 7 jan. 2014.

; MIROUDOT, Sébastien. Poison in the wine? Tracing gats-minus commitments in regional trade agreements. WTO Staff Working Paper. Genebra, Fevereiro de 2012. Disponível em: 〈http://www.wto.org/english/res_e/reser_e/ersd201204_e.htm>. Acesso em: 3 fev. 2014.

ADUANEIRAS. Resultados da Rodada do Uruguai do GATT. São Paulo, Aduaneiras, 1995.

AHN, Dukgeun. Legal and Institutional Issues of Korea-EU FTA: New Model for PostNAFTA FTAs? Seul, Outubro de 2010. Disponível em: http://gem.sciencespo.fr/content/publications/pdf/AHN_KOREU\%20FTA\%20201010.pdf. Acesso em: 20 abr. 2014.

ARSALANIAN NETO, Michel. A liberalização do comércio de serviços do Mercosul. Brasília: Fundação Alexandre Gusmão, 2010.

BALDWIN, Richard E.; LOW, Patrick. Multilarizing Regionalism. Challenges for the Global Trading System, Cambridge: Cambridge University Press, 2009.

21st Century Regionalism: Filling the gap between 21st century trade and 20th century trade rules. Organização Mundial do Comércio. Staff Working Paper ERSD-2011-08, 23 de maio de 2011. 
Multilateralising regionalism: Spaghetti bowls as building blocs

on the path $\mathrm{t}$ o global free trade. National Bureau of Economic Reserach Working Paper No. 12545. Setembro de 2006. Disponível em: 〈http://www.nber.org/papers/w12545>. Acesso em: 3 fev. 2014.

A domino theory of regionalism. National Bureau of Economic Reserach Working Paper No. 4465. Setembro 1993. Disponível em: <http://www.nber.org/papers/w4465>. Acesso em: 3 fev. 2014.

BANCO MUNDIAL. Global Economic Prospects. Trade, Regionalism and Development. 2005 Disponível em: <http://www.siteresources.worldbank.org>. Acesso em: 20 jun. 2012.

BANCO INTERAMERICANO DE DESENVOLVIMENTO (BID), INSTITUTO PARA A INTEGRAÇÃO DA AMÉRICA LATINA E DO CARIBE (INTAL). Como as negociações de mega-acordos influirão na América Latina? Carta Mensal INTAL N 204 , Agosto 2013. Disponível em:

<http://www10.iadb.org/intal/cartamensual/Cartas/PDF/204/pt/CartaMensal204_Coluna\% 20de\%20An\%C3\%A1lise_Art1.pdf>. Acesso em: 14 mai. 2014.

BARTELS, Lorand; ORTINO, Federico. Regional trade agreements and the WTO legal system (International Economic Law Series). Oxford University Press. Nova Iorque: 2006.

BAPTISTA, Luiz Olavo; RODAS, João Grandino; SOARES, Guido Fernando Silva Soares (coord.). Normas de Direito Internacional: tomo III - comércio internacional / OMC. São Paulo: LTr, 2001.

; CELLI JUNIOR, Umberto; YANOVICH, Alan (Org.). 10 anos de OMC: uma análise do sistema de solução de controvérsias e perspectivas. São Paulo: Aduaneiras, 2007.

BHAGWATI, Jagdish. Reshaping the WTO. 2005. Disponível em: <http://time.dufe.edu.cn/wencong/bhagwati/FEEER.Final.pdf>. Acesso em: 20 jun. 2012. 
Termites in the Trading System How Preferential

Agreements Undermine Free Trade. Nova York: Oxford University Press, 2008.

BONELLI, Regis; MOTTA VEIGA, Pedro da; FERNANDES DE BRITO, Adriana. As Políticas Industrial e de Comércio Exterior no Brasil: Rumos e Indefinições. Texto Para Discussão No 527, Instituto De Pesquisa Econômica Aplicada (IPEA). Rio de Janeiro, novembro de $1997 . \quad$ Disponível em: $<$ http://repositorio.ipea.gov.br/bitstream/11058/2306/1/td_0527.pdf>. Acesso em: 21 mai. 2014.

BURFISHER, Mary E.; ROBINSON, Sherman; THIERFELDER, Karen. Regionalism: Old And New, Theory And Practice. MTID Discussion Paper No. 65. Fevereiro de 2004. Disponível em: <http://ageconsearch.umn.edu/bitstream/16137/1/mt040065.pdf>. Acesso em: 29 jun. 2012.

CANÇADO TRINDADE, Otávio Augusto Drummond. O Mercosul no direito brasileiro: incorporação de normas e segurança jurídica. Belo Horizonte, Del Rey: 2006.

CELli JUNIOR, Umberto (org.). Comércio de Serviços na OMC. Curitiba: Juruá Editora, 2005.

Os acordos de serviços (GATS) e de investimentos (TRIMS) na OMC: espaço para políticas de desenvolvimento. São Paulo, 2006. Disponível em: <http://www.usp.br/prolam/downloads/gats.pdf>. Acesso em: 9 jan. 2008. ; SAYEG, Fernanda Manzano (org.). Comércio de Serviços, OMC e Desenvolvimento. São Paulo: Instituto de Direito do Comércio Internacional e Desenvolvimento - IDCID, 2008. 
. O impacto dos acordos de investimentos sobre os EstadosMembros do MERCOSUl. Cadernos PROLAM/USP, São Paulo, ano 4, v. 1, 81-96 p., 2005. Disponível em: <http://www.usp.br/prolam/downloads/2005_1_4.pdf>. Acesso em: 10 jan. 2008.

. Comércio de Serviços na OMC: Liberalização, Condições e Desafios. Curitiba: Juruá, 2009.

; SALLES, Marcus; TUSSIE, Diana; PEIXOTO, Juliana. MERCOSUR in South-South Agreements: In the middle of two models of regionalism. Instituto Virtual da Organização para a Cooperação Econômica e o Desenvolvimento: 2010. Disponível em: <http://vi.unctad.org/resources-mainmenu64/digital-library?i=VI\&op=all\&q=Mercosur+in+Southsouth+Agreements $\% 3 \mathrm{~A}+\mathrm{In}+$ the+Middle+of + Two+Models + of + Regionalism $+\&$ act=search \&option=com_gslink>. Acesso em: 13 jun. 2011.

. Brazil in the South America economy and in the international scenario. Disponível em: $<$ http://disciplinas.stoa.usp.br/pluginfile.php/115627/mod_resource/content/2/Umberto\%20 Celli\%20-\%20paperfordiscussion.pdf >. Acesso em: 5 jan 2013.

- A Organização Mundial do Comércio e o regionalismo do século XXI. Densidades, Buenos Aires, n. 9, 91-107 p., 2012.

CERNAT, Lucian; ONGUGLO, Bonapas; ITO, Taisuke. RTAs and WTO compatibility: Catch me if you can? The case of EPA negotiations. UNCTAD. 16 de abril de 2007. Disponível em: <http://mpra.ub.uni-muenchen.de/3645/>. Acesso em: 26 jan. 2014.

CHEONG Juyoung e; WONG, Kar-yiu. Economic Integration, Trade Divertion and Welfare Change. 30 de novembro de 2007. Disponível em: <http://faculty.washington.edu/karyiu/papers/trade-divert.pdf>. Acesso em: 28 jun. 2012. 
CHEONG, Inkyo. Negotiations for the Trans-Pacific Partnership Agreement: Evaluation and Implications for East Asian Regionalism. ADBI Working Paper Series $n^{\circ} 428$. Julho de 2013. Disponível em:

<http://www.adbi.org/files/2013.07.11.wp428.trans.pacific.partnership.east.asian.regionali sm.pdf>. Acesso em: 11 jul. 2014.

CONZENDEY, Carlos Márcio B. O Sistema de Incorporação das Normas do Mercosul à Ordem Jurídica Interna. VAZ, Alcides Costa (Org.) Dimensões da integração no Mercosul. Brasília: Cadernos do CEAM, No. 7, 2002, p. 45-61.

CRAWFORD, Jo-Ann; FIORENTINO, Roberto V. The Changing Landscape of Regional Trade Agreements. WTO Discussion Paper No. 8. Disponível em: <http://www.wto.org/english/res_e/booksp_e/discussion_papers8_e.pdf>. Acesso em: 1 jan. 2013.

COMISSÃO EUROPÉIA. The Trade in Services Agreement ('TiSA'). Disponível em: <http://trade.ec.europa.eu/doclib/docs/2013/june/tradoc_151374.pdf>. Acesso em: 10 jul. 2014.

Member States endorse EU-US trade and investment negotiations. Bruxelas, 14 de junho de 2013. Disponível em: <http://trade.ec.europa.eu/doclib/press/index.cfm?id=918> . Acesso em: 11 jul. 2014.

COTTIER, Thomas; MOLINUEVO, Martín. Article V GATS Economic Integration. WOLFRUM, Rüdiger, STROLL, Peter-Tobias; FEINÄUGLE Clemens (ed.). WTO Trade in Services. (Max Planck Commentaires on World Trade Law): Martinus Nijhoff Publishers, 2008, p. 126-151.

ESTEVADEORDAL, Antoni; SUOMINEN, Kati; THE, Robert. Regional Rules in the Global Trading System. Cambridge: Cambrigde Unversity Press, 2009. 
FEDERAÇÃO DO COMÉRCIO DE BENS, SERVIÇOS E TURISMO DO ESTADO DE SÃO PAULO - FECOMERCIO SP. Cadernos FECOMERCIO de Economia Internacional, No. 2, Setembro de 2007. Disponível em: <www.fecomercio.com.br/cmssite/Files/.../8ff402c2b9_caderno30.pdf>. Acesso em: 13 mai. 2014.

FINK, Carsten; JANSEN, Marion. Services provisions in regional trade agreements: stumbling or building blocks for multilateral liberalization? Agosto de 2007. Disponível em: <http://www.cepr.org/meets/wkcn/2/2380/papers/Fink-Jansen.pdf>. Acesso em: 10 ago. 2013.

; MOLINUEVO, Martin. East Asian free trade agreements in services: Key architectural elements. Journal of International Economic Law, Vol. 11, No. 2. Oxford: Oxford University Press, 2008, p. 263-311.

East Asian preferential trade agreements in services: liberalization content and WTO rules. World Trade Review, Vol. 7, No. 4. Cambridge: Cambridge University Press, 2008, p. 641-673.

FLÔRES JR., Renato G. In Search of a Feasible EU-Mercosul Free Trade Agreement. CEPS Working Document. No. 378. Fevereiro 2013. Disponível em: <http://www.ceps.eu/book/search-feasible-eu-mercosul-free-trade-agreement>. Acesso em: 12 mai. 2014.

FRANCOIS, Joseph; HOECKMAN, Bernard; MANCHIN, Miriam. Preference Erosion and Multilateral Trade Liberalization. World Bank Policy Research Working Paper 3730. Outubro de 2005. Disponível em: <http://wber.oxfordjournals.org/content/20/2/197.short>. Acesso em: 1 fev. 2014.

FÓRUM ECONÔMICO MUNDIAL. Mega-regional Trade Agreements Game-Changers or Costly Distractions for the World Trading System? Julho de 2014. Disponível em: $<$ http://www.weforum.org/reports/mega-regional-trade-agreements-game-changers-orcostly-distractions-world-trading-system-0>. Acesso em: 11 jul. 2014. 
FUKUNAGA, Yoshifumi; ISHIDO Hikari. Assessing the Progress of Services Liberalization in the ASEAN-China Free Trade Area (ACFTA). ERIA Discussion Paper 2013-07, maio de 2013. Disponível em: <http://www.eria.org/publications/discussion_papers/assessing-the-progress-of-servicesliberalization-in-the-asean-china-free-trade-area-acfta.html>. Acesso em: 5 mai. 2014.

GANTZ, David A. Regional trade agreements: law, policy and practice. Durham: Carolina Academic Press, 2009.

GLICK, Leslie Allan. Understanding the North America Free Trade Agreement: Legal and Business Consequences of NAFTA. $3^{\mathrm{a}}$. Ed. Alphen aan den Rijn: Wolters Kluwer Law \& Business, 2010.

HOECKMAN, Bernard M.; MARTIN, William J.; PRIMO BRAGA, Carlos Alberto. Trade Preference Erosion: Measurement and Policy Response. Washington D.C: Banco Mundial, 2009. Disponível em:

<http://econ.worldbank.org/WBSITE/EXTERNAL/EXTDEC/EXTRESEARCH/EXTPRO GRAMS/EXTTRADERESEARCH/0,,contentMDK:21067622 pagePK:64168182 piPK:6 4168060 theSitePK:544849,00.html>. Acesso em: 3 fev. 2014.

; ENGLISH, Philip; MATTOO, Aaditya (Ed.);

Development, trade and the WTO: a handbook. Washington D.C.: Banco Mundial, 2002. Disponível em:

$<$ http://econ.worldbank.org/external/default/main?pagePK=64165259\&theSitePK=469382 \&piPK=64165421\&menuPK=64166093\&entityID=000160016_20040819140633>. Acesso em: 3 fev. 2014.

HORNG, Der-Chin. Reshaping the EU's FTA Policy in a Globalizing Economy: The Case of the EU-Korea FTA. Journal of World Trade, N. 46, Ed. 2. Kluwer Law International, 2012, pp. 301-326.

HORN, Henrik; MAVROIDIS, Petros C.; SAPIR, André. Beyond the WTO? An anatomy of EU and US preferential trade agreements. Bruegel Blueprint Series. Volume VII. Bruxelas: Bruegel, 2008. 
HOUDE, Marie-France, KOLSE-PATIL, Akshay; MIROUDOT, Sébastien. The Interaction between Investment and Services Chapters in Selected Regional trade Agreements”, OECD Trade Policy Papers, No. 55, OECD Publishing, 2007. Disponível em: <http://dx.doi.org/10.1787/054761108710>. Acesso em: 1 mar. 2014.

HUFBAUER, Gary Clyde et al. Framework for the International Services Agreement. Peterson Institute for International Economics. Policy Brief PB12-10. Washington, DC. Abril 2012. Disponível em: <http://www.iie.com/publications/pb/pb12-10.pdf>. Acesso em: 19 mai. 2014.

KOTSCHWAR, Barbara. The Mega-agreements - New Actors and New Rules. Presented at FGB-SP and the Center on Global Trade "The Impacts of Mega-agreements (TTIP and TPP) and the future of Mercosur". São Paulo, Brasil. 8 de maio de 2014. Disponível em:<http://ccgi.fgv.br/sites/ccgi.fgv.br/files/u5/Megas\%20x\%20Mercosul\%208-52014.pdf>. Acesso em: 10 jul. 2014.

KOCH-WESER, Iacob. Should China Join the WTO's Services Agreement? Março 2014. Disponível em: <http://www.uscc.gov/Research/should-china-join-wto\%E2\%80\%99sservices-agreement>. Acesso em: 19 mai. 2014.

KUME, Honorio; PIANI, Guida; MIRANDA, Pedro; CASTILHO, Marta. Acordo de Livre Comércio Mercosul - União Européia: uma estimativa dos impactos no comércio brasileiro. Texto Para Discussão No 1054, Instituto De Pesquisa Econômica Aplicada (IPEA). Rio de Janeiro, novembro de 2004. Disponível em: <http://www.ipea.gov.br/portal/index.php?option=com_content\&view=article\&id=4650> Acesso em: 12 mai. 2014.

LAMPREIA, Luiz Felipe P. Resultados da Rodada Uruguai: uma tentativa de síntese. Revista Estudos Avançados. São Paulo, v. 9, n. 23, p. 247-260, jan./abr. 1995. Disponível em: $<$ http://www.scielo.br/scielo.php?pid=S010340141995000100016\&script=sci_arttext>. Acesso em: $18 \mathrm{dez} .2007$. 
LAFER, Celso. A OMC e a regulamentação do comércio internacional: uma visão brasileira. Porto Alegre: Livraria do Advogado, 1998.

- A OMC face à globalização e à regionalização. Revista Política Externa. São Paulo, v. 6, n. 2, p. 83-93, out../nov. 1997.

LATRILLE, Pierre; LEE, Jouneyoung. Services rules in regional trade agréments. How diverse and how creative as compared to the GATS multilateral rules? WTO Working Paper. Genebra, Outubro de 2012. Disponível em: <http://www.wto.org/english/res_e/reser_e/ersd201219_e.htm>. Acesso em: 16 jan. 2013.

LIPSEY, R. G.; LANCASTER, Kelvin. The general theory of second best. The review of economic studies. Oxford: Oxford University Press, 1956 - 1957. Vol. 24, no. 1. P. 11 32. Disponível em: 〈http://www.jstor.org/stable/10.2307/2296233>. Acesso em: 28 jun. 2012.

MARCHETTI; Juan A.; ROY, Martin (ed.). Opening markets for trade in services. Countries and sectors in Bilateral and WTO negotiations. New York: Cambridge University Press, 2008.

; The new kid on the block: The Trade in

Services Agreement. Dezembro 2013. Disponível em: <http://www.voxeu.org/article/trade-services-agreement>. Acesso em: 19 mai. 2014. ; HOE, Lim. Services Liberalization in the New Generation of Preferential Trade Agreements (PTAs): How Much Further than the GATS? Staff Working Paper ERSD-2006-07. World Trade Organization, Economic Research and Statistics Division. Setembro de 2006. Disponível em: <http://www.wto.org/english/res_e/reser_e/ersd200607_e.pdf>. Acesso em: 1 jan. 2013.

MATHIS, James H. Regional trade agreements in the GATT-WTO: Article XXIV and the internal trade requirement. Haia: T.M.C. Asser Press, 2002. 
MATTOO, Aaditya; FINK, Carsten. Regional agreements and trade services - policy issues. Policy Research Working Paper Series No 2852. The World Bank. Junho de 2002. Disponível em: < http://econpapers.repec.org/paper/wbkwbrwps>. Aceseso em: 10 jul. 2012.

; OLARREAGA, Marcelo. Reciprocity across modes of supply in the World Trade Organization: A negotiating formula. Washington: Banco Mundial, 2000. Disponível em: <http://wwwwds.worldbank.org/servlet/WDSContentServer/WDSP/IB/2000/08/14/000094946_000727 05354792/Rendered/PDF/multi_page.pdf >. Acesso em: 7 jul. 2012.

; SAUVÉ, Pierre. Services. CHAUFFOUR, Jean-Pierre; MAUR, Jean-Christophe (ed.). Preferential Trade Agreements Policies for Development: A handbook. Washington D.C.: Banco Mundial, 2011, p. 235-274. Disponível em: $<$ http://wbi.worldbank.org/wbi/news/2011/07/11/preferential-trade-agreement-policiesdevelopment>. Acesso em: 10 jul. 2012.

; STERN, Robert M.; ZANINI, Gianni. A Handbook of International Trade in Services. Nova York: Oxford University Press, 2007.

MERCADANTE, Araminta de Azevedo; CELLI JUNIOR, Umberto; ROCHA DE ARAÚJO, Leandro (coords.). Blocos econômicos e integração na América Latina, África e Ásia. Curitiba: Juruá, 2007.

. Guerra Comercial ou Integração Mundial

pelo Comércio? A OMC e o Brasil. São Paulo: LTr, 1998.

MESSERLIN, Patrick. The Mercosur-EU Preferential Trade Agreement A view from Europe. CEPS Working Document. No. 377. Fevereiro 2013. Disponível em: <http://aei.pitt.edu/40233/1/WD_377_Messerlin_Mercosur-EU_Trade.pdf〉. Acesso em: 12 mai. 2014. 
MIROUDOT, Sébastien; SAUVAGE, Jehan; SUDREAU, Marie. Multilateralising Regionalism: How Preferential Are Services Commitments in Regional Trade Agreements. OECD Trade Policy Papers, No. 106, Dezembro de 2010. Disponível em: <http://dx.doi.org/10.1787/5km362n24t8n-en>. Acesso em: 15 fev. 2014.

MUKUNOKI, Hiroshi. Understanding the Effects of Preferential Trade Agreements: A Theoretical Overview. Bulletin of Gakushuin University Research Institute of Economics and Management, No. 19, Dezembro de 2005. Disponível em: <http://wwwcc.gakushuin.ac.jp/ 20030012/paper/GEM19-mukunoki.pdf>. Acesso em: 28 jun. 2012.

NAG, Biswajit; DE, Debdeep. Services in Regional Trade Agreements: Implications for India. International Trade Research Series, Working Paper N. 05-08, Setembro 2008, p. 130. Disponível em: < http://mpra.ub.uni-muenchen.de/15871/>. Acesso em: 5 mai. 2014.

NAKATOMI, Michitaka. Plurilateral Agreements: A Viable Alternative to the World Trade Organization? ADBI Working Paper Series nº 439. Outubro de 2013. Disponível em:

$<$ http://www.adbi.org/working-

paper/2013/10/24/5914.plurilateral.agreements.alternative.wto>. Acesso em: 11 jul. 2014.

NATENS, Bregt; WOUTERS, Jan. Mapping Services Liberalisation Commitments in European Union Regional Trade Agreements. KU Leuven Centre for Global Governance Studies Working Paper, n. 116, 2013. Disponível em: $<$ http://ghum.kuleuven.be/ggs/projects/policy-research-centre/documents-1/5-bregt-natensjan-wouters.pdf>. Acesso em: 12 mai. 2014.

NIELSON, Julia. Labour mobility in regional trade agreements. Abril de 2002. Disponível em: https://www.wto.org/english/tratop_e/serv_e/symp_apr_02_nielson1_e.doc. Acesso em: 20 abr. 2014. 
OLIVEIRA, Ivan Tiago M; SANCHEZ BADIN, Michelle R. (org.). Tendências regulatórias nos acordos preferenciais de comércio no século XXI: os casos de Estados Unidos, União Europeia, China e Índia. Brasília: Ipea, 2013. Disponível em: <http://repositorio.ipea.gov.br/bitstream/11058/2528/1/Livro_Tendencias_regulatorias_nos _acordos_preferenciais_de_com\%C3\%A9rcio_no_s\%C3\%A9culo_XXI\%20os_casos_de_Estados_Unidos_Uni\%C3\%A3o_Europeia_China_e_\%C3\%8Dndia.pdf $>$. Acesso em: 14 fev. 2014.

OLIVEIRA JÚNIOR, Márcio de. Uma Análise da Liberalização do Comércio Internacional de Serviços no Mercosul. Texto Para Discussão No 727 , Instituto De Pesquisa Econômica Aplicada (IPEA). Rio de Janeiro, junho de 2000. Disponível em: <http://www.ipea.gov.br/portal/index.php?option=com_content\&view=article\&id=3996>. Acesso em: 18 ago. 2013.

ORGANIZAÇÃO PARA A COOPERAÇÃO ECONÔMICA E O DESENVOLVIMENTO.

The General Agreement on Trade in Services (GATS): an analysis. Paris: OECD Press, 1994.

ORGANIZAÇÃO MUNDIAL DO COMÉRCIO. Guide to the GATS. 1 ed. Genebra: Kluwer International, 2000. Analytical Index: guide to GATT Law and practice. Genebra: Bernan Press, 1995.

- Market access: unfinished business. Post Uruguay Round inventory and issues - special studies, n. 6, p. 97-140. Disponível em: <http://www.wto.int/english/res_e/booksp_e/special_study_6_e.pdf>. Acesso em: 12 dez. 2007.

From GATT to the WTO: the multilateral trading system in the new millennium. Haia: Kluwer Law International, 2000. 
International Trade Statistics 2010.

2010. Disponível em: <http://www.wto.org/statistics>. Acesso em: 20 out. 2010.

ORTINO, Federico. Regional Trade Agreements and Trade in Services. In: LESTER, S.; MERCURIO, B. Bilateral and regional trade agreements: commentary and analysis (Ed.). Nova York: Cambridge University Press, 2009, p. 184-214.

PEÑA, Félix. Understanding Mercosur and its Future. The Jean Monnet/Robert Schuman Paper Series. Vol. 5 No. 14. Junho 2005. Disponível em: <http://aei.pitt.edu/8143/1/penafinal.pdf>. Acesso em: 12 mai. 2014.

El Mercosur en un mundo de mega acuerdos preferenciales. Sugerencias para debatir su adaptación a nuevas realidades del comercio global. Boletim $\begin{array}{llll}\text { Techint. Maio } 2014 . & \text { Disponível em: }\end{array}$ $<$ http://www.felixpena.com.ar/index.php?contenido=wpapers\&wpagno=documentos/201405-mercosur-en-un-mundo-de-mega-acuerdos-preferenciales>. Acesso em: 9 jul. 2014.

Grietas Estructurales en el Mercosur: ¿Es posible adaptar algunas de sus reglas de juego a las realidades actuales? Novembro de $2009 . \quad$ Disponível em: <http://www.felixpena.com.ar/index.php?contenido=negociaciones\&neagno=informes $/ 200$ 9-11-grietas-estructurales-en-mercosur> . Acesso em: 9 jul. 2014.

Mercosur-EU: options if the goal is not achieved. Abril de 2013. Disponível em:

$<$ http://www.felixpena.com.ar/index.php?contenido=wpapers\&wpagno=documentos/201304-23-mercosur-eu-options-if-the-goal-is-not-achieved>. Acesso em: 12 jul. 2014.

ROY, Martin. Services Commitments in Preferential Trade Agreements: An Expanded Dataset. Novembro de 2011.2 Disponível em: <http://www.wto.org/english/tratop_e/serv_e/dataset_e/dataset_e.htm>. Acesso em: 17 jul. 2013. 
. Services Commitments in Preferential Trade Agreements: Surveying the Empirical Landscape. NCCR Trade Working Paper No. 2012/2. Janeiro 2012. Disponível em: <http://www.nccr-trade.org/publication/services-commitments-in-preferential-tradeagreements-surveying-the-empirical-landscape/>. Acesso em: 17 jul. 2013.

SAEZ, Sebastian (Ed.). Trade in Services Negotiations: A Guide for Developing Countries. Washington, D.C.: The World Bank. Junho 2010. Disponível em: <http://elibrary.worldbank.org/doi/book/10.1596/978-0-8213-8410-7>. Acesso em: 15 mai. 2014.

SALLY, Razeen. Looking East: The European Union's New FTA Negotiations in Asia. European Centre for International Political Economy. Jan Tumlir Policy Essays N. 3. Outubro 2007. Disponível em: <http://www.externarelationer.adm.gu.se/infoglueCalendar/digitalAssets/1765115868_Bif ogadFil_Razeen\%20Sally\%20on\%20EU\%20FTAs.pdf>. Acesso em: 1 mai. 2014.

SAUVÉ, Pierre; STERN, Robert M. GATS 2000 - New directions in services trade liberalization. Washington: Brookings Institutions Press, 2000.

. The relationship between regional trade agreements and the multilateral trading system. Outubro 2002. Disponível em: $<$ http://search.oecd.org/officialdocuments/displaydocumentpdf/?doclanguage=en \&cote=td/ tc/wp(2002)27/final>. Acesso em: 1 mar. 2014.

A Plurilateral Agenda for Services? Assessing the case for a Trade in Services Agreement (TISA). NCCR Trade Working Paper No. 2013/29. Maio 2013. Disponível em: <http://www.wti.org/fileadmin/user_upload/nccrtrade.ch/wp2/publications/TISA_P_Sauve.pdf.>. Acesso em: 19 mai. 2014.

; SHINGAL, Anirudh. The Preferential Liberalization of Trade in Services: Comparative Regionalism. Cheltenham: Edward Elgar Publishing, 2014. 
SAYEG, Fernanda M. As negociações para a liberalização do comércio de serviços na OMC. Pontes entre o Comércio e o Desenvolvimento Sustentável, v. 1, n. 3, ago./set. 2005. Disponível em: <http://www.edesp.edu.br/subportais/Pontes1-3.pdf>. Acesso em: 10 dez. 2008.

SCHIFF, Maurice; WINTERS, L. Alan. Regional Integration and Development. Washington: World Bank e Oxford University Press, 2003.

SEWADEH, Mirvat. General Background on Regional Trade Agreements in Latin America. Disponível em: $<$ http://siteresources.worldbank.org/INTRANETTRADE/Resources/LACAgreementsBkgr d.pdf>. Acesso em: 26 jan. 2014.

SOUTH CENTRE. Negotiating services Free Trade Agreements (FTAs) with the European Union: Some issues for developing countries to consider. Analytical Note SC/AN/TDP/EPA/21, junho de 2009. Disponível em: <http://www.southcentre.int/wpcontent/uploads/2013/08/AN_EPA21_Negotiating-Services-FTAs-with-EU_EN.pdf>. Acesso em: 1 mai. 2014.

STEPHENSON, Sherry; ROBERT, Maryse. Innovations of Regionalism in Services in the Americas. NCCR Trade Working Paper No 2011/34, maio de 2011. Disponível em: < http://www.nccr-trade.org/fileadmin/user_upload/nccr-

trade.ch/wp2/people/WPInnovations\%20of\%20Regionalism\%20in\%20Services\%20\%20Americas\%20-\%20May\%202011\%20FINAL.pdf>. Acesso em: 3 mar. 2014.

THORSTENSEN, Vera. OMC - Organização Mundial do Comércio: as regras do comércio internacional e a nova rodada de negociações multilaterais. São Paulo: Aduaneiras, 2001.

O multissistema da regulação do comércio global: proposta de novo referencial teórico e nova metodologia de análise. Working Paper. 
et al. A multiplicação dos acordos preferenciais de comércio e o isolamento do Brasil. Junho 2013. Disponível em: <http://retaguarda.iedi.org.br/midias/artigos/51d18e9168afa9d0.pdf>. Acesso em: 15 mai. 2014.

TORRENT, Ramom. The legal toolbox for regional integration: a legal analysis from an interdisciplinary perspective. Barcelona, 2007. TORRENT, Ramon. Disponível em: <http://www.iadb.org/intal/intalcdi/PE/2012/11120a18.pdf>. Acesso em: 31 dez. 2013.

; MOLINUEVO, Martín. Keeping multilateralism and development in mind: proposals: For a new model of north-south agreements. UNCTAD. Multilateralism and regionalism: the new interface. Nova Iorque/Genebra, 2005. Disponível em: <http://www.unctad.org/en/docs/ditctncd20047ch6_en.pdf>. Acesso em: 13 dez. 2008.

TREBILOCK, Michael J.; HOWSE, Robert. The regulation of international trade. Londres: Routledge, 1999.

UNCTAD. Trade and Development Report, 2007. Chapter III - The "New Regionalism" and North-South Trade Agreements. Nova Iorque e Genebra: 2007. Disponível em: <http://archive.unctad.org/templates/Page.asp?intItemID=4329\&lang=1>. Acesso em: 8 jul. 2012.

Curso de Solução de Controvérsias: Organização Mundial do Comércio. Capítulo 3.13 - GATS. Nova Iorque/Genebra: 2003. Disponível em: 〈http://www.unctad.org/pt/docs/edmmisc232add31_pt.pdf〉. Acesso em: 10 jul. 2012.

UNIÃO EUROPEIA - DG TRADE. EU-South Korea Free Trade Agreement: A Quick Reading Guide. Outubro de 2010. Disponível em: <http://trade.ec.europa.eu/doclib/docs/2009/october/tradoc_145203.pdf>. Acesso em: 15 mai. 2014. 
UNITED STATES TRADE REPRESENTATIVE. Final Report of the U.S.-EU High Level Working Group on Jobs and Growth. 11 de fevereiro de 2013. Disponível em: $<$ http://www.ustr.gov/about-us/press-office/reports-and-publications/2013/final-report-useu-hlwg>. Acesso em: 11 jul. 2014.

WATSON, William, DO, Viet D. Economic Analysis of Regional Trade Agreements. Montreal, 2006. Disponível em: <http://www.mcgill.ca/files/economics/economicanalysisof.pdf>. Acesso em: 20 jun. 2012.

WIGNARAJA, Ganeshan; LAZARO, Dorothea. North-South Vs. South-South Asian FTAs: Trends, compatibilities, and ways forward. UNU-CRIS Working Papers. W-2010/3. Disponível em: <http://www.cris.unu.edu/UNU-CRIS-WorkingPapers.19.0.html?cHash=473030703299e32e338dcad87da47192\&tx_ttnews[tt_news]=79> . Acesso em: 7 mai. 2014.

WOOLCOCK, Stephen. European Union policy towards Free Trade Agreements. ECIPE Working Paper, No. 03. Bruxelas, 2007. Disponível em: http://www.felixpena.com.ar/contenido/negociaciones/anexos/2010-09-european-unionpolicy-towards-free-trade-agreements.pdf. Acesso em: 19 abr. 2014.

WONNACOTT, Ronald J. Free-Trade Agreements: For Better or Worse? The American Economic Review. Vol. 86, No. 2, (May, 1996), São Francisco: American Economic Association, 2006.

VAngRASSTEK, Craig. The Political Economy of Services in Regional Trade Agreements. OECD Trade Policy Papers, No. 112. OECD Publishing, 2011. Disponível em: 〈http://dx.doi.org/10.1787/5kgdst6lc344-en>. Acesso em: 10 ago. 2013.

VOON, Tania; YANOVICH, Alan. What is the measure at issue? MITCHELL, Andrew (ed.). Challenges and Prospects for the WTO. Londres: Cameron May Publishers, 2005. p. 115-163. 


\section{LEGISLAÇÃO BRASILEIRA}

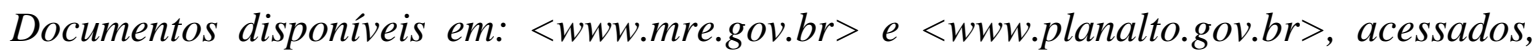
pela última vez, em 9 de maio de 2014.

Decreto $\mathrm{n}^{\circ} 1.355$, de 30 de dezembro de 1994, que promulga a Ata Final que incorpora os resultados da Rodada Uruguai de negociações comerciais multilaterais do GATT.

Decreto ${ }^{\circ}$ 1.901, de 09 de maio de 1996, que promulga o Protocolo Adicional ao Tratado de Assunção sobre a Estrutura Institucional do MERCOSUL (Protocolo de Ouro Preto), de 17 de dezembro de 1994.

Decreto No 2.075, de 19 de novembro de 1996, que dispõe sobre a execução do Acordo de Complementação Econômica, entre Brasil, Argentina, Paraguai, Uruguai e Chile, de 30 de setembro de 1996.

Decreto $\mathrm{n}^{\mathrm{o}}$ 313, de 30 de julho de 1948, que autoriza o Poder Executivo a aplicar, provisoriamente, o Acordo Geral sobre Tarifas Aduaneiras e Comércio; reajusta as tarifas aduaneiras e dá outras providências.

Decreto $n^{\circ} 5361$, de 31 de janeiro de 2005, que dispõe sobre a execução do Acordo de Complementação Econômica no 59, entre os Governos da República Argentina, da República Federativa do Brasil, da República do Paraguai, da República Oriental do Uruguai, Estados Partes do Mercosul, e os Governos da República da Colômbia, da República do Equador, da República Bolivariana da Venezuela, Países Membros da Comunidade Andina.

Decreto $N^{o}$ 550, De 27 de maio de 1992, que dispõe sobre a execução do Acordo de Alcance Parcial de Complementação Econômica n 18, entre Brasil, Argentina, Paraguai e Uruguai. 
Decreto $\mathrm{n}^{\mathrm{o}}$ 6.480, de 11 de junho 2008, que promulga o Protocolo de Montevidéu sobre o Comércio de Serviços do MERCOSUL, concluído em Montevidéu, em 15 de dezembro de 1997, acompanhado de seus quatro Anexos Setoriais, adotados pela Decisão 9/98 do Conselho Mercado Comum, em 23 de julho de 1998, e a "Lista de Compromissos Específicos Iniciais" do Brasil, aprovada pela Decisão no 9/98 do Conselho Mercado Comum, em 23 de julho de 1998.

Decreto $\mathrm{n}^{\mathrm{o}} 7.159$, de 27 de abril de 2010, que promulga o Acordo de Livre Comércio entre o Mercosul e o Estado de Israel, assinado em Montevidéu, em 18 de dezembro de 2007.

Entendimento Sobre A Interpretação do Artigo XXIV do Acordo Geral sobre Tarifas e Comércio 1994.

Projeto de Decreto Legislativo n ${ }^{\circ}$ 214/92, de 8 de novembro de 1995, que aprova o texto da Convenção de Viena sobre o Direito dos Tratados.

\section{DOCUMENTOS INTERNACIONAIS}

\subsection{Documentos oficiais do GATT/OMC}

Documentos disponíveis em: 〈http://www.wto.org> $e$ 〈http://docsonline.wto.org >, acessados, pela última vez, em 12 de julho de 2014.

Agreement Establishing the World Trade Organization.

Final Act and Related Documents - United Nations Conference on Trade and Development held at Havana, Cuba, from November 21, 1947, to March 24, 1948 (UN Document E/Conf. 2/78).

GATT. L/4903. Decision of 28 November 1979.

International Trade Statistics 2013.

Measuring Trade In Services. Novembro de 2010. 
MTN.GNS/W/120. Services Sectoral Classification List. 10 de julho de 1991.

S/C/M/31. Council for Trade in Services - Report of the Meeting Held on 23 and 24 November 1998 - Note by the Secretariat. de 9 de dezembro de 1998.

S/C/W/92. Procedures on Reporting on Regional Trade Agreements. 4 de janeiro de 1999.

S/L/5. Guidelines for Notifications under the General Agreement on Trade in Services. 1 de março de 1995.

Trade Profiles 2013.

World Trade Report 2011.

WT/L/127. Committee On Regional Trade Agreements. 7 de fevereiro de 1996.

WT/L/61. Transparency Mechanism for Regional Trade Agreements. 18 de dezembro de 2006.

WT/L/61. Transparency Mechanism for Regional Trade Agreements. 18 de dezembro de 2006.

\subsection{Documentos oficiais do Mercosul}

Documentos disponíveis em: <http://www.mercosul.gov.br/tratados-e-protocolos>, $\langle w w w . h t t p: / / w w w . m e r c o s u r . i n t>e \quad\langle h t t p: / / w w w . s i c e . o a s . o r g\rangle$, acessados, pela última vez, em 21 de maio de 2014.

Tratado para a Constituição de um Mercado Comum entre a República Argentina, a República Federativa do Brasil, a República do Paraguai e a República Oriental do Uruguai. 
Protocolo de Montevidéu sobre o Comércio de Serviços do Mercosul.

Protocolo Adicional ao Tratado de Assunção sobre a Estrutura Institucional do Mercosul (Protocolo de Ouro Preto).

MERCOSUL/CMC/DEC. N $N^{o}$ 23/00 - Relançamento do Mercosul - Incorporação da Normativa Mercosul ao Ordenamento Jurídico dos Estados Partes.

MERCOSUL/CMC/DEC. No 32/00 - Relançamento do Mercosul - Relacionamento Externo.

MERCOSUL/CMC/DEC. N 49/08 - Plano de Ação para o Aprofundamento do Programa de Liberalização do Comércio de Serviços no âmbito do Mercosul.

MERCOSUL/CMC/DEC. N 54/10 - Aprofundamento da Liberalização em Serviços.

\subsection{Documentos oficiais da ALADI}

Acordo de Complementação Econômica No 18 Celebrado entre Argentina, Brasil, Paraguai e Uruguai. Disponível em:

<http://www.aladi.org/nsfaladi/textacdos.nsf/5103963ecba1a07703256aa9005cc620/008a4 d1048debbdc0325742d004fabb9/\$FILE/ACE\%20N\%C2\%B0\%2018-59-p.doc>. Acesso em: 13 mai. 2014.

Acordo de Complementação Econômica No. 59 Assinado entre os Estados Partes do Mercosul e os Países Membros da Comunidade Andina. Disponível em:

$<$ http://www.mdic.gov.br/sitio/interna/interna.php?area=5\&menu=468>. Acesso em: 13 mai. 2014.

Acordo de Complementação Econômica No 35 Celebrado entre os Governos dos Estados Partes do Mercosul e o Governo da República do Chile. Disponível em: $<$ http://www.mdic.gov.br/sitio/interna/interna.php?area=5\&menu=461>. Acesso em: Acesso em: 12 mai. 2014. 
Acordo de Complementação Econômica $N^{\circ} 35$ Celebrado entre os Governos dos Estados Partes do Mercosul e o Governo da República do Chile. Quinquagésimo Terceiro Protocolo Adicional. Protocolo Sobre o Comércio de Serviços entre o Mercosul e o Chile. Disponível em: <http://www.mdic.gov.br/sitio/interna/interna.php?area=5\&menu=461>. Acesso em: Acesso em: 12 mai. 2014.

\subsection{Acordos Regionais de Comércio}

\subsubsection{Acordos regionais de comércio celebrados pelos Estados Unidos}

Documentos disponíveis em: <http://www.ustr.gov/trade-agreements/free-tradeagreements >, acessados, pela última vez, em 20 de maio de 2014.

Agreement between the Government of the United States of America and the Government of the Sultanate of Oman on the Establishment of a Free Trade Area.

Agreement Between the United States of America and the Hashemite Kingdom of Jordan on the Establishment of a Free Trade Area.

Agreement on the Establishment of a Free Trade Area between the Government of Israel and the Government of the United States of America.

Australia-United States Free Trade Agreement.

Dominican Republic-Central America-United States Free Trade Agreement.

Free Trade Agreement Between the United States of America and the Republic of Korea.

North American Free Trade Agreement.

United States-Bahrain Free Trade Agreement.

United States-Chile Free Trade Agreement. 
United States-Colombia Trade Promotion Agreement.

United States-Morocco Free Trade Agreement.

United States-Panama Trade Promotion Agreement.

United States-Peru Trade Promotion Agreement.

United States-Singapore Free Trade Agreement.

\subsubsection{Acordos regionais de comércio celebrados pela União Europeia}

Documentos disponíveis em: <http://eur-lex.europa.eu>, acessados, pela última vez, em 20 de maio de 2014.

Agreement establishing an association between the European Community and its Member States, of the one part, and the Republic of Chile, of the other part.

Agreement in the form of an Exchange of Letters concerning the provisional application of the Agreement on Trade, Development and Cooperation between the European Community and its Member States, of the one part, and the Republic of South Africa, of the other part.

Economic Partnership Agreement between the CARIFORUM States, of the one part, and the European Community and its Member States, of the other part.

Economic Partnership, Political Coordination and Cooperation Agreement between the European Community and its Member States, of the one part, and the United Mexican States, of the other part.

Euro-Mediterranean Agreement establishing an Association between the European Communities and their Member States, of the one part, and the Hashemite Kingdom of Jordan, of the other part. 
Euro-Mediterranean Agreement establishing an association between the European Communities and their Members States, of the one part, and the State of Israel, of the other part.

Euro-Mediterranean Agreement establishing an association between the European Communities and their Member States, of the one part, and the Kingdom of Morocco, of the other part.

Euro-Mediterranean Agreement establishing an Association between the European Communities and their Member States, of the one part, and the Arab Republic of Egypt, of the other part.

Euro-Mediterranean Agreement establishing an association between the European Communities and their Member States, of the one part, and the Republic of Tunisia, of the other part.

Euro-Mediterranean Agreement establishing an Association between the European Community and its Member States, of the one part, and the People's Democratic Republic of Algeria, of the other part.

Free trade Agreement between the European Union and its Member States, of the one part, and the Republic of Korea, of the other part.

Interim Agreement with a view to an Economic Partnership Agreement between the European Community and its Member States, of the one part, and the Central Africa Party.

Stepping stone Economic Partnership Agreement between Côte d'Ivoire, of the one part, and the European Community and its Member States. 


\subsubsection{Acordos regionais de comércio celebrados pela China}

Documentos disponíveis em: <http://fta.mofcom.gov.cn/english/index.shtml>, acessados, pela última vez, em 20 de maio de 2014.

Agreement on the Early Harvest Programme for the Free Trade Agreement Between the Government of the People's Republic of China and the Government of the Islamic Republic of Pakistan.

Agreement on Trade in Services of the Framework Agreement on Comprehensive Economic Co-operation between the Association of Southeast Asian Nations and the People's Republic of China.

Framework Agreement on Comprehensive Economic Co-operation between the Association of Southeast Asian Nations and the People's Republic of China.

Free Trade Agreement Between the Government of the People's Republic of China and the Government of New Zealand.

Free Trade Agreement Between the Government of the People's Republic of China and the Government of the Republic of Chile.

Free Trade Agreement Between the Government of the People's Republic of China and the Government of the Republic of Singapore.

Free Trade Agreement Between the Government of the People's Republic of China and the Government of the Republic of Costa Rica.

Free Trade Agreement Between the Government of the Republic of Peru and the Government of the People's Republic of China.

Supplementary Agreement on Trade in Services of the Free Trade Agreement between China and Chile. 


\subsubsection{Acordos regionais de comércio celebrados pela Índia}

Documentos disponíveis em:

<http://rtais.wto.org/UI/PublicSearchByMemberResult.aspx? MemberCode $=356 \&$ lang $=1$ \&redirect=1>, acessados, pela última vez, em 20 de maio de 2014.

Comprehensive Economic Cooperation Agreement Between the Government of the Republic of India and the Government of Malaysia.

Comprehensive Economic Cooperation Agreement Between the Republic of India and the Republic of Singapore.

Comprehensive Economic Partnership Agreement Between Japan and the Republic of India.

Comprehensive Economic Partnership Agreement Between the Republic of Korea and the Republic of India.

\subsubsection{Acordos regionais de comércio celebrados pelo Mercosul com Estados que não são membros da ALADI}

Documentos disponíveis em:

<http://www.desenvolvimento.gov.br/sitio/interna/interna.php?area=5\&menu=405>, acessados, pela última vez, em 12 de maio de 2014.

Acordo de Comércio Preferencial entre o Mercosul e a República da Índia.

Acordo de Livre Comércio entre o Mercosul e a República Árabe do Egito.

Acordo de Livre Comércio entre o Mercosul e o Estado da Palestina.

Acordo de Livre Comércio entre o Mercosul e o Estado de Israel.

Acordo Preferencial de Comércio entre o Mercado Comum do Sul (MERCOSUL) e a União Aduaneira da África do Sul (SACU). 
Acordo-Quadro de Comércio e Cooperação Econômica entre o Mercosul e a Autoridade Nacional Palestina.

Acordo-Quadro sobre Comércio entre o Mercosul e o Estado de Israel.

\section{PÁGINAS DA INTERNET}

ALADI: <http://www.aladi.org>

Banco Mundial: <http://www.worldbank.org>

Canada Foreign Affairs, Trade and Development: 〈http://www.international.gc.ca>

European Commission - $\quad$ Trade - Policy - Agreements:

<http://ec.europa.eu/trade/policy/countries-and-regions/agreements/>

European Union - Access to European Union Law: 〈http://eur-lex.europa.eu>

IBGE: < http://www.ibge.gov.br>

Mercosul: <http://www.mercosul.gov.br>

Ministério do Desenvolvimento, Indústria e Comércio Exterior: 〈http://www.mdic.gov.br>

Ministério de Relações Exteriores: 〈http://www.itamaraty.gov.br>

MOFCOM - China FTA Network: <http:/fta.mofcom.gov.cn/topic/enpakistan.shtml>

OCDE: < http://www.oecd.org>

OMC: <http://www.wto.org> 
OMC - Regional Trade Agreements Gateway: <http://rtais.wto.org>

SICE: <http://www.sice.oas.org>

The Coalition of Services Industries: <https://servicescoalition.org>

The European Services Forum: <http://www.esf.be>

UNCTADSTAT: <http://www.unctadstat.unctad.org>

USTR Free Trade Agreements: <http://www.ustr.gov/trade-agreements/free-tradeagreements> 
ANEXOS 


\section{ANEXO I}

RELAÇÃO DE ACORDOS DE LIVRE COMÉRCIO ANALISADOS 
Tabela 1 - Acordos celebrados pelos Estados Unidos

\begin{tabular}{|c|c|c|c|c|c|c|}
\hline Acordo & $\begin{array}{l}\text { Nome oficial do } \\
\text { Acordo, em } \\
\text { português }\end{array}$ & $\begin{array}{l}\text { Nome oficial do } \\
\text { Acordo, em inglês }\end{array}$ & Partes & $\begin{array}{c}\text { Data da } \\
\text { assinatura }\end{array}$ & $\begin{array}{c}\text { Data em } \\
\text { que } \\
\text { entrou } \\
\text { em vigor }\end{array}$ & Status \\
\hline $\begin{array}{l}\text { CAFTA- } \\
\text { DR }\end{array}$ & $\begin{array}{c}\text { Acordo de Livre } \\
\text { Comércio Entre } \\
\text { República } \\
\text { Dominicana, América } \\
\text { Central e Estados } \\
\text { Unidos }\end{array}$ & $\begin{array}{c}\text { Dominican } \\
\text { Republic-Central } \\
\text { America-United } \\
\text { States Free Trade } \\
\text { Agreement }\end{array}$ & $\begin{array}{l}\text { Estados } \\
\text { Unidos, } \\
\text { Costa Rica, } \\
\text { República } \\
\text { Dominicana, } \\
\text { El Salvador, } \\
\text { Guatemala, } \\
\text { Honduras e } \\
\text { Nicarágua }\end{array}$ & $\begin{array}{l}17 \mathrm{de} \\
\text { março de } \\
2006\end{array}$ & $\begin{array}{c}1 \mathrm{de} \\
\text { março de } \\
2006\end{array}$ & $\begin{array}{l}\text { Em } \\
\text { vigor }\end{array}$ \\
\hline KORUS & $\begin{array}{c}\text { Acordo de Livre } \\
\text { Comércio Entre os } \\
\text { Estados Unidos da } \\
\text { América e a } \\
\text { República da Coreia }\end{array}$ & $\begin{array}{c}\text { Free Trade } \\
\text { Agreement } \\
\text { Between the } \\
\text { United States of } \\
\text { America and the } \\
\text { Republic of Korea }\end{array}$ & $\begin{array}{l}\text { Estados } \\
\text { Unidos e } \\
\text { Coreia }\end{array}$ & $\begin{array}{l}15 \mathrm{de} \\
\text { março de } \\
2012\end{array}$ & $\begin{array}{l}15 \text { de } \\
\text { março de } \\
2012\end{array}$ & $\begin{array}{l}\text { Em } \\
\text { vigor }\end{array}$ \\
\hline NAFTA & $\begin{array}{c}\text { Acordo de Livre } \\
\text { Comércio da América } \\
\text { do Norte }\end{array}$ & $\begin{array}{l}\text { North American } \\
\text { Free Trade } \\
\text { Agreement }\end{array}$ & $\begin{array}{l}\text { Estados } \\
\text { Unidos, } \\
\text { Canadá e } \\
\text { México }\end{array}$ & $\begin{array}{c}29 \text { de } \\
\text { janeiro de } \\
1993 \text { (bens) } \\
\text { e } 1 \text { de } \\
\text { março de } \\
1995 \\
\text { (serviços) }\end{array}$ & $\begin{array}{c}\text { 1de } \\
\text { janeiro } \\
\text { de1994 }\end{array}$ & $\begin{array}{l}\text { Em } \\
\text { vigor }\end{array}$ \\
\hline $\begin{array}{l}\text { Estados } \\
\text { Unidos- } \\
\text { Austrália }\end{array}$ & $\begin{array}{c}\text { Acordo de Livre } \\
\text { Comércio Entre } \\
\text { Austrália e Estados } \\
\text { Unidos }\end{array}$ & $\begin{array}{c}\text { Australia-United } \\
\text { States Free Trade } \\
\text { Agreement }\end{array}$ & $\begin{array}{l}\text { Estados } \\
\text { Unidos e } \\
\text { Austrália }\end{array}$ & $\begin{array}{c}22 \text { de } \\
\text { dezembro } \\
\text { de } 2004\end{array}$ & $\begin{array}{c}1 \text { de } \\
\text { janeiro de } \\
2005\end{array}$ & $\begin{array}{l}\text { Em } \\
\text { vigor }\end{array}$ \\
\hline $\begin{array}{l}\text { Estados } \\
\text { Unidos- } \\
\text { Bahrain }\end{array}$ & $\begin{array}{c}\text { Acordo de Livre } \\
\text { Comércio Entre } \\
\text { Estados Unidos e } \\
\text { Bahrain }\end{array}$ & $\begin{array}{l}\text { United States- } \\
\text { Bahrain Free } \\
\text { Trade Agreement }\end{array}$ & $\begin{array}{l}\text { Estados } \\
\text { Unidos e } \\
\text { Bahrain }\end{array}$ & $\begin{array}{c}8 \mathrm{de} \\
\text { setembro de } \\
2006\end{array}$ & $\begin{array}{c}1 \mathrm{de} \\
\text { agosto de } \\
2006\end{array}$ & $\begin{array}{l}\text { Em } \\
\text { vigor }\end{array}$ \\
\hline $\begin{array}{l}\text { Estados } \\
\text { Unidos- } \\
\text { Chile }\end{array}$ & $\begin{array}{c}\text { Acordo de Livre } \\
\text { Comércio Entre } \\
\text { Estados Unidos e } \\
\text { Chile }\end{array}$ & $\begin{array}{l}\text { United States- } \\
\text { Chile Free Trade } \\
\text { Agreement }\end{array}$ & $\begin{array}{l}\text { Estados } \\
\text { Unidos e } \\
\text { Chile }\end{array}$ & $\begin{array}{c}16 \text { de } \\
\text { dezembro } \\
\text { de } 2003\end{array}$ & $\begin{array}{c}1 \mathrm{de} \\
\text { janeiro de } \\
2004\end{array}$ & $\begin{array}{l}\text { Em } \\
\text { vigor }\end{array}$ \\
\hline $\begin{array}{l}\text { Estados } \\
\text { Unidos- } \\
\text { Colômbia }\end{array}$ & $\begin{array}{l}\text { Acordo de Promoção } \\
\text { Comercial Entre } \\
\text { Estados Unidos e } \\
\text { Colômbia }\end{array}$ & $\begin{array}{l}\text { United States- } \\
\text { Colombia Trade } \\
\text { Promotion } \\
\text { Agreement }\end{array}$ & $\begin{array}{l}\text { Estados } \\
\text { Unidos e } \\
\text { Colômbia }\end{array}$ & $\begin{array}{l}8 \text { de maio } \\
\text { de } 2012\end{array}$ & $\begin{array}{l}15 \text { de } \\
\text { maio de } \\
2012\end{array}$ & $\begin{array}{l}\text { Em } \\
\text { vigor }\end{array}$ \\
\hline $\begin{array}{l}\text { Estados } \\
\text { Unidos- } \\
\text { Jordânia }\end{array}$ & $\begin{array}{l}\text { Acordo Entre os } \\
\text { Estados Unidos da } \\
\text { América e o Reino } \\
\text { Hachemita da } \\
\text { Jordânia para o } \\
\text { Estabelecimento de } \\
\text { uma Área de Livre } \\
\text { Comércio }\end{array}$ & $\begin{array}{l}\text { Agreement } \\
\text { Between the } \\
\text { United States of } \\
\text { America and the } \\
\text { Hashemite } \\
\text { Kingdom of } \\
\text { Jordan on the } \\
\text { Establishment of a } \\
\text { Free Trade Area }\end{array}$ & $\begin{array}{l}\text { Estados } \\
\text { Unidos e } \\
\text { Jordânia }\end{array}$ & $\begin{array}{c}15 \text { de } \\
\text { janeiro de } \\
2002\end{array}$ & $\begin{array}{c}17 \text { de } \\
\text { dezembro } \\
\text { de } 2001\end{array}$ & $\begin{array}{l}\text { Em } \\
\text { vigor }\end{array}$ \\
\hline
\end{tabular}




\begin{tabular}{|c|c|c|c|c|c|c|}
\hline $\begin{array}{l}\text { Estados } \\
\text { Unidos- } \\
\text { Marrocos }\end{array}$ & $\begin{array}{l}\text { Acordo de Livre } \\
\text { Comércio Entre } \\
\text { Estados Unidos e } \\
\text { Marrocos }\end{array}$ & $\begin{array}{l}\text { United States- } \\
\text { Morocco Free } \\
\text { Trade Agreement }\end{array}$ & $\begin{array}{l}\text { Estados } \\
\text { Unidos e } \\
\text { Marrocos }\end{array}$ & $\begin{array}{c}30 \text { de } \\
\text { dezembro } \\
\text { de } 2005\end{array}$ & $\begin{array}{c}1 \mathrm{de} \\
\text { janeiro de } \\
2006\end{array}$ & $\begin{array}{l}\text { Em } \\
\text { vigor }\end{array}$ \\
\hline $\begin{array}{l}\text { Estados } \\
\text { Unidos- } \\
\text { Omã }\end{array}$ & $\begin{array}{c}\text { Acordo Entre o } \\
\text { Governo dos Estados } \\
\text { Unidos da América e } \\
\text { o Governo do } \\
\text { Sultanato de Omã } \\
\text { para o } \\
\text { Estabelecimento de } \\
\text { uma Área de Livre } \\
\text { Comércio }\end{array}$ & $\begin{array}{l}\text { Agreement } \\
\text { between the } \\
\text { Government of the } \\
\text { United States of } \\
\text { America and the } \\
\text { Government of the } \\
\text { Sultanate of Oman } \\
\text { on the } \\
\text { Establishment of a } \\
\text { Free Trade Area }\end{array}$ & $\begin{array}{l}\text { Estados } \\
\text { Unidos e } \\
\text { Omã }\end{array}$ & $\begin{array}{l}30 \text { de } \\
\text { janeiro de } \\
2009\end{array}$ & $\begin{array}{c}1 \mathrm{de} \\
\text { janeiro de } \\
2009\end{array}$ & $\begin{array}{l}\text { Em } \\
\text { vigor }\end{array}$ \\
\hline $\begin{array}{l}\text { Estados } \\
\text { Unidos- } \\
\text { Panamá }\end{array}$ & $\begin{array}{l}\text { Acordo de Promoção } \\
\text { Comercial Entre } \\
\text { Estados Unidos e } \\
\text { Panamá }\end{array}$ & $\begin{array}{l}\text { United States- } \\
\text { Panama Trade } \\
\text { Promotion } \\
\text { Agreement }\end{array}$ & $\begin{array}{l}\text { Estados } \\
\text { Unidos e } \\
\text { Panamá }\end{array}$ & $\begin{array}{c}29 \text { de } \\
\text { outubro de } \\
2012\end{array}$ & $\begin{array}{c}31 \text { de } \\
\text { outubro } \\
\text { de } 2012\end{array}$ & $\begin{array}{c}\text { Em } \\
\text { vigor }\end{array}$ \\
\hline $\begin{array}{l}\text { Estados } \\
\text { Unidos- } \\
\text { Israel }\end{array}$ & $\begin{array}{l}\text { Acordo para o } \\
\text { Estabelecimento de } \\
\text { uma Área de Livre } \\
\text { Comércio Entre o } \\
\text { Governo de Israel e o } \\
\text { Governo dos Estados } \\
\text { Unidos da América }\end{array}$ & $\begin{array}{l}\text { Agreement on the } \\
\text { Establishment of a } \\
\text { Free Trade Area } \\
\text { between the } \\
\text { Government of } \\
\text { Israel and the } \\
\text { Government of the } \\
\text { United States of } \\
\text { America }\end{array}$ & $\begin{array}{l}\text { Estados } \\
\text { Unidos e } \\
\text { Israel }\end{array}$ & $\begin{array}{l}22 \text { de abril } \\
\text { de } 1985\end{array}$ & $\begin{array}{c}19 \text { de } \\
\text { agosto de } \\
1985\end{array}$ & $\begin{array}{l}\text { Em } \\
\text { vigor }\end{array}$ \\
\hline $\begin{array}{l}\text { Estados } \\
\text { Unidos- } \\
\text { Peru }\end{array}$ & $\begin{array}{l}\text { Acordo de Promoção } \\
\text { Comercial Entre } \\
\text { Estados Unidos e Peru }\end{array}$ & $\begin{array}{c}\text { United States-Peru } \\
\text { Trade Promotion } \\
\text { Agreement }\end{array}$ & $\begin{array}{l}\text { Estados } \\
\text { Unidos e } \\
\text { Peru }\end{array}$ & $\begin{array}{c}3 \text { de } \\
\text { fevereiro de } \\
2009\end{array}$ & $\begin{array}{c}1 \text { de } \\
\text { fevereiro } \\
\text { de } 2009\end{array}$ & $\begin{array}{c}\text { Em } \\
\text { vigor }\end{array}$ \\
\hline $\begin{array}{l}\text { Estados } \\
\text { Unidos- } \\
\text { Cingapura }\end{array}$ & $\begin{array}{l}\text { Acordo de Livre } \\
\text { Comércio entre } \\
\text { Estados Unidos e } \\
\text { Cingapura }\end{array}$ & $\begin{array}{l}\text { United States- } \\
\text { Singapore Free } \\
\text { Trade Agreement }\end{array}$ & $\begin{array}{l}\text { Estados } \\
\text { Unidos e } \\
\text { Cingapura }\end{array}$ & $\begin{array}{c}17 \text { de } \\
\text { dezembro } \\
\text { de } 2003\end{array}$ & $\begin{array}{c}1 \text { de } \\
\text { janeiro de } \\
2004\end{array}$ & $\begin{array}{l}\text { Em } \\
\text { vigor }\end{array}$ \\
\hline
\end{tabular}


Tabela 2 - Acordos celebrados pela União Europeia

\begin{tabular}{|c|c|c|c|c|c|c|}
\hline Acordo & $\begin{array}{l}\text { Nome oficial } \\
\text { do Acordo, } \\
\text { em português }\end{array}$ & $\begin{array}{l}\text { Nome oficial } \\
\text { do Acordo, } \\
\text { em inglês }\end{array}$ & Partes $^{371}$ & $\begin{array}{c}\text { Data da } \\
\text { assinatura }\end{array}$ & $\begin{array}{c}\text { Data em } \\
\text { que } \\
\text { entrou } \\
\text { em vigor }\end{array}$ & $\begin{array}{c}\text { Statu } \\
\mathbf{S}\end{array}$ \\
\hline $\begin{array}{l}\text { ALC UE- } \\
\text { Coreia }\end{array}$ & $\begin{array}{c}\text { Acordo de } \\
\text { Livre } \\
\text { Comércio } \\
\text { entre a União } \\
\text { Europeia e os } \\
\text { seus Estados- } \\
\text { Membros, por } \\
\text { um lado, e a } \\
\text { República da } \\
\text { Coreia, por } \\
\text { outro }\end{array}$ & $\begin{array}{l}\text { Free trade } \\
\text { Agreement } \\
\text { between the } \\
\text { European } \\
\text { Union and its } \\
\text { Member } \\
\text { States, of the } \\
\text { one part, and } \\
\text { the Republic } \\
\text { of Korea, of } \\
\text { the other part }\end{array}$ & $\begin{array}{l}\text { Áustria; Bélgica; } \\
\text { Bulgária; Croácia; } \\
\text { Chipre; República } \\
\text { Checa; Dinamarca; } \\
\text { Estônia; Finlândia; } \\
\text { França; Alemanha; } \\
\text { Grécia; Hungria; } \\
\text { Irlanda; Itália; Letônia; } \\
\text { Lituânia; Luxemburgo; } \\
\text { Malta; Países Baixos; } \\
\text { Polônia; Portugal; } \\
\text { Romênia; República } \\
\text { Eslovaca; Eslovênia; } \\
\text { Espanha; Suécia; } \\
\text { Reino Unido; Coreia. }\end{array}$ & $\begin{array}{c}6 \text { de } \\
\text { outubro de } \\
2010\end{array}$ & $\begin{array}{c}1 \text { de } \\
\text { julho de } \\
2011\end{array}$ & $\begin{array}{l}\text { Em } \\
\text { vigor }\end{array}$ \\
\hline UE-Jordânia & $\begin{array}{l}\text { Acordo de } \\
\text { Euro- } \\
\text { Mediterrânico } \\
\text { que cria uma } \\
\text { Associação } \\
\text { entre as } \\
\text { Comunidades } \\
\text { Europeias e os } \\
\text { seus Estados- } \\
\text { Membros, por } \\
\text { um lado, e o } \\
\text { Reino } \\
\text { Hachemita da } \\
\text { Jordânia, por } \\
\text { outro }\end{array}$ & $\begin{array}{l}\text { Euro- } \\
\text { Mediterranean } \\
\text { Agreement } \\
\text { establishing an } \\
\text { Association } \\
\text { between the } \\
\text { European } \\
\text { Communities } \\
\text { and their } \\
\text { Member } \\
\text { States, of the } \\
\text { one part, and } \\
\text { the Hashemite } \\
\text { Kingdom of } \\
\text { Jordan, of the } \\
\text { other part }\end{array}$ & $\begin{array}{l}\text { Áustria; Bélgica; } \\
\text { Bulgária; Croácia; } \\
\text { Chipre; República } \\
\text { Checa; Dinamarca; } \\
\text { Estônia; Finlândia; } \\
\text { França; Alemanha; } \\
\text { Grécia; Hungria; } \\
\text { Irlanda; Itália; Letônia; } \\
\text { Lituânia; Luxemburgo; } \\
\text { Malta; Países Baixos; } \\
\text { Polônia; Portugal; } \\
\text { Romênia; República } \\
\text { Eslovaca; Eslovênia; } \\
\text { Espanha; Suécia; } \\
\text { Reino Unido; Jordânia }\end{array}$ & $\begin{array}{c}24 \text { de } \\
\text { novembro } \\
\text { de } 1997\end{array}$ & $\begin{array}{l}1 \text { de maio } \\
\text { de } 2002\end{array}$ & \\
\hline $\begin{array}{c}\text { APE UE- } \\
\text { CARIFORUM }\end{array}$ & $\begin{array}{c}\text { Acordo de } \\
\text { Parceria } \\
\text { Econômica } \\
\text { entre os } \\
\text { Estados do } \\
\text { CARIFORUM } \\
\text {, por um lado, } \\
\text { e a } \\
\text { Comunidade } \\
\text { Europeia e os } \\
\text { seus Estados- } \\
\text { Membros, por } \\
\text { outro }\end{array}$ & $\begin{array}{l}\text { Economic } \\
\text { Partnership } \\
\text { Agreement } \\
\text { between the } \\
\text { CARIFORUM } \\
\text { States, of the } \\
\text { one part, and } \\
\text { the European } \\
\text { Community } \\
\text { and its } \\
\text { Member } \\
\text { States, of the } \\
\text { other part }\end{array}$ & $\begin{array}{l}\text { Antígua e Barbuda; } \\
\text { Áustria; Bélgica; } \\
\text { Bulgária; Croácia; } \\
\text { Chipre; República } \\
\text { Checa; Dinamarca; } \\
\text { Estônia; Finlândia; } \\
\text { França; Alemanha; } \\
\text { Grécia; Hungria; } \\
\text { Irlanda; Itália; Letônia; } \\
\text { Lituânia; Luxemburgo; } \\
\text { Malta; Países Baixos; } \\
\text { Polônia; Portugal; } \\
\text { Romênia; República } \\
\text { Eslovaca; Eslovênia; } \\
\text { Espanha; Suécia; } \\
\text { Reino Unido; } \\
\text { Bahamas; Barbados; }\end{array}$ & $\begin{array}{c}15 \text { de } \\
\text { outubro de } \\
2008\end{array}$ & $\begin{array}{c}1 \mathrm{de} \\
\text { novembr } \\
\text { o de } 2008\end{array}$ & $\begin{array}{l}\text { Em } \\
\text { vigor }\end{array}$ \\
\hline
\end{tabular}

${ }^{371}$ Inclui todos os Estados-membros da União Europeia que eram Partes do acordo em 9 de julho de 2014. 


\begin{tabular}{|c|c|c|c|c|c|c|}
\hline & & & $\begin{array}{c}\text { Belize; Dominica; } \\
\text { República } \\
\text { Dominicana; Granada; } \\
\text { Guiana; Jamaica; São } \\
\text { Cristóvão e Nevis; } \\
\text { Santa Lúcia; São } \\
\text { Vicente e Grenadinas; } \\
\text { Suriname; Trinidade e } \\
\text { Tobago }\end{array}$ & & & \\
\hline UE-Chile & $\begin{array}{l}\text { Acordo que } \\
\text { estabelece } \\
\text { uma } \\
\text { associação } \\
\text { entre as } \\
\text { Comunidades } \\
\text { Europeias e os } \\
\text { seus Estados- } \\
\text { membros, por } \\
\text { um lado, e a } \\
\text { República do } \\
\text { Chile, por } \\
\text { outro }\end{array}$ & $\begin{array}{l}\text { Agreement } \\
\text { establishing an } \\
\text { association } \\
\text { between the } \\
\text { European } \\
\text { Community } \\
\text { and its } \\
\text { Member } \\
\text { States, of the } \\
\text { one part, and } \\
\text { the Republic } \\
\text { of Chile, of } \\
\text { the other part }\end{array}$ & $\begin{array}{l}\text { Áustria; Bélgica; } \\
\text { Bulgária; Croácia; } \\
\text { Chipre; República } \\
\text { Checa; Dinamarca; } \\
\text { Estônia; Finlândia; } \\
\text { França; Alemanha; } \\
\text { Grécia; Hungria; } \\
\text { Irlanda; Itália; Letônia; } \\
\text { Lituânia; Luxemburgo; } \\
\text { Malta; Países Baixos; } \\
\text { Polônia; Portugal; } \\
\text { Romênia; República } \\
\text { Eslovaca; Eslovênia; } \\
\text { Espanha; Suécia; } \\
\text { Reino Unido; Chile }\end{array}$ & $\begin{array}{c}18 \text { de } \\
\text { novembro } \\
\text { de } 2002\end{array}$ & $\begin{array}{c}1 \text { de } \\
\text { fevereiro } \\
\text { de } 2003 \\
\text { (bens) e } 1 \\
\text { de março } \\
\text { de } 2005 \\
\text { (serviços) }\end{array}$ & $\begin{array}{c}\text { Em } \\
\text { vigor }\end{array}$ \\
\hline UE-Israel & $\begin{array}{c}\text { Acordo Euro- } \\
\text { Mediterrânico } \\
\text { que cria uma } \\
\text { associação } \\
\text { entre as } \\
\text { Comunidades } \\
\text { Europeias e os } \\
\text { seus Estados- } \\
\text { membros, por } \\
\text { um lado, o } \\
\text { Estado de } \\
\text { Israel, por } \\
\text { outro }\end{array}$ & $\begin{array}{l}\text { Euro- } \\
\text { Mediterranean } \\
\text { Agreement } \\
\text { establishing an } \\
\text { association } \\
\text { between the } \\
\text { European } \\
\text { Communities } \\
\text { and their } \\
\text { Members } \\
\text { States, of the } \\
\text { one part, and } \\
\text { the State of } \\
\text { Israel, of the } \\
\text { other part }\end{array}$ & $\begin{array}{l}\text { Áustria; Bélgica; } \\
\text { Bulgária; Croácia; } \\
\text { Chipre; República } \\
\text { Checa; Dinamarca; } \\
\text { Estônia; Finlândia; } \\
\text { França; Alemanha; } \\
\text { Grécia; Hungria; } \\
\text { Irlanda; Itália; Letônia; } \\
\text { Lituânia; Luxemburgo; } \\
\text { Malta; Países Baixos; } \\
\text { Polônia; Portugal; } \\
\text { Romênia; República } \\
\text { Eslovaca; Eslovênia; } \\
\text { Espanha; Suécia; } \\
\text { Reino Unido; Israel }\end{array}$ & $\begin{array}{c}20 \text { de } \\
\text { novembro } \\
\text { de } 1995\end{array}$ & $\begin{array}{c}1 \mathrm{de} \\
\text { junho de } \\
2000\end{array}$ & $\begin{array}{l}\text { Em } \\
\text { vigor }\end{array}$ \\
\hline UE-Marrocos & $\begin{array}{c}\text { Acordo Euro- } \\
\text { Mediterrânico } \\
\text { que cria uma } \\
\text { Associação } \\
\text { entre as } \\
\text { Comunidades } \\
\text { Europeias e os } \\
\text { seus Estados- } \\
\text { membros, por } \\
\text { um lado, e o } \\
\text { Reino do } \\
\text { Marrocos, por } \\
\text { outro }\end{array}$ & $\begin{array}{l}\text { Euro- } \\
\text { Mediterranean } \\
\text { Agreement } \\
\text { establishing an } \\
\text { association } \\
\text { between the } \\
\text { European } \\
\text { Communities } \\
\text { and their } \\
\text { Member } \\
\text { States, of the } \\
\text { one part, and } \\
\text { the Kingdom } \\
\text { of Morocco, of } \\
\text { the other part }\end{array}$ & $\begin{array}{l}\text { Áustria; Bélgica; } \\
\text { Bulgária; Croácia; } \\
\text { Chipre; República } \\
\text { Checa; Dinamarca; } \\
\text { Estônia; Finlândia; } \\
\text { França; Alemanha; } \\
\text { Grécia; Hungria; } \\
\text { Irlanda; Itália; Letônia; } \\
\text { Lituânia; Luxemburgo; } \\
\text { Malta; Países Baixos; } \\
\text { Polônia; Portugal; } \\
\text { Romênia; República } \\
\text { Eslovaca; Eslovênia; } \\
\text { Espanha; Suécia; } \\
\text { Reino Unido; } \\
\text { Marrocos }\end{array}$ & $\begin{array}{c}26 \text { de } \\
\text { fevereiro } \\
\text { de } 1996\end{array}$ & $\begin{array}{c}1 \mathrm{de} \\
\text { março de } \\
2000\end{array}$ & $\begin{array}{l}\text { Em } \\
\text { vigor }\end{array}$ \\
\hline
\end{tabular}




\begin{tabular}{|c|c|c|c|c|c|c|}
\hline UE-Egito & $\begin{array}{c}\text { Acordo Euro- } \\
\text { Mediterrânico } \\
\text { que estabelece } \\
\text { uma } \\
\text { Associação } \\
\text { entre as } \\
\text { Comunidades } \\
\text { Europeias e os } \\
\text { seus Estados- } \\
\text { membros, por } \\
\text { um lado, e a } \\
\text { República } \\
\text { Árabe do } \\
\text { Egito, por } \\
\text { outro }\end{array}$ & $\begin{array}{c}\text { Euro- } \\
\text { Mediterranean } \\
\text { Agreement } \\
\text { establishing an } \\
\text { Association } \\
\text { between the } \\
\text { European } \\
\text { Communities } \\
\text { and their } \\
\text { Member } \\
\text { States, of the } \\
\text { one part, and } \\
\text { the Arab } \\
\text { Republic of } \\
\text { Egypt, of the } \\
\text { other part }\end{array}$ & $\begin{array}{l}\text { Áustria; Bélgica; } \\
\text { Bulgária; Croácia; } \\
\text { Chipre; República } \\
\text { Checa; Dinamarca; } \\
\text { Estônia; Finlândia; } \\
\text { França; Alemanha; } \\
\text { Grécia; Hungria; } \\
\text { Irlanda; Itália; Letônia; } \\
\text { Lituânia; Luxemburgo; } \\
\text { Malta; Países Baixos; } \\
\text { Polônia; Portugal; } \\
\text { Romênia; República } \\
\text { Eslovaca; Eslovênia; } \\
\text { Espanha; Suécia; } \\
\text { Reino Unido; Egito }\end{array}$ & $\begin{array}{c}25 \mathrm{de} \\
\text { junho de } \\
2001\end{array}$ & $\begin{array}{c}1 \mathrm{de} \\
\text { junho de } \\
2004\end{array}$ & $\begin{array}{l}\text { Em } \\
\text { vigor }\end{array}$ \\
\hline UE-Tunísia & $\begin{array}{c}\text { Acordo Euro- } \\
\text { Mediterrânico } \\
\text { que estabelece } \\
\text { uma } \\
\text { Associação } \\
\text { entre as } \\
\text { Comunidades } \\
\text { Europeias e os } \\
\text { seus Estados- } \\
\text { membros, por } \\
\text { um lado, e a } \\
\text { República da } \\
\text { Tunísia, por } \\
\text { outro }\end{array}$ & $\begin{array}{l}\text { Euro- } \\
\text { Mediterranean } \\
\text { Agreement } \\
\text { establishing an } \\
\text { association } \\
\text { between the } \\
\text { European } \\
\text { Communities } \\
\text { and their } \\
\text { Member } \\
\text { States, of the } \\
\text { one part, and } \\
\text { the Republic } \\
\text { of Tunisia, of } \\
\text { the other part }\end{array}$ & $\begin{array}{l}\text { Áustria; Bélgica; } \\
\text { Bulgária; Croácia; } \\
\text { Chipre; República } \\
\text { Checa; Dinamarca; } \\
\text { Estônia; Finlândia; } \\
\text { França; Alemanha; } \\
\text { Grécia; Hungria; } \\
\text { Irlanda; Itália; Letônia; } \\
\text { Lituânia; Luxemburgo; } \\
\text { Malta; Países Baixos; } \\
\text { Polônia; Portugal; } \\
\text { Romênia; República } \\
\text { Eslovaca; Eslovênia; } \\
\text { Espanha; Suécia; } \\
\text { Reino Unido; Tunísia }\end{array}$ & $\begin{array}{c}7 \text { de julho } \\
\text { de } 1995\end{array}$ & $\begin{array}{c}1 \mathrm{de} \\
\text { março de } \\
1998\end{array}$ & $\begin{array}{l}\text { Em } \\
\text { vigor }\end{array}$ \\
\hline $\begin{array}{l}\text { UE-África do } \\
\quad \text { Sul }\end{array}$ & $\begin{array}{c}\text { Acordo sob a } \\
\text { forma de } \\
\text { Troca de } \\
\text { Cartas relativo } \\
\text { à aplicação } \\
\text { provisória do } \\
\text { Acordo de } \\
\text { Comércio, } \\
\text { Desenvolvime } \\
\text { nto e } \\
\text { Cooperação } \\
\text { entre a } \\
\text { Comunidade } \\
\text { Europeia e os } \\
\text { seus Estados- } \\
\text { Membros, por } \\
\text { um lado, e a } \\
\text { República da } \\
\text { África do Sul, } \\
\text { por outro }\end{array}$ & $\begin{array}{l}\text { Agreement in } \\
\text { the form of an } \\
\text { Exchange of } \\
\text { Letters } \\
\text { concerning the } \\
\text { provisional } \\
\text { application of } \\
\text { the Agreement } \\
\text { on Trade, } \\
\text { Development } \\
\text { and } \\
\text { Cooperation } \\
\text { between the } \\
\text { European } \\
\text { Community } \\
\text { and its } \\
\text { Member } \\
\text { States, of the } \\
\text { one part, and } \\
\text { the Republic } \\
\text { of South } \\
\text { Africa, of the } \\
\text { other part }\end{array}$ & $\begin{array}{c}\text { Áustria; Bélgica; } \\
\text { Bulgária; Croácia; } \\
\text { Chipre; República } \\
\text { Checa; Dinamarca; } \\
\text { Estônia; Finlândia; } \\
\text { França; Alemanha; } \\
\text { Grécia; Hungria; } \\
\text { Irlanda; Itália; Letônia; } \\
\text { Lituânia; Luxemburgo; } \\
\text { Malta; Países Baixos; } \\
\text { Polônia; Portugal; } \\
\text { Romênia; República } \\
\text { Eslovaca; Eslovênia; } \\
\text { Espanha; Suécia; } \\
\text { Reino Unido; África } \\
\text { do Sul }\end{array}$ & $\begin{array}{c}11 \mathrm{de} \\
\text { outubro de } \\
1999\end{array}$ & $\begin{array}{c}1 \mathrm{de} \\
\text { janeiro de } \\
2000\end{array}$ & $\begin{array}{l}\text { Em } \\
\text { vigor }\end{array}$ \\
\hline
\end{tabular}




\begin{tabular}{|c|c|c|c|c|c|c|}
\hline UE-México & $\begin{array}{c}\text { Acordo de } \\
\text { Parceria } \\
\text { Económica, de } \\
\text { Concertação } \\
\text { Política e de } \\
\text { Cooperação } \\
\text { entre a } \\
\text { Comunidade } \\
\text { Europeia e os } \\
\text { seus Estados- } \\
\text { Membros, por } \\
\text { um lado, e os } \\
\text { Estados } \\
\text { Unidos } \\
\text { Mexicanos, } \\
\text { por outro }\end{array}$ & $\begin{array}{l}\text { Economic } \\
\text { Partnership, } \\
\text { Political } \\
\text { Coordination } \\
\text { and } \\
\text { Cooperation } \\
\text { Agreement } \\
\text { between the } \\
\text { European } \\
\text { Community } \\
\text { and its } \\
\text { Member } \\
\text { States, of the } \\
\text { one part, and } \\
\text { the United } \\
\text { Mexican } \\
\text { States, of the } \\
\text { other part }\end{array}$ & $\begin{array}{l}\text { Áustria; Bélgica; } \\
\text { Bulgária; Croácia; } \\
\text { Chipre; República } \\
\text { Checa; Dinamarca; } \\
\text { Estônia; Finlândia; } \\
\text { França; Alemanha; } \\
\text { Grécia; Hungria; } \\
\text { Irlanda; Itália; Letônia; } \\
\text { Lituânia; Luxemburgo; } \\
\text { Malta; Países Baixos; } \\
\text { Polônia; Portugal; } \\
\text { Romênia; República } \\
\text { Eslovaca; Eslovênia; } \\
\text { Espanha; Suécia; } \\
\text { Reino Unido; México }\end{array}$ & $\begin{array}{c}1 \text { de julho } \\
\text { de } 2000\end{array}$ & $\begin{array}{c}1 \mathrm{de} \\
\text { outubro } \\
\text { de } 2000\end{array}$ & $\begin{array}{l}\text { Em } \\
\text { vigor }\end{array}$ \\
\hline $\begin{array}{l}\text { UE-Costa do } \\
\text { Marfim }\end{array}$ & $\begin{array}{c}\text { Acordo de } \\
\text { Parceria } \\
\text { Económica } \\
\text { Intercalar } \\
\text { entre a Costa } \\
\text { do Marfim, } \\
\text { por um lado, e } \\
\text { a Comunidade } \\
\text { Europeia e os } \\
\text { seus Estados- } \\
\text { Membros, por } \\
\text { outro }\end{array}$ & $\begin{array}{l}\text { Stepping stone } \\
\text { Economic } \\
\text { Partnership } \\
\text { Agreement } \\
\text { between Côte } \\
\text { d'Ivoire, of the } \\
\text { one part, and } \\
\text { the European } \\
\text { Community } \\
\text { and its } \\
\text { Member States }\end{array}$ & $\begin{array}{c}\text { Áustria; Bélgica; } \\
\text { Bulgária; Croácia; } \\
\text { Chipre; República } \\
\text { Checa; Dinamarca; } \\
\text { Estônia; Finlândia; } \\
\text { França; Alemanha; } \\
\text { Grécia; Hungria; } \\
\text { Irlanda; Itália; Letônia; } \\
\text { Lituânia; Luxemburgo; } \\
\text { Malta; Países Baixos; } \\
\text { Polônia; Portugal; } \\
\text { Romênia; República } \\
\text { Eslovaca; Eslovênia; } \\
\text { Espanha; Suécia; } \\
\text { Reino Unido; Costa do } \\
\text { Marfim }\end{array}$ & $\begin{array}{c}26 \text { de } \\
\text { novembro } \\
\text { de } 2008\end{array}$ & $\begin{array}{c}1 \mathrm{de} \\
\text { janeiro de } \\
2009\end{array}$ & $\begin{array}{l}\text { Em } \\
\text { vigor }\end{array}$ \\
\hline UE-Algéria & $\begin{array}{c}\text { Acordo Euro- } \\
\text { Mediterrânico } \\
\text { que cria uma } \\
\text { associação } \\
\text { entre a } \\
\text { Comunidade } \\
\text { Europeia e os } \\
\text { seus Estados- } \\
\text { Membros, por } \\
\text { um lado, e a } \\
\text { República } \\
\text { Argelina } \\
\text { Democrática e } \\
\text { Popular, por } \\
\text { outro }\end{array}$ & $\begin{array}{c}\text { Euro- } \\
\text { Mediterranean } \\
\text { Agreement } \\
\text { establishing an } \\
\text { Association } \\
\text { between the } \\
\text { European } \\
\text { Community } \\
\text { and its } \\
\text { Member } \\
\text { States, of the } \\
\text { one part, and } \\
\text { the People's } \\
\text { Democratic } \\
\text { Republic of } \\
\text { Algeria, of the } \\
\text { other part }\end{array}$ & $\begin{array}{c}\text { Áustria; Bélgica; } \\
\text { Bulgária; Croácia; } \\
\text { Chipre; República } \\
\text { Checa; Dinamarca; } \\
\text { Estônia; Finlândia; } \\
\text { França; Alemanha; } \\
\text { Grécia; Hungria; } \\
\text { Irlanda; Itália; Letônia; } \\
\text { Lituânia; Luxemburgo; } \\
\text { Malta; Países Baixos; } \\
\text { Polônia; Portugal; } \\
\text { Romênia; República } \\
\text { Eslovaca; Eslovênia; } \\
\text { Espanha; Suécia; } \\
\text { Reino Unido; Algéria }\end{array}$ & $\begin{array}{l}22 \text { de abril } \\
\text { de } 2002\end{array}$ & $\begin{array}{c}1 \mathrm{de} \\
\text { setembro } \\
\text { de } 2005\end{array}$ & $\begin{array}{l}\text { Em } \\
\text { vigor }\end{array}$ \\
\hline
\end{tabular}




\begin{tabular}{|c|c|c|c|c|c|c|}
\hline UE-Camarões & $\begin{array}{c}\text { Acordo } \\
\text { Intercalar para } \\
\text { um Acordo de } \\
\text { Parceria } \\
\text { Econômica } \\
\text { entre a } \\
\text { Comunidade } \\
\text { Europeia e os } \\
\text { seus Estados- } \\
\text { Membros, por } \\
\text { um lado, e a } \\
\text { Parte África } \\
\text { Central, por } \\
\text { outro }\end{array}$ & $\begin{array}{c}\text { Interim } \\
\text { Agreement } \\
\text { with a view to } \\
\text { an Economic } \\
\text { Partnership } \\
\text { Agreement } \\
\text { between the } \\
\text { European } \\
\text { Community } \\
\text { and its } \\
\text { Member } \\
\text { States, of the } \\
\text { one part, and } \\
\text { the Central } \\
\text { Africa Party }\end{array}$ & $\begin{array}{l}\text { Áustria; Bélgica; } \\
\text { Bulgária; Croácia; } \\
\text { Chipre; República } \\
\text { Checa; Dinamarca; } \\
\text { Estônia; Finlândia; } \\
\text { França; Alemanha; } \\
\text { Grécia; Hungria; } \\
\text { Irlanda; Itália; Letônia; } \\
\text { Lituânia; Luxemburgo; } \\
\text { Malta; Países Baixos; } \\
\text { Polônia; Portugal; } \\
\text { Romênia; República } \\
\text { Eslovaca; Eslovênia; } \\
\text { Espanha; Suécia; } \\
\text { Reino Unido; } \\
\text { Camarões }\end{array}$ & $\begin{array}{c}15 \mathrm{de} \\
\text { janeiro de } \\
2009\end{array}$ & $\begin{array}{c}1 \text { de } \\
\text { outubro } \\
\text { de } 2009\end{array}$ & $\begin{array}{l}\text { Em } \\
\text { vigor }\end{array}$ \\
\hline
\end{tabular}


Tabela 3 - Acordos celebrados pela China

\begin{tabular}{|c|c|c|c|c|c|c|}
\hline Acordo & $\begin{array}{c}\text { Nome oficial } \\
\text { do Acordo, em } \\
\text { português }\end{array}$ & $\begin{array}{l}\text { Nome oficial do } \\
\text { Acordo, em } \\
\text { inglês }\end{array}$ & Partes & $\begin{array}{c}\text { Data da } \\
\text { assinatura }\end{array}$ & $\begin{array}{l}\text { Data em } \\
\text { que entrou } \\
\text { em vigor }\end{array}$ & Status \\
\hline $\begin{array}{l}\text { China- } \\
\text { Chile }\end{array}$ & $\begin{array}{c}\text { Acordo de } \\
\text { Livre } \\
\text { Comércio entre } \\
\text { o Governo da } \\
\text { República } \\
\text { Popular da } \\
\text { China e o } \\
\text { Governo da } \\
\text { República } \\
\text { Popular do } \\
\text { Chile; Acordo } \\
\text { Suplementar } \\
\text { sobre o } \\
\text { Comércio de } \\
\text { Serviços do } \\
\text { Acordo de } \\
\text { Livre } \\
\text { Comércio entre } \\
\text { China e Chile }\end{array}$ & $\begin{array}{l}\text { Free Trade } \\
\text { Agreement } \\
\text { Between the } \\
\text { Government of } \\
\text { the People's } \\
\text { Republic of } \\
\text { China and the } \\
\text { Government of } \\
\text { the Republic of } \\
\text { Chile; } \\
\text { Supplementary } \\
\text { Agreement on } \\
\text { Trade in } \\
\text { Services of the } \\
\text { Free Trade } \\
\text { Agreement } \\
\text { between China } \\
\text { and Chile }\end{array}$ & China e Chile & $\begin{array}{c}18 \text { de } \\
\text { novembro de } \\
2005 \text { (bens) e } \\
13 \text { de abril de } \\
2008 \\
\text { (serviços) }\end{array}$ & $\begin{array}{c}1 \text { de outubro } \\
\text { de } 2006 \\
\text { (bens) e } 1 \\
\text { de agosto de } \\
2010 \\
\text { (serviços) }\end{array}$ & $\begin{array}{l}\text { Em } \\
\text { vigor }\end{array}$ \\
\hline $\begin{array}{l}\text { China- } \\
\text { ASEAN }\end{array}$ & $\begin{array}{c}\text { Acordo-quadro } \\
\text { para } \\
\text { Cooperação } \\
\text { Econômica } \\
\text { Abrangente } \\
\text { entre a } \\
\text { Associação das } \\
\text { Nações do } \\
\text { Sudeste } \\
\text { Ásiático e a } \\
\text { República } \\
\text { Popular da } \\
\text { China; Acordo } \\
\text { sobre o } \\
\text { Comércio de } \\
\text { Serviços do } \\
\text { Acordo-quadro } \\
\text { para } \\
\text { Cooperação } \\
\text { Econômica } \\
\text { Abrangente } \\
\text { entre a } \\
\text { Associação das } \\
\text { Nações do } \\
\text { Sudeste } \\
\text { Ásiático e a } \\
\text { República } \\
\text { Popular da } \\
\text { China }\end{array}$ & $\begin{array}{c}\text { Framework } \\
\text { Agreement on } \\
\text { Comprehensive } \\
\text { Economic Co- } \\
\text { operation } \\
\text { between the } \\
\text { Association of } \\
\text { Southeast Asian } \\
\text { Nations and the } \\
\text { People's } \\
\text { Republic of } \\
\text { China; } \\
\text { Agreement on } \\
\text { Trade in } \\
\text { Services of the } \\
\text { Framework } \\
\text { Agreement on } \\
\text { Comprehensive } \\
\text { Economic Co- } \\
\text { operation } \\
\text { between the } \\
\text { Association of } \\
\text { Southeast Asian } \\
\text { Nations and the } \\
\text { People's } \\
\text { Republic of } \\
\text { China }\end{array}$ & $\begin{array}{c}\text { Brunei. } \\
\text { Darussalam, } \\
\text { Mianmar, } \\
\text { Cambodja, } \\
\text { Indonésia, } \\
\text { Laos, } \\
\text { Malásia, } \\
\text { Filipinas, } \\
\text { Cingapura } \\
\text { Vietnam, } \\
\text { Tailândia e } \\
\text { China }\end{array}$ & $\begin{array}{c}29 \text { de } \\
\text { novembro de } \\
2004 \text { (bens) e } \\
14 \text { de janeiro } \\
\text { de } 2007 \\
\text { (serviços) }\end{array}$ & $\begin{array}{c}1 \text { de janeiro } \\
\text { de } 2005 \\
\text { (bens) e } 1 \\
\text { de julho de } \\
2007 \\
\text { (serviços) }\end{array}$ & $\begin{array}{l}\text { Em } \\
\text { vigor }\end{array}$ \\
\hline $\begin{array}{l}\text { China- } \\
\text { Nova } \\
\text { Zelândia }\end{array}$ & $\begin{array}{l}\text { Acordo de } \\
\text { Livre } \\
\text { Comércio }\end{array}$ & $\begin{array}{l}\text { Free Trade } \\
\text { Agreement } \\
\text { Between the }\end{array}$ & $\begin{array}{l}\text { China e Nova } \\
\text { Zelândia }\end{array}$ & $\begin{array}{l}7 \text { de abril de } \\
2008\end{array}$ & $\begin{array}{c}1 \text { de outubro } \\
\text { de } 2008\end{array}$ & $\begin{array}{l}\text { Em } \\
\text { vigor }\end{array}$ \\
\hline
\end{tabular}




\begin{tabular}{|c|c|c|c|c|c|c|}
\hline & $\begin{array}{c}\text { Entre o } \\
\text { Governo da } \\
\text { República } \\
\text { Popular da } \\
\text { China e o } \\
\text { Governo da } \\
\text { Nova Zelândia }\end{array}$ & $\begin{array}{l}\text { Government of } \\
\text { the People's } \\
\text { Republic of } \\
\text { China and the } \\
\text { Government of } \\
\text { New Zealand }\end{array}$ & & & & \\
\hline $\begin{array}{l}\text { China- } \\
\text { Cingapura }\end{array}$ & $\begin{array}{l}\text { Acordo de } \\
\text { Livre } \\
\text { Comércio } \\
\text { Entre o } \\
\text { Governo da } \\
\text { República } \\
\text { Popular da } \\
\text { China e o } \\
\text { Governo da } \\
\text { República de } \\
\text { Cingapura }\end{array}$ & $\begin{array}{l}\text { Free Trade } \\
\text { Agreement } \\
\text { Between the } \\
\text { Government of } \\
\text { the People's } \\
\text { Republic of } \\
\text { China and the } \\
\text { Government of } \\
\text { the Republic of } \\
\text { Singapore }\end{array}$ & $\begin{array}{l}\text { China e } \\
\text { Cingapura }\end{array}$ & $\begin{array}{l}23 \text { de outubro } \\
\text { de } 2008\end{array}$ & $\begin{array}{c}1 \text { de janeiro } \\
\text { de } 2009\end{array}$ & $\begin{array}{l}\text { Em } \\
\text { vigor }\end{array}$ \\
\hline $\begin{array}{l}\text { China- } \\
\text { Peru }\end{array}$ & $\begin{array}{l}\text { Acordo de } \\
\text { Livre } \\
\text { Comércio } \\
\text { Entre o } \\
\text { Governo da } \\
\text { República do } \\
\text { Peru e o } \\
\text { Governo da } \\
\text { República } \\
\text { Popular da } \\
\text { China }\end{array}$ & $\begin{array}{l}\text { Free Trade } \\
\text { Agreement } \\
\text { Between the } \\
\text { Government of } \\
\text { the Republic of } \\
\text { Peru and the } \\
\text { Government of } \\
\text { the People's } \\
\text { Republic of } \\
\text { China }\end{array}$ & China e Peru & $\begin{array}{c}28 \text { de abril de } \\
2009\end{array}$ & $\begin{array}{l}1 \text { de março } \\
\text { de } 2010\end{array}$ & $\begin{array}{l}\text { Em } \\
\text { vigor }\end{array}$ \\
\hline $\begin{array}{l}\text { China- } \\
\text { Costa Rica }\end{array}$ & $\begin{array}{l}\text { Acordo de } \\
\text { Livre } \\
\text { Comércio } \\
\text { Entre o } \\
\text { Governo da } \\
\text { República } \\
\text { Popular da } \\
\text { China e o } \\
\text { Governo da } \\
\text { República de } \\
\text { Costa Rica }\end{array}$ & $\begin{array}{l}\text { Free Trade } \\
\text { Agreement } \\
\text { Between the } \\
\text { Government of } \\
\text { the People's } \\
\text { Republic of } \\
\text { China and the } \\
\text { Government of } \\
\text { the Republic of } \\
\text { Costa Rica }\end{array}$ & $\begin{array}{c}\text { China e Costa } \\
\text { Rica }\end{array}$ & $\begin{array}{c}8 \text { de abril de } \\
2010\end{array}$ & $\begin{array}{l}1 \text { de agosto } \\
\text { de } 2011\end{array}$ & $\begin{array}{l}\text { Em } \\
\text { vigor }\end{array}$ \\
\hline $\begin{array}{l}\text { China- } \\
\text { Paquistão }\end{array}$ & $\begin{array}{c}\text { Acordo sobre o } \\
\text { Programa } \\
\text { Preliminar para } \\
\text { o Acordo de } \\
\text { Livre } \\
\text { Comércio } \\
\text { Entre o } \\
\text { Governo da } \\
\text { República } \\
\text { Popular da } \\
\text { China e o } \\
\text { Governo da } \\
\text { República } \\
\text { Islâmica do } \\
\text { Paquistão }\end{array}$ & $\begin{array}{l}\text { Agreement on } \\
\text { the Early } \\
\text { Harvest } \\
\text { Programme for } \\
\text { the Free Trade } \\
\text { Agreement } \\
\text { Between the } \\
\text { Government of } \\
\text { the People's } \\
\text { Republic of } \\
\text { China and the } \\
\text { Government of } \\
\text { the Islamic } \\
\text { Republic of } \\
\text { Pakistan }\end{array}$ & $\begin{array}{l}\text { China e } \\
\text { Paquistão }\end{array}$ & $\begin{array}{c}24 \text { de } \\
\text { novembro de } \\
2006 \text { (bens) e } \\
21 \text { de } \\
\text { fevereiro de } \\
2009 \\
\text { (serviços) }\end{array}$ & $\begin{array}{c}1 \text { de julho } \\
\text { de } 2007 \\
\text { (bens) e } 10 \\
\text { de outubro } \\
\text { de } 2009 \\
\text { (serviços) }\end{array}$ & $\begin{array}{l}\text { Em } \\
\text { vigor }\end{array}$ \\
\hline
\end{tabular}


Tabela 4 - Acordos celebrados pela Índia

\begin{tabular}{|c|c|c|c|c|c|c|}
\hline Acordo & $\begin{array}{c}\text { Nome oficial } \\
\text { do Acordo, } \\
\text { em } \\
\text { português }\end{array}$ & $\begin{array}{c}\text { Nome oficial } \\
\text { do Acordo, em } \\
\text { inglês }\end{array}$ & Partes & $\begin{array}{c}\text { Data da } \\
\text { assinatura }\end{array}$ & $\begin{array}{l}\text { Data em que } \\
\text { entrou em } \\
\text { vigor }\end{array}$ & Status \\
\hline $\begin{array}{l}\text { Índia- } \\
\text { Coreia }\end{array}$ & $\begin{array}{l}\text { Acordo de } \\
\text { Parceria } \\
\text { Econômica } \\
\text { Abrangente } \\
\text { entre a } \\
\text { República da } \\
\text { Coreia e a } \\
\text { República da } \\
\text { Índia }\end{array}$ & $\begin{array}{l}\text { Comprehensive } \\
\text { Economic } \\
\text { Partnership } \\
\text { Agreement } \\
\text { Between the } \\
\text { Republic of } \\
\text { Korea and the } \\
\text { Republic of } \\
\text { India }\end{array}$ & $\begin{array}{l}\text { Índia e } \\
\text { Coreia }\end{array}$ & $\begin{array}{c}7 \text { de agosto de } \\
2009\end{array}$ & $\begin{array}{c}1 \text { de janeiro de } \\
2010\end{array}$ & $\begin{array}{l}\text { Em } \\
\text { vigor }\end{array}$ \\
\hline $\begin{array}{c}\text { Índia- } \\
\text { Cingapura }\end{array}$ & $\begin{array}{l}\text { Acordo de } \\
\text { Parceria } \\
\text { Econômica } \\
\text { Abrangente } \\
\text { entre a } \\
\text { República da } \\
\text { India e a } \\
\text { República de } \\
\text { Cingapura }\end{array}$ & $\begin{array}{l}\text { Comprehensive } \\
\text { Economic } \\
\text { Cooperation } \\
\text { Agreement } \\
\text { Between the } \\
\text { Republic of } \\
\text { India and the } \\
\text { Republic of } \\
\text { Singapore }\end{array}$ & $\begin{array}{c}\text { Índia e } \\
\text { Cingapura }\end{array}$ & $\begin{array}{l}29 \text { de junho de } \\
2005\end{array}$ & $\begin{array}{c}1 \text { de agosto de } \\
2005\end{array}$ & $\begin{array}{l}\text { Em } \\
\text { vigor }\end{array}$ \\
\hline Índia-Japão & $\begin{array}{l}\text { Acordo de } \\
\text { Parceria } \\
\text { Econômica } \\
\text { Abrangente } \\
\text { entre o Japão } \\
\text { e a República } \\
\text { da Índia }\end{array}$ & $\begin{array}{l}\text { Comprehensive } \\
\text { Economic } \\
\text { Partnership } \\
\text { Agreement } \\
\text { Between Japan } \\
\text { and the } \\
\text { Republic of } \\
\text { India }\end{array}$ & $\begin{array}{c}\text { Índia e } \\
\text { Japão }\end{array}$ & $\begin{array}{c}16 \text { de fevereiro } \\
\text { de } 2011\end{array}$ & $\begin{array}{c}1 \text { de agosto de } \\
2011\end{array}$ & $\begin{array}{l}\text { Em } \\
\text { vigor }\end{array}$ \\
\hline $\begin{array}{l}\text { Índia- } \\
\text { Malásia }\end{array}$ & $\begin{array}{c}\text { Acordo de } \\
\text { Parceria } \\
\text { Econômica } \\
\text { Abrangente } \\
\text { entre o } \\
\text { Governo da } \\
\text { República da } \\
\text { India e o } \\
\text { Governo da } \\
\text { República da } \\
\text { Malásia }\end{array}$ & $\begin{array}{l}\text { Comprehensive } \\
\text { Economic } \\
\text { Cooperation } \\
\text { Agreement } \\
\text { Between the } \\
\text { Government of } \\
\text { the Republic of } \\
\text { India and the } \\
\text { Government of } \\
\text { Malaysia }\end{array}$ & $\begin{array}{l}\text { Índia e } \\
\text { Malásia }\end{array}$ & $\begin{array}{l}18 \text { de fevereiro } \\
\text { de } 2011\end{array}$ & $\begin{array}{l}1 \text { de julho de } \\
2011\end{array}$ & $\begin{array}{l}\text { Em } \\
\text { vigor }\end{array}$ \\
\hline
\end{tabular}


Tabela 5 - Acordos celebrados pelo Mercosul

\begin{tabular}{|c|c|c|c|c|c|}
\hline Acordo & $\begin{array}{c}\text { Nome oficial do } \\
\text { Acordo, em } \\
\text { português }\end{array}$ & Partes & $\begin{array}{c}\text { Data da } \\
\text { assinatura }\end{array}$ & $\begin{array}{l}\text { Data em que } \\
\text { entrou em } \\
\text { vigor }\end{array}$ & Status \\
\hline $\begin{array}{l}\text { Mercosul- } \\
\text { Índia }\end{array}$ & $\begin{array}{l}\text { Acordo de Comércio } \\
\text { Preferencial entre o } \\
\text { Mercosul e a } \\
\text { República da Índia }\end{array}$ & $\begin{array}{c}\text { Argentina, } \\
\text { Brasil, } \\
\text { Paraguai, } \\
\text { Uruguai e Índia }\end{array}$ & $\begin{array}{l}25 \text { de janeiro } \\
\text { de } 2004\end{array}$ & $\begin{array}{l}1 \text { de junho de } \\
2009\end{array}$ & $\begin{array}{l}\text { Em } \\
\text { vigor }\end{array}$ \\
\hline $\begin{array}{l}\text { Mercosul- } \\
\text { Israel }\end{array}$ & $\begin{array}{c}\text { Acordo de Livre } \\
\text { Comércio entre o } \\
\text { Mercosul e o Estado } \\
\text { de Israel; Acordo- } \\
\text { Quadro sobre } \\
\text { Comércio entre o } \\
\text { Mercosul e o Estado } \\
\text { de Israel }\end{array}$ & $\begin{array}{c}\text { Argentina, } \\
\text { Brasil, } \\
\text { Paraguai, } \\
\text { Uruguai e Israel }\end{array}$ & $\begin{array}{c}18 \mathrm{de} \\
\text { dezembro de } \\
2007\end{array}$ & $\begin{array}{l}28 \text { de abril de } \\
2010\end{array}$ & $\begin{array}{l}\text { Em } \\
\text { vigor }\end{array}$ \\
\hline $\begin{array}{l}\text { Mercosul- } \\
\text { Egito }\end{array}$ & $\begin{array}{l}\text { Acordo de Livre } \\
\text { Comércio entre o } \\
\text { Mercosul e a } \\
\text { República Árabe do } \\
\text { Egito }\end{array}$ & $\begin{array}{c}\text { Argentina, } \\
\text { Brasil, } \\
\text { Paraguai, } \\
\text { Uruguai e Egito }\end{array}$ & $\begin{array}{c}2 \text { de agosto de } \\
2010\end{array}$ & $\begin{array}{c}\text { Entrará em } \\
\text { vigor } 30 \text { dias } \\
\text { após a } \\
\text { aprovação } \\
\text { legislativa e } \\
\text { internalização } \\
\text { das Partes }\end{array}$ & $\begin{array}{c}\text { Sem } \\
\text { vigência }\end{array}$ \\
\hline $\begin{array}{l}\text { Mercosul- } \\
\text { SACU }\end{array}$ & $\begin{array}{l}\text { Acordo Preferencial de } \\
\text { Comércio entre o } \\
\text { Mercado Comum do } \\
\text { Sul (MERCOSUL) e a } \\
\text { União Aduaneira da } \\
\text { África do Sul (SACU) }\end{array}$ & $\begin{array}{l}\text { Argentina, } \\
\text { Brasil, } \\
\text { Paraguai, } \\
\text { Uruguai, } \\
\text { África do Sul, } \\
\text { Namíbia, } \\
\text { Botsuana, } \\
\text { Lesoto e } \\
\text { Suazilândia. }\end{array}$ & $\begin{array}{c}15 \text { de } \\
\text { dezembro de } \\
2008 \\
\text { (Salvador) e } 3 \\
\text { de abril de } \\
2009 \text { (Maserú), }\end{array}$ & $\begin{array}{l}30 \text { dias depois } \\
\text { da última } \\
\text { notificação } \\
\text { entre as Partes }\end{array}$ & $\begin{array}{c}\text { Sem } \\
\text { vigência }\end{array}$ \\
\hline $\begin{array}{l}\text { Mercosul- } \\
\text { Palestina }\end{array}$ & $\begin{array}{c}\text { Acordo de Livre } \\
\text { Comércio entre o } \\
\text { Mercosul e o Estado } \\
\text { da Palestina; Acordo- } \\
\text { Quadro de Comércio e } \\
\text { Cooperação } \\
\text { Econômica entre o } \\
\text { Mercosul e a } \\
\text { Autoridade Nacional } \\
\text { Palestina }\end{array}$ & $\begin{array}{l}\text { Argentina, } \\
\text { Brasil, } \\
\text { Paraguai, } \\
\text { Uruguai e } \\
\text { Palestina }\end{array}$ & $\begin{array}{c}16 \text { de } \\
\text { dezembro de } \\
2010 \text { (Acordo- } \\
\text { Quadro) e } 20 \\
\text { de dezembro } \\
\text { de } 2011 \\
\text { (Acordo de } \\
\text { Livre } \\
\text { Comércio) }\end{array}$ & $\begin{array}{l}30 \text { dias depois } \\
\text { da última } \\
\text { notificação } \\
\text { entre as Partes }\end{array}$ & $\begin{array}{c}\text { Sem } \\
\text { vigência }\end{array}$ \\
\hline $\begin{array}{l}\text { Mercosul- } \\
\text { Chile }\end{array}$ & $\begin{array}{c}\text { Acordo de } \\
\text { Complementação } \\
\text { Econômica no. 35; } \\
\text { Quinquagésimo } \\
\text { Terceiro Protocolo } \\
\text { Adicional. Protocolo } \\
\text { Sobre o Comércio de } \\
\text { Serviços entre o } \\
\text { Mercosul e o Chile }\end{array}$ & $\begin{array}{c}\text { Argentina, } \\
\text { Brasil, } \\
\text { Paraguai, } \\
\text { Uruguai e Chile }\end{array}$ & $\begin{array}{c}25 \text { de junho de } \\
1996 \text { (ACE) e } \\
25 \text { de maio de } \\
2009 \\
\text { (Protocolo } \\
\text { sobre Serviços) }\end{array}$ & $\begin{array}{c}19 \text { de } \\
\text { novembro de } \\
1996 \text { (ACE) e } \\
19 \text { de junho de } \\
2011 \\
\text { (Protocolo } \\
\text { sobre Serviços) }\end{array}$ & $\begin{array}{l}\text { Em } \\
\text { vigor }\end{array}$ \\
\hline
\end{tabular}




\begin{tabular}{|c|c|c|c|c|c|}
\hline $\begin{array}{l}\text { Mercosul- } \\
\text { Colômbia }\end{array}$ & $\begin{array}{c}\text { Acordo de } \\
\text { Complementação } \\
\text { Econômica n. }{ }^{\circ} 59\end{array}$ & $\begin{array}{c}\text { Argentina, } \\
\text { Brasil, } \\
\text { Paraguai, } \\
\text { Uruguai, } \\
\text { Colômbia, } \\
\text { Equador e } \\
\text { Venezuela }\end{array}$ & $\begin{array}{c}16 \text { de } \\
\text { dezembro de } \\
2003\end{array}$ & Abril de 2005 & $\begin{array}{c}\text { Em } \\
\text { vigor }\end{array}$ \\
\hline
\end{tabular}




\section{$\underline{\text { ANEXO II }}$}

ANÁLISE COMPARATIVA DAS PRINCIPAIS CLÁUSULAS SOBRE SERVIÇOS DOS ACORDOS DE LIVRE COMÉRCIO CELEBRADOS PELOS ESTADOS UNIDOS 


\section{Tabela 6 - NAFTA e CAFTA-DR}

\begin{tabular}{|c|c|c|}
\hline & NAFTA & CAFTA-DR \\
\hline $\begin{array}{l}\text { Escopo do capítulo } \\
\text { sobre serviços }\end{array}$ & $\begin{array}{l}\text { Medidas adotadas ou mantidas por uma } \\
\text { parte em relação ao comércio } \\
\text { transfronteiriço de serviços por } \\
\text { prestadores estrangeiros, incluindo: (a) } \\
\text { produção, distribuição, } \\
\text { comercialização e entrega de um } \\
\text { serviço; (b) compra, uso ou pagamento } \\
\text { por um serviço; (c) acesso e uso de } \\
\text { sistemas de distribuição e transporte } \\
\text { em conexão com a prestação de um } \\
\text { serviço; (d) presença no território de } \\
\text { um prestador de outra parte; e (e) } \\
\text { provisão de "bond" ou outra forma de } \\
\text { seguro financeiro como condição para } \\
\text { a prestação de um serviço. Setores não } \\
\text { abrangidos: (a) Serviços financeiros, } \\
\text { definidos no Cap. 14; (b) transporte } \\
\text { aéreo doméstico e internacionais, ou } \\
\text { serviços de apoio correlatos, exceto: (i) } \\
\text { serviços de reparo e manutenção de } \\
\text { aeronaves enquanto não estiverem em } \\
\text { serviço; (ii) serviços especializados; (c) } \\
\text { licitações realizadas por alguma das } \\
\text { partes ou por empresas } \\
\text { governamentais; e (d) subsídios ou } \\
\text { empréstimos governamentais. }\end{array}$ & $\begin{array}{l}\text { Medidas adotadas ou mantidas por uma } \\
\text { parte em relação ao comércio } \\
\text { transfronteiriço de serviços por } \\
\text { prestadores estrangeiros, incluindo: (a) } \\
\text { produção, distribuição, comercialização, } \\
\text { venda e entrega de um serviço; (b) } \\
\text { compra, uso ou pagamento por um } \\
\text { serviço; (c) acesso e uso de sistemas de } \\
\text { distribuição, transporte e } \\
\text { telecomunicaçoses e serviços em conexão } \\
\text { com a prestação de um serviço; (d) } \\
\text { presença no território de um prestador de } \\
\text { outra parte; e (e) provisão de "bond" ou } \\
\text { outra forma de seguro financeiro como } \\
\text { condição para a prestação de um serviço. } \\
\text { Setores não abrangidos: (a) Serviços } \\
\text { financeiros definidos no artigo 12.20, } \\
\text { exceto se o serviço financeiro for } \\
\text { fornecido por um investimento coberto; } \\
\text { (b) transporte aéreo doméstico e } \\
\text { internacional, ou serviços de apoio } \\
\text { correlatos, exceto: (i) serviços de reparo e } \\
\text { manutenção de aeronaves enquanto não } \\
\text { estiverem em serviço; (ii) serviços } \\
\text { especializados; (c) licitações; (d) } \\
\text { subsídios ou concessões, incluindo } \\
\text { empréstimos, garantias e seguro } \\
\text { governamentais; e (e) serviços } \\
\text { prestadores no exercício de autoridade } \\
\text { governamental. } \\
\end{array}$ \\
\hline $\begin{array}{c}\text { Forma de assunção dos } \\
\text { compromissos }\end{array}$ & Lista negativa & Lista negativa \\
\hline $\begin{array}{c}\text { Modos de prestação } \\
\text { abrangidos }\end{array}$ & $\begin{array}{c}\text { Modos } 1,2,3 \text { e } 4 \text {, sendo o último } \\
\text { tratado apenas em relação a serviços } \\
\text { profissionais. }\end{array}$ & $\begin{array}{c}\text { Modos } 1,2,3 \text { e } 4 \text {, sendo o último tratado } \\
\text { apenas em relação a serviços } \\
\text { profissionais. }\end{array}$ \\
\hline $\begin{array}{c}\text { Regras sobre regulação } \\
\text { doméstica }\end{array}$ & $\begin{array}{l}\text { Não há um artigo específico sobre } \\
\text { regulação doméstica. As obrigações } \\
\text { relativas a esse tema estão dispostas } \\
\text { em um artigo sobre licenciamento e } \\
\text { certificação profissional. }\end{array}$ & $\begin{array}{l}\text { Regras sobre regulação doméstica } \\
\text { relativas a requisitos e procedimentos de } \\
\text { qualificação, padrões técnicos e } \\
\text { requisitos de licenças. }\end{array}$ \\
\hline $\begin{array}{l}\text { Regras setoriais } \\
\text { específicas }\end{array}$ & $\begin{array}{l}\text { Serviços financeiros (Capítulo 13) e } \\
\text { Telecomunicações (Capítulo 14). O } \\
\text { capítulo sobre serviços possui anexos } \\
\text { sobre Serviços Profissionais e } \\
\text { Transporte Terrestre. }\end{array}$ & $\begin{array}{c}\text { Serviços financeiros (Capítulo 12), } \\
\text { Telecomunicações (Capítulo 13) e } \\
\text { Comércio Eletrônico (Capítulo 14). O } \\
\text { capítulo sobre serviços possui um anexo } \\
\text { sobre Serviços Profissionais. }\end{array}$ \\
\hline $\begin{array}{c}\text { Capítulo sobre } \\
\text { investimentos } \\
\text { relacionados a serviços }\end{array}$ & Sim (Capítulo 11). & Sim (Capítulo 10). \\
\hline
\end{tabular}




\begin{tabular}{|c|c|c|}
\hline & NAFTA & CAFTA-DR \\
\hline $\begin{array}{l}\text { Regras sobre } \\
\text { transparência }\end{array}$ & $\begin{array}{l}\text { Notificação de novas medidas } \\
\text { quantitativas restritivas. "3. Each Party } \\
\text { shall notify the other Parties of any } \\
\text { quantitative restriction that it adopts, } \\
\text { other than at the local government } \\
\text { level, after the date of entry into force } \\
\text { of this Agreement and shall set out the } \\
\text { restriction in its Schedule to Annex V." }\end{array}$ & $\begin{array}{l}\text { Oportunidade para comentários sobre } \\
\text { qualquer regulamentação que vier a ser } \\
\text { criada ou aplicada, além das regras gerais } \\
\text { de transparência do Capítulo } 18 \text {. }\end{array}$ \\
\hline $\begin{array}{l}\text { Tratamento nacional: } \\
\text { abrangência e } \\
\text { parâmetros } \\
\text { semelhantes ao GATS } \\
\text { (like services and like } \\
\text { services suppliers) }\end{array}$ & $\begin{array}{l}\text { Aplicação abrangente, exceto medidas } \\
\text { não conformes, setores e serviços } \\
\text { excluídos. Parâmetros diferentes. } \\
\text { Conceito utilizado: "like } \\
\text { circumstances". "1. Each Party shall } \\
\text { accord to service providers of another } \\
\text { Party treatment no less favorable than } \\
\text { that it accords, in like circumstances, } \\
\text { to its own service providers. } \\
\text { 2. The treatment accorded by a Party } \\
\text { under paragraph } 1 \text { means, with respect } \\
\text { to a state or province, treatment no } \\
\text { less favorable than the most favorable } \\
\text { treatment accorded, in like } \\
\text { circumstances, by that state or } \\
\text { province to service providers of the } \\
\text { Party of which it forms a part. }\end{array}$ & $\begin{array}{l}\text { Aplicação abrangente, exceto medidas } \\
\text { não conformes, setores e serviços } \\
\text { excluídos. Parâmetros diferentes. } \\
\text { Conceito utilizado: "like circumstances". } \\
\text { "1. Each Party shall accord to service } \\
\text { suppliers of another Party treatment no } \\
\text { less favorable than that it accords, in like } \\
\text { circumstances, to its own service } \\
\text { suppliers. } \\
\text { 2. The treatment to be accorded by a } \\
\text { Party under paragraph } 1 \text { means, with } \\
\text { respect to a regional level of government, } \\
\text { treatment no less favorable than the } \\
\text { most favorable treatment accorded, in } \\
\text { like circumstances, by that regional } \\
\text { level of government to service suppliers } \\
\text { of the Party of which it forms a part." }\end{array}$ \\
\hline $\begin{array}{l}\text { Acesso a mercados: } \\
\text { abrangência e } \\
\text { parâmetros } \\
\text { semelhantes ao Art. } \\
\text { XVI do GATS }\end{array}$ & $\begin{array}{l}\text { Aplicação abrangente, exceto medidas } \\
\text { não conformes, setores e serviços } \\
\text { excluídos. Parâmetros diferentes. Há } \\
\text { cláusula ou parâmetros específicos } \\
\text { sobre acesso a mercados. }\end{array}$ & $\begin{array}{l}\text { Aplicação abrangente, exceto medidas } \\
\text { não conformes, setores e serviços } \\
\text { excluídos. Parâmetros semelhantes. } \\
\text { Exceção quanto ao GATS: não há } \\
\text { limitações à participação de capital } \\
\text { estrangeiro em termos de porcentagem } \\
\text { máxima de detenção de participação } \\
\text { societária ou de valor total do } \\
\text { investimento estrangeiro. }\end{array}$ \\
\hline $\begin{array}{l}\text { Obrigações permissivas } \\
\text { que possibilitam } \\
\text { tratamento desigual } \\
\text { entre as partes do } \\
\text { acordo }\end{array}$ & Não & Não \\
\hline $\begin{array}{l}\text { Cláusula de nação mais } \\
\text { favorecida ratione } \\
\text { materiae et temporis }\end{array}$ & Sim & Sim \\
\hline $\begin{array}{l}\text { Exceções à Cláusula de } \\
\text { Nação Mais Favorecida }\end{array}$ & $\begin{array}{c}\text { Não se aplica, tendo em vista que a } \\
\text { liberalização se dá por lista negativa. } \\
\text { As partes deverão listar as medidas não } \\
\text { conformes em seus respectivos } \\
\text { Anexos. }\end{array}$ & $\begin{array}{l}\text { Não se aplica, tendo em vista que a } \\
\text { liberalização se dá por lista negativa. As } \\
\text { partes deverão listar as medidas não } \\
\text { conformes em seus respectivos Anexos. }\end{array}$ \\
\hline
\end{tabular}




\begin{tabular}{|c|c|c|}
\hline & NAFTA & CAFTA-DR \\
\hline $\begin{array}{l}\text { Regra de origem } \\
\text { (Denial of benefits) }\end{array}$ & $\begin{array}{l}\text { Sim, nas seguintes hipóteses: (i) o } \\
\text { serviço for prestado por uma empresa } \\
\text { pertencente ou controlada por } \\
\text { nacionais de uma não parte, em } \\
\text { algumas circunstâncias (inexistência de } \\
\text { relações diplomáticas ou proibição de } \\
\text { operações com determinada empresa) } \\
\text { ou utiliza equipamentos não } \\
\text { permitidos; e (ii) o serviço for prestado } \\
\text { por empresa pertencente ou controlada } \\
\text { por não partes que não exerça } \\
\text { operações comerciais substanciais no } \\
\text { território de nenhuma parte } \\
\text { (procedimento sujeito à consulta e à } \\
\text { notificação). }\end{array}$ & $\begin{array}{l}\text { Sim, nas seguintes hipóteses: (i) o serviço } \\
\text { for prestado por uma empresa } \\
\text { pertencente ou controlada por nacionais } \\
\text { de uma não parte, em algumas } \\
\text { circunstâncias (inexistência de relações } \\
\text { diplomáticas ou proibição de operações } \\
\text { com determinada empresa); e (ii) o } \\
\text { serviço for prestado por empresa que não } \\
\text { exerça operações comerciais substanciais } \\
\text { no território de nenhuma parte, exceto na } \\
\text { parte que denegar o benefício, e for } \\
\text { pertencente ou controlada por pessoas de } \\
\text { uma não parte ou da parte que denegar o } \\
\text { benefício (procedimento sujeito à } \\
\text { consulta, fornecimento de informações e } \\
\text { notificação). }\end{array}$ \\
\hline $\begin{array}{l}\text { Procedimento para } \\
\text { modificação dos } \\
\text { compromissos }\end{array}$ & $\begin{array}{c}\text { Não está regulamentado. Ficou a cargo } \\
\text { da Comissão desenvolver a } \\
\text { regulamentação a esse respeito. }\end{array}$ & $\begin{array}{c}\text { Não está regulamentado. Ficou a cargo } \\
\text { da Comissão desenvolver a } \\
\text { regulamentação a esse respeito. }\end{array}$ \\
\hline $\begin{array}{l}\text { Procedimento para } \\
\text { futuras negociações }\end{array}$ & $\begin{array}{l}\text { Não está regulamentado. Ficou a cargo } \\
\text { da Comissão desenvolver a } \\
\text { regulamentação a esse respeito. Há } \\
\text { apenas uma previsão para que as partes } \\
\text { se esforcem para liberalizar ou remover } \\
\text { as restrições quantitativas } \\
\text { periodicamente, no mínimo a cada } 2 \\
\text { anos. }\end{array}$ & $\begin{array}{l}\text { Não está regulamentado. Ficou a cargo } \\
\text { da Comissão desenvolver a } \\
\text { regulamentação a esse respeito. Há } \\
\text { apenas uma previsão para que as partes } \\
\text { se consultem anualmente para rever a } \\
\text { implementação do capítulo relativo a } \\
\text { serviços e discutir questões de interesse } \\
\text { mútuo. }\end{array}$ \\
\hline $\begin{array}{l}\text { Criação de comitês } \\
\text { para supervisionar a } \\
\text { evolução do Acordo }\end{array}$ & $\begin{array}{l}\text { Prevê a criação de uma Comissão, que } \\
\text { deverá estabelecer parâmetros relativos } \\
\text { a: (a) inclusão de medidas estaduais ou } \\
\text { provinciais em conformidade com o } \\
\text { Art. 1206(2), (ii) restrições } \\
\text { quantitativas, conforme Art. 1207(2) e } \\
\text { (3), (iii) compromissos celebrados } \\
\text { conforme oArt. 1208, e (iv) aditamento } \\
\text { de medidas a que se refere o Art. } \\
\text { 1206(1)(c); e (b) consultas sobre } \\
\text { reservas, restrições quantitativas ou } \\
\text { compromissos com vistas a uma maior } \\
\text { liberalização. }\end{array}$ & $\begin{array}{l}\text { Prevê a criação de uma Comissão de } \\
\text { Livre Comércio, que deverá } \\
\text { supervisionar a implementação do } \\
\text { Acordo. }\end{array}$ \\
\hline
\end{tabular}




\section{Tabela 7 - KORUS e Acordo Estados Unidos-Austrália}

\begin{tabular}{|c|c|c|}
\hline & KORUS & Acordo Estados Unidos-Austrália \\
\hline $\begin{array}{l}\text { Escopo do capítulo } \\
\text { sobre serviços }\end{array}$ & $\begin{array}{l}\text { Medidas adotadas ou mantidas por uma } \\
\text { parte em relação ao comércio } \\
\text { transfronteiriço de serviços por } \\
\text { prestadores estrangeiros, incluindo: (a) } \\
\text { produção, distribuição, } \\
\text { comercialização, venda e entrega de } \\
\text { um serviço; (b) compra, uso ou } \\
\text { pagamento por um serviço; (c) acesso e } \\
\text { uso de sistemas de distribuição, } \\
\text { transporte e telecomunicações e } \\
\text { serviços em conexão com a prestação } \\
\text { de um serviço; (d) presença no } \\
\text { território de um prestador de outra } \\
\text { parte; e (e) provisão de "bond" ou outra } \\
\text { forma de seguro financeiro como } \\
\text { condição para a prestação de um } \\
\text { serviço. Setores não abrangidos: (a) } \\
\text { Serviços financeiros definidos no } \\
\text { artigo 13.20, exceto se o serviço } \\
\text { financeiro for fornecido por um } \\
\text { investimento coberto que não seja } \\
\text { coberto em uma instituição financeira; } \\
\text { (b) licitações governamentais; (c) } \\
\text { transporte aéreo doméstico e } \\
\text { internacional, ou serviços de apoio } \\
\text { correlatos, exceto: (i) serviços de } \\
\text { reparo e manutenção de aeronaves } \\
\text { enquanto não estiverem em serviço; (ii) } \\
\text { serviços especializados; (d) subsídios } \\
\text { ou concessões, incluindo empréstimos, } \\
\text { garantias e seguro governamentais; e } \\
\text { (e) serviços prestadores no exercício de } \\
\text { autoridade governamental. } \\
\end{array}$ & $\begin{array}{l}\text { Medidas adotadas ou mantidas por uma } \\
\text { parte em relação ao comércio } \\
\text { transfronteiriço de serviços por } \\
\text { prestadores estrangeiros, incluindo: (a) } \\
\text { produção, distribuição, comercialização, } \\
\text { venda e entrega de um serviço; (b) } \\
\text { compra, uso ou pagamento por um } \\
\text { serviço; (c) acesso e uso de sistemas de } \\
\text { distribuição, transporte e } \\
\text { telecomunicaços e serviços em conexão } \\
\text { com a prestação de um serviço; (d) } \\
\text { presença no território de um prestador de } \\
\text { outra parte; e (e) provisão de "bond" ou } \\
\text { outra forma de seguro financeiro como } \\
\text { condição para a prestação de um serviço. } \\
\text { Setores não abrangidos: (a) Serviços } \\
\text { financeiros definidos no artigo 13.19, } \\
\text { exceto se o serviço financeiro for } \\
\text { fornecido por um investimento coberto } \\
\text { que não seja coberto em uma instituição } \\
\text { financeira; (b) licitações governamentais; } \\
\text { (c) transporte aéreo doméstico e } \\
\text { internacional, ou serviços de apoio } \\
\text { correlatos, exceto: (i) serviços de reparo e } \\
\text { manutenção de aeronaves enquanto não } \\
\text { estiverem em serviço; (ii) serviços } \\
\text { especializados; (d) subsídios ou } \\
\text { concessões, incluindo empréstimos, } \\
\text { garantias e seguro governamentais; e (e) } \\
\text { serviços prestadores no exercício de } \\
\text { autoridade governamental. }\end{array}$ \\
\hline $\begin{array}{l}\text { Forma de assunção dos } \\
\text { compromissos }\end{array}$ & Lista negativa & Lista negativa \\
\hline $\begin{array}{c}\text { Modos de prestação } \\
\text { abrangidos }\end{array}$ & $\begin{array}{c}\text { Modos } 1,2,3 \text { e } 4 \text {, sendo o último } \\
\text { tratado apenas em relação a serviços } \\
\text { profissionais. }\end{array}$ & $\begin{array}{c}\text { Modos } 1,2,3 \text { e } 4 \text {, sendo o último tratado } \\
\text { apenas em relação a serviços } \\
\text { profissionais. }\end{array}$ \\
\hline $\begin{array}{c}\text { Regras sobre regulação } \\
\text { doméstica }\end{array}$ & $\begin{array}{l}\text { Regras sobre regulação doméstica } \\
\text { relativas a requisitos e procedimentos } \\
\text { de qualificação, padrões técnicos e } \\
\text { requisitos para licenças. }\end{array}$ & $\begin{array}{l}\text { Regras sobre regulação doméstica } \\
\text { relativas a requisitos e procedimentos de } \\
\text { qualificação, padrões técnicos e } \\
\text { requisitos para licenças. }\end{array}$ \\
\hline $\begin{array}{l}\text { Regras setoriais } \\
\text { específicas }\end{array}$ & $\begin{array}{l}\text { Serviços financeiros (Capítulo 13), } \\
\text { Telecomunicações (Capítulo 14) e } \\
\text { Comércio Eletrônico (Capítulo 15). O } \\
\text { capítulo sobre serviços possui anexos } \\
\text { sobre Serviços Profissionais, } \\
\text { Reconhecimento Mútuo Setorial e } \\
\text { Licenças Temporárias, Serviços de } \\
\text { Entrega Expressa e Consultas sobre }\end{array}$ & $\begin{array}{c}\text { Serviços financeiros (Capítulo 13), } \\
\text { Telecomunicações (Capítulo 12) e } \\
\text { Comércio Eletrônico (Capítulo 16). O } \\
\text { capítulo sobre serviços possui um anexo } \\
\text { sobre Serviços Profissionais. }\end{array}$ \\
\hline
\end{tabular}




\begin{tabular}{|c|c|c|}
\hline & KORUS & Acordo Estados Unidos-Austrália \\
\hline & $\begin{array}{c}\text { Medidas Não Conformes Mantidas por } \\
\text { Autoridades Governamentais } \\
\text { Regionais. } \\
\end{array}$ & \\
\hline $\begin{array}{c}\text { Capítulo sobre } \\
\text { investimentos } \\
\text { relacionados a serviços }\end{array}$ & Sim (Capítulo 11). & Sim (Capítulo 11). \\
\hline $\begin{array}{l}\text { Regras sobre } \\
\text { transparência }\end{array}$ & $\begin{array}{l}\text { Notificação e oportunidade para } \\
\text { comentários sobre qualquer } \\
\text { regulamentação que vier a ser criada } \\
\text { ou aplicada, além das regras gerais de } \\
\text { transparência do Capítulo } 21 \text {. }\end{array}$ & $\begin{array}{l}\text { Notificação e oportunidade para } \\
\text { comentários sobre qualquer } \\
\text { regulamentação que vier a ser criada ou } \\
\text { aplicada, além das regras gerais de } \\
\text { transparência do Capítulo } 20 .\end{array}$ \\
\hline $\begin{array}{c}\text { Tratamento nacional: } \\
\text { abrangência e } \\
\text { parâmetros } \\
\text { semelhantes ao GATS } \\
\text { (like services and like } \\
\text { services suppliers) }\end{array}$ & $\begin{array}{c}\text { Aplicação abrangente, exceto medidas } \\
\text { não conformes, setores e serviços } \\
\text { excluídos. Parâmetros diferentes. } \\
\text { Conceito utilizado: "like } \\
\text { circumstances". "1. Each Party shall } \\
\text { accord to service suppliers of another } \\
\text { Party treatment no less favorable than } \\
\text { that it accords, in like circumstances, } \\
\text { to its own service suppliers. } \\
\text { 2. The treatment to be accorded by a } \\
\text { Party under paragraph } 1 \text { means, with } \\
\text { respect to a regional level of } \\
\text { government, treatment no less } \\
\text { favorable than the most favorable } \\
\text { treatment accorded, in like } \\
\text { circumstances, by that regional level } \\
\text { of government to service suppliers of } \\
\text { the Party of which it forms a part." }\end{array}$ & $\begin{array}{l}\text { Aplicação abrangente, exceto medidas } \\
\text { não conformes, setores e serviços } \\
\text { excluídos. Parâmetros diferentes. } \\
\text { Conceito utilizado: "like circumstances". } \\
\text { "1. Each Party shall accord to service } \\
\text { suppliers of another Party treatment no } \\
\text { less favorable than that it accords, in like } \\
\frac{\text { circumstances, to its own service }}{\text { suppliers. }}\end{array}$ \\
\hline $\begin{array}{l}\text { Acesso a mercados: } \\
\text { abrangência e } \\
\text { parâmetros } \\
\text { semelhantes ao Art. } \\
\text { XVI do GATS }\end{array}$ & $\begin{array}{l}\text { Aplicação abrangente, exceto medidas } \\
\text { não conformes, setores e serviços } \\
\text { excluídos. Parâmetros semelhantes. } \\
\text { Exceção quanto ao GATS: não há } \\
\text { limitações à participação de capital } \\
\text { estrangeiro em termos de porcentagem } \\
\text { máxima de detenção de participação } \\
\text { societária ou de valor total do } \\
\text { investimento estrangeiro. } \\
\end{array}$ & $\begin{array}{l}\text { Aplicação abrangente, exceto medidas } \\
\text { não conformes, setores e serviços } \\
\text { excluídos. Parâmetros semelhantes. } \\
\text { Exceção quanto ao GATS: não há } \\
\text { limitações à participação de capital } \\
\text { estrangeiro em termos de porcentagem } \\
\text { máxima de detenção de participação } \\
\text { societária ou de valor total do } \\
\text { investimento estrangeiro. }\end{array}$ \\
\hline $\begin{array}{c}\text { Obrigações permissivas } \\
\text { que possibilitam } \\
\text { tratamento desigual } \\
\text { entre as partes do } \\
\text { acordo } \\
\end{array}$ & Não & Não \\
\hline $\begin{array}{l}\text { Cláusula de nação mais } \\
\text { favorecida ratione } \\
\text { materiae et temporis }\end{array}$ & Sim & Sim \\
\hline $\begin{array}{l}\text { Exceções à Cláusula de } \\
\text { Nação Mais Favorecida }\end{array}$ & $\begin{array}{l}\text { Não se aplica, tendo em vista que a } \\
\text { liberalização se dá por lista negativa. } \\
\text { As partes deverão listar as medidas não } \\
\text { conformes em seus respectivos } \\
\text { Anexos. }\end{array}$ & $\begin{array}{l}\text { Não se aplica, tendo em vista que a } \\
\text { liberalização se dá por lista negativa. As } \\
\text { partes deverão listar as medidas não } \\
\text { conformes em seus respectivos Anexos. }\end{array}$ \\
\hline
\end{tabular}




\begin{tabular}{|c|c|c|}
\hline & KORUS & Acordo Estados Unidos-Austrália \\
\hline $\begin{array}{l}\text { Regra de origem } \\
\text { (Denial of benefits) }\end{array}$ & $\begin{array}{l}\text { Sim, nas seguintes hipóteses: (i) o } \\
\text { serviço for prestado por uma empresa } \\
\text { pertencente ou controlada por } \\
\text { nacionais de uma não parte, em } \\
\text { algumas circunstâncias (inexistência de } \\
\text { relações diplomáticas ou proibição de } \\
\text { operações com determinada empresa); } \\
\text { e (ii) o serviço for prestado por } \\
\text { empresa que não exerça operações } \\
\text { comerciais substanciais no território de } \\
\text { nenhuma parte, exceto na parte que } \\
\text { denegar o benefício, e for pertencente } \\
\text { ou controlada por pessoas de uma não } \\
\text { parte ou da parte que denegar o } \\
\text { benefício (procedimento sujeito à } \\
\text { consulta, fornecimento de informações } \\
\text { e notificação). }\end{array}$ & $\begin{array}{l}\text { Sim, nas seguintes hipóteses: (i) o serviço } \\
\text { ser prestado por uma empresa } \\
\text { pertencente ou controlada por nacionais } \\
\text { de uma não parte, em algumas } \\
\text { circunstâncias (inexistência de relações } \\
\text { diplomáticas ou proibição de operações } \\
\text { com determinada empresa); e (ii) pode } \\
\text { ser negada a prestação a um prestador de } \\
\text { outra parte se o serviço for prestador por } \\
\text { empresa que não exerça operações } \\
\text { comerciais substanciais no território de } \\
\text { nenhuma parte que é detida ou controlada } \\
\text { por nacionais de não partes ou da parte } \\
\text { que denegar o benefício. }\end{array}$ \\
\hline $\begin{array}{l}\text { Procedimento para } \\
\text { modificação dos } \\
\text { compromissos }\end{array}$ & $\begin{array}{l}\text { Não está regulamentado. Ficou a cargo } \\
\text { do Comitê Adjunto desenvolver a } \\
\text { regulamentação a esse respeito. }\end{array}$ & $\begin{array}{l}\text { Não está regulamentado. Ficou a cargo } \\
\text { do Comitê Adjunto desenvolver a } \\
\text { regulamentação a esse respeito. }\end{array}$ \\
\hline $\begin{array}{l}\text { Procedimento para } \\
\text { futuras negociações }\end{array}$ & $\begin{array}{l}\text { Não está regulamentado. Ficou a cargo } \\
\text { do Comitê Adjunto desenvolver a } \\
\text { regulamentação a esse respeito. }\end{array}$ & $\begin{array}{l}\text { Não está regulamentado. Ficou a cargo } \\
\text { do Comitê Adjunto desenvolver a } \\
\text { regulamentação a esse respeito. Há } \\
\text { apenas uma previsão para que as partes } \\
\text { se consultem anualmente para rever a } \\
\text { implementação do capítulo relativo a } \\
\text { serviços ou discutir questões de interesse } \\
\text { relacionadas a serviços. }\end{array}$ \\
\hline $\begin{array}{l}\text { Criação de comitês } \\
\text { para supervisionar a } \\
\text { evolução do Acordo }\end{array}$ & $\begin{array}{l}\text { Prevê a criação de um Comitê Adjunto, } \\
\text { que deverá supervisionar a } \\
\text { implementação do Acordo. }\end{array}$ & $\begin{array}{l}\text { Prevê a criação de um Comitê Adjunto, } \\
\text { que deverá supervisionar a } \\
\text { implementação do Acordo. }\end{array}$ \\
\hline
\end{tabular}




\section{Tabela 8 - Acordos Estados Unidos-Bahrain e Estados Unidos-Chile}

\begin{tabular}{|c|c|c|}
\hline & Acordo Estados Unidos-Bahrain & Acordo Estados Unidos-Chile \\
\hline $\begin{array}{l}\text { Escopo do capítulo } \\
\text { sobre serviços }\end{array}$ & 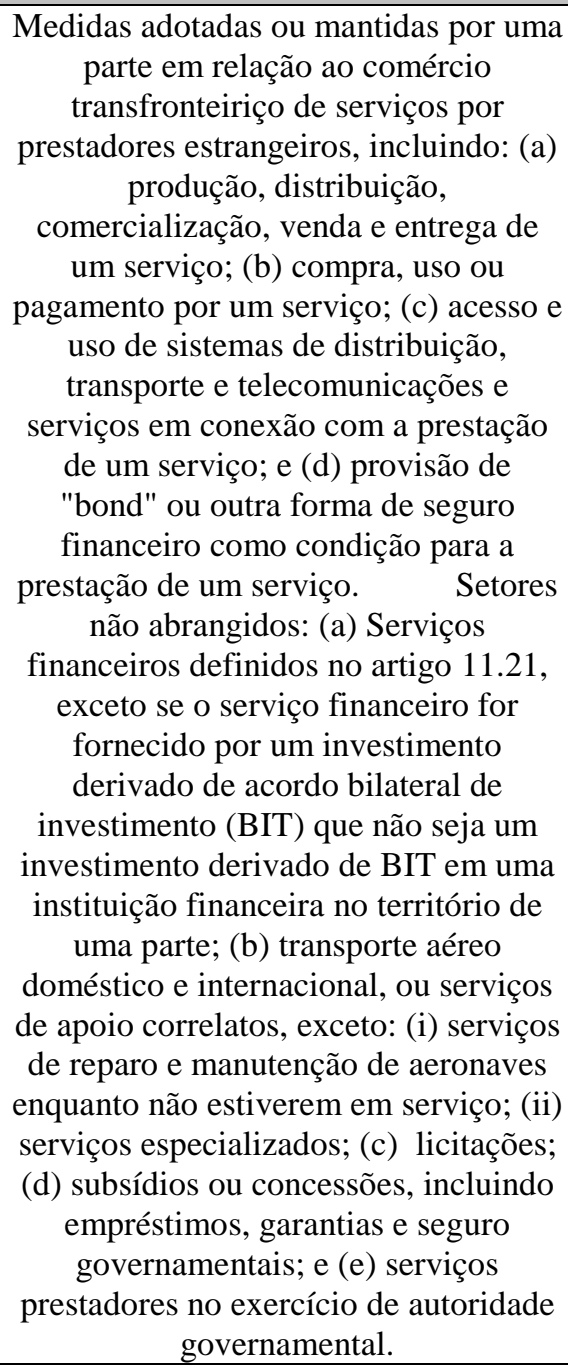 & $\begin{array}{l}\text { Medidas adotadas ou mantidas por uma } \\
\text { parte em relação ao comércio } \\
\text { transfronteiriço de serviços por } \\
\text { prestadores estrangeiros, incluindo: (a) } \\
\text { produção, distribuição, comercialização, } \\
\text { venda e entrega de um serviço; (b) } \\
\text { compra, uso ou pagamento por um } \\
\text { serviço; (c) acesso e uso de sistemas de } \\
\text { distribuição, transporte e } \\
\text { telecomunicaços e serviços em conexão } \\
\text { com a prestação de um serviço; (d) } \\
\text { presença no território de um prestador de } \\
\text { outra parte; e (e) provisão de "bond" ou } \\
\text { outra forma de seguro financeiro como } \\
\text { condição para a prestação de um serviço. } \\
\text { Setores não abrangidos: (a) Serviços } \\
\text { financeiros definidos no artigo } 12.19, \\
\text { exceto se o serviço financeiro for } \\
\text { fornecido por um investidor da outra } \\
\text { parte ou por um investimento coberto; (b) } \\
\text { transporte aéreo doméstico e } \\
\text { internacional, ou serviços de apoio } \\
\text { correlatos, exceto: (i) serviços de reparo e } \\
\text { manutenção de aeronaves enquanto não } \\
\text { estiverem em serviço; (ii) serviços } \\
\text { especializados; (c) licitações; (d) } \\
\text { subsídios ou concessões, incluindo } \\
\text { empréstimos, garantias e seguro } \\
\text { governamentais; e (e) serviços } \\
\text { prestadores no exercício de autoridade } \\
\text { governamental. }\end{array}$ \\
\hline $\begin{array}{c}\text { Forma de assunção dos } \\
\text { compromissos }\end{array}$ & Lista negativa & Lista negativa \\
\hline $\begin{array}{c}\text { Modos de prestação } \\
\text { abrangidos }\end{array}$ & $\begin{array}{c}\text { Modos } 1,2,3 \text { e } 4 \text {, sendo o último } \\
\text { tratado apenas em relação a serviços } \\
\text { profissionais. }\end{array}$ & $\begin{array}{c}\text { Modos } 1,2,3 \text { e } 4 \text {, sendo o último tratado } \\
\text { apenas em relação a serviços } \\
\text { profissionais. }\end{array}$ \\
\hline $\begin{array}{c}\text { Regras sobre regulação } \\
\text { doméstica }\end{array}$ & $\begin{array}{l}\text { Regras sobre regulação doméstica } \\
\text { relativas a requisitos e procedimentos } \\
\text { de qualificação, padrões técnicos e } \\
\text { requisitos para licenças. }\end{array}$ & $\begin{array}{l}\text { Regras sobre regulação doméstica } \\
\text { relativas a requisitos e procedimentos de } \\
\text { qualificação, padrões técnicos e } \\
\text { requisitos para licenças. }\end{array}$ \\
\hline $\begin{array}{l}\text { Regras setoriais } \\
\text { específicas }\end{array}$ & $\begin{array}{c}\text { Serviços financeiros (Capítulo 11), } \\
\text { Telecomunicações (Capítulo 12) e } \\
\text { Comércio Eletrônico (Capítulo 13). O } \\
\text { capítulo sobre serviços possui anexos } \\
\text { sobre Serviços Profissionais e Serviços } \\
\text { de Entrega Expressa. }\end{array}$ & $\begin{array}{c}\text { Serviços financeiros (Capítulo 12), } \\
\text { Telecomunicações (Capítulo 13), Entrada } \\
\text { Temporária de Pessoas de Negócios } \\
\text { (Capítulo 14) e Comércio Eletrônico } \\
\text { (Capítulo 15). O capítulo sobre serviços } \\
\text { possui anexos sobre Serviços } \\
\text { Profissionais e Serviços de Entrega }\end{array}$ \\
\hline
\end{tabular}




\begin{tabular}{|c|c|c|}
\hline & Acordo Estados Unidos-Bahrain & Acordo Estados Unidos-Chile \\
\hline & & Expressa. \\
\hline $\begin{array}{c}\text { Capítulo sobre } \\
\text { investimentos } \\
\text { relacionados a serviços } \\
\end{array}$ & Sim (Capítulo 10). & Sim (Capítulo 10). \\
\hline $\begin{array}{l}\text { Regras sobre } \\
\text { transparência }\end{array}$ & $\begin{array}{l}\text { Notificação e oportunidade para } \\
\text { comentários sobre qualquer } \\
\text { regulamentação que vier a ser criada } \\
\text { ou aplicada, além das regras gerais de } \\
\text { transparência do Capítulo } 17 .\end{array}$ & $\begin{array}{c}\text { Oportunidade para comentários sobre } \\
\text { qualquer regulamentação que vier a ser } \\
\text { criada ou aplicada, além das regras gerais } \\
\text { de transparência do Capítulo } 20 \text {. }\end{array}$ \\
\hline $\begin{array}{c}\text { Tratamento nacional: } \\
\text { abrangência e } \\
\text { parâmetros } \\
\text { semelhantes ao GATS } \\
\text { (like services and like } \\
\text { services suppliers) }\end{array}$ & $\begin{array}{l}\text { Aplicação abrangente, exceto medidas } \\
\text { não conformes, setores e serviços } \\
\text { excluídos. Parâmetros diferentes. } \\
\text { Conceito utilizado: "like } \\
\text { circumstances". "1. Each Party shall } \\
\text { accord to service suppliers of another } \\
\text { Party treatment no less favorable than } \\
\text { that it accords, in like circumstances, } \\
\text { to its own service suppliers. } \\
\text { 2. The treatment to be accorded by a } \\
\text { Party under paragraph } 1 \text { means, with } \\
\text { respect to a regional level of } \\
\text { government, treatment no less } \\
\text { favorable than the most favorable } \\
\text { treatment accorded, in like } \\
\text { circumstances, by that regional level } \\
\text { of government to service suppliers of } \\
\text { the Party of which it forms a part." }\end{array}$ & $\begin{array}{l}\text { Aplicação abrangente, exceto medidas } \\
\text { não conformes, setores e serviços } \\
\text { excluídos. Parâmetros diferentes. } \\
\text { Conceito utilizado: "like circumstances". } \\
\text { "1. Each Party shall accord to service } \\
\text { suppliers of another Party treatment no } \\
\text { less favorable than that it accords, in like } \\
\text { circumstances, to its own service } \\
\text { suppliers. } \\
\text { 2. The treatment to be accorded by a } \\
\text { Party under paragraph } 1 \text { means, with } \\
\text { respect to a regional level of government, } \\
\text { treatment no less favorable than the } \\
\frac{\text { most favorable treatment accorded, in }}{\text { like circumstances, by that regional }} \\
\underline{\text { level of government to service suppliers }} \\
\text { of the Party of which it forms a part." }\end{array}$ \\
\hline $\begin{array}{l}\text { Acesso a mercados: } \\
\text { abrangência e } \\
\text { parâmetros } \\
\text { semelhantes ao Art. } \\
\text { XVI do GATS }\end{array}$ & $\begin{array}{l}\text { Aplicação abrangente, exceto medidas } \\
\text { não conformes, setores e serviços } \\
\text { excluídos. Parâmetros semelhantes. } \\
\text { Exceção quanto ao GATS: não há } \\
\text { limitações à participação de capital } \\
\text { estrangeiro em termos de porcentagem } \\
\text { máxima de detenção de participação } \\
\text { societária ou de valor total do } \\
\text { investimento estrangeiro. }\end{array}$ & $\begin{array}{l}\text { Aplicação abrangente, exceto medidas } \\
\text { não conformes, setores e serviços } \\
\text { excluídos. Parâmetros semelhantes. } \\
\text { Exceção quanto ao GATS: não há } \\
\text { limitações à participação de capital } \\
\text { estrangeiro em termos de porcentagem } \\
\text { máxima de detenção de participação } \\
\text { societária ou de valor total do } \\
\text { investimento estrangeiro. }\end{array}$ \\
\hline $\begin{array}{c}\text { Obrigações permissivas } \\
\text { que possibilitam } \\
\text { tratamento desigual } \\
\text { entre as partes do } \\
\text { acordo } \\
\end{array}$ & Não & Não \\
\hline $\begin{array}{l}\text { Cláusula de nação mais } \\
\text { favorecida ratione } \\
\text { materiae et temporis }\end{array}$ & Sim & Sim \\
\hline $\begin{array}{l}\text { Exceções à Cláusula de } \\
\text { Nação Mais Favorecida }\end{array}$ & $\begin{array}{l}\text { Não se aplica, tendo em vista que a } \\
\text { liberalização se dá por lista negativa. } \\
\text { As partes deverão listar as medidas não } \\
\text { conformes em seus respectivos } \\
\text { Anexos. }\end{array}$ & $\begin{array}{l}\text { Não se aplica, tendo em vista que a } \\
\text { liberalização se dá por lista negativa. As } \\
\text { partes deverão listar as medidas não } \\
\text { conformes em seus respectivos Anexos. }\end{array}$ \\
\hline
\end{tabular}




\begin{tabular}{|c|c|c|}
\hline & Acordo Estados Unidos-Bahrain & Acordo Estados Unidos-Chile \\
\hline $\begin{array}{l}\text { Regra de origem } \\
\text { (Denial of benefits) }\end{array}$ & $\begin{array}{l}\text { Sim, nas seguintes hipóteses: (i) o } \\
\text { serviço for prestado por uma empresa } \\
\text { pertencente ou controlada por } \\
\text { nacionais de uma não parte, em } \\
\text { algumas circunstâncias (inexistência de } \\
\text { relações diplomáticas ou proibição de } \\
\text { operações com determinada empresa); } \\
\text { e (ii) o serviço for prestado por } \\
\text { empresa que não exerça operações } \\
\text { comerciais substanciais no território de } \\
\text { nenhuma parte, exceto na parte que } \\
\text { denegar o benefício, e for pertencente } \\
\text { ou controlada por pessoas de uma não } \\
\text { parte ou da parte que denegar o } \\
\text { benefício (procedimento sujeito à } \\
\text { consulta, fornecimento de informações } \\
\text { e notificação). }\end{array}$ & $\begin{array}{l}\text { Sim, nas seguintes hipóteses: (i) o serviço } \\
\text { for prestado por uma empresa } \\
\text { pertencente ou controlada por nacionais } \\
\text { de uma não parte, em algumas } \\
\text { circunstâncias (inexistência de relações } \\
\text { diplomáticas ou proibição de operações } \\
\text { com determinada empresa); e (ii) o } \\
\text { serviço for prestado por empresa que não } \\
\text { exerça operações comerciais substanciais } \\
\text { no território de nenhuma parte, exceto na } \\
\text { parte que denegar o benefício, e for } \\
\text { pertencente ou controlada por pessoas de } \\
\text { uma não parte ou da parte que denegar o } \\
\text { benefício (procedimento sujeito à } \\
\text { consulta, fornecimento de informações e } \\
\text { notificação). }\end{array}$ \\
\hline $\begin{array}{l}\text { Procedimento para } \\
\text { modificação dos } \\
\text { compromissos }\end{array}$ & $\begin{array}{l}\text { Não está regulamentado. Ficou a cargo } \\
\text { do Comitê Adjunto desenvolver a } \\
\text { regulamentação a esse respeito. }\end{array}$ & $\begin{array}{l}\text { Não está regulamentado. Ficou a cargo } \\
\text { da Comissão desenvolver a } \\
\text { regulamentação a esse respeito. }\end{array}$ \\
\hline $\begin{array}{l}\text { Procedimento para } \\
\text { futuras negociações }\end{array}$ & $\begin{array}{c}\text { Não está regulamentado. Ficou a cargo } \\
\text { do Comitê Adjunto desenvolver a } \\
\text { regulamentação a esse respeito. Há } \\
\text { apenas uma previsão para que as partes } \\
\text { se consultem anualmente para discutir } \\
\text { questões de interesse relacionadas à } \\
\text { implementação do capítulo relativo a } \\
\text { serviços. }\end{array}$ & $\begin{array}{c}\text { Não está regulamentado. Ficou a cargo } \\
\text { da Comissão desenvolver a } \\
\text { regulamentação a esse respeito. Há } \\
\text { apenas uma previsão para que as partes } \\
\text { se consultem anualmente para rever a } \\
\text { implementação do capítulo relativo a } \\
\text { serviços ou discutir questões de interesse } \\
\text { mútuo. }\end{array}$ \\
\hline $\begin{array}{l}\text { Criação de comitês } \\
\text { para supervisionar a } \\
\text { evolução do Acordo }\end{array}$ & $\begin{array}{l}\text { Prevê a criação de um Comitê Adjunto, } \\
\text { que deverá supervisionar a } \\
\text { implementação do Acordo. }\end{array}$ & $\begin{array}{l}\text { Prevê a criação de uma Comissão de } \\
\text { Livre Comércio, que deverá } \\
\text { supervisionar a implementação do } \\
\text { Acordo. }\end{array}$ \\
\hline
\end{tabular}




\section{Tabela 9 - Acordos Estados Unidos-Colômbia e Estados Unidos-Israel}

\begin{tabular}{|c|c|c|}
\hline & Acordo Estados Unidos-Colômbia & Acordo Estados Unidos-Israel \\
\hline $\begin{array}{l}\text { Escopo do capítulo } \\
\text { sobre serviços }\end{array}$ & 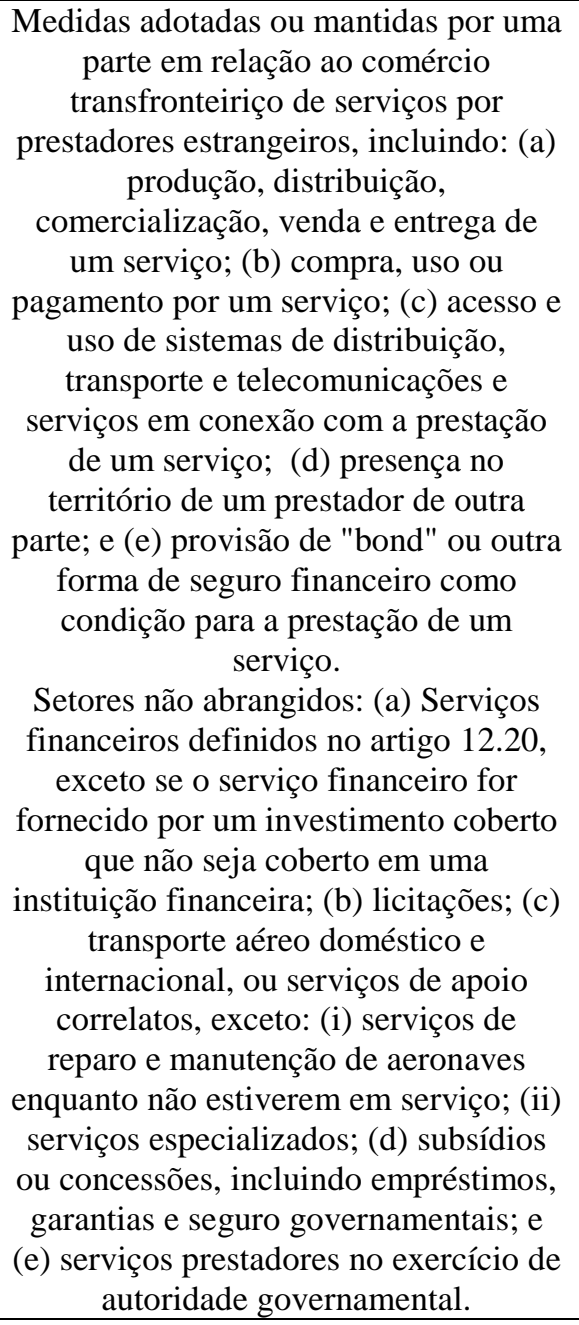 & $\begin{array}{l}\text { As Partes reconhecem a importância do } \\
\text { comércio de serviços e a necessidade de } \\
\text { manter um sistema aberto que minimize } \\
\text { restrições no fluxo de comércio de } \\
\text { serviços. Neste sentido, as partes } \\
\text { concordam em desenvolver meios de } \\
\text { cooperação no comércio de serviços, de } \\
\text { acordo com as previsões da Declaração (a } \\
\text { Declaração Sobre o Comércio de } \\
\text { Serviços não é vinculante). } \\
\text { Os serviços incluem, mas não se limitam } \\
\text { a: transporte; serviços de viagem e } \\
\text { turismo; comunicações; serviços } \\
\text { bancários; seguro; outras atividades } \\
\text { financeiras; serviços prestador, como } \\
\text { consultoria em contrução, engenharia, } \\
\text { contabilidade, medicina, educação e } \\
\text { direito, e o fornecimento de outros } \\
\text { serviços como consultoria em } \\
\text { administração; serviços informáticos; } \\
\text { filmes cinematográficos; propaganda. }\end{array}$ \\
\hline $\begin{array}{l}\text { Forma de assunção dos } \\
\text { compromissos }\end{array}$ & Lista negativa & Não há lista \\
\hline $\begin{array}{c}\text { Modos de prestação } \\
\text { abrangidos }\end{array}$ & $\begin{array}{l}\text { Modos } 1,2,3 \text { e } 4 \text {, sendo o último } \\
\text { tratado apenas em relação a serviços } \\
\text { profissionais. }\end{array}$ & $\begin{array}{c}\text { Modos } 1,2,3 \text { e } 4 \text {, sendo o último tratado } \\
\text { apenas em relação a serviços } \\
\text { profissionais. }\end{array}$ \\
\hline $\begin{array}{c}\text { Regras sobre regulação } \\
\text { doméstica }\end{array}$ & $\begin{array}{c}\text { Regras sobre regulação doméstica } \\
\text { relativas a requisitos e procedimentos } \\
\text { de qualificação, padrões técnicos e } \\
\text { requisitos para licenças. }\end{array}$ & Não há. \\
\hline $\begin{array}{l}\text { Regras setoriais } \\
\text { específicas }\end{array}$ & $\begin{array}{l}\text { Serviços financeiros (Capítulo 12), } \\
\text { Telecomunicações (Capítulo 14) e } \\
\text { Comércio Eletrônico (Capítulo 15). O } \\
\text { capítulo sobre serviços possui anexos } \\
\text { sobre Serviços Profissionais e Serviços } \\
\text { de Entrega Expressa. }\end{array}$ & Não. \\
\hline $\begin{array}{l}\text { Capítulo sobre } \\
\text { investimentos } \\
\text { relacionados a serviços }\end{array}$ & Sim (Capítulo 10). & Não. \\
\hline
\end{tabular}




\begin{tabular}{|c|c|c|}
\hline & Acordo Estados Unidos-Colômbia & Acordo Estados Unidos-Israel \\
\hline $\begin{array}{l}\text { Regras sobre } \\
\text { transparência }\end{array}$ & $\begin{array}{l}\text { Notificação e oportunidade para } \\
\text { comentários sobre qualquer } \\
\text { regulamentação que vier a ser criada } \\
\text { ou aplicada, além das regras gerais de } \\
\text { transparência do Capítulo } 19 .\end{array}$ & $\begin{array}{l}\text { Notificação prévia sobre qualquer } \\
\text { regulamentação que vier a ser criada e } \\
\text { acesso a meios de revisão e } \\
\text { procedimentos judiciais relacionados. }\end{array}$ \\
\hline $\begin{array}{l}\text { Tratamento nacional: } \\
\text { abrangência e } \\
\text { parâmetros } \\
\text { semelhantes ao GATS } \\
\text { (like services and like } \\
\text { services suppliers) }\end{array}$ & $\begin{array}{c}\text { Aplicação abrangente, exceto medidas } \\
\text { não conformes, setores e serviços } \\
\text { excluídos. Parâmetros diferentes. } \\
\text { Conceito utilizado: "like } \\
\text { circumstances". "1. Each Party shall } \\
\text { accord to service suppliers of another } \\
\text { Party treatment no less favorable than } \\
\text { that it accords, in like circumstances, } \\
\text { to its own service suppliers. } \\
\text { 2. The treatment to be accorded by a } \\
\text { Party under paragraph } 1 \text { means, with } \\
\text { respect to a regional level of } \\
\text { government, treatment no less } \\
\text { favorable than the most favorable } \\
\text { treatment accorded, in like } \\
\text { circumstances, by that regional level } \\
\text { of government to service suppliers of } \\
\text { the Party of which it forms a part." }\end{array}$ & $\begin{array}{l}\text { Aplicação abrangente, exceto medidas } \\
\text { não conformes, setores e serviços } \\
\text { excluídos. Parâmetros semelhantes. } \\
\text { "Each Party will endeavor to assure that } \\
\text { trade in services with the other nation is } \\
\text { governed by the principle of national } \\
\text { treatment. Each Party will endeavor to } \\
\text { provide that a supplier of a service } \\
\text { produced within the other nation is able } \\
\text { to market or distribute that } \\
\text { service under the same conditions as a } \\
\text { like service produced within the first } \\
\text { nation, } \\
\text { including situations where a commercial } \\
\text { presence within the nation is necessary to } \\
\text { facilitate the export of a service from the } \\
\text { other nation or is required by that } \\
\text { Party". }\end{array}$ \\
\hline $\begin{array}{l}\text { Acesso a mercados: } \\
\text { abrangência e } \\
\text { parâmetros } \\
\text { semelhantes ao Art. } \\
\text { XVI do GATS }\end{array}$ & $\begin{array}{l}\text { Aplicação abrangente, exceto medidas } \\
\text { não conformes, setores e serviços } \\
\text { excluídos. Parâmetros semelhantes. } \\
\text { Exceção quanto ao GATS: não há } \\
\text { limitações à participação de capital } \\
\text { estrangeiro em termos de porcentagem } \\
\text { máxima de detenção de participação } \\
\text { societária ou de valor total do } \\
\text { investimento estrangeiro. }\end{array}$ & $\begin{array}{l}\text { Parâmetros distintos. "Each Party will } \\
\text { endeavor to achieve open market access } \\
\text { for trade in services with the } \\
\text { other nation, taking into account the } \\
\text { different regulatory regimes for specific } \\
\text { service sectors in the two nations". }\end{array}$ \\
\hline $\begin{array}{l}\text { Obrigações permissivas } \\
\text { que possibilitam } \\
\text { tratamento desigual } \\
\text { entre as partes do } \\
\text { acordo } \\
\end{array}$ & Não. & Não. \\
\hline $\begin{array}{l}\text { Cláusula de nação mais } \\
\text { favorecida ratione } \\
\text { materiae et temporis }\end{array}$ & Sim. & Não há menção. \\
\hline $\begin{array}{l}\text { Exceções à Cláusula de } \\
\text { Nação Mais Favorecida }\end{array}$ & $\begin{array}{l}\text { Não se aplica, tendo em vista que a } \\
\text { liberalização se dá por lista negativa. } \\
\text { As partes deverão listar as medidas não } \\
\text { conformes em seus respectivos } \\
\text { Anexos. }\end{array}$ & Não há menção. \\
\hline $\begin{array}{l}\text { Regra de origem } \\
\text { (Denial of benefits) }\end{array}$ & $\begin{array}{l}\text { Sim, nas seguintes hipóteses: (i) o } \\
\text { serviço for prestado por uma empresa } \\
\text { pertencente ou controlada por } \\
\text { nacionais de uma não parte, em } \\
\text { algumas circunstâncias (inexistência de } \\
\text { relações diplomáticas ou proibição de } \\
\text { operações com determinada empresa); } \\
\text { e (ii) o serviço for prestado por } \\
\text { empresa que não exerça operações } \\
\text { comerciais substanciais no território de }\end{array}$ & Não. \\
\hline
\end{tabular}




\begin{tabular}{|c|c|c|}
\hline & Acordo Estados Unidos-Colômbia & Acordo Estados Unidos-Israel \\
\hline & $\begin{array}{l}\text { nenhuma parte, exceto na parte que } \\
\text { denegar o benefício, e for pertencente } \\
\text { ou controlada por pessoas de uma não } \\
\text { parte ou da parte que denegar o } \\
\text { benefício (procedimento sujeito à } \\
\text { consulta, fornecimento de informações } \\
\text { e notificação). }\end{array}$ & \\
\hline $\begin{array}{l}\text { Procedimento para } \\
\text { modificação dos } \\
\text { compromissos }\end{array}$ & $\begin{array}{c}\text { Não está regulamentado. Ficou a cargo } \\
\text { da Comissão desenvolver a } \\
\text { regulamentação a esse respeito. }\end{array}$ & $\begin{array}{l}\text { Não está regulamentado. Ficou a cargo } \\
\text { do Comitê Adjunto desenvolver a } \\
\text { regulamentação a esse respeito. }\end{array}$ \\
\hline $\begin{array}{l}\text { Procedimento para } \\
\text { futuras negociações }\end{array}$ & $\begin{array}{l}\text { Não está regulamentado. Ficou a cargo } \\
\text { da Comissão desenvolver a } \\
\text { regulamentação a esse respeito. Há } \\
\text { apenas uma previsão para que as partes } \\
\text { se consultem anualmente para rever a } \\
\text { implementação do capítulo relativo a } \\
\text { serviços ou discutir questões de } \\
\text { interesse relacionadas a serviços. }\end{array}$ & $\begin{array}{l}\text { Não está regulamentado. Ficou a cargo } \\
\text { do Comitê Adjunto desenvolver a } \\
\text { regulamentação a esse respeito. Há } \\
\text { apenas uma previsão para que as partes } \\
\text { se consultem periodicamente para } \\
\text { discutir questões relativas a serviços e } \\
\text { rever regimes regulatórios, de ambas as } \\
\text { partes, que afetem o comércio de serviços }\end{array}$ \\
\hline $\begin{array}{l}\text { Criação de comitês } \\
\text { para supervisionar a } \\
\text { evolução do Acordo }\end{array}$ & $\begin{array}{l}\text { Prevê a criação de uma Comissão de } \\
\text { Livre Comércio, que deverá } \\
\text { supervisionar a implementação do } \\
\text { Acordo. }\end{array}$ & $\begin{array}{l}\text { Criação de um Comitê Adjunto, que } \\
\text { deverá supervisionar a implementação do } \\
\text { Acordo e rever a Declaração Sobre o } \\
\text { Comércio de Serviços (não vinculante). }\end{array}$ \\
\hline
\end{tabular}




\section{Tabela 10 - Acordos Estados Unidos-Jordânia e Estados Unidos-}

\section{Marrocos}

\begin{tabular}{|c|c|c|}
\hline & Acordo Estados Unidos-Jordânia & Acordo Estados Unidos-Marrocos \\
\hline $\begin{array}{l}\text { Escopo do capítulo } \\
\text { sobre serviços }\end{array}$ & $\begin{array}{l}\text { Serviços incluem qualquer serviço } \\
\text { exceto aqueles prestadores no exercício } \\
\text { de autoridade governamental, } \\
\text { conforme Artigo I do GATS. }\end{array}$ & $\begin{array}{l}\text { Medidas adotadas ou mantidas por uma } \\
\text { parte em relação ao comércio } \\
\text { transfronteiriço de serviços por } \\
\text { prestadores estrangeiros, incluindo: (a) } \\
\text { produção, distribuição, comercialização, } \\
\text { venda e entrega de um serviço; (b) } \\
\text { compra, uso ou pagamento por um } \\
\text { serviço; (c) acesso e uso de sistemas de } \\
\text { distribuição, transporte e } \\
\text { telecomunicações e serviços em conexão } \\
\text { com a prestação de um serviço; (d) } \\
\text { presença no território de um prestador de } \\
\text { outra parte; e (e) provisão de "bond" ou } \\
\text { outra forma de seguro financeiro como } \\
\text { condição para a prestação de um serviço. } \\
\text { Setores não abrangidos: (a) Serviços } \\
\text { financeiros definidos no artigo 12.19, } \\
\text { exceto se o serviço financeiro for } \\
\text { fornecido por um investimento coberto; } \\
\text { (b) transporte aéreo doméstico e } \\
\text { internacional, ou serviços de apoio } \\
\text { correlatos, exceto: (i) serviços de reparo e } \\
\text { manutenção de aeronaves enquanto não } \\
\text { estiverem em serviço; (ii) serviços } \\
\text { especializados; (c) licitações } \\
\text { governamentais; (d) subsídios ou } \\
\text { concessões, incluindo empréstimos, } \\
\text { garantias e seguro governamentais; e (e) } \\
\text { serviços prestadores no exercício de } \\
\text { autoridade governamental. }\end{array}$ \\
\hline $\begin{array}{l}\text { Forma de assunção dos } \\
\text { compromissos }\end{array}$ & Lista positiva & Lista negativa. \\
\hline $\begin{array}{l}\text { Modos de prestação } \\
\text { abrangidos }\end{array}$ & $\begin{array}{c}\text { Modos } 1,2,3 \text { e } 4 \text {, sendo o último } \\
\text { tratado apenas em relação a serviços } \\
\text { profissionais. }\end{array}$ & $\begin{array}{c}\text { Modos } 1,2,3 \text { e } 4 \text {, sendo o último tratado } \\
\text { apenas em relação a serviços } \\
\text { profissionais. }\end{array}$ \\
\hline $\begin{array}{c}\text { Regras sobre regulação } \\
\text { doméstica }\end{array}$ & Não. & $\begin{array}{l}\text { Regras sobre regulação doméstica } \\
\text { relativas a requisitos e procedimentos de } \\
\text { qualificação, padrões técnicos e } \\
\text { requisitos para licenças. }\end{array}$ \\
\hline $\begin{array}{l}\text { Regras setoriais } \\
\text { específicas }\end{array}$ & $\begin{array}{c}\text { Comércio Eletrônico (Artigo 7) e } \\
\text { referência à criação de direitos e } \\
\text { obrigações às partes pelos anexos } \\
\text { relativos a Serviços Financeiros, } \\
\text { Transporte Aéreo (parágrafos } 1,2,4,6 \text { ) e } \\
\text { Telecomunicações (parágrafos } \\
1,2,3,4,5 \text { ) do GATS. }\end{array}$ & $\begin{array}{c}\text { Serviços financeiros (Capítulo 12), } \\
\text { Telecomunicações (Capítulo 13) e } \\
\text { Comércio Eletrônico (Capítulo 14). O } \\
\text { capítulo sobre serviços possui anexos } \\
\text { sobre Serviços Profissionais e Serviços } \\
\text { de Entrega Expressa. }\end{array}$ \\
\hline
\end{tabular}




\begin{tabular}{|c|c|c|}
\hline & Acordo Estados Unidos-Jordânia & Acordo Estados Unidos-Marrocos \\
\hline $\begin{array}{l}\text { Capítulo sobre } \\
\text { investimentos } \\
\text { relacionados a serviços }\end{array}$ & Não. & Sim (Capítulo 10). \\
\hline $\begin{array}{l}\text { Regras sobre } \\
\text { transparência }\end{array}$ & $\begin{array}{c}\text { Sim. Referência apenas à não } \\
\text { obrigação de abertura de informações } \\
\text { confidenciais. }\end{array}$ & $\begin{array}{l}\text { Notificação e oportunidade para } \\
\text { comentários sobre qualquer } \\
\text { regulamentação que vier a ser criada ou } \\
\text { aplicada, além das regras gerais de } \\
\text { transparência do Capítulo } 18 .\end{array}$ \\
\hline $\begin{array}{c}\text { Tratamento nacional: } \\
\text { abrangência e } \\
\text { parâmetros } \\
\text { semelhantes ao GATS } \\
\text { (like services and like } \\
\text { services suppliers) }\end{array}$ & $\begin{array}{l}\text { Parâmetros semelhantes. [...] each } \\
\text { Party shall accord to services and } \\
\text { service suppliers of the other Party, in } \\
\text { respect of all measures affecting the } \\
\text { supply of services, treatment no less } \\
\text { favorable than that it accords to its } \\
\text { own like services and service suppliers. }\end{array}$ & $\begin{array}{l}\text { Aplicação abrangente, exceto medidas } \\
\text { não conformes, setores e serviços } \\
\text { excluídos. Parâmetros diferentes. } \\
\text { Conceito utilizado: "like circumstances". } \\
\text { "1. Each Party shall accord to service } \\
\text { suppliers of another Party treatment no } \\
\text { less favorable than that it accords, in like } \\
\text { circumstances, to its own service } \\
\text { suppliers. } \\
\text { 2. The treatment to be accorded by a } \\
\text { Party under paragraph } 1 \text { means, with } \\
\text { respect to a regional level of government, } \\
\text { treatment no less favorable than the } \\
\text { most favorable treatment accorded, in } \\
\text { like circumstances, by that regional } \\
\text { level of government to service suppliers } \\
\text { of the Party of which it forms a part." }\end{array}$ \\
\hline $\begin{array}{l}\text { Acesso a mercados: } \\
\text { abrangência e } \\
\text { parâmetros } \\
\text { semelhantes ao Art. } \\
\text { XVI do GATS }\end{array}$ & Parâmetros idênticos. & $\begin{array}{l}\text { Aplicação abrangente, exceto medidas } \\
\text { não conformes, setores e serviços } \\
\text { excluídos. Parâmetros semelhantes. } \\
\text { Exceção quanto ao GATS: não há } \\
\text { limitações à participação de capital } \\
\text { estrangeiro em termos de porcentagem } \\
\text { máxima de detenção de participação } \\
\text { societária ou de valor total do } \\
\text { investimento estrangeiro. }\end{array}$ \\
\hline $\begin{array}{c}\text { Obrigações permissivas } \\
\text { que possibilitam } \\
\text { tratamento desigual } \\
\text { entre as partes do } \\
\text { acordo } \\
\end{array}$ & $\begin{array}{l}\text { Sim. "In view of Jordan's developing } \\
\text { status, and the size of its economy and } \\
\text { resources, the United States shall } \\
\text { strive to furnish Jordan with economic } \\
\text { technical assistance, as appropriate". }\end{array}$ & Não. \\
\hline $\begin{array}{l}\text { Cláusula de nação mais } \\
\text { favorecida ratione } \\
\text { materiae et temporis }\end{array}$ & Sim. & Sim. \\
\hline $\begin{array}{l}\text { Exceções à Cláusula de } \\
\text { Nação Mais Favorecida }\end{array}$ & $\begin{array}{l}\text { Sim. A Jordânia listou as medidas que } \\
\text { não estão em conformidade, com base } \\
\text { em requisitos de reciprocidade, em seu } \\
\text { respectivo Anexo. }\end{array}$ & $\begin{array}{l}\text { Não se aplica, tendo em vista que a } \\
\text { liberalização se dá por lista negativa. As } \\
\text { partes deverão listar as medidas não } \\
\text { conformes em seus respectivos Anexos. }\end{array}$ \\
\hline
\end{tabular}




\begin{tabular}{|c|c|c|}
\hline & Acordo Estados Unidos-Jordânia & Acordo Estados Unidos-Marrocos \\
\hline $\begin{array}{l}\text { Regra de origem } \\
\text { (Denial of benefits) }\end{array}$ & Não. & $\begin{array}{l}\text { Sim, nas seguintes hipóteses: (i) o serviço } \\
\text { ser prestado por uma empresa } \\
\text { pertencente ou controlada por nacionais } \\
\text { de uma não parte, em algumas } \\
\text { circunstâncias (inexistência de relações } \\
\text { diplomáticas ou proibição de operações } \\
\text { com determinada empresa); e (ii) pode } \\
\text { ser negada a prestação a um prestador de } \\
\text { outra parte se o serviço for prestador por } \\
\text { empresa que não exerça operações } \\
\text { comerciais substanciais no território de } \\
\text { nenhuma parte que é detida ou controlada } \\
\text { por nacionais de não partes ou da parte } \\
\text { que denegar o benefício. }\end{array}$ \\
\hline $\begin{array}{l}\text { Procedimento para } \\
\text { modificação dos } \\
\text { compromissos }\end{array}$ & $\begin{array}{l}\text { Não está regulamentado. Ficou a cargo } \\
\text { do Comitê Adjunto desenvolver a } \\
\text { regulamentação a esse respeito. }\end{array}$ & $\begin{array}{l}\text { Não está regulamentado. Ficou a cargo } \\
\text { do Comitê Adjunto desenvolver a } \\
\text { regulamentação a esse respeito. }\end{array}$ \\
\hline $\begin{array}{l}\text { Procedimento para } \\
\text { futuras negociações }\end{array}$ & $\begin{array}{l}\text { Não está regulamentado. Ficou a cargo } \\
\text { do Comitê Adjunto desenvolver a } \\
\text { regulamentação a esse respeito. Há } \\
\text { apenas uma previsão para que as partes } \\
\text { se consultem periodicamente para } \\
\text { discutir questões relativas à } \\
\text { implementação do Acordo. }\end{array}$ & $\begin{array}{l}\text { Não está regulamentado. Ficou a cargo } \\
\text { do Comitê Adjunto desenvolver a } \\
\text { regulamentação a esse respeito. Há } \\
\text { apenas uma previsão para que as partes } \\
\text { se consultem anualmente para rever a } \\
\text { implementação do capítulo relativo a } \\
\text { serviços. }\end{array}$ \\
\hline $\begin{array}{l}\text { Criação de comitês } \\
\text { para supervisionar a } \\
\text { evolução do Acordo }\end{array}$ & $\begin{array}{c}\text { Criação de um Comitê Adjunto, que } \\
\text { deverá supervisionar a implementação } \\
\text { do Acordo. }\end{array}$ & $\begin{array}{l}\text { Prevê a criação de um Comitê Adjunto, } \\
\text { que deverá supervisionar a } \\
\text { implementação do Acordo. }\end{array}$ \\
\hline
\end{tabular}




\section{Tabela 11 - Acordos Estados Unidos-Omã e Estados Unidos-Peru}

\begin{tabular}{|c|c|c|}
\hline & Acordo Estados Unidos-Omã & Acordo Estados Unidos-Peru \\
\hline $\begin{array}{l}\text { Escopo do capítulo } \\
\text { sobre serviços }\end{array}$ & $\begin{array}{l}\text { Medidas adotadas ou mantidas por uma } \\
\text { parte em relação ao comércio } \\
\text { transfronteiriço de serviços por } \\
\text { prestadores estrangeiros, incluindo: (a) } \\
\text { produção, distribuição, } \\
\text { comercialização, venda e entrega de } \\
\text { um serviço; (b) compra, uso ou } \\
\text { pagamento por um serviço; (c) acesso e } \\
\text { uso de sistemas de distribuição, } \\
\text { transporte e telecomunicações e } \\
\text { serviços em conexão com a prestação } \\
\text { de um serviço; e (d) provisão de } \\
\text { "bond" ou outra forma de seguro } \\
\text { financeiro como condição para a } \\
\text { prestação de um serviço. Setores não } \\
\text { abrangidos: (a) Servços financeiros } \\
\text { definidos no artigo 12.20, exceto se o } \\
\text { serviço financeiro for fornecido por um } \\
\text { investimento coberto que não seja } \\
\text { coberto em uma instituição financeira; } \\
\text { (b) licitações governamentais; (c) } \\
\text { transporte aéreo doméstico e } \\
\text { internacional, ou serviços de apoio } \\
\text { correlatos, exceto: (i) serviços de } \\
\text { reparo e manutenção de aeronaves } \\
\text { enquanto não estiverem em serviço; (ii) } \\
\text { serviços especializados; (d) subsídios } \\
\text { ou concessões, incluindo empréstimos, } \\
\text { garantias e seguro governamentais; e } \\
\text { (e) serviços prestadores no exercício de } \\
\text { autoridade governamental. }\end{array}$ & $\begin{array}{l}\text { Medidas adotadas ou mantidas por uma } \\
\text { parte em relação ao comércio } \\
\text { transfronteiriço de serviços por } \\
\text { prestadores estrangeiros, incluindo: (a) } \\
\text { produção, distribuição, comercialização, } \\
\text { venda e entrega de um serviço; (b) } \\
\text { compra, uso ou pagamento por um } \\
\text { serviço; (c) acesso e uso de sistemas de } \\
\text { distribuição, transporte e } \\
\text { telecomunicaçôs e serviços em conexão } \\
\text { com a prestação de um serviço; (d) } \\
\text { presença no território de um prestador de } \\
\text { outra parte; e (e) provisão de "bond" ou } \\
\text { outra forma de seguro financeiro como } \\
\text { condição para a prestação de um serviço. } \\
\text { Setores não abrangidos: (a) Serviços } \\
\text { financeiros definidos no artigo 12.20, } \\
\text { exceto se o serviço financeiro for } \\
\text { fornecido por um investimento coberto } \\
\text { que não seja coberto em uma instituição } \\
\text { financeira; (b) licitações; (c) transporte } \\
\text { aéreo doméstico e internacional, ou } \\
\text { serviços de apoio correlatos, exceto: (i) } \\
\text { serviços de reparo e manutenção de } \\
\text { aeronaves enquanto não estiverem em } \\
\text { serviço; (ii) serviços especializados; (d) } \\
\text { subsídios ou concessões, incluindo } \\
\text { empréstimos, garantias e seguro } \\
\text { governamentais; e (e) serviços } \\
\text { prestadores no exercício de autoridade } \\
\text { governamental. }\end{array}$ \\
\hline $\begin{array}{l}\text { Forma de assunção dos } \\
\text { compromissos }\end{array}$ & Lista negativa. & Lista negativa \\
\hline $\begin{array}{l}\text { Modos de prestação } \\
\text { abrangidos }\end{array}$ & $\begin{array}{l}\text { Modos } 1,2,3 \text { e } 4 \text {, sendo o último } \\
\text { tratado apenas em relação a serviços } \\
\text { profissionais. }\end{array}$ & $\begin{array}{c}\text { Modos } 1,2,3 \text { e } 4 \text {, sendo o último tratado } \\
\text { apenas em relação a serviços } \\
\text { profissionais. }\end{array}$ \\
\hline $\begin{array}{c}\text { Regras sobre regulação } \\
\text { doméstica }\end{array}$ & $\begin{array}{l}\text { Regras sobre regulação doméstica } \\
\text { relativas a requisitos e procedimentos } \\
\text { de qualificação, padrões técnicos e } \\
\text { requisitos para licenças. }\end{array}$ & $\begin{array}{l}\text { Regras sobre regulação doméstica } \\
\text { relativas a requisitos e procedimentos de } \\
\text { qualificação, padrões técnicos e } \\
\text { requisitos para licenças. }\end{array}$ \\
\hline $\begin{array}{l}\text { Regras setoriais } \\
\text { específicas }\end{array}$ & $\begin{array}{l}\text { Serviços financeiros (Capítulo 12), } \\
\text { Telecomunicações (Capítulo 13) e } \\
\text { Comércio Eletrônico (Capítulo 14). O } \\
\text { capítulo sobre serviços possui um } \\
\text { anexo sobre Serviços Profissionais. }\end{array}$ & $\begin{array}{l}\text { Serviços financeiros (Capítulo 12), } \\
\text { Telecomunicações (Capítulo 14) e } \\
\text { Comércio Eletrônico (Capítulo 15). O } \\
\text { capítulo sobre serviços possui anexos } \\
\text { sobre Serviços Profissionais e Serviços } \\
\text { de Entrega Expressa. }\end{array}$ \\
\hline $\begin{array}{c}\text { Capítulo sobre } \\
\text { investimentos } \\
\text { relacionados a serviços }\end{array}$ & Sim (Capítulo 10). & Sim (Capítulo 10). \\
\hline
\end{tabular}




\begin{tabular}{|c|c|c|}
\hline & Acordo Estados Unidos-Omã & Acordo Estados Unidos-Peru \\
\hline $\begin{array}{l}\text { Regras sobre } \\
\text { transparência }\end{array}$ & $\begin{array}{l}\text { Notificação e oportunidade para } \\
\text { comentários sobre qualquer } \\
\text { regulamentação que vier a ser criada } \\
\text { ou aplicada, além das regras gerais de } \\
\text { transparência do Capítulo } 18 .\end{array}$ & $\begin{array}{l}\text { Notificação e oportunidade para } \\
\text { comentários sobre qualquer } \\
\text { regulamentação que vier a ser criada ou } \\
\text { aplicada, além das regras gerais de } \\
\text { transparência do Capítulo } 19 .\end{array}$ \\
\hline $\begin{array}{c}\text { Tratamento nacional: } \\
\text { abrangência e } \\
\text { parâmetros } \\
\text { semelhantes ao GATS } \\
\text { (like services and like } \\
\text { services suppliers) }\end{array}$ & $\begin{array}{c}\text { Aplicação abrangente, exceto medidas } \\
\text { não conformes, setores e serviços } \\
\text { excluídos. Parâmetros diferentes. } \\
\text { Conceito utilizado: "like } \\
\text { circumstances". "1. Each Party shall } \\
\text { accord to service suppliers of another } \\
\text { Party treatment no less favorable than } \\
\text { that it accords, in like circumstances, } \\
\text { to its own service suppliers. } \\
\text { 2. The treatment to be accorded by a } \\
\text { Party under paragraph } 1 \text { means, with } \\
\text { respect to a regional level of } \\
\text { government, treatment no less } \\
\text { favorable than the most favorable } \\
\text { treatment accorded, in like } \\
\text { circumstances, by that regional level } \\
\text { of government to service suppliers of } \\
\text { the Party of which it forms a part." }\end{array}$ & $\begin{array}{l}\text { Aplicação abrangente, exceto medidas } \\
\text { não conformes, setores e serviços } \\
\text { excluídos. Parâmetros diferentes. } \\
\text { Conceito utilizado: "like circumstances". } \\
\text { "1. Each Party shall accord to service } \\
\text { suppliers of another Party treatment no } \\
\text { less favorable than that it accords, in like } \\
\text { circumstances, to its own service } \\
\text { suppliers.. } \\
\text { 2. The treatment to be accorded by a } \\
\text { Party under paragraph } 1 \text { means, with } \\
\text { respect to a regional level of government, } \\
\text { treatment no less favorable than the } \\
\text { most favorable treatment accorded, in } \\
\text { like circumstances, by that regional } \\
\text { level of government to service suppliers } \\
\underline{\text { of the Party of which it forms a part." }}\end{array}$ \\
\hline $\begin{array}{l}\text { Acesso a mercados: } \\
\text { abrangência e } \\
\text { parâmetros } \\
\text { semelhantes ao Art. } \\
\text { XVI do GATS }\end{array}$ & $\begin{array}{l}\text { Aplicação abrangente, exceto medidas } \\
\text { não conformes, setores e serviços } \\
\text { excluídos. Parâmetros semelhantes. } \\
\text { Exceção quanto ao GATS: não há } \\
\text { limitações à participação de capital } \\
\text { estrangeiro em termos de porcentagem } \\
\text { máxima de detenção de participação } \\
\text { societária ou de valor total do } \\
\text { investimento estrangeiro. }\end{array}$ & $\begin{array}{l}\text { Aplicação abrangente, exceto medidas } \\
\text { não conformes, setores e serviços } \\
\text { excluídos. Parâmetros semelhantes. } \\
\text { Exceção quanto ao GATS: não há } \\
\text { limitações à participação de capital } \\
\text { estrangeiro em termos de porcentagem } \\
\text { máxima de detenção de participação } \\
\text { societária ou de valor total do } \\
\text { investimento estrangeiro. }\end{array}$ \\
\hline $\begin{array}{c}\text { Obrigações permissivas } \\
\text { que possibilitam } \\
\text { tratamento desigual } \\
\text { entre as partes do } \\
\text { acordo } \\
\end{array}$ & Não. & Não. \\
\hline $\begin{array}{c}\text { Cláusula de nação mais } \\
\text { favorecida ratione } \\
\text { materiae et temporis }\end{array}$ & Sim & Sim \\
\hline $\begin{array}{l}\text { Exceções à Cláusula de } \\
\text { Nação Mais Favorecida }\end{array}$ & $\begin{array}{l}\text { Não se aplica, tendo em vista que a } \\
\text { liberalização se dá por lista negativa. } \\
\text { As partes deverão listar as medidas não } \\
\text { conformes em seus respectivos } \\
\text { Anexos. }\end{array}$ & $\begin{array}{l}\text { Não se aplica, tendo em vista que a } \\
\text { liberalização se dá por lista negativa. As } \\
\text { partes deverão listar as medidas não } \\
\text { conformes em seus respectivos Anexos. }\end{array}$ \\
\hline $\begin{array}{l}\text { Regra de origem } \\
\text { (Denial of benefits) }\end{array}$ & $\begin{array}{l}\text { Sim, nas seguintes hipóteses: (i) o } \\
\text { serviço ser prestado por uma empresa } \\
\text { pertencente ou controlada por } \\
\text { nacionais de uma não parte, em } \\
\text { algumas circunstâncias (inexistência de } \\
\text { relações diplomáticas ou proibição de } \\
\text { operações com determinada empresa); } \\
\text { e (ii) pode ser negada a prestação a um } \\
\text { prestador de outra parte se o serviço for } \\
\text { prestador por empresa que não exerça }\end{array}$ & $\begin{array}{l}\text { Sim, nas seguintes hipóteses: (i) o serviço } \\
\text { ser prestado por uma empresa } \\
\text { pertencente ou controlada por nacionais } \\
\text { de uma não parte, em algumas } \\
\text { circunstâncias (inexistência de relações } \\
\text { diplomáticas ou proibição de operações } \\
\text { com determinada empresa); e (ii) pode } \\
\text { ser negada a prestação a um prestador de } \\
\text { outra parte se o serviço for prestador por } \\
\text { empresa que não exerça operações }\end{array}$ \\
\hline
\end{tabular}




\begin{tabular}{|c|c|c|}
\hline & Acordo Estados Unidos-Omã & Acordo Estados Unidos-Peru \\
\hline $\begin{array}{c}\text { Procedimento para } \\
\text { modificação dos } \\
\text { compromissos comerciais substanciais no } \\
\text { território de nenhuma parte que é } \\
\text { detida ou controlada por nacionais de } \\
\text { não partes ou da parte que denegar o } \\
\text { benefício. }\end{array}$ & $\begin{array}{c}\text { Não está regulamentado. Ficou a cargo } \\
\text { do Comitê Adjunto desenvolver a } \\
\text { regulamentação a esse respeito. } \\
\text { por nacionais de não partes ou da parte } \\
\text { que denegar o benefício. }\end{array}$ & $\begin{array}{c}\text { Não está regulamentado. Ficou a cargo } \\
\text { da Comissão desenvolver a } \\
\text { regulamentação a esse respeito. }\end{array}$ \\
\hline $\begin{array}{c}\text { Procedimento para } \\
\text { futuras negociações }\end{array}$ & $\begin{array}{c}\text { Não está regulamentado. Ficou a cargo } \\
\text { do Comitê Adjunto desenvolver a } \\
\text { regulamentação a esse respeito. Há } \\
\text { apenas uma previsão para que as partes } \\
\text { se consultem anualmente para discutir }\end{array}$ & $\begin{array}{c}\text { Não está regulamentado. Ficou a cargo } \\
\text { da Comissão desenvolver a } \\
\text { regulamentação a esse respeito. Há } \\
\text { apenas uma previsão para que as partes } \\
\text { se consultem anualmente para rever a } \\
\text { implementação do capítulo relativo a à implementação serviços. } \\
\text { serviços ou discutir questões de interesse } \\
\text { relacionadas a serviços. }\end{array}$ \\
\hline $\begin{array}{c}\text { Criação de comitês } \\
\text { para supervisionar a } \\
\text { evolução do Acordo }\end{array}$ & $\begin{array}{c}\text { Prevê a criação de um Comitê Adjunto, } \\
\text { que deverá supervisionar a } \\
\text { implementação do Acordo. }\end{array}$ & $\begin{array}{c}\text { Prevê a criação de uma Comissão de } \\
\text { Livre Comércio, que deverá } \\
\text { supervisionar a implementação do } \\
\text { Acordo. }\end{array}$ \\
\hline
\end{tabular}




\section{Tabela 12 - Acordos Estados Unidos-Panamá e Estados Unidos- Cingapura}

\begin{tabular}{|c|c|c|}
\hline & Acordo Estados Unidos-Panamá & Acordo Estados Unidos-Cingapura \\
\hline $\begin{array}{l}\text { Escopo do capítulo } \\
\text { sobre serviços }\end{array}$ & $\begin{array}{c}\text { Medidas adotadas ou mantidas por uma } \\
\text { parte em relação ao comércio } \\
\text { transfronteiriço de serviços por } \\
\text { prestadores estrangeiros, incluindo: (a) } \\
\text { produção, distribuição, } \\
\text { comercialização, venda e entrega de } \\
\text { um serviço; (b) compra, uso ou } \\
\text { pagamento por um serviço; (c) acesso e } \\
\text { uso de sistemas de distribuição, } \\
\text { transporte e telecomunicaçôes e } \\
\text { serviços em conexão com a prestação } \\
\text { de um serviço; (d) presença no } \\
\text { território de um prestador de outra } \\
\text { parte; e (e) provisão de "bond" ou outra } \\
\text { forma de seguro financeiro como } \\
\text { condição para a prestação de um } \\
\text { serviço. Setores não abrangidos: (a) } \\
\text { Serviços financeiros definidos no } \\
\text { artigo 12.20, exceto se o serviço } \\
\text { financeiro for fornecido por um } \\
\text { investidor da outra parte ou por } \\
\text { investimento coberto; (b) transporte } \\
\text { aéreo doméstico e internacional, ou } \\
\text { serviços de apoio correlatos, exceto: (i) } \\
\text { serviços de reparo e manutenção de } \\
\text { aeronaves enquanto não estiverem em } \\
\text { serviço; (ii) serviços especializados; (c) } \\
\text { licitações; (d) subsídios ou concessões, } \\
\text { incluindo empréstimos, garantias e } \\
\text { seguro governamentais; e (e) serviços } \\
\text { prestadores no exercício de autoridade } \\
\text { governamental. } \\
\end{array}$ & $\begin{array}{l}\text { Medidas adotadas ou mantidas por uma } \\
\text { parte em relação ao comércio } \\
\text { transfronteiriço de serviços por } \\
\text { prestadores estrangeiros, incluindo: (a) } \\
\text { produção, distribuição, comercialização, } \\
\text { venda e entrega de um serviço; (b) } \\
\text { compra, uso ou pagamento por um } \\
\text { serviço; (c) acesso e uso de sistemas de } \\
\text { distribuição, transporte e } \\
\text { telecomunicações e serviços em conexão } \\
\text { com a prestação de um serviço; e (d) } \\
\text { provisão de "bond" ou outra forma de } \\
\text { seguro financeiro como condição para a } \\
\text { prestação de um serviço. Setores não } \\
\text { abrangidos: (a) Serviços financeiros } \\
\text { definidos no artigo 10.20, exceto se o } \\
\text { serviço financeiro for fornecido por um } \\
\text { investidor ou investimento da outra parte } \\
\text { que não seja um investidor ou } \\
\text { investimento em uma instituiçãa } \\
\text { financeira; (b) licitações governamentais; } \\
\text { (c) transporte aéreo doméstico e } \\
\text { internacional, ou serviços de apoio } \\
\text { correlatos, exceto: (i) serviços de reparo e } \\
\text { manutenção de aeronaves enquanto não } \\
\text { estiverem em serviço; (ii) serviços } \\
\text { especializados; (d) subsídios ou } \\
\text { concessões, incluindo empréstimos } \\
\text { garantias e seguro governamentais; e (e) } \\
\text { serviços prestadores no exercício de } \\
\text { autoridade governamental. }\end{array}$ \\
\hline $\begin{array}{l}\text { Forma de assunção dos } \\
\text { compromissos }\end{array}$ & $\begin{array}{l}\text { Modos } 1,2,3 \text { e } 4 \text {, sendo o último } \\
\text { tratado apenas em relação a serviços } \\
\text { profissionais. }\end{array}$ & $\begin{array}{c}\text { Modos } 1,2,3 \text { e } 4 \text {, sendo o último tratado } \\
\text { apenas em relação a serviços } \\
\text { profissionais. }\end{array}$ \\
\hline $\begin{array}{l}\text { Modos de prestação } \\
\text { abrangidos }\end{array}$ & $\begin{array}{c}\text { Regras sobre regulação doméstica } \\
\text { relativas a requisitos e procedimentos } \\
\text { de qualificação, padrões técnicos e } \\
\text { requisitos de licenças. }\end{array}$ & $\begin{array}{c}\text { Regras sobre regulação doméstica } \\
\text { relativas a requisitos e procedimentos de } \\
\text { qualificação, padrões técnicos e } \\
\text { requisitos para licenças. }\end{array}$ \\
\hline $\begin{array}{c}\text { Regras sobre regulação } \\
\text { doméstica }\end{array}$ & $\begin{array}{l}\text { Regras sobre regulação doméstica } \\
\text { relativas a requisitos e procedimentos } \\
\text { de qualificação, padrões técnicos e } \\
\text { requisitos de licenças. }\end{array}$ & $\begin{array}{l}\text { Regras sobre regulação doméstica } \\
\text { relativas a requisitos e procedimentos de } \\
\text { qualificação, padrões técnicos e } \\
\text { requisitos para licenças. }\end{array}$ \\
\hline $\begin{array}{l}\text { Regras setoriais } \\
\text { específicas }\end{array}$ & $\begin{array}{l}\text { Serviços financeiros (Capítulo 12), } \\
\text { Telecomunicações (Capítulo 13) e } \\
\text { Comércio Eletrônico (Capítulo 14). O } \\
\text { capítulo sobre serviços possui um } \\
\text { anexo sobre Serviços Profissionais. }\end{array}$ & $\begin{array}{c}\text { Serviços financeiros (Capítulo 10), } \\
\text { Telecomunicações (Capítulo 9) e } \\
\text { Comércio Eletrônico (Capítulo 14). O } \\
\text { capítulo sobre serviços possui um anexo } \\
\text { sobre Serviços Profissionais. }\end{array}$ \\
\hline
\end{tabular}




\begin{tabular}{|c|c|c|}
\hline & Acordo Estados Unidos-Panamá & Acordo Estados Unidos-Cingapura \\
\hline $\begin{array}{l}\text { Capítulo sobre } \\
\text { investimentos } \\
\text { relacionados a serviços }\end{array}$ & Sim (Capítulo 10). & Sim (Capítulo 15). \\
\hline $\begin{array}{l}\text { Regras sobre } \\
\text { transparência }\end{array}$ & $\begin{array}{l}\text { Oportunidade para comentários sobre } \\
\text { qualquer regulamentação que vier a ser } \\
\text { criada ou aplicada, além das regras } \\
\text { gerais de transparência do Capítulo } 18 .\end{array}$ & $\begin{array}{l}\text { Notificação e oportunidade para } \\
\text { comentários sobre qualquer } \\
\text { regulamentação que vier a ser criada ou } \\
\text { aplicada, além das regras gerais de } \\
\text { transparência do Capítulo } 19 .\end{array}$ \\
\hline $\begin{array}{l}\text { Tratamento nacional: } \\
\text { abrangência e } \\
\text { parâmetros } \\
\text { semelhantes ao GATS } \\
\text { (like services and like } \\
\text { services suppliers) }\end{array}$ & $\begin{array}{l}\text { Aplicação abrangente, exceto medidas } \\
\text { não conformes, setores e serviços } \\
\text { excluídos. Parâmetros diferentes. } \\
\text { Conceito utilizado: "like } \\
\text { circumstances". "1. Each Party shall } \\
\text { accord to service suppliers of another } \\
\text { Party treatment no less favorable than } \\
\text { that it accords, in like circumstances, } \\
\text { to its own service suppliers. } \\
\text { 2. The treatment to be accorded by a } \\
\text { Party under paragraph } 1 \text { means, with } \\
\text { respect to a regional level of } \\
\text { government, treatment no less } \\
\text { favorable than the most favorable } \\
\text { treatment accorded, in like } \\
\text { circumstances, by that regional level } \\
\text { of government to service suppliers of } \\
\text { the Party of which it forms a part." } \\
\end{array}$ & $\begin{array}{l}\text { Aplicação abrangente, exceto medidas } \\
\text { não conformes, setores e serviços } \\
\text { excluídos. Parâmetros diferentes. } \\
\text { Conceito utilizado: "like circumstances". } \\
\text { "1. Each Party shall accord to service } \\
\text { suppliers of another Party treatment no } \\
\text { less favorable than that it accords, in like } \\
\text { circumstances, to its own service } \\
\text { suppliers. } \\
\text { 2. The treatment to be accorded by a } \\
\text { Party under paragraph } 1 \text { means, with } \\
\text { respect to a regional level of government, } \\
\text { treatment no less favorable than the } \\
\frac{\text { most favorable treatment accorded, in }}{\text { like circumstances, by that regional }} \\
\underline{\text { level of government to service suppliers }} \\
\underline{\text { of the Party of which it forms a part." }} \\
\end{array}$ \\
\hline $\begin{array}{l}\text { Acesso a mercados: } \\
\text { abrangência e } \\
\text { parâmetros } \\
\text { semelhantes ao Art. } \\
\text { XVI do GATS }\end{array}$ & $\begin{array}{l}\text { Aplicação abrangente, exceto medidas } \\
\text { não conformes, setores e serviços } \\
\text { excluídos. Parâmetros semelhantes. } \\
\text { Exceção quanto ao GATS: não há } \\
\text { limitações à participação de capital } \\
\text { estrangeiro em termos de porcentagem } \\
\text { máxima de detenção de participação } \\
\text { societária ou de valor total do } \\
\text { investimento estrangeiro. } \\
\end{array}$ & $\begin{array}{l}\text { Aplicação abrangente, exceto medidas } \\
\text { não conformes, setores e serviços } \\
\text { excluídos. Parâmetros semelhantes. } \\
\text { Exceção quanto ao GATS: não há } \\
\text { limitações à participaçã̃o de capital } \\
\text { estrangeiro em termos de porcentagem } \\
\text { máxima de detenção de participação } \\
\text { societária ou de valor total do } \\
\text { investimento estrangeiro. }\end{array}$ \\
\hline $\begin{array}{c}\text { Obrigações permissivas } \\
\text { que possibilitam } \\
\text { tratamento desigual } \\
\text { entre as partes do } \\
\text { acordo } \\
\end{array}$ & Não. & Não. \\
\hline $\begin{array}{l}\text { Cláusula de nação mais } \\
\text { favorecida ratione } \\
\text { materiae et temporis }\end{array}$ & Sim. & Sim. \\
\hline $\begin{array}{l}\text { Exceções à Cláusula de } \\
\text { Nação Mais Favorecida }\end{array}$ & $\begin{array}{l}\text { Não se aplica, tendo em vista que a } \\
\text { liberalização se dá por lista negativa. } \\
\text { As partes deverão listar as medidas não } \\
\text { conformes em seus respectivos } \\
\text { Anexos. }\end{array}$ & $\begin{array}{l}\text { Não se aplica, tendo em vista que a } \\
\text { liberalização se dá por lista negativa. As } \\
\text { partes deverão listar as medidas não } \\
\text { conformes em seus respectivos Anexos. }\end{array}$ \\
\hline $\begin{array}{l}\text { Regra de origem } \\
\text { (Denial of benefits) }\end{array}$ & $\begin{array}{l}\text { Sim, nas seguintes hipóteses: (i) o } \\
\text { serviço ser prestado por uma empresa } \\
\text { pertencente ou controlada por } \\
\text { nacionais de uma não parte, em } \\
\text { algumas circunstâncias (inexistência de } \\
\text { relações diplomáticas ou proibição de } \\
\text { operações com determinada empresa); }\end{array}$ & $\begin{array}{l}\text { Sim, nas seguintes hipóteses: (i) o serviço } \\
\text { ser prestado por uma empresa } \\
\text { pertencente ou controlada por nacionais } \\
\text { de uma não parte, em algumas } \\
\text { circunstâncias (inexistência de relações } \\
\text { diplomáticas ou proibição de operações } \\
\text { com determinada empresa); e (ii) pode }\end{array}$ \\
\hline
\end{tabular}




\begin{tabular}{|c|c|c|}
\hline & Acordo Estados Unidos-Panamá & Acordo Estados Unidos-Cingapura \\
\hline & $\begin{array}{c}\text { e (ii) o serviço for prestado por } \\
\text { empresa que não exerça operações } \\
\text { comerciais substanciais no território de } \\
\text { nenhuma parte, exceto na parte que } \\
\text { denegar o benefício, e for pertencente } \\
\text { ou controlada por pessoas de uma não } \\
\text { parte ou da parte que denegar o } \\
\text { benefício (procedimento sujeito à } \\
\text { consulta, fornecimento de informações } \\
\text { e notificação). }\end{array}$ & $\begin{array}{l}\text { ser negada a prestação a um prestador de } \\
\text { outra parte se o serviço for prestador por } \\
\text { empresa que não exerça operações } \\
\text { comerciais substanciais no território de } \\
\text { nenhuma parte que é detida ou controlada } \\
\text { por nacionais de não partes ou da parte } \\
\text { que denegar o benefício. }\end{array}$ \\
\hline $\begin{array}{l}\text { Procedimento para } \\
\text { modificação dos } \\
\text { compromissos }\end{array}$ & $\begin{array}{c}\text { Não está regulamentado. Ficou a cargo } \\
\text { da Comissão desenvolver a } \\
\text { regulamentação a esse respeito. }\end{array}$ & $\begin{array}{l}\text { Não está regulamentado. Ficou a cargo } \\
\text { do Comitê Adjunto desenvolver a } \\
\text { regulamentação a esse respeito. }\end{array}$ \\
\hline $\begin{array}{l}\text { Procedimento para } \\
\text { futuras negociações }\end{array}$ & $\begin{array}{c}\text { Não está regulamentado. Ficou a cargo } \\
\text { da Comissão desenvolver a } \\
\text { regulamentação a esse respeito. Há } \\
\text { apenas uma previsão para que as partes } \\
\text { se consultem anualmente para rever a } \\
\text { implementação do capítulo relativo a } \\
\text { serviços e discutir questões de interesse } \\
\text { mútuo. }\end{array}$ & $\begin{array}{l}\text { Não está regulamentado. Ficou a cargo } \\
\text { do Comitê Adjunto desenvolver a } \\
\text { regulamentação a esse respeito. Há } \\
\text { apenas uma previsão para que as partes } \\
\text { se consultem anualmente para rever a } \\
\text { implementação do capítulo relativo a } \\
\text { serviços e questões de interesse mútuo. }\end{array}$ \\
\hline $\begin{array}{l}\text { Criação de comitês } \\
\text { para supervisionar a } \\
\text { evolução do Acordo }\end{array}$ & $\begin{array}{l}\text { Prevê a criação de uma Comissão de } \\
\text { Livre Comércio, que deverá } \\
\text { supervisionar a implementação do } \\
\text { Acordo. }\end{array}$ & $\begin{array}{l}\text { Prevê a criação de um Comitê Adjunto, } \\
\text { que deverá supervisionar a } \\
\text { implementação do Acordo. }\end{array}$ \\
\hline
\end{tabular}




\section{ANEXO III}

ANÁLISE COMPARATIVA DAS PRINCIPAIS CLÁUSULAS SOBRE SERVIÇOS DOS ACORDOS DE LIVRE COMÉRCIO CELEBRADOS PELA UNIÃO EUROPEIA 


\section{Tabela 13 - APE UE-CARIFORUM e Acordo UE-Costa do Marfim}

\begin{tabular}{|c|c|c|}
\hline & APE UE-CARIFORUM & Acordo UE-Costa do Marfim \\
\hline $\begin{array}{l}\text { Escopo do capítulo } \\
\text { sobre serviços }\end{array}$ & $\begin{array}{l}\text { O Título II (Investimentos, Comércio } \\
\text { de Serviços e Comércio Eletrônico) } \\
\text { aborda serviços, investimentos e } \\
\text { comércio eletrônico de forma conjunta. } \\
\text { Em relação a serviços, o acordo } \\
\text { abrange as seguintes medidas: (i) } \\
\text { medidas adotadas ou mantidas por uma } \\
\text { parte na forma de lei, regulamento, } \\
\text { norma, procedimento, decisão, ato } \\
\text { administrativo ou outra forma; (ii) } \\
\text { medidas adotadas ou mantidas pelas } \\
\text { partes tomadas pelos governos ou por } \\
\text { autoridades centrais, regionais ou } \\
\text { locais; bem como medidas tomadas por } \\
\text { órgãos não governamentais agindo } \\
\text { com poderes delegados pelo governo } \\
\text { ou por autoridades centrais, regionais } \\
\text { ou locais. Não estão abrangidos pelo } \\
\text { acordo: (i) subsídios concedido por } \\
\text { uma das partes; (ii) medidas afetando e } \\
\text { entrada e a permanência de pessoas } \\
\text { físicas; (iiii) medidas afetando pessoas } \\
\text { físicas que buscam emprego, cidadania } \\
\text { ou residência; (iv) medidas que afetem } \\
\text { a presença comercial nas atividades de } \\
\text { mineração, produção ou processamento } \\
\text { de materiais nucleares; produção ou } \\
\text { comércio de armas, munições e } \\
\text { equipamento bélico; serviços } \\
\text { audiovisuais; cabotagem marítima; } \\
\text { transporte aéreo nacional ou } \\
\text { internacional e serviços diretamente } \\
\text { relacionados ao exercício de direitos de } \\
\text { tráfego (exceto manutenção e } \\
\text { reparação de aeronaves em solo, a } \\
\text { venda e a comercialização de serviços } \\
\text { de transporte aéreo; serviços de reserva } \\
\text { computadorizados e outros serviços } \\
\text { que facilitem a operação das } \\
\text { aeronaves). }\end{array}$ & $\begin{array}{l}\text { Não se aplica. O Art. } 44 \text { prevê apenas } \\
\text { que as Partes se comprometem a tomar } \\
\text { todas as medidas necessárias ou a } \\
\text { cooperar para favorecer a negociação e a } \\
\text { celebração de um Acordo de Parceria } \\
\text { Econômica global, que abranja, dentre } \\
\text { outros temas, o comércio dos serviços e o } \\
\text { comércio eletrônico. Não há menção a } \\
\text { serviços incluídos ou excluídos do } \\
\text { escopo do acordo. }\end{array}$ \\
\hline $\begin{array}{l}\text { Forma de assunção dos } \\
\text { compromissos }\end{array}$ & Lista positiva. & Não se aplica. \\
\hline $\begin{array}{l}\text { Modos de prestação } \\
\text { abrangidos }\end{array}$ & Todos (Modos 1, 2, 3 e 4). & Não se aplica. \\
\hline $\begin{array}{c}\text { Regras sobre regulação } \\
\text { doméstica }\end{array}$ & $\begin{array}{l}\text { Regras sobre regulação doméstica } \\
\text { relativas a reconhecimento mútuo, } \\
\text { transparência, procedimento para } \\
\text { autorização, como concessão de } \\
\text { licenças de funcionamento. A maior } \\
\text { parte das regras contidas neste artigo } \\
\text { trata de questões setoriais específicas, } \\
\text { relativas a telecomunicações, serviços } \\
\text { financeiros, serviços de courier, }\end{array}$ & Não há. \\
\hline
\end{tabular}




\begin{tabular}{|c|c|c|}
\hline & APE UE-CARIFORUM & Acordo UE-Costa do Marfim \\
\hline & $\begin{array}{l}\text { serviços de computação, transporte } \\
\text { marítimo e turismo. }\end{array}$ & \\
\hline $\begin{array}{l}\text { Regras setoriais } \\
\text { específicas }\end{array}$ & $\begin{array}{l}\text { Regras específicas sobre: (i) prestação } \\
\text { transfronteiriça (Capítulo 3); (ii) } \\
\text { presença temporária de pessoas físicas } \\
\text { para fins comerciais (Capítulo 4); (iii) } \\
\text { telecomunicações (Capítulo 5); (iv) } \\
\text { serviços financeiros (Capítulo 5); (v) } \\
\text { serviços de courier (Capítulo 5); (vi) } \\
\text { serviços de computação (Capítulo 5); } \\
\text { (vii) transporte marítimo (Capitulo 5); } \\
\text { (viii) turismo (Capítulo 5) ; e (ix) } \\
\text { comércio eletrônico (Capítulo 6). } \\
\text { Também há regras sobre standards } \\
\text { ambientais (Art. 116). }\end{array}$ & Não há. \\
\hline $\begin{array}{c}\text { Capítulo sobre } \\
\text { investimentos } \\
\text { relacionados a serviços }\end{array}$ & $\begin{array}{c}\text { Não há. A previsão sobre } \\
\text { investimentos encontra-se no próprio } \\
\text { capítulo referente a serviços (Título II), } \\
\text { que engloba investimentos, comércio } \\
\text { de serviços e comércio eletrônico. }\end{array}$ & Não há. \\
\hline $\begin{array}{l}\text { Regras sobre } \\
\text { transparência }\end{array}$ & $\begin{array}{l}\text { Sim. Existem regras de transparência } \\
\text { no Capítulo 5, que tratam apenas da } \\
\text { transparência na resposta aos pedidos } \\
\text { de outras partes para o fornecimento de } \\
\text { informações sobre medidas abrangidas } \\
\text { pelo acordo. Também determina que as } \\
\text { partes devem estabelecer um ou mais } \\
\text { pontos de contato (enquiry points) para } \\
\text { fornecer informações a investidores } \\
\text { estrangeiros ou prestadores de serviços } \\
\text { nacionais de outras Partes. }\end{array}$ & Não há. \\
\hline $\begin{array}{l}\text { Tratamento nacional: } \\
\text { abrangência e } \\
\text { parâmetros } \\
\text { semelhantes ao GATS } \\
\text { (like services and like } \\
\text { services suppliers) }\end{array}$ & $\begin{array}{l}\text { Há regras específicas sobre tratamento } \\
\text { nacional nos capítulos sobre presença } \\
\text { comercial (Capítulo 2) e prestação } \\
\text { transfronteiriça (Capítulo 3).1. } \\
\text { Presença Comercial: Em vez de "like } \\
\text { services and services suppliers", foi } \\
\text { utilizada a expressão "like commercial } \\
\text { presences and investors". Foi } \\
\text { adicionado um quarto parágrafo que } \\
\text { não existe no GATS, a saber: "4. } \\
\text { Specific commitments assumed under } \\
\text { this Article shall not be construed to } \\
\text { require the EC Party or the Signatory } \\
\text { CARIFORUM States to compensate for } \\
\text { inherent competitive disadvantages } \\
\text { which result from the foreign character } \\
\text { of the relevant commercial presences } \\
\text { and investors.". 2. Prestação } \\
\text { Transfronteiriça: Conceito idêntico ao } \\
\text { do GATS. Foi inserido um quarto } \\
\text { requisito, a saber: "4. Specific } \\
\text { commitments assumed under this } \\
\text { Article shall not be construed to } \\
\text { require the EC Party or the Signatory } \\
\text { CARIFORUM States to compensate for } \\
\text { inherent competitive disadvantages } \\
\end{array}$ & Não há. \\
\hline
\end{tabular}




\begin{tabular}{|c|c|c|}
\hline & APE UE-CARIFORUM & Acordo UE-Costa do Marfim \\
\hline & $\begin{array}{l}\text { which result from the foreign character } \\
\text { of the relevant services or services } \\
\text { suppliers". As limitações de tratamento } \\
\text { nacional devem ser listadas pelas } \\
\text { partes no Anexo IV. }\end{array}$ & \\
\hline $\begin{array}{l}\text { Acesso a mercados: } \\
\text { abrangência e } \\
\text { parâmetros } \\
\text { semelhantes ao Art. } \\
\text { XVI do GATS }\end{array}$ & $\begin{array}{l}\text { Há regras específicas sobre acesso a } \\
\text { mercados nos capítulos sobre presença } \\
\text { comercial (Capítulo 2) e prestação } \\
\text { transfronteiriça (Capítulo 3). } 1 . \\
\text { Presença Comercial: Parâmetros } \\
\text { quantitativos muito semelhantes } \\
\text { àqueles adotados pelo GATS, com } \\
\text { algumas diferenças. A principal delas é } \\
\text { que não há impedimento à limitação } \\
\text { em relação ao número de pessoas } \\
\text { físicas que pode ser empregada por } \\
\text { determinado prestador ou setor. } 2 . \\
\text { Prestação Transfronteiriça: Prevề } \\
\text { apenas as limitações estabelecidas nos } \\
\text { artigos XVI: (a), (b) e (c) do GATS. } \\
\text { Não foi prevista a limitação em } \\
\text { relação ao número de pessoas físicas } \\
\text { que pode ser empregada por } \\
\text { determinado prestador ou setor, ao tipo } \\
\text { de sociedade ou à participação de } \\
\text { capital ou investidores estrangeiros. As } \\
\text { limitações de acesso a mercados devem } \\
\text { ser listadas pelas partes no Anexo IV. }\end{array}$ & Não há. \\
\hline $\begin{array}{l}\text { Obrigações permissivas } \\
\text { que possibilitam } \\
\text { tratamento desigual } \\
\text { entre as partes do } \\
\text { acordo }\end{array}$ & Não há. & Não há. \\
\hline $\begin{array}{l}\text { Cláusula de nação mais } \\
\text { favorecida ratione } \\
\text { materiae et temporis }\end{array}$ & $\begin{array}{l}\text { A princípio sim, mas há a previsão de } \\
\text { que um Comitê analise se os Estados } \\
\text { podem negar-se a estender esse } \\
\text { tratamento mais favorável, além de } \\
\text { diversas exceções no Art. 70, como } \\
\text { ocorre no item 2: "2. When a Party or } \\
\text { a Signatory CARIFORUM State } \\
\text { concludes a regional economic } \\
\text { integration agreement creating an } \\
\text { internal market or requiring the parties } \\
\text { thereto to significantly approximate } \\
\text { their legislation with a view to } \\
\text { removing nondiscriminatory obstacles } \\
\text { to commercial presence and to trade in } \\
\text { services, the treatment that such Party } \\
\text { or Signatory CARIFORUM State } \\
\text { grants to commercial presences and } \\
\text { investors of third countries in sectors } \\
\text { subject to the internal market or to the } \\
\text { significant approximation of legislation } \\
\text { is not covered by the provision of } \\
\text { paragraph l". }\end{array}$ & Não há. \\
\hline
\end{tabular}




\begin{tabular}{|c|c|c|}
\hline & APE UE-CARIFORUM & Acordo UE-Costa do Marfim \\
\hline $\begin{array}{l}\text { Exceções à Cláusula de } \\
\text { Nação Mais Favorecida }\end{array}$ & Não há. & Não há. \\
\hline $\begin{array}{l}\text { Regra de origem } \\
\text { (Denial of benefits) }\end{array}$ & Não há. & Não há. \\
\hline $\begin{array}{l}\text { Procedimento para } \\
\text { modificação dos } \\
\text { compromissos }\end{array}$ & $\begin{array}{l}\text { As partes iniciarão negociações para } \\
\text { aprofundar os compromissos } \\
\text { assumidos em até } 5 \text { anos da data em } \\
\text { que o acordo entrar em vigor. Também } \\
\text { há a previsão de que as partes irão } \\
\text { revisar o framework relativo a } \\
\text { investimentos, o ambiente para } \\
\text { investimentos e seu fluxo de } \\
\text { investimentos, no mais tardar } 3 \text { anos } \\
\text { após a entrada em vigor do acordo, de } \\
\text { modo a torná-los consistentes com os } \\
\text { compromissos celebrados em acordos } \\
\text { internacionais. }\end{array}$ & $\begin{array}{l}\text { Há apenas previsão de que as Partes } \\
\text { continuem as negociações, em } \\
\text { conformidade com as disposições do } \\
\text { Acordo. }\end{array}$ \\
\hline $\begin{array}{l}\text { Procedimento para } \\
\text { futuras negociações }\end{array}$ & Não há. & $\begin{array}{l}\text { Há a previsão de constituição de um } \\
\text { Comitê responsável pela administração } \\
\text { de todos os domínios abrangidos pelo } \\
\text { acordo e a realização de todas as tarefas } \\
\text { nele mencionadas. }\end{array}$ \\
\hline $\begin{array}{l}\text { Criação de comitês } \\
\text { para supervisionar a } \\
\text { evolução do Acordo }\end{array}$ & $\begin{array}{l}\text { As partes iniciarão negociações para } \\
\text { aprofundar os compromissos } \\
\text { assumidos em até } 5 \text { anos da data em } \\
\text { que o acordo entrar em vigor. Também } \\
\text { há a previsão de que as partes irão } \\
\text { revisar o framework relativo a } \\
\text { investimentos, o ambiente para } \\
\text { investimentos e seu fluxo de } \\
\text { investimentos, no mais tardar } 3 \text { anos } \\
\text { após a entrada em vigor do acordo, de } \\
\text { modo a torná-los consistentes com os } \\
\text { compromissos celebrados em acordos } \\
\text { internacionais. }\end{array}$ & $\begin{array}{l}\text { Há apenas previsão de que as Partes } \\
\text { continuem as negociações, em } \\
\text { conformidade com as disposições do } \\
\text { Acordo. }\end{array}$ \\
\hline
\end{tabular}




\section{Tabela 14 - Acordos UE-Argélia e UE-Egito}

\begin{tabular}{|c|c|c|}
\hline & Acordo UE-Argélia & Acordo UE-Egito \\
\hline $\begin{array}{l}\text { Escopo do capítulo } \\
\text { sobre serviços }\end{array}$ & $\begin{array}{l}\text { O Título III (Comércio de Serviços) } \\
\text { aborda apenas a prestação de serviços } \\
\text { por meio de prestação transfronteiriça, } \\
\text { presença comercial ou movimento } \\
\text { pessoas físicas. Há cláusulas } \\
\text { específicas sobre serviços de } \\
\text { transportes e regulação doméstica. Não } \\
\text { estão abrangidos pelo acordo: (i) } \\
\text { serviços de transporte aéreo, fluvial, } \\
\text { terrestre e cabotagem marítima } \\
\text { nacional (exceto atividades exercidas } \\
\text { por companhias de navegação para a } \\
\text { prestação de serviços internacionais de } \\
\text { transporte marítimo). O Acordo } \\
\text { também prevê que as partes poderão } \\
\text { negociar acordos específicos sobre as } \\
\text { condições de acesso recíproco ao } \\
\text { mercado e de prestação de serviços nos } \\
\text { setores dos transportes aéreos, } \\
\text { rodoviários, ferroviários e fluviais. }\end{array}$ & $\begin{array}{l}\text { No Título III (Direito de Estabelecimento } \\
\text { e de Prestação de Serviços), as partes } \\
\text { reafirmam os compromissos assumidos } \\
\text { no GATS, especialmente no tocante ao } \\
\text { tratamento de nação mais favorecida. } \\
\text { Também estabelecem que analisarão a } \\
\text { possibilidade de alargarem o âmbito de } \\
\text { aplicação do acordo de forma a incluir o } \\
\text { direito de estabelecimento das sociedades } \\
\text { de uma das partes no território da outra } \\
\text { parte e a liberalização da prestação de } \\
\text { serviços pelas sociedades de qualquer das } \\
\text { partes aos destinatários desses serviços } \\
\text { na outra parte. Não há menção a serviços } \\
\text { incluídos ou excluídos do escopo do } \\
\text { acordo. }\end{array}$ \\
\hline $\begin{array}{l}\text { Forma de assunção dos } \\
\text { compromissos }\end{array}$ & $\begin{array}{l}\text { Não há lista. Apenas obrigações } \\
\text { genéricas sobre tratamento nacional e } \\
\text { sobre o movimento de pessoas físicas. }\end{array}$ & Não há lista. \\
\hline $\begin{array}{l}\text { Modos de prestação } \\
\text { abrangidos }\end{array}$ & Todos (Modos 1, 2, 3 e 4). & Não se aplica. \\
\hline $\begin{array}{c}\text { Regras sobre regulação } \\
\text { doméstica }\end{array}$ & $\begin{array}{c}\text { O Artigo } 35 \text { (Regulação Doméstica) } \\
\text { estabelece que as normas de regulação } \\
\text { doméstica estão sujeitas a limitações de } \\
\text { política pública, segurança e saúde. } \\
\text { Além disso, as partes podem adotar } \\
\text { medidas prudenciais para proteger a } \\
\text { estabilidade de seu sistema financeiro, } \\
\text { desde que não sejam mais restritivas do } \\
\text { que o necessário para atingir esse } \\
\text { objetivo. Quanto ao movimento de } \\
\text { pessoas naturais, as partes podem } \\
\text { adotar regulamentos e normas relatiaos } \\
\text { à entrada, estadia e condiç̃̃es de } \\
\text { trabalho, desde que sua adoção não } \\
\text { anule ou comprometa as vantagens } \\
\text { provenientes do acordo. }\end{array}$ & Não há. \\
\hline $\begin{array}{l}\text { Regras setoriais } \\
\text { específicas }\end{array}$ & Não há. & Não há. \\
\hline $\begin{array}{l}\text { Capítulo sobre } \\
\text { investimentos } \\
\text { relacionados a serviços }\end{array}$ & Não há. & Não há. \\
\hline $\begin{array}{l}\text { Regras sobre } \\
\text { transparência }\end{array}$ & Não há. & Não há. \\
\hline
\end{tabular}




\begin{tabular}{|c|c|c|}
\hline & Acordo UE-Argélia & Acordo UE-Egito \\
\hline $\begin{array}{c}\text { Tratamento nacional: } \\
\text { abrangência e } \\
\text { parâmetros } \\
\text { semelhantes ao GATS } \\
\text { (like services and like } \\
\text { services suppliers) }\end{array}$ & $\begin{array}{l}\text { Sim, apenas no que se refere a "like } \\
\text { service suppliers". Não há menção a } \\
\text { "like services". }\end{array}$ & Não há. \\
\hline $\begin{array}{c}\text { Acesso a mercados: } \\
\text { abrangência e } \\
\text { parâmetros } \\
\text { semelhantes ao Art. } \\
\text { XVI do GATS } \\
\end{array}$ & Não há. & Não há. \\
\hline $\begin{array}{c}\text { Obrigações permissivas } \\
\text { que possibilitam } \\
\text { tratamento desigual } \\
\text { entre as partes do } \\
\text { acordo }\end{array}$ & Não há. & Não há. \\
\hline $\begin{array}{l}\text { Cláusula de nação mais } \\
\text { favorecida ratione } \\
\text { materiae et temporis }\end{array}$ & $\begin{array}{c}\text { Há a previsão de extensão à Argélia } \\
\text { das concessões outorgadas pela UE no } \\
\text { âmbito do GATS. A Argélia, por sua } \\
\text { vez, se comprometeu a dar aos } \\
\text { prestadores de serviços da UE } \\
\text { tratamento nãoorável menos favorável } \\
\text { do que concede a terceiros países, nos } \\
\text { modos } 2 \text { e } 3 \text {. }\end{array}$ & Não há. \\
\hline $\begin{array}{l}\text { Exceções à Cláusula de } \\
\text { Nação Mais Favorecida }\end{array}$ & Não há. & Não há. \\
\hline $\begin{array}{c}\text { Regra de origem } \\
\text { (Denial of benefits) }\end{array}$ & Não há. & Não há. \\
\hline $\begin{array}{l}\text { Procedimento para } \\
\text { modificação dos } \\
\text { compromissos }\end{array}$ & Não há. & Não há. \\
\hline $\begin{array}{l}\text { Procedimento para } \\
\text { futuras negociações }\end{array}$ & Não há. & Não há. \\
\hline $\begin{array}{l}\text { Criação de comitês } \\
\text { para supervisionar a } \\
\text { evolução do Acordo }\end{array}$ & $\begin{array}{l}\text { O acordo estabelece que será criado } \\
\text { um Conselho de Associação, que seria } \\
\text { responsável pela análise dos problemas } \\
\text { que surjam no âmbito do acordo, bem } \\
\text { como todas as outras questões } \\
\text { bilaterais ou internacionais de interesse } \\
\text { comum. Também há a previsão de } \\
\text { criação do Comitê de Associação, } \\
\text { responsável pela gestão do acordo, sem } \\
\text { prejuízo das competências atribuídas } \\
\text { ao Conselho de Associação. }\end{array}$ & $\begin{array}{l}\text { Há a previsão de constituição de o } \\
\text { Conselho de Associação, responsável } \\
\text { pela análise dos problemas que surjam no } \\
\text { âmbito do acordo, bem como todas as } \\
\text { outras questões bilaterais ou } \\
\text { internacionais de interesse comum. } \\
\text { Também deverá ser criado um Comitê de } \\
\text { Associação, responsável pela gestão do } \\
\text { acordo, sem prejuízo das competências } \\
\text { atribuídas ao Conselho de Associação. } \\
\text {. }\end{array}$ \\
\hline
\end{tabular}




\section{Tabela 15 - Acordos UE-Camarões e UE-Egito}

\begin{tabular}{|c|c|c|}
\hline & Acordo UE-Camarões & Acordo UE-Chile \\
\hline $\begin{array}{l}\text { Escopo do capítulo } \\
\text { sobre serviços }\end{array}$ & $\begin{array}{l}\text { No Título IV (Estabelecimento, } \\
\text { Comércio de Serviços e Comércio } \\
\text { Eletrônico), as Partes reiteram seus } \\
\text { compromissos no âmbito do GATS e } \\
\text { comprometem-se a alargar o âmbito de } \\
\text { aplicação do acordo, negociando as } \\
\text { disposições necessárias para a } \\
\text { liberalização progressiva, assimétrica e } \\
\text { recíproca do estabelecimento e do } \\
\text { comércio dos serviços. Não há menção } \\
\text { a serviços incluídos ou excluídos do } \\
\text { escopo do acordo. }\end{array}$ & $\begin{array}{l}\text { O Título III (Comércio em Serviços e } \\
\text { Estabelecimento) regula a liberalização } \\
\text { do comércio de serviços entre as partes e } \\
\text { incide sobre medidas adotadas ou } \\
\text { mantidas por uma parte do acordo em } \\
\text { relação ao comércio de serviços. Não } \\
\text { estão abrangidos pelo capítulo: (i) } \\
\text { serviços financeiros, que estão regulados } \\
\text { em um capítulo distinto (Capítulo II); (ii) } \\
\text { serviços audiovisuais; (iii) serviços de } \\
\text { cabotagem marítima nacional; (iv) } \\
\text { serviços de transporte aéreo, incluindo } \\
\text { serviços de transporte aéreo nacionais e } \\
\text { internacionais, regulares ou não, e os } \\
\text { serviços diretamente relacionados ao } \\
\text { exercício dos direitos de tráfego aéreo } \\
\text { (exceto reparação e manutenção de } \\
\text { aeronaves; venda e comercialização de } \\
\text { serviços de transporte aéreo; e sistemas } \\
\text { informatizados de reserva); e (v) } \\
\text { subsídios concedidos por uma parte. }\end{array}$ \\
\hline $\begin{array}{c}\text { Forma de assunção dos } \\
\text { compromissos }\end{array}$ & Não há lista. & Lista positiva. \\
\hline $\begin{array}{l}\text { Modos de prestação } \\
\text { abrangidos }\end{array}$ & Não se aplica. & Todos (Modos 1, 2, 3 e 4). \\
\hline $\begin{array}{c}\text { Regras sobre regulação } \\
\text { doméstica }\end{array}$ & Não há. & $\begin{array}{l}\text { Regras sobre regulação doméstica sobre } \\
\text { requisitos e procedimentos para } \\
\text { licenciamento e certificação similares às } \\
\text { do GATS. Também há a previsão de } \\
\text { realização de consultas para a exclusão } \\
\text { do requerimento de cidadania ou } \\
\text { residência permanente para } \\
\text { licenciamento ou certificação. }\end{array}$ \\
\hline $\begin{array}{l}\text { Regras setoriais } \\
\text { específicas }\end{array}$ & Não há. & $\begin{array}{l}\text { Regras especificas para os seguinte } \\
\text { setores de serviços: (i) comércio } \\
\text { eletrônico (Artigos 104 e 105); (ii) } \\
\text { transporte marítimo (Artigos 106 a 108); } \\
\text { (iii) telecomunicações (Artigos 109 a } \\
\text { 115); e (iv) serviços financeiros (Capítulo } \\
\text { II - Artigos 116 a 129. }\end{array}$ \\
\hline $\begin{array}{l}\text { Capítulo sobre } \\
\text { investimentos } \\
\text { relacionados a serviços }\end{array}$ & Não há. & Não há. \\
\hline $\begin{array}{l}\text { Regras sobre } \\
\text { transparência }\end{array}$ & Não há. & Não há. \\
\hline $\begin{array}{l}\text { Tratamento nacional: } \\
\text { abrangência e } \\
\text { parâmetros } \\
\text { semelhantes ao GATS } \\
\text { (like services and like } \\
\text { services suppliers) }\end{array}$ & Não há. & $\begin{array}{l}\text { Sim, idêntico ao GATS. "Each Party } \\
\text { shall grant to services and service } \\
\text { suppliers of the other Party, in respect of } \\
\text { all measures affecting the supply of } \\
\text { services, treatment no less favourable } \\
\text { than that it accords to its own like } \\
\text { services and services suppliers". }\end{array}$ \\
\hline
\end{tabular}




\begin{tabular}{|c|c|c|}
\hline & Acordo UE-Camarões & Acordo UE-Chile \\
\hline $\begin{array}{l}\text { Acesso a mercados: } \\
\text { abrangência e } \\
\text { parâmetros } \\
\text { semelhantes ao Art. } \\
\text { XVI do GATS }\end{array}$ & Não há. & Sim. Parâmetros idênticos ao do GATS. \\
\hline $\begin{array}{c}\text { Obrigações permissivas } \\
\text { que possibilitam } \\
\text { tratamento desigual } \\
\text { entre as partes do } \\
\text { acordo } \\
\end{array}$ & Não há. & Não há. \\
\hline $\begin{array}{l}\text { Cláusula de nação mais } \\
\text { favorecida ratione } \\
\text { materiae et temporis }\end{array}$ & Não há. & Não há. \\
\hline $\begin{array}{l}\text { Exceções à Cláusula de } \\
\text { Nação Mais Favorecida }\end{array}$ & Não há. & $\begin{array}{l}\text { Sim. As medidas devem ser listadas no } \\
\text { Anexo VII. }\end{array}$ \\
\hline $\begin{array}{l}\text { Regra de origem } \\
\text { (Denial of benefits) }\end{array}$ & Não há. & Não há. \\
\hline $\begin{array}{l}\text { Procedimento para } \\
\text { modificação dos } \\
\text { compromissos }\end{array}$ & Não há. & $\begin{array}{l}\text { O Comitê de Associação analisará o } \\
\text { funcionamento do capítulo relativo a } \\
\text { serviços de três em três anos, } \\
\text { apresentando propostas ao Conselho de } \\
\text { Associação. } \\
\text {. }\end{array}$ \\
\hline $\begin{array}{l}\text { Procedimento para } \\
\text { futuras negociações }\end{array}$ & $\begin{array}{l}\text { Há previsão de que as partes devem } \\
\text { prosseguir as negociações em } \\
\text { conformidade com os calendários } \\
\text { definidos no acordo, no âmbito das } \\
\text { estruturas de negociação existentes. }\end{array}$ & $\begin{array}{l}\text { Há a previsão de que, três anos após a } \\
\text { entrada em vigor do acordo, as partes } \\
\text { procederão a um reexame do capítulo } \\
\text { relativo a serviços, com o objetivo de } \\
\text { aprofundar a liberalização e reduzir ou } \\
\text { eliminar as restrições ainda existentes. }\end{array}$ \\
\hline $\begin{array}{l}\text { Criação de comitês } \\
\text { para supervisionar a } \\
\text { evolução do Acordo }\end{array}$ & $\begin{array}{c}\text { O acordo prevê a criação de um } \\
\text { Comitê responsável pela administração } \\
\text { de todos os domínios abrangidos pelo } \\
\text { acordo e a realização de todas as } \\
\text { tarefas nele mencionadas. }\end{array}$ & $\begin{array}{l}\text { O acordo prevê a criação de um Conselho } \\
\text { de Associação, que acompanhará a } \\
\text { aplicação do acordo, analisará todas as } \\
\text { questões importantes suscitadas no } \\
\text { âmbito do acordo, todas as outras } \\
\text { questões bilaterais, multilaterais ou } \\
\text { internacionais; de interesse comum, e as } \\
\text { propostas e recomendações formuladas } \\
\text { pelas partes tendo em vista a melhoria do } \\
\text { acordo. Também prevê a criação do } \\
\text { Comitê de Associação, que será } \\
\text { responsável pela aplicação global do } \\
\text { acordo e assistido no desempenho das } \\
\text { suas atribuições pelos Comitês Especiais } \\
\text { Parlamentar, Misto e de Serviços } \\
\text { Financeiros. } \\
\end{array}$ \\
\hline
\end{tabular}




\section{Tabela 16 - Acordos UE-Israel e UE-Jordânia}

\begin{tabular}{|c|c|c|}
\hline & Acordo UE-Israel & Acordo UE-Jordânia \\
\hline $\begin{array}{l}\text { Escopo do capítulo } \\
\text { sobre serviços }\end{array}$ & $\begin{array}{c}\text { No Título III (Direito de } \\
\text { Estabelecimento e Prestação de } \\
\text { Serviços), as partes acordam em } \\
\text { alargar o âmbito de aplicação do } \\
\text { acordo de forma a incluir o direito de } \\
\text { estabelecimento das empresas de uma } \\
\text { parte no território da outra parte e a } \\
\text { liberalização da prestação de serviços } \\
\text { pelas empresas de uma parte aos } \\
\text { destinatários de serviços da outra parte. }\end{array}$ & $\begin{array}{l}\text { O Título III (Direito de Estabelecimento } \\
\text { e Serviços) prevê obrigações de } \\
\text { tratamento nacional e de nação mais } \\
\text { favorecida à União Europeia em relação } \\
\text { às empresas da Jordânia sediadas em seus } \\
\text { Estados Membros, com exclusão de } \\
\text { serviços de transporte aéreo, navegação } \\
\text { de cabotagem e transporte marítimo. } \\
\text { Também estabelece que as partes } \\
\text { envidarão esforços para permitir } \\
\text { progressivamente a prestação } \\
\text { transfronteiriça de serviços por empresas } \\
\text { da União Europeia ou Jordânia, com } \\
\text { exceção de serviços de transporte aéreo, } \\
\text { terrestre, ferroviário e de cabotagem, que } \\
\text { devem estar sujeitos a um acordo } \\
\text { específico, e serviços exercidos por } \\
\text { autoridades públicas. O Acordo também } \\
\text { prevê no Capítulo } 3 \text { que as partes } \\
\text { comprometem-se a ter em consideração a } \\
\text { possibilidade de alargar o Título III, a fim } \\
\text { de estabelecer um acordo de integração } \\
\text { econômica, na acepção do Artigo V do } \\
\text { GATS. }\end{array}$ \\
\hline $\begin{array}{c}\text { Forma de assunção dos } \\
\text { compromissos }\end{array}$ & Não há lista. & Não há lista. \\
\hline $\begin{array}{c}\text { Modos de prestação } \\
\text { abrangidos }\end{array}$ & Não se aplica. & Modos 1,2 e 3. \\
\hline $\begin{array}{c}\text { Regras sobre regulação } \\
\text { doméstica }\end{array}$ & Não há. & $\begin{array}{l}\text { O Artigo } 42 \text { estabelecem que nada no } \\
\text { acordo poderá impedir que as partes } \\
\text { regulem a entrada, estadia, trabalho, } \\
\text { condições de trabalho e estabelecimento } \\
\text { de pessoas físicas e a prestação de } \\
\text { serviços, desde que não prejudiquem os } \\
\text { anulem os benefícios do Acordo e } \\
\text { observadas as limitações de política } \\
\text { pública, segurança e saúde. }\end{array}$ \\
\hline $\begin{array}{l}\text { Regras setoriais } \\
\text { específicas }\end{array}$ & Não há. & $\begin{array}{l}\text { Há regras sobre: (i) transporte (ii) } \\
\text { pagamentos e movimento de capitais;(iii) } \\
\text { direito de estabelecimento. Há também o } \\
\text { Título VI, que prevê regras de } \\
\text { cooperação econômica relacionadas a: (i) } \\
\text { promoção e proteção de investimentos } \\
\text { (Artigo 67); (ii) serviços financeiros } \\
\text { (Artigo 70); (iii) transportes (Artigo 72); } \\
\text { (iv) telecomunicações e tecnologias da } \\
\text { informação (Artigo 73); (v) energia } \\
\text { (Artigo 74); (vi) turismo (Artigo 75). }\end{array}$ \\
\hline $\begin{array}{c}\text { Capítulo sobre } \\
\text { investimentos } \\
\text { relacionados a serviços }\end{array}$ & Não há. & Não há. \\
\hline $\begin{array}{l}\text { Regras sobre } \\
\text { transparência }\end{array}$ & Não há. & Não há. \\
\hline
\end{tabular}




\begin{tabular}{|c|c|c|}
\hline & Acordo UE-Israel & Acordo UE-Jordânia \\
\hline $\begin{array}{c}\text { Tratamento nacional: } \\
\text { abrangência e } \\
\text { parâmetros } \\
\text { semelhantes ao GATS } \\
\text { (like services and like } \\
\text { services suppliers) }\end{array}$ & Não há. & $\begin{array}{l}\text { Sim, apenas no que se refere a "like } \\
\text { service suppliers" (no caso, "like } \\
\text { Community company" / like branches of } \\
\text { companies of any suppliers with which } \\
\text { the service seller has established } \\
\text { third country"). Não há menção a "like } \\
\text { services". Obrigações apenas para modo } \\
\text { 3. Há Anexos em que as Partes } \\
\text { relacionaram os setores e operações a que } \\
\text { não se aplicam as obrigações de } \\
\text { tratamento nacional. O Art. } 39 \text { contém } \\
\text { obrigações específicas para o setor de } \\
\text { transporte marítimo, a saber: "Each Party } \\
\text { shall grant, inter alia, a treatment no less } \\
\text { favourable than that accorded to its own } \\
\text { ships, for the ships used for the transport } \\
\text { of goods, passengers or both, and } \\
\text { operated by nationals or companies of } \\
\text { the other Party, with respect to access to } \\
\text { ports, the use of infrastructure and } \\
\text { auxiliary maritime services of those } \\
\text { ports, as well as related fees and } \\
\text { charges, customs facilities and the } \\
\text { assignment of berths and facilities or } \\
\text { loading and unloading". }\end{array}$ \\
\hline $\begin{array}{l}\text { Acesso a mercados: } \\
\text { abrangência e } \\
\text { parâmetros } \\
\text { semelhantes ao Art. } \\
\text { XVI do GATS }\end{array}$ & Não há. & Não há. \\
\hline $\begin{array}{l}\text { Obrigações permissivas } \\
\text { que possibilitam } \\
\text { tratamento desigual } \\
\text { entre as partes do } \\
\text { acordo }\end{array}$ & Não há. & Não há. \\
\hline $\begin{array}{l}\text { Cláusula de nação mais } \\
\text { favorecida ratione } \\
\text { materiae et temporis }\end{array}$ & Não há. & $\begin{array}{c}\text { Com relação ao direito de } \\
\text { estabelecimento, o acordo prevê que a } \\
\text { União Europeia deverá estender às } \\
\text { empresas da Jordânia o tratamento dado a } \\
\text { terceiros países. }\end{array}$ \\
\hline $\begin{array}{l}\text { Exceções à Cláusula de } \\
\text { Nação Mais Favorecida }\end{array}$ & Não há. & $\begin{array}{l}\text { As reservas relacionadas ao tratamento } \\
\text { nacional para estabelecimento estão } \\
\text { descritas nos Anexos V e VI. }\end{array}$ \\
\hline $\begin{array}{l}\text { Regra de origem } \\
\text { (Denial of benefits) }\end{array}$ & Não há. & Não há. \\
\hline $\begin{array}{l}\text { Procedimento para } \\
\text { modificação dos } \\
\text { compromissos }\end{array}$ & Não há. & $\begin{array}{l}\text { O Conselho de Associação fará as } \\
\text { recomendações necessárias para a } \\
\text { liberalização do comércio de serviços } \\
\text { (Artigo 37). }\end{array}$ \\
\hline
\end{tabular}




\begin{tabular}{|c|c|c|}
\hline & Acordo UE-Israel & Acordo UE-Jordânia \\
\hline $\begin{array}{l}\text { Procedimento para } \\
\text { futuras negociações }\end{array}$ & $\begin{array}{l}\text { O acordo prevê que a liberalização do } \\
\text { comércio de serviços será objeto de } \\
\text { análise pelo Conselho de Associação, } \\
\text { no mais tardar, três anos após sua } \\
\text { entrada em vigor. }\end{array}$ & $\begin{array}{l}\text { Há apenas uma previsão de que as Partes } \\
\text { podem negociar, quando adequado, } \\
\text { acordos especiais sobre as condições de } \\
\text { acesso recíproco ao mercado e prestação } \\
\text { de serviços de transporte rodoviário, } \\
\text { ferroviário, por vias navegáveis interiores } \\
\text { e, eventualmente, aéreo. }\end{array}$ \\
\hline $\begin{array}{l}\text { Criação de comitês } \\
\text { para supervisionar a } \\
\text { evolução do Acordo }\end{array}$ & $\begin{array}{l}\text { Há a previsão de criação do Conselho } \\
\text { de Associação, responsável pela } \\
\text { analise de quaisquer assuntos } \\
\text { importantes que surjam no âmbito do } \\
\text { acordo, bem como todas as outras } \\
\text { questões bilaterais ou internacionais de } \\
\text { interesse mútuo. Também está previsto } \\
\text { um Comité de Associação responsável } \\
\text { pela execução do acordo, sob reserva } \\
\text { das competências atribuídas ao } \\
\text { Conselho de Associação, e que poderá } \\
\text { constituir grupos de trabalho ou órgãos } \\
\text { necessários para a execução do acordo. }\end{array}$ & $\begin{array}{c}\text { O acordo estabelece a criação do } \\
\text { Conselho de Associação, responsável } \\
\text { pela análise dos problemas que surjam no } \\
\text { âmbito do mesmo, bem como todas as } \\
\text { outras questões bilaterais ou } \\
\text { internacionais de interesse comum. } \\
\text { Também foi prevista a criação do Comitê } \\
\text { de Associação, responsável pela gestão } \\
\text { do acordo, sem prejuízo das } \\
\text { competências atribuídas ao Conselho de } \\
\text { Associação, e que poderá criar um grupo } \\
\text { de trabalho ou órgão necessário para a } \\
\text { aplicação do acordo. }\end{array}$ \\
\hline
\end{tabular}




\section{Tabela 17 - ALC UE-Coreia e Acordo UE-México}

\begin{tabular}{|c|c|c|}
\hline & ALC UE-Coreia & Acordo UE-México \\
\hline $\begin{array}{l}\text { Escopo do capítulo } \\
\text { sobre serviços }\end{array}$ & $\begin{array}{c}\text { O Capítulo } 7 \text { (Prestação } \\
\text { Transfronteiriça de Serviços, } \\
\text { Estabelecimento e Comércio } \\
\text { Eletrônico) é aplicável às medidas } \\
\text { adotadas por uma parte que afetem o } \\
\text { comércio de serviços. No que se refere } \\
\text { à prestação transfronteiriça, estão } \\
\text { excluídos da abrangência do acordo: (i) } \\
\text { serviços audiovisuais; (ii) cabotagem } \\
\text { marítima nacional; (iii) serviços de } \\
\text { transporte aéreo nacional ou } \\
\text { internacional diretamente relacionados } \\
\text { ao exercício de direitos de tráfico aéreo } \\
\text { (exceto manutenção e reparação de } \\
\text { aeronaves, venda e a comercialização } \\
\text { de serviços de transporte aéreo; } \\
\text { serviços de reserva computadorizada e } \\
\text { outros serviços complementares). As } \\
\text { disposições do Capítulo } 7 \text { também não } \\
\text { se aplicam a: (i) licitações públicas; (ii) } \\
\text { subsídios e subvenções (garantias, } \\
\text { seguros e empréstimos); (iii) medidas } \\
\text { que afetem pessoas físicas que } \\
\text { pretendam entrar no mercado de } \\
\text { trabalho de uma Parte; (iv) medidas } \\
\text { referentes à cidadania, residência ou } \\
\text { emprego permanente; e (v) serviços } \\
\text { prestados no exercício da autoridade } \\
\text { governamental. }\end{array}$ & $\begin{array}{l}\text { No Título III (Comércio de Serviços) está } \\
\text { previsto que o Conselho Conjunto do } \\
\text { acordo decidirá no formato dos } \\
\text { compromissos com vistas à liberalização } \\
\text { progressiva e recíproca do comércio de } \\
\text { serviços entre as partes, levando em } \\
\text { consideração os compromissos já } \\
\text { assumidos por elas no âmbito do GATS. }\end{array}$ \\
\hline $\begin{array}{c}\text { Forma de assunção dos } \\
\text { compromissos }\end{array}$ & Lista positiva. & Não há lista. \\
\hline $\begin{array}{c}\text { Modos de prestação } \\
\text { abrangidos }\end{array}$ & $\begin{array}{l}\text { Todos (Modos } 1,2,3 \text { e 4). Note-se que } \\
\text { a seção D, intitulada "Presença } \\
\text { temporária de pessoas naturais para } \\
\text { negócios", regula o modo } 4 \text { de } \\
\text { prestação de serviço. No entanto, não } \\
\text { há compromissos efetivos nesse modo, } \\
\text { apenas a menção de que o Comitê de } \\
\text { Comércio adotará lista de } \\
\text { compromissos sobre o acesso de } \\
\text { contratual de prestadores de serviços e } \\
\text { profissionais liberais de uma Parte ao } \\
\text { território da outra Parte, o que levará } \\
\text { em conta os resultados dessas } \\
\text { negociações no âmbito do GATS. }\end{array}$ & Não se aplica. \\
\hline $\begin{array}{c}\text { Regras sobre regulação } \\
\text { doméstica }\end{array}$ & $\begin{array}{l}\text { Sim (Artigo 7.23). As regras sobre } \\
\text { regulamentação interna falam sobre } \\
\text { autorização para prestação de um } \\
\text { serviço; existência de tribunais } \\
\text { (judiciais, arbitrais ou administrativos) } \\
\text { que posam rever as decisões a respeito } \\
\text { de autorizações; transparência e direito } \\
\text { de regulamentar a prestação de } \\
\text { serviços no que tange a qualificações, }\end{array}$ & Não há. \\
\hline
\end{tabular}




\begin{tabular}{|c|c|c|}
\hline & ALC UE-Coreia & Acordo UE-México \\
\hline & $\begin{array}{c}\text { normas técnicas e os requisitos em } \\
\text { matéria de concessão de licenças. Há } \\
\text { também previsão de as Partes tem o } \\
\text { direito de regulamentar a admissão ou } \\
\text { a permanência temporária de pessoas } \\
\text { físicas no seu território (incluindo } \\
\text { medidas necessárias para proteger a } \\
\text { integridade } \\
\text { das suas fronteiras e assegurar ordem } \\
\text { na travessia de pessoas físicas). }\end{array}$ & \\
\hline $\begin{array}{l}\text { Regras setoriais } \\
\text { específicas }\end{array}$ & $\begin{array}{l}\text { Regras específicas sobre: (i) serviços } \\
\text { de informática (Subseção B, Capítulo } \\
\text { 7); (ii) serviços postais e courier } \\
\text { (Subseção C, Capítulo 7); (iii) } \\
\text { telecomunicações (Subseção D, } \\
\text { Capítulo 7); (iv) serviços financeiros } \\
\text { (Subseção E, Capítulo 7);(v) transporte } \\
\text { marítimo internacional (Subseção F, } \\
\text { Capítulo 7); e (vi) comércio eletrônico } \\
\text { (Seção F, Capítulo 7). }\end{array}$ & $\begin{array}{c}\text { Há a previsão de cooperação com relação } \\
\text { a serviços financeiros (Artigo 16). }\end{array}$ \\
\hline $\begin{array}{c}\text { Capítulo sobre } \\
\text { investimentos } \\
\text { relacionados a serviços }\end{array}$ & $\begin{array}{l}\text { Não há. A previsão sobre } \\
\text { investimentos encontra-se no próprio } \\
\text { capítulo referente a serviços (Artigo } \\
7.16 \text { ). }\end{array}$ & Não há. \\
\hline $\begin{array}{l}\text { Regras sobre } \\
\text { transparência }\end{array}$ & $\begin{array}{l}\text { Sim. Determinam que as partes } \\
\text { respondam prontamente pedidos de } \\
\text { informação a respeito de: (i) normas e } \\
\text { acordos internacionais, incluindo } \\
\text { reconhecimento mútuo; e (ii) normas e } \\
\text { critérios de licenciamento e } \\
\text { certificação de prestadores de serviços. } \\
\text { Também há regras sobre: (i) } \\
\text { confidencialidade de informaçães; (ii) } \\
\text { publicidade das exigências de } \\
\text { preenchimento dos pedidos de } \\
\text { prestação de serviços; e (iii) } \\
\text { procedimentos para decisão a respeito } \\
\text { de pedido de prestação de serviços. }\end{array}$ & Não há. \\
\hline $\begin{array}{c}\text { Tratamento nacional: } \\
\text { abrangência e } \\
\text { parâmetros } \\
\text { semelhantes ao GATS } \\
\text { (like services and like } \\
\text { services suppliers) }\end{array}$ & $\begin{array}{l}\text { Sim, idêntico ao GATS com relação à } \\
\text { prestação transfronteiriça. "Each Party } \\
\text { shall accord to services and service } \\
\text { suppliers of the other Party, in respect } \\
\text { of all measures affecting the cross- } \\
\text { border supply of services, treatment no } \\
\text { less favourable than that it accords to } \\
\text { its own like services and service } \\
\text { suppliers". Com relação a } \\
\text { estabelecimento, é utilizado o mesmo } \\
\text { critério, mas utiliza-se como referência } \\
\text { "estabelecimentos e investidores } \\
\text { similares": "In the sectors inscribed in } \\
\text { Annex 7-A, and subject to any } \\
\text { conditions and qualifications set out } \\
\text { therein, with respect to all measures } \\
\text { affecting establishment, each Party } \\
\text { shall accord to establishments and } \\
\text { investors of the other Party treatment }\end{array}$ & Não há. \\
\hline
\end{tabular}




\begin{tabular}{|c|c|c|}
\hline & ALC UE-Coreia & Acordo UE-México \\
\hline & $\begin{array}{c}\text { no less favourable than that it accords } \\
\text { to its own like establishments and } \\
\text { investors. Além disso, foi adicionado } \\
\text { um quarto parágrafo que não existe no } \\
\text { GATS, a saber: "4. Specific } \\
\text { commitments assumed under this } \\
\text { Article shall not be construed to } \\
\text { require any Party to compensate for } \\
\text { inherent competitive disadvantages } \\
\text { which result from the foreign character } \\
\text { of the relevant establishment or } \\
\text { investors." }\end{array}$ & \\
\hline $\begin{array}{l}\text { Acesso a mercados: } \\
\text { abrangência e } \\
\text { parâmetros } \\
\text { semelhantes ao Art. } \\
\text { XVI do GATS }\end{array}$ & $\begin{array}{c}\text { Com relação à prestação } \\
\text { transfronteiriça de serviços, foram } \\
\text { replicadas apenas as alíneas (a), (b) e } \\
\text { (c) do Art. XVI do GATS. Já com } \\
\text { relação a estabelecimento, os } \\
\text { parâmetros se assemelham às alíneas } \\
\text { (a) a (f) do Artigo XVI do GATS, com } \\
\text { algumas adaptações em razão da } \\
\text { especificidade dos serviços a que se } \\
\text { referem. }\end{array}$ & Não há. \\
\hline $\begin{array}{l}\text { Obrigações permissivas } \\
\text { que possibilitam } \\
\text { tratamento desigual } \\
\text { entre as partes do } \\
\text { acordo }\end{array}$ & Não há. & Não há. \\
\hline $\begin{array}{l}\text { Cláusula de nação mais } \\
\text { favorecida ratione } \\
\text { materiae et temporis }\end{array}$ & $\begin{array}{c}\text { Sim, há a previsão de extensão, por } \\
\text { uma parte do acordo do tratamento } \\
\text { mais favorável dado a terceiros aos } \\
\text { serviços e prestadores de serviços da } \\
\text { outra parte. Não se refere a novas } \\
\text { concessões, mas àquelas que estiverem } \\
\text { em vigor quando o Acordo entrar em } \\
\text { vigor. No entanto, foram excluídos } \\
\text { setores em que há compromissos } \\
\text { setoriais ou horizontais decorrentes de } \\
\text { acordos regionais que são muito mais } \\
\text { abrangentes do que aqueles decorrentes } \\
\text { do presente Acordo, conforme consta } \\
\text { do Anexo 7-B. }\end{array}$ & Não há. \\
\hline $\begin{array}{l}\text { Exceções à Cláusula de } \\
\text { Nação Mais Favorecida }\end{array}$ & $\begin{array}{l}\text { Sim. As medidas devem ser listadas no } \\
\text { Anexo 7-C. }\end{array}$ & Não há. \\
\hline $\begin{array}{c}\text { Regra de origem } \\
\text { (Denial of benefits) }\end{array}$ & Não há. & Não há. \\
\hline $\begin{array}{l}\text { Procedimento para } \\
\text { modificação dos } \\
\text { compromissos }\end{array}$ & $\begin{array}{c}\text { O Comitê de Comércio pode } \\
\text { considerar alterações no Acordo ou } \\
\text { alterar disposições do mesmo nos casos } \\
\text { nele especificamente previstos. }\end{array}$ & Não há. \\
\hline
\end{tabular}




\begin{tabular}{|c|c|c|}
\hline & ALC UE-Coreia & Acordo UE-México \\
\hline $\begin{array}{l}\text { Procedimento para } \\
\text { futuras negociações }\end{array}$ & Não há. & $\begin{array}{l}\text { O Conselho Conjunto decidirá sobre o } \\
\text { regime adequado aplicável à liberalização } \\
\text { progressiva e recíproca do comércio de } \\
\text { serviços, em conformidade com as regras } \\
\text { aplicáveis da OMC, nomeadamente o } \\
\text { artigo V do GATS, tendo em conta os } \\
\text { compromissos já assumidos por ambas as } \\
\text { Partes no âmbito desse acordo. }\end{array}$ \\
\hline $\begin{array}{l}\text { Criação de comitês } \\
\text { para supervisionar a } \\
\text { evolução do Acordo }\end{array}$ & $\begin{array}{l}\text { O Comitê do Comércio de Serviços, } \\
\text { Estabelecimento e Comércio } \\
\text { Eletrônico será responsável pela } \\
\text { supervisão, avaliação e aplicação do } \\
\text { capítulo referente a serviços; exame de } \\
\text { questões apresentadas pelas Partes; e } \\
\text { promoverá a troca de informações, no } \\
\text { caso de tomada de medidas } \\
\text { prudenciais. Está subordinado ao } \\
\text { Comitê de Comércio, responsável por } \\
\text { garantir o funcionamento do Acordo e } \\
\text { supervisionar sua aplicação. }\end{array}$ & $\begin{array}{l}\text { O acordo prevê a criação do Conselho } \\
\text { Conjunto, que fiscalizará a aplicação do } \\
\text { acordo e analisará todas as questões } \\
\text { importantes suscitadas e quaisquer outras } \\
\text { questões bilaterais ou internacionais de } \\
\text { interesse comum. Também prevê a } \\
\text { criação de um Comitê Misto, que } \\
\text { assistirá o Conselho Conjunto no } \\
\text { desempenho de suas funções. }\end{array}$ \\
\hline
\end{tabular}




\section{Tabela 18 - Acordos UE-Marrocos e UE-África do Sul}

\begin{tabular}{|c|c|c|}
\hline & Acordo UE-Marrocos & Acordo UE-África do Sul \\
\hline $\begin{array}{l}\text { Escopo do capítulo } \\
\text { sobre serviços }\end{array}$ & $\begin{array}{c}\text { O Título III (Direito de } \\
\text { Estabelecimento e Serviços) prevê } \\
\text { apenas que as partes acordam em } \\
\text { alargar o âmbito de aplicação do } \\
\text { presente acordo de forma a incluir o } \\
\text { direito de estabelecimento das } \\
\text { sociedades de uma parte no território } \\
\text { da outra parte e a liberalização da } \\
\text { prestação de serviços pelas sociedades } \\
\text { de uma parte aos destinatários de } \\
\text { serviços da outra parte. }\end{array}$ & $\begin{array}{l}\text { Na Seção B (Direito de Estabelecimento } \\
\text { e Prestação de Serviços), as partes } \\
\text { reafirmam os compromissos assumidos } \\
\text { no âmbito do GATS e se comprometem a } \\
\text { envidar melhores esforços para estender } \\
\text { o escopo do acordo a serviços. }\end{array}$ \\
\hline $\begin{array}{c}\text { Forma de assunção dos } \\
\text { compromissos }\end{array}$ & Não há lista. & Não há lista. \\
\hline $\begin{array}{l}\text { Modos de prestação } \\
\text { abrangidos }\end{array}$ & Não se aplica. & $\begin{array}{l}\text { Previsão de que os compromissos futuros } \\
\text { abranjam todos os modos (Modos } 1,2,3 \\
\text { e 4). }\end{array}$ \\
\hline $\begin{array}{c}\text { Regras sobre regulação } \\
\text { doméstica }\end{array}$ & Não há. & Não há. \\
\hline $\begin{array}{l}\text { Regras setoriais } \\
\text { específicas }\end{array}$ & Não há. & $\begin{array}{c}\text { Há a previsão de extensão do tratamento } \\
\text { de nação mais favorecida dado a terceiros } \\
\text { no âmbito de transportes marítimos } \\
\text { (Artigo 31). }\end{array}$ \\
\hline $\begin{array}{c}\text { Capítulo sobre } \\
\text { investimentos } \\
\text { relacionados a serviços }\end{array}$ & Não há. & Não há. \\
\hline $\begin{array}{l}\text { Regras sobre } \\
\text { transparência }\end{array}$ & Não há. & Não há. \\
\hline $\begin{array}{l}\text { Tratamento nacional: } \\
\text { abrangência e } \\
\text { parâmetros } \\
\text { semelhantes ao GATS } \\
\text { (like services and like } \\
\text { services suppliers) }\end{array}$ & Não há. & Não há. \\
\hline $\begin{array}{l}\text { Acesso a mercados: } \\
\text { abrangência e } \\
\text { parâmetros } \\
\text { semelhantes ao Art. } \\
\text { XVI do GATS }\end{array}$ & Não há. & Não há. \\
\hline $\begin{array}{l}\text { Obrigações permissivas } \\
\text { que possibilitam } \\
\text { tratamento desigual } \\
\text { entre as partes do } \\
\text { acordo }\end{array}$ & Não há. & Não há. \\
\hline $\begin{array}{l}\text { Cláusula de nação mais } \\
\text { favorecida ratione } \\
\text { materiae et temporis }\end{array}$ & Não há. & $\begin{array}{c}\text { Há a previsão de extensão do tratamento } \\
\text { de nação mais favorecida dado a } \\
\text { terceiros, mas apenas para transportes } \\
\text { marítimos. }\end{array}$ \\
\hline
\end{tabular}




\begin{tabular}{|c|c|c|}
\hline & Acordo UE-Marrocos & Acordo UE-África do Sul \\
\hline $\begin{array}{l}\text { Exceções à Cláusula de } \\
\text { Nação Mais Favorecida }\end{array}$ & Não há. & Não há. \\
\hline $\begin{array}{l}\text { Regra de origem } \\
\text { (Denial of benefits) }\end{array}$ & Não há. & Não há. \\
\hline $\begin{array}{l}\text { Procedimento para } \\
\text { modificação dos } \\
\text { compromissos }\end{array}$ & Não há. & Não há. \\
\hline $\begin{array}{l}\text { Procedimento para } \\
\text { futuras negociações }\end{array}$ & $\begin{array}{c}\text { O Conselho de Associação apresentará } \\
\text { as recomendações necessárias para o } \\
\text { cumprimento do objetivo de } \\
\text { liberalização do comércio de serviços, } \\
\text { no prazo máximo de } 5 \text { anos, contados } \\
\text { da data em que o acordo entrar em } \\
\text { vigor. }\end{array}$ & $\begin{array}{c}\text { O Conselho de Cooperação deve buscar a } \\
\text { promoção da liberalização do comércio } \\
\text { de serviços no mínimo } 5 \text { anos após a } \\
\text { entrada em vigor do acordo. }\end{array}$ \\
\hline $\begin{array}{l}\text { Criação de comitês } \\
\text { para supervisionar a } \\
\text { evolução do Acordo }\end{array}$ & $\begin{array}{l}\text { O acordo determina que será criado o } \\
\text { Conselho de Associação, responsável } \\
\text { pela analise dos problemas } \\
\text { importantes que surjam no âmbito do } \\
\text { acordo, bem como todas as outras } \\
\text { questões bilaterais ou internacionais de } \\
\text { interesse comum. Prevê ainda a criação } \\
\text { do Comitê de Associação, responsável } \\
\text { pela gestão do acordo, sem prejuízo } \\
\text { das competências do Conselho. }\end{array}$ & $\begin{array}{l}\text { Há a previsão de criação de um Conselho } \\
\text { de Cooperação, responsável por } \\
\text { assegurar a aplicação e o funcionamento } \\
\text { corretos do acordo, o diálogo entre as } \\
\text { partes e a definição de ações futuras. }\end{array}$ \\
\hline
\end{tabular}




\section{Tabela 19 - Acordo UE-Tunísia}

\begin{tabular}{|c|c|}
\hline & Acordo UE-Tunísia \\
\hline Escopo do capítulo sobre serviços & $\begin{array}{l}\text { No Título III (Direito de Estabelecimento e } \\
\text { Serviços), as partes acordam em alargar o âmbito de } \\
\text { aplicação do acordo de forma a incluir o direito de } \\
\text { estabelecimento das empresas de uma parte no } \\
\text { território da outra parte e a liberalização da prestação } \\
\text { de serviços pelas empresas de uma parte aos } \\
\text { destinatários de serviços da outra parte. }\end{array}$ \\
\hline Forma de assunção dos compromissos & Não há lista. \\
\hline Modos de prestação abrangidos & Não se aplica. \\
\hline Regras sobre regulação doméstica & Não há. \\
\hline Regras setoriais específicas & Não há. \\
\hline $\begin{array}{c}\text { Capítulo sobre investimentos relacionados a } \\
\text { serviços }\end{array}$ & Não há. \\
\hline Regras sobre transparência & Não há. \\
\hline $\begin{array}{c}\text { Tratamento nacional: abrangência e parâmetros } \\
\text { semelhantes ao GATS (like services and like services } \\
\text { suppliers) }\end{array}$ & Não há. \\
\hline $\begin{array}{l}\text { Acesso a mercados: abrangência e parâmetros } \\
\text { semelhantes ao Art. XVI do GATS }\end{array}$ & Não há. \\
\hline $\begin{array}{l}\text { Obrigações permissivas que possibilitam tratamento } \\
\text { desigual entre as partes do acordo }\end{array}$ & Não há. \\
\hline $\begin{array}{c}\text { Cláusula de nação mais favorecida ratione materiae } \\
\text { et temporis }\end{array}$ & Não há. \\
\hline Exceções à Cláusula de Nação Mais Favorecida & Não há. \\
\hline Regra de origem (Denial of benefits) & Não há. \\
\hline Procedimento para modificação dos compromissos & Não há. \\
\hline Procedimento para futuras negociações & $\begin{array}{l}\text { O Conselho de Associação apresentará as } \\
\text { recomendações necessárias para o cumprimento do } \\
\text { objetivo de liberalização do comércio de serviços, no } \\
\text { prazo máximo de } 5 \text { anos, contados da data em que o } \\
\text { acordo entrar em vigor. }\end{array}$ \\
\hline $\begin{array}{l}\text { Criação de comitês para supervisionar a evolução } \\
\text { do Acordo }\end{array}$ & $\begin{array}{l}\text { O acordo determina que será criado o Conselho de } \\
\text { Associação, responsável pela analise dos problemas } \\
\text { importantes que surjam no âmbito do acordo, bem } \\
\text { como todas as outras questões bilaterais ou } \\
\text { internacionais de interesse comum. Prevê ainda a } \\
\text { criação do Comitê de Associação, responsável pela } \\
\text { gestão do acordo, sem prejuízo das competências do } \\
\text { Conselho. }\end{array}$ \\
\hline
\end{tabular}


ANEXO IV

ANÁLISE COMPARATIVA DAS PRINCIPAIS CLÁUSULAS SOBRE SERVIÇOS DOS ACORDOS DE LIVRE COMÉRCIO CELEBRADOS PELA CHINA 


\section{Tabela 20 - Acordos China-ASEAN e China-Costa Rica}

\begin{tabular}{|c|c|c|}
\hline & Acordo China-ASEAN & Acordo China-Costa Rica \\
\hline $\begin{array}{l}\text { Escopo do capítulo } \\
\text { sobre serviços }\end{array}$ & $\begin{array}{l}\text { O acordo abrange medidas que afetem } \\
\text { o comércio de serviços, exceto: (i) } \\
\text { medidas adotadas no exercício da } \\
\text { autoridade governamental; (ii) } \\
\text { regulações ou requerimentos } \\
\text { governando a contratação de serviços } \\
\text { para fins governamentais; e (iii) } \\
\text { medidas de natureza tributária das } \\
\text { Filipinas. }\end{array}$ & $\begin{array}{l}\text { O capítulo sobre serviços abrange } \\
\text { medidas adotadas ou mantidas por } \\
\text { governos e autoridades centrais, regionais } \\
\text { ou locais das Partes, bem como por } \\
\text { órgãos não governamentais que exerçam } \\
\text { poderes delegados por esses governos ou } \\
\text { autoridades, que afetem o comércio de } \\
\text { serviços, incluído: (i) o pagamento, a } \\
\text { compra e o uso de um serviço; (ii) o } \\
\text { acesso a e o uso de serviços que sejam } \\
\text { necessários, por uma Parte, para a } \\
\text { prestação de serviços públicos; e (iii) a } \\
\text { presença, incluindo a presença comercial, } \\
\text { de pessoas de uma Parte para a prestação } \\
\text { de um serviço no território de outra Parte. } \\
\text { Não estão abrangidas medidas adotadas } \\
\text { no exercício da autoridade } \\
\text { governamental. Também não estão } \\
\text { abrangidos: (i) as compras } \\
\text { governamentais; (ii) os serviços aéreos, } \\
\text { incluindo serviços de transporte aéreo } \\
\text { nacional e internacional, agendados ou } \\
\text { não agendados, e serviços correlatos, } \\
\text { exceto serviços de reparo e manutenção } \\
\text { de aeronaves, a comercialização de } \\
\text { serviços de transporte aéreo, sistemas de } \\
\text { reservas computadorizadas; (iii) } \\
\text { subsídios ou auxílios concedidos por uma } \\
\text { Parte, incluindo empréstimos, garantias e } \\
\text { seguros concedidos pelo governo; (iv) } \\
\text { transporte marítimo nacional de } \\
\text { cabotagem; e (v) serviços financeiros. Há } \\
\text { uma ressalva em relação à não } \\
\text { aplicabilidade do capítulo sobre serviços } \\
\text { para regular o acesso ao mercado de } \\
\text { trabalho de uma das Partes, incluindo a } \\
\text { possibilidade de requerimento de vistos a } \\
\text { pessoas físicas. }\end{array}$ \\
\hline $\begin{array}{l}\text { Forma de assunção dos } \\
\text { compromissos }\end{array}$ & Lista positiva. & Lista positiva. \\
\hline $\begin{array}{l}\text { Modos de prestação } \\
\text { abrangidos }\end{array}$ & Todos (Modos 1, 2, 3 e 4). & Todos (Modos 1, 2, 3 e 4). \\
\hline $\begin{array}{c}\text { Regras sobre regulação } \\
\text { doméstica }\end{array}$ & $\begin{array}{l}\text { Sim. As Partes devem: (i) garantir que } \\
\text { todas as medidas que afetem o } \\
\text { comércio de serviços sejam } \\
\text { administradas de forma razoável, } \\
\text { objetiva e imparcial; (ii) estabelecer ou } \\
\text { manter tribunais ou procedimentos } \\
\text { para a revisão de medidas } \\
\text { administrativas que afetem o comércio } \\
\text { de serviços, que devem ser objetivos e } \\
\text { imparciais, exceto se essa previsão for }\end{array}$ & $\begin{array}{l}\text { Sim. As Partes devem garantir que todas } \\
\text { as medidas que afetem o comércio de } \\
\text { serviços sejam administradas de forma } \\
\text { razoável, objetiva e imparcial; a } \\
\text { existência de regras claras sobre } \\
\text { requerimentos de licenciamento, normas } \\
\text { técnicas, entre outras., de modo que não } \\
\text { constituam barreiras desnecessárias ao } \\
\text { comércio de serviços; e que as } \\
\text { autoridades respondam prontamente a }\end{array}$ \\
\hline
\end{tabular}




\begin{tabular}{|c|c|c|}
\hline & Acordo China-ASEAN & Acordo China-Costa Rica \\
\hline & $\begin{array}{l}\text { inconstitucional ou não estiver prevista } \\
\text { no sistema jurídico da Parte. }\end{array}$ & $\begin{array}{l}\text { requerimentos sempre que uma } \\
\text { autorização for necessária. Há ainda } \\
\text { menção à necessidade de revisão das } \\
\text { regras sobre regulação doméstica, no } \\
\text { caso de regulamentação do Art. VI do } \\
\text { GATS. }\end{array}$ \\
\hline $\begin{array}{l}\text { Regras setoriais } \\
\text { específicas }\end{array}$ & Não há. & $\begin{array}{l}\text { Há regras específicas para o movimento } \\
\text { temporário de pessoas físicas. }\end{array}$ \\
\hline $\begin{array}{c}\text { Capítulo sobre } \\
\text { investimentos } \\
\text { relacionados a serviços }\end{array}$ & Não há um capítulo específico. & $\begin{array}{l}\text { Não há um capítulo específico. Esse tema } \\
\text { é tratado de modo superficial no mesmo } \\
\text { Capítulo sobre Serviços. Há apenas uma } \\
\text { disposição reafirmando os compromissos } \\
\text { celebrados entre os governos das Partes } \\
\text { em } 2007 \text {, sem a previsão de quaisquer } \\
\text { regras sobre esse tema. }\end{array}$ \\
\hline $\begin{array}{l}\text { Regras sobre } \\
\text { transparência }\end{array}$ & $\begin{array}{l}\text { Sim, conforme estabelecido no Art. III } \\
\text { do GATS. Esse artigo é incorporado e } \\
\text { constitui parte integrante do Acordo. }\end{array}$ & $\begin{array}{l}\text { Sim, que consistem na (i) Necessidade de } \\
\text { as partes estabelecerem e manterem } \\
\text { mecanismos apropriados para } \\
\text { responderem às solicitações de pessoas } \\
\text { interessadas sobre suas leis e } \\
\text { regulamentos relacionados ao acordo; (ii) } \\
\text { Que, na medida do possível, sejam } \\
\text { levados em consideração os comentários } \\
\text { substanciais realizados por partes } \\
\text { interessadas sobre novas leis e } \\
\text { regulamentos; e (iii) Que haja um período } \\
\text { de tempo razoável entre a promulgação } \\
\text { de novas leis e regulamentos e sua } \\
\text { entrada em vigor. }\end{array}$ \\
\hline $\begin{array}{l}\text { Tratamento nacional: } \\
\text { abrangência e } \\
\text { parâmetros } \\
\text { semelhantes ao GATS } \\
\text { (like services and like } \\
\text { services suppliers) }\end{array}$ & $\begin{array}{l}\text { Sim, idêntico ao GATS. Parâmetros } \\
\text { são os mesmos (like services and } \\
\text { services suppliers). }\end{array}$ & $\begin{array}{c}\text { Sim, idêntico ao GATS. Parâmetros são } \\
\text { os mesmos (like services and services } \\
\text { suppliers). }\end{array}$ \\
\hline $\begin{array}{l}\text { Acesso a mercados: } \\
\text { abrangência e } \\
\text { parâmetros } \\
\text { semelhantes ao Art. } \\
\text { XVI do GATS }\end{array}$ & $\begin{array}{l}\text { Sim, idêntico ao GATS. Parâmetros } \\
\text { são os mesmos. }\end{array}$ & $\begin{array}{l}\text { Sim, idêntico ao GATS. Parâmetros são } \\
\text { os mesmos }\end{array}$ \\
\hline $\begin{array}{c}\text { Obrigações permissivas } \\
\text { que possibilitam } \\
\text { tratamento desigual } \\
\text { entre as partes do } \\
\text { acordo }\end{array}$ & $\begin{array}{l}\text { Há a previsão de que, tão logo seja } \\
\text { concluída a negociação do Art. X do } \\
\text { GATS, as Partes conduzirão uma } \\
\text { revisão para discutir o aditamento no } \\
\text { Acordo com vistas a incorporar os } \\
\text { resultados das negociações } \\
\text { multilaterais. Se for verificado que, } \\
\text { antes da conclusão das negociações } \\
\text { multilaterais, uma das partes estiver } \\
\text { sendo prejudicada pelo aumento das } \\
\text { exportações de serviços de outra parte, } \\
\text { podem ser realizadas consultas. Nesse } \\
\text { caso, só poderá ser adotada uma } \\
\text { medida de salvaguarda se ela for } \\
\text { consensual. Há cláusulas } \\
\text { desenvolvimentistas similares às do }\end{array}$ & Não há. \\
\hline
\end{tabular}




\begin{tabular}{|c|c|c|}
\hline & Acordo China-ASEAN & Acordo China-Costa Rica \\
\hline & $\begin{array}{l}\text { GATS com relação a Camboja, Laos, } \\
\text { Myanmar e Vietnã. As condições são } \\
\text { as seguintes: (i) o fortalecimento da } \\
\text { capacidade de prestação de serviços, } \\
\text { eficiência e competitividade por meio, } \\
\text { entre outros, do acesso à tecnologia em } \\
\text { bases comerciais; (ii) a melhoria do } \\
\text { acesso aos canais de distribuição e às } \\
\text { redes de informação; (iii) a } \\
\text { liberalização do acesso a mercados em } \\
\text { setores e modos de prestação para } \\
\text { exportação de seu interesse; (iv) a } \\
\text { concessão de flexibilidade apropriada } \\
\text { para que essas Partes liberalizem } \\
\text { menos setores e tipos de operação, e } \\
\text { que estendam progressivamente o } \\
\text { acesso a mercados de acordo com a sua } \\
\text { situação específica de } \\
\text { desenvolvimento. }\end{array}$ & \\
\hline $\begin{array}{l}\text { Cláusula de nação mais } \\
\text { favorecida ratione } \\
\text { materiae et temporis }\end{array}$ & $\begin{array}{l}\text { Há apenas a previsão de concessão às } \\
\text { Partes de tratamento não menos } \\
\text { favorável do que aquele determinado } \\
\text { no Acordo. }\end{array}$ & Não há. \\
\hline $\begin{array}{l}\text { Exceções à Cláusula de } \\
\text { Nação Mais Favorecida }\end{array}$ & Não há. & $\begin{array}{c}\text { Não estão previstas exceções à cláusula } \\
\text { de nação mais favorecida. }\end{array}$ \\
\hline $\begin{array}{l}\text { Regra de origem } \\
\text { (Denial of benefits) }\end{array}$ & $\begin{array}{c}\text { Sim, mas não é adotado o critério de } \\
\text { operações comerciais substanciais. A } \\
\text { Parte poderá negar os benefícios do } \\
\text { Acordo nos seguintes casos: (i) à } \\
\text { prestação de serviços, caso o serviço } \\
\text { seja prestado do território de uma não } \\
\text { Parte; (ii) à prestação de serviços de } \\
\text { transporte marítimo, se o serviço for } \\
\text { prestado por uma embarcação } \\
\text { registrada em uma não Parte ou for } \\
\text { prestado por uma pessoa originária de } \\
\text { uma não Parte que utilize a } \\
\text { embarcação, no todo ou em parte; e } \\
\text { (iii) ao prestador de serviços, caso ele } \\
\text { seja originário de uma não Parte. }\end{array}$ & $\begin{array}{l}\text { Sim. Critério de operações comerciais } \\
\text { substanciais. As partes poderão negar as } \\
\text { preferência concedidas no Acordo para: } \\
\text { (i) prestadores de serviços da outra Parte } \\
\text { se o serviço for prestador por pessoa } \\
\text { jurídica detidas ou controladas por } \\
\text { pessoas originárias de uma não Parte e a } \\
\text { pessoa jurídica não desenvolver } \\
\text { operações substanciais no território da } \\
\text { outra Parte; ou (ii) prestadores de } \\
\text { serviços da outra Parte se o serviço for } \\
\text { prestado por pessoa jurídica que é detida } \\
\text { ou controlada por pessoas da Parte que } \\
\text { denegar os benefícios e a pessoa jurídica } \\
\text { não desenvolver operações substanciais } \\
\text { na outra Parte. Há a previsão de que, no } \\
\text { caso de solicitação por escrito, a Parte } \\
\text { que negar os benefícios deve informar o } \\
\text { fato à outra, por escrito, além de entrar } \\
\text { em consultas. }\end{array}$ \\
\hline $\begin{array}{l}\text { Procedimento para } \\
\text { modificação dos } \\
\text { compromissos }\end{array}$ & $\begin{array}{l}\text { As partes poderão modificar ou } \\
\text { revogar compromissos a qualquer } \\
\text { momento após } 3 \text { anos da entrada em } \\
\text { vigor do Acordo. Tanto as Partes } \\
\text { quanto a Secretaria da ASEAN devem } \\
\text { ser notificadas, no mínimo, } 3 \text { meses } \\
\text { antes da revogação ou modificação do } \\
\text { compromisso. Devem ser iniciadas } \\
\text { negociações com a Parte interessada } \\
\text { para que seja definida uma } \\
\text { compensação. Caso não seja possível }\end{array}$ & Não há previsão. \\
\hline
\end{tabular}




\begin{tabular}{|c|c|c|}
\hline & Acordo China-ASEAN & Acordo China-Costa Rica \\
\hline & $\begin{array}{c}\text { alcançar um acordo sobre a } \\
\text { compensação, a questão será decidia } \\
\text { por arbitragem, nos termos do Acordo } \\
\text { sobre Solução de Controvérsias. }\end{array}$ & \\
\hline $\begin{array}{l}\text { Procedimento para } \\
\text { futuras negociações }\end{array}$ & $\begin{array}{c}\text { As partes do Acordo devem: (i) } \\
\text { ampliar substancialmente o primeiro } \\
\text { pacote de compromissos; (ii) negociar } \\
\text { um segundo pacote de compromissos } \\
\text { um ano após a entrada em vigor do } \\
\text { Acordo; (iii) ingressar em rodadas } \\
\text { sucessivas de negociações, de modo a } \\
\text { ampliar a liberalização progressiva do } \\
\text { comércio de serviços. Também há a } \\
\text { previsão de que o Ministro de } \\
\text { Comércio da China e o Ministro da } \\
\text { Economia da ASEAN se encontrem } \\
\text { um ano após a entrada em vigor do } \\
\text { Acordo e, posteriormente, a cada dois } \\
\text { anos para revisar o Acordo com o } \\
\text { objetivo de adotar medidas para } \\
\text { ampliar a liberalização do comércio de } \\
\text { serviços, bem como negociar e } \\
\text { desenvolver as disciplinas previstas no } \\
\text { Acordo. }\end{array}$ & $\begin{array}{l}\text { As Partes devem entrar em consultas } \\
\text { anualmente para revisar e implementar o } \\
\text { Capítulo sobre Serviços e considerar } \\
\text { questões de interesse mútuo envolvendo } \\
\text { o comércio de serviços, exceto se for } \\
\text { acordado de outra forma. }\end{array}$ \\
\hline $\begin{array}{l}\text { Criação de comitês } \\
\text { para supervisionar a } \\
\text { evolução do Acordo }\end{array}$ & $\begin{array}{l}\text { Não há a previsão de criação de um } \\
\text { Comitê. Cada Parte deverá } \\
\text { disponibilizar uma pessoa como ponto } \\
\text { de contato para tratar de questões } \\
\text { relativas ao Acordo. }\end{array}$ & $\begin{array}{l}\text { Foi prevista apenas a criação de um } \\
\text { Grupo de Trabalho sobre a Entrada } \\
\text { Temporária de Pessoas de Negócios. }\end{array}$ \\
\hline
\end{tabular}




\section{Tabela 21 - Acordos China-Chile e China-Nova Zelândia}

\begin{tabular}{|c|c|c|}
\hline & Acordo China-Chile & Acordo China-Nova Zelândia \\
\hline $\begin{array}{l}\text { Escopo do capítulo } \\
\text { sobre serviços }\end{array}$ & $\begin{array}{l}\text { Em } 14 \text { de abril de 2008, foi celebrado } \\
\text { um Acordo Suplementar sobre o } \\
\text { Comércio de Serviços, em } \\
\text { complementação ao Acordo de Livre } \\
\text { Comércio celebrado entre China e } \\
\text { Chile, que incide apenas sobre o } \\
\text { comércio de bens. O Acordo } \\
\text { Suplementar sobre Serviços abrange } \\
\text { medidas adotadas ou mantidas por } \\
\text { autoridades centrais, regionais ou } \\
\text { locais das Partes ou por órgãos não } \\
\text { governamentais que exerçam funções } \\
\text { delegadas por autoridades centrais, } \\
\text { regionais ou locais que afetem o } \\
\text { comércio de serviços. Não estão } \\
\text { abrangidas medidas adotadas no } \\
\text { exercício da autoridade governamental. } \\
\text { O Acordo Suplementar não incide } \\
\text { sobre: (i) serviços financeiros; (ii) } \\
\text { compras governamentais; (iii) } \\
\text { subsídios ou auxílios concedidos por } \\
\text { uma Parte, incluindo empréstimos, } \\
\text { garantias e seguros concedidos pelo } \\
\text { governo; (iv) transporte marítimo } \\
\text { nacional de cabotagem; (v) serviços } \\
\text { aéreos, incluindo serviços de transporte } \\
\text { aéreo nacional e internacional, } \\
\text { agendados ou não agendados, e } \\
\text { serviços correlatos, exceto serviços } \\
\text { aéreos especiais, serviços de reparo e } \\
\text { manutenção de aeronaves em solo, a } \\
\text { comercialização de serviços de } \\
\text { transporte aéreo, sistemas de reservas } \\
\text { computadorizadas, operações } \\
\text { aeroportuárias e serviços de assistência } \\
\text { em terra. } \\
\end{array}$ & $\begin{array}{l}\text { O capítulo sobre serviços abrange as } \\
\text { seguintes medidas: leis, regulamentos, } \\
\text { normas, procedimentos, decisões, atos } \\
\text { administrativos ou de outra forma } \\
\text { adotadas ou mantidas por: governos ou } \\
\text { por autoridades centrais, regionais ou } \\
\text { locais; órgãos não governamentais no } \\
\text { exercício de poderes delegados pelo } \\
\text { governo ou por autoridades centrais, } \\
\text { regionais ou locais. Tais medidas } \\
\text { incluem: a compra, pagamento ou uso de } \\
\text { um serviço; o acesso ou o uso de serviços } \\
\text { que são requeridos pelas partes e } \\
\text { prestados ao público em geral, em } \\
\text { conexão com a prestação do serviço; e a } \\
\text { presença. incluindo a presença comercial, } \\
\text { de pessoas de uma parte para a prestação } \\
\text { de serviços em outra parte. Não estão } \\
\text { abrangidos pelo acordo: (i) leis, } \\
\text { regulamentos, políticas ou procedimentos } \\
\text { de aplicação geral relacionados a serviços } \\
\text { para uso governamental e sem a } \\
\text { finalidade de comercialização; (ii) } \\
\text { serviços prestados no exercício da } \\
\text { autoridade governamental; (iii) subsídios } \\
\text { ou auxílios concedidos por uma parte; } \\
\text { (iv) medidas que afetem pessoas físicas } \\
\text { em busca de empregos em outra parte; } \\
\text { (v) direitos de tráfico aéreo e serviços } \\
\text { diretamente relacionados, excluindo-se os } \\
\text { serviços de reparo e manutenção de } \\
\text { aeronaves, a comercialização de serviços } \\
\text { de transporte aéreo e sistemas de reservas } \\
\text { computadorizadas. }\end{array}$ \\
\hline $\begin{array}{c}\text { Forma de assunção dos } \\
\text { compromissos }\end{array}$ & Lista positiva. & $\begin{array}{l}\text { Lista positiva. Os serviços objeto de } \\
\text { compromissos específicos estão } \\
\text { relacionados no Anexo } 9 \text { do Acordo. }\end{array}$ \\
\hline $\begin{array}{c}\text { Modos de prestação } \\
\text { abrangidos }\end{array}$ & Todos (Modos 1, 2, 3 e 4). & $\begin{array}{c}\text { Todos (Modos 1, 2, } 3 \text { e 4). Não obstante, } \\
\text { há um capítulo específico sobre o } \\
\text { movimento de pessoas físicas (Capítulo } \\
10) .\end{array}$ \\
\hline $\begin{array}{c}\text { Regras sobre regulação } \\
\text { doméstica }\end{array}$ & $\begin{array}{l}\text { Sim. As Partes devem garantir que } \\
\text { todas as medidas que afetem o } \\
\text { comércio de serviços sejam } \\
\text { administradas de forma razoável, } \\
\text { objetiva e imparcial; a existência de } \\
\text { regras claras sobre requerimentos de } \\
\text { licenciamento, normas técnicas, entre } \\
\text { outras., de modo que não constituam } \\
\text { barreiras desnecessárias ao comércio } \\
\text { de serviços; e que as autoridades } \\
\text { respondam prontamente a }\end{array}$ & $\begin{array}{l}\text { Sim. Existem regras que tratam da } \\
\text { necessidade de tribunais ou } \\
\text { procedimentos administrativos para a } \\
\text { revisão imparcial e independente dos } \\
\text { atos; da negativa de autorização; da } \\
\text { necessidade de regras claras sobre } \\
\text { requerimentos de licenciamento, normas } \\
\text { técnicas, entre outras. de modo que não } \\
\text { constituam barreiras desnecessárias ao } \\
\text { comércio de serviços; e manter } \\
\text { procedimentos adequados para verificar a }\end{array}$ \\
\hline
\end{tabular}




\begin{tabular}{|c|c|c|}
\hline & Acordo China-Chile & Acordo China-Nova Zelândia \\
\hline & $\begin{array}{l}\text { requerimentos sempre que uma } \\
\text { autorização for necessária. O artigo faz } \\
\text { menção á necessidade de revisão das } \\
\text { regras sobre regulação doméstica em } \\
\text { caso de regulamentação do Art. V do } \\
\text { GATS. Também há a previsão de que } \\
\text { as partes realizem consultas periódicas } \\
\text { com o objetivo de remover a } \\
\text { necessidade de vistos ou residência } \\
\text { para o licenciamento e a certificação de } \\
\text { provedores de serviços. }\end{array}$ & $\begin{array}{l}\text { competência dos profissionais da outra } \\
\text { parte. }\end{array}$ \\
\hline $\begin{array}{l}\text { Regras setoriais } \\
\text { específicas }\end{array}$ & $\begin{array}{l}\text { Há um anexo sobre o Movimento } \\
\text { Temporário de Pessoas Físicas. }\end{array}$ & $\begin{array}{c}\text { Há um capítulo específico para regular o } \\
\text { movimento de pessoas físicas (Capítulo } \\
10) .\end{array}$ \\
\hline $\begin{array}{c}\text { Capítulo sobre } \\
\text { investimentos } \\
\text { relacionados a serviços }\end{array}$ & $\begin{array}{l}\text { Não há um capítulo específico sobre } \\
\text { investimentos no Acordo Suplementar } \\
\text { sobre o Comércio de Serviços. }\end{array}$ & Sim (Capítulo 11). \\
\hline $\begin{array}{l}\text { Regras sobre } \\
\text { transparência }\end{array}$ & $\begin{array}{l}\text { Sim, que consistem na (i) Necessidade } \\
\text { de as partes estabelecerem e manterem } \\
\text { mecanismos apropriados para } \\
\text { responderem às solicitações de pessoas } \\
\text { interessadas sobre suas leis e } \\
\text { regulamentos relacionados ao acordo; } \\
\text { (ii) Que, na medida do possível, sejam } \\
\text { levados em consideração os } \\
\text { comentários realizados por partes } \\
\text { interessadas sobre novas leis e } \\
\text { regulamentos; e (iii) Que haja um } \\
\text { período de tempo razoável entre a } \\
\text { promulgação de novas leis e } \\
\text { regulamentos e sua entrada em vigor. }\end{array}$ & $\begin{array}{l}\text { Sim, relativas à publicação de acordos } \\
\text { internacionais sobre ou que afetem o } \\
\text { comércio de serviços dos quais a Parte é } \\
\text { signatária, as quais deverão ser } \\
\text { transmitidas por meio dos pontos de } \\
\text { contato previstos no Acordo. }\end{array}$ \\
\hline $\begin{array}{l}\text { Tratamento nacional: } \\
\text { abrangência e } \\
\text { parâmetros } \\
\text { semelhantes ao GATS } \\
\text { (like services and like } \\
\text { services suppliers) }\end{array}$ & $\begin{array}{c}\text { Sim, idêntico ao GATS. Parâmetros } \\
\text { são os mesmos (like services and } \\
\text { services suppliers). }\end{array}$ & $\begin{array}{c}\text { Sim, idêntico ao GATS. Parâmetros são } \\
\text { os mesmos (like services and services } \\
\text { suppliers). }\end{array}$ \\
\hline $\begin{array}{l}\text { Acesso a mercados: } \\
\text { abrangência e } \\
\text { parâmetros } \\
\text { semelhantes ao Art. } \\
\text { XVI do GATS }\end{array}$ & $\begin{array}{l}\text { Sim, idêntico ao GATS. Parâmetros } \\
\text { são os mesmos }\end{array}$ & $\begin{array}{l}\text { Sim, idêntico ao GATS. Parâmetros são } \\
\text { os mesmos. Também há uma previsão de } \\
\text { que as Partes não poderão estabelecer } \\
\text { restrições à transferências e pagamentos } \\
\text { internacionais em questões objeto de } \\
\text { compromissos específicos, exceto em } \\
\text { relação ao Art. } 202 \text { do Acordo (medidas } \\
\text { para proteger a balança de pagamentos) e } \\
\text { por determinação do FMI. }\end{array}$ \\
\hline $\begin{array}{l}\text { Obrigações permissivas } \\
\text { que possibilitam } \\
\text { tratamento desigual } \\
\text { entre as partes do } \\
\text { acordo }\end{array}$ & $\begin{array}{c}\text { Há apenas a previsão de exceção para a } \\
\text { proteção de problemas graves de } \\
\text { balança de pagamentos, em } \\
\text { conformidade com as regras da OMC e } \\
\text { do FMI. }\end{array}$ & $\begin{array}{l}\text { Há previsão de discussão sobre } \\
\text { salvaguardas emergenciais após a } \\
\text { regulamentação do Art. X do GATS. }\end{array}$ \\
\hline
\end{tabular}




\begin{tabular}{|c|c|c|}
\hline & Acordo China-Chile & Acordo China-Nova Zelândia \\
\hline $\begin{array}{l}\text { Cláusula de nação mais } \\
\text { favorecida ratione } \\
\text { materiae et temporis }\end{array}$ & Não há. & $\begin{array}{l}\text { Sim, haverá a extensão das } \\
\text { preferências apenas para os setores } \\
\text { objeto de compromissos específicos, } \\
\text { mas apenas para acordos posteriores. } \\
\text { Não haverá a extensão das } \\
\text { preferências garantidas por acordos } \\
\text { bilaterais ou multilaterais celebrados } \\
\text { antes do referido Acordo. Com } \\
\text { relação a serviços acessórios à } \\
\text { agricultura e florestas, a obrigação } \\
\text { está limitada ao tratamento mais } \\
\text { favorável concedido aos Membros da } \\
\text { OCDE. }\end{array}$ \\
\hline $\begin{array}{l}\text { Exceções à Cláusula de } \\
\text { Nação Mais Favorecida }\end{array}$ & Não há. & $\begin{array}{l}\text { Não há essa previsão, exceto para a } \\
\text { extensão das preferências garantidas por } \\
\text { acordos bilaterais ou multilaterais } \\
\text { celebrados antes do referido Acordo. }\end{array}$ \\
\hline $\begin{array}{l}\text { Regra de origem } \\
\text { (Denial of benefits) }\end{array}$ & $\begin{array}{l}\text { Sim. Critério de operações comerciais } \\
\text { substanciais. As partes poderão negar } \\
\text { as preferência concedidas no acordo } \\
\text { para: (i) prestadores de serviços da } \\
\text { outra Parte se o serviço for prestado } \\
\text { por pessoa jurídica detida ou } \\
\text { controlada por pessoas de não parte e a } \\
\text { pessoa jurídica não desenvolver } \\
\text { operações substanciais na outra Parte; e } \\
\text { (ii) prestadores de serviços da outra } \\
\text { Parte se o serviço for prestado por } \\
\text { pessoa jurídica detida ou controlada } \\
\text { por pessoas da parte que denegar o } \\
\text { benefício e a pessoa jurídica não } \\
\text { desenvolver operações substanciais na } \\
\text { outra Parte. Há a previsão de que, no } \\
\text { caso de solicitação por escrito, a Parte } \\
\text { que negar os benefícios deve informar } \\
\text { o fato à outra, por escrito, além de } \\
\text { entrar em consultas. }\end{array}$ & $\begin{array}{l}\text { Sim. Critério de operações comerciais } \\
\text { substanciais. As partes poderão negar as } \\
\text { preferência concedidas no acordo para: } \\
\text { (i) prestadores de serviços da outra Parte } \\
\text { se o serviço for prestado por pessoa } \\
\text { jurídica detida ou controlada por pessoas } \\
\text { de não parte e a pessoa jurídica não } \\
\text { desenvolver operações substanciais na } \\
\text { outra Parte; e (ii) prestadores de serviços } \\
\text { da outra Parte se o serviço for prestado } \\
\text { por pessoa jurídica detida ou controlada } \\
\text { por pessoas da parte que denegar o } \\
\text { benefício e a pessoa jurídica não } \\
\text { desenvolver operações substanciais na } \\
\text { outra Parte. }\end{array}$ \\
\hline $\begin{array}{l}\text { Procedimento para } \\
\text { modificação dos } \\
\text { compromissos }\end{array}$ & $\begin{array}{l}\text { As partes podem realizar modificações } \\
\text { ou realizar adições ao Acordo. }\end{array}$ & $\begin{array}{c}\text { Há a possibilidade de modificação ou } \\
\text { revogação dos compromissos adotados } \\
\text { por uma Parte após } 3 \text { anos de sua entrada } \\
\text { em vigor, desde que notifique sua } \\
\text { intenção à outra Parte até } 3 \text { meses da data } \\
\text { em que a modificação ou revogação } \\
\text { entrará em vigor e que as Partes } \\
\text { promovam consultas para buscar uma } \\
\text { compensação adequada. A compensação } \\
\text { não poderá estabelecer um nível de } \\
\text { compromissos menos favorável do que } \\
\text { aquele existente antes da modificação. } \\
\text { Caso não seja alcançado um acordo entre } \\
\text { as Partes no período de } 3 \text { meses, a Parte } \\
\text { afetada poderá recorrer à arbitragem em } \\
\text { conformidade com os procedimentos } \\
\text { previstos no Capítulo } 16 \text { do Acordo. A } \\
\text { modificação ou revogação do } \\
\text { compromisso só poderá ocorrer quando }\end{array}$ \\
\hline
\end{tabular}




\begin{tabular}{|c|c|c|}
\hline & Acordo China-Chile & Acordo China-Nova Zelândia \\
\hline & & $\begin{array}{l}\text { forem realizados os ajustes determinados } \\
\text { pelo procedimento arbitral. }\end{array}$ \\
\hline $\begin{array}{l}\text { Procedimento para } \\
\text { futuras negociações }\end{array}$ & $\begin{array}{c}\text { Prevê também a realização de } \\
\text { negociações relacionadas a } \\
\text { investimentos. }\end{array}$ & $\begin{array}{l}\text { Após } 2 \text { anos da entrada em vigor, as } \\
\text { Partes deverão iniciar consultas, no } \\
\text { mínimo a cada } 3 \text { anos, para revisar a } \\
\text { implementação do Capítulo sobre o } \\
\text { Comércio de Serviços e considerar outras } \\
\text { questões relacionadas ao tema que sejam } \\
\text { de interesse mútuo, incluindo a extensão } \\
\text { de tratamento de nação mais favorecida a } \\
\text { outros setores serviços, de modo a } \\
\text { promover a liberalização progressiva } \\
\text { desse setor, em bases mutuamente } \\
\text { vantajosas. }\end{array}$ \\
\hline $\begin{array}{l}\text { Criação de comitês } \\
\text { para supervisionar a } \\
\text { evolução do Acordo }\end{array}$ & $\begin{array}{l}\text { Há a previsão de criação de um Comitê } \\
\text { sobre o Comércio de Serviços no } \\
\text { âmbito da Comissão, que seria } \\
\text { formado por representantes das duas } \\
\text { Partes. O Comitê se reuniria a pedido } \\
\text { das Partes ou da Comissão para } \\
\text { analisar questões de interesse das } \\
\text { Partes relacionadas a serviços. As } \\
\text { funções do Comitê devem incluir: (i) a } \\
\text { promoção do comércio de serviços } \\
\text { entre as Partes; e (ii) analisar barreiras } \\
\text { ao comércio de serviços entre as partes } \\
\text { e, se for apropriado, levar essas } \\
\text { questões à Comissão. }\end{array}$ & $\begin{array}{l}\text { Foi prevista a criação de um Comitê } \\
\text { sobre o Comércio de Serviços, o qual se } \\
\text { reuniria a pedido das Partes ou da } \\
\text { Comissão Conjunta do Acordo, para: (i) } \\
\text { revisão a implementação e } \\
\text { operacionalização do Capítulo sobre o } \\
\text { Comércio de Serviços; (ii) identificar e } \\
\text { recomendar medidas para promover e } \\
\text { aumentar o comércio de serviços entre as } \\
\text { Partes; e (iii) considerar questões de } \\
\text { interesse das Partes relacionadas a } \\
\text { serviços. }\end{array}$ \\
\hline
\end{tabular}




\section{Tabela 22 - Acordos China-Cingapura e China-Paquistão}

\begin{tabular}{|c|c|c|}
\hline & Acordo China-Cingapura & Acordo China-Paquistão \\
\hline $\begin{array}{l}\text { Escopo do capítulo } \\
\text { sobre serviços }\end{array}$ & $\begin{array}{l}\text { O Capítulo sobre Serviços abrange } \\
\text { medidas que afetem o comércio de } \\
\text { serviços, exceto: (i) medidas adotadas } \\
\text { no exercício da autoridade } \\
\text { governamental no território de outra } \\
\text { Parte; (ii) regulações ou requerimentos } \\
\text { governando a contratação de serviços } \\
\text { para fins governamentais. Não estão } \\
\text { abrangidos pelo acordo: (i) subsídios } \\
\text { ou aportes concedidos por uma Parte } \\
\text { relacionados ao recebimento de } \\
\text { subsídios ou aportes, exceto se } \\
\text { especificado em contrário no Acordo } \\
\text { ou relacionados às disciplinas que } \\
\text { podem vir a ser desenvolvidas no } \\
\text { âmbito do Art. XV do GATS; (ii) } \\
\text { direitos de tráfico aéreo; (iii) serviços } \\
\text { diretamente relacionados aos direitos } \\
\text { de tráfico aéreo, exceto: serviços de } \\
\text { reparo e manutenção de aeronaves, a } \\
\text { comercialização de serviços de } \\
\text { transporte aéreo e serviços de reservas } \\
\text { computadorizadas. }\end{array}$ & $\begin{array}{l}\text { O Acordo abrange medidas adotadas } \\
\text { pelas Partes que afetem o comércio de } \\
\text { serviços, exceto: (i) medidas adotadas no } \\
\text { exercício da autoridade governamental no } \\
\text { território de outra Parte; (ii) regulaçães } \\
\text { ou requerimentos de agencias } \\
\text { governamentais sobre a contratação de } \\
\text { serviços para fins governamentais e não } \\
\text { com vistas à comercialização; (iii) } \\
\text { subsídios ou aportes concedidos por uma } \\
\text { Parte; (iv) direitos de tráfico aéreo ou } \\
\text { serviços diretamente relacionados aos } \\
\text { direitos de tráfego aéreo, com exceção de } \\
\text { serviços de reparo e manutenção de } \\
\text { aeronaves, da comercialização de } \\
\text { serviços de transporte aéreo e de serviços } \\
\text { de reservas computadorizadas; (v) } \\
\text { transporte marítimo de cabotagem; e (vi) } \\
\text { medidas afetando pessoas físicas } \\
\text { buscando acesso ao mercado de } \\
\text { empregos de uma Parte ou relacionadas à } \\
\text { cidadania, residência e emprego de forma } \\
\text { permanente. O Acordo não afeta o direito } \\
\text { das Partes de adotarem medidas para } \\
\text { regular a entrada de pessoas físicas em } \\
\text { seus territórios, desde que tais medidas } \\
\text { não prejudiquem ou anulem os benefícios } \\
\text { do Acordo. }\end{array}$ \\
\hline $\begin{array}{l}\text { Forma de assunção dos } \\
\text { compromissos }\end{array}$ & Lista positiva. & Lista positiva. \\
\hline $\begin{array}{l}\text { Modos de prestação } \\
\text { abrangidos }\end{array}$ & $\begin{array}{c}\text { Todos (Modos 1, 2, } 3 \text { e } 4 \text { ). O Modo } 4 \text { é } \\
\text { objeto de um capítulo específico } \\
\text { (Capítulo } 9 \text { - Movimento de Pessoas } \\
\text { Físicas). }\end{array}$ & Todos $(\operatorname{modos} 1,2,3$ e 4$)$ \\
\hline $\begin{array}{c}\text { Regras sobre regulação } \\
\text { doméstica }\end{array}$ & $\begin{array}{l}\text { Sim. As Partes devem: (i) garantir que } \\
\text { todas as medidas que afetem o } \\
\text { comércio de serviços sejam } \\
\text { administradas de forma razoável, } \\
\text { objetiva e imparcial; (ii) estabelecer ou } \\
\text { manter tribunais ou procedimentos } \\
\text { para a revisão de medidas } \\
\text { administrativas que afetem o comércio } \\
\text { de serviços, que devem ser objetivos e } \\
\text { imparciais, exceto se essa previsão for } \\
\text { inconstitucional ou não estiver prevista } \\
\text { no sistema jurídico da Parte. }\end{array}$ & $\begin{array}{l}\text { Sim. As Partes devem garantir que todas } \\
\text { as medidas que afetem o comércio de } \\
\text { serviços: (i) sejam administradas de } \\
\text { forma razoável, objetiva e imparcial; (ii) } \\
\text { sejam baseadas em critérios objetivos e } \\
\text { transparentes, como a competência e a } \\
\text { habilidade para prestar o serviço; (iii) não } \\
\text { sejam mais onerosas que o necessário } \\
\text { para assegurar a qualidade do serviço; e } \\
\text { (iv) no caso de procedimentos para } \\
\text { licenciamento, que estes não constituam } \\
\text { uma restrição à prestação do serviço. O } \\
\text { Acordo prevê que as autoridades } \\
\text { competentes apresentem informações } \\
\text { sobre requerimentos realizados em } \\
\text { relação à prestação de serviços objeto de } \\
\text { compromissos específicos. O artigo faz } \\
\text { menção à necessidade de revisão das } \\
\text { regras sobre regulação doméstica em }\end{array}$ \\
\hline
\end{tabular}




\begin{tabular}{|c|c|c|}
\hline & Acordo China-Cingapura & Acordo China-Paquistão \\
\hline & & $\begin{array}{l}\text { caso de regulamentação do Art. VI do } \\
\text { GATS. Também há a previsão de que as } \\
\text { partes realizem consultas periódicas com } \\
\text { o objetivo de remover a necessidade de } \\
\text { vistos ou residência para o licenciamento } \\
\text { e a certificação de provedores de } \\
\text { serviços. }\end{array}$ \\
\hline $\begin{array}{l}\text { Regras setoriais } \\
\text { específicas }\end{array}$ & $\begin{array}{l}\text { Os Anexos sobre o Movimento } \\
\text { Temporário de Pessoas Físicas, sobre } \\
\text { Serviços Financeiros, sobre Transporte } \\
\text { Aéreo e sobre Telecomunicações do } \\
\text { GATS foram incorporados ao Acordo e } \\
\text { são parte integral do mesmo. }\end{array}$ & $\begin{array}{l}\text { Não há. Contudo, os Anexos do GATS } \\
\text { sobre serviços financeiros, } \\
\text { telecomunicações, movimento de pessoas } \\
\text { físicas e transporte aéreo foram } \\
\text { integralmente incorporados ao Acordo. }\end{array}$ \\
\hline $\begin{array}{c}\text { Capítulo sobre } \\
\text { investimentos } \\
\text { relacionados a serviços }\end{array}$ & $\begin{array}{l}\text { No acordo relativo ao comércio de } \\
\text { bens, há um capítulo sobre } \\
\text { investimentos. Todavia, não há um } \\
\text { capítulo específico sobre investimentos } \\
\text { relacionados a serviços. }\end{array}$ & $\begin{array}{l}\text { Há um capítulo específico sobre } \\
\text { investimentos (Capítulo 10). }\end{array}$ \\
\hline $\begin{array}{l}\text { Regras sobre } \\
\text { transparência }\end{array}$ & $\begin{array}{l}\text { Sim, conforme estabelecido no Art. III } \\
\text { do GATS. Esse artigo é incorporado e } \\
\text { constitui parte integrante do Acordo. }\end{array}$ & $\begin{array}{l}\text { Sim, que consistem na (i) Necessidade de } \\
\text { as Partes estabelecerem e manterem } \\
\text { mecanismos apropriados para } \\
\text { responderem às solicitações de pessoas } \\
\text { interessadas sobre suas leis e } \\
\text { regulamentos relacionados ao Capítulo; } \\
\text { (ii) Que, na medida do possível, sejam } \\
\text { levados em consideração os comentários } \\
\text { realizados por partes interessadas sobre } \\
\text { novas leis e regulamentos; e (iii) Que } \\
\text { haja um período de tempo razoável entre } \\
\text { a promulgação de novas leis e } \\
\text { regulamentos e sua entrada em vigor. }\end{array}$ \\
\hline $\begin{array}{l}\text { Tratamento nacional: } \\
\text { abrangência e } \\
\text { parâmetros } \\
\text { semelhantes ao GATS } \\
\text { (like services and like } \\
\text { services suppliers) }\end{array}$ & $\begin{array}{l}\text { Sim, idêntico ao GATS. Parâmetros } \\
\text { são os mesmos (like services and } \\
\text { services suppliers). Está previsto ainda } \\
\text { que nada nesse artigo pode ser } \\
\text { utilizado como compensação para } \\
\text { possíveis desvantagens competitivas } \\
\text { resultantes do fato de o serviço ou } \\
\text { prestador de serviço relevante ser } \\
\text { estrangeiro. }\end{array}$ & $\begin{array}{l}\text { Há uma pequena diferença em relação ao } \\
\text { parâmetro adotado pelo GATS. No } \\
\text { Acordo, é adotado o critério de "like } \\
\text { circumstances". As Partes devem } \\
\text { conceder aos serviços e aos prestadores } \\
\text { de serviços de outras Partes tratamento } \\
\text { não menos favorável do que aquele } \\
\text { concedido, em circunstâncias } \\
\text { semelhantes, a sus próprios serviços e } \\
\text { prestadores de serviços. }\end{array}$ \\
\hline $\begin{array}{l}\text { Acesso a mercados: } \\
\text { abrangência e } \\
\text { parâmetros } \\
\text { semelhantes ao Art. } \\
\text { XVI do GATS } \\
\end{array}$ & $\begin{array}{l}\text { Sim, idêntico ao GATS. Parâmetros } \\
\text { são os mesmos. }\end{array}$ & $\begin{array}{l}\text { Sim, idêntico ao GATS. Parâmetros são } \\
\text { os mesmos. }\end{array}$ \\
\hline $\begin{array}{l}\text { Obrigações permissivas } \\
\text { que possibilitam } \\
\text { tratamento desigual } \\
\text { entre as partes do } \\
\text { acordo }\end{array}$ & $\begin{array}{l}\text { Há a previsão de que, tão logo seja } \\
\text { concluída a negociação do Art. X do } \\
\text { GATS, as Partes conduzirão uma } \\
\text { revisão para discutir o aditamento no } \\
\text { Acordo com vistas a incorporar os } \\
\text { resultados das negociações } \\
\text { multilaterais. Se for verificado que, } \\
\text { antes da conclusão das negociações } \\
\text { multilaterais, uma das partes estiver } \\
\text { sendo prejudicada pelo aumento das } \\
\text { exportações de serviços de outra parte, }\end{array}$ & Não há. \\
\hline
\end{tabular}




\begin{tabular}{|c|c|c|}
\hline & Acordo China-Cingapura & Acordo China-Paquistão \\
\hline & $\begin{array}{c}\text { podem ser realizadas consultas. Nesse } \\
\text { caso, só poderá ser adotada uma } \\
\text { medida de salvaguarda se ela for } \\
\text { consensual. }\end{array}$ & \\
\hline $\begin{array}{l}\text { Cláusula de nação mais } \\
\text { favorecida ratione } \\
\text { materiae et temporis }\end{array}$ & $\begin{array}{c}\text { Há apenas a previsão de concessão às } \\
\text { Partes de tratamento não menos } \\
\text { favorável do que aquele determinado } \\
\text { no Acordo. }\end{array}$ & $\begin{array}{l}\text { Há apenas a previsão de concessão às } \\
\text { Partes de tratamento não menos favorável } \\
\text { do que aquele determinado em sua Lista } \\
\text { de Compromissos. }\end{array}$ \\
\hline $\begin{array}{l}\text { Exceções à Cláusula de } \\
\text { Nação Mais Favorecida }\end{array}$ & Não há. & Não há. \\
\hline $\begin{array}{l}\text { Regra de origem } \\
\text { (Denial of benefits) }\end{array}$ & $\begin{array}{l}\text { Critério híbrido (operações comerciais } \\
\text { substanciais e relações diplomáticas). } \\
\text { Após a realização de notificação e } \\
\text { consultas, as Partes poderão negar os } \\
\text { benefícios concedidos no Acordo aos: } \\
\text { (i) prestadores de serviços da outra } \\
\text { Parte, se o serviço for prestado por } \\
\text { pessoa jurídica que é detida ou } \\
\text { controlada por pessoas originárias de } \\
\text { Estados não parte e a pessoa jurídica } \\
\text { não desenvolver operações substanciais } \\
\text { no território da outra Parte; ou (ii) } \\
\text { prestadores de serviços da outra Parte, } \\
\text { se serviço for prestado por pessoa } \\
\text { jurídica que é detida ou controlada por } \\
\text { pessoas da Parte que negar os } \\
\text { benefícios e a pessoa jurídica não } \\
\text { desenvolver operações substanciais na } \\
\text { outra Parte. A Parte também poderá } \\
\text { negar os benefícios concedidos no } \\
\text { Acordo - sem a necessidade de } \\
\text { realização de notificação e consultas - } \\
\text { aos prestadores de serviços da outra } \\
\text { Parte se o serviço for prestado por } \\
\text { pessoa jurídica que é detida ou } \\
\text { controlada por pessoas originárias de } \\
\text { uma não Parte e a Parte que negar o } \\
\text { benefício não mantenha relações } \\
\text { diplomáticas com essa não Parte. }\end{array}$ & $\begin{array}{l}\text { Sim. Critério de operações comerciais } \\
\text { substanciais. As Partes poderão negar os } \\
\text { benefícios concedidos no Acordo aos: (i) } \\
\text { prestadores de serviços da outra Parte, se } \\
\text { o serviço for prestado por pessoa jurídica } \\
\text { que é detida ou controlada por pessoas } \\
\text { originárias de Estados não parte e a } \\
\text { pessoa jurídica não desenvolver } \\
\text { operações substanciais no território da } \\
\text { outra Parte; ou (ii) prestadores de } \\
\text { serviços da outra Parte, se serviço for } \\
\text { prestado por pessoa jurídica que é detida } \\
\text { ou controlada por pessoas da Parte que } \\
\text { negar os benefícios e a pessoa jurídica } \\
\text { não desenvolver operações substanciais } \\
\text { na outra Parte. A denegação do benefício } \\
\text { deve ser comunicada por escrito à outra } \\
\text { Parte. }\end{array}$ \\
\hline $\begin{array}{l}\text { Procedimento para } \\
\text { modificação dos } \\
\text { compromissos }\end{array}$ & $\begin{array}{c}\text { Os compromissos assumidos no } \\
\text { âmbito do Acordo poderão ser revistos } \\
\text { e modificados pelas Partes a qualquer } \\
\text { tempo. }\end{array}$ & Não há previsão. \\
\hline $\begin{array}{l}\text { Procedimento para } \\
\text { futuras negociações }\end{array}$ & $\begin{array}{c}\text { Os compromissos assumidos serão } \\
\text { revisados pela Comissão de Livre } \\
\text { Comércio três anos após a entrada em } \\
\text { vigor do Acordo com base nos avanços } \\
\text { nas regulações sobre serviços das } \\
\text { Partes e nos progressos realizados no } \\
\text { âmbito da OMC. }\end{array}$ & $\begin{array}{l}\text { As Partes deverão realizar consultas } \\
\text { anualmente para revisar a implementação } \\
\text { do capítulo e considerar outras questões } \\
\text { de interesse mútuo que afetem o } \\
\text { comércio de serviços. }\end{array}$ \\
\hline
\end{tabular}




\begin{tabular}{|c|c|c|}
\hline & Acordo China-Cingapura & Acordo China-Paquistão \\
\hline $\begin{array}{l}\text { Criação de comitês } \\
\text { para supervisionar a } \\
\text { evolução do Acordo }\end{array}$ & $\begin{array}{l}\text { Há a previsão de criação de um Comitê } \\
\text { sobre o Comércio de Serviços no } \\
\text { âmbito do Acordo, que seria formado } \\
\text { por representantes das duas Partes e } \\
\text { presidido por oficiais das Partes. A } \\
\text { primeira reunião do Comitê ocorreria } \\
\text { um ano após a entrada em vigor do } \\
\text { Acordo e as reuniões posteriores } \\
\text { seriam definidas pelas Partes. As } \\
\text { funções do Comitê incluem: (i) a } \\
\text { revisão dos compromissos relacionados } \\
\text { a medidas que afetem o comércio de } \\
\text { serviços, com vistas a promover uma } \\
\text { maior liberalização do comércio de } \\
\text { serviços; (ii) a revisão da } \\
\text { implementação e operacionalização do } \\
\text { Acordo; (iii) a revisão e a discussão de } \\
\text { questões relacionadas a } \\
\text { reconhecimento mútuo e salvaguardas } \\
\text { emergenciais; (iv) reportar o resultado } \\
\text { das discussões à Comissão de Livre } \\
\text { Comércio; e (v) desenvolver outras } \\
\text { tarefas delegadas pela Comissão de } \\
\text { Livre Comércio. Foi prevista também a } \\
\text { criação de grupos de trabalho no } \\
\text { âmbito do Comitê sobre o Comércio de } \\
\text { Serviços. }\end{array}$ & Não há previsão. \\
\hline
\end{tabular}


Tabela 23 - Acordo China-Peru

\begin{tabular}{|c|c|}
\hline & Acordo China-Peru \\
\hline Escopo do capítulo sobre serviços & $\begin{array}{l}\text { O capítulo sobre serviços abrange medidas adotadas ou } \\
\text { mantidas por governos e autoridades centrais, regionais ou } \\
\text { locais das Partes, bem como por órgãos não } \\
\text { governamentais que exerçam poderes delegados por esses } \\
\text { governos ou autoridades, que afetem o comércio de } \\
\text { serviços, incluído: (i) o pagamento e o uso ou o pagamento } \\
\text { por um serviço; (ii) o acesso a e o uso de serviços que } \\
\text { sejam necessários, por uma Parte, para a prestação de } \\
\text { serviços públicos; e (iii) a presença, incluindo a presença } \\
\text { comercial, de pessoas de uma Parte para a prestação de um } \\
\text { serviço no território de outra Parte. Não estão abrangidas } \\
\text { medidas adotadas no exercício da autoridade } \\
\text { governamental. Também não estão abrangidos: (i) as } \\
\text { compras governamentais; (ii) os serviços aéreos, incluindo } \\
\text { serviços de transporte aéreo nacional e internacional, } \\
\text { agendados ou não agendados, e serviços correlatos, exceto } \\
\text { serviços de reparo e manutenção de aeronaves, a } \\
\text { comercialização de serviços de transporte aéreo, sistemas } \\
\text { de reservas computadorizadas; (iii) subsídios ou auxílios } \\
\text { concedidos por uma Parte, incluindo empréstimos, } \\
\text { garantias e seguros concedidos pelo governo; (iv) } \\
\text { transporte marítimo nacional de cabotagem; (v) o acesso } \\
\text { ao mercado de trabalho de uma das Partes, incluindo a } \\
\text { possibilidade de requerimento de vistos a pessoas físicas; } \\
\text { (vi) serviços financeiros que não estejam especificados nas } \\
\text { listas de compromissos específicos, dado que as obrigações } \\
\text { sobre esses serviços serão reguladas de acordo com o } \\
\text { GATS; (vii) serviços de telecomunicações, dado que as } \\
\text { obrigações sobre esses serviços serão reguladas de acordo } \\
\text { com o respectivo Anexo do GATS. }\end{array}$ \\
\hline Forma de assunção dos compromissos & Lista positiva. \\
\hline Modos de prestação abrangidos & Todos $(\operatorname{modos} 1,2,3$ e 4$)$ \\
\hline Regras sobre regulação doméstica & $\begin{array}{l}\text { Sim. As Partes devem garantir: (i) que todas as medidas } \\
\text { que afetem o comércio de serviços sejam administradas de } \\
\text { forma razoável, objetiva e imparcial; (ii) que sejam } \\
\text { mantidos ou instituídos tribunais ou procedimentos para a } \\
\text { revisão de medidas administrativas que afetem o comércio } \\
\text { de serviços, que devem ser objetivos e imparciais; (iii) que } \\
\text { seja prontamente informado ao solicitante de um } \\
\text { autorização para a prestação de um serviço a decisão acerca } \\
\text { do seu requerimento; (iii) que as medidas relacionadas a } \\
\text { requerimentos para licenciamento, qualificação, normas } \\
\text { técnicas não constituam uma barreira à prestação do } \\
\text { serviço. O artigo faz menção à necessidade consultas entre } \\
\text { as Partes em caso de regulamentação do Art. VI do GATS, } \\
\text { com o objetivo de incorporar essas novas regras ao Acordo, } \\
\text { se apropriado. }\end{array}$ \\
\hline Regras setoriais específicas & $\begin{array}{l}\text { Não há. Contudo, os Anexos do GATS sobre serviços } \\
\text { financeiros e telecomunicações foram integralmente } \\
\text { incorporados ao Capítulo. }\end{array}$ \\
\hline
\end{tabular}




\begin{tabular}{|c|c|}
\hline & Acordo China-Peru \\
\hline $\begin{array}{c}\text { Capítulo sobre investimentos relacionados a } \\
\text { serviços }\end{array}$ & $\begin{array}{l}\text { Há um capítulo específico sobre investimentos (Capítulo } \\
10) .\end{array}$ \\
\hline Regras sobre transparência & $\begin{array}{l}\text { Sim, que consistem na (i) Necessidade de as Partes } \\
\text { estabelecerem e manterem mecanismos apropriados para } \\
\text { responderem às solicitações de pessoas interessadas sobre } \\
\text { suas leis e regulamentos relacionados ao Capítulo; (ii) Que, } \\
\text { na medida do possível, sejam levados em consideração os } \\
\text { comentários realizados por partes interessadas sobre novas } \\
\text { leis e regulamentos; e (iii) Que haja um período de tempo } \\
\text { razoável entre a promulgação de novas leis e regulamentos } \\
\text { e sua entrada em vigor. }\end{array}$ \\
\hline $\begin{array}{c}\text { Tratamento nacional: abrangência e parâmetros } \\
\text { semelhantes ao GATS (like services and like } \\
\text { services suppliers) }\end{array}$ & $\begin{array}{l}\text { Há uma pequena diferença em relação ao parâmetro } \\
\text { adotado pelo GATS. No Acordo, é adotado o critério de } \\
\text { "like circumstances". As Partes devem conceder aos } \\
\text { serviços e aos prestadores de serviços de outras Partes } \\
\text { tratamento não menos favorável do que aquele concedido, } \\
\text { em circunstâncias semelhantes, a sus próprios serviços e } \\
\text { prestadores de serviços. }\end{array}$ \\
\hline $\begin{array}{l}\text { Acesso a mercados: abrangência e parâmetros } \\
\text { semelhantes ao Art. XVI do GATS }\end{array}$ & Sim, idêntico ao GATS. Parâmetros são os mesmos. \\
\hline $\begin{array}{l}\text { Obrigações permissivas que possibilitam } \\
\text { tratamento desigual entre as partes do acordo }\end{array}$ & Não há. \\
\hline $\begin{array}{c}\text { Cláusula de nação mais favorecida ratione } \\
\text { materiae et temporis }\end{array}$ & $\begin{array}{l}\text { Há apenas a previsão de concessão às Partes de tratamento } \\
\text { não menos favorável do que aquele determinado em sua } \\
\text { Lista de Compromissos. }\end{array}$ \\
\hline Exceções à Cláusula de Nação Mais Favorecida & Não há. \\
\hline Regra de origem (Denial of benefits) & $\begin{array}{l}\text { Sim. Critério de operações comerciais substanciais. As } \\
\text { Partes poderão negar os benefícios concedidos no Acordo } \\
\text { aos: (i) prestadores de serviços da outra Parte, se o serviço } \\
\text { for prestado por pessoa jurídica que é detida ou controlada } \\
\text { por pessoas originárias de Estados não parte e a pessoa } \\
\text { jurídica não desenvolver operações substanciais no } \\
\text { território da outra Parte; ou (ii) prestadores de serviços da } \\
\text { outra Parte, se serviço for prestado por pessoa jurídica que } \\
\text { é detida ou controlada por pessoas da Parte que negar os } \\
\text { benefícios e a pessoa jurídica não desenvolver operações } \\
\text { substanciais na outra Parte. A denegação do benefício deve } \\
\text { ser comunicada por escrito à outra Parte. }\end{array}$ \\
\hline $\begin{array}{l}\text { Procedimento para modificação dos } \\
\text { compromissos }\end{array}$ & Não há previsão. \\
\hline Procedimento para futuras negociações & $\begin{array}{l}\text { As Partes deverão realizar consultas anualmente para } \\
\text { revisar a implementação do capítulo e considerar outras } \\
\text { questões de interesse mútuo que afetem o comércio de } \\
\text { serviços. }\end{array}$ \\
\hline $\begin{array}{c}\text { Criação de comitês para supervisionar a } \\
\text { evolução do Acordo }\end{array}$ & Não há previsão. \\
\hline
\end{tabular}


ANEXO V

ANÁLISE COMPARATIVA DAS PRINCIPAIS CLÁUSULAS SOBRE SERVIÇOS DOS ACORDOS DE LIVRE COMÉRCIO CELEBRADOS PELA ÍNDIA 


\section{Tabela 24 - Acordos Índia-Coreia e Índia-Cingapura}

\begin{tabular}{|c|c|c|}
\hline & Acordo Índia-Coreia & Acordo Índia-Cingapura \\
\hline $\begin{array}{l}\text { Escopo do capítulo } \\
\text { sobre serviços }\end{array}$ & $\begin{array}{l}\text { O capítulo sobre serviços é aplicável às } \\
\text { medidas adotadas por uma Parte que } \\
\text { afetem o comércio de serviços. } \\
\text { Contudo, este capítulo não incide } \\
\text { sobre: (i) serviços prestados no } \\
\text { exercício da autoridade governamental; } \\
\text { (ii) compras governamentais; (iii) } \\
\text { pessoa jurídica que não seja pessoa } \\
\text { jurídica de outra parte e pessoa natural } \\
\text { que não seja pessoa natural de outra } \\
\text { parte; (iii) subsídios ou aportes, } \\
\text { incluindo empréstimos financiados } \\
\text { pelo governo, garantias e seguro ou } \\
\text { quaisquer condições atreladas ao } \\
\text { recebimento destes subsídios ou } \\
\text { empréstimos, sejam eles concedidos } \\
\text { exclusivamente ou não a provedores de } \\
\text { serviços, consumidores ou serviços } \\
\text { domésticos; (iv) serviços aéreos de } \\
\text { transporte ou não, sejam eles } \\
\text { agendados ou não, e outros serviços } \\
\text { correlatos, exceto medidas que afetem } \\
\text { os serviços de reparo e manutenção de } \\
\text { aeronaves, a comercialização de } \\
\text { serviços de transporte aéreo e sistemas } \\
\text { de reservas computadorizadas; (v) } \\
\text { medidas que afetem pessoas físicas em } \\
\text { busca do mercado de emprego ou } \\
\text { relacionadas à cidadania, residência ou } \\
\text { emprego, em base permanente. Novos } \\
\text { serviços, incluindo novos serviços } \\
\text { financeiros, poderão ser incorporados a } \\
\text { este capítulo em futuras revisões, de } \\
\text { acordo com o Art. } 6.19 \text { ou } \\
\text { imediatamente, a pedido de uma Parte. } \\
\text { A prestação de serviços que não são } \\
\text { tecnicamente ou tecnologicamente } \\
\text { exequíveis quando o Acordo entrar em } \\
\text { vigor poderão ser incorporados caso se } \\
\text { tornem exequíveis, seja em uma futura } \\
\text { revisão, seja imediatamente, a pedido } \\
\text { de uma Parte. } \\
\end{array}$ & $\begin{array}{l}\text { O capítulo sobre serviços é aplicável às } \\
\text { medidas adotadas por uma Parte que } \\
\text { afetem o comércio de serviços, exceto: (i) } \\
\text { serviços prestados no exercício da } \\
\text { autoridade governamental; (ii) subsídios } \\
\text { ou aportes concedidos por uma Parte, } \\
\text { sejam eles oferecidos exclusivamente ou } \\
\text { não para serviços, consumidores ou } \\
\text { prestadores de serviços domésticos, (iii) } \\
\text { empresa de prateleira localizada no } \\
\text { território de uma das Partes; (iv) medidas } \\
\text { que afetem pessoas físicas em busca do } \\
\text { mercado de emprego ou relacionadas à } \\
\text { cidadania, residência ou emprego, em } \\
\text { base permanente. Os compromissos } \\
\text { específicos celebrados pelas Partes } \\
\text { também não se aplicam a compras } \\
\text { governamentais. }\end{array}$ \\
\hline $\begin{array}{l}\text { Forma de assunção dos } \\
\text { compromissos }\end{array}$ & Lista positiva. & Lista positiva. \\
\hline $\begin{array}{l}\text { Modos de prestação } \\
\text { abrangidos }\end{array}$ & $\begin{array}{l}\text { Todos (Modos 1, } 2,3 \text { e } 4 \text { ). Há um } \\
\text { capítulo específico sobre o movimento } \\
\text { de pessoas físicas (Capítulo } 8 \text { ). }\end{array}$ & $\begin{array}{l}\text { Todos (Modos } 1,2,3 \text { e } 4 \text { ). Há um } \\
\text { capítulo específico sobre o movimento de } \\
\text { pessoas físicas (Capítulo 9). }\end{array}$ \\
\hline
\end{tabular}




\begin{tabular}{|c|c|c|}
\hline & Acordo Índia-Coreia & Acordo Índia-Cingapura \\
\hline $\begin{array}{c}\text { Regras sobre regulação } \\
\text { doméstica }\end{array}$ & $\begin{array}{l}\text { Sim. As Partes devem: (i) garantir que } \\
\text { todas as medidas que afetem o } \\
\text { comércio de serviços sejam } \\
\text { administradas de forma razoável, } \\
\text { objetiva e imparcial; (ii) estabelecer ou } \\
\text { manter tribunais ou procedimentos } \\
\text { para a revisão de medidas } \\
\text { administrativas que afetem o comércio } \\
\text { de serviços, que devem ser objetivos e } \\
\text { imparciais, exceto se essa previsão for } \\
\text { inconstitucional ou seja inconsistente } \\
\text { com o sistema jurídico da Parte; (iii) se } \\
\text { houver a necessidade de autorização, } \\
\text { as autoridades competentes devem } \\
\text { informar sobre o status do } \\
\text { requerimento sem demora. As Partes } \\
\text { deverão discutir regras específicas } \\
\text { sobre qualificação, licenciamento e } \\
\text { normas técnicas desenvolvidos no } \\
\text { âmbito do parágrafo IV do Art. } 6 \text { do } \\
\text { GATS com vistas a incorporar essas } \\
\text { disciplinas e garantir que não } \\
\text { constituam barreiras desnecessárias ao } \\
\text { comércio. }\end{array}$ & $\begin{array}{l}\text { Sim. As Partes devem: (i) garantir que } \\
\text { todas as medidas que afetem o comércio } \\
\text { de serviços sejam administradas de forma } \\
\text { razoável, objetiva e imparcial; (ii) } \\
\text { estabelecer ou manter tribunais ou } \\
\text { procedimentos para a revisão de medidas } \\
\text { administrativas que afetem o comércio de } \\
\text { serviços, que devem ser objetivos e } \\
\text { imparciais, exceto se essa previsão for } \\
\text { inconstitucional ou seja inconsistente } \\
\text { com o sistema jurídico da Parte; (iii) se } \\
\text { houver a necessidade de autorização, as } \\
\text { autoridades competentes devem informar } \\
\text { sobre o status do requerimento sem } \\
\text { demora. As Partes deverão discutir regras } \\
\text { específicas sobre qualificação, } \\
\text { licenciamento e normas técnicas } \\
\text { desenvolvidos no âmbito do parágrafo IV } \\
\text { do Art. } 6 \text { do GATS com vistas a } \\
\text { incorporar essas disciplinas e garantir que } \\
\text { não constituam barreiras desnecessárias } \\
\text { ao comércio. }\end{array}$ \\
\hline $\begin{array}{l}\text { Regras setoriais } \\
\text { específicas }\end{array}$ & $\begin{array}{l}\text { Há um anexo específico sobre serviços } \\
\text { de transporte marítimo (Anexo 6B), } \\
\text { um anexo específico sobre serviços } \\
\text { financeiros (Anexo 6C) e capítulos } \\
\text { específicos sobre Telecomunicações } \\
\text { (capítulo 7), Movimento de Pessoas } \\
\text { Físicas (Capítulo 8) e Co-produção } \\
\text { Audiovisual (Capítulo 9). } \\
\end{array}$ & $\begin{array}{c}\text { Há um anexo específico sobre serviços de } \\
\text { telecomunicações e um anexo específico } \\
\text { sobre serviços financeiros (Anexos 7C e } \\
\text { 7D, respectivamente). Também há } \\
\text { capítulos específicos no Acordo sobre } \\
\text { Serviços Aéreos (Capítulo 8), } \\
\text { Movimento de Pessoas Físicas (Capítulo } \\
\text { 9) e E-Commerce (Capítulo 10). }\end{array}$ \\
\hline $\begin{array}{l}\text { Capítulo sobre } \\
\text { investimentos } \\
\text { relacionados a serviços }\end{array}$ & $\begin{array}{l}\text { Há um capítulo específico para regular } \\
\text { questões relacionadas a investimentos } \\
\text { (Capítulo 10). }\end{array}$ & $\begin{array}{l}\text { Há um capítulo específico para regular } \\
\text { questões relacionadas a investimentos } \\
\text { (Capítulo 7). Não obstante, está previsto } \\
\text { que alguns dos artigos do capítulo } \\
\text { aplicar-se-ão às medidas que afetem a } \\
\text { prestação de serviços por um prestador de } \\
\text { uma Parte por meio de presença } \\
\text { comercial no território da outra Parte, } \\
\text { apenas à medida que elas se relacionam a } \\
\text { um investimento, independentemente } \\
\text { desse setor ser ou não objeto de } \\
\text { compromissos específicos das Partes. }\end{array}$ \\
\hline $\begin{array}{l}\text { Regras sobre } \\
\text { transparência }\end{array}$ & $\begin{array}{l}\text { Cada Parte deverá publicar as medidas } \\
\text { que afetem a operacionalização do } \\
\text { capítulo prontamente e, exceto em } \\
\text { situações emergenciais, até a entrada } \\
\text { em vigor da mesma. Acordos } \\
\text { internacionais assinados por uma Parte } \\
\text { que afetem a prestação de serviços } \\
\text { também deverão ser publicados. Se a } \\
\text { publicação dessas medidas e acordos } \\
\text { não for possível, a Parte deve levá-las } \\
\text { ao conhecimento público por outra } \\
\text { forma. Cada Parte deverá responder } \\
\text { prontamente aos pedidos da outra Parte } \\
\text { a respeito de informações sobre }\end{array}$ & $\begin{array}{l}\text { Cada Parte deverá publicar as medidas } \\
\text { que afetem a operacionalização do } \\
\text { capítulo prontamente e, exceto em } \\
\text { situações emergenciais, até a entrada em } \\
\text { vigor da mesma. Acordos internacionais } \\
\text { assinados por uma Parte que afetem a } \\
\text { prestação de serviços também deverão } \\
\text { ser publicados. Se a publicação dessas } \\
\text { medidas e acordos não for possível, a } \\
\text { Parte deve levá-las ao conhecimento } \\
\text { público por outra forma. Cada Parte } \\
\text { deverá responder prontamente aos } \\
\text { pedidos da outra Parte a respeito de } \\
\text { informações sobre medidas de aplicação }\end{array}$ \\
\hline
\end{tabular}




\begin{tabular}{|c|c|c|}
\hline & Acordo Índia-Coreia & Acordo Índia-Cingapura \\
\hline & $\begin{array}{l}\text { medidas de aplicação geral ou acordos } \\
\text { internacionais. Cada Parte deverá } \\
\text { estabelecer um ou mais pontos de } \\
\text { contato para fornecer informações } \\
\text { específicas para a outra Parte, mediante } \\
\text { solicitação. }\end{array}$ & $\begin{array}{l}\text { geral ou acordos internacionais. Cada } \\
\text { Parte deverá estabelecer um ou mais } \\
\text { pontos de contato para fornecer } \\
\text { informações específicas para a outra } \\
\text { Parte, mediante solicitação. }\end{array}$ \\
\hline $\begin{array}{l}\text { Tratamento nacional: } \\
\text { abrangência e } \\
\text { parâmetros } \\
\text { semelhantes ao GATS } \\
\text { (like services and like } \\
\text { services suppliers) }\end{array}$ & $\begin{array}{c}\text { Sim, idêntico ao GATS. Parâmetros } \\
\text { são os mesmos (like services and } \\
\text { services suppliers). Foi previsto que } \\
\text { qualquer estabelecimento, aquisição } \\
\text { adicional ou expansão de } \\
\text { investimentos por um prestador de } \\
\text { serviços que for incorporado, } \\
\text { constituído ou organizado sob as leis } \\
\text { de uma Parte e que for controlado pelo } \\
\text { prestador de serviços da outra Parte } \\
\text { deve ser considerado como um } \\
\text { investimento da outra Parte para fins } \\
\text { de tratamento nacional. Também há } \\
\text { um esclarecimento no sentido de que o } \\
\text { tratamento nacional também abrange o } \\
\text { tratamento concedido a nível local ou } \\
\text { regional. }\end{array}$ & $\begin{array}{l}\text { Sim, idêntico ao GATS. Parâmetros são } \\
\text { os mesmos (like services and services } \\
\text { suppliers). Foi previsto que qualquer } \\
\text { estabelecimento, aquisição adicional ou } \\
\text { expansão de investimentos por um } \\
\text { prestador de serviços que for } \\
\text { incorporado, constituído ou organizado } \\
\text { sob as leis de uma Parte e que for } \\
\text { controlado pelo prestador de serviços da } \\
\text { outra Parte deve ser considerado como } \\
\text { um investimento da outra Parte para fins } \\
\text { de tratamento nacional. Também há um } \\
\text { esclarecimento no sentido de que o } \\
\text { tratamento nacional também abrange o } \\
\text { tratamento concedido a nível local ou } \\
\text { regional. }\end{array}$ \\
\hline $\begin{array}{l}\text { Acesso a mercados: } \\
\text { abrangência e } \\
\text { parâmetros } \\
\text { semelhantes ao Art. } \\
\text { XVI do GATS }\end{array}$ & $\begin{array}{c}\text { Sim, os parâmetros são os mesmos do } \\
\text { GATS. }\end{array}$ & $\begin{array}{c}\text { Sim, os parâmetros são os mesmos do } \\
\text { GATS. }\end{array}$ \\
\hline $\begin{array}{c}\text { Obrigações permissivas } \\
\text { que possibilitam } \\
\text { tratamento desigual } \\
\text { entre as partes do } \\
\text { acordo }\end{array}$ & $\begin{array}{l}\text { (i) Salvaguardas: Há a previsão de que, } \\
\text { após a entrada em vigor do Acordo, } \\
\text { nenhuma das Partes poderá adotar } \\
\text { salvaguardas, iniciar ou continuar } \\
\text { investigações de salvaguarda } \\
\text { relacionadas a serviços ou prestadores } \\
\text { de serviços da outra Parte. A questão } \\
\text { das salvaguardas será revista de acordo } \\
\text { com o desenvolvimento deste tema em } \\
\text { foros internacionais nos quais ambas as } \\
\text { Partes são partes. (ii) Subsídios: A } \\
\text { questão dos subsídios será revista de } \\
\text { acordo com o desenvolvimento deste } \\
\text { tema em foros internacionais nos quais } \\
\text { ambas as Partes são partes. Caso uma } \\
\text { Parte entenda que seus interesses foram } \\
\text { prejudicados pela concessão de um } \\
\text { subsídio ou aporte pela outra Parte, } \\
\text { pode iniciar consultas para solucionar a } \\
\text { questão. }\end{array}$ & $\begin{array}{l}\text { (i) Salvaguardas: Há a previsão de que } \\
\text { nenhuma das Partes poderá adotar } \\
\text { salvaguardas, iniciar ou continuar } \\
\text { investigações de salvaguarda } \\
\text { relacionadas a serviços ou prestadores de } \\
\text { serviços da outra Parte. A questão das } \\
\text { salvaguardas será revista de acordo com } \\
\text { o desenvolvimento deste tema em foros } \\
\text { internacionais nos quais ambas as Partes } \\
\text { são membros. (ii) Subsídios: A questão } \\
\text { dos subsídios será revista de acordo com } \\
\text { o desenvolvimento deste tema em foros } \\
\text { internacionais nos quais ambas as Partes } \\
\text { são membros. Caso uma Parte entenda } \\
\text { que seus interesses foram prejudicados } \\
\text { pela concessão de um subsídio ou aporte } \\
\text { pela outra Parte, pode iniciar consultas } \\
\text { para solucionar a questão. }\end{array}$ \\
\hline $\begin{array}{l}\text { Cláusula de nação mais } \\
\text { favorecida ratione } \\
\text { materiae et temporis }\end{array}$ & $\begin{array}{l}\text { Há a previsão de concessão de } \\
\text { tratamento não menos favorável do que } \\
\text { aquele determinado na Lista de } \\
\text { Compromissos Específicos, tanto em } \\
\text { termos de acesso a mercados quanto } \\
\text { em termos de tratamento nacional. Se } \\
\text { após a entrada em vigor do Acordo } \\
\text { uma Parte celebrar acordos que } \\
\text { envolvam o comércio de serviços com }\end{array}$ & $\begin{array}{l}\text { Há a previsão de concessão de tratamento } \\
\text { não menos favorável do que aquele } \\
\text { determinado na Lista de Compromissos } \\
\text { Específicos, tanto em termos de acesso a } \\
\text { mercados quanto em termos de } \\
\text { tratamento nacional. Está previsto que, } \\
\text { se após a entrada em vigor do Acordo } \\
\text { uma Parte celebrar acordos que envolvam } \\
\text { o comércio de serviços com uma não }\end{array}$ \\
\hline
\end{tabular}




\begin{tabular}{|c|c|c|}
\hline & Acordo Índia-Coreia & Acordo Índia-Cingapura \\
\hline & $\begin{array}{l}\text { uma não Parte, deverá considerar os } \\
\text { pedidos da Parte para a extensão desses } \\
\text { compromissos. As incorporações } \\
\text { deverão manter o nível geral de } \\
\text { compromissos celebrados por cada } \\
\text { Parte. } \\
\end{array}$ & $\begin{array}{l}\text { Parte, deverá considerar os pedidos da } \\
\text { Parte para a extensão desses } \\
\text { compromissos. As incorporações deverão } \\
\text { manter o nível geral de compromissos } \\
\text { celebrados por cada Parte. }\end{array}$ \\
\hline $\begin{array}{l}\text { Exceções à Cláusula de } \\
\text { Nação Mais Favorecida }\end{array}$ & $\begin{array}{l}\text { Há a previsão de exceções gerais e de } \\
\text { exceções de segurança. }\end{array}$ & $\begin{array}{c}\text { Há um Anexo específico sobre Exceções } \\
\text { de Segurança para Serviços (Anexo 8) }\end{array}$ \\
\hline $\begin{array}{l}\text { Regra de origem } \\
\text { (Denial of benefits) }\end{array}$ & $\begin{array}{l}\text { Sim. As partes poderão negar as } \\
\text { preferências concedidas no Acordo, } \\
\text { condicionadas à realização de } \\
\text { notificação e consultas, para: (i) a } \\
\text { prestação de serviços, caso o serviço } \\
\text { seja prestado do território de uma não } \\
\text { Parte; (ii) no caso de transporte } \\
\text { marítimo, se o serviço for prestado por } \\
\text { uma embarcação registrada sob as leis } \\
\text { de uma não Parte e operada por pessoa } \\
\text { que seja de uma não Parte; (iii) o } \\
\text { prestador de serviço da outra Parte } \\
\text { caso a Parte estabelecer que o serviço } \\
\text { está sendo prestado por uma pessoa } \\
\text { jurídica que é detida ou controlada por } \\
\text { pessoas de uma não Parte ou da Parte } \\
\text { que denegar o benefício e que não } \\
\text { tenha atividades operacionais reais e } \\
\text { contínuas ou operações substanciais no } \\
\text { território da outra Parte; (iv) o } \\
\text { prestador de serviço da outra Parte } \\
\text { caso o prestador de serviço seja uma } \\
\text { pessoa jurídica detida ou controlada } \\
\text { por pessoas de uma não Parte e a Parte } \\
\text { que denegar o benefício adote ou } \\
\text { mantenha medidas que incluam a } \\
\text { notificação ou uma ordem a respeito da } \\
\text { não Parte ou da pessoa da não Parte } \\
\text { que proibir operações com a pessoa } \\
\text { jurídica ou que sejam violadas ou } \\
\text { prejudicadas se os benefícios desse } \\
\text { capítulo se aplicaram a essa pessoa } \\
\text { jurídica. }\end{array}$ & $\begin{array}{l}\text { Sim. As partes poderão negar as } \\
\text { preferências concedidas no Acordo para: } \\
\text { (i) a prestação de serviços, caso o serviço } \\
\text { seja prestado do território de uma não } \\
\text { Parte; (ii) no caso de transporte marítimo, } \\
\text { se o serviço for prestado por uma } \\
\text { embarcação registrada sob as leis de uma } \\
\text { não Parte e operada por pessoa que seja } \\
\text { de uma não Parte; (iii) a prestação de um } \\
\text { serviço por meio de presença comercial, } \\
\text { se a Parte estabelecer que, naquele } \\
\text { momento, a pessoa de uma não Parte } \\
\text { detiver ou controlar, ou adquiriu } \\
\text { propriedade ou controle, sob o prestador } \\
\text { do serviço; (iv) a prestação de um serviço } \\
\text { a partir ou no território de outra Parte, se } \\
\text { a Parte estabelecer que o serviço é } \\
\text { prestador por um prestador que é detido } \\
\text { ou controlado por uma pessoa da Parte } \\
\text { que denegar o benefício. }\end{array}$ \\
\hline $\begin{array}{c}\text { Procedimento para } \\
\text { modificação dos } \\
\text { compromissos }\end{array}$ & $\begin{array}{l}\text { As Partes poderão modificar ou } \\
\text { revogar os compromissos assumidos a } \\
\text { qualquer momento passados três anos } \\
\text { da entrada em vigor do Acordo. A } \\
\text { outra Parte deverá ser notificada no } \\
\text { mínimo três meses antes da data de } \\
\text { implementação da suspensão ou } \\
\text { revogação. Se a outra Parte solicitar, } \\
\text { deverá ser negociada uma } \\
\text { compensação, com o intuito de manter } \\
\text { o nível de compromissos existentes } \\
\text { antes da negociação. A referida } \\
\text { negociação deverá terminar em até seis } \\
\text { meses. Caso não haja acordo dentro } \\
\text { deste prazo, poderá ser acionado o }\end{array}$ & $\begin{array}{c}\text { As Partes poderão modificar ou revogar } \\
\text { os compromissos assumidos a qualquer } \\
\text { momento passados três anos da entrada } \\
\text { em vigor do Acordo. A outra Parte } \\
\text { deverá ser notificada no mínimo três } \\
\text { meses antes da data de implementação da } \\
\text { suspensão ou revogação. Se a outra Parte } \\
\text { solicitar, deverá ser negociada uma } \\
\text { compensação, com o intuito de manter o } \\
\text { nível de compromissos existentes antes } \\
\text { da modificação ou suspensão } \\
\text { implementada. Esta negociação deverá } \\
\text { terminar em até seis meses. Caso não } \\
\text { haja acordo dentro deste prazo, poderá } \\
\text { ser acionado o Sistema de Solução de }\end{array}$ \\
\hline
\end{tabular}




\begin{tabular}{|c|c|c|}
\hline & Acordo Índia-Coreia & Acordo Índia-Cingapura \\
\hline & $\begin{array}{l}\text { Sistema de Solução de Controvérsias } \\
\text { estabelecido pelo Acordo. }\end{array}$ & Controvérsias estabelecido pelo Acordo. \\
\hline $\begin{array}{l}\text { Procedimento para } \\
\text { futuras negociações }\end{array}$ & $\begin{array}{c}\text { As Partes devem revisar os } \\
\text { compromissos em serviços pelo menos } \\
\text { uma vez a cada três anos, ou dentro de } \\
\text { um prazo menor, a pedido de uma das } \\
\text { Partes, com vistas a eliminar as } \\
\text { discriminações existentes nos } \\
\text { compromissos assumidos no âmbito do } \\
\text { Capítulo. Deverão ser respeitados os } \\
\text { objetivos de política pública e o nível } \\
\text { de desenvolvimento das partes, tanto } \\
\text { de modo geral quanto em relação aos } \\
\text { setores individualmente considerados. }\end{array}$ & $\begin{array}{c}\text { As Partes devem revisar os } \\
\text { compromissos em serviços pelo menos } \\
\text { uma vez a cada três anos, ou dentro de } \\
\text { um prazo menor, a pedido de uma das } \\
\text { Partes, com vistas a eliminar as } \\
\text { discriminações existentes nos } \\
\text { compromissos assumidos no âmbito do } \\
\text { Capítulo. Deverão ser respeitados os } \\
\text { objetivos de política pública e o nível de } \\
\text { desenvolvimento das partes, tanto de } \\
\text { modo geral quanto em relação aos setores } \\
\text { individualmente considerados. }\end{array}$ \\
\hline $\begin{array}{l}\text { Criação de comitês } \\
\text { para supervisionar a } \\
\text { evolução do Acordo }\end{array}$ & Não há previsão. & Não há previsão. \\
\hline
\end{tabular}




\section{Tabela 25 - Acordos Índia-Japão e Índia-Malásia}

\begin{tabular}{|c|c|c|}
\hline & Acordo Índia-Japão & Acordo Índia-Malásia \\
\hline $\begin{array}{l}\text { Escopo do capítulo } \\
\text { sobre serviços }\end{array}$ & $\begin{array}{l}\text { O capítulo sobre serviços é aplicável às } \\
\text { medidas adotadas por uma Parte que } \\
\text { afetem o comércio de serviços, com } \\
\text { exceção de: (i) medidas que afetem os } \\
\text { serviços de tráfego aéreo ou os serviços } \\
\text { diretamente relacionados ao exercício de } \\
\text { direitos de tráfego aéreo além de serviços } \\
\text { de reparo e manutenção de aeronaves, } \\
\text { comercialização de serviços de transporte } \\
\text { aéreo e sistemas de reservas } \\
\text { computadorizadas; (ii) transporte } \\
\text { marítimo de cabotagem; (ii) medidas que } \\
\text { afetem pessoas físicas que buscam acesso } \\
\text { ao mercado de empregos de uma Parte ou } \\
\text { medidas relacionadas à cidadania, } \\
\text { residência ou emprego, de forma } \\
\text { permanente; (iii) compras } \\
\text { governamentais. }\end{array}$ & $\begin{array}{c}\text { O capítulo sobre serviços é aplicável } \\
\text { às medidas adotadas por uma Parte } \\
\text { que afetem o comércio de serviços, } \\
\text { com exceção de: (i) serviços prestados } \\
\text { no âmbito da autoridade } \\
\text { governamental; (ii) pessoa jurídica que } \\
\text { não seja pessoa jurídica de outra parte } \\
\text { e pessoa natural que não seja pessoa } \\
\text { natural de outra parte; (iii) quaisquer } \\
\text { medidas de uma parte relacionadas a } \\
\text { compras governamentais; (iv) } \\
\text { subsídios ou aportes, incluindo } \\
\text { empréstimos financiados pelo } \\
\text { governo, garantias e seguro ou } \\
\text { quaisquer condições atreladas ao } \\
\text { recebimento destes subsídios ou } \\
\text { empréstimos, sejam eles concedidos } \\
\text { exclusivamente ou não a provedores } \\
\text { de serviços, consumidores ou serviços } \\
\text { domésticos, exceto na hipótese do Art. } \\
\text { 8.41 (subsídios); (v) transporte } \\
\text { marítimo de cabotagem; e (vi) medidas } \\
\text { que afetem pessoas naturais buscando } \\
\text { o acesso a emprego no mercado da } \\
\text { Parte ou medidas sobre cidadania, } \\
\text { residência ou emprego em base } \\
\text { permanente; (vii) medidas que afetem } \\
\text { os serviços de tráfego aéreo ou } \\
\text { serviços diretamente relacionados ao } \\
\text { exercício de direitos de tráfego aéreo, } \\
\text { exceto medidas que afetem os serviços } \\
\text { de reparo e manutenção de aeronaves, } \\
\text { a comercialização de serviços de } \\
\text { transporte aéreo e sistemas de reservas } \\
\text { computadorizadas. }\end{array}$ \\
\hline $\begin{array}{c}\text { Forma de assunção dos } \\
\text { compromissos }\end{array}$ & Lista positiva. & Lista positiva. \\
\hline $\begin{array}{l}\text { Modos de prestação } \\
\text { abrangidos }\end{array}$ & $\begin{array}{l}\text { Todos (Modos } 1,2,3 \text { e } 4 \text { ). Há um } \\
\text { capítulo específico sobre o movimento de } \\
\text { pessoas físicas (Capítulo } 7 \text { ). }\end{array}$ & $\begin{array}{l}\text { Todos (Modos 1, 2, } 3 \text { e 4). Há um } \\
\text { capítulo específico sobre o movimento } \\
\text { de pessoas físicas (Capítulo 9). }\end{array}$ \\
\hline $\begin{array}{c}\text { Regras sobre regulação } \\
\text { doméstica }\end{array}$ & $\begin{array}{l}\text { Sim. As Partes devem: (i) garantir que } \\
\text { todas as medidas que afetem o comércio } \\
\text { de serviços sejam administradas de forma } \\
\text { razoável, objetiva e imparcial; (ii) } \\
\text { estabelecer ou manter tribunais ou } \\
\text { procedimentos para a revisão de medidas } \\
\text { administrativas que afetem o comércio de } \\
\text { serviços, que devem ser objetivos e } \\
\text { imparciais, exceto se essa previsão for } \\
\text { inconstitucional ou não estiver prevista no } \\
\text { sistema jurídico da Parte; (iii) se houver a } \\
\text { necessidade de autorização, as }\end{array}$ & $\begin{array}{l}\text { Sim. As Partes devem: (i) garantir que } \\
\text { todas as medidas que afetem o } \\
\text { comércio de serviços sejam } \\
\text { administradas de forma razoável, } \\
\text { objetiva e imparcial; (ii) estabelecer ou } \\
\text { manter tribunais ou procedimentos } \\
\text { para a revisão de medidas } \\
\text { administrativas que afetem o comércio } \\
\text { de serviços, que devem ser objetivos e } \\
\text { imparciais, exceto se essa previsão for } \\
\text { inconstitucional ou não estiver prevista } \\
\text { no sistema jurídico da Parte; (iii) se }\end{array}$ \\
\hline
\end{tabular}




\begin{tabular}{|c|c|c|}
\hline & Acordo Índia-Japão & Acordo Índia-Malásia \\
\hline & $\begin{array}{l}\text { autoridades competentes devem informar } \\
\text { sobre o status do requerimento sem } \\
\text { demora. As Partes deverão discutir regras } \\
\text { específicas sobre qualificação, } \\
\text { licenciamento e normas técnicas } \\
\text { desenvolvidos no âmbito do parágrafo IV } \\
\text { do Art. } 6 \text { do GATS com vistas a } \\
\text { incorporar essas disciplinas e garantir que } \\
\text { não constituam barreiras desnecessárias } \\
\text { ao comércio. }\end{array}$ & $\begin{array}{c}\text { houver a necessidade de autorização, } \\
\text { as autoridades competentes devem } \\
\text { informar sobre o status do } \\
\text { requerimento sem demora. As Partes } \\
\text { deverão discutir regras específicas } \\
\text { sobre qualificação, licenciamento e } \\
\text { normas técnicas desenvolvidos no } \\
\text { âmbito do parágrafo IV do Art. } 6 \text { do } \\
\text { GATS com vistas a incorporar essas } \\
\text { disciplinas e garantir que não } \\
\text { constituam barreiras desnecessárias ao } \\
\text { comércio. }\end{array}$ \\
\hline $\begin{array}{l}\text { Regras setoriais } \\
\text { específicas }\end{array}$ & $\begin{array}{c}\text { Há um anexo específico sobre serviços de } \\
\text { telecomunicações e um anexo específico } \\
\text { sobre serviços financeiros. }\end{array}$ & $\begin{array}{l}\text { Não há. No entanto, as partes } \\
\text { reafirmam entre elas os direitos e } \\
\text { obrigações assumidos no Anexo sobre } \\
\text { Serviços Financeiros do GATS. }\end{array}$ \\
\hline $\begin{array}{l}\text { Capítulo sobre } \\
\text { investimentos } \\
\text { relacionados a serviços }\end{array}$ & $\begin{array}{c}\text { Há um capítulo específico para regular } \\
\text { questões relacionadas a investimentos } \\
\text { (Capítulo 8). }\end{array}$ & $\begin{array}{c}\text { Há um capítulo específico para regular } \\
\text { questões relacionadas a investimentos } \\
\text { (Capítulo 10). }\end{array}$ \\
\hline $\begin{array}{l}\text { Regras sobre } \\
\text { transparência }\end{array}$ & $\begin{array}{l}\text { As autoridades competentes devem } \\
\text { responder prontamente aos } \\
\text { questionamentos da outra Parte ou de } \\
\text { prestadores de serviços da outra Parte por } \\
\text { meio de pontos de contato. As Partes } \\
\text { deverão preparar, encaminhar para a outra } \\
\text { Parte e publicar uma lista com todas as } \\
\text { medidas existentes no escopo deste } \\
\text { capítulo que são incompatíveis com as } \\
\text { obrigações de acesso a mercados e } \\
\text { tratamento nacional, que será revisada } \\
\text { anualmente e revista quando necessário. }\end{array}$ & $\begin{array}{l}\text { Não há regras de transparências } \\
\text { específicas no Capítulo } 8 \text { do Acordo. } \\
\text { As regras sobre transparência foram } \\
\text { tratadas em um capítulo específico } \\
\text { (Capítulo 13). Neste capítulo, as regras } \\
\text { sobre transparência referem-se à: (i) } \\
\text { publicação de procedimentos, leis } \\
\text { regulamentos, de modo a garantir sua } \\
\text { publicidade antes da entrada em vigor } \\
\text { e permitir que sejam feitos } \\
\text { comentários a seu conteúdo; (ii) } \\
\text { manutenção de procedimentos } \\
\text { administrativos imparciais que prestem } \\
\text { as informações solicitadas e } \\
\text { possibilitem a prestação de } \\
\text { esclarecimentos e informações } \\
\text { adicionais antes da decisão final sobre } \\
\text { determinada questão; (iii) } \\
\text { possibilidade de revisão das decisões } \\
\text { administrativas; e (iv) notificação das } \\
\text { decisões a prestação de informações } \\
\text { no idioma inglês, em domínio de } \\
\text { acesso público. }\end{array}$ \\
\hline $\begin{array}{c}\text { Tratamento nacional: } \\
\text { abrangência e } \\
\text { parâmetros } \\
\text { semelhantes ao GATS } \\
\text { (like services and like } \\
\text { services suppliers) }\end{array}$ & $\begin{array}{l}\text { Sim, idêntico ao GATS. Parâmetros são } \\
\text { os mesmos (like services and services } \\
\text { suppliers). Há um esclarecimento no } \\
\text { sentido de que os compromissos } \\
\text { específicos assumidos não poderão ser } \\
\text { utilizados de forma a compensar por } \\
\text { desvantagens competitivas resultantes da } \\
\text { prestação de serviços por estrangeiros. }\end{array}$ & $\begin{array}{c}\text { Sim, idêntico ao GATS. Parâmetros } \\
\text { são os mesmos (like services and } \\
\text { services suppliers). }\end{array}$ \\
\hline $\begin{array}{l}\text { Acesso a mercados: } \\
\text { abrangência e }\end{array}$ & $\begin{array}{l}\text { Sim, os parâmetros são os mesmos do } \\
\text { GATS. Porém, há a uma nota que diz que, }\end{array}$ & $\begin{array}{c}\text { Sim, os parâmetros são os mesmos do } \\
\text { GATS. }\end{array}$ \\
\hline
\end{tabular}




\begin{tabular}{|c|c|c|}
\hline & Acordo Índia-Japão & Acordo Índia-Malásia \\
\hline $\begin{array}{c}\text { parâmetros } \\
\text { semelhantes ao Art. } \\
\text { XVI do GATS }\end{array}$ & $\begin{array}{l}\text { se uma Parte assumir compromissos no } \\
\text { modo prestação transfronteiriça e o } \\
\text { movimento de capitais constituir uma } \\
\text { parte importante desse serviço, essa Parte } \\
\text { compromete-se a permitir esse } \\
\text { movimento de capital. Da mesma forma, } \\
\text { se uma Parte assumir compromissos no } \\
\text { modo presença comercial, ela também se } \\
\text { compromete a permitir a transferência de } \\
\text { capital para o seu território. Há também a } \\
\text { previsão de que as Partes devem buscar } \\
\text { reduzir os seguintes requerimentos um } \\
\text { prestador de um serviço da outra Parte: (i) } \\
\text { que estabeleça ou mantenha um escritório } \\
\text { de representação ou qualquer outra forma } \\
\text { de empresa; ou (ii) que seja residente em } \\
\text { sua área. }\end{array}$ & \\
\hline $\begin{array}{l}\text { Obrigações permissivas } \\
\text { que possibilitam } \\
\text { tratamento desigual } \\
\text { entre as partes do } \\
\text { acordo }\end{array}$ & $\begin{array}{l}\text { Há apenas a previsão de salvaguardas no } \\
\text { capítulo sobre investimentos (Capítulo 8), } \\
\text { aplicável a movimento de capital. }\end{array}$ & $\begin{array}{l}\text { Há a previsão de que, tão logo seja } \\
\text { concluída a negociação sobre } \\
\text { salvaguardas emergenciais previstas } \\
\text { no Art. X do GATS, as Partes } \\
\text { conduzirão uma revisão para discutir o } \\
\text { aditamento no Acordo com vistas a } \\
\text { incorporar os resultados das } \\
\text { negociações multilaterais. Se for } \\
\text { verificado que, antes da conclusão das } \\
\text { negociações multilaterais, uma das } \\
\text { partes estiver sendo prejudicada pelo } \\
\text { aumento das exportações de serviços } \\
\text { de outra parte, podem ser realizadas } \\
\text { consultas. Nesse caso, só poderá ser } \\
\text { adotada uma medida de salvaguarda se } \\
\text { ela for consensual. }\end{array}$ \\
\hline $\begin{array}{l}\text { Cláusula de nação mais } \\
\text { favorecida ratione } \\
\text { materiae et temporis }\end{array}$ & $\begin{array}{l}\text { Há a previsão de concessão de tratamento } \\
\text { não menos favorável do que aquele } \\
\text { determinado na Lista de Compromissos } \\
\text { Específicos, tanto em termos de acesso a } \\
\text { mercados quanto em termos de } \\
\text { tratamento nacional. Também está } \\
\text { previsto que, caso as Partes celebrem } \\
\text { acordos sobre serviços com não partes, } \\
\text { deverão considerar a solicitação da outra } \\
\text { Parte para a concessão de tratamento não } \\
\text { menos favorável do que aquele } \\
\text { determinado no Acordo celebrado com } \\
\text { terceiro. As incorporações deverão } \\
\text { manter o nível geral de compromissos } \\
\text { celebrados por cada Parte. }\end{array}$ & $\begin{array}{c}\text { Há a previsão de concessão de } \\
\text { tratamento não menos favorável do } \\
\text { que aquele determinado na Lista de } \\
\text { compromissos específicos, tanto em } \\
\text { termos de acesso a mercados quanto } \\
\text { em termos de tratamento nacional. } \\
\text { Também há previsão de concessão às } \\
\text { Partes de tratamento não menos } \\
\text { favorável do que aquele determinado } \\
\text { na Lista de Compromissos } \\
\text { Específicos. }\end{array}$ \\
\hline $\begin{array}{l}\text { Exceções à Cláusula de } \\
\text { Nação Mais Favorecida }\end{array}$ & Não há. & Não há. \\
\hline
\end{tabular}




\begin{tabular}{|c|c|c|}
\hline & Acordo Índia-Japão & Acordo Índia-Malásia \\
\hline $\begin{array}{l}\text { Regra de origem } \\
\text { (Denial of benefits) }\end{array}$ & Não há. & $\begin{array}{l}\text { Sim. As partes poderão negar as } \\
\text { preferência concedidas no Acordo } \\
\text { para: (i) a prestação de serviços, caso o } \\
\text { serviço seja prestado do território de } \\
\text { uma não Parte; (ii) no caso de } \\
\text { transporte marítimo, se o serviço for } \\
\text { prestado por uma embarcação } \\
\text { registrada sob as leis de uma não Parte } \\
\text { e operada por pessoa que seja de uma } \\
\text { não Parte; (iii) a prestação de um } \\
\text { serviço a partir ou no território de } \\
\text { outra Parte, se a Parte estabelecer que } \\
\text { o serviço é prestador por um prestador } \\
\text { que é detido ou controlado por uma } \\
\text { pessoa de uma não Parte e a Parte que } \\
\text { denegar o benefício não mantenha } \\
\text { relações diplomáticas com a não Parte } \\
\text { e adote ou mantenha medidas com } \\
\text { respeito à não Parte que proíba } \\
\text { transações com as pessoas jurídicas ou } \\
\text { por meio de outras formas de presença } \\
\text { comercial, tais como uma agência ou } \\
\text { escritório de representação, que seriam } \\
\text { violados ou prejudicados se os } \\
\text { benefícios deste capítulo forem } \\
\text { acordados à pessoa jurídica ou por } \\
\text { meio de outras formas de presença } \\
\text { comercial. }\end{array}$ \\
\hline $\begin{array}{l}\text { Procedimento para } \\
\text { modificação dos } \\
\text { compromissos }\end{array}$ & Não há previsão. & Não há previsão. \\
\hline $\begin{array}{l}\text { Procedimento para } \\
\text { futuras negociações }\end{array}$ & $\begin{array}{c}\text { As Partes devem revisar os compromissos } \\
\text { em serviços três anos após a entrada em } \\
\text { vigor do Acordo, com vistas a aprimorar } \\
\text { os compromissos, de acordo com o } \\
\text { parágrafo } 1 \text { do Art. IV do GATS } \\
\text { (Aumento da participação dos países em } \\
\text { desenvolvimento). }\end{array}$ & Não há previsão. \\
\hline $\begin{array}{l}\text { Criação de comitês } \\
\text { para supervisionar a } \\
\text { evolução do Acordo }\end{array}$ & $\begin{array}{c}\text { Foi criado o Subcomitê sobre o Comércio } \\
\text { de Serviços com o propósito de } \\
\text { implementar e operacionalizar o capítulo. } \\
\text { O Subcomitê teria as seguintes funções: } \\
\text { (i) revisar a implementação e } \\
\text { operacionalização do capítulo; (ii) o } \\
\text { intercâmbio de informações sobre leis } \\
\text { domésticas e regulamentos; (iii) discutir } \\
\text { aspectos relacionados ao capítulo que } \\
\text { tenham sido acordados pelas partes; (iv) } \\
\text { reportar as conclusões do Subcomitê ao } \\
\text { Comitê Conjunto; e (v) assumir funções } \\
\text { delegadas pelo Comitê Conjunto. }\end{array}$ & $\begin{array}{l}\text { Há a previsão de criação de um Sub } \\
\text { Comitê de serviços, que seria } \\
\text { responsável pela análise de assuntos } \\
\text { relacionados à implementação do } \\
\text { Capítulo sobre Serviços. }\end{array}$ \\
\hline
\end{tabular}


ANEXO VI

ANÁLISE COMPARATIVA DAS PRINCIPAIS CLÁUSULAS SOBRE SERVIÇOS DOS ACORDOS DE LIVRE COMÉRCIO CELEBRADOS PELO MERCOSUL 


\section{Tabela 26 -Acordos Mercosul-Índia e Mercosul-Israel}

\begin{tabular}{|c|c|c|}
\hline & Acordo Mercosul-Índia & Acordo Mercosul-Israel \\
\hline $\begin{array}{l}\text { Escopo do capítulo } \\
\text { sobre serviços }\end{array}$ & $\begin{array}{l}\text { Não se aplica, pois o acordo não se } \\
\text { refere ao comércio de serviços. }\end{array}$ & $\begin{array}{l}\text { Não se aplica, pois o acordo não incide } \\
\text { sobre o comércio de serviços. Há apenas } \\
\text { uma previsão genérica de negociação de } \\
\text { compromissos em serviços: “Artigo } 9- \\
\text { Investimentos e Comércio de Serviços } \\
\text { 1. As Partes reconhecem a importância } \\
\text { das áreas de investimentos e de comércio } \\
\text { de serviços. Em seus esforços para } \\
\text { aprofundar e expandir gradualmente } \\
\text { suas relações econômicas, as Partes } \\
\text { considerarão, no Comitê Conjunto, as } \\
\text { possíveis modalidades para iniciar } \\
\text { negociações sobre acesso a mercados em } \\
\text { investimentos e sobre comércio de } \\
\text { serviços, tendo como base a arquitetura } \\
\text { do GATS, quando aplicável. } \\
\text { 2. Com vistas a ampliar o conhecimento } \\
\text { recíproco sobre oportunidades de } \\
\text { comércio e de investimentos em ambas as } \\
\text { Partes, as Partes Signatárias estimularão } \\
\text { atividades de promoção comercial tais } \\
\text { como seminários, missóes comerciais, } \\
\text { feiras, simpósios e exibiçôes". }\end{array}$ \\
\hline $\begin{array}{c}\text { Forma de assunção dos } \\
\text { compromissos }\end{array}$ & Não se aplica. & Não se aplica. \\
\hline $\begin{array}{l}\text { Modos de prestação } \\
\text { abrangidos }\end{array}$ & Não se aplica. & Não se aplica. \\
\hline $\begin{array}{c}\text { Regras sobre regulação } \\
\text { doméstica }\end{array}$ & Não se aplica. & Não se aplica. \\
\hline $\begin{array}{l}\text { Regras setoriais } \\
\text { específicas }\end{array}$ & Não se aplica. & Não se aplica. \\
\hline $\begin{array}{c}\text { Capítulo sobre } \\
\text { investimentos } \\
\text { relacionados a serviços }\end{array}$ & Não se aplica. & Não se aplica. \\
\hline $\begin{array}{l}\text { Regras sobre } \\
\text { transparência }\end{array}$ & Não se aplica. & Não se aplica. \\
\hline $\begin{array}{c}\text { Tratamento nacional: } \\
\text { abrangência e } \\
\text { parâmetros } \\
\text { semelhantes ao GATS } \\
\text { (like services and like } \\
\text { services suppliers) }\end{array}$ & Não se aplica. & Não se aplica. \\
\hline $\begin{array}{l}\text { Acesso a mercados: } \\
\text { abrangência e } \\
\text { parâmetros } \\
\text { semelhantes ao Art. } \\
\text { XVI do GATS }\end{array}$ & Não se aplica. & Não se aplica. \\
\hline
\end{tabular}




\begin{tabular}{|c|c|c|}
\hline & Acordo Mercosul-Índia & Acordo Mercosul-Israel \\
\hline $\begin{array}{c}\text { Obrigações permissivas } \\
\text { que possibilitam } \\
\text { tratamento desigual } \\
\text { entre as partes do } \\
\text { acordo }\end{array}$ & Não se aplica. & Não se aplica. \\
\hline $\begin{array}{c}\text { Cláusula de nação mais } \\
\text { favorecida ratione } \\
\text { materiae et temporis }\end{array}$ & Não se aplica. & Não se aplica. \\
\hline $\begin{array}{c}\text { Exceções à Cláusula de } \\
\text { Nação Mais Favorecida }\end{array}$ & Não se aplica. & Não se aplica. \\
\hline $\begin{array}{c}\text { Regra de origem } \\
\text { (Denial of benefits) }\end{array}$ & Não se aplica. & Não se aplica. \\
\hline $\begin{array}{c}\text { Procedimento para } \\
\text { modificação dos } \\
\text { compromissos }\end{array}$ & Não se aplica. & Não se aplica. \\
\hline $\begin{array}{c}\text { Procedimento para } \\
\text { futuras negociações }\end{array}$ & Não se aplica. & Não se aplica. \\
\hline $\begin{array}{c}\text { Criação de comitês } \\
\text { para supervisionar a } \\
\text { evolução do Acordo }\end{array}$ & Não se aplica. & \\
\hline
\end{tabular}


Tabela 27 - Acordos Mercosul-Egito e Mercosul-SACU

\begin{tabular}{|c|c|c|}
\hline & Acordo Mercosul-Egito & Acordo Mercosul-SACU \\
\hline $\begin{array}{l}\text { Escopo do capítulo } \\
\text { sobre serviços }\end{array}$ & $\begin{array}{l}\text { Não se aplica, pois o acordo não se } \\
\text { refere ao comércio de serviços. Não } \\
\text { se aplica, pois o acordo não incide } \\
\text { sobre o comércio de serviços. Há } \\
\text { apenas uma previsão genérica de } \\
\text { negociação de compromissos em } \\
\text { serviços, com base no GATS: } \\
\text { "Article } 24 \text {-Trade in Services } \\
\text { 1. The Parties and Signatory Parties } \\
\text { shall aim at achieving gradual } \\
\text { liberalization and the opening of } \\
\text { their markets for trade in services in } \\
\text { accordance with the provisions of } \\
\text { the WTO General Agreement on } \\
\text { Trade in Services (hereinafter } \\
\text { referred to as "GATS"). } \\
\text { 2. In their efforts to gradually deepen } \\
\text { and broaden their economic relations, } \\
\text { the Parties will consider, in the Joint } \\
\text { Committee, the possible modalities for } \\
\text { opening negotiations on market access } \\
\text { on trade in services, on the basis of the } \\
\text { GATS framework". }\end{array}$ & $\begin{array}{l}\text { Não se aplica, pois o acordo não se refere } \\
\text { ao comércio de serviços. }\end{array}$ \\
\hline $\begin{array}{c}\text { Forma de assunção dos } \\
\text { compromissos }\end{array}$ & Não se aplica. & Não se aplica. \\
\hline $\begin{array}{l}\text { Modos de prestação } \\
\text { abrangidos }\end{array}$ & Não se aplica. & Não se aplica. \\
\hline $\begin{array}{c}\text { Regras sobre regulação } \\
\text { doméstica }\end{array}$ & Não se aplica. & Não se aplica. \\
\hline $\begin{array}{l}\text { Regras setoriais } \\
\text { específicas }\end{array}$ & Não se aplica. & Não se aplica. \\
\hline $\begin{array}{c}\text { Capítulo sobre } \\
\text { investimentos } \\
\text { relacionados a serviços }\end{array}$ & Não se aplica. & Não se aplica. \\
\hline $\begin{array}{l}\text { Regras sobre } \\
\text { transparência }\end{array}$ & Não se aplica. & Não se aplica. \\
\hline $\begin{array}{c}\text { Tratamento nacional: } \\
\text { abrangência e } \\
\text { parâmetros } \\
\text { semelhantes ao GATS } \\
\text { (like services and like } \\
\text { services suppliers) }\end{array}$ & Não se aplica. & Não se aplica. \\
\hline $\begin{array}{l}\text { Acesso a mercados: } \\
\text { abrangência e } \\
\text { parâmetros } \\
\text { semelhantes ao Art. } \\
\text { XVI do GATS }\end{array}$ & Não se aplica. & Não se aplica. \\
\hline
\end{tabular}




\begin{tabular}{|c|c|c|}
\hline & Acordo Mercosul-Egito & Acordo Mercosul-SACU \\
\hline $\begin{array}{c}\text { Obrigações permissivas } \\
\text { que possibilitam } \\
\text { tratamento desigual } \\
\text { entre as partes do } \\
\text { acordo }\end{array}$ & Não se aplica. & Não se aplica. \\
\hline $\begin{array}{c}\text { Cláusula de nação mais } \\
\text { favorecida ratione } \\
\text { materiae et temporis }\end{array}$ & Não se aplica. & Não se aplica. \\
\hline $\begin{array}{c}\text { Exceções à Cláusula de } \\
\text { Nação Mais Favorecida }\end{array}$ & Não se aplica. & Não se aplica. \\
\hline $\begin{array}{c}\text { Regra de origem } \\
\text { (Denial of benefits) }\end{array}$ & Não se aplica. & Não se aplica. \\
\hline $\begin{array}{c}\text { Procedimento para } \\
\text { modificação dos } \\
\text { compromissos }\end{array}$ & Não se aplica. & Não se aplica. \\
\hline $\begin{array}{c}\text { Procedimento para } \\
\text { futuras negociações }\end{array}$ & Não se aplica. & Não se aplica. \\
\hline $\begin{array}{c}\text { Criação de comitês } \\
\text { para supervisionar a } \\
\text { evolução do Acordo }\end{array}$ & Não se aplica. & Nãca. \\
\hline
\end{tabular}




\section{Tabela 28 - Acordo Mercosul-Palestina e ACE Mercosul-Chile}

\begin{tabular}{|c|c|c|}
\hline & Acordo Mercosul-Palestina & ACE Mercosul-Chile \\
\hline $\begin{array}{l}\text { Escopo do capítulo } \\
\text { sobre serviços }\end{array}$ & $\begin{array}{l}\text { Não se aplica, pois o acordo não se } \\
\text { refere ao comércio de serviços. }\end{array}$ & $\begin{array}{l}\text { O Quinquagésimo Terceiro protocolo } \\
\text { Adicional ao ACE adotou o Protocolo } \\
\text { sobre o Comércio de Serviços entre o } \\
\text { MERCOSUL e o Chile, que incide sobre } \\
\text { medidas adotadas ou mantidas pelas } \\
\text { Partes que afetem o comércio de serviços } \\
\text { entre elas, com exceção das medidas } \\
\text { relacionadas a: (i) direitos de tráfego } \\
\text { aéreo e aos serviços diretamente } \\
\text { relacionados ao exercício de tais direitos, } \\
\text { salvo: serviços de reparação e } \\
\text { manutenção de aeronaves enquanto a } \\
\text { aeronave estiver fora de serviço, venda e } \\
\text { comercialização dos serviços de } \\
\text { transporte aéreo e serviços de sistemas de } \\
\text { reserva informatizados; (ii) compras } \\
\text { governamentais; (iii) subsídios ou } \\
\text { doações concedidas por uma Parte ou } \\
\text { empresa do Estado, incluídos os } \\
\text { empréstimos, garantias e seguros } \\
\text { outorgados pelo governo. }\end{array}$ \\
\hline $\begin{array}{l}\text { Forma de assunção dos } \\
\text { compromissos }\end{array}$ & Não se aplica. & Lista positiva. \\
\hline $\begin{array}{l}\text { Modos de prestação } \\
\text { abrangidos }\end{array}$ & Não se aplica. & Todos $(1,2,3$ e 4$)$ \\
\hline $\begin{array}{c}\text { Regras sobre regulação } \\
\text { doméstica }\end{array}$ & Não se aplica. & $\begin{array}{l}\text { Sim. As Partes devem garantir que todas } \\
\text { as medidas que afetem o comércio de } \\
\text { serviços sejam administradas de forma } \\
\text { razoável, objetiva e imparcial; a } \\
\text { existência de regras claras sobre } \\
\text { requerimentos de licenciamento, normas } \\
\text { técnicas, entre outras, de modo que não } \\
\text { constituam barreiras desnecessárias ao } \\
\text { comércio de serviços; e que as } \\
\text { autoridades respondam prontamente a } \\
\text { requerimentos sempre que uma } \\
\text { autorização for necessária. O artigo faz } \\
\text { menção ao desenvolvimento de novas } \\
\text { disciplinas sobre regulação doméstica, } \\
\text { que levará em consideração os avanços } \\
\text { da disciplina na OMC. Também há a } \\
\text { previsão de que as Partes realizem } \\
\text { consultas periódicas com o objetivo de } \\
\text { remover a necessidade de vistos ou } \\
\text { residência para o licenciamento e a } \\
\text { certificação de provedores de serviços. }\end{array}$ \\
\hline $\begin{array}{l}\text { Regras setoriais } \\
\text { específicas }\end{array}$ & Não se aplica. & Não há. \\
\hline
\end{tabular}




\begin{tabular}{|c|c|c|}
\hline & Acordo Mercosul-Palestina & ACE Mercosul-Chile \\
\hline $\begin{array}{l}\text { Capítulo sobre } \\
\text { investimentos } \\
\text { relacionados a serviços }\end{array}$ & Não se aplica. & Não há. \\
\hline $\begin{array}{l}\text { Regras sobre } \\
\text { transparência }\end{array}$ & Não se aplica. & $\begin{array}{l}\text { Sim. As Partes devem: (i) publicar } \\
\text { prontamente e, salvo em situações de } \\
\text { força maior, no mais tardar na data de sua } \\
\text { entrada em vigor, todas as medidas } \\
\text { pertinentes de aplicação geral que se } \\
\text { refiram ao presente Protocolo ou afetem } \\
\text { seu funcionamento, incluindo os acordos } \\
\text { internacionais celebrados que se refiram } \\
\text { a ou afetem o comércio de serviços; (ii) } \\
\text { informar prontamente à Comissão } \\
\text { Administradora do ACE } 35 \text { sobre a } \\
\text { adoção de novas leis, regulamentos ou } \\
\text { diretrizes administrativas ou a introdução } \\
\text { de modificações às leis, regulamentos ou } \\
\text { diretrizes administrativas já existentes } \\
\text { que considere afetar significativamente o } \\
\text { comércio de serviços compreendido pelos } \\
\text { compromissos específicos (iii) responder } \\
\text { com presteza a todos os pedidos de } \\
\text { informação específicos apresentados pela } \\
\text { outra Parte Contratante acerca de } \\
\text { quaisquer medidas de aplicação geral; } \\
\text { (iv) por intermédio de suas autoridades } \\
\text { competentes, prestar informação aos } \\
\text { prestadores de serviços da outra Parte } \\
\text { Contratante sobre as questões sujeitas a } \\
\text { notificação. As Partes devem designar } \\
\text { um ponto focal. }\end{array}$ \\
\hline $\begin{array}{c}\text { Tratamento nacional: } \\
\text { abrangência e } \\
\text { parâmetros } \\
\text { semelhantes ao GATS } \\
\text { (like services and like } \\
\text { services suppliers) }\end{array}$ & Não se aplica. & $\begin{array}{c}\text { Sim, idêntico ao GATS. Parâmetros são } \\
\text { os mesmos (like services and services } \\
\text { suppliers). }\end{array}$ \\
\hline $\begin{array}{l}\text { Acesso a mercados: } \\
\text { abrangência e } \\
\text { parâmetros } \\
\text { semelhantes ao Art. } \\
\text { XVI do GATS }\end{array}$ & Não se aplica. & $\begin{array}{l}\text { Sim, idêntico ao GATS. Parâmetros são } \\
\text { os mesmos }\end{array}$ \\
\hline $\begin{array}{l}\text { Obrigações permissivas } \\
\text { que possibilitam } \\
\text { tratamento desigual } \\
\text { entre as partes do } \\
\text { acordo }\end{array}$ & Não se aplica. & Não há. \\
\hline $\begin{array}{l}\text { Cláusula de nação mais } \\
\text { favorecida ratione } \\
\text { materiae et temporis }\end{array}$ & Não se aplica. & Não há. \\
\hline $\begin{array}{l}\text { Exceções à Cláusula de } \\
\text { Nação Mais Favorecida }\end{array}$ & Não se aplica. & Não há. \\
\hline
\end{tabular}




\begin{tabular}{|c|c|c|}
\hline & Acordo Mercosul-Palestina & ACE Mercosul-Chile \\
\hline $\begin{array}{l}\text { Regra de origem } \\
\text { (Denial of benefits) }\end{array}$ & Não se aplica. & $\begin{array}{c}\text { Uma Parte poderá denegar os benefícios } \\
\text { derivados deste Protocolo, mediante } \\
\text { prévia notificação e realização de } \\
\text { consultas, aos prestadores de serviços da } \\
\text { outra Parte se o prestador de serviços: (i) } \\
\text { for uma pessoa que não seja considerada } \\
\text { como das Partes; ou (ii) prestar o serviço } \\
\text { a partir do ou no território de uma não- } \\
\text { Parte. }\end{array}$ \\
\hline $\begin{array}{l}\text { Procedimento para } \\
\text { modificação dos } \\
\text { compromissos }\end{array}$ & Não se aplica. & Não há. \\
\hline $\begin{array}{l}\text { Procedimento para } \\
\text { futuras negociações }\end{array}$ & Não se aplica. & $\begin{array}{l}\text { Há a previsão de que o Protocolo será } \\
\text { revisto três anos depois de sua entrada } \\
\text { em vigor, com vistas a aprofundar ainda } \\
\text { mais o alcance de suas disciplinas, o } \\
\text { nível de liberalização e a reduzir ou } \\
\text { eliminar as restrições restantes, bem } \\
\text { como a considerar os avanços obtidos em } \\
\text { matéria de serviços na OMC. }\end{array}$ \\
\hline $\begin{array}{l}\text { Criação de comitês } \\
\text { para supervisionar a } \\
\text { evolução do Acordo }\end{array}$ & Não se aplica. & $\begin{array}{l}\text { A Comissão Administradora do ACE-35 } \\
\text { será o âmbito formal para tratamento das } \\
\text { questões relativas à implementação do } \\
\text { Protocolo. }\end{array}$ \\
\hline
\end{tabular}




\section{Tabela 29 - ACE Mercosul-Colômbia}

\begin{tabular}{|c|c|}
\hline & ACE Mercosul-Colômbia \\
\hline Escopo do capítulo sobre serviços & $\begin{array}{l}\text { Não se aplica, pois o acordo não se refere ao comércio de } \\
\text { serviços. Há apenas a previsão de que as partes facilitem a } \\
\text { prestação de serviços e estabeleçam mecanismos para a } \\
\text { liberalização do setor: “Artigo } 28 \text { - As Partes Contratantes } \\
\text { promoverão a adoção de medidas tendentes a facilitar a } \\
\text { prestação de serviços. Igualmente, e em um prazo a ser } \\
\text { definido pela Comissão Administradora, as Partes } \\
\text { Signatárias estabelecerão os mecanismos adequados para a } \\
\text { liberalização, expansão e diversificação progressiva do } \\
\text { comércio de serviços nos seus territórios, conforme os } \\
\text { direitos, obrigaçóes e compromissos derivados da } \\
\text { participação respectiva no Acordo Geral sobre o Comércio } \\
\text { de Serviços da OMC (GATS), assim como em outros foros } \\
\text { regionais e hemisféricos". }\end{array}$ \\
\hline Forma de assunção dos compromissos & Não se aplica. \\
\hline Modos de prestação abrangidos & Não se aplica. \\
\hline Regras sobre regulação doméstica & Não se aplica. \\
\hline Regras setoriais específicas & Não se aplica. \\
\hline $\begin{array}{c}\text { Capítulo sobre investimentos relacionados a } \\
\text { serviços }\end{array}$ & Não se aplica. \\
\hline Regras sobre transparência & Não se aplica. \\
\hline $\begin{array}{c}\text { Tratamento nacional: abrangência e parâmetros } \\
\text { semelhantes ao GATS (like services and like } \\
\text { services suppliers) }\end{array}$ & Não se aplica. \\
\hline $\begin{array}{l}\text { Acesso a mercados: abrangência e parâmetros } \\
\text { semelhantes ao Art. XVI do GATS }\end{array}$ & Não se aplica. \\
\hline $\begin{array}{l}\text { Obrigações permissivas que possibilitam } \\
\text { tratamento desigual entre as partes do acordo }\end{array}$ & Não se aplica. \\
\hline $\begin{array}{c}\text { Cláusula de nação mais favorecida ratione } \\
\text { materiae et temporis }\end{array}$ & Não se aplica. \\
\hline Exceções à Cláusula de Nação Mais Favorecida & Não se aplica. \\
\hline Regra de origem (Denial of benefits) & Não se aplica. \\
\hline $\begin{array}{c}\text { Procedimento para modificação dos } \\
\text { compromissos }\end{array}$ & Não se aplica. \\
\hline Procedimento para futuras negociações & Não se aplica. \\
\hline $\begin{array}{c}\text { Criação de comitês para supervisionar a } \\
\text { evolução do Acordo }\end{array}$ & Não se aplica. \\
\hline
\end{tabular}

